BNL-77407-2007-IR

\title{
Preliminary Cross Section and n-bar Covariances for WPEC Subgroup 26
}

\author{
by \\ D. Rochman, M. Herman, P. Oblozinsky, \\ S. F. Mughabghab \\ January 2007 \\ Report prepared for WPEC Subgroup 26 \\ INuclear Data Needs for Advanced Reactor \\ Systems" \\ coordinated by: M. Salvatores
Energy Sciences \& Technology Department National Nuclear Data Center \\ Brookhaven National Laboratory \\ P.O. Box 5000 \\ Upton, NY 11973-5000 \\ www.bnl.gov
}

Notice: This manuscript has been authored by employees of Brookhaven Science Associates, LLC under Contract No. DE-AC02-98CH10886 with the U.S. Department of Energy. The publisher by accepting the manuscript for publication acknowledges that the United States Government retains a non-exclusive, paid-up, irrevocable, world-wide license to publish or reproduce the published form of this manuscript, or allow others to do so, for United States Government purposes. 


\section{DISCLAIMER}

This report was prepared as an account of work sponsored by an agency of the United States Government. Neither the United States Government nor any agency thereof, nor any of their employees, nor any of their contractors, subcontractors, or their employees, makes any warranty, express or implied, or assumes any legal liability or responsibility for the accuracy, completeness, or any third party's use or the results of such use of any information, apparatus, product, or process disclosed, or represents that its use would not infringe privately owned rights. Reference herein to any specific commercial product, process, or service by trade name, trademark, manufacturer, or otherwise, does not necessarily constitute or imply its endorsement, recommendation, or favoring by the United States Government or any agency thereof or its contractors or subcontractors. The views and opinions of authors expressed herein do not necessarily state or reflect those of the United States Government or any agency thereof. 


\title{
Preliminary Cross Section and $\nu$-bar Covariances for WPEC Subgroup 26
}

\author{
by
}

D. Rochman, M. Herman, P. Obložinský

and S. F. Mughabghab

January 2007

Report prepared for WPEC Subgroup 26

"Nuclear Data Needs for Advanced Reactor Systems"

Proposed by P.J. Finck, coordinated by M. Salvatores

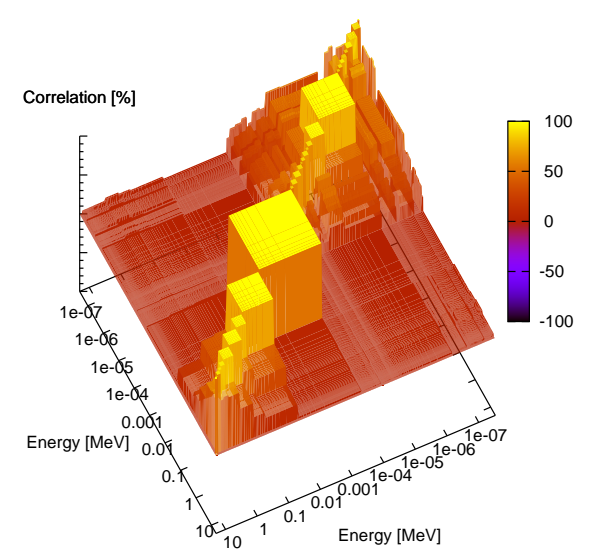

\section{NNDC National Nuclear Data Center}

BNL Report: BNL-77407-2007-IR 


\section{Distribution List}

- M. Salvatores

Program Nuclear Safety Research, c/o J. Knebel, Forschungszentrum Karlsruhe GmbH, P.O. Box 3640, 76021 Karlsruhe, Germany

- P.J. Finck

Associate Lab Director for Nuclear Programs, Idaho National Laboratory, MS 3860, 2525 N. Fremont Avenue, PO Box 1625, Idaho Falls, ID 83415, USA

- G. Aliberti, R.D. McKnight, G. Palmiotti

Argonne National Laboratory, Nuclear Science Division, 9700 Cass Avenue, Argonne, IL 60439, USA

- M.B. Chadwick, T. Kawano, P. Young and R.C. Little

Los Alamos National Laboratory, X-1, T-16 and X-5, Los Alamos, NM 87545, USA

- M. Williams

Oak Ridge National Laboratory, PO Box 2008, MS-6170, Oak Ridge, TN 37831-6170, USA

- A. Koning

Nuclear Research and Consulting Group NRG, Westerduinweg, PO Box 25, NL-1755 ZG Petten, The Netherlands

- P. Talou

CEA Cadarache, DEN/DER/SPRC, Bât. 230, F-13108, Saint-Paul lèz Durance, Cedex, France

BNL Report: BNL-77407-2007-IR 


\title{
Preliminary Cross Section and $\nu$-bar Covariances for WPEC Subgroup 26
}

\author{
D. Rochman, M. Herman, P. Obložinský, \\ S. F. Mughabghab \\ National Nuclear Data Center, Brookhaven National Laboratory, \\ Upton, NY 11973-5000
}

\begin{abstract}
We report preliminary cross section covariances developed for the WPEC Subgroup 26 for 45 out of 52 requested materials. The covariances were produced in 15- and 187-group representations as follows:

- 36 isotopes $\left({ }^{16} \mathrm{O},{ }^{19} \mathrm{~F},{ }^{23} \mathrm{Na},{ }^{27} \mathrm{Al},{ }^{28} \mathrm{Si},{ }^{52} \mathrm{Cr},{ }^{56,57} \mathrm{Fe},{ }^{58} \mathrm{Ni},{ }^{90,91,92,94} \mathrm{Zr}\right.$, ${ }^{166,167,168,170} \mathrm{Er}, \quad{ }^{206,207,208} \mathrm{~Pb}, \quad{ }^{209} \mathrm{Bi}, \quad{ }^{233,234,236} \mathrm{U}, \quad{ }^{237} \mathrm{~Np}, \quad{ }^{238,240,241,242} \mathrm{Pu}$, ${ }^{241,242 m, 243} \mathrm{Am},{ }^{242,243,244,245} \mathrm{Cm}$ ) were evaluated using the BNL-LANL methodology. For the thermal region and the resolved and unresolved resonance regions, the methodology has been based on the Atlas-Kalman approach; in the fast neutron region the Empire-Kalman method has been used;

- 6 isotopes $\left({ }^{155,156,157,158,160} \mathrm{Gd}\right.$ and $\left.{ }^{232} \mathrm{Th}\right)$ were taken from ENDF/B-VII.0; and

- 3 isotopes $\left({ }^{1} \mathrm{H},{ }^{238} \mathrm{U}\right.$ and $\left.{ }^{239} \mathrm{Pu}\right)$ were taken from JENDL-3.3.

For 6 light nuclei $\left({ }^{4} \mathrm{He},{ }^{6,7} \mathrm{Li},{ }^{9} \mathrm{Be},{ }^{10} \mathrm{~B},{ }^{12} \mathrm{C}\right)$, only partial cross section covariance results were obtained, additional work is needed and we do not report our results here. Likewise, the cross section covariances for ${ }^{235} \mathrm{U}$, which we recommend to take from JENDL-3.3, will be included once the multigroup processing is successfully completed.
\end{abstract}

Covariances for the average number of neutrons per fission, total $\nu$-bar, are provided for 10 actinides identified as priority by SG26.

Further work is needed to resolve some of the issues and to produce covariances for the full set of 52 materials. 


\section{Contents}

1 Introduction $\quad 1$

2 BNL-LANL Methodology for Cross Section Covariances 4

2.1 Basic components . . . . . . . . . . . . . . . 4

2.1.1 Atlas of Neutron Resonances . . . . . . . . . . . . . . . . . 4

2.1.2 Nuclear reaction model code EMPIRE . . . . . . . . . . . . 7

2.1.3 Bayesian code KALMAN . . . . . . . . . . . . . . 8

2.2 Evaluation methods . . . . . . . . . . . . . . . . . . . 9

2.2.1 Atlas-KALMAN method for the resonance region . . . . . . . 9

2.2.2 EMPIRE-KALMAN method for the fast neutron region . . . . 9

3 Processing $\quad 11$

3.1 Merging of covariance files . . . . . . . . . . . . . . . . . 11

3.2 Multigroup processing . . . . . . . . . . . . . . . . . . 11

4 Results for Cross Section Covariances 13

4.1 BNL evaluations: 36 isotopes . . . . . . . . . . . . . . . 13

4.1 Resonance region . . . . . . . . . . . . . . . . . 13

4.1 .2 Fast neutron region . . . . . . . . . . . . . . . . . . . 14

4.1 .3 Priority actinides . . . . . . . . . . . . . . . . . 14

4.1 .4 Light nuclei . . . . . . . . . . . . . . . . . . . . . . . 18

4.2 ENDF/B-VII.0 evaluations: 6 isotopes . . . . . . . . . . . . . 20

$4.2 .1 \quad 155,156,157,158,160 \mathrm{Gd} \ldots \ldots \ldots \ldots$

$4.2 .2{ }^{232} \mathrm{Th} \ldots \ldots \ldots \ldots \ldots \ldots$

4.3 JENDL-3.3 evaluations: 3 isotopes . . . . . . . . . . . . . . . . 21

4.4 Missing evaluations: 7 isotopes . . . . . . . . . . . . . . . . . . 21

4.5 Discussion . . . . . . . . . . . . . . . . . . . . . . . 21

4.5.1 Thermal cross sections . . . . . . . . . . . . . . 22

4.5.2 Resonance integrals . . . . . . . . . . . . . . . . 25

4.5 .3 Fast neutron region . . . . . . . . . . . . . . . . . 30

$5 \quad \nu$-bar Covariances $\quad 32$

5.1 Procedure . . . . . . . . . . . . . . . . . . . . . 32

5.2 Results . . . . . . . . . . . . . . . . . . . . . 32 
6 Conclusions, Bibliography 34

A Appendix: Plots of cross section covariances 38

B Appendix: Tables of cross section covariances 135

C Appendix: Plots and tables of $\nu$-bar covariances 218 


\section{List of Figures}

$2.1{ }^{241} \mathrm{Am}$ from the Atlas of Neutron Resonances . . . . . . . . . . . . 6

$4.1{ }^{16} \mathrm{O}(\mathrm{n}, \mathrm{el})$ and ${ }^{16} \mathrm{O}(\mathrm{n}, \gamma)$ cross sections . . . . . . . . . . . . . . 19

A.1 ${ }^{1} \mathrm{H} \ldots \ldots \ldots \ldots \ldots$

A.2 ${ }^{16} \mathrm{O}(\mathrm{n}, \mathrm{el}) \ldots \ldots \ldots \ldots$

A.3 ${ }^{16} \mathrm{O}(\mathrm{n}, \gamma) \ldots \ldots \ldots \ldots \ldots \ldots$

A.4 ${ }^{19} \mathrm{~F}(\mathrm{n}, \mathrm{el}) \ldots \ldots \ldots \ldots \ldots$

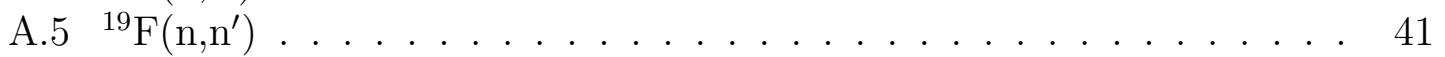

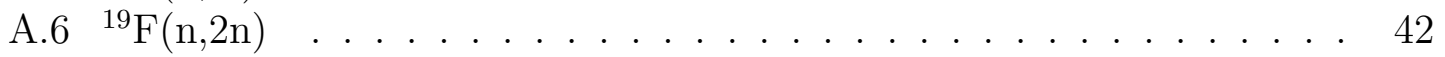

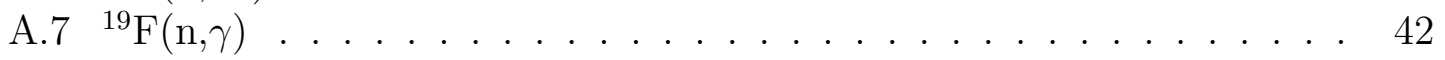

A.8 ${ }^{13} \mathrm{Na}(\mathrm{n}, \mathrm{el}) \ldots \ldots \ldots \ldots$

A.9 ${ }^{13} \mathrm{Na}\left(\mathrm{n}, \mathrm{n}^{\prime}\right) \ldots \ldots \ldots \ldots \ldots \ldots$

A.10 ${ }^{13} \mathrm{Na}(\mathrm{n}, 2 \mathrm{n}) \ldots \ldots \ldots \ldots \ldots \ldots . \ldots \ldots \ldots$

A.11 ${ }^{13} \mathrm{Na}(\mathrm{n}, \gamma) \ldots \ldots \ldots \ldots \ldots \ldots \ldots \ldots$

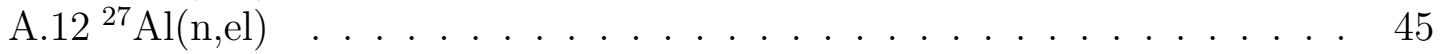

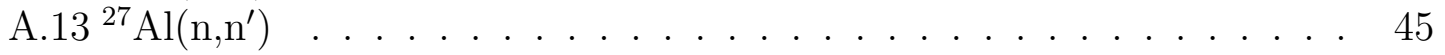

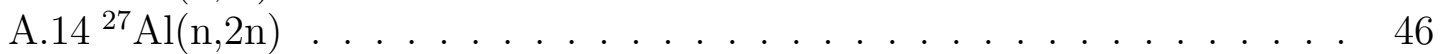

$\mathrm{A} .15{ }^{27} \mathrm{Al}(\mathrm{n}, \gamma) \ldots \ldots \ldots \ldots \ldots \ldots \ldots$

A.16 ${ }^{28} \mathrm{Si}(\mathrm{n}, \mathrm{el}) \ldots \ldots \ldots \ldots \ldots \ldots . \ldots \ldots \ldots$

A.17 ${ }^{28} \mathrm{Si}\left(\mathrm{n}, \mathrm{n}^{\prime}\right) \ldots \ldots \ldots \ldots \ldots \ldots \ldots$. . . . . . . . . . . . . . . . . . . . . . . . . . . . . . . . . . .

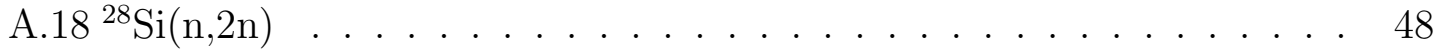

A.19 ${ }^{28} \mathrm{Si}(\mathrm{n}, \gamma) \ldots \ldots \ldots \ldots \ldots \ldots \ldots$

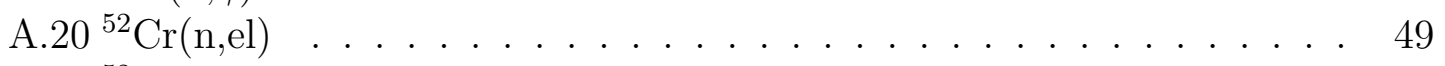

A.21 ${ }^{52} \mathrm{Cr}\left(\mathrm{n}, \mathrm{n}^{\prime}\right) \ldots \ldots \ldots \ldots \ldots \ldots . \ldots \ldots \ldots$

A. $22{ }^{52} \mathrm{Cr}(\mathrm{n}, 2 \mathrm{n}) \ldots \ldots \ldots \ldots \ldots \ldots \ldots$

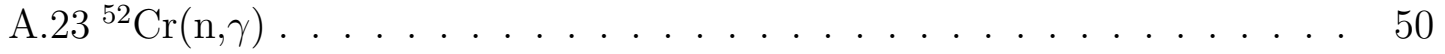

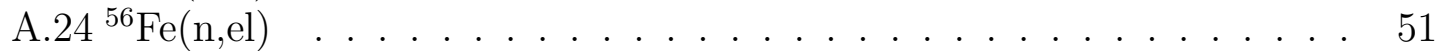

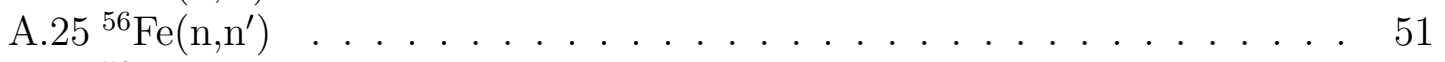

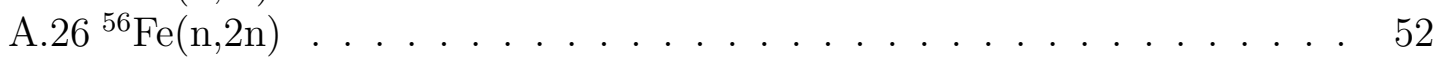

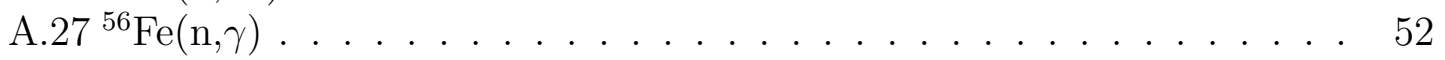

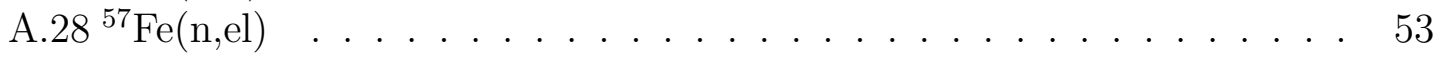

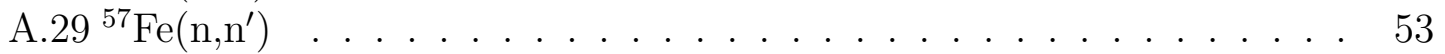

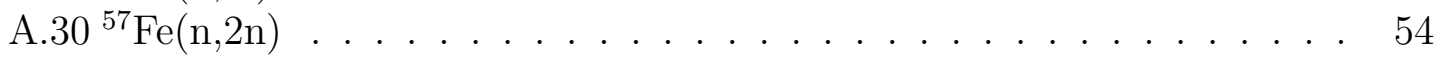

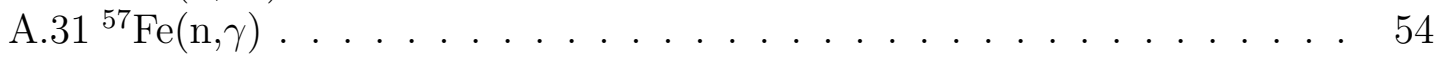


A.32 ${ }^{58} \mathrm{Ni}(\mathrm{n}, \mathrm{el})$. . . . . . . . . . . . . . . . . . . . . . . . 55

A.33 ${ }^{58} \mathrm{Ni}\left(\mathrm{n}, \mathrm{n}^{\prime}\right)$. . . . . . . . . . . . . . . . . . . . . . . 55

A.34 ${ }^{58} \mathrm{Ni}(\mathrm{n}, 2 \mathrm{n})$. . . . . . . . . . . . . . . . . . . . . . . . . 56

A.35 ${ }^{58} \mathrm{Ni}(\mathrm{n}, \gamma)$. . . . . . . . . . . . . . . . . . . . . . . 56

A.36 ${ }^{90} \operatorname{Zr}(\mathrm{n}, \mathrm{el})$......................... 57

A.37 ${ }^{90} \operatorname{Zr}\left(\mathrm{n}, \mathrm{n}^{\prime}\right)$.. . . . . . . . . . . . . . . . . . . . . 57

A.38 ${ }^{90} \operatorname{Zr}(\mathrm{n}, 2 \mathrm{n})$. . . . . . . . . . . . . . . . . . . . . . . 58

A.39 ${ }^{90} \operatorname{Zr}(\mathrm{n}, \gamma)$. . . . . . . . . . . . . . . . . . . . . . 58

A.40 ${ }^{91} \operatorname{Zr}(\mathrm{n}, \mathrm{el})$.. . . . . . . . . . . . . . . . . . . . . 59

A.41 ${ }^{91} \operatorname{Zr}\left(\mathrm{n}, \mathrm{n}^{\prime}\right)$. . . . . . . . . . . . . . . . . . . . . 59

A.42 ${ }^{91} \operatorname{Zr}(\mathrm{n}, 2 \mathrm{n})$. . . . . . . . . . . . . . . . . . . . . . . . 60

A.43 ${ }^{91} \operatorname{Zr}(\mathrm{n}, \gamma)$. . . . . . . . . . . . . . . . . . . . . . . . . 60

A.44 ${ }^{92} \operatorname{Zr}(\mathrm{n}, \mathrm{el})$. . . . . . . . . . . . . . . . . . . . . . . . 61

A.45 ${ }^{92} \operatorname{Zr}\left(\mathrm{n}, \mathrm{n}^{\prime}\right)$. . . . . . . . . . . . . . . . . . . . . . 61

A.46 ${ }^{92} \operatorname{Zr}(\mathrm{n}, 2 \mathrm{n})$. . . . . . . . . . . . . . . . . . . . . . . . 62

A.47 ${ }^{92} \operatorname{Zr}(\mathrm{n}, \gamma)$. . . . . . . . . . . . . . . . . . . . . . . . . 62

A.48 ${ }^{94} \operatorname{Zr}(\mathrm{n}, \mathrm{el})$.......................... . . . 63

A.49 ${ }^{94} \operatorname{Zr}\left(\mathrm{n}, \mathrm{n}^{\prime}\right)$. . . . . . . . . . . . . . . . . . . . . . . . . 63

A.50 ${ }^{94} \operatorname{Zr}(\mathrm{n}, 2 \mathrm{n})$. . . . . . . . . . . . . . . . . . . . . . . . . 64

A.51 ${ }^{94} \operatorname{Zr}(\mathrm{n}, \gamma)$. . . . . . . . . . . . . . . . . . . . 64

A.52 ${ }^{155} \mathrm{Gd}(\mathrm{n}, \mathrm{el})$. . . . . . . . . . . . . . . . . . . . . . . . . 65

$\mathrm{A} .53{ }^{155} \mathrm{Gd}\left(\mathrm{n}, \mathrm{n}^{\prime}\right)$. . . . . . . . . . . . . . . . . . . . . . . . 65

$\mathrm{A} .54{ }^{155} \mathrm{Gd}(\mathrm{n}, 2 \mathrm{n})$. . . . . . . . . . . . . . . . . . . . . . . . 66

$\mathrm{A} .55{ }^{155} \mathrm{Gd}(\mathrm{n}, \gamma)$. . . . . . . . . . . . . . . . . . . . . . . . 66

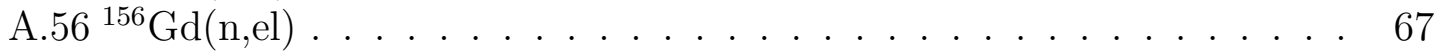

A.57 ${ }^{156} \mathrm{Gd}\left(\mathrm{n}, \mathrm{n}^{\prime}\right)$. . . . . . . . . . . . . . . . . . . . . . . . 67

A.58 ${ }^{156} \mathrm{Gd}(\mathrm{n}, 2 \mathrm{n})$. . . . . . . . . . . . . . . . . . . . . . . . . . 68

$\mathrm{A} .59{ }^{156} \mathrm{Gd}(\mathrm{n}, \gamma)$. . . . . . . . . . . . . . . . . . . . . . . . 68

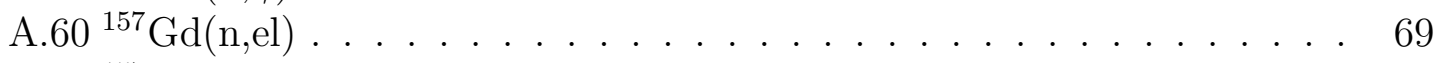

A.61 ${ }^{157} \mathrm{Gd}\left(\mathrm{n}, \mathrm{n}^{\prime}\right)$. . . . . . . . . . . . . . . . . . . . . . . . . . 69

A.62 ${ }^{157} \mathrm{Gd}(\mathrm{n}, 2 \mathrm{n})$. . . . . . . . . . . . . . . . . . . . . . . . . 70

A.63 ${ }^{157} \mathrm{Gd}(\mathrm{n}, \gamma)$. . . . . . . . . . . . . . . . . . . . . . . . . 70

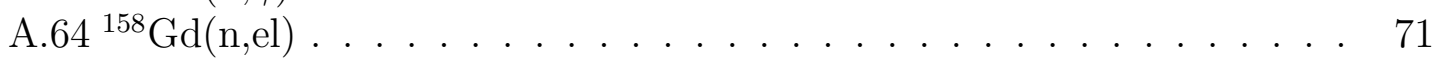

A. $65{ }^{158} \mathrm{Gd}\left(\mathrm{n}, \mathrm{n}^{\prime}\right)$. . . . . . . . . . . . . . . . . . . . . . . . . . . . 71

A. $66{ }^{158} \mathrm{Gd}(\mathrm{n}, 2 \mathrm{n})$. . . . . . . . . . . . . . . . . . . . . . . . . . . 72

A. $67{ }^{158} \mathrm{Gd}(\mathrm{n}, \gamma)$. . . . . . . . . . . . . . . . . . . . . . . . . . . 72

A. $68{ }^{160} \mathrm{Gd}(\mathrm{n}, \mathrm{el})$. . . . . . . . . . . . . . . . . . . . . . . . . . . . . . 73

A.69 ${ }^{160} \mathrm{Gd}\left(\mathrm{n}, \mathrm{n}^{\prime}\right)$. . . . . . . . . . . . . . . . . . . . . . . . 73

A.70 ${ }^{160} \mathrm{Gd}(\mathrm{n}, 2 \mathrm{n})$. . . . . . . . . . . . . . . . . . . . . . . . . . . . . . . 74

A.71 ${ }^{160} \mathrm{Gd}(\mathrm{n}, \gamma)$. . . . . . . . . . . . . . . . . . . . . . . . . . 74

A.72 ${ }^{166} \operatorname{Er}(\mathrm{n}, \mathrm{el})$. . . . . . . . . . . . . . . . . . . . . . . . 75

A.73 ${ }^{166} \operatorname{Er}\left(\mathrm{n}, \mathrm{n}^{\prime}\right)$. . . . . . . . . . . . . . . . . . . . . . . . 75

A.74 ${ }^{166} \operatorname{Er}(\mathrm{n}, 2 \mathrm{n})$. . . . . . . . . . . . . . . . . . . . . . . . . . . 76

A.75 ${ }^{166} \operatorname{Er}(\mathrm{n}, \gamma)$. . . . . . . . . . . . . . . . . . . . . . . . . 76

A.76 ${ }^{167} \operatorname{Er}(\mathrm{n}, \mathrm{el})$. . . . . . . . . . . . . . . . . . . . . . . . . 77 


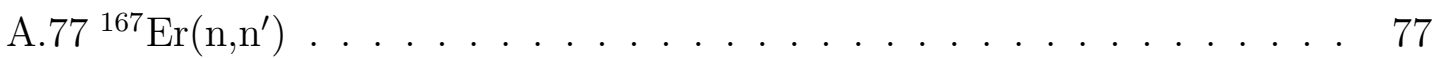

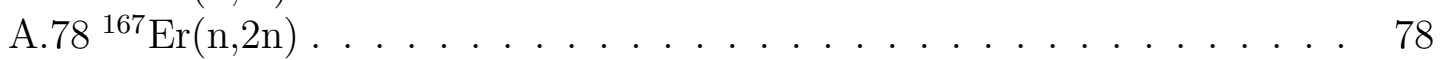

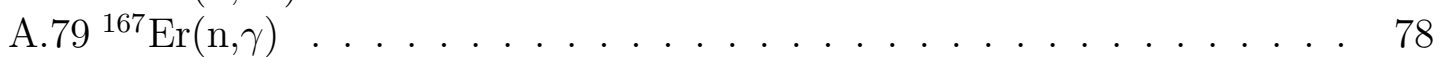

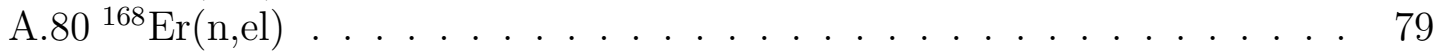

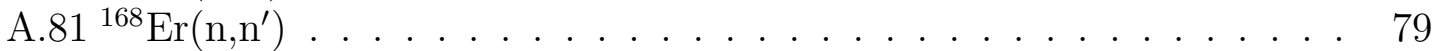

A.82 ${ }^{168} \operatorname{Er}(\mathrm{n}, 2 \mathrm{n}) \ldots \ldots \ldots \ldots \ldots \ldots$

A.83 ${ }^{168} \operatorname{Er}(\mathrm{n}, \gamma) \ldots \ldots \ldots \ldots \ldots \ldots$

A. $84{ }^{170} \operatorname{Er}(\mathrm{n}, \mathrm{el}) \ldots \ldots \ldots \ldots \ldots$. . . . . . . . . . . . . . . . . . . . . . . . . . . . . . . . . . . . . . . . . 81

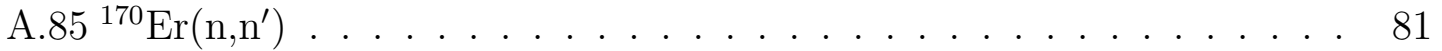

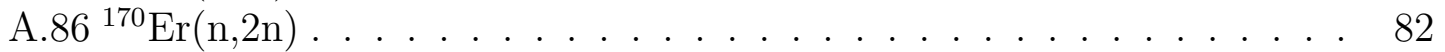

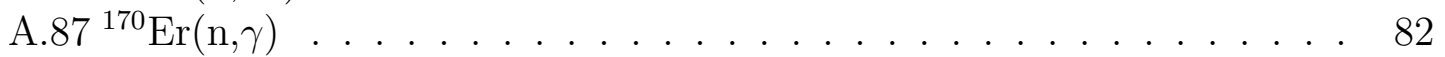

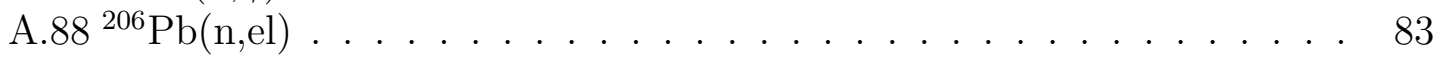

A.89 ${ }^{206} \mathrm{~Pb}\left(\mathrm{n}, \mathrm{n}^{\prime}\right) \ldots \ldots \ldots \ldots \ldots \ldots \ldots \ldots$

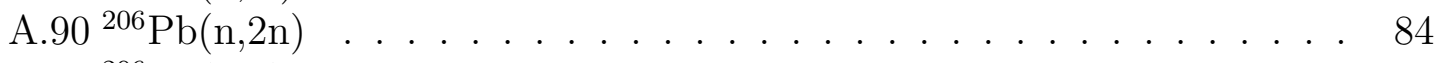

A.91 ${ }^{206} \mathrm{~Pb}(\mathrm{n}, \gamma) \ldots \ldots \ldots \ldots \ldots \ldots \ldots$

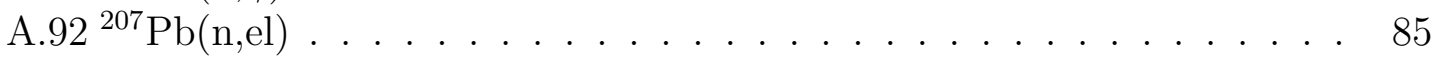

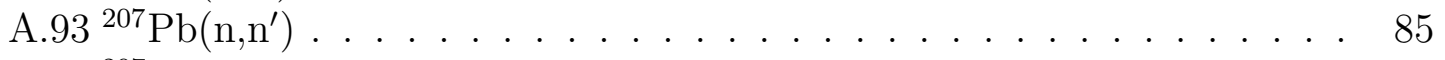

$\mathrm{A} .94{ }^{207} \mathrm{~Pb}(\mathrm{n}, 2 \mathrm{n}) \ldots \ldots \ldots \ldots \ldots \ldots$

$\mathrm{A} .95{ }^{207} \mathrm{~Pb}(\mathrm{n}, \gamma) \ldots \ldots \ldots \ldots \ldots \ldots . \ldots \ldots$

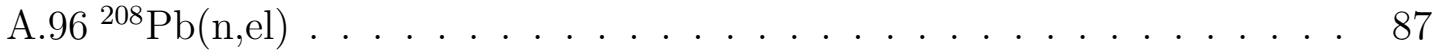

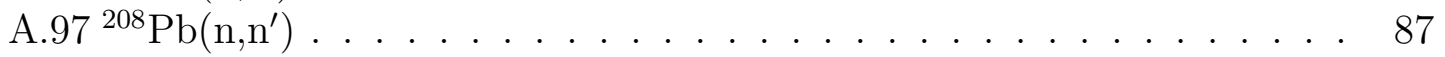

$\mathrm{A} .98{ }^{208} \mathrm{~Pb}(\mathrm{n}, 2 \mathrm{n}) \ldots \ldots \ldots \ldots \ldots . \ldots \ldots . \ldots \ldots$

$\mathrm{A} .99{ }^{208} \mathrm{~Pb}(\mathrm{n}, \gamma) \ldots \ldots \ldots \ldots \ldots$

A.100 ${ }^{209} \operatorname{Bi}(\mathrm{n}, \mathrm{el}) \ldots \ldots \ldots \ldots \ldots \ldots \ldots \ldots$

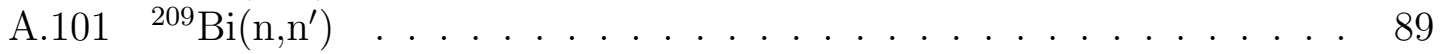

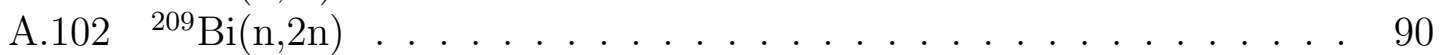

A.103 ${ }^{209} \operatorname{Bi}(n, \gamma) \ldots \ldots \ldots \ldots \ldots \ldots$

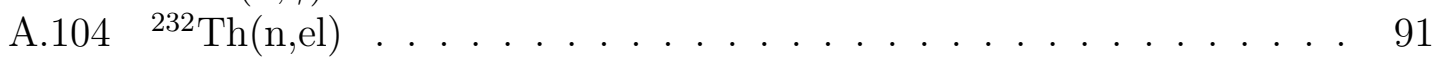

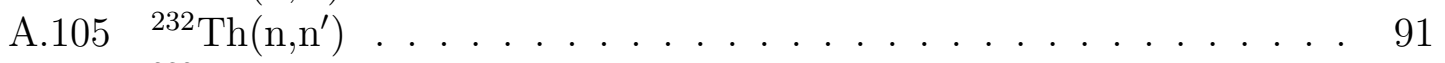

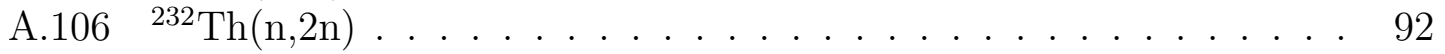

A.107 ${ }^{232} \operatorname{Th}(\mathrm{n}, \mathrm{f}) \ldots \ldots \ldots \ldots \ldots \ldots$

A.108 ${ }^{232} \operatorname{Th}(\mathrm{n}, \gamma) \ldots \ldots \ldots \ldots \ldots \ldots$

A.109 ${ }^{233} \mathrm{U}(\mathrm{n}, \mathrm{el}) \ldots \ldots \ldots \ldots \ldots \ldots . \ldots \ldots \ldots$

A.110 ${ }^{233} \mathrm{U}\left(\mathrm{n}, \mathrm{n}^{\prime}\right) \ldots \ldots \ldots \ldots \ldots \ldots \ldots \ldots \ldots \ldots$

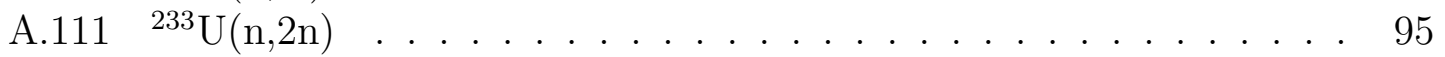

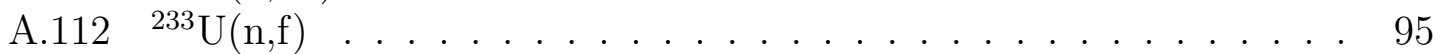

A.113 ${ }^{233} \mathrm{U}(\mathrm{n}, \gamma) \ldots \ldots \ldots \ldots \ldots \ldots$

A.114 ${ }^{234} \mathrm{U}(\mathrm{n}, \mathrm{el}) \ldots \ldots \ldots \ldots \ldots \ldots$

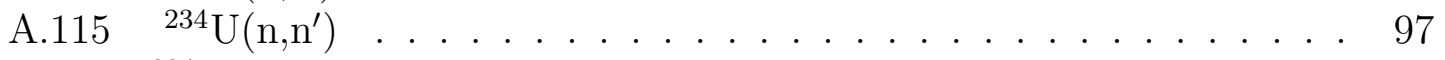

A.116 ${ }^{234} \mathrm{U}(\mathrm{n}, 2 \mathrm{n}) \ldots \ldots \ldots \ldots . \ldots \ldots \ldots$

A.117 ${ }^{234} \mathrm{U}(\mathrm{n}, \mathrm{f}) \ldots \ldots \ldots \ldots$

A.118 ${ }^{234} \mathrm{U}(\mathrm{n}, \gamma) \ldots \ldots \ldots \ldots . \ldots \ldots$

A.119 ${ }^{236} \mathrm{U}(\mathrm{n}, \mathrm{el}) \ldots \ldots \ldots \ldots \ldots . \ldots \ldots \ldots$

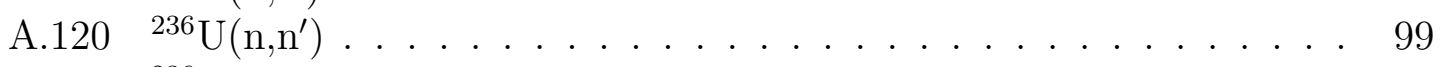

A.121 ${ }^{236} \mathrm{U}(\mathrm{n}, 2 \mathrm{n}) \ldots \ldots \ldots \ldots$

D. Rochman et al. 
A.122 ${ }^{236} \mathrm{U}(\mathrm{n}, \mathrm{f}) \ldots \ldots \ldots \ldots \ldots$

A.123 ${ }^{236} \mathrm{U}(\mathrm{n}, \gamma) \ldots \ldots \ldots \ldots \ldots 1 . \ldots \ldots \ldots \ldots$

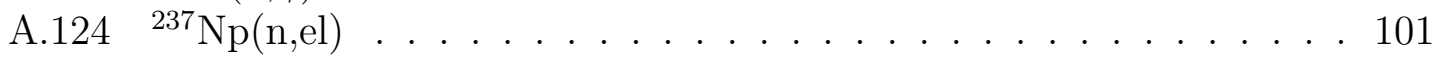

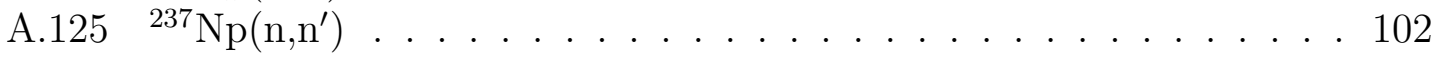

A.126 ${ }^{237} \mathrm{~Np}(\mathrm{n}, 2 \mathrm{n}) \ldots \ldots \ldots \ldots$

A.127 ${ }^{237} \mathrm{~Np}(\mathrm{n}, \mathrm{f}) \ldots \ldots \ldots \ldots \ldots$

A.128 ${ }^{237} \mathrm{~Np}(\mathrm{n}, \gamma) \ldots \ldots \ldots \ldots \ldots \ldots$

A.129 ${ }^{238} \mathrm{U} \ldots \ldots \ldots \ldots \ldots \ldots \ldots$

A.130 ${ }^{238} \mathrm{Pu}(\mathrm{n}, \mathrm{el}) \ldots \ldots \ldots \ldots \ldots$

A.131 ${ }^{238} \mathrm{Pu}\left(\mathrm{n}, \mathrm{n}^{\prime}\right) \ldots \ldots \ldots \ldots \ldots \ldots$

A.132 ${ }^{238} \mathrm{Pu}(\mathrm{n}, 2 \mathrm{n}) \ldots \ldots \ldots \ldots \ldots \ldots$

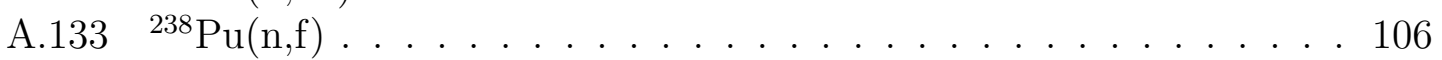

A.134 ${ }^{238} \mathrm{Pu}(\mathrm{n}, \gamma) \ldots \ldots \ldots \ldots \ldots \ldots$

A.135 ${ }^{239} \mathrm{Pu}(\mathrm{n}, \mathrm{el}) \ldots \ldots \ldots \ldots \ldots$

A.136 ${ }^{239} \mathrm{Pu}\left(\mathrm{n}, \mathrm{n}^{\prime}\right) \ldots \ldots \ldots \ldots \ldots \ldots$

A.137 ${ }^{239} \mathrm{Pu}(\mathrm{n}, 2 \mathrm{n}) \ldots \ldots \ldots \ldots \ldots \ldots \ldots$

A.138 ${ }^{239} \mathrm{Pu}(\mathrm{n}, \mathrm{f}) \ldots \ldots \ldots \ldots \ldots \ldots$

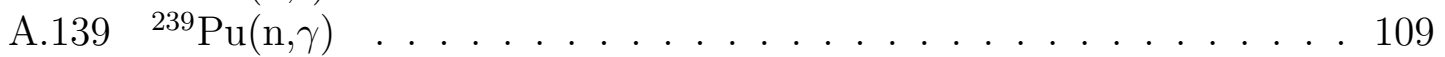

A.140 ${ }^{240} \mathrm{Pu}(\mathrm{n}, \mathrm{el}) \ldots \ldots \ldots \ldots$

A.141 ${ }^{240} \mathrm{Pu}\left(\mathrm{n}, \mathrm{n}^{\prime}\right) \ldots \ldots \ldots \ldots \ldots \ldots$

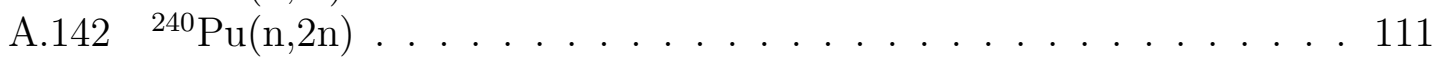

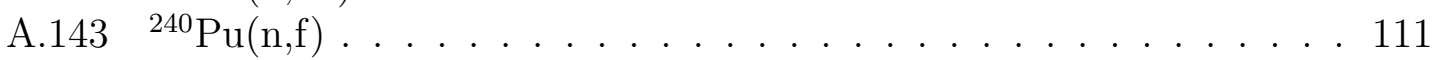

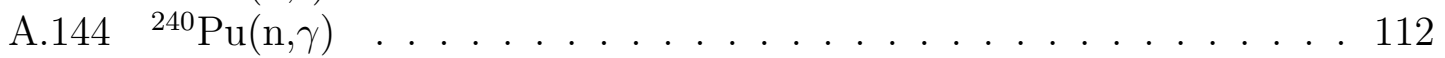

A.145 ${ }^{241} \mathrm{Pu}(\mathrm{n}, \mathrm{el}) \ldots \ldots \ldots \ldots . \ldots \ldots 112$

A.146 ${ }^{241} \mathrm{Pu}\left(\mathrm{n}, \mathrm{n}^{\prime}\right) \ldots \ldots \ldots \ldots \ldots \ldots$

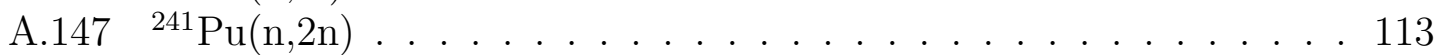

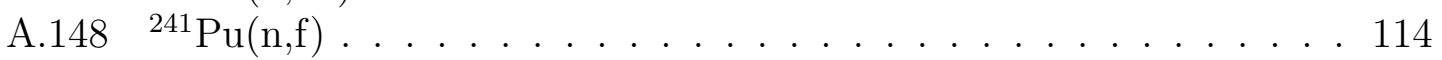

A.149 ${ }^{241} \mathrm{Pu}(\mathrm{n}, \gamma) \ldots \ldots \ldots \ldots \ldots \ldots \ldots$

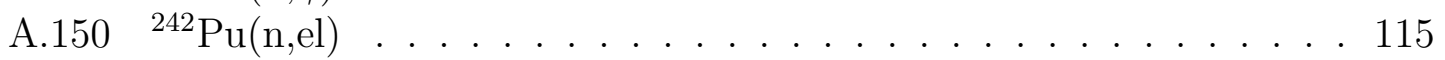

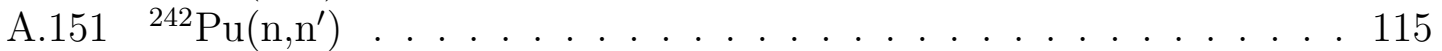

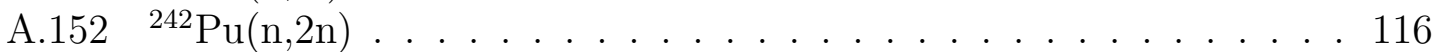

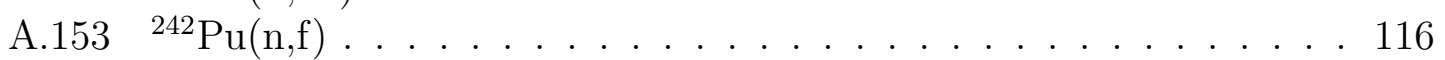

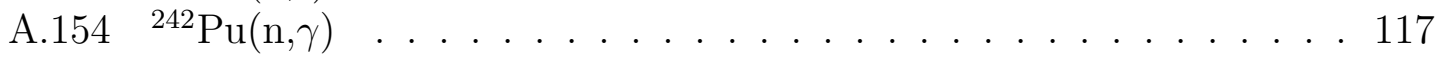

A.155 ${ }^{241} \mathrm{Am}(\mathrm{n}, \mathrm{el}) \ldots \ldots \ldots \ldots \ldots \ldots \ldots$

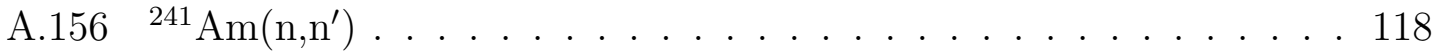

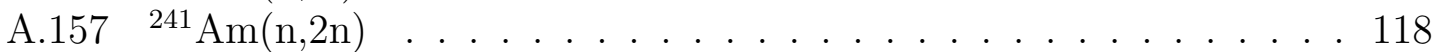

A.158 ${ }^{241} \mathrm{Am}(\mathrm{n}, \mathrm{f}) \ldots \ldots \ldots \ldots \ldots \ldots$

A.159 ${ }^{241} \mathrm{Am}(\mathrm{n}, \gamma) \ldots \ldots \ldots \ldots \ldots \ldots$

A.160 ${ }^{242 m} \mathrm{Am}(\mathrm{n}, \mathrm{el}) \ldots \ldots \ldots \ldots \ldots$

A.161 ${ }^{242 m} \operatorname{Am}\left(\mathrm{n}, \mathrm{n}^{\prime}\right) \quad \ldots \ldots \ldots \ldots \ldots . \ldots \ldots 120 . \ldots \ldots$

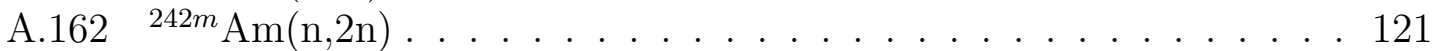

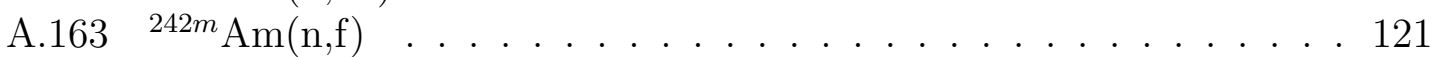

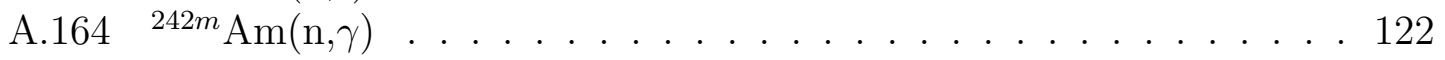

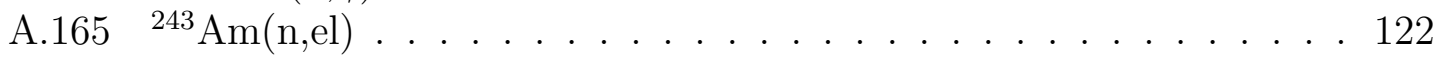

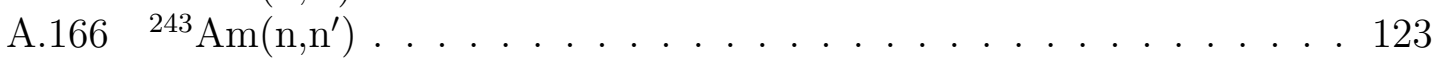




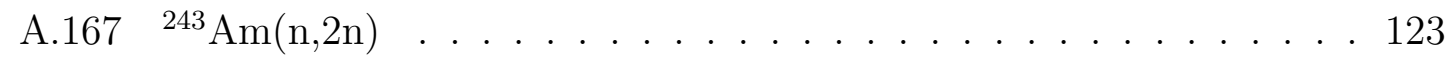

A.168 ${ }^{243} \mathrm{Am}(\mathrm{n}, \mathrm{f}) \ldots \ldots \ldots \ldots \ldots \ldots \ldots . \ldots \ldots \ldots$

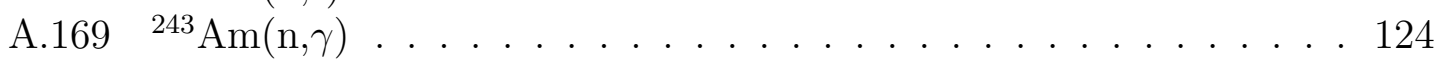

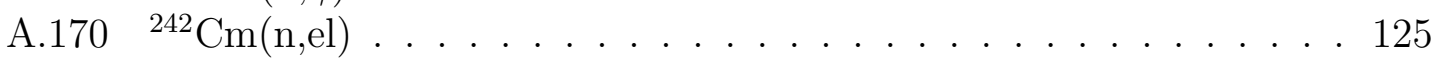

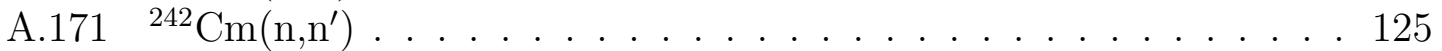

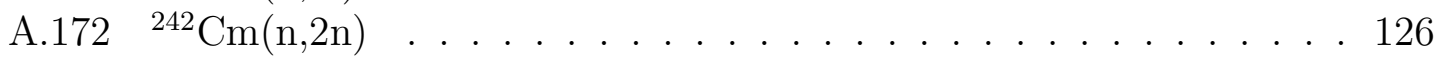

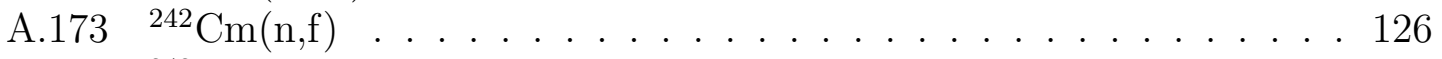

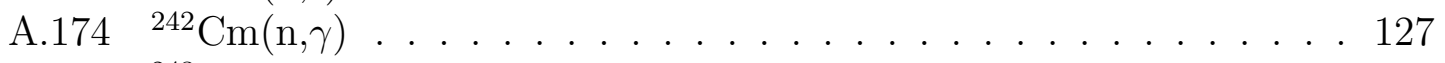

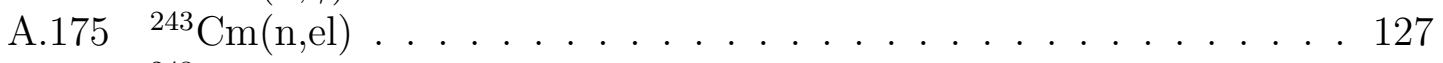

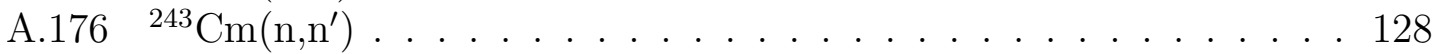

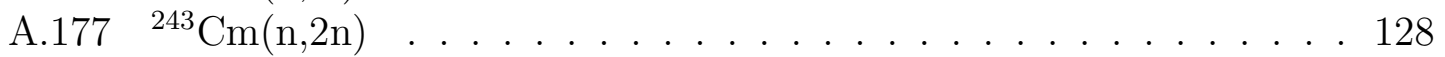

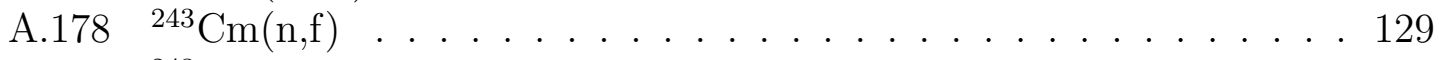

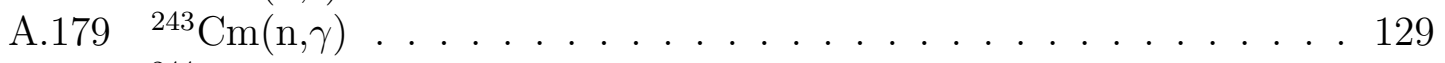

A.180 ${ }^{244} \mathrm{Cm}(\mathrm{n}, \mathrm{el}) \ldots \ldots \ldots \ldots . \ldots \ldots$

A.181 ${ }^{244} \mathrm{Cm}\left(\mathrm{n}, \mathrm{n}^{\prime}\right) \ldots \ldots \ldots \ldots \ldots \ldots$

A.182 ${ }^{244} \mathrm{Cm}(\mathrm{n}, 2 \mathrm{n}) \ldots \ldots \ldots \ldots \ldots . \ldots \ldots \ldots$

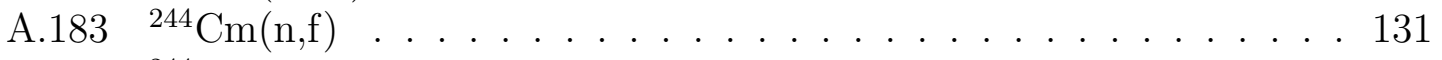

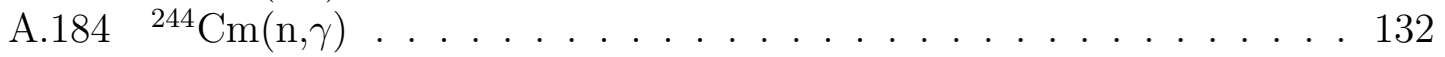

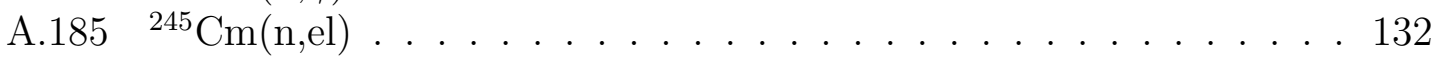

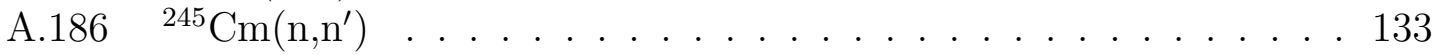

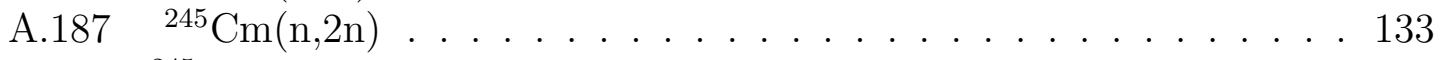

A.188 ${ }^{245} \mathrm{Cm}(\mathrm{n}, \mathrm{f}) \ldots \ldots \ldots \ldots \ldots \ldots . \ldots \ldots \ldots \ldots$

A.189 ${ }^{245} \mathrm{Cm}(\mathrm{n}, \gamma) \ldots \ldots \ldots \ldots \ldots \ldots \ldots . \ldots \ldots \ldots$

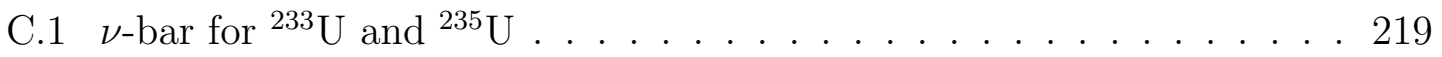

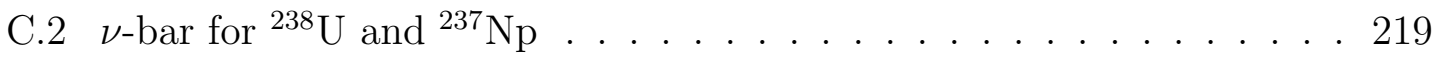

C.3 $\nu$-bar for ${ }^{239} \mathrm{Pu}$ and ${ }^{240} \mathrm{Pu}$. . . . . . . . . . . . . . . . . . . . . . 220

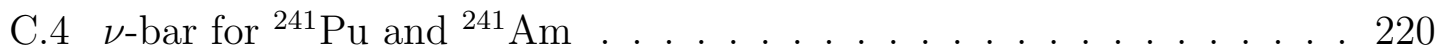

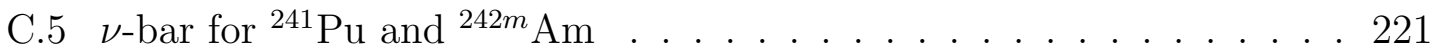




\section{List of Tables}

1.1 Priority list of WPEC SG26 materials . . . . . . . . . . . . . . 3

4.1 Thermal-energy elastic, fission and capture cross section uncertainties 24

4.2 Capture resonance integrals . . . . . . . . . . . . . . . . . . . 28

4.3 Fission resonance integrals . . . . . . . . . . . . . . . . . . 30

B.1 Definition of the 15-energy groups . . . . . . . . . . . . 135

B.2 ${ }^{1} \mathrm{H}(\mathrm{n}, \mathrm{el}) \ldots \ldots \ldots \ldots$

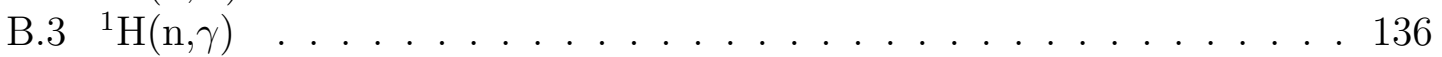

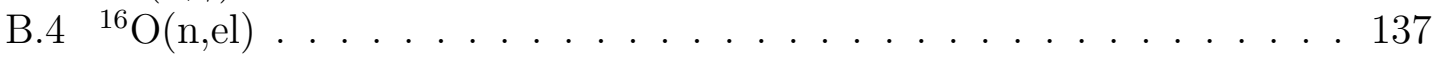

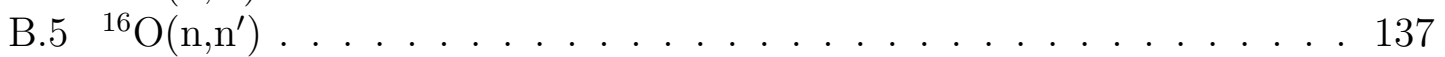

B.6 ${ }^{16} \mathrm{O}(\mathrm{n}, 2 \mathrm{n}) \ldots \ldots \ldots \ldots$

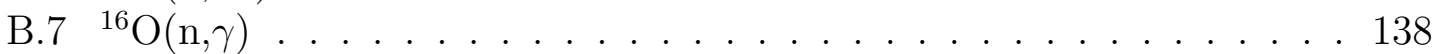

B.8 ${ }^{19} \mathrm{~F}(\mathrm{n}, \mathrm{el}) \ldots \ldots \ldots \ldots$

B.9 ${ }^{19} \mathrm{~F}\left(\mathrm{n}, \mathrm{n}^{\prime}\right) \ldots \ldots \ldots \ldots \ldots \ldots \ldots$

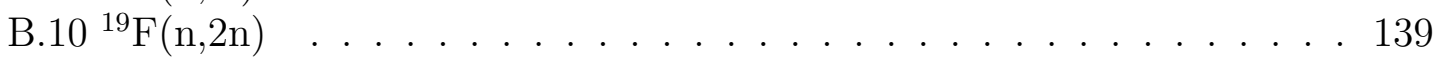

B. $11{ }^{19} \mathrm{~F}(\mathrm{n}, \gamma) \ldots \ldots \ldots \ldots \ldots \ldots$

B.12 ${ }^{23} \mathrm{Na}(\mathrm{n}, \mathrm{el}) \ldots \ldots \ldots \ldots$

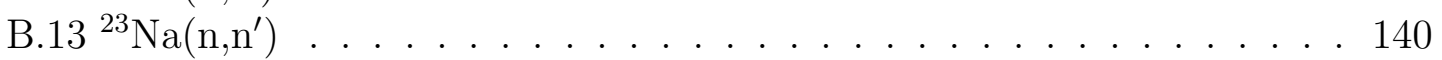

B.14 ${ }^{23} \mathrm{Na}(\mathrm{n}, 2 \mathrm{n}) \ldots \ldots \ldots \ldots \ldots \ldots . \ldots \ldots \ldots$

B.15 ${ }^{23} \mathrm{Na}(\mathrm{n}, \gamma) \ldots \ldots \ldots \ldots \ldots$

B.16 ${ }^{27} \mathrm{Al}(\mathrm{n}, \mathrm{el}) \ldots \ldots \ldots \ldots \ldots$

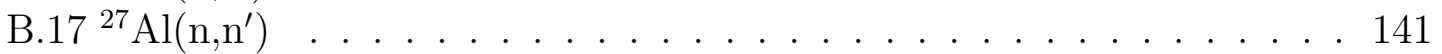

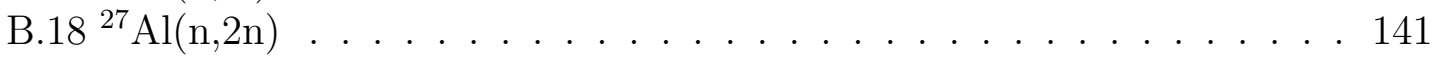

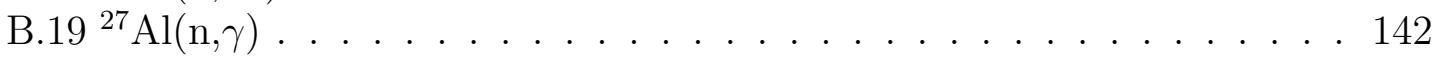

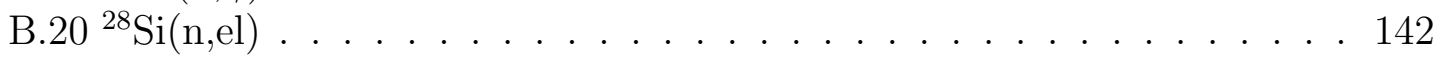

B. $21{ }^{28} \mathrm{Si}\left(\mathrm{n}, \mathrm{n}^{\prime}\right) \ldots \ldots \ldots \ldots \ldots$

B.22 ${ }^{28} \mathrm{Si}(\mathrm{n}, 2 \mathrm{n}) \ldots \ldots \ldots \ldots$

B. $23{ }^{28} \mathrm{Si}(\mathrm{n}, \gamma) \ldots \ldots \ldots \ldots \ldots \ldots \ldots . \ldots \ldots \ldots$

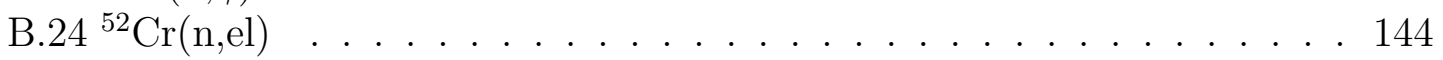

B. $25{ }^{52} \mathrm{Cr}\left(\mathrm{n}, \mathrm{n}^{\prime}\right) \ldots \ldots \ldots \ldots \ldots \ldots . \ldots \ldots \ldots$

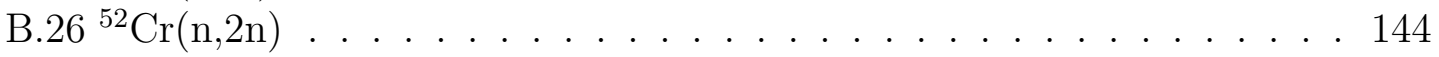

B. $27{ }^{52} \mathrm{Cr}(\mathrm{n}, \gamma) \ldots \ldots \ldots \ldots \ldots \ldots \ldots \ldots \ldots$

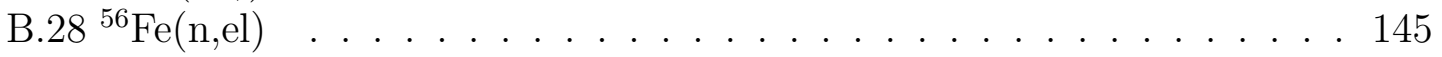

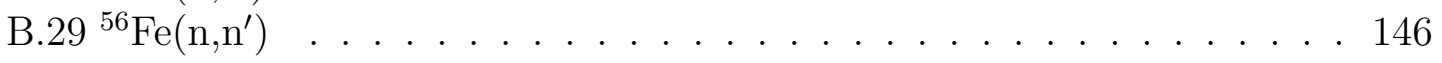




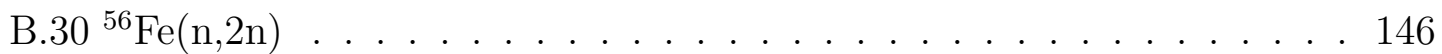

B. $31{ }^{56} \mathrm{Fe}(\mathrm{n}, \gamma) \ldots \ldots \ldots \ldots \ldots \ldots \ldots \ldots$

B.32 ${ }^{57} \mathrm{Fe}(\mathrm{n}, \mathrm{el}) \ldots \ldots \ldots \ldots \ldots \ldots \ldots \ldots$

B.33 ${ }^{57} \mathrm{Fe}\left(\mathrm{n}, \mathrm{n}^{\prime}\right) \ldots \ldots \ldots \ldots \ldots \ldots$

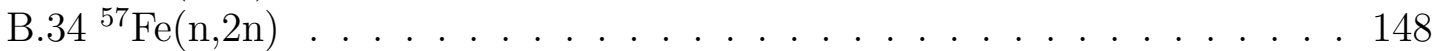

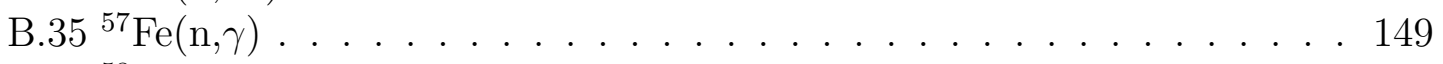

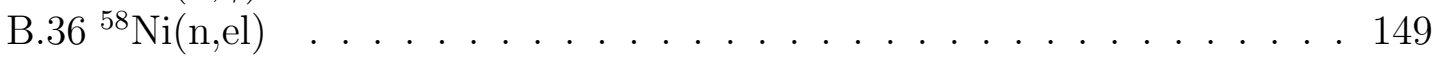

B. $37^{58} \mathrm{Ni}\left(\mathrm{n}, \mathrm{n}^{\prime}\right) \ldots \ldots \ldots \ldots \ldots \ldots \ldots \ldots$

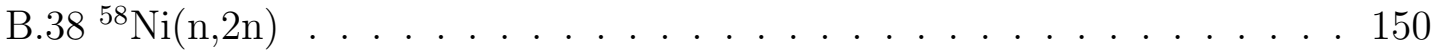

B.39 ${ }^{58} \mathrm{Ni}(\mathrm{n}, \gamma) \ldots \ldots \ldots \ldots \ldots \ldots$

B.40 ${ }^{90} \operatorname{Zr}(\mathrm{n}, \mathrm{el}) \ldots \ldots \ldots \ldots \ldots \ldots \ldots$

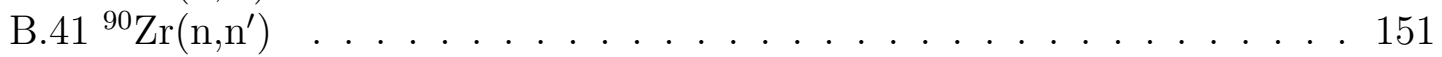

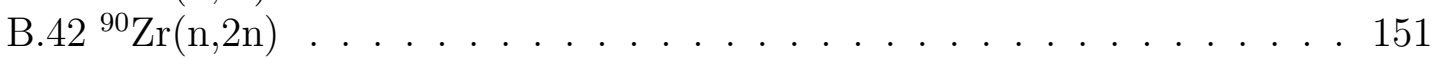

B.43 ${ }^{90} \operatorname{Zr}(\mathrm{n}, \gamma) \ldots \ldots \ldots \ldots \ldots \ldots \ldots$

B.44 ${ }^{91} \operatorname{Zr}(\mathrm{n}, \mathrm{el}) \ldots \ldots \ldots \ldots \ldots \ldots$

B. $45^{91} \operatorname{Zr}\left(\mathrm{n}, \mathrm{n}^{\prime}\right) \ldots \ldots \ldots \ldots \ldots \ldots \ldots \ldots \ldots$

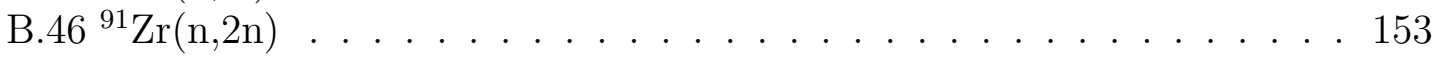

B.47 ${ }^{91} \mathrm{Zr}(\mathrm{n}, \gamma) \ldots \ldots \ldots \ldots \ldots \ldots \ldots \ldots$

B.48 ${ }^{92} \operatorname{Zr}(\mathrm{n}, \mathrm{el}) \ldots \ldots \ldots \ldots \ldots \ldots$

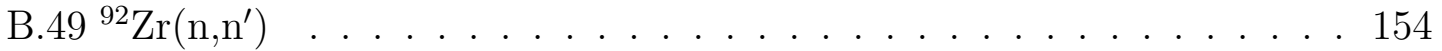

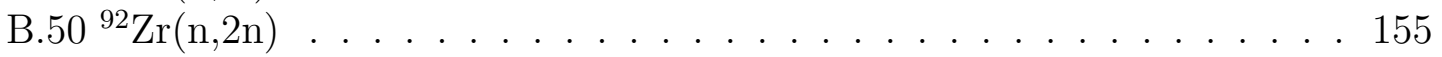

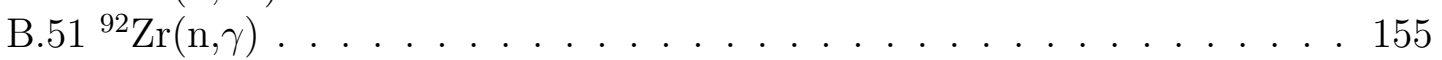

B.52 ${ }^{94} \operatorname{Zr}(\mathrm{n}, \mathrm{el}) \ldots \ldots \ldots \ldots \ldots \ldots$

B.53 ${ }^{94} \operatorname{Zr}\left(\mathrm{n}, \mathrm{n}^{\prime}\right) \ldots \ldots \ldots \ldots \ldots \ldots \ldots \ldots \ldots$

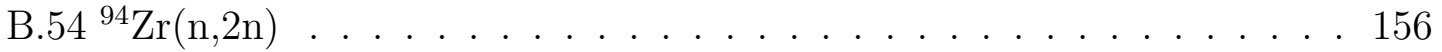

B.55 ${ }^{94} \operatorname{Zr}(\mathrm{n}, \gamma) \ldots \ldots \ldots \ldots \ldots \ldots \ldots \ldots \ldots \ldots$

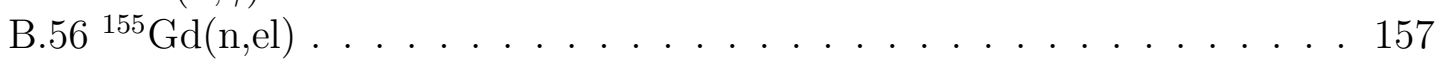

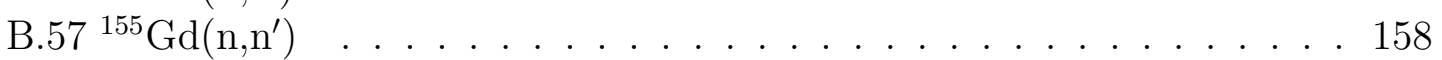

B.58 ${ }^{155} \mathrm{Gd}(\mathrm{n}, 2 \mathrm{n}) \ldots \ldots \ldots \ldots \ldots \ldots \ldots$

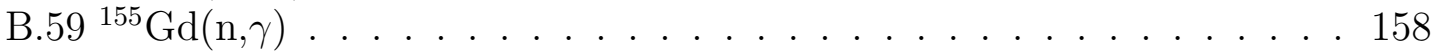

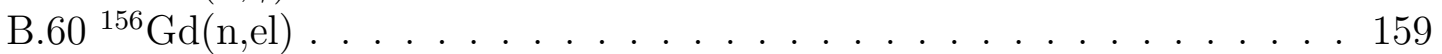

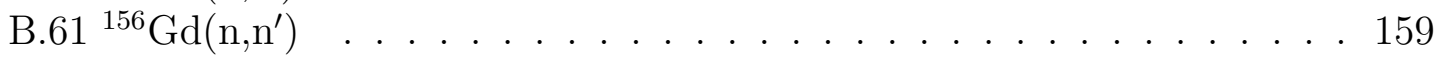

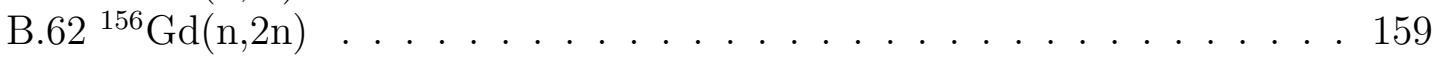

B.63 ${ }^{156} \mathrm{Gd}(\mathrm{n}, \gamma) \ldots \ldots \ldots \ldots \ldots \ldots$

B.64 ${ }^{157} \mathrm{Gd}(\mathrm{n}, \mathrm{el}) \ldots \ldots \ldots \ldots \ldots$

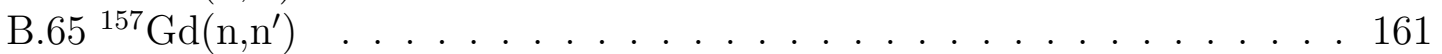

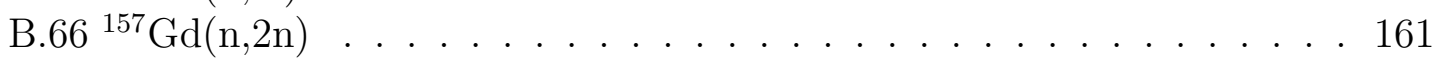

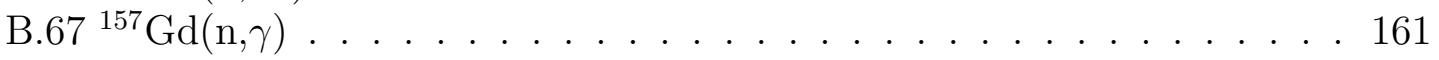

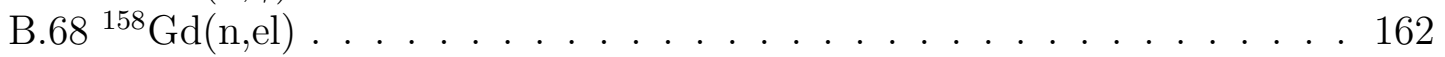

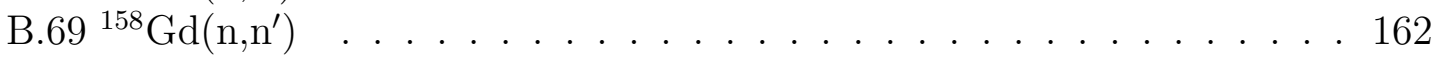

B.70 ${ }^{158} \mathrm{Gd}(\mathrm{n}, 2 \mathrm{n}) \ldots \ldots \ldots \ldots \ldots$

B.71 ${ }^{158} \mathrm{Gd}(\mathrm{n}, \gamma) \ldots \ldots \ldots \ldots \ldots \ldots \ldots$

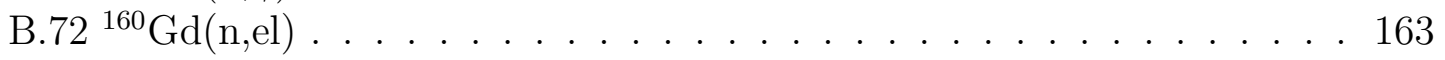

B.73 ${ }^{160} \mathrm{Gd}\left(\mathrm{n}, \mathrm{n}^{\prime}\right) \ldots \ldots \ldots \ldots \ldots . \ldots \ldots \ldots$

B. $74{ }^{160} \mathrm{Gd}(\mathrm{n}, 2 \mathrm{n}) \ldots \ldots \ldots \ldots \ldots$ 
B.75 ${ }^{160} \mathrm{Gd}(\mathrm{n}, \gamma) \ldots \ldots \ldots \ldots \ldots \ldots \ldots \ldots \ldots$

B.76 ${ }^{166} \operatorname{Er}(\mathrm{n}, \mathrm{el}) \ldots \ldots \ldots \ldots \ldots \ldots$

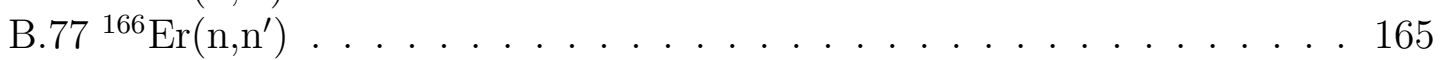

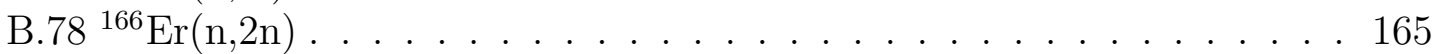

B.79 ${ }^{166} \operatorname{Er}(\mathrm{n}, \gamma) \ldots \ldots \ldots \ldots \ldots \ldots$

B.80 ${ }^{167} \operatorname{Er}(\mathrm{n}, \mathrm{el}) \ldots \ldots \ldots \ldots \ldots \ldots$

B.81 ${ }^{167} \operatorname{Er}\left(n, n^{\prime}\right) \ldots \ldots \ldots \ldots \ldots \ldots$

B.82 ${ }^{167} \operatorname{Er}(\mathrm{n}, 2 \mathrm{n}) \ldots \ldots \ldots \ldots \ldots \ldots \ldots$

B.83 ${ }^{167} \operatorname{Er}(\mathrm{n}, \gamma) \ldots \ldots \ldots \ldots \ldots \ldots \ldots$

B. $84{ }^{168} \operatorname{Er}(\mathrm{n}, \mathrm{el}) \ldots \ldots \ldots \ldots$

B.85 ${ }^{168} \operatorname{Er}\left(\mathrm{n}, \mathrm{n}^{\prime}\right) \ldots \ldots \ldots \ldots \ldots \ldots$

B.86 ${ }^{168} \operatorname{Er}(\mathrm{n}, 2 \mathrm{n}) \ldots \ldots \ldots \ldots \ldots$

B.87 ${ }^{168} \operatorname{Er}(\mathrm{n}, \gamma) \ldots \ldots \ldots \ldots \ldots \ldots \ldots$

B. $88{ }^{170} \operatorname{Er}(\mathrm{n}, \mathrm{el}) \ldots \ldots \ldots \ldots$

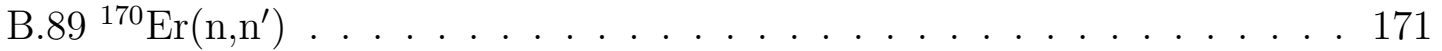

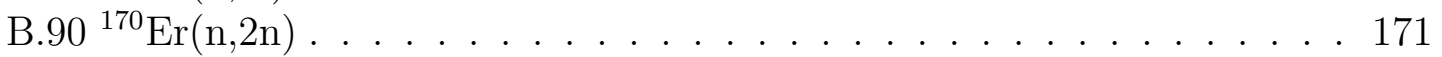

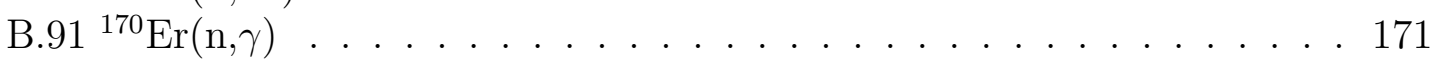

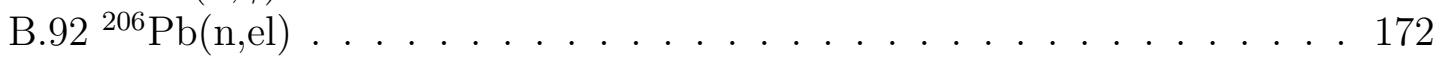

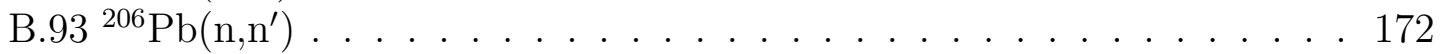

B.94 ${ }^{206} \mathrm{~Pb}(\mathrm{n}, 2 \mathrm{n}) \ldots \ldots \ldots \ldots$

B.95 ${ }^{206} \mathrm{~Pb}(\mathrm{n}, \gamma) \ldots \ldots \ldots \ldots \ldots \ldots$

B.96 ${ }^{207} \mathrm{~Pb}(\mathrm{n}, \mathrm{el}) \ldots \ldots \ldots \ldots \ldots \ldots$

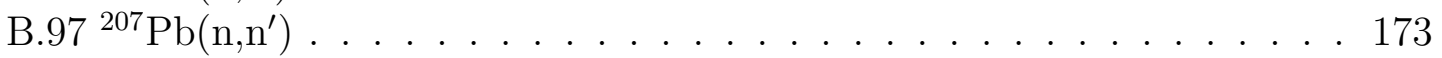

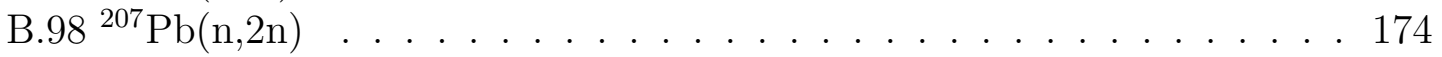

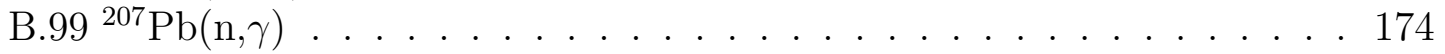

B.100 ${ }^{208} \mathrm{~Pb}(\mathrm{n}, \mathrm{el}) \ldots \ldots \ldots \ldots \ldots$. . . . . . . . . . . . . . . . . . . . . . . . . . . .

B.101 ${ }^{208} \mathrm{~Pb}\left(\mathrm{n}, \mathrm{n}^{\prime}\right) \ldots \ldots \ldots \ldots \ldots \ldots \ldots . \ldots \ldots \ldots$

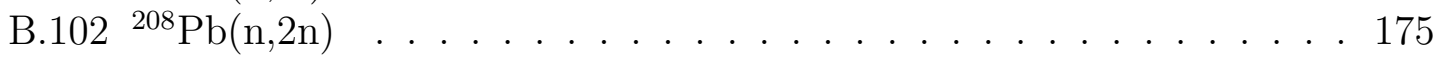

B.103 ${ }^{208} \mathrm{~Pb}(\mathrm{n}, \gamma) \ldots \ldots \ldots \ldots \ldots \ldots \ldots$

B.104 ${ }^{209} \mathrm{Bi}(\mathrm{n}, \mathrm{el}) \ldots \ldots \ldots \ldots \ldots$

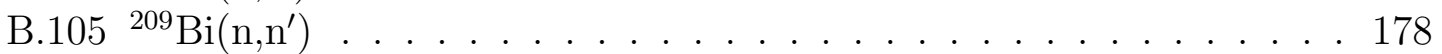

B.106 ${ }^{209} \operatorname{Bi}(\mathrm{n}, 2 \mathrm{n}) \ldots \ldots \ldots \ldots \ldots \ldots \ldots$

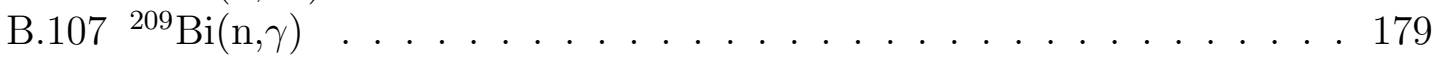

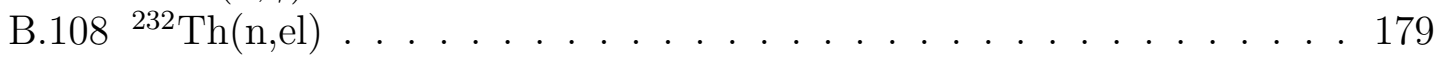

B.109 ${ }^{232} \operatorname{Th}\left(\mathrm{n}, \mathrm{n}^{\prime}\right) \ldots \ldots \ldots \ldots \ldots$

B.110 ${ }^{232} \operatorname{Th}(\mathrm{n}, 2 \mathrm{n}) \ldots \ldots \ldots \ldots \ldots$

B.111 ${ }^{232} \operatorname{Th}(\mathrm{n}, \mathrm{f}) \ldots \ldots \ldots \ldots \ldots \ldots \ldots$

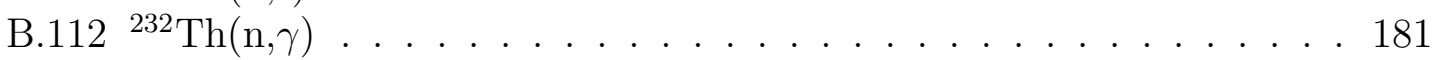

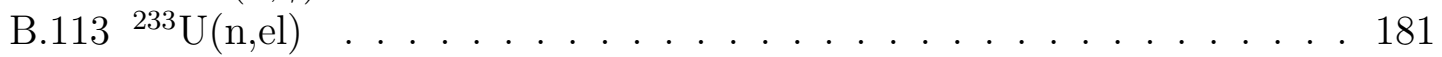

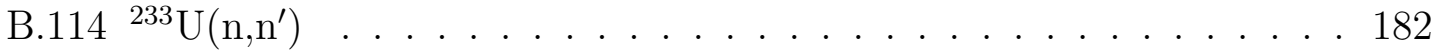

B.115 ${ }^{233} \mathrm{U}(\mathrm{n}, 2 \mathrm{n}) \ldots \ldots \ldots \ldots$

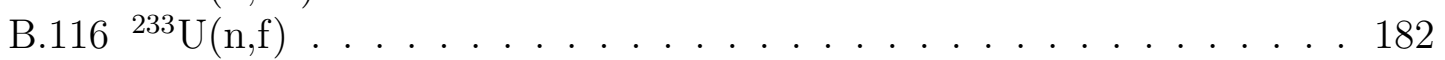

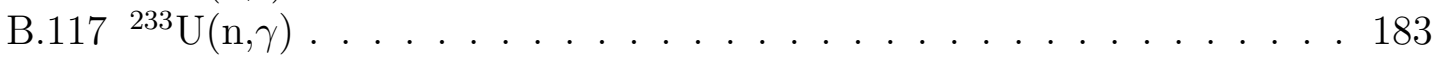

B.118 ${ }^{234} \mathrm{U}(\mathrm{n}, \mathrm{el}) \ldots \ldots \ldots \ldots$

B.119 ${ }^{234} \mathrm{U}\left(\mathrm{n}, \mathrm{n}^{\prime}\right) \ldots \ldots \ldots \ldots \ldots . \ldots \ldots \ldots$ 
B.120 ${ }^{234} \mathrm{U}(\mathrm{n}, 2 \mathrm{n}) \ldots \ldots \ldots \ldots \ldots \ldots \ldots$

B.121 ${ }^{234} \mathrm{U}(\mathrm{n}, \mathrm{f}) \ldots \ldots \ldots \ldots \ldots \ldots \ldots$

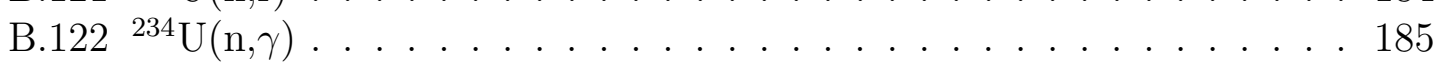

B.123 ${ }^{236} \mathrm{U}(\mathrm{n}, \mathrm{el}) \ldots \ldots \ldots \ldots \ldots$

B.124 ${ }^{236} \mathrm{U}\left(\mathrm{n}, \mathrm{n}^{\prime}\right) \ldots \ldots \ldots \ldots \ldots$

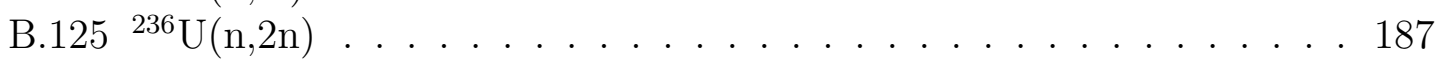

B.126 ${ }^{236} \mathrm{U}(\mathrm{n}, \mathrm{f}) \ldots \ldots \ldots \ldots \ldots \ldots$

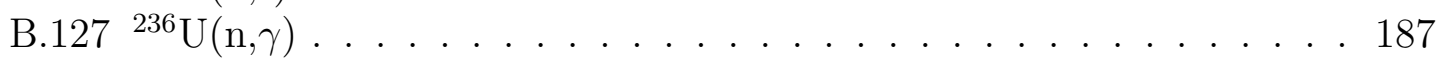

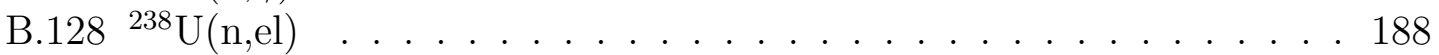

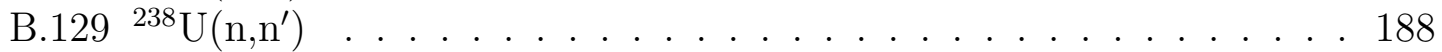

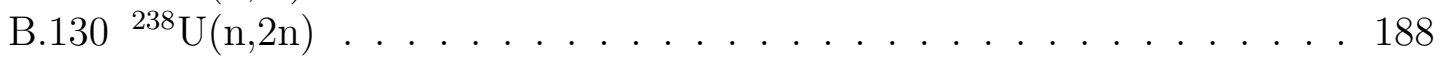

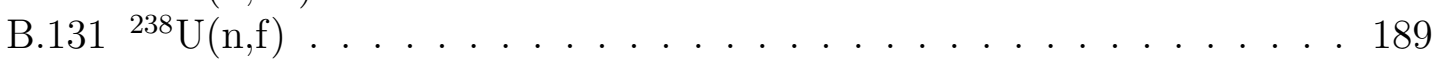

B.132 ${ }^{238} \mathrm{U}(\mathrm{n}, \gamma) \ldots \ldots \ldots \ldots \ldots \ldots . \ldots \ldots \ldots$

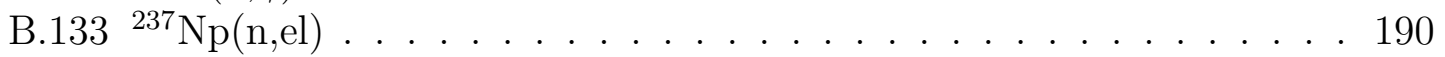

B.134 ${ }^{237} \mathrm{~Np}\left(\mathrm{n}, \mathrm{n}^{\prime}\right) \ldots \ldots \ldots \ldots \ldots$

B.135 ${ }^{237} \mathrm{~Np}(\mathrm{n}, 2 \mathrm{n}) \ldots \ldots \ldots \ldots \ldots$

B.136 ${ }^{237} \mathrm{~Np}(\mathrm{n}, \mathrm{f}) \ldots \ldots \ldots \ldots \ldots \ldots 1 . \ldots \ldots \ldots \ldots$

B.137 ${ }^{237} \mathrm{~Np}(\mathrm{n}, \gamma) \ldots \ldots \ldots \ldots \ldots \ldots 1 . \ldots \ldots \ldots \ldots$

B.138 ${ }^{238} \mathrm{Pu}(\mathrm{n}, \mathrm{el}) \ldots \ldots \ldots \ldots$

B.139 ${ }^{238} \mathrm{Pu}\left(\mathrm{n}, \mathrm{n}^{\prime}\right) \ldots \ldots \ldots \ldots \ldots$

B.140 ${ }^{238} \mathrm{Pu}(\mathrm{n}, 2 \mathrm{n}) \ldots \ldots \ldots \ldots . \ldots \ldots \ldots$

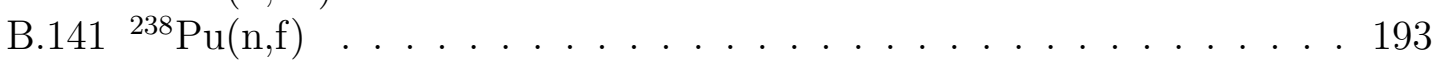

B.142 ${ }^{238} \mathrm{Pu}(\mathrm{n}, \gamma) \ldots \ldots \ldots \ldots \ldots \ldots . \ldots \ldots \ldots$

B.143 ${ }^{239} \mathrm{Pu}(\mathrm{n}, \mathrm{el}) \ldots \ldots \ldots \ldots \ldots \ldots \ldots$

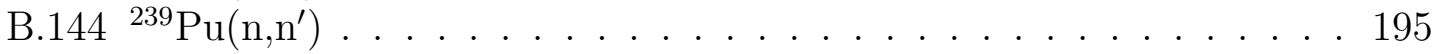

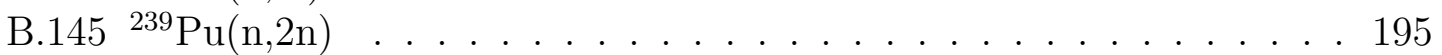

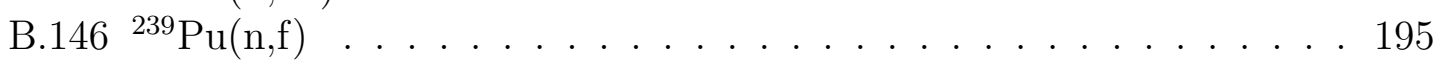

B.147 ${ }^{239} \mathrm{Pu}(\mathrm{n}, \gamma) \ldots \ldots \ldots \ldots \ldots \ldots$

B.148 ${ }^{240} \mathrm{Pu}(\mathrm{n}, \mathrm{el}) \ldots \ldots \ldots \ldots \ldots \ldots \ldots$

B.149 ${ }^{240} \mathrm{Pu}\left(\mathrm{n}, \mathrm{n}^{\prime}\right) \ldots \ldots \ldots \ldots \ldots \ldots \ldots$

B.150 ${ }^{240} \mathrm{Pu}(\mathrm{n}, 2 \mathrm{n}) \ldots \ldots \ldots \ldots \ldots$

B.151 ${ }^{240} \mathrm{Pu}(\mathrm{n}, \mathrm{f}) \ldots \ldots \ldots \ldots \ldots \ldots$

B.152 ${ }^{240} \mathrm{Pu}(\mathrm{n}, \gamma) \ldots \ldots \ldots \ldots \ldots \ldots \ldots$

B.153 ${ }^{241} \mathrm{Pu}(\mathrm{n}, \mathrm{el}) \ldots \ldots \ldots \ldots . \ldots \ldots$

B.154 ${ }^{241} \mathrm{Pu}\left(\mathrm{n}, \mathrm{n}^{\prime}\right) \ldots \ldots \ldots \ldots \ldots$

B.155 ${ }^{241} \mathrm{Pu}(\mathrm{n}, 2 \mathrm{n}) \ldots \ldots \ldots \ldots \ldots$

B.156 ${ }^{241} \mathrm{Pu}(\mathrm{n}, \mathrm{f}) \ldots \ldots \ldots \ldots \ldots \ldots \ldots$

B.157 ${ }^{241} \mathrm{Pu}(\mathrm{n}, \gamma) \ldots \ldots \ldots \ldots \ldots \ldots \ldots$

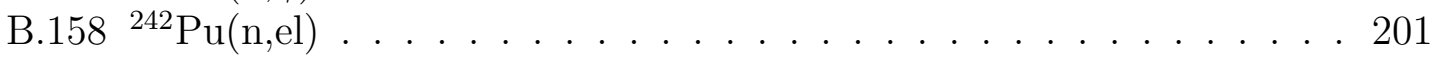

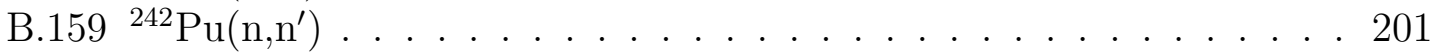

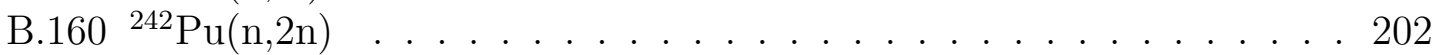

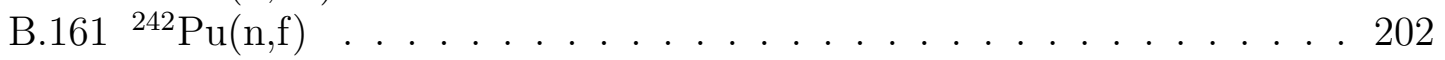

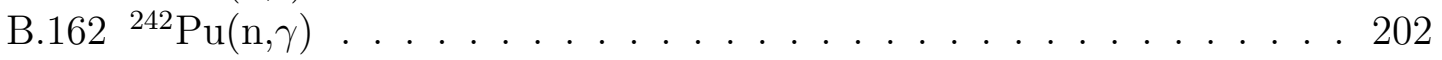

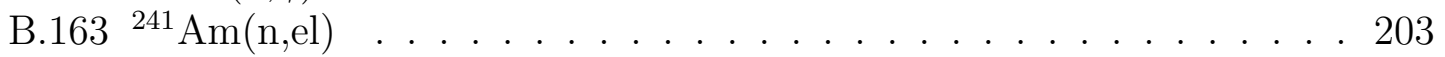

B.164 ${ }^{241} \mathrm{Am}\left(\mathrm{n}, \mathrm{n}^{\prime}\right) \ldots \ldots \ldots \ldots . \ldots \ldots . \ldots \ldots 20 . \ldots \ldots$ 


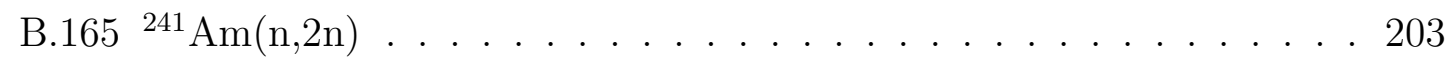

B.166 ${ }^{241} \mathrm{Am}(\mathrm{n}, \mathrm{f}) \ldots \ldots \ldots \ldots \ldots \ldots \ldots . \ldots \ldots \ldots . \ldots \ldots \ldots$

B.167 ${ }^{241} \mathrm{Am}(\mathrm{n}, \gamma) \ldots \ldots \ldots \ldots \ldots \ldots . \ldots \ldots \ldots$

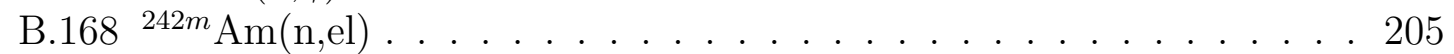

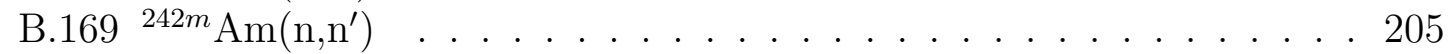

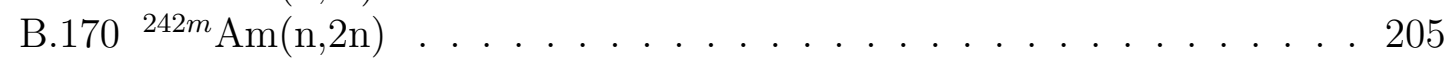

B.171 ${ }^{242 m} \mathrm{Am}(\mathrm{n}, \mathrm{f}) \ldots \ldots \ldots \ldots \ldots \ldots \ldots$

B.172 ${ }^{242 m} \mathrm{Am}(\mathrm{n}, \gamma) \ldots \ldots \ldots \ldots \ldots \ldots \ldots$

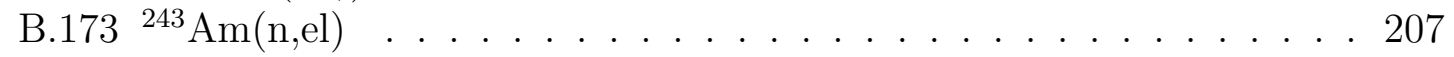

B.174 ${ }^{243} \mathrm{Am}\left(\mathrm{n}, \mathrm{n}^{\prime}\right) \ldots \ldots \ldots \ldots \ldots \ldots . \ldots \ldots 20 \ldots \ldots$

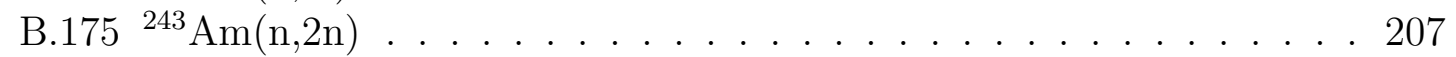

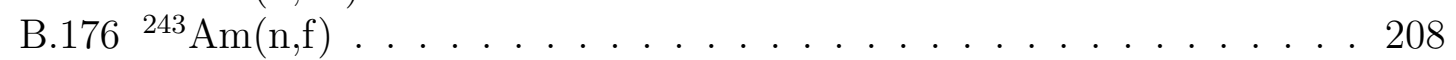

B.177 ${ }^{243} \mathrm{Am}(\mathrm{n}, \gamma) \ldots \ldots \ldots \ldots \ldots . \ldots \ldots . \ldots \ldots$

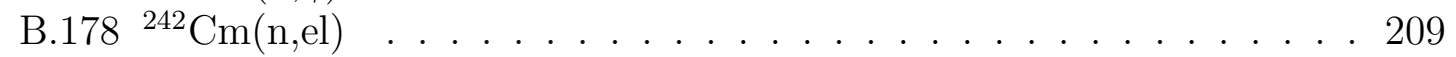

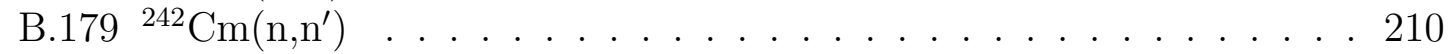

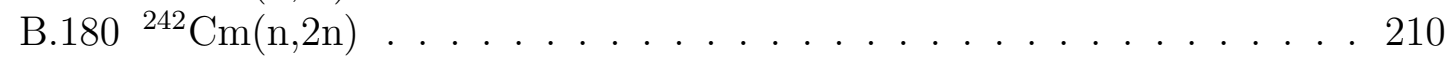

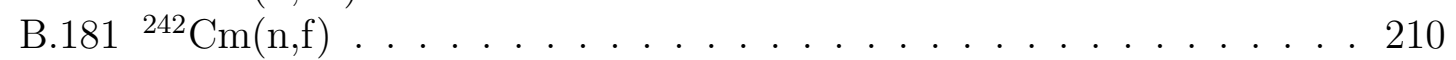

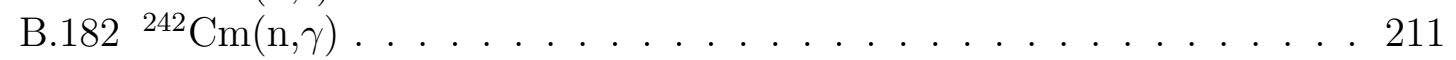

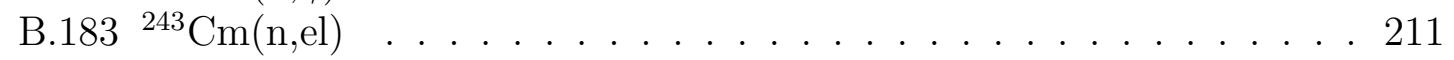

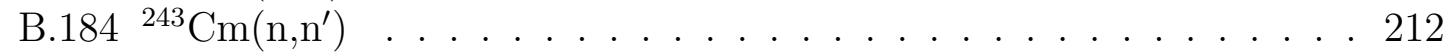

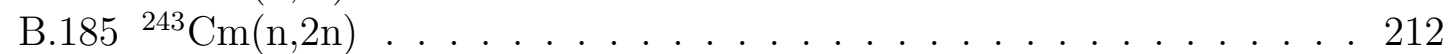

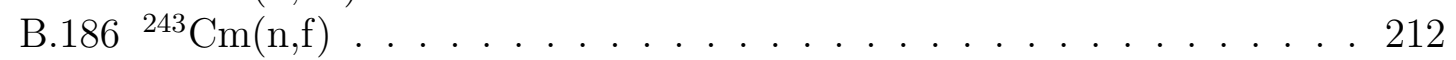

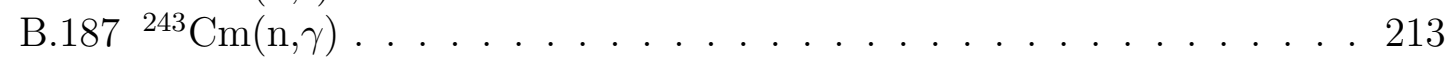

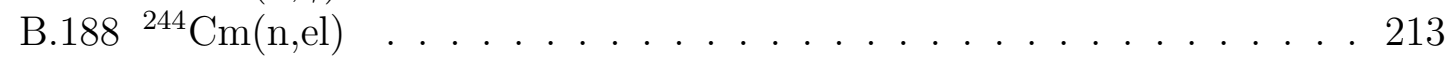

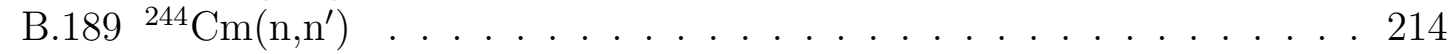

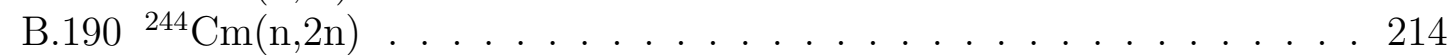

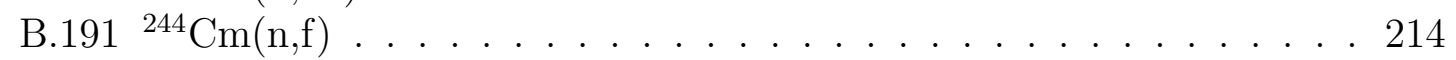

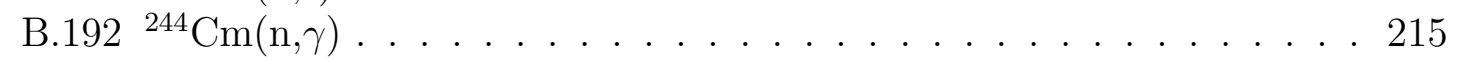

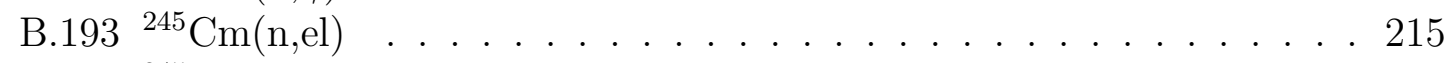

B.194 ${ }^{245} \mathrm{Cm}\left(\mathrm{n}, \mathrm{n}^{\prime}\right) \ldots \ldots \ldots \ldots \ldots . \ldots \ldots 216$

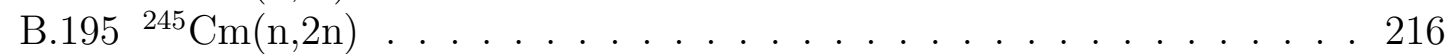

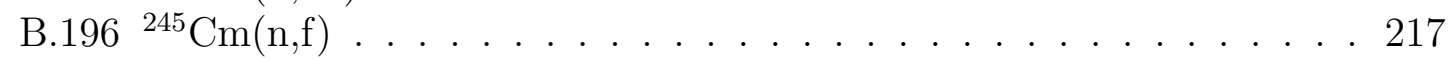

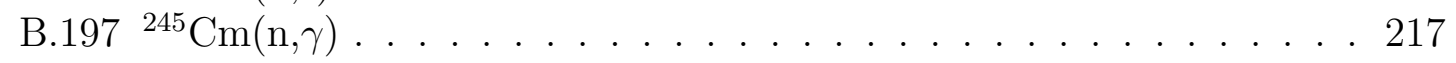

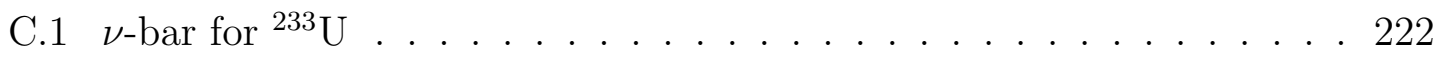

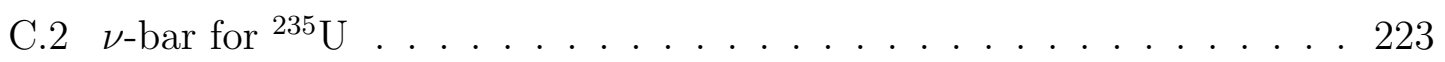

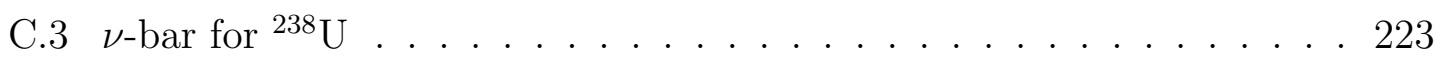

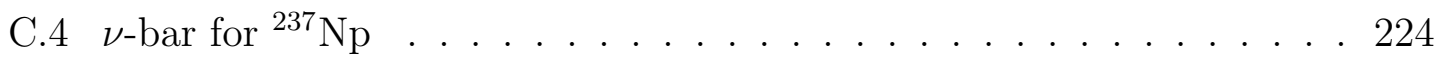

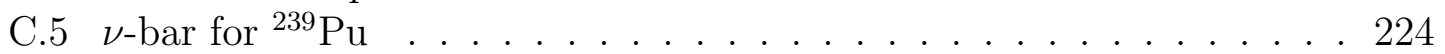

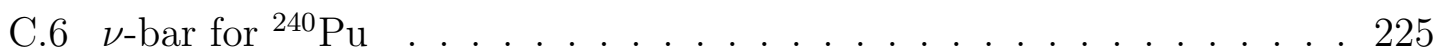

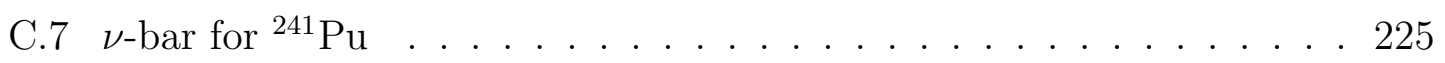

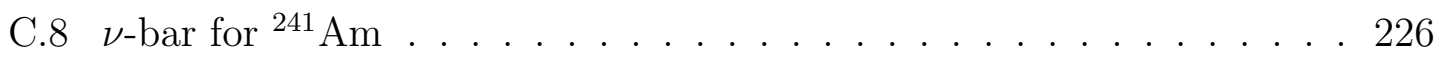

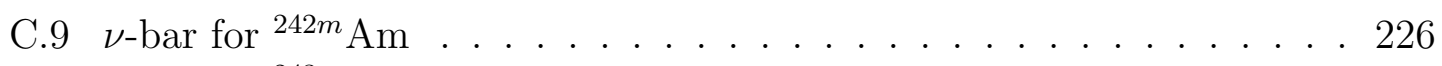

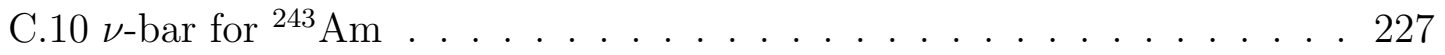




\section{Chapter 1}

\section{Introduction}

This report presents a set of preliminary cross section and $\nu$-bar covariances produced for the OECD Nuclear Energy Agency, Working Party on International Nuclear Data Evaluation Co-operation (WPEC), Subgroup 26. Following the proposal by P. Finck, ANL (now INL), SG26 "Nuclear Data Needs for Advanced Reactor Systems" has been established in 2005. Its charge is to identify nuclear data needs for advanced nuclear power reactors (Gen-IV) using sensitivity analysis. To this end, a considerable amount of covariance data is needed.

SG26, chaired by M. Salvatores, CEA Cadarache and ANL, prepared a list of materials relevant to its charge. When translated into the list of isotopes, it consists of 19 actinides and 33 structural, coolant and moderator materials. SG26 is interested in cross section covariances for (n,elastic), (n,inelastic), (n,2n), (n, $\gamma)$ and (n,f) cross sections $[1,2]$. These covariances should be provided in the 15-group representation, from the thermal energy up to $20 \mathrm{MeV}$. In addition, the $\nu$-bar covariances are needed for all actinides.

Table 1.1 provides a complete list of covariances of interest to SG26 (52 in total), ordered by priority. The first two priority groups of isotopes will enable to complete the study for fast sodium cooled reactors. The third group should be available in order to complete Gen-IV system study foreseen by SG26. The last two priority groups are needed for more detailed analysis of advanced systems.

This report presents cross section covariances for 45 isotopes out of the 52 requested isotopes, see Table 1.1. The covariances not finalized so far are indicated in underlined italic and include 6 light isotopes, where further work is needed, and ${ }^{235} \mathrm{U}$ for which processing problems were encountered. It should be noted that the covariances for $\mathrm{Gd}$ isotopes as well as ${ }^{232} \mathrm{Th}$ were taken from the ENDF/B-VII.0 library that was released on December 15, 2006. The covariances for ${ }^{1} \mathrm{H},{ }^{238} \mathrm{U}$ and ${ }^{239} \mathrm{Pu}$ were taken from the JENDL-3.3 library released in 2002.

We also report $\nu$-bar covariances for 10 materials, including all 9 materials listed under priority 1 and 2 actinides, and one another material under priority 5 . 
The present report is organized as follows: In Chapter 2 we describe our cross section covariance evaluation methodology, followed by Chapter 3 with short description of the processing. In Chapter 4 we summarize our results for cross section covariances and discuss them by addressing the thermal values, resonance integrals and fast neutron region. The results in the graphical form are given in Appendix A, and the numerical values in the 15-group representation can be found in Appendix B. Chapter 5 is devoted to $\nu$-bar covariances, with resulting plots and tables given in Appendix C. Our conclusions are given in Chapter 6. 
Table 1.1: Priority list of WPEC SG26 materials for $\sigma_{e l}, \sigma_{i n l}, \sigma_{n, 2 n}, \sigma_{\text {capt }}, \sigma_{f}$ cross section covariances in 15-energy groups. The cross section covariances not finalized so far are indicated in underlined italic. The $\nu$-bar covariances are required for all actinides, they are not finalized for the actinides of priority 5.

\begin{tabular}{|c|c|c|c|c|c|c|c|c|}
\hline Priority & \multicolumn{3}{|c|}{ Actinides } & Sum & \multicolumn{3}{|c|}{ Structural Materials } & Sum \\
\hline 1 & $\frac{{ }^{235} \mathrm{U}}{{ }^{239} \mathrm{Pu}}$ & ${ }^{238} \mathrm{U}$ & & $\begin{array}{l}2 \\
1\end{array}$ & & & & \\
\hline 2 & $\begin{array}{l}{ }^{237} \mathrm{~Np} \\
{ }^{240} \mathrm{Pu} \\
{ }^{241} \mathrm{Am}\end{array}$ & $\begin{array}{c}{ }^{241} \mathrm{Pu} \\
{ }^{242 m} \mathrm{Am}\end{array}$ & ${ }^{243} \mathrm{Am}$ & $\begin{array}{l}1 \\
2 \\
3\end{array}$ & & & & \\
\hline 3 & & & & & $\begin{array}{l}{ }^{16} \mathrm{O} \\
{ }^{23} \mathrm{Na} \\
{ }^{52} \mathrm{Cr} \\
{ }^{58} \mathrm{Ni}\end{array}$ & & & $\begin{array}{l}1 \\
1 \\
1 \\
1\end{array}$ \\
\hline 4 & & & & & $\begin{array}{c}{ }^{1} \mathrm{H} \\
\frac{{ }^{12} \mathrm{C}}{{ }^{28} \mathrm{Si}} \\
{ }^{90} \mathrm{Zr} \\
{ }^{94} \mathrm{Zr} \\
{ }^{206} \mathrm{~Pb} \\
{ }^{209} \mathrm{Bi}\end{array}$ & $\begin{array}{l}{ }^{91} \mathrm{Zr} \\
{ }^{207} \mathrm{~Pb}\end{array}$ & $\begin{array}{l}{ }^{92} \mathrm{Zr} \\
{ }^{208} \mathrm{~Pb}\end{array}$ & $\begin{array}{l}1 \\
1 \\
1 \\
3 \\
1 \\
3 \\
1\end{array}$ \\
\hline 5 & $\begin{array}{l}{ }^{232} \mathrm{Th} \\
{ }^{233} \mathrm{U} \\
{ }^{238} \mathrm{Pu} \\
{ }^{242} \mathrm{Cm} \\
{ }^{245} \mathrm{Cm}\end{array}$ & $\begin{array}{c}{ }^{234} \mathrm{U} \\
{ }^{242} \mathrm{Pu} \\
{ }^{243} \mathrm{Cm}\end{array}$ & $\begin{array}{l}{ }^{236} \mathrm{U} \\
{ }^{244} \mathrm{Cm}\end{array}$ & $\begin{array}{l}1 \\
3 \\
2 \\
3 \\
1\end{array}$ & $\begin{array}{l}\frac{{ }^{4} \mathrm{He}}{\frac{{ }^{6} \mathrm{Li}}{}} \frac{{ }^{9} \mathrm{Be}}{\frac{10 \mathrm{~B}}{10}} \\
\frac{{ }^{19} \mathrm{~F}}{{ }^{27} \mathrm{Al}} \\
{ }^{56} \mathrm{Fe} \\
{ }^{155} \mathrm{Gd} \\
{ }^{158} \mathrm{Gd} \\
{ }^{166} \mathrm{Er} \\
{ }^{170} \mathrm{Er}\end{array}$ & $\begin{array}{c}\frac{{ }^{7} \mathrm{Li}}{} \\
{ }^{57} \mathrm{Fe} \\
{ }^{156} \mathrm{Gd} \\
{ }^{160} \mathrm{Gd} \\
{ }^{167} \mathrm{Er}\end{array}$ & 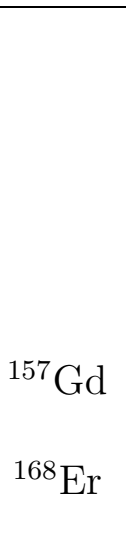 & $\begin{array}{l}1 \\
2 \\
1 \\
1 \\
1 \\
1 \\
2 \\
3 \\
2 \\
3 \\
1\end{array}$ \\
\hline & esente & $\begin{array}{l}\text { Cotal } \\
\text { in this } \mathrm{r}\end{array}$ & ort & $\begin{array}{l}19 \\
18\end{array}$ & & & & $\begin{array}{l}33 \\
27\end{array}$ \\
\hline
\end{tabular}




\section{Chapter 2}

\section{BNL-LANL Methodology for Cross Section Covariances}

The National Nuclear Data Center, BNL in collaboration with T-16, LANL is developing methodology for evaluation of cross section covariance data. The methodology covers the thermal energy, resolved resonance region, unresolved resonance region as well as the fast neutron region. It builds on the following three major components:

- Atlas of Neutron Resonances by S.F. Mughabghab, BNL [3];

- Nuclear reaction model code EMPIRE by M. Herman et al., BNL [4]; and

- Bayesian code KALMAN by T. Kawano, LANL [5].

These three basic components are combined into two methods, Atlas-KALMAN for the resonance region, and EMPIRE-KALMAN for the fast neutron region.

\subsection{Basic components}

\subsubsection{Atlas of Neutron Resonances}

In 2006, Said Mughabghab (NNDC, BNL) published his "Atlas of Neutron Resonances: Resonance Parameters and Thermal Cross Sections, $Z=1-100$ " [3], superseeding its earlier version published in two volumes, in 1981 and 1984. This monumental work contains recommended parameters of neutron resonances evaluated on the basis of virtually all pertinent experimental data available in 2005. The Atlas contains evaluated neutron data for all elements and 486 ground and isomeric states of 476 isotopes (resonance data are available for 381 isotopes) including uncertainties for virtually all quantities and parameters. The most important quantities for the present project, as illustrated in the case of ${ }^{241} \mathrm{Am}$ shown in Fig. 2.1, are the following:

- Thermal cross sections for capture, fission and elastic reactions as well as $\nu$-bar: absolute value, uncertainty; 
- Resonance integrals for capture and fission: absolute value, uncertainty;

- The scattering radius R': absolute value, uncertainty;

- Resonance parameters including radiative, neutron and fission width, partly also resonance energy and spin: absolute value, uncertainty.

The wealth of information contained in the Atlas constitutes an enormous resource for the evaluation of nuclear data in the resonance region. Strikingly, reported uncertainties were never utilized for generation of covariances on a large scale. We are primarily interested in the uncertainties on resonance parameters, scattering radii, and thermal cross sections that provide necessary input for quantification of uncertainty information in the evaluated files. For the time being, we do not consider uncertainties on the resonance integrals in determining covariances although we use them for checking the internal consistency of the covariances derived from the resonance parameters. Eventually, uncertainties on the resonance integrals can be used as additional constrains allowing to reduce cross section uncertainties.

The R-matrix theory of Wigner that constitutes framework for the description of resonance reactions, leads to representations known as the Multi-level Breit-Wigner (MLBW) and Reich-Moore (RM) formalisms. The Atlas mostly uses the MLBW approach where the cross section between the incoming channel $c$ and the outgoing channel $c^{\prime}$ (elastic, fission or capture) for $n$ resonances can be expressed as

$$
\begin{aligned}
\sigma_{c c^{\prime}} & =\sigma_{t o t} \delta_{c c^{\prime}}-\lambda^{2} g_{c} \Re e\left[\sum_{j=1}^{n} \frac{\Gamma_{c, j}^{1 / 2} \Gamma_{c^{\prime}, j}^{1 / 2}}{\Gamma_{t o t}} W_{c c^{\prime}}\left(E_{j}\right)\left(\psi_{j}+i \chi_{j}\right)\right], \\
W_{c c^{\prime}}\left(E_{j}\right) & =\delta_{c c^{\prime}}+i \sum_{m=1}^{m=n} \frac{\Gamma_{c, m}^{1 / 2} \Gamma_{c^{\prime}, m}^{1 / 2}}{E_{m}-E_{j}-i\left(\Gamma_{t o t, m}+\Gamma_{t o t, j}\right) / 2},
\end{aligned}
$$

where $j$ and $m$ are resonance indexes, $\delta_{c c^{\prime}}$ is equal to 1 for $c=c^{\prime}$ and 0 for $c \neq c^{\prime}$. The functions $\psi_{c}$ and $\chi_{c}$ are defined as

$$
\psi+i \chi=\frac{\Gamma^{2} / 4}{\left(E-E_{0}\right)^{2}+\Gamma^{2} / 4}+i \frac{\left(E-E_{0}\right) \Gamma / 2}{\left(E-E_{0}\right)^{2}+\Gamma^{2} / 4} .
$$

The uncertainties on the individual resonance widths $\left(\Gamma_{n}, \Gamma_{\gamma}\right.$, and $\left.\Gamma_{f}\right)$, as well as on the scattering radius $R^{\prime}$, are the major sources of the cross section uncertainties in the resonance region. In future, one may also take into account uncertainties on the resonance energies, $\mathrm{E}_{0}$, and eventually also on the resonance spins. Another important element of our future work would be inclusion of correlations between resonance parameters such as $\Gamma_{n}$ and $\Gamma_{\gamma}$. 
$\underset{9433 \mathrm{yr}]}{241} \mathrm{Am}$
THERMAL CROSS SECTIONS

${ }_{95}^{241} \mathrm{Am}$

[433 yr]

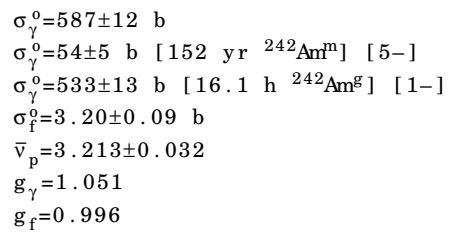

RESONANCE PROPERTIES

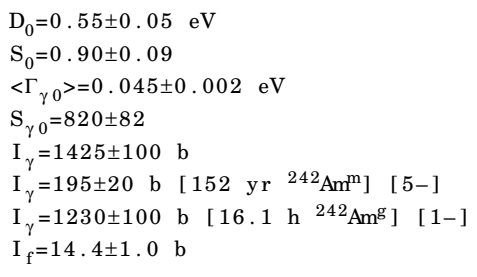

RESONANCE PARAMETERS

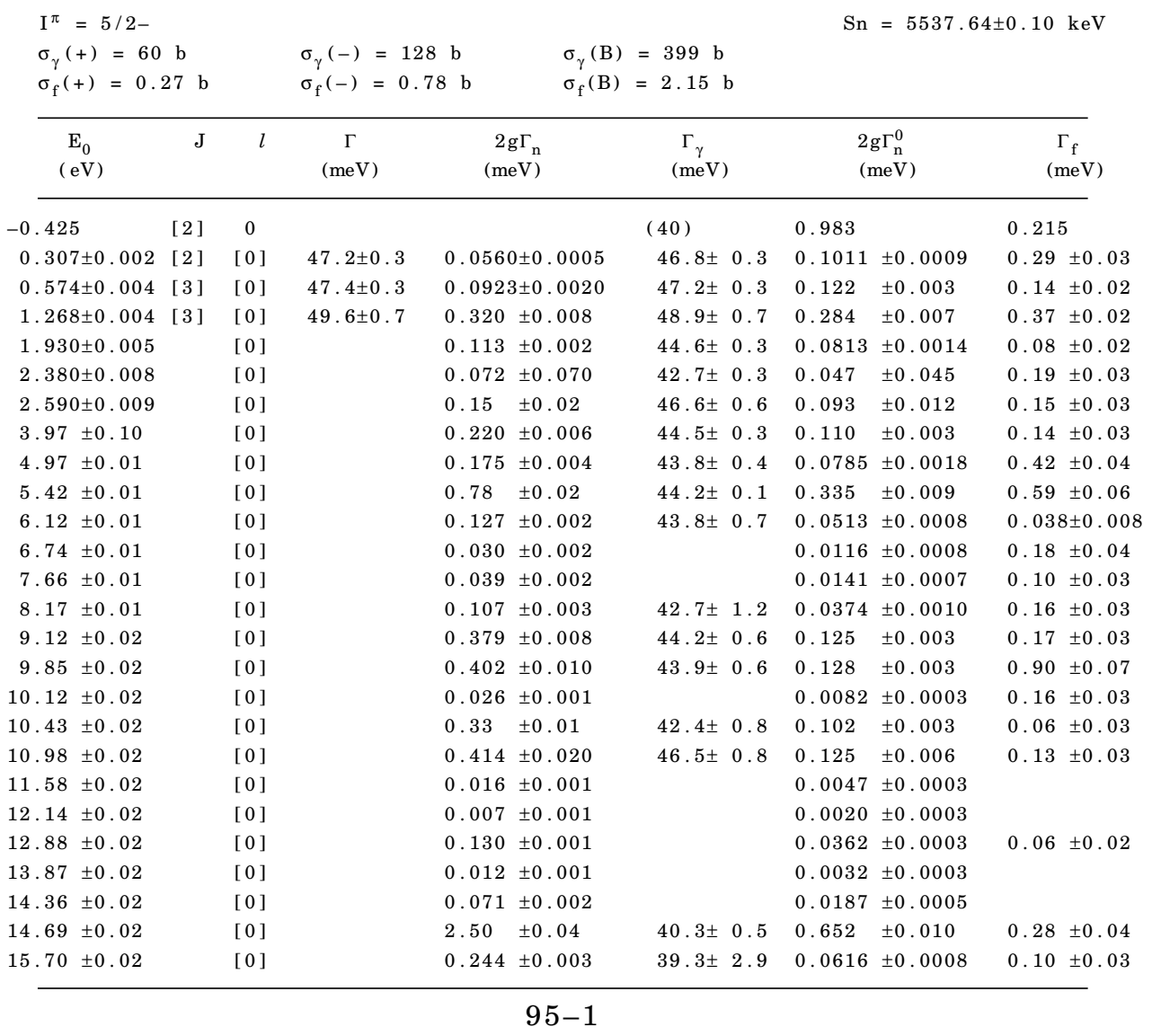

Figure 2.1: Example of data in the Atlas of Neutron Resonances [3] - the first page for ${ }^{241} \mathrm{Am}$. Seen at the top are thermal cross sections (capture, fission), followed by the resonance properties (include resonance integrals) and resonance parameters (energy, spin, widths - total, neutron, radiative and fission). Of primary interest for the present project are uncertainties, though they are not always fully available. 


\subsubsection{Nuclear reaction model code EMPIRE}

EMPIRE is a modular system of codes that is well suited for model assisted determination of covariances. A suite of nuclear reaction models includes the spherical optical model, Coupled Channels, Distorted Wave Born Approximation, Multi-step Direct, Multi-step Compound, the exciton model with preequilibrium emission of clusters and gamma rays, and the full featured Hauser-Feshbach (HF) model with multi-particle emission and detailed $\gamma$-cascade. At low incident energies the HF model is replaced with the HRTW approach to account for the width fluctuation correction. The code includes advanced fission model [6], accounting for the multimodal fission through multiple-humped fission barriers.

The cross section for a reaction $(a, b)$ that proceeds through the compound nucleus mechanism is expressed in terms of the decay widths $\Gamma_{c}$ given as

$$
\Gamma_{c}=\frac{1}{2 \pi \rho_{C N}(E)} \sum_{c^{\prime}} \int_{0}^{E-B_{c}} \rho_{c}\left(E^{\prime}\right) T_{c}\left(E-B_{c}-E^{\prime}\right) d E^{\prime},
$$

where $B_{c}$ is the binding energy of particle $c, \rho$ is the level density, and $T_{c}(\epsilon)$ stands for the transmission coefficient for a particle $c$ having channel energy $\epsilon=E-B_{c}-E^{\prime}$. For simplicity, we drop explicit reference to the spin and parity in Eq.(2.4) and the summation extends over all open channels $c^{\prime}$. Eq.(2.4) shows that the compound nucleus cross section depends on the product of the two major quantities: optical model transmission coefficients $T_{c}$, and level densities $\rho_{c}\left(E^{\prime}\right)$, indicating that related parameters have a decisive impact on the model generated cross section uncertainties.

EMPIRE eliminates laborious preparation of the input by automatic retrieval of the necessary data from the comprehensive library of input parameters. This library covers optical model, level densities, deformations, discrete levels and decay schemes, fission barriers, moments of inertia, nuclear masses, and $\gamma$-ray strength functions. Energy dependent tuning of selected model parameters allows for internally consistent reproduction of measurements while preserving capacity of large scale calculations with the default global parameters.

The output of the EMPIRE code is converted into the ENDF-6 formatted file for cross sections, angular distributions, energy spectra, energy-angle correlated distributions as well as $\gamma$ - and recoil-production. This file is supplemented with neutron resonances extracted from ENDF/B-VII.0 to produce complete and processable ENDF-6 file that subsequently undergoes a verification procedure involving checking codes and processing with the NJOY code. The EMPIRE package contains also the library of experimental data that are automatically plotted against calculated results.

The code has been extensively tested during the development of the ENDF/BVII.0 library to which it provided more than 70 complete new evaluations. In this major exercise EMPIRE proved to be a valuable nuclear reaction evaluation tool that fulfills all requirements requested for the determination of covariances. The 
code is easy to use, fast, flexible, and prepared for mass production. When employed for determining covariances, the code generates sensitivity matrices describing how various cross sections change in response to the perturbation of certain model parameters. These matrices are then used as input for the Bayesian code KALMAN to incorporate experimental cross section data.

We note that the unresolved resonance region can be treated within the EMPIRE code as well as with the resonance methodology. This overlap constitutes a link between the two approaches that might be exploited for determining correlations between the resonance and fast neutron regions.

\subsubsection{Bayesian code KALMAN}

The KALMAN code [7] based on the theory of the Kalman filter allows to estimate covariances by combining experimental uncertainties and correlations with theory predictions. The model parameters are adjusted to reproduce experimental data, and the uncertainties are propagated from the experimental results to the model parameters. In this method, the evaluated covariances strongly depend on the nuclear reaction theory, and the appropriate models have to be used to adequately describe physical processes involved in the reaction. The Hauser-Feshbach statistical theory, the optical model, and various formulations of the preequilibrium emission are the typical examples in the fast neutron range, while Reich-Moore or multilevel Breit-Wigner are applicable in the resonance region. The uncertainties (covariances) for the parameters of a nuclear reaction model are determined taking into account the accuracy of the experimental data, quality of the data fitting, and the a priori knowledge of the parameters themselves.

The Bayesian parameter estimation code KALMAN calculates the cross section covariances $P$ in the two following steps: (i) the model parameter covariance matrix $X$ is calculated from the experimental covariances $V$, and (ii) the error propagation is used to calculate cross section covariances $P$ from the model parameter covariances $X$

$$
\begin{aligned}
P & =\left(X^{-1}+C^{t} V^{-1} C\right)^{-1} \\
& =X-X C^{t}\left(C X C^{t}+V\right)^{-1} C X
\end{aligned}
$$

where $C$ is the sensitivity matrix describing response of the model to the perturbation of its parameters. 


\subsection{Evaluation methods}

\subsubsection{Atlas-KALMAN method for the resonance region}

This covariance evaluation method combines the wealth of data given in the Atlas of Neutron Resonances of BNL with the Bayesian code KALMAN of LANL. The resonance parameters and their uncertainties are taken from the Atlas, and KALMAN propagates them to cross section uncertainties and correlations. The procedure can be summarized as follows:

- One starts with the resonance parameters given in the original ENDF/B-VII.0 file. In general, for new evaluations these are identical or very close to the parameters in the Atlas.

- Cross sections in the thermal and resolved resonance regions are calculated using the MLBW (or RM) formalism and converted into a suitable multigroup representation.

- Uncertainties of resonance parameters and thermal-energy values from the Atlas are propagated with the KALMAN code to obtain uncertainties and correlations for cross sections. Missing uncertainties of resonance parameters were estimated either by extrapolating and interpolating available resonance data or from the neighboring nuclei.

- Cross section covariances are formatted $(\mathrm{MF}=33)$ and introduced into the file.

When fitting the uncertainty for the thermal capture, the adequate uncertainties are assigned to the resonance energy $\left(E_{0}\right)$, neutron width $\left(\Gamma_{n}\right)$, radiative width $\left(\Gamma_{\gamma}\right)$ and, if applicable, to the fission width $\left(\Gamma_{f}\right)$ of the bound level (negative-energy resonance). If there is no bound level the parameter uncertainties for the first resonance can be adjusted.

The resulting cross section uncertainties are based on a solid ground of all experimental uncertainties collected in the Atlas of Neutron Resonances. This represents a considerable step forward compared to a credible but simple estimate by M. Williams [8] who has only been using uncertainties of integral quantities, ignoring resonance parameters, and using the old 1981/84 values rather than the latest Mughabghab'2006 values. We also have an option of generating covariances for the resonance parameters $(\mathrm{MF}=32)$ using information contained in the Atlas.

\subsubsection{EMPIRE-KALMAN method for the fast neutron re- gion}

This methodology for generating cross section covariances in the fast neutron range was developed recently by the National Nuclear Data Center (BNL) in collaboration 
with the T-16 group (LANL). It employs a sensitivity matrix produced with the nuclear reaction theory code EMPIRE, and uses it in the Bayesian KALMAN code for determining covariances while taking into account relevant experimental data.

To obtain the sensitivity matrix with the EMPIRE code, about 10-15 of the most relevant model parameters (optical model, level density, preequilibrium strength) are varied independently, typically by $\pm 5 \%$ around the optimal value, to determine their effect on total, elastic, inelastic, capture, fission, (n,2n), (n,p) and (n, $\alpha)$ cross sections in the full energy range of the evaluation. Sensitivity matrix elements are calculated as a change of a given reaction cross sections in response to the change of a particular model parameter. A series of scripts is employed to transfer such sensitivity matrix information along with the experimental data to the KALMAN code, and to prepare adequate input.

The results include cross section uncertainties and energy-energy correlations ready to be implemented in transport calculations for benchmarking against integral experiments and other applications. In addition, uncertainties and correlations among model parameters constrained by experimental cross sections are produced. 


\section{Chapter 3}

\section{Processing}

\subsection{Merging of covariance files}

In the case of the 36 isotopes treated with the BNL-LANL methodology, covariances in the fast neutron region were produced separately from the thermal and resonance region. As a consequence the covariances in two uncorrelated regions were obtained:

- Thermal and resonance region, and

- Fast neutron region.

The computational tools for the merging of correlation matrices were developed by the NNDC. The two covariance files were properly merged, following the ENDF6 format requirements in order to produce a full $\mathrm{MF}=33$ file with cross section covariance data. Then, a complete ENDF-6 formatted file was created by adding $\mathrm{MF}=33$ to the basic file containing information on the resonance parameters $(\mathrm{MF}=2)$, cross sections $(\mathrm{MF}=3)$ and other observables. In all cases, except of ${ }^{19} \mathrm{~F}$, the basic files were taken from the ENDF/B-VII.0 library. For ${ }^{19} \mathrm{~F}$, the JENDL-3.3 file was chosen because the ENDF/B-VII.0 evaluation does not contain resonance parameters.

\subsection{Multigroup processing}

Each file was processed into multi-group structure with the LANL processing code NJOY-99.161, coupled to the code ERRORJ [7,9]. Plots as well as tables with cross section uncertainties and correlations were produced. These are given in Appendix A and Appendix B.

In some cases $\left({ }^{1} \mathrm{H}\right.$ and $\left.{ }^{238} \mathrm{U}\right)$ we encountered certain limitations and no correlation plots were obtained from ERRORJ. However, these files were correctly processed and tables with uncertainties and correlations are given in Appendix B.

The processing was performed for the 15-energy groups as requested by SG26 and also for the 187-energy group structure. The latter representation provides use- 
ful insight about the details of uncertainties and correlations.

The processing was always done with the constant neutron flux ('iwt=2' option in NJOY) for both the 15-energy groups (no option in NJOY, added manually) and the 187-energy groups ('ign=10' option in NJOY). 


\section{Chapter 4}

\section{Results for Cross Section Covariances}

\subsection{BNL evaluations: 36 isotopes}

Covariances in the thermal, resolved resonance and unresolved resonance regions were produced using the Atlas-KALMAN approach as described in the methodology chapter. In the fast neutron region, covariances were produced with the EMPIRE-KALMAN approach. This methodology was applied to 36 isotopes: ${ }^{16} \mathrm{O}$, ${ }^{19} \mathrm{~F},{ }^{23} \mathrm{Na},{ }^{27} \mathrm{Al},{ }^{28} \mathrm{Si},{ }^{52} \mathrm{Cr},{ }^{56,57} \mathrm{Fe},{ }^{58} \mathrm{Ni},{ }^{90,91,92,94} \mathrm{Zr},{ }^{166,167,168,170} \mathrm{Er},{ }^{206,207,208} \mathrm{~Pb},{ }^{209} \mathrm{Bi}$, ${ }^{233,234,236} \mathrm{U},{ }^{237} \mathrm{~Np},{ }^{238,240,241,242} \mathrm{Pu},{ }^{241,242 m, 243} \mathrm{Am},{ }^{242,243,244,245} \mathrm{Cm}$.

\subsubsection{Resonance region}

Two general comments should be made on the use of data from the Atlas of Neutron Resonances [3] in the present work.

First, missing uncertainties of resonance parameters in the Atlas of Neutron Resonances were estimated by assigning 20 to $50 \%$ to $\Gamma_{\gamma}, \Gamma_{n}$ or $\Gamma_{f}$ and 0.1 to $0.5 \%$ for the resonance energy.

Second, for some actinides, the number of resonances given in the Atlas of Neutron Resonances can be as high as 1000 (major actinides, ${ }^{237} \mathrm{~Np},{ }^{233} \mathrm{U}, \ldots$... In these cases, considering four parameters per resonance, the matrices used for the correlation and uncertainty calculations can exceed the maximum memory allowed within a 32-bit machine (which corresponds to 2200 parameters in the KALMAN code). To avoid this technical issue, a restricted number of resonances was used.

\section{Case 1: All resonances considered}

All resonances were considered for 34 isotopes. These are: ${ }^{16} \mathrm{O},{ }^{19} \mathrm{~F},{ }^{23} \mathrm{Na},{ }^{27} \mathrm{Al},{ }^{28} \mathrm{Si}$, ${ }^{52} \mathrm{Cr},{ }^{56,57} \mathrm{Fe},{ }^{58} \mathrm{Ni},{ }^{90,91,92,94} \mathrm{Zr},{ }^{166,167,168,170} \mathrm{Er},{ }^{206,207,208,209} \mathrm{~Pb},{ }^{234,236} \mathrm{U},{ }^{238,240,241,242} \mathrm{Pu}$, 
${ }^{241,242 m, 243} \mathrm{Am},{ }^{242,243,244,245} \mathrm{Cm}$.

\section{Case 2: Not all resonances considered}

Restricted number of resonances was considered for 2 isotopes: ${ }^{237} \mathrm{~Np}$ and ${ }^{233} \mathrm{U}$.

Atlas of Neutron Resonances [3] as well as the ENDF/B-VII.0 evaluation contain a large number of resonances for ${ }^{237} \mathrm{~Np}$ (more than 700). Therefore, the covariance calculation with the total number of resonances could not be done and a 64-bit machine is necessary for this specific calculation if all resonances are taken into account. To produce a reasonable preliminary result in the 15-energy groups, the 91 strongest resonances ( $\simeq 2$ resonances per decade) from the bound level to $600 \mathrm{eV}$ were selected and used for the covariance calculation.

Similarly, ${ }^{233} \mathrm{U}$ has more than 700 resonances given in Ref. [3]. As a consequence, we restricted ourselves to the 85 strongest resonances, from the bound level to $1 \mathrm{keV}$, and used them for our covariance calculation.

\subsubsection{Fast neutron region}

Two comments should made on the use of the EMPIRE-KALMAN method in the present work.

First, in general, our covariances are based on estimates of the model parameter uncertainties on the level of $5-10 \%$.

Second, experimental data were taken into account approximately only, no attempt was made to consider them in detail. This would be too time consuming, and it should be done in future.

\subsubsection{Priority actinides}

In Table 1.1, three major actinides are listed under priority 1, and six other actinides are listed under priority 2. The covariances for ${ }^{235,238} \mathrm{U}$ and ${ }^{239} \mathrm{Pu}$ will be taken from the recent JENDL-3.3 library as the ENDF/B-VII data are not yet available. The covariances for ${ }^{237} \mathrm{~Np},{ }^{240,241} \mathrm{Pu}$ and ${ }^{241,242 m, 243} \mathrm{Am}$ were evaluated by us and some details of the evaluation procedure are briefly discussed below.

${ }^{237} \mathrm{~Np}$. In the resonance region, restricted number of resonances was used. In the fast neutron region, $10 \%$ uncertainties on optical model parameters and $5 \%$ on other model parameters were assumed. This assumption was checked against experimental data for capture and fission.

- Elastic cross section: uncertainties on resonance energies and $\Gamma_{n}$ are given in the Atlas up to $600 \mathrm{eV}$. The uncertainty on the scattering radius is set to $5 \%$. 
In the fast neutron region, covariance calculation was performed taking into account the only available experimental data from Hoffman et al. [10]. This measurement represents about 13000 data points from $1 \mathrm{keV}$ to $2 \mathrm{MeV}$ with a maximum uncertainty of $30 \%$. After grouping and processing, the elastic cross section uncertainties are between 2 and $4 \%$. As seen in plots A.124, no strong correlation is present in the fast region, as is usually true for model calculations, because of the usage of experimental data.

- $(n, 2 n)$ cross section: experimental data are available around $14 \mathrm{MeV}$ [11] with $4 \%$ uncertainty. At $14 \mathrm{MeV}$, our approach gives a more conservative value of $\simeq 10 \%$.

- Fission cross section: in the resonance region, fission widths are presented in the Atlas up to $600 \mathrm{eV}$ and fission width uncertainties are partially known to $600 \mathrm{eV}$. For unknown uncertainties, we assumed values from 10 to $50 \%$, depending on the energy range. In the fast neutron region many experimental data are available up to $20 \mathrm{MeV}$. Experimental uncertainties range from $1 \%$ to $10 \%$. We quote a $6 \%$ uncertainty on the grouped cross section, which corresponds to a conservative approach, considering all experimental data.

- Capture cross section: in the resonance region, capture widths and capture width uncertainties are known up to $60 \mathrm{eV}$. For resonances at higher energies, we assumed an average capture width of $40 \mathrm{meV}$ with 10 to $100 \%$ uncertainties. In the fast region, many experimental data are available up to $200 \mathrm{keV}$ (see flat uncertainties in the present calculation). Above $200 \mathrm{keV}$, experimental data become sparse with increasing uncertainties. Our calculation above few hundreds of keV gives uncertainties strongly increasing with neutron energy.

${ }^{240} \mathrm{Pu}$. In the resonance region, there are many missing uncertainties on the resonance parameters. These were estimated as follows: from $10 \%$ to $45 \%$ for $\Gamma_{\gamma}$ and $\Gamma_{n}$, and $10 \%$ to $90 \%$ for $\Gamma_{f}$. Neutron and capture widths are known only for the first two positive resonances. This determines the uncertainties up to $\simeq 25-30 \mathrm{eV}$, since the next resonance is at $38 \mathrm{eV}$. In the fast neutron region, $5 \%$ uncertainties on model parameters were assumed. This assumption was checked against experimental data for capture and fission. There are quite a few data for $(n, f)$ indicating uncertainties for fission cross sections around $5-10 \%$ in the fast neutron region.

- Elastic cross section: even if neutron widths are given without uncertainties in the Atlas, as there is a large number of resonances and the scattering radius is known to $\simeq 2 \%$, the cross section uncertainties from $30 \mathrm{eV}$ to $5 \mathrm{keV}$ are around $3 \%$ in the 187 group representation. In the fast neutron region, experimental data from Smith [12] are considered with an uncertainty of about $10 \%$. With the knowledge of the optical model, our calculation gives an uncertainty between 4 and $5 \%$ in the 187 group representation.

- $\left(\mathrm{n}, \mathrm{n}^{\prime}\right)$ and $(\mathrm{n}, 2 \mathrm{n})$ cross sections: no experimental data are available. In the plateau of the $\left(n, n^{\prime}\right)$ cross section, the uncertainties are of the order of $10 \%$ 
with an increasing trend when the cross section decreases. The $(n, 2 n)$ cross section uncertainty is in the vicinity of $50 \%$, in both the 187-and 15-group representations.

- Fission cross section: no uncertainties are given in the Atlas for fission widths. Uncertainties from $10 \%$ to $90 \%$ are assumed, linearly increasing with the resonance energy. The deep in the fission cross section uncertainties at $1 \mathrm{eV}$ is dictated by the $0.04 \%$ uncertainty on the resonance energy. In the fast neutron region, measurements present uncertainties in the $5 \%$ range. Our calculation gives values from 4 to $10 \%$.

- Capture cross section: uncertainties in the resonance region are known for the first resonance only (less than $1 \%$ on capture width). At higher energy, we are using uncertainties from 10 to $50 \%$ up to $6 \mathrm{keV}$. In the fast neutron region, the capture cross section is measured up to $300 \mathrm{keV}$, with 8 to $15 \%$ uncertainty. Our calculation gives $\simeq 10-15 \%$ uncertainty up to $300 \mathrm{keV}$, with an increasing behavior at higher energies.

${ }^{241} \mathrm{Pu}$. In the resonance region, there are many missing uncertainties on the resonance parameters. These were estimated as follows: from $10 \%$ to $50 \%$ for $\Gamma_{\gamma}, \Gamma_{f}$ and also for $\Gamma_{n}$. In the fast neutron region, $10 \%$ uncertainties on model parameters were assumed as almost no data are available.

- Elastic cross section: no uncertainties are given for the neutron widths in the Atlas, but central values are known. As no information for the scattering radius is given in the Atlas, the ENDF/B-VII.0 value is used, with a $5 \%$ uncertainty. In the fast neutron region, no measurements are available for (n,el), but we considered experimental data from (n,tot) in order to lower the impact of anticorrelations due to the usage of models only. The quoted uncertainties are around $5 \%$ in the 187 group representation.

- $(n, n ')$ and $(n, 2 n)$ cross sections: no experimental data are available. In the plateau of the (n,n') cross section, the uncertainties are in the order of $20 \%$ with an increasing trend when the cross section decreases. The $(\mathrm{n}, 2 \mathrm{n})$ cross section uncertainty is in the vicinity of $50 \%$, in both group representations.

- Fission cross section: in the resonance region, central values of the fission widths are known up to $400 \mathrm{eV}$, but without uncertainties. Uncertainties from 10 to $50 \%$ were assumed. In the fast neutron region, experimental data are scarse with 5 to $10 \%$ uncertainty. Our calculation presents 10 to $25 \%$ for uncertainty at high neutron energy.

- Capture cross section: in the resonance region, capture neutron widths are partially measured, mostly without uncertainties. Uncertainties from 10 to $50 \%$ were assumed. In the fast neutron region, no experimental data exist at energy higher than $30 \mathrm{keV}$. Our calculation gives a minimum of $10 \%$ uncertainty up to $100 \mathrm{keV}$ and $60 \%$ above $10 \mathrm{MeV}$. 
${ }^{241} \mathrm{Am}$. In the resonance region, some missing uncertainties on the resonance parameters were estimated as follows: 50 to $80 \%$ for $\Gamma_{\gamma}$, and 10 to $80 \%$ for $\Gamma_{f}$. In the fast neutron region, our evaluation was based on the experience from our earlier study of fission cross sections [13].

- Elastic cross section: all neutron widths are known up to $150 \mathrm{eV}$, with uncertainties. In the fast neutron region, no experimental data exist for the elastic cross section, but those for the total cross section were considered instead.

- (n,n') cross section: no experimental data are available. In the plateau of the $\left(n, n^{\prime}\right)$ cross section, the uncertainties are in the order of $20 \%$ with an increasing trend when the cross section decreases.

- $(n, 2 n)$ cross section: the $(n, 2 n)$ cross section uncertainty is in the vicinity of $10 \%$, in 15 group representation. This cross section was recently measured from 13 to $15 \mathrm{MeV}$, with an experimental uncertainty of $10 \%$.

- Fission cross section: in the resonance region, fission widths and uncertainties are known up to $30 \mathrm{eV}$. At higher energies, $\Gamma_{f}$ values were taken from ENDF/B-VII.0 with 10 to $80 \%$ uncertainties, depending on the energy range. In the fast neutron region, fission cross section was extensively measured, and discrepancies between experiments resolved. We quote uncertainties from 8 to $12 \%$.

- Capture cross section: capture widths are partially known up to $30 \mathrm{eV}$. For unknown $\Gamma_{\gamma}$, uncertainties from 50 to $70 \%$ were assigned. In the fast neutron region, experimental data exist up to $450 \mathrm{keV}$, with 10-15\% uncertainties. Our calculation gives uncertainties in the order of $8 \%$ in the 15 group representation, up to $1 \mathrm{MeV}$. At higher energies, as no experimental data exist for total capture (but some measurements provide results for the $(n, \gamma)$ to metastable states), our uncertainties are increasing up to $40 \%$.

${ }^{242 m} \mathrm{Am}$. In the resonance region, there are many missing uncertainties on the resonance parameters. These were estimated as follows: 10 to $80 \%$ for $\Gamma_{\gamma}, \Gamma_{n}$ and $\Gamma_{f}$. In the fast neutron region, our evaluation was based on the experience from our earlier study of fission cross sections [13].

- Elastic cross section: all neutron widths are known up to $20 \mathrm{eV}$, but without uncertainties. In the fast neutron region, no experimental data exist neither for the elastic nor total cross sections.

- (n,n') and (n,2n) cross sections: no experimental data are available. In the plateau of the $(n, n ')$ cross section, the uncertainties are in the order of 20 to $30 \%$ with an increasing trend when the cross section decreases. The $(n, 2 n)$ cross section uncertainty is in the vicinity of $35 \%$, in 15 group representation. 
- Fission cross section: in the resonance region, fission widths are known up to $20 \mathrm{eV}$ (end of the resonance region), but without uncertainties. In the fast neutron region, fission cross section was measured, but experimental data are scattered. We quote uncertainties from 15 to $25 \%$.

- Capture cross section: capture widths are practically unknown up to $20 \mathrm{eV}$. Uncertainties from 50 to $70 \%$ were assigned. In the fast neutron region, one measurement exists at $1.2 \mathrm{MeV}$, without uncertainties. Our calculation gives uncertainties higher than $30 \%$ in the 15 group representation, up to $1 \mathrm{MeV}$. At higher energies, as no experimental data exist, our uncertainties are increasing up to $60 \%$.

${ }^{243} \mathrm{Am}$. In the resonance region, some missing uncertainties on the resonance parameters were estimated as follows: $20 \%$ to $60 \%$ for $\Gamma_{\gamma}$ and $\Gamma_{f}$. In the fast neutron region, our evaluation was based on the experience from our earlier study of fission cross sections [13].

- Elastic cross section: all neutron widths are known up to $250 \mathrm{eV}$, with uncertainties. In the fast neutron region, no experimental data exist for the elastic and total cross sections.

- $(n, n ')$ cross section: no experimental data are available. In the plateau of the (n,n') cross section, the uncertainties are in the order of $20 \%$ with an increasing trend when the cross section decreases.

- $(n, 2 n)$ cross section: the $(n, 2 n)$ cross section uncertainty is in the vicinity of $25 \%$, in 15 group representation. This cross section was measured at $14 \mathrm{MeV}$, but no uncertainties are given.

- Fission cross section: in the resonance region, fission widths and uncertainties are partially known up to $50 \mathrm{eV}$. At higher energy, $\Gamma_{f}$ are taken from ENDF/BVII.0 with 20 to $60 \%$ uncertainties, depending on the energy range. In the fast neutron region, fission cross section was extensively measured. We quote uncertainties from 8 to $14 \%$.

- Capture cross section: capture widths are partially known up to $20 \mathrm{eV}$. For unknown $\Gamma_{\gamma}$, uncertainties from 20 to $80 \%$ were assigned. In the fast neutron region, experimental data exist up to $100 \mathrm{keV}$, with $10 \%$ uncertainties. Our calculation gives uncertainties in the order of $7 \%$ in the 15 group representation, up to $1 \mathrm{MeV}$. At higher energy, as no experimental data exist, our uncertainties are increasing up to $60 \%$.

\subsubsection{Light nuclei}

For light nuclei with the atomic mass number $\mathrm{A}<20$, the basic ENDF/B-VII.0 files in the resonance region are given in the pointwise representation $(\mathrm{MF}=3)$, rather than in the resonance parameter representation $(\mathrm{MF}=2)$. The reason is that the 
compound nucleus physics becomes gradually invalid for these light nuclei, and cross sections were evaluated with the more fundamental approach of the R-matrix theory. This concept is adopted by all three major libraries, ENDF/B-VII.0, JENDL-3.3 and JEFF-3.1, the only exception being ${ }^{19} \mathrm{~F}$ file in JENDL-3.3.

Despite of this, the Atlas of Neutron Resonances [3] gives resonance parameters for these light nuclei, such as the resonance parameters for elastic scattering and capture in the multi-level Breit-Wigner representation. An illustration for ${ }^{16} \mathrm{O}$, given in Figure 4.1, compares such cross sections with those taken from the ENDF/B-VII.0 library. It is seen that the thermal region is described well, while considerable deviations are in the resonance region. This is particularly true for capture. On the other hand, ${ }^{16} \mathrm{O}$ is tightly bound even-even nucleus and capture cross sections are extremely small and unlikely of much importance for SG26 purposes.

The present work reports covariances for two light nuclei, ${ }^{19} \mathrm{~F}$ and ${ }^{16} \mathrm{O}$. Further study is needed to better understand the differences in cross sections between the ENDF/B-VII.0 library and Atlas for the remaining 6 light nuclei. This also includes the impact of these differences on covariances. For this reason, we do not include our tentative results for elements lighter than oxygen in the present report and defer more detailed discussion to a future work.

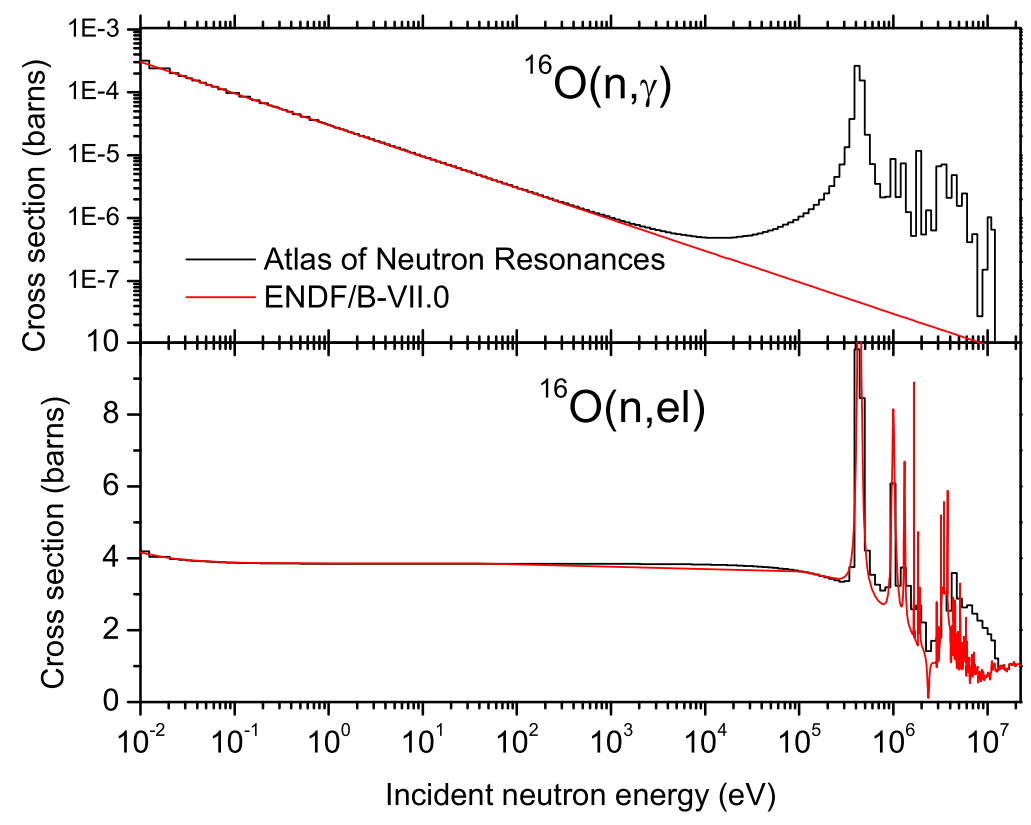

Figure 4.1: Comparison for the capture (top) and elastic (bottom) cross sections on ${ }^{16} \mathrm{O}$ between the Atlas of Neutron Resonances [3] and ENDF/B-VII.0. 


\subsection{ENDF/B-VII.0 evaluations: 6 isotopes}

\subsection{1 $155,156,157,158,160 \mathrm{Gd}$}

Covariances for 5 major isotopes of gadolinium, ${ }^{155,156,157,158,160} \mathrm{Gd}$, were taken from the new ENDF/B-VII.0 library [14]. They were produced as follows:

- In the resolved resonance region, covariances were evaluated by ORNL using the SAMMY retroactive method. To this end, the multi-level Breit-Wigner (MLBW) resonance parameters evaluated by BNL for the basic ENDF/B-VII.0 library were used $(\mathrm{MF}=2)$. Then, the retroactive method was employed for generating the resonance parameter covariance matrix, which was subsequently converted into the ENDF-6 format. In this process, the original multi-level Breit-Wigner representation for $\mathrm{MF}=2$ was replaced by the Reich-Moore representation. The resulting covariance data were stored in the file $\mathrm{MF}=32$.

- In the unresolved resonance and fast neutron regions, covariances were evaluated by BNL-LANL using the EMPIRE-KALMAN approach. We started from our cross section evaluations performed by the nuclear reaction model code EMPIRE. Then, we calculated sensitivity matrices by perturbing the optimal model parameters used in the evaluation. Afterwards, we included the experimental information on uncertainties and correlations using the Bayesian code KALMAN.

The resulting correlation matrices for Gd reveal complicated structure with strong correlations aligned within a relatively narrow band along the diagonal. This comes from the inclusion of experimental data in the correlation calculation. Without experimental data, an essentially flat and a highly correlated shape is obtained in the model-based calculations. The positive long-range correlations, typical for model predictions, are annihilated or turned into anticorrelations, leaving only short- and medium-range positive correlations when the experimental data are factored in.

\subsection{2 $\quad{ }^{232} \mathrm{Th}$}

Covariances for ${ }^{232} \mathrm{Th}$ were taken from the ENDF/B-VII.0 library. This evaluation was produced by the IAEA international project as follows:

- In the resolved resonance region, the Reich-Moore representation was used in the energy range from 0 to $4 \mathrm{keV}$ [15]. In this case the direct SAMMY method was used, meaning that genuine experimental data were analyzed to evaluate both the cross sections and covariances. The covariance data are given in terms of the correlation matrix for the resonance parameters (file $\mathrm{MF}=32$ ). 
- In the unresolved resonance region the experimental method was used to evaluate covariances.

- In the fast neutron region, covariance data were generated by the Monte Carlo technique [16] using the EMPIRE code. First, nuclear model covariance results were produced by EMPIRE. Then, the GANDR code [17] was used to update these results by adding the uncertainty information from experimental data using the generalized least-squares technique.

We note that $(\mathrm{n}, 2 \mathrm{n})$ covariance data for ${ }^{232} \mathrm{Th}$ are not explicitly given in the evaluated file as no MT16 cross section covariances are available. These should be extracted from the lumped covariance data given under MT851-855.

\subsection{JENDL-3.3 evaluations: 3 isotopes}

Covariances for ${ }^{1} \mathrm{H},{ }^{238} \mathrm{U}$ and ${ }^{239} \mathrm{Pu}$ were taken from JENDL-3.3, the latest release (2002) of the Japanese Evaluated Nuclear Data Library [18]. These evaluations are based on the modern methodology and, according to our judgment, they are of good quality and suitable for SG26 purposes.

The only added work by us was the processing. No plots could be generated for the H-1 and U-238 isotopes using NJOY-99.161 and ERRORJ processing codes, but tables for uncertainties and correlations were generated and they are given in Appendix B.

We intend to use also the JENDL-3.3 covariance data for ${ }^{235} \mathrm{U}$. However, we encountered processing difficulty, most likely due to the huge size of the file. Further work is needed to solve this problem.

\subsection{Missing evaluations: 7 isotopes}

Altogether, cross section covariances for 7 materials given in the SG26 list are not covered by the present report:

- 6 light nuclei. As discussed earlier, further study is needed for ${ }^{4} \mathrm{He},{ }^{6,7} \mathrm{Li},{ }^{9} \mathrm{~B}$, ${ }^{10} \mathrm{~B}$ and ${ }^{12} \mathrm{C}$.

- ${ }^{235} \mathbf{U}$. We intend to use the JENDL-3.3 covariance data for ${ }^{235} \mathrm{U}$, but we encountered processing difficulty that need further work.

\subsection{Discussion}

In the low energy region, we discuss integral quantities, including both the thermal values and resonance integrals. These quantities and their uncertainties provide an 
important information about the quality of our evaluations. Such discussion is facilitated by the fact that the Atlas of Neutron Resonances almost always contains integral data.

Detailed discussion of the fast neutron region is not attempted here. It would be too complex and it is deferred to the future report.

\subsubsection{Thermal cross sections}

In Table 4.1 we compare the thermal-energy elastic, capture and fission cross section uncertainties obtained in the present work with the values of the Atlas of Neutron Resonances. Our thermal cross section uncertainties for elastic scattering, capture and fission are taken directly from the 187-energy group representation. We note that if the cross section uncertainties are not constant up to $0.1 \mathrm{eV}$ (upper limit of the $15^{\text {th }}$ energy group in the 15-energy group representation), values for the thermal energy group given in Appendix B might differ from the values in Table 4.1. Still, averaged uncertainties and correlations from the 187-energy groups are consistent with those from the 15-energy groups.

BNL evaluations. As explained above, if no bound level is given in the Atlas [3] (the only case out of the 36 isotopes studied here is ${ }^{242 m} \mathrm{Am}$ ), the calculated cross section uncertainties are obtained from the positive resonance parameter uncertainties. In these cases, our uncertainties may differ from the thermal values given in the Atlas.

If a bound level is available, the cross section uncertainties are due to two contributors: positive resonances and the bound level. As parameter uncertainties are given for the positive resonances and none are given for the bound resonance, the uncertainties on the bound resonance parameters are adjusted so that the calculated thermal cross section uncertainty agrees with the one given in the Atlas. This is the case for:

- $(n, \gamma)$ on ${ }^{27} \mathrm{Al},{ }^{57} \mathrm{Fe},{ }^{58} \mathrm{Ni},{ }^{91,92,94} \mathrm{Zr},{ }^{166,167,168,170} \mathrm{Er},{ }^{206,207} \mathrm{~Pb},{ }^{209} \mathrm{Bi},{ }^{237} \mathrm{~Np},{ }^{238} \mathrm{Pu}$ and ${ }^{241} \mathrm{Am}$;

- $(\mathrm{n}, \mathrm{el})$ on ${ }^{56,57} \mathrm{Fe},{ }^{91,92,94} \mathrm{Zr},{ }^{166,167,168,170} \mathrm{Er},{ }^{206} \mathrm{~Pb},{ }^{237} \mathrm{~Np},{ }^{240,241} \mathrm{Pu}$ and ${ }^{244} \mathrm{Am}$;

- $(\mathrm{n}, \mathrm{f})$ on ${ }^{237} \mathrm{~Np},{ }^{240} \mathrm{Pu}$ and ${ }^{241,243} \mathrm{Am}$.

For the other isotopes and reactions, the effect of the bound resonance is not important enough to lower the thermal cross section uncertainties to the desired value. In these cases, the uncertainties on the bound resonance parameters are assumed to be zero, and only uncertainties from the positive resonances contribute to the thermal values. Therefore, our thermal cross section uncertainties would be higher than the ones given in the Atlas, often by a considerable margin. At the moment, we adopted this philosophy as it makes our values pretty conservative, though this 
may be reconsidered in future.

ENDF/B-VII.0 evaluations. For the gadolinium isotopes, the ENDF/B-VII.0 covariance evaluations explicitly considered the thermal capture values from the Atlas [3]. As a consequence, a good agreement exists between these two evaluations. No thermal elastic cross section uncertainties are given in the Atlas for the Gd isotopes.

In the case of ${ }^{232} \mathrm{Th}$, the elastic cross section uncertainties are in agreement, while the capture cross section uncertainty is larger by a factor 3 compared to that in the Atlas.

JENDL-3.3 evaluations. As shown in the table, three evaluations were taken from the JENDL-3.3 library: ${ }^{1} \mathrm{H},{ }^{238} \mathrm{U}$, and ${ }^{239} \mathrm{Pu}$. In general, the JENDL-3.3 uncertainties are somewhat different compared to those given in the Atlas. As the JENDL-3.3 evaluations are independent, these differences are legitimate. But, in general, Atlas's uncertainties are smaller (except for the thermal elastic cross section uncertainty of ${ }^{239} \mathrm{Pu}$ ), which shows that the JENDL-3.3 adopted more conservative values.

Our overall conclusion is that we have either pretty good agreement with experimental thermal cross section uncertainties or our we adopt higher uncertainties. This means that our approach is fairly conservative. 
Table 4.1: Thermal-energy elastic, fission and capture cross section uncertainties of the present work, compared to the values of the Atlas of Neutron Resonances [3].

\begin{tabular}{|c|c|c|c|c|c|c|c|c|}
\hline \multirow{2}{*}{\multicolumn{2}{|c|}{ Nuclide }} & \multicolumn{2}{|c|}{ Elastic (\%) } & \multicolumn{2}{|c|}{ Fission (\%) } & \multicolumn{2}{|c|}{ Capture (\%) } & \multirow[t]{2}{*}{ Comment } \\
\hline & & $\begin{array}{l}\text { Atlas } \\
2006\end{array}$ & $\begin{array}{c}\text { Present } \\
\text { work }\end{array}$ & $\begin{array}{l}\text { Atlas } \\
2006\end{array}$ & $\begin{array}{c}\text { Present } \\
\text { work }\end{array}$ & $\begin{array}{l}\text { Atlas } \\
2006\end{array}$ & $\begin{array}{c}\text { Present } \\
\text { work }\end{array}$ & \\
\hline 1. & ${ }^{1} \mathrm{H}$ & 0.07 & 0.1 & & & 0.2 & 0.5 & JENDL-3.3 \\
\hline 2. & ${ }^{4} \mathrm{He}$ & 25 & & & & & & Not started \\
\hline 3. & ${ }^{6} \mathrm{Li}$ & 2.7 & 7.9 & & & 7.8 & 7.8 & Not finalized \\
\hline 4. & ${ }^{7} \mathrm{Li}$ & 4.1 & 4.1 & & & 5.9 & 5.9 & Not finalized \\
\hline 5. & ${ }^{9} \mathrm{Be}$ & 0.1 & 1.2 & & & 4.0 & 4.0 & Not finalized \\
\hline 6. & ${ }^{10} \mathrm{~B}$ & 2.7 & 2.8 & & & 5.2 & 5.2 & Not finalized \\
\hline 7. & ${ }^{12} \mathrm{C}$ & 0.1 & & & & 2 & & Not started \\
\hline 8. & ${ }^{16} \mathrm{O}$ & 0.1 & 2.2 & & & 10 & 10 & \\
\hline 9. & ${ }^{19} \mathrm{~F}$ & 0.3 & 2.0 & & & 1.0 & 6.1 & \\
\hline 10. & ${ }^{23} \mathrm{Na}$ & 0.2 & 4.7 & & & 1.0 & 2.2 & \\
\hline 11. & ${ }^{27} \mathrm{Al}$ & 0.07 & 0.6 & & & 1.3 & 1.3 & \\
\hline 12. & ${ }^{28} \mathrm{Si}$ & 0.3 & 3.0 & & & 2.2 & 3.2 & \\
\hline 13 & ${ }^{52} \mathrm{Cr}$ & 0.8 & 7.2 & & & 2.3 & 2.7 & \\
\hline 14. & ${ }^{56} \mathrm{Fe}$ & 3.9 & 4.3 & & & 5.4 & 11 & \\
\hline 15. & ${ }^{57} \mathrm{Fe}$ & 8.8 & 7.6 & & & 12 & 12 & \\
\hline 16. & ${ }^{58} \mathrm{Ni}$ & 0.2 & 2.7 & & & 2.3 & 2.4 & \\
\hline 17. & ${ }^{90} \mathrm{Zr}$ & 5.7 & 6.7 & & & 2.1 & 2.5 & \\
\hline 18. & ${ }^{91} \mathrm{Zr}$ & 5.6 & 5.9 & & & 10 & 10 & \\
\hline 19. & ${ }^{92} \mathrm{Zr}$ & 5.5 & 5.4 & & & 31 & 31 & \\
\hline 20. & ${ }^{94} \mathrm{Zr}$ & 4.8 & 4.7 & & & 3.4 & 3.5 & \\
\hline 21. & ${ }^{155} \mathrm{Gd}$ & - & 1.0 & & & 0.8 & 1.0 & ENDF/B-VII.0 \\
\hline 22. & ${ }^{156} \mathrm{Gd}$ & - & 11.4 & & & 39 & 41 & ENDF/B-VII.0 \\
\hline 23. & ${ }^{157} \mathrm{Gd}$ & - & 0.4 & & & 0.3 & 0.4 & ENDF/B-VII.0 \\
\hline 24. & ${ }^{158} \mathrm{Gd}$ & - & 3.1 & & & 9.1 & 8.6 & ENDF/B-VII.0 \\
\hline 25. & ${ }^{160} \mathrm{Gd}$ & - & 9.8 & & & 21 & 17 & ENDF/B-VII.0 \\
\hline 26. & ${ }^{166} \mathrm{Er}$ & 3.5 & 3.7 & & & 9.5 & 9.4 & \\
\hline 27. & ${ }^{167} \operatorname{Er}$ & 56 & 58 & & & 1.2 & 1.3 & \\
\hline 28. & ${ }^{168} \operatorname{Er}$ & 8.4 & 8.8 & & & 2.9 & 3.0 & \\
\hline 29. & ${ }^{170} \mathrm{Er}$ & 17.3 & 18 & & & 3.4 & 3.7 & \\
\hline 30. & ${ }^{206} \mathrm{~Pb}$ & 1.0 & 1.0 & & & 2.1 & 2.0 & \\
\hline 31. & ${ }^{207} \mathrm{~Pb}$ & - & 9.6 & & & 2.2 & 2.0 & \\
\hline 32. & ${ }^{208} \mathrm{~Pb}$ & 1.3 & 1.7 & & & 8.7 & 27 & \\
\hline 33. & ${ }^{209} \mathrm{Bi}$ & 0.04 & 1.8 & & & 2.0 & 1.9 & \\
\hline 34. & ${ }^{232} \mathrm{Th}$ & 0.6 & 0.6 & 77 & See ${ }^{1)}$ & 0.4 & 1.2 & ENDF/B-VII.0 \\
\hline 35. & ${ }^{233} \mathrm{U}$ & 2.4 & 6.5 & 0.2 & 1.1 & 1.5 & 5.2 & \\
\hline 36. & ${ }^{234} \mathrm{U}$ & 5.1 & 2.0 & 21 & 25 & 1.3 & 2.9 & \\
\hline
\end{tabular}


Table 4.1 - continued from previous page

\begin{tabular}{|cc|cc|cc|cc|c|}
\hline \multirow{2}{*}{ Nuclide } & \multicolumn{2}{|c|}{ Elastic (\%) } & \multicolumn{2}{c|}{ Fission (\%) } & \multicolumn{2}{c|}{ Capture (\%) } & Comment \\
& & Atlas & Present & Atlas & Present & Atlas & Present & \\
& & 2006 & work & 2006 & work & 2006 & work & \\
\hline 37. & ${ }^{235} \mathrm{U}$ & 1.6 & & 0.2 & & 0.8 & & Not finalized \\
38. & ${ }^{236} \mathrm{U}$ & 0.9 & 5.0 & 14 & 20 & 2.0 & 3.6 & \\
39. & ${ }^{237} \mathrm{~Np}$ & 2.0 & 2.1 & 5.0 & 5.0 & 1.6 & 1.7 & \\
40. & ${ }^{238} \mathrm{U}$ & 0.2 & 0.6 & - & 0.9 & 0.7 & 1.9 & JENDL-3.3 \\
\hline 41. & ${ }^{238} \mathrm{Pu}$ & 8.1 & 4.6 & 2.2 & 4.9 & 1.3 & 1.4 & \\
42. & ${ }^{239} \mathrm{Pu}$ & 4.5 & 1.0 & 0.3 & 1.45 & 1.1 & 1.9 & JENDL-3.3 \\
43. & ${ }^{240} \mathrm{Pu}$ & 5.8 & 6.1 & 53 & 54 & 4.8 & 5.3 & \\
44. & ${ }^{241} \mathrm{Pu}$ & 11 & 11.6 & 0.6 & 3.3 & 1.4 & 3.2 & \\
45. & ${ }^{242} \mathrm{Pu}$ & 2.5 & 7.0 & - & 5.2 & 2.7 & 7.1 & \\
\hline 46. & ${ }^{241} \mathrm{Am}$ & - & 13 & 2.8 & 3.0 & 2.0 & 2.1 & \\
47. & ${ }^{242 m} \mathrm{Am}$ & - & 25 & 3.2 & 9.2 & 25 & 23 & \\
48. & ${ }^{243} \mathrm{Am}$ & - & 12 & 2.2 & 2.3 & 2.4 & 3.8 & \\
49. & ${ }^{242} \mathrm{Cm}$ & - & 20 & - & 43 & 31 & 41 & \\
50. & ${ }^{243} \mathrm{Cm}$ & - & 23 & 3.2 & 10 & 7 & 17 & \\
\hline 51. & ${ }^{244} \mathrm{Cm}$ & 6.0 & 6.1 & 19 & 27 & 8 & 12 & \\
52. & ${ }^{245} \mathrm{Cm}$ & - & 20 & 2.7 & 3.8 & 4.6 & 8.4 & \\
\hline \hline
\end{tabular}

1) The thermal fission cross section uncertainty for ${ }^{232} \mathrm{Th}$ is not given in the ENDF/B-VII.0 library, since the fission has the threshold at $\simeq 1 \mathrm{MeV}$.

\subsubsection{Resonance integrals}

In order to gain confidence in our predictions of cross section uncertainties we have calculated capture and fission resonance integrals and compared them, as well as their respective uncertainties, with the results reported in the Atlas. The resonance integral is defined as

$$
I=\int_{0.5 \mathrm{eV}}^{E_{\max }} \sigma(E) \frac{d E}{E},
$$

where $\sigma$ is either the capture or fission cross section. Usually, the integration is performed up to $\mathrm{E}_{\max }=20 \mathrm{MeV}$, but we follow the convention adopted in the Atlas $\left(\mathrm{E}_{\max }=\right.$ energy of the last resonance) in order to ensure a meaningful comparison. The impact of the $20 \mathrm{MeV}$ upper limit should be pretty small for capture, while it is expected to be more pronounced in the case of the fission integral and particularly dramatic for the threshold fissioners.

We have calculated resonance integrals replacing the integral in Eq. 4.1 with a sum

$$
I \approx \sum_{0.5 \mathrm{eV}}^{E_{\max }} \frac{1}{E_{i}} \sigma\left(E_{i}\right) \Delta E_{i},
$$


where $\sigma\left(E_{i}\right)$ is the capture or fission cross section averaged over the energy groups of boundaries $E_{i}$ and $E_{i-1}$ and $\Delta E_{i}=E_{i}-E_{i-1}$. In practice, the 187 energy group structure, defined as ' $i g n=10$ ' in the NJOY processing code, was used.

The uncertainty $\delta I$ should be calculated by taking into account the energy-energy correlations among cross sections. The following formula was used:

$$
\begin{aligned}
\delta I & =\sqrt{\sum_{i}\left[\delta \sigma\left(E_{i}\right) \frac{\Delta E_{i}}{E_{i}}\right]^{2}+\sum_{i} \sum_{j \neq i} \operatorname{corr}(i, j) \cdot \delta \sigma\left(E_{i}\right) \frac{\Delta E_{i}}{E_{i}} \cdot \delta \sigma\left(E_{j}\right) \frac{\Delta E_{j}}{E_{j}}} \\
& =\sqrt{\sum_{i} \sum_{j} \frac{1}{E_{i}} \frac{1}{E_{j}} \operatorname{corr}(i, j) \cdot \delta \sigma\left(E_{i}\right) \Delta E_{i} \cdot \delta \sigma\left(E_{j}\right) \Delta E_{j}},
\end{aligned}
$$

where $\delta \sigma\left(E_{i}\right)$ is the fractional uncertainty of the group cross section $\sigma\left(E_{i}\right)$ between $E_{i}$ and $E_{i-1}$, and $\operatorname{corr}(i, j)$ is the correlation coefficient between cross sections in groups $i$ and $j$. We note that predominantly positive correlations will increase the uncertainty of the resonance integral compared to the fully uncorrelated case (all off-diagonal $\operatorname{corr}(i, j)=0$ ). On the other hand, strong anti-correlations can substantially decrease uncertainty due to the negative second term in Eq. 4.3.

In Tables 4.2 and 4.3 we compare capture and fission resonance integral values from the Atlas of Neutron Resonances with those obtained in our analysis. In general, our resonance integrals agree within uncertainties with those from the Atlas. The only exception is the fission resonance integral for ${ }^{241} \mathrm{Pu}$ where further study is needed to understand the differences. We note, however, that if there is no calculated value for the resonance integral in the Atlas (as in the case for ${ }^{241} \mathrm{Pu}$ ), Tables 4.2 and 4.3 quote a measured value and denote it with an $\left(^{*}\right)$. Our estimates might differ from the measured resonance integrals because of different energy integration limit $E_{\text {max }}$.

Good agreement obtained for the values of the capture and fission integrals justifies extending the comparison to the related uncertainties. In doing this we should keep in mind that our uncertainties on the resonance integrals were obtained by propagating evaluated experimental uncertainties on the thermal cross sections (generally pretty accurate) and the resonance parameters. As such, our uncertainties are based on the measurements that are independent from the resonance integral measurements. Therefore, the comparison with the calculated Atlas uncertainties is only testing the methodology of estimating uncertainties while comparison with the experimental uncertainties faces also a possible discrepancy between microscopic and integral experiments.

Tables 4.2 and 4.3 include estimates of the resonance integral uncertainties calculated under three different assumptions regarding the energy-energy cross section correlations: 
1. Our correlations obtained using all relevant information contained in the Atlas,

2. No correlations $(\operatorname{corr}(i, j)=0$ for all off-diagonal terms), and

3. Full correlation $(\operatorname{corr}(i, j)=1$ for all terms).

The first option is currently our recommended estimate, although we are aware that certain sources of correlations (e.g., correlation between $\Gamma_{\gamma}$ and $\Gamma_{n}$ for each resonance) are not included in the present analysis. Therefore, we include the two limitting cases (no-correlations and full-correlations) to shed light on the effect of the missed correlations and margins of our estimates. The uncertainties calculated assuming lack of any correlations are generally by a factor 2 to 5 lower from those assuming full correlations. As expected, most of our results fall between the two limits, except of the three cases $\left({ }^{236} \mathrm{U},{ }^{237} \mathrm{~Np},{ }^{239} \mathrm{Pu}\right)$ that appear to be smaller. This shortage can be understood as an effect of negative correlations in the capture cross sections (e.g., see Figs. A.123, A.128, and A.139) as indicated in the discussion of Eq. 4.3 .

Tables 4.2 and 4.3 reveal that in 8 cases the present uncertainties are significantly larger than those reported in the Atlas. In 16 cases they are comparable, and 31 results of the present work are lower than the uncertainties in the Atlas. Particularly striking discrepancies are found for the uncertainties on capture integrals for ${ }^{27} \mathrm{Al}$, ${ }^{28} \mathrm{Si}$, and ${ }^{209} \mathrm{Bi}$. In the latter case, the Atlas reports $14 \%$ that is to be compared with $1 \%$ resulting from the present exercise. After detailed scrutiny it turned out, that the Atlas uncertainty has been arbitrarily increased by Mughabghab to accomodate the expected deviation of the capture cross section from the $1 / v$ behavior. So far, our results do not include such considerations. 
Table 4.2: Capture resonance integrals, $\mathrm{I}_{\gamma}$, and their uncertainties, $\delta \mathrm{I}_{\gamma}$. Values denoted with $\left(^{*}\right)$ are measured quantities (see page 25 for details), no calculated values are given in the Atlas of Neutron Resonances [3] in these cases.

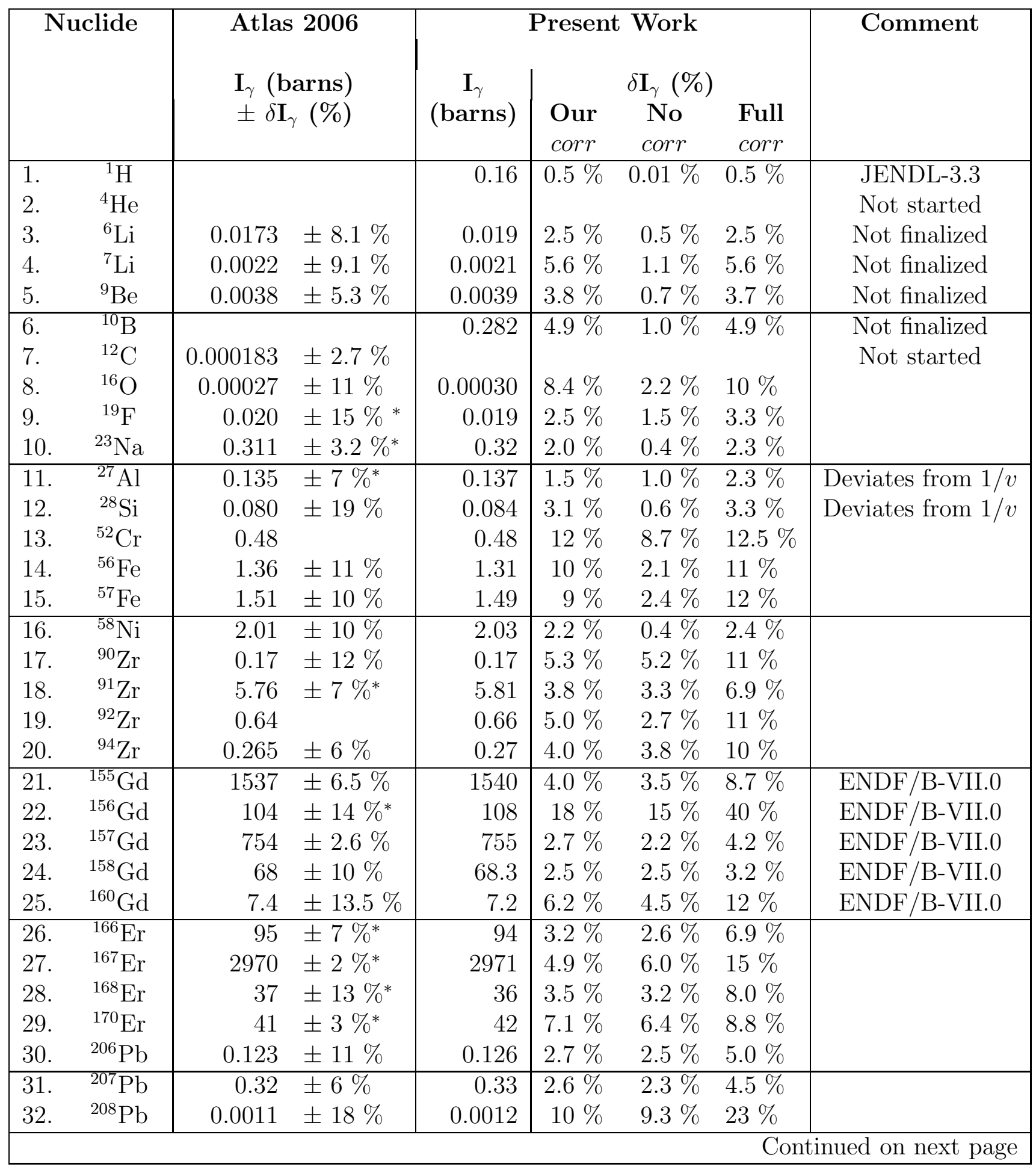


Table 4.2 - continued from previous page

\begin{tabular}{|c|c|c|c|c|c|c|}
\hline Nuclide & $\begin{array}{l}\text { Atlas } 2006 \\
\mathbf{I}_{\gamma} \text { (barns) } \\
\pm \delta \mathbf{I}_{\gamma}(\%)\end{array}$ & $\begin{array}{c}\mathbf{I}_{\gamma} \\
\text { (barns) }\end{array}$ & Presen & $\begin{array}{l}\text { Work } \\
\delta \mathbf{I}_{\gamma}(\%) \\
\text { No } \\
\text { corr }\end{array}$ & $\begin{array}{l}\text { Full } \\
\text { corr }\end{array}$ & Comment \\
\hline${ }^{209} \mathrm{Bi}$ & $0.140 \pm 14 \%$ & 0.146 & $1.0 \%$ & $0.3 \%$ & $1.4 \%$ & Deviates from $1 / v$ \\
\hline${ }^{232} \mathrm{Th}$ & $83.3 \pm 1.8 \%$ & 85 & $1.9 \%$ & $1.9 \%$ & $5.7 \%$ & ENDF/B-VII.0 \\
\hline${ }^{233} \mathrm{U}$ & $138 \pm 4.3 \%^{*}$ & 133 & $3.8 \%$ & $2.8 \%$ & $6.0 \%$ & \\
\hline${ }^{234} \mathrm{U}$ & $640 \pm 3.1 \%$ & 642 & $1.4 \%$ & $0.9 \%$ & $2.6 \%$ & \\
\hline${ }^{235} \mathrm{U}$ & $146 \pm 4.1 \% *$ & & & & & Not finalized \\
\hline${ }^{236} \mathrm{U}$ & $345 \pm 4.4 \% *$ & 341 & $6.2 \%$ & $7.5 \%$ & $19 \%$ & \\
\hline${ }^{237} \mathrm{~Np}$ & 636 & 638 & $0.7 \%$ & $1.0 \%$ & $2.5 \%$ & \\
\hline${ }^{238} \mathrm{U}$ & $277 \pm 1.1 \% *$ & 281 & $2.0 \%$ & $1.7 \%$ & $3.0 \%$ & JENDL-3.3 \\
\hline${ }^{238} \mathrm{Pu}$ & $162 \pm 9.2 \%$ & 163 & $2.9 \%$ & $2.8 \%$ & $8.2 \%$ & \\
\hline${ }^{239} \mathrm{Pu}$ & $\pm 11 \% *$ & 181 & $1.0 \%$ & $1.2 \%$ & $3.9 \%$ & JENDL-3.3 \\
\hline${ }^{240} \mathrm{Pu}$ & $\pm 2.4 \% *$ & 8530 & $4.2 \%$ & $2.3 \%$ & $7.7 \%$ & \\
\hline${ }^{241} \mathrm{Pu}$ & $\pm 5.0 \% *$ & 162 & $6.0 \%$ & $4.8 \%$ & $12 \%$ & \\
\hline${ }^{242} \mathrm{Pu}$ & $\pm 3.6 \%$ & 1100 & $3.6 \%$ & $2.8 \%$ & $4.1 \%$ & \\
\hline${ }^{241} \mathrm{Am}$ & $\pm 7.0 \% *$ & 1410 & $2.2 \%$ & $1.6 \%$ & $5.0 \%$ & \\
\hline${ }^{242 m} \mathrm{Am}$ & 211 & 211 & $10 \%$ & $6.0 \%$ & $19 \%$ & \\
\hline${ }^{243} \mathrm{Am}$ & $\pm 3.8 \% *$ & 1810 & $3.0 \%$ & $2.0 \%$ & $4.3 \%$ & \\
\hline${ }^{242} \mathrm{Cm}$ & $\pm 18 \% *$ & 100 & $3.3 \%$ & $2.9 \%$ & $9.8 \%$ & \\
\hline${ }^{243} \mathrm{Cm}$ & $\pm 7 \% *$ & 209 & $5.4 \%$ & $3.0 \%$ & $14 \%$ & \\
\hline${ }^{244} \mathrm{Cm}$ & $\pm 4.6 \% *$ & 655 & $6.5 \%$ & $6.1 \%$ & $9.3 \%$ & \\
\hline 52. $\quad{ }^{245} \mathrm{Cm}$ & $\pm 8 \% *$ & 102 & $5.5 \%$ & $3.2 \%$ & $13 \%$ & \\
\hline
\end{tabular}


Table 4.3: Fission resonance integrals, $\mathrm{I}_{f}$, and their uncertainties, $\delta \mathrm{I}_{f}$. Values denoted with $\left(^{*}\right)$ are the measured quantities (see page 25 for details); no calculated values are in the Atlas of Neutron Resonances [3].

\begin{tabular}{|c|c|c|c|c|c|c|c|}
\hline \multirow{2}{*}{\multicolumn{2}{|c|}{ Nuclide }} & \multirow{2}{*}{$\begin{array}{l}\text { Atlas } 2006 \\
\mathbf{I}_{f} \text { (barns) } \\
\pm \delta \mathbf{I}_{f}(\%)\end{array}$} & \multicolumn{4}{|c|}{ Present Work } & \multirow{2}{*}{ Comment } \\
\hline & & & $\begin{array}{c}\mathbf{I}_{f} \\
\text { (barns) }\end{array}$ & $\begin{array}{l}\text { Our } \\
\text { corr }\end{array}$ & $\begin{array}{c}\delta \mathbf{I}_{f}(\% \\
\text { No } \\
\text { corr }\end{array}$ & $\begin{array}{l}\text { Full } \\
\text { corr }\end{array}$ & \\
\hline 34. & ${ }^{232} \mathrm{Th}$ & & & & & & ENDF/B-VII.0 \\
\hline 35. & ${ }^{233} \mathrm{U}$ & $775 \pm 2.2 \% *$ & 761 & $1.3 \%$ & $0.7 \%$ & $1.5 \%$ & \\
\hline 36. & ${ }^{234} \mathrm{U}$ & 0.56 & 0.56 & $20 \%$ & $10 \%$ & $20 \%$ & \\
\hline 37. & ${ }^{235} \mathrm{U}$ & $275 \pm 1.1 \%$ & & & & & Not finalized \\
\hline 38. & ${ }^{236} \mathrm{U}$ & $4.1 \pm 24 \%$ & 4.3 & $14 \%$ & $4.3 \%$ & $15 \%$ & \\
\hline 39. & ${ }^{237} \mathrm{~Np}$ & $4.7 \pm 4.9 \% *$ & 4.7 & $5.9 \%$ & $1.7 \%$ & $9.0 \%$ & \\
\hline 40. & ${ }^{238} \mathrm{U}$ & $\pm 10 \%$ & 0.00169 & $2.8 \%$ & $2.8 \%$ & $3.0 \%$ & JENDL-3.3 \\
\hline 41. & ${ }^{238} \mathrm{Pu}$ & $\pm 15 \%$ & 32 & $7.7 \%$ & $2.7 \%$ & $18 \%$ & \\
\hline 42. & ${ }^{239} \mathrm{Pu}$ & $\pm 3.3 \% *$ & 302 & $3.4 \%$ & $1.8 \%$ & $6.7 \%$ & JENDL-3.3 \\
\hline 43. & ${ }^{240} \mathrm{Pu}$ & 3.16 & 3.17 & $3.1 \%$ & $2.3 \%$ & $7.2 \%$ & \\
\hline 44. & ${ }^{241} \mathrm{Pu}$ & $\pm 2.6 \% *$ & 320 & $6.0 \%$ & $3.5 \%$ & $14 \%$ & \\
\hline 45. & ${ }^{242} \mathrm{Pu}$ & 0.12 & 0.13 & $3.8 \%$ & $3.8 \%$ & $3.8 \%$ & \\
\hline 46. & ${ }^{241} \mathrm{Am}$ & $\pm 7.0 \% *$ & 14.0 & $4.1 \%$ & $2.3 \%$ & $12 \%$ & \\
\hline 47. & ${ }^{242 m} \mathrm{Am}$ & $\pm 5.1 \% *$ & 1460 & $3.3 \%$ & $1.7 \%$ & $6.6 \%$ & \\
\hline 48. & ${ }^{243} \mathrm{Am}$ & $\pm 5.6 \% *$ & 7.3 & $5.0 \%$ & $2.0 \%$ & $11 \%$ & \\
\hline 49. & ${ }^{242} \mathrm{Cm}$ & $\pm 5.4 \% *$ & 13.5 & $18 \%$ & $18 \%$ & $34 \%$ & \\
\hline 50. & ${ }^{243} \mathrm{Cm}$ & $\pm 6.4 \% *$ & 1570 & $4.8 \%$ & $2.8 \%$ & $11 \%$ & \\
\hline 51. & ${ }^{244} \mathrm{Cm}$ & $\pm 20 \% *$ & 12.3 & $16 \%$ & $5.2 \%$ & $28 \%$ & \\
\hline 52. & ${ }^{245} \mathrm{Cm}$ & $\pm 4.8 \% *$ & 814 & $3.1 \%$ & $1.6 \%$ & $9.5 \%$ & \\
\hline
\end{tabular}

\subsubsection{Fast neutron region}

Comparison of our cross section uncertainties with the experimental data available in the CSISRS/EXFOR library is not attempted here. This would be impossible within the limited time available for the present work. Such a discussion is deferred to future report.

At this point we will just make a couple of basic observations about the cross section uncertainties that we obtained:

- (n,el): In general, the uncertainties look reasonable. The observed shape is driven by the optical model, with several minima in the uncertainties. This can be explained by nodes, predicted by the optical model. 
- (n,n'): In quite a few cases we observe one or two strong bumps in the threshold energy region. This feature needs more study, although its impact on SG26 applications should be small due to low cross sections near the threshold energies. At higher energies the uncertainties have the expected shape.

- $(\mathrm{n}, 2 \mathrm{n})$ : In all cases the uncertainties look very reasonable.

- $(\mathrm{n}, \gamma)$ : The uncertainties look very reasonable. The only issue to be addressed in future is drop of the uncertainties at around $15 \mathrm{MeV}$, although this should have no impact on SG26 applications.

- $(n, f)$ : The uncertainties need more detailed analysis in future.

- 15-groups versus 187-groups: In quite a few cases one can observe that the uncertainties in the 15-group representation are lower, sometimes even much lower, than those seen in the 187-group representation. This can be explained by the impact of correlations that reduce the multi-group uncertainties due to $\operatorname{corr}(\mathrm{i}, \mathrm{j})<1.0$ terms. 


\section{Chapter 5}

\section{$\nu$-bar Covariances}

\section{$5.1 \quad$ Procedure}

The covariances for the average number of neutrons per fission (total $\nu$-bar) were produced for 10 priority actinides listed in Table 1.1. This was based on the following two considerations.

First, for ${ }^{233,235,238} \mathrm{U}$ and ${ }^{239,240,241} \mathrm{Pu}$ we used the data from the JENDL-3.3 library released in 2002 . These data were processed by us in the 15-energy group representation with the constant flux.

Second, for ${ }^{237} \mathrm{~Np}$ and ${ }^{241,242 m, 243} \mathrm{Am}$ simple estimates were made. In doing so we made sure that our uncertainties agree reasonably well with the experimental data, while the correlations were assumed to be the same as those of the appropriately selected neighboring nuclei. Our procedure consisted of three steps:

- We took into account the odd-even effects and assumed that there is reasonable correspondence between the $\nu$-bar covariances: ${ }^{237} \mathrm{~Np} \Leftrightarrow{ }^{240} \mathrm{Pu},{ }^{241,243} \mathrm{Am} \Leftrightarrow$ ${ }^{240} \mathrm{Pu}$, and ${ }^{242 m} \mathrm{Am} \Leftrightarrow{ }^{241} \mathrm{Pu}$. In other words, we assumed that the uncertainties for the corresponding nuclei have the similar shape, while the correlations are identical.

- In the thermal region, the actual $\nu$-bar uncertainties given in the Atlas of Neutron Resonances were adopted and the above uncertainties were renormalized.

- The renormalized uncertainties were checked against the available data at higher energies and the $\nu$-bar uncertainties were adjusted as necessary. The correlation matrices in the original ENDF-6 files were not modified, although the change of the diagonal terms impacted the final 15-group correlations.

\subsection{Results}

The $\nu$-bar covariances are provided only for the first 10 actinides, listed in the priority order in Table 1.1. The plots and tables are given in Appendix C. These are 
provided for ${ }^{235,238} \mathrm{U},{ }^{239,240,241} \mathrm{Pu},{ }^{237} \mathrm{~Np},{ }^{241,242 m, 243} \mathrm{Am}$, and also for ${ }^{233} \mathrm{U}$.

The remaining $\nu$-bar covariances (9 actinides, all priority 5 ) will be produced later in 2007. 


\section{Chapter 6}

\section{Conclusions, Bibliography}

We produced preliminary cross section covariances for 45 out of 52 materials requested by the WPEC Subgroup 26. We performed our own evaluations for 36 materials, and processed additional 9 materials from the latest evaluated data libraries.

In the low energy region our evaluations are based on the solid ground of the experimental data incorporated in the Atlas of Neutron Resonances. In the fast neutron region our evaluations are driven by the model calculations, though the experimental data from the library of experimental cross sections (CSISRS/EXFOR) were consulted.

The preliminary covariances for $\nu$-bar are reported for 10 actinides. For 6 materials we used the recent evaluated data libraries, the other 4 materials are based on simple estimates.

We emphasize that all results reported in the present report are preliminary. Although we have done our best and, within the limited resources available, attempted to produce the best values, there is a number of issues to be addressed in future. Some of them are listed below:

1. Thermal region: Discrepancies in the uncertainties between the experimental values given in the Atlas and calculated values obtained from the resonance parameter uncertainties.

2. Resonance region: Discrepancies in the uncertainties of the resonance integrals given in the Atlas and the calculated values obtained from the resonance parameter uncertainties. Impact of deviations from $1 / v$ on the resonance integrals.

3. Resonance region: Correlations between the resonance parameters, such as $\Gamma_{n}$ and $\Gamma_{\gamma}$, should be taken into account.

4. Unresolved resonance region: Two approaches should be compared, the use of 
URR parameters and their estimated uncertainties (extended Atlas-KALMAN approach), and the EMPIRE-KALMAN approach.

5. Fast neutron region, (n,el): High-energy minima in uncertainties should be better understood.

6. Fast neutron region, $(\mathrm{n}, \mathrm{n}$ '): Low-energy bumps in the uncertainties should be resolved.

7. High-energy capture: Drop in the uncertainties above $15 \mathrm{MeV}$ should be resolved.

8. Fast neutron region, $(\mathrm{n}, \mathrm{f})$ : Fission channel needs additional work, experimental data should be taken into account more carefully, all uncertainties should be analyzed in more detail.

9. $\nu$-bar covariances: More refined evaluation procedure is needed, including adjustments to the latest values in Atlas (especially ${ }^{233} \mathrm{U}$ ).

10. Multigroup processing: Differences in the uncertainties between the 15-group and 187-group representations, intuitively somewhat difficult to accept, should be analyzed in more detail.

11. Positive definiteness: Eigen-values of randomly selected covariance matrices were calculated to check for positive definiteness. In some cases we have found negative eigen-values that can be due to the rounding errors and to the collapsing of the initial fine group structure ( 200 groups) into 15 groups. In all these cases, the absolute value of the negative eigen-values was at least three orders of magnitude lower than the positive ones. Thus, we expect that some non-positive definite covariance matrices that were produced in the current exercise should not pose any problems in the sensitivity studies. More systematic study of the issue should, however, be carried out in the future.

We aim to improve this work, address some of the above issues, and, in collaboration with LANL (light nuclei, actinides), complete covariances for all 52 materials later in 2007. As soon as new US covariance evaluations for ${ }^{235,238} \mathrm{U}$ and ${ }^{239} \mathrm{Pu}$ will become available we will incorporate them and replace the current JENDL-3.3 data.

\section{Acknowledgments}

We are grateful to Max Salvatores, CEA and ANL, for the stimulation and encouragement. We want to thank Tom Burrows, BNL, for converting selected data from the Atlas of Neutron Resonances to the electronic database. We are grateful to Marco Pigni, BNL, for performing positive definiteness analysis of the BNL covariance matrices. 


\section{Bibliography}

[1] M. Salvatores, "Working party on international nuclear data evaluation cooperation (WPEC), Subgroup 26: Nuclear Data Needs for Advanced Reactor Systems," 2006. 18th Meeting on 3 - 5 May, 2006, NEA, Paris, France.

[2] G. Aliberti, G. Palmiotti, M. Salvatores, T. K. Kim, T. A. Taiwo, M. Anitescu, I. Kodeli, E. Sartori, and J. C. B. amd J. Tommasi, "Nuclear data sensitivity, uncertainty and target accuracy assessment for future nuclear systems," Annals of Nuclear Energy, vol. 33, p. 700, 2006.

[3] S. F. Mughabghab, Atlas of Neutron Resonances: Resonance Parameters and Thermal Cross Sections. Amsterdam: Elsevier, 2006.

[4] M. Herman, R. Capote, B. Carlson, P. Obložinský, M. Sin, A. Trkov, and V. Zerkin, "EMPIRE nuclear reaction model code, version 2.19 (Lodi)." www.nndc.bnl.gov/empire219/, March 2005.

[5] T. Kawano Tech. Rep. JAERI-Research 99-009, JAERI, 1999. (in Japanese).

[6] M. Sin, R. Capote, A. Ventura, M. Herman, and P. Obložinský, "Fission of light

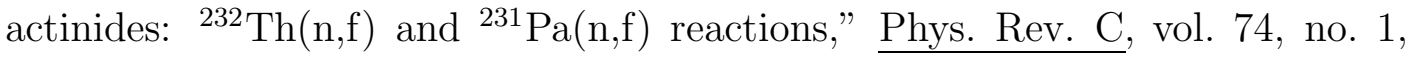
p. $014608,2006$.

[7] K. Kosako and N. Yanano, "Preparation of a covariance processing system for the evaluated nuclear data file, JENDL," Tech. Rep. JNC TJ-9440, 99-003, JAERI, 1999. (in Japanese).

[8] M. Williams, "Generation of Approximate Covariance Data." ORNL memo, August 2004.

[9] K. Kosako, "Covariance data processing code: ERRORJ," in the Specialists' Meeting of Reactor Group Constants (J. Katakura, ed.), JAERI, Tokai, Japan, February 22-23 2001. JAERI-Conf 2001-009.

[10] M. M. Hoffman, W. M. Sanders, and M. D. Semon Bull. of Amer. Physics, vol. 21, p. 655, 1976.

[11] J. H. Landrum, R. J. Nagle, and M. Lindner, " $(n, 2 n)$ cross sections for ${ }^{238} \mathrm{U}$ and ${ }^{237} \mathrm{~Np}$ in the region of $14 \mathrm{MeV}$," Phys. Rev. C, vol. 8, pp. 1938-1944, Nov 1973. 
[12] A. B. Smith, J. F. Whalen, and P. Lambropoulos Nucl. Sci. and Eng., vol. 47, p. $19,1972$.

[13] D. Rochman, M. Herman, P. Obložinský, and M. Sin, "Modeling and neutroninduced fission cross sections for americium," Nucl. Sci. and Eng., vol. 154, p. 280, 2006.

[14] M. Chadwick, P. Obložinský, M. Herman, N. Greene, R. McKnight, D. Smith, P. Young, R. MacFarlane, G. Hale, S. Frankle, A. Kahler, T. Kawano, R. Little, D. Madland, P. Moller, R. Mosteller, P. Page, P. Talou, H. Trellue, M. White, W. Wilson, R. Arcilla, C. Dunford, S. Mughabghab, B. Pritychenko, D. Rochman, A. Sonzogni, C. Lubitz, T. Trumbull, J. Weinman, D. Brown, D. Cullen, D. Heinrichs, D. McNabb, H. Derrien, M. Dunn, N. Larson, L. Leal, A. Carlson, R. Block, J. Briggs, E. Cheng, H. Huria, M. Zerkle, K. Kozier, A. Courcelle, V. Pronyaev, and S. van der Marck, "ENDF/B-VII.0: Next generation evaluated nuclear data library for nuclear science and technology," Nuclear Data Sheets, vol. 107, pp. 2931-3118, December 2006.

[15] H. Derrien, L. C. Leal, and N. M. Larson, "Evaluation of ${ }^{232}$ Th Neutron Resonance Parameters in the Energy Range 0 to $4 \mathrm{keV}, "$ Tech. Rep. ORNL/TM2006/53, Oak Ridge National Lab, 2006.

[16] D. Smith, "Covariance matrices for nuclear cross sections derived from nuclear model calculations," report ANL/NDM-159 November, Argonne National Lab, 2004.

[17] A. Trkov, "Summary report of the IAEA technical meeting," INDC(NDS)-471, IAEA, Vienna, 2005.

[18] K. Shibata, T. Kawano, T. Nakagawa, O. Iwamoto, J. Katakura, T. Fukahori, S. Chiba, A. Hasegawa, T. Murata, H. Matsunobu, T. Ohsawa, Y. Nakajima, T. Yoshida, A. Zukeran, M. Kawai, M. Baba, M. Ishikawa, T. Asami, T. Watanabe, Y. Watanabe, M. Igashira, N. Yamamuro, H. Kitazawa, N. Yamano, and H. Takano, "Evaluated Nuclear Data Library Version 3 Revision-3: JENDL3.3," J. Nucl. Sci. Technol., vol. 39, p. 1125, 2002. 


\section{Appendix A}

Graphical representation of cross section uncertainties and correlations are given in Figs. A.1 to A.189. 


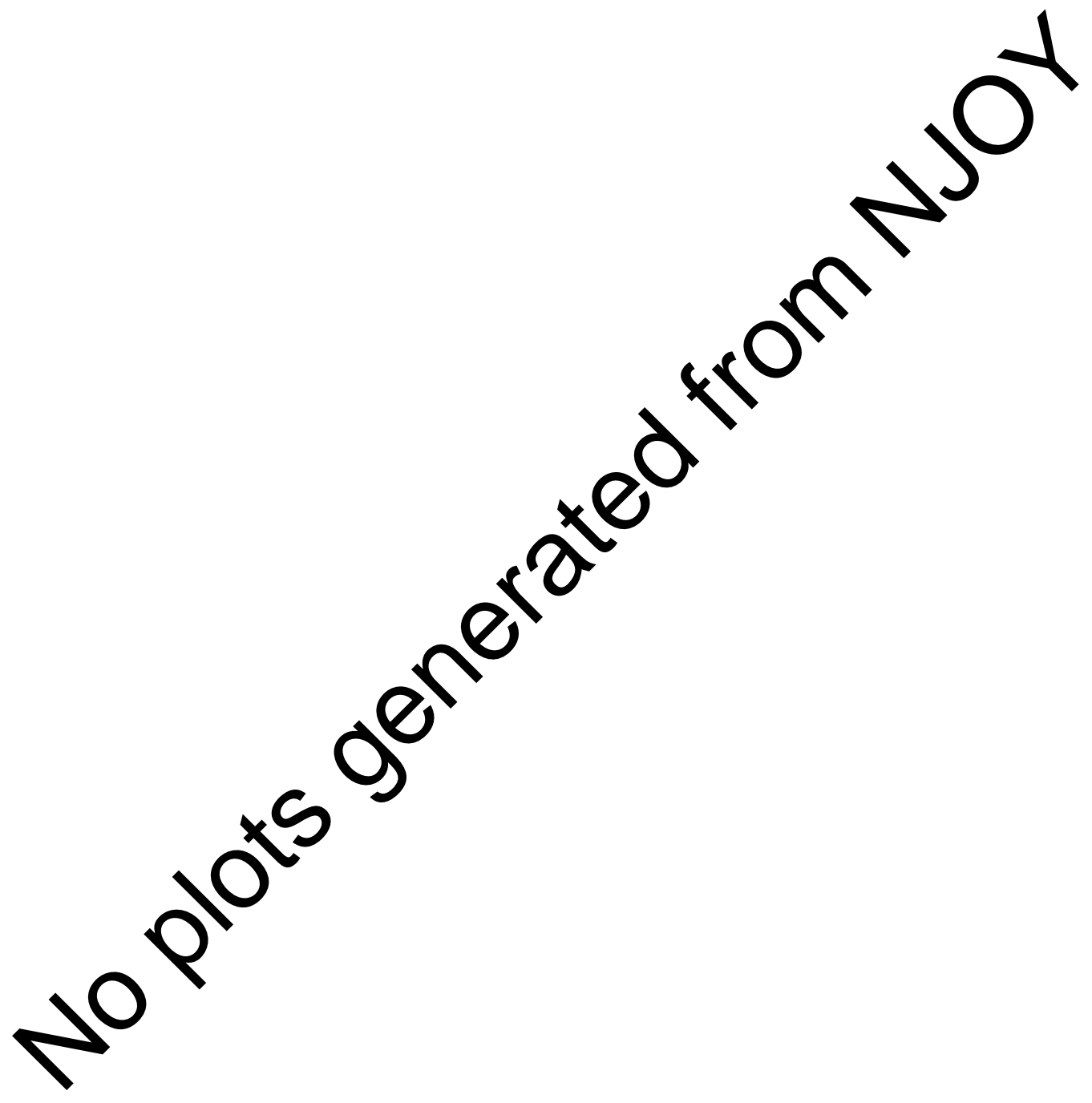

Figure A.1: Correlation and uncertainties in 187 and 15 groups for ${ }^{1} \mathrm{H}$ 


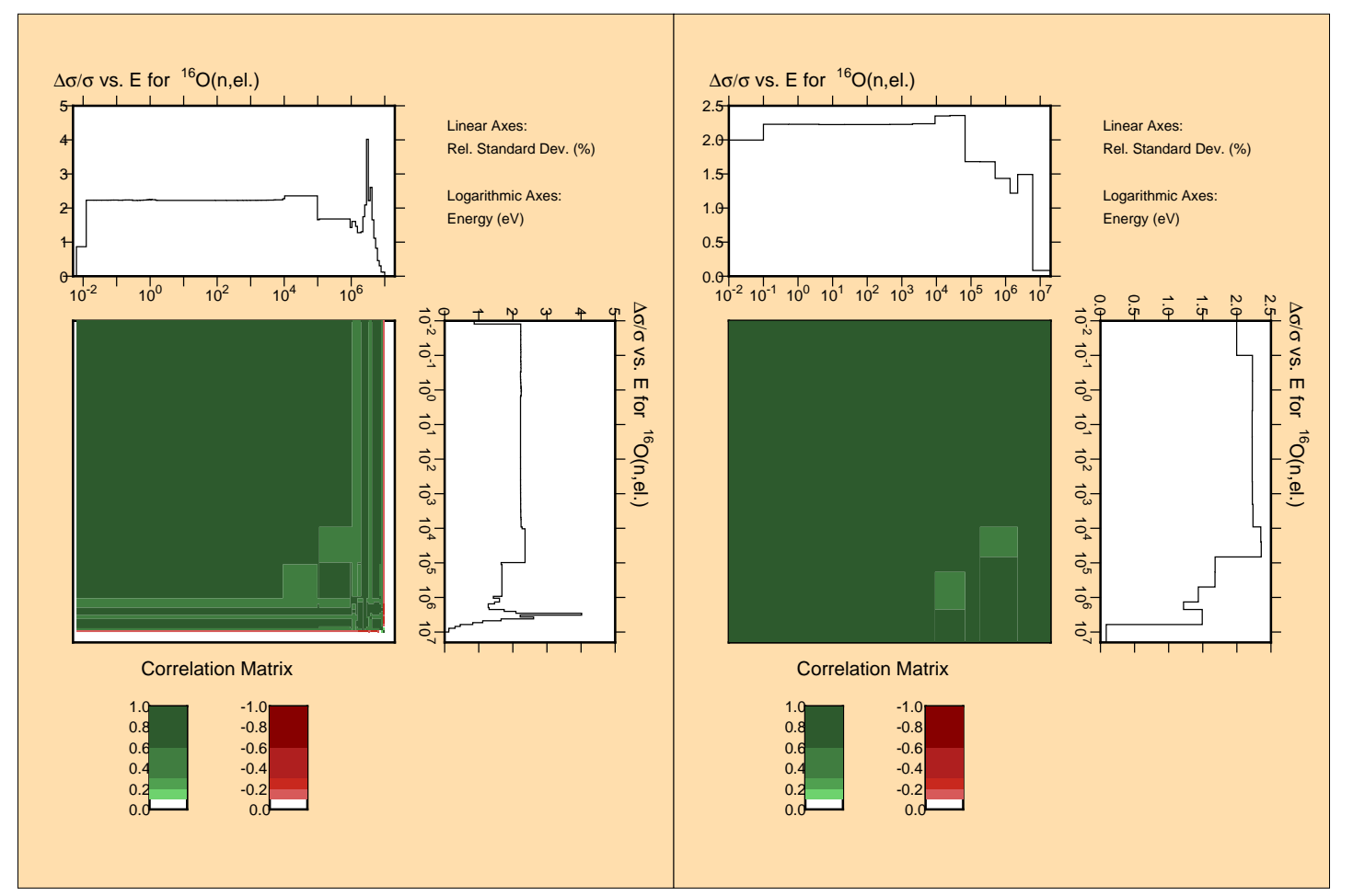

Figure A.2: Correlation and uncertainties in 187 (left) and 15 (right) groups for the ${ }^{16} \mathrm{O}(\mathrm{n}, \mathrm{el})$ reaction. Note: uncertainties in the high energy part, above few $\mathrm{MeV}$ are not correct. The corrected numbers are given in tables.

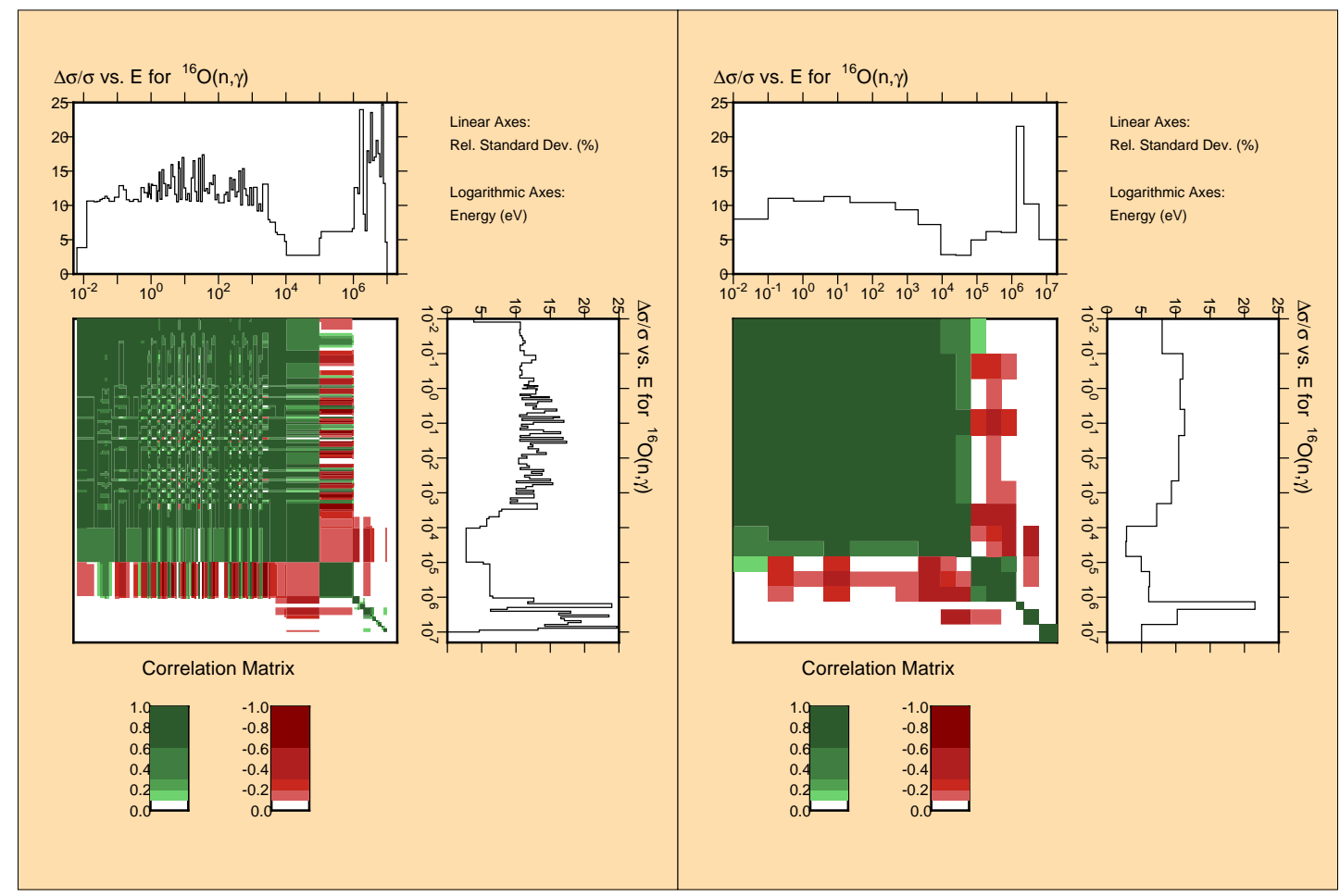

Figure A.3: Correlation and uncertainties in 187 (left) and 15 (right) groups for the ${ }^{16} \mathrm{O}(\mathrm{n}, \gamma)$ reaction. Note: uncertainties in the high energy part, above few $\mathrm{MeV}$ are not correct. The corrected numbers are given in tables.

BNL-77407-2007-IR

D. Rochman et al. 


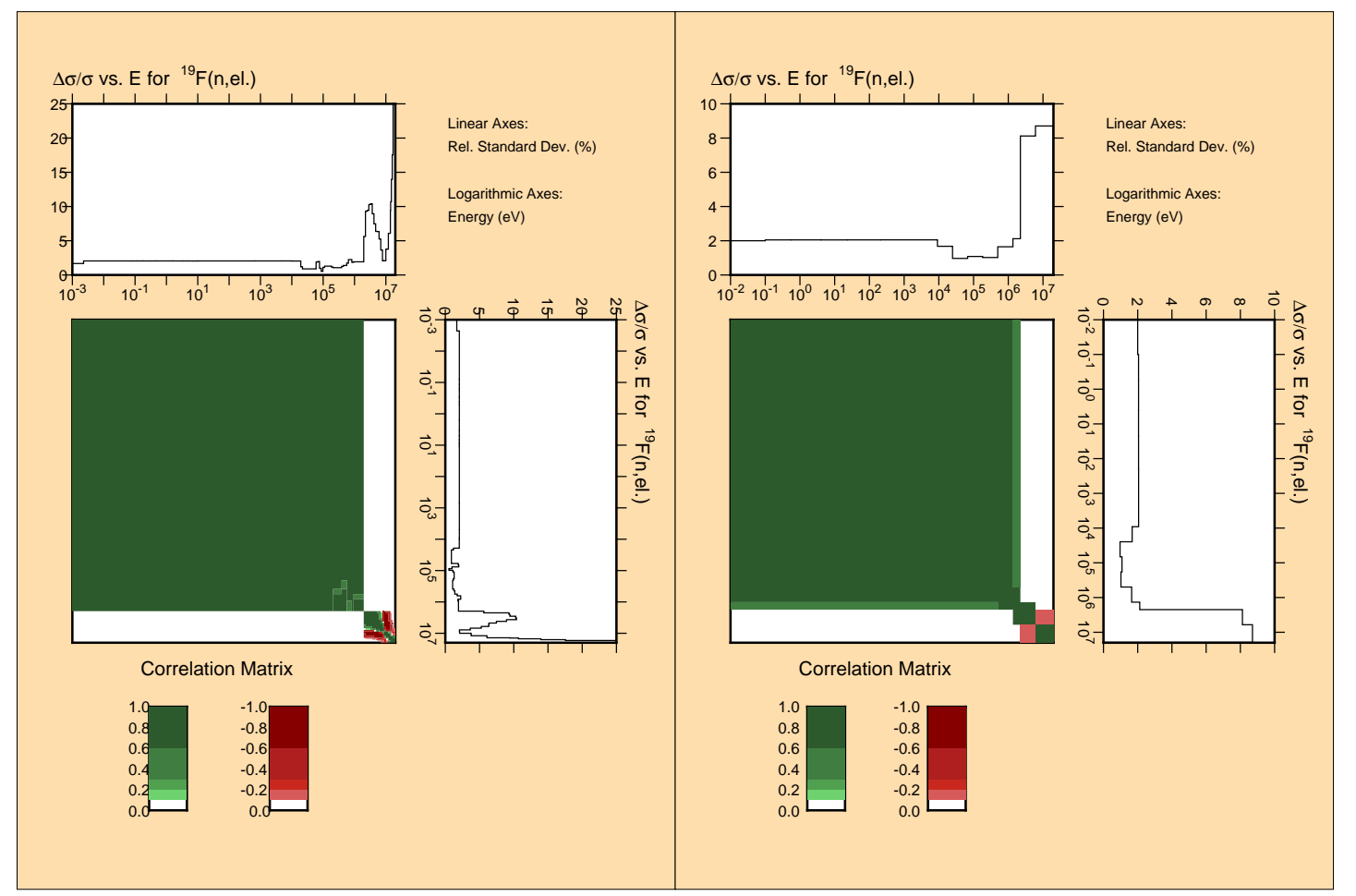

Figure A.4: Correlation and uncertainties in 187 (left) and 15 (right) groups for the ${ }^{19} \mathrm{~F}(\mathrm{n}, \mathrm{el})$ reaction

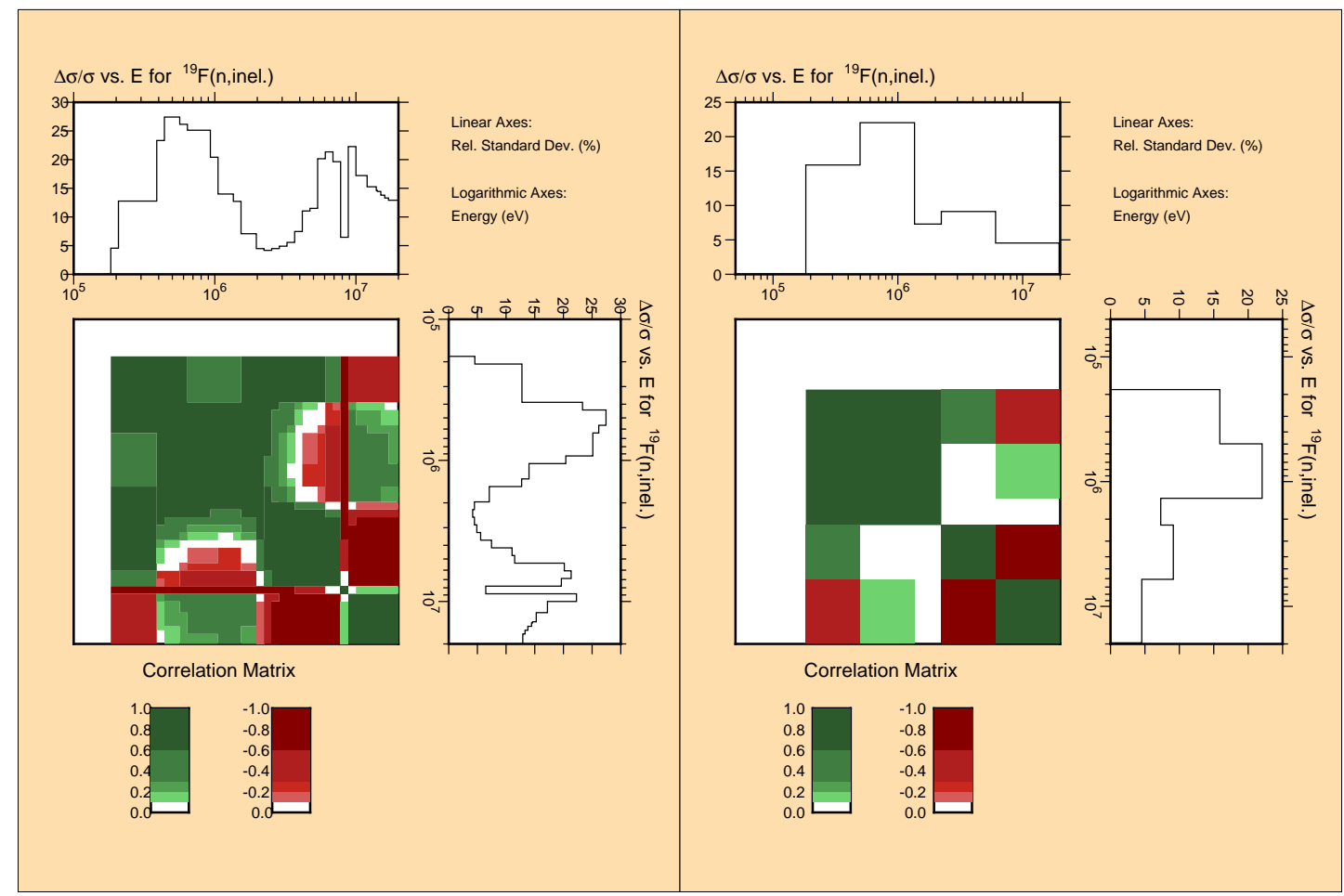

Figure A.5: Correlation and uncertainties in 187 (left) and 15 (right) groups for the ${ }^{19} \mathrm{~F}(\mathrm{n}, \mathrm{el})$ reaction

D. Rochman et al. 


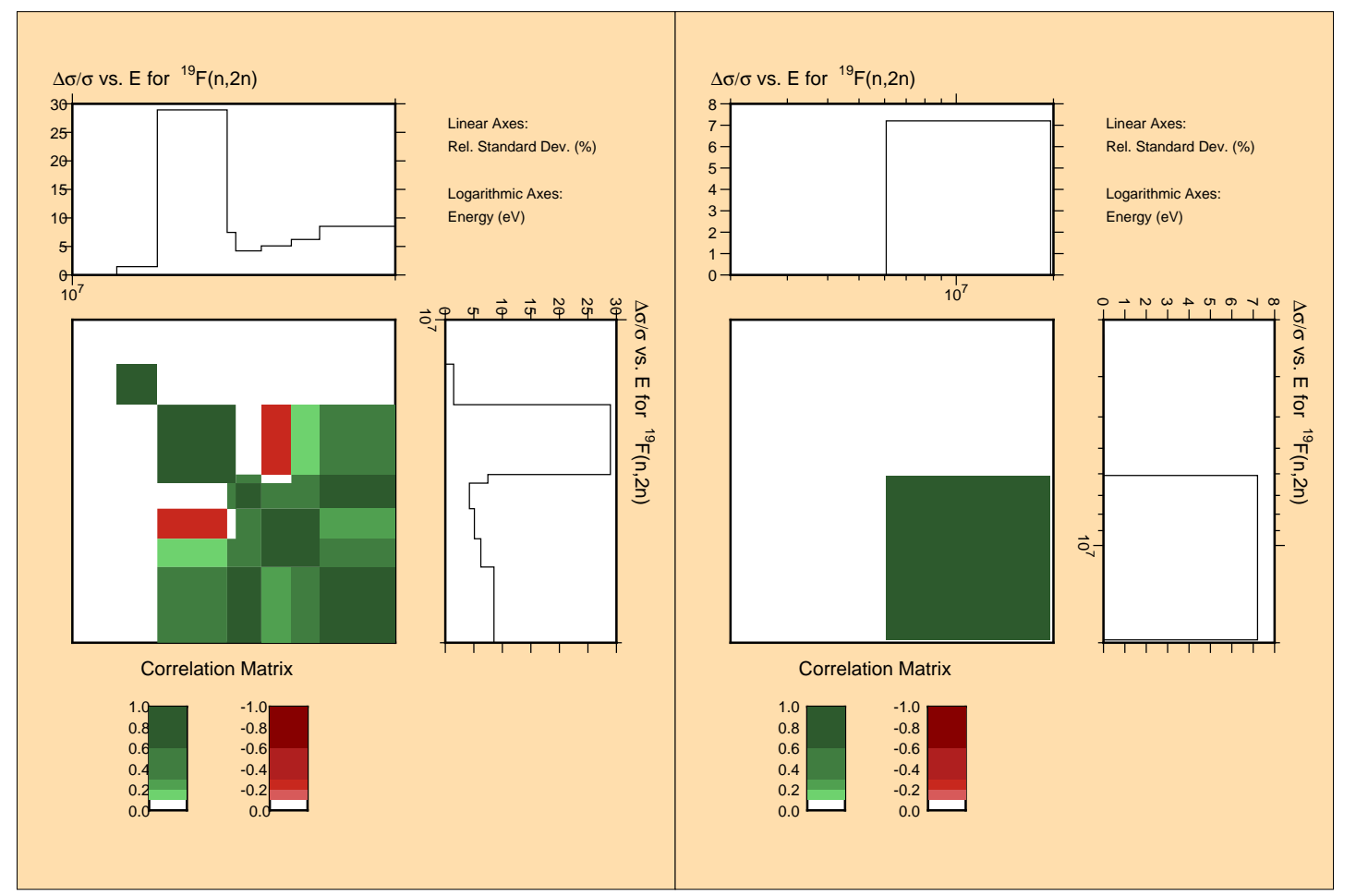

Figure A.6: Correlation and uncertainties in 187 (left) and 15 (right) groups for the ${ }^{19} \mathrm{~F}(\mathrm{n}, 2 \mathrm{n})$ reaction

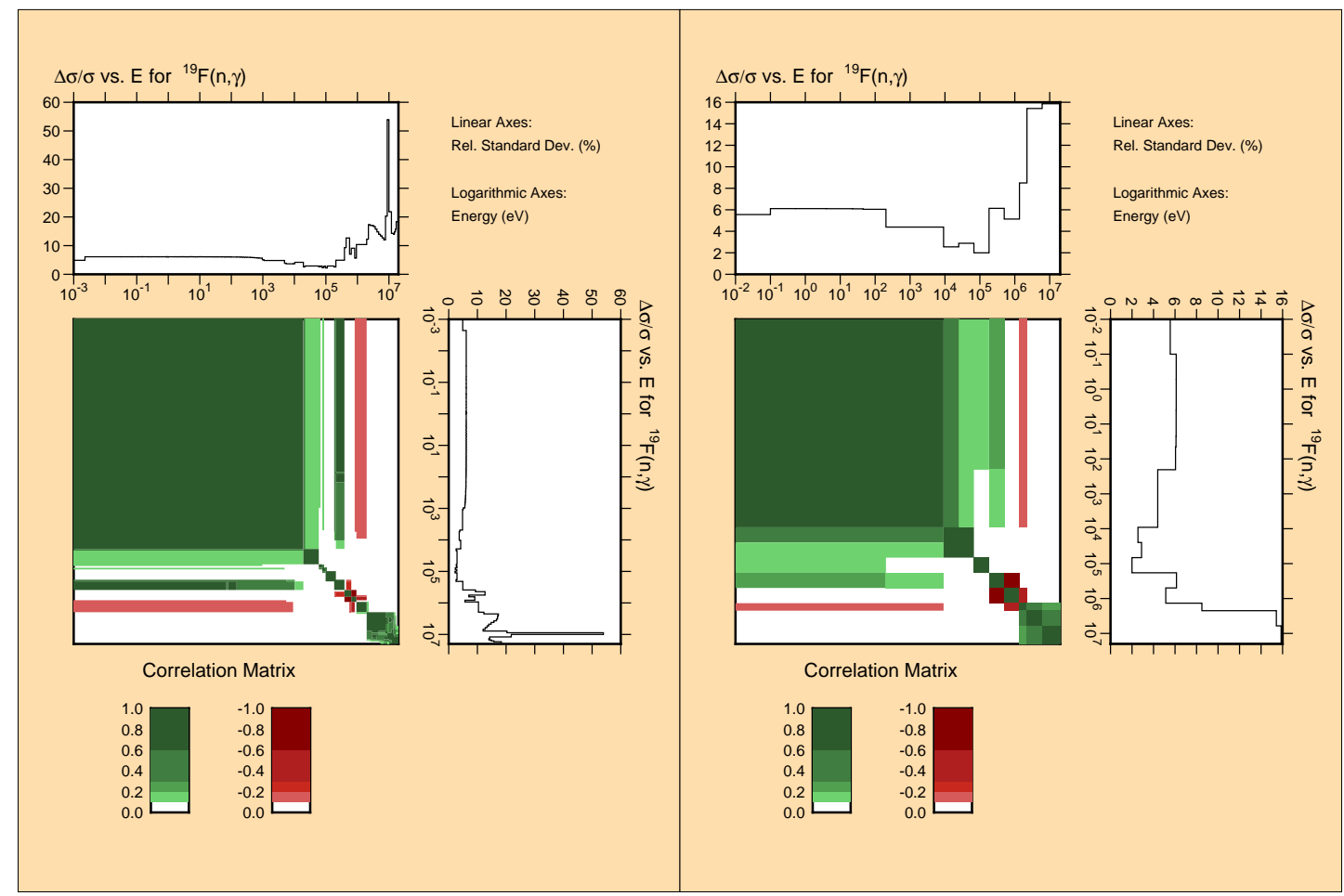

Figure A.7: Correlation and uncertainties in 187 (left) and 15 (right) groups for the ${ }^{19} \mathrm{~F}(\mathrm{n}, \gamma)$ reaction 


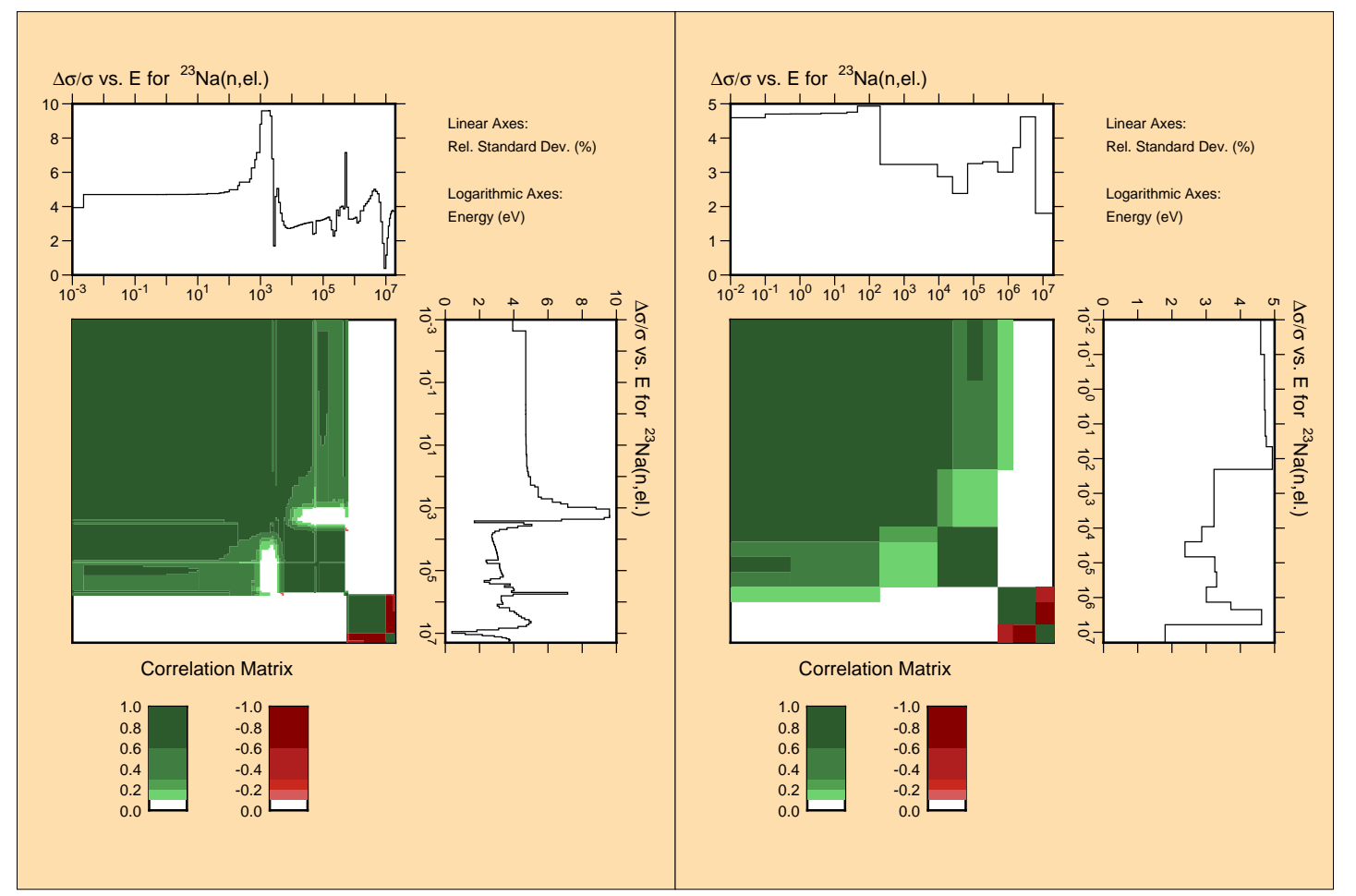

Figure A.8: Correlation and uncertainties in 187 (left) and 15 (right) groups for the ${ }^{13} \mathrm{Na}(\mathrm{n}, \mathrm{el})$ reaction

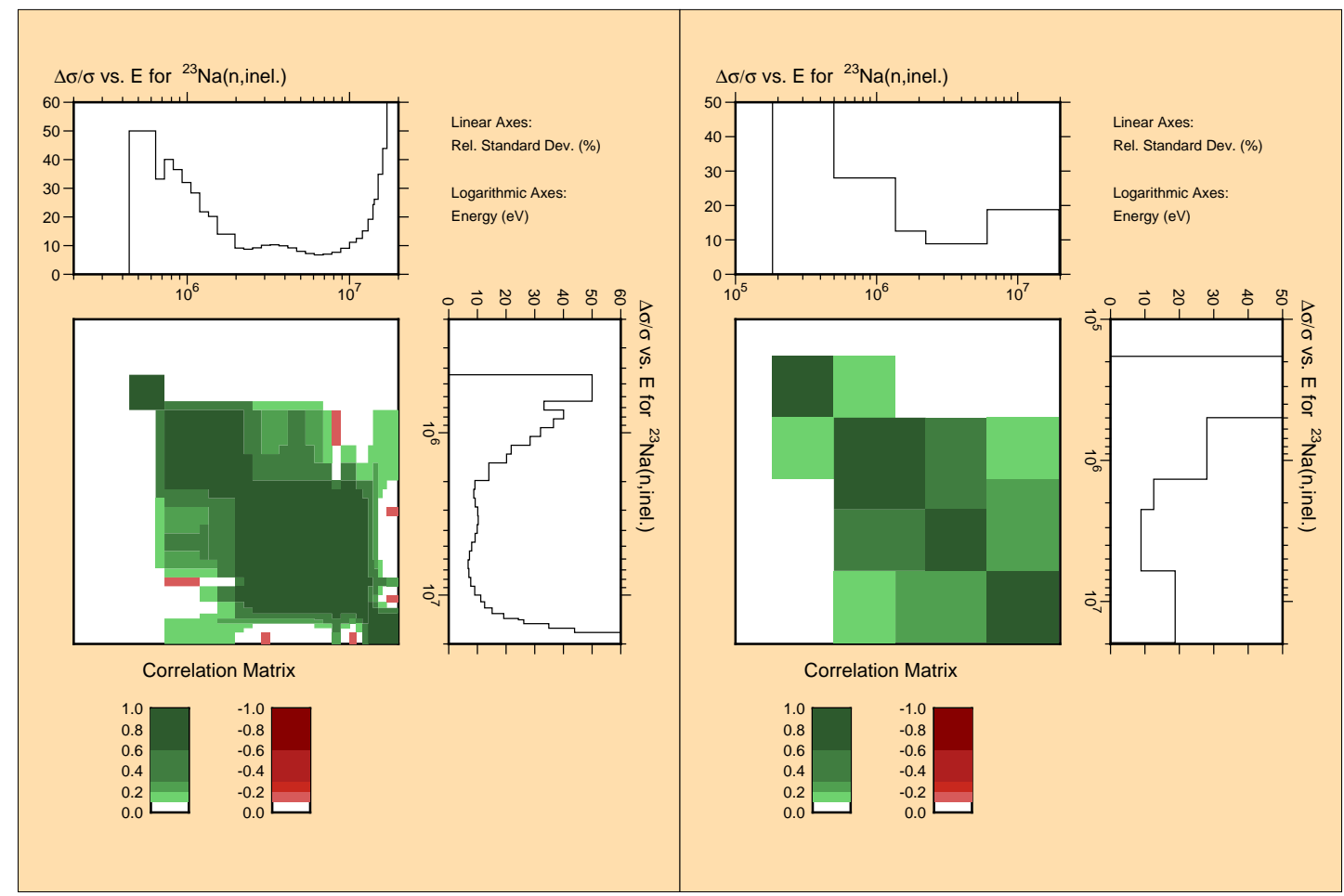

Figure A.9: Correlation and uncertainties in 187 (left) and 15 (right) groups for the ${ }^{13} \mathrm{Na}\left(\mathrm{n}, \mathrm{n}^{\prime}\right)$ reaction 


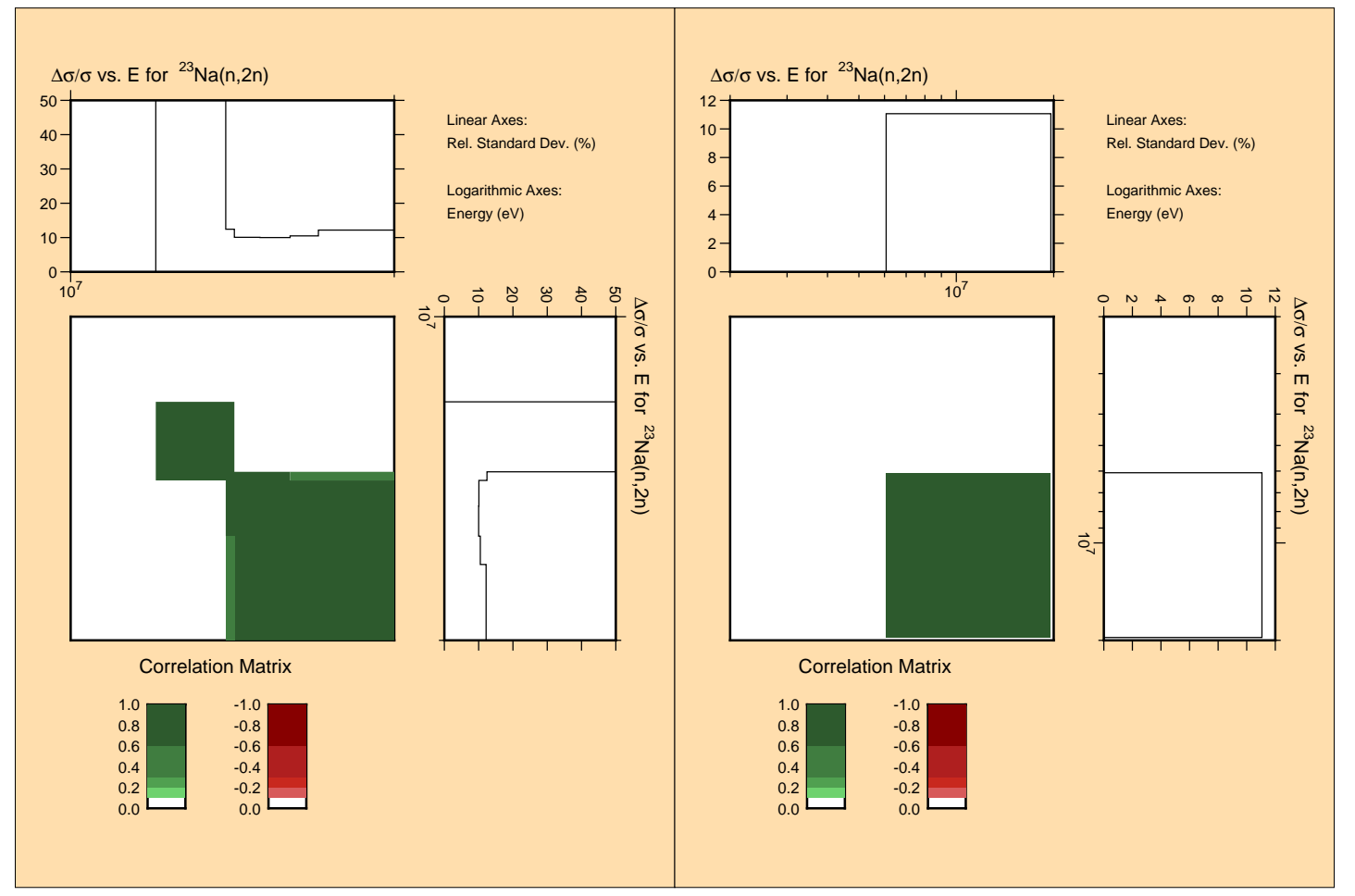

Figure A.10: Correlation and uncertainties in 187 (left) and 15 (right) groups for the ${ }^{13} \mathrm{Na}(\mathrm{n}, 2 \mathrm{n})$ reaction

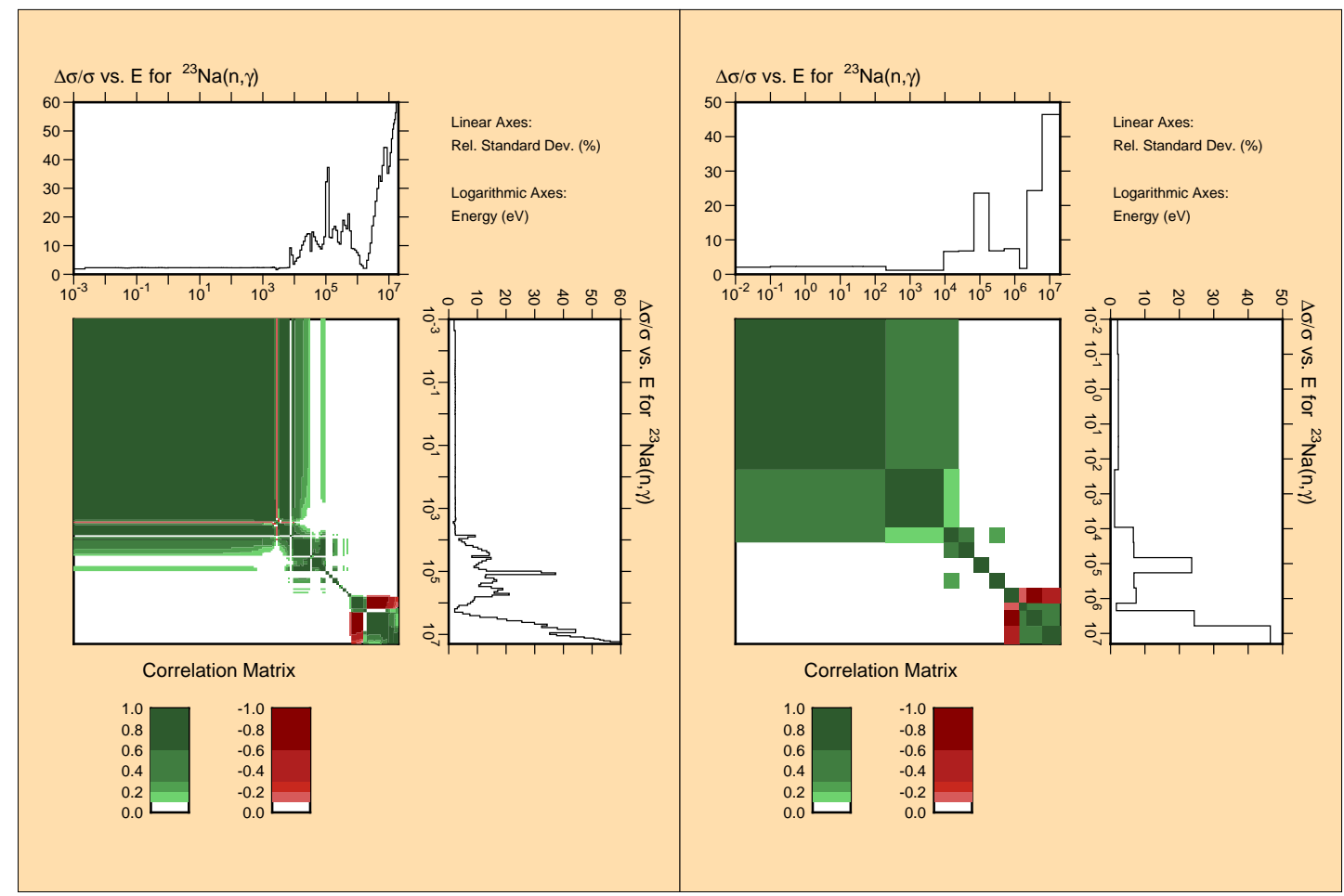

Figure A.11: Correlation and uncertainties in 187 (left) and 15 (right) groups for the ${ }^{13} \mathrm{Na}(\mathrm{n}, \gamma)$ reaction

D. Rochman et al. 


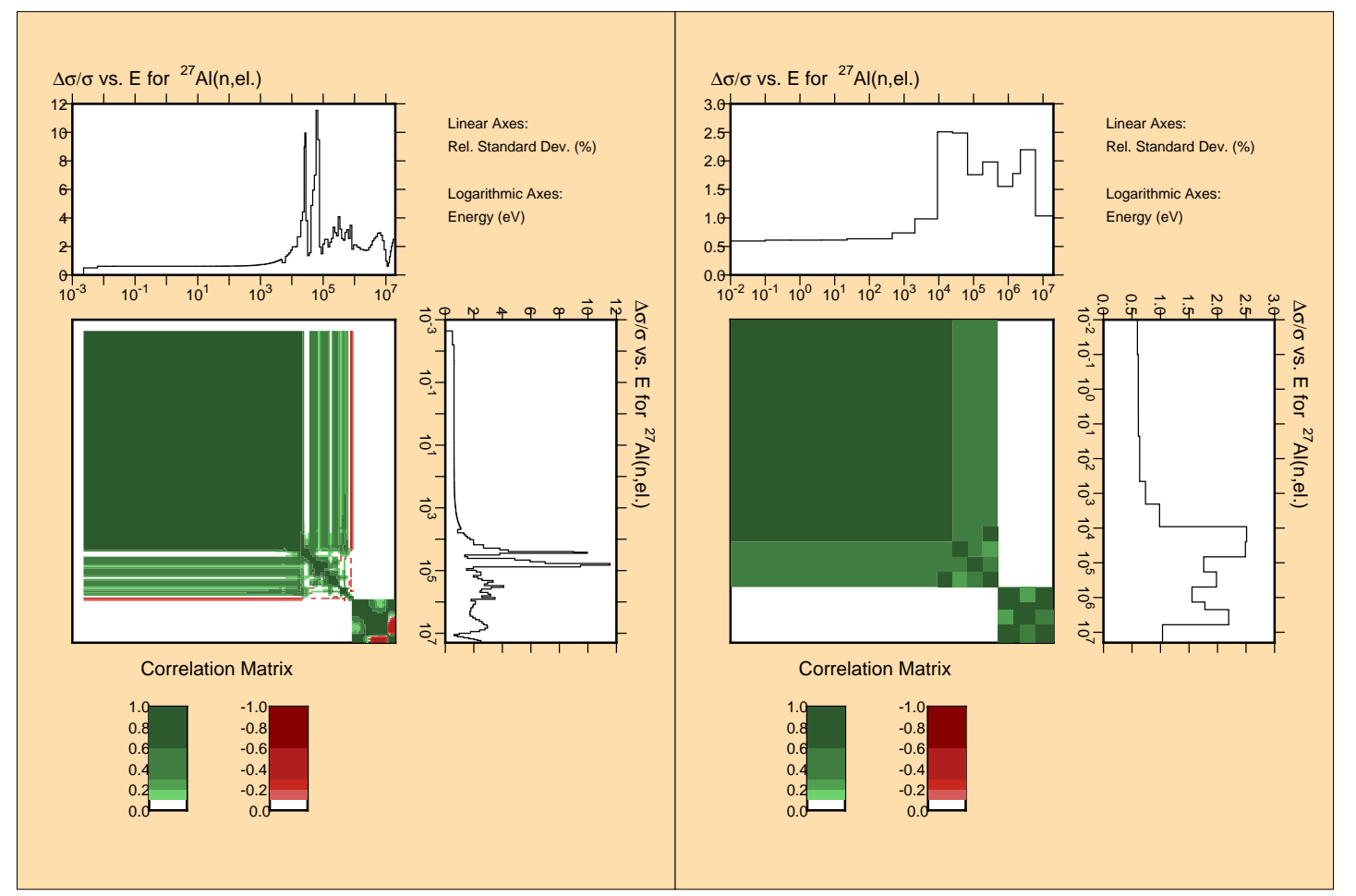

Figure A.12: Correlation and uncertainties in 187 (left) and 15 (right) groups for the ${ }^{27} \mathrm{Al}(\mathrm{n}, \mathrm{el})$ reaction

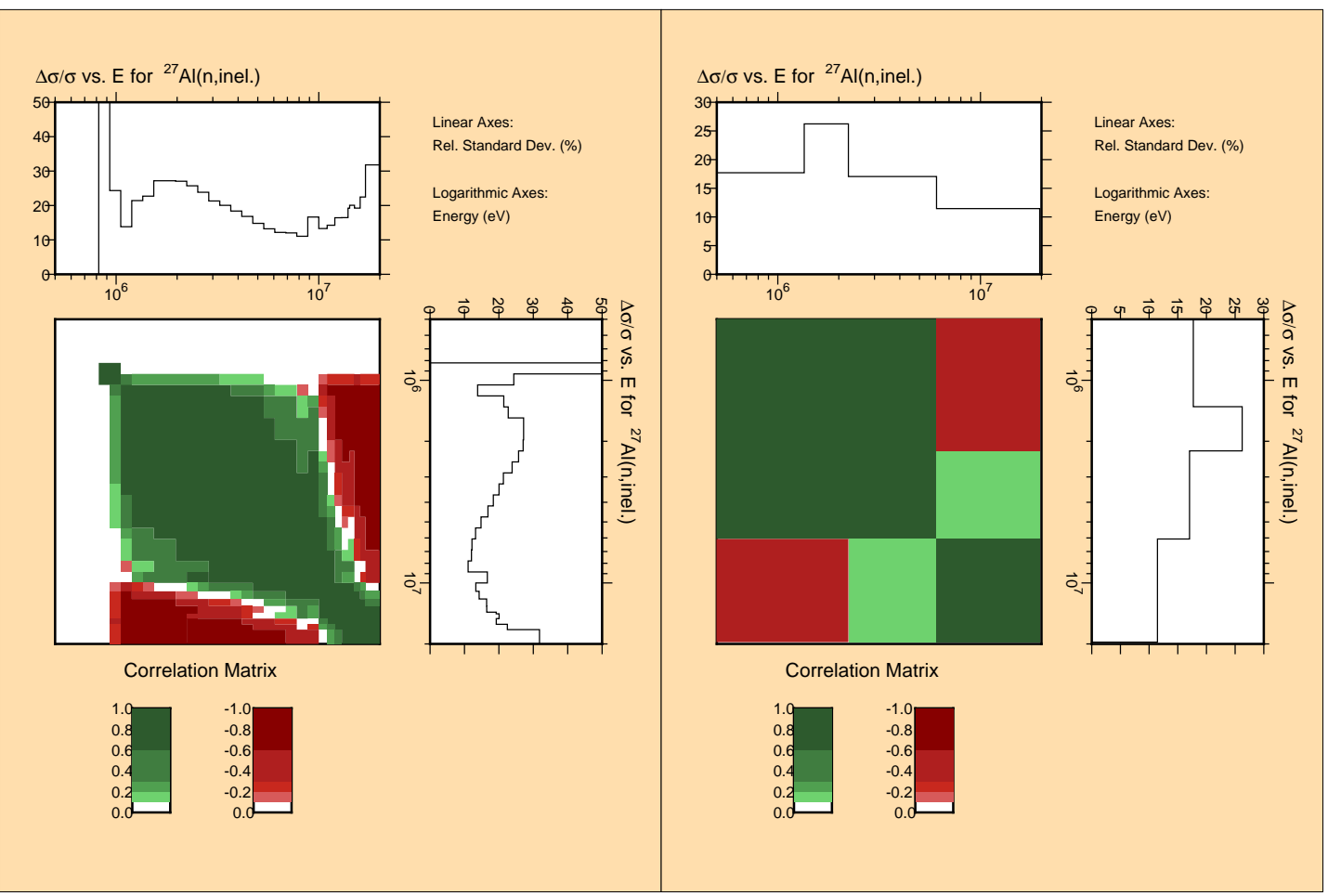

Figure A.13: Correlation and uncertainties in 187 (left) and 15 (right) groups for the ${ }^{27} \mathrm{Al}\left(\mathrm{n}, \mathrm{n}^{\prime}\right)$ reaction 


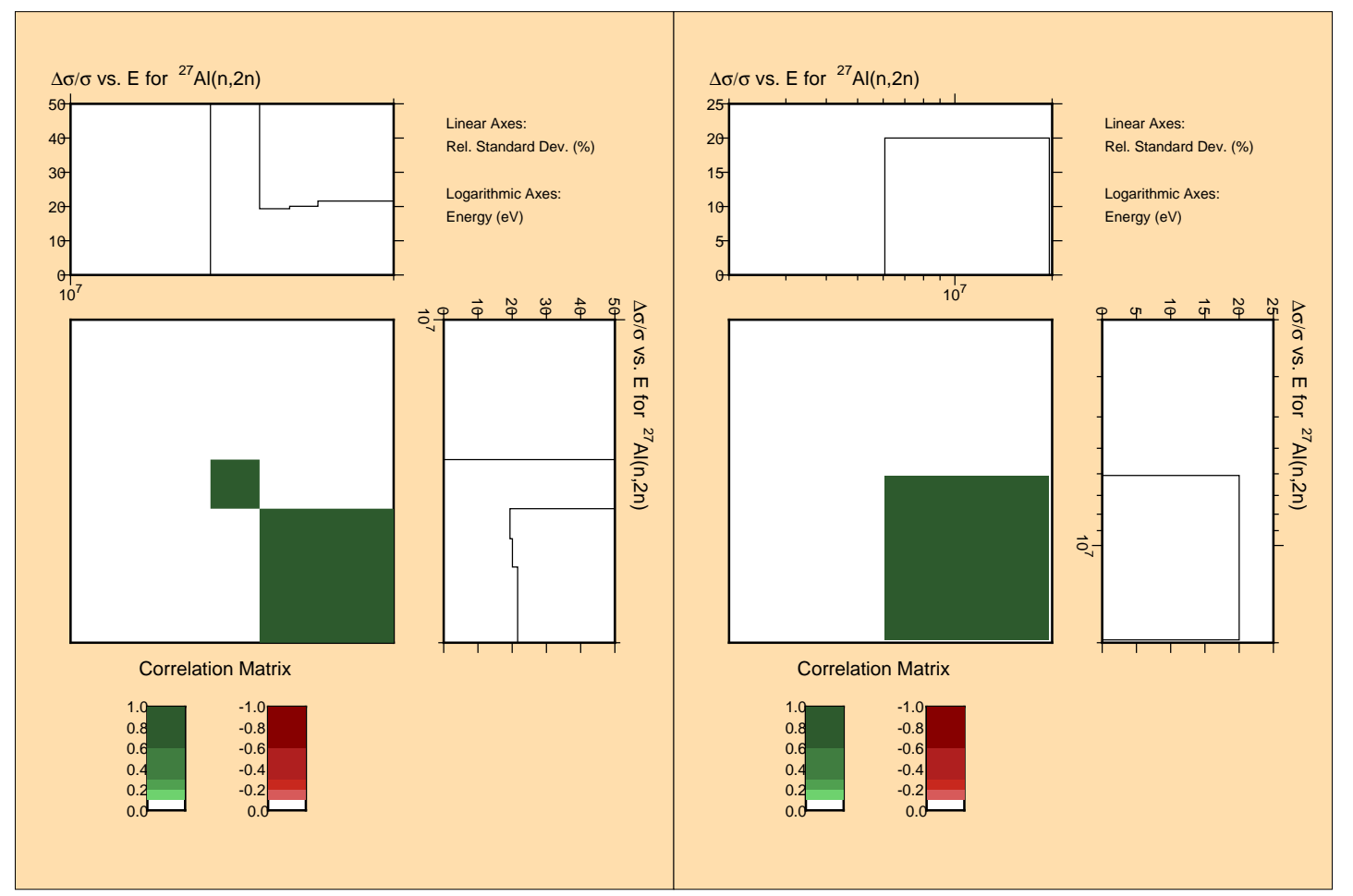

Figure A.14: Correlation and uncertainties in 187 (left) and 15 (right) groups for the ${ }^{27} \mathrm{Al}(\mathrm{n}, 2 \mathrm{n})$ reaction

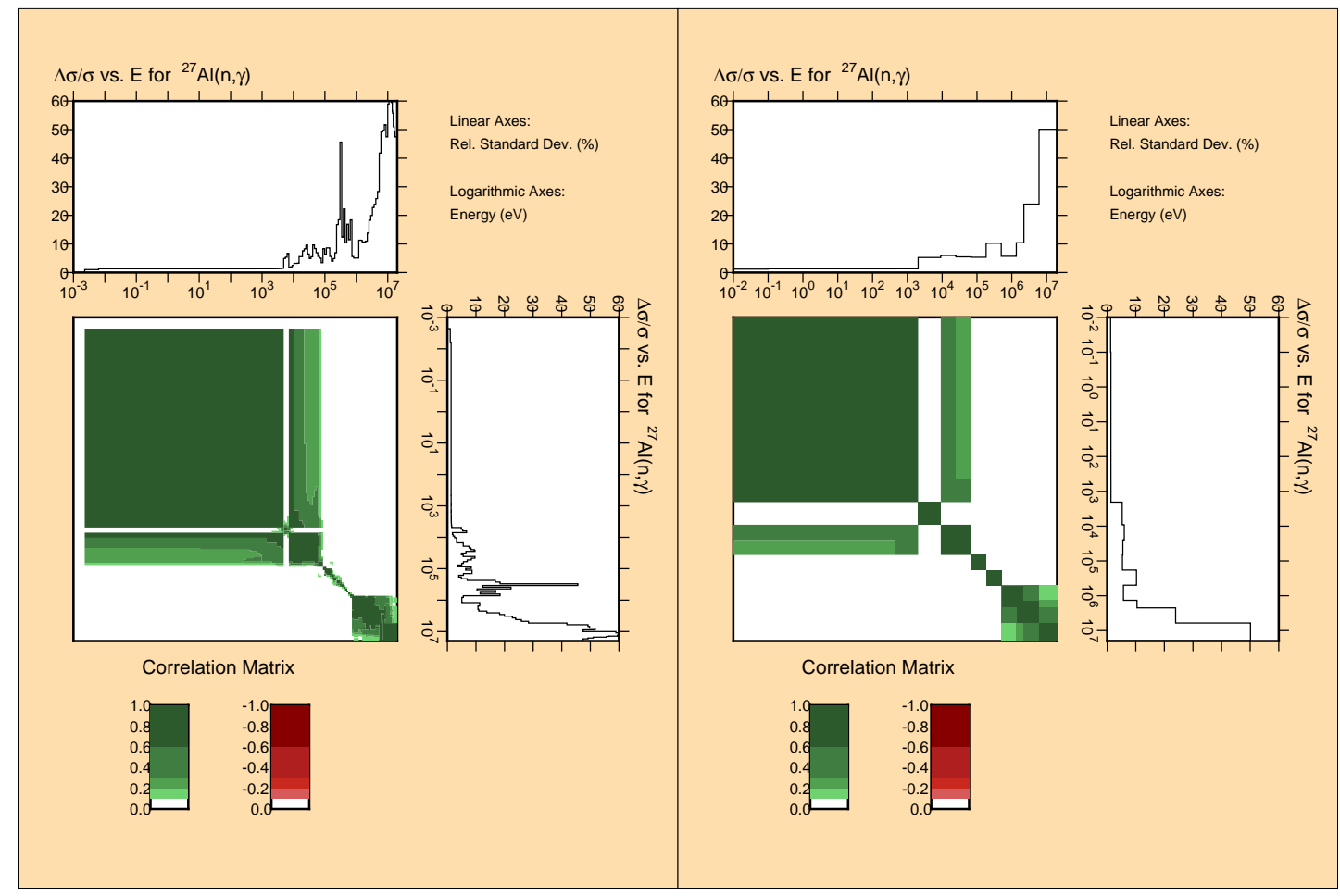

Figure A.15: Correlation and uncertainties in 187 (left) and 15 (right) groups for the ${ }^{27} \mathrm{Al}(\mathrm{n}, \gamma)$ reaction 


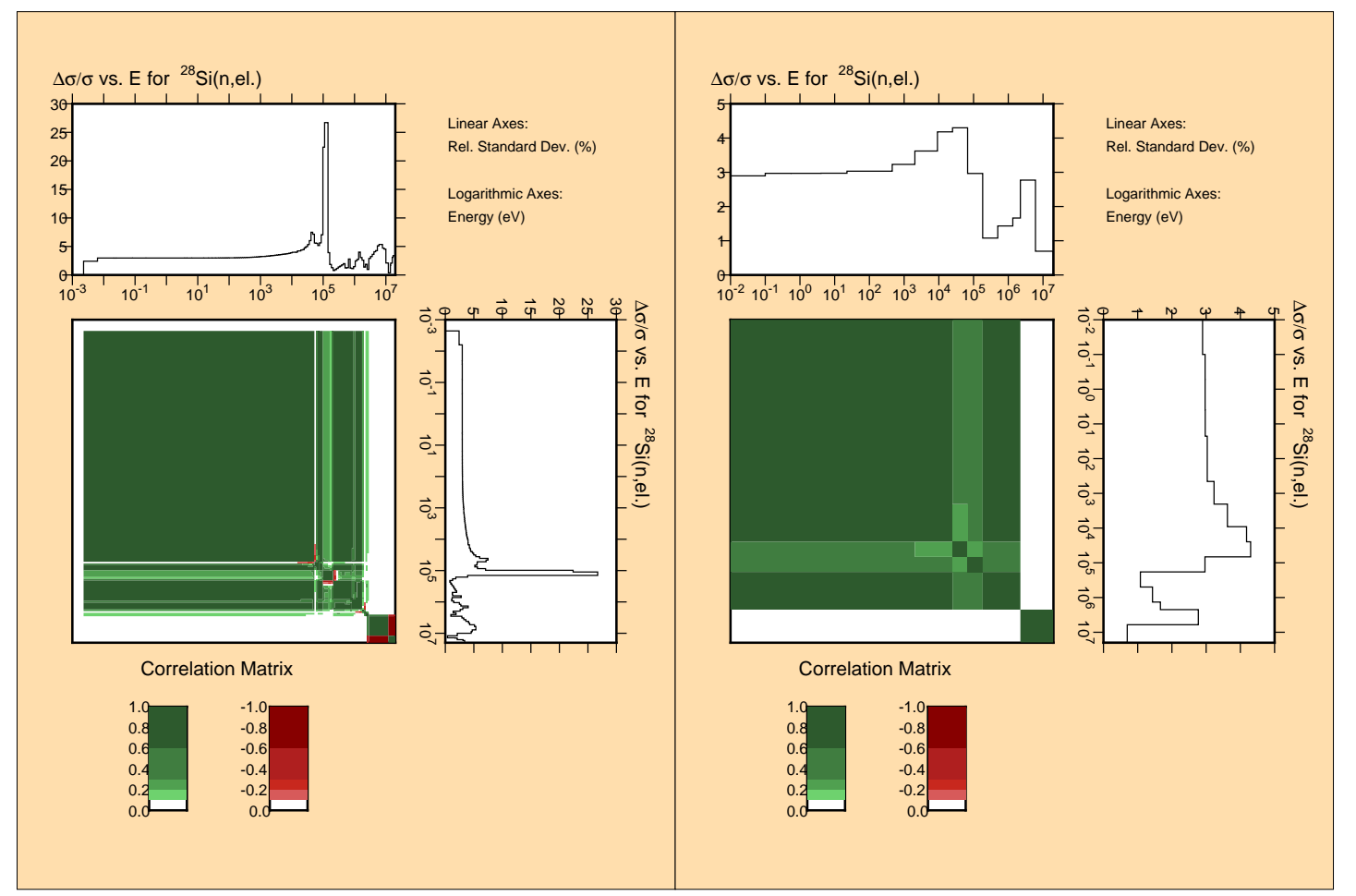

Figure A.16: Correlation and uncertainties in 187 (left) and 15 (right) groups for the ${ }^{28} \mathrm{Si}(\mathrm{n}, \mathrm{el})$ reaction

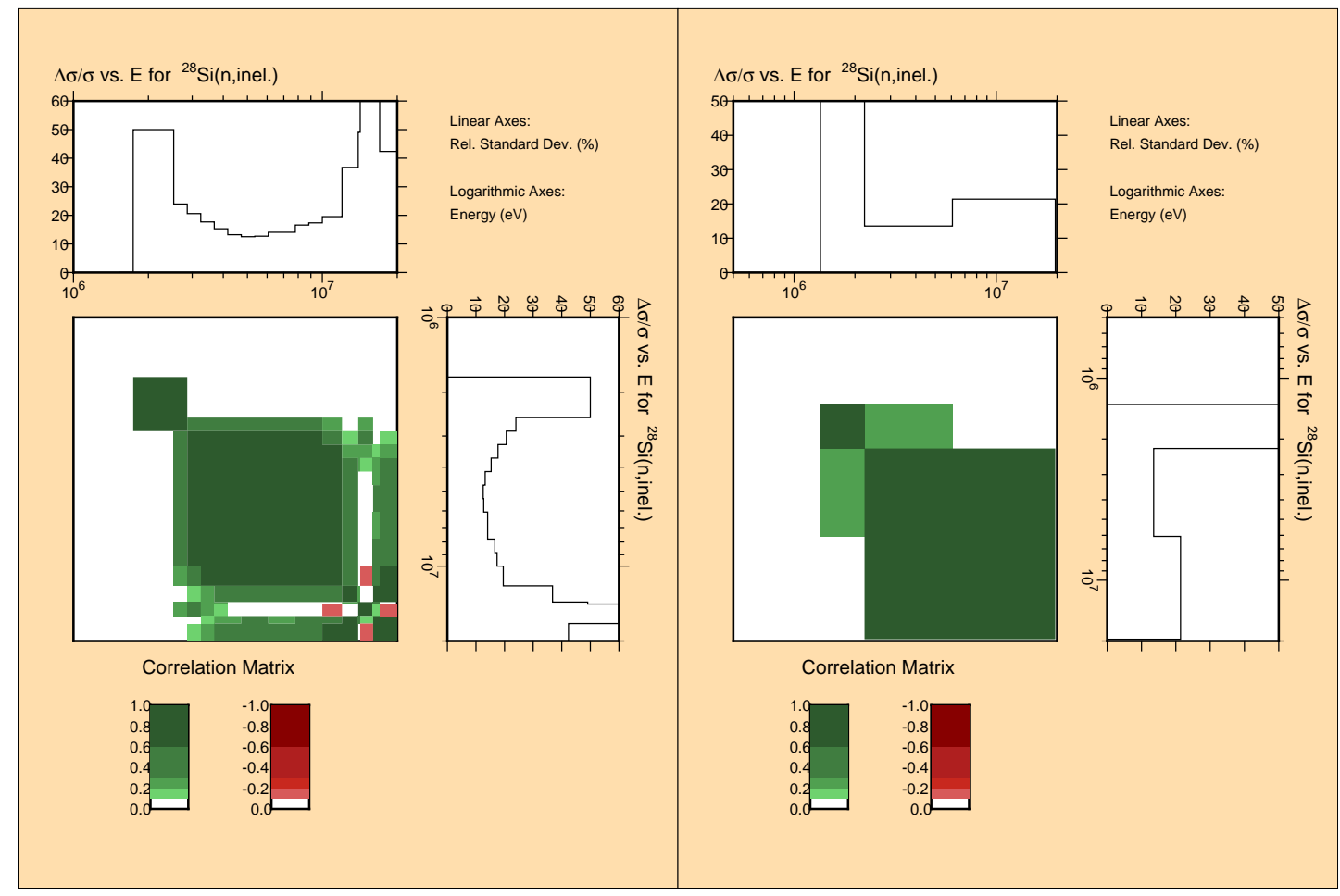

Figure A.17: Correlation and uncertainties in 187 (left) and 15 (right) groups for the ${ }^{28} \mathrm{Si}\left(\mathrm{n}, \mathrm{n}^{\prime}\right)$ reaction

D. Rochman et al. 


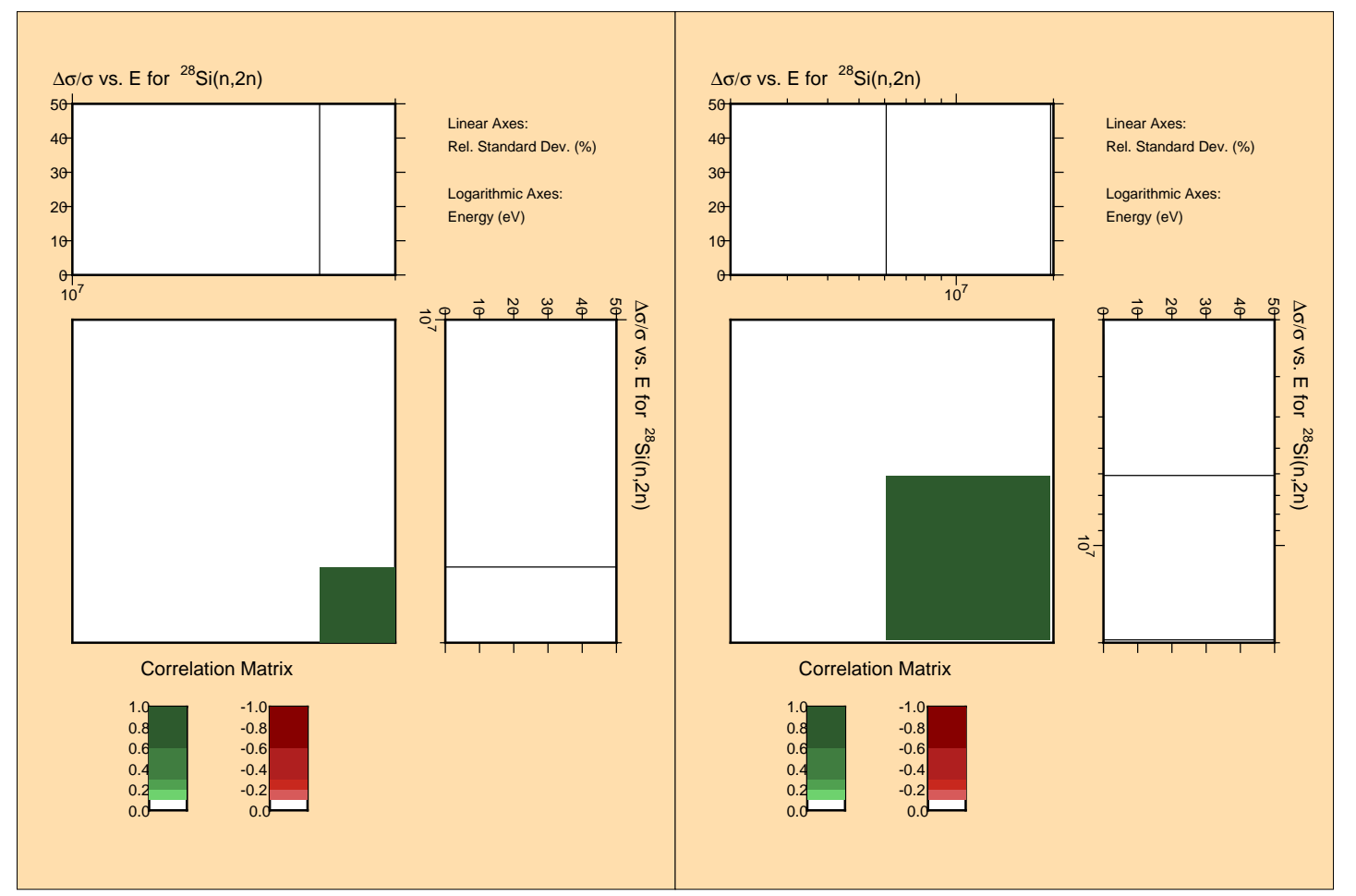

Figure A.18: Correlation and uncertainties in 187 (left) and 15 (right) groups for the ${ }^{28} \mathrm{Si}(\mathrm{n}, 2 \mathrm{n})$ reaction

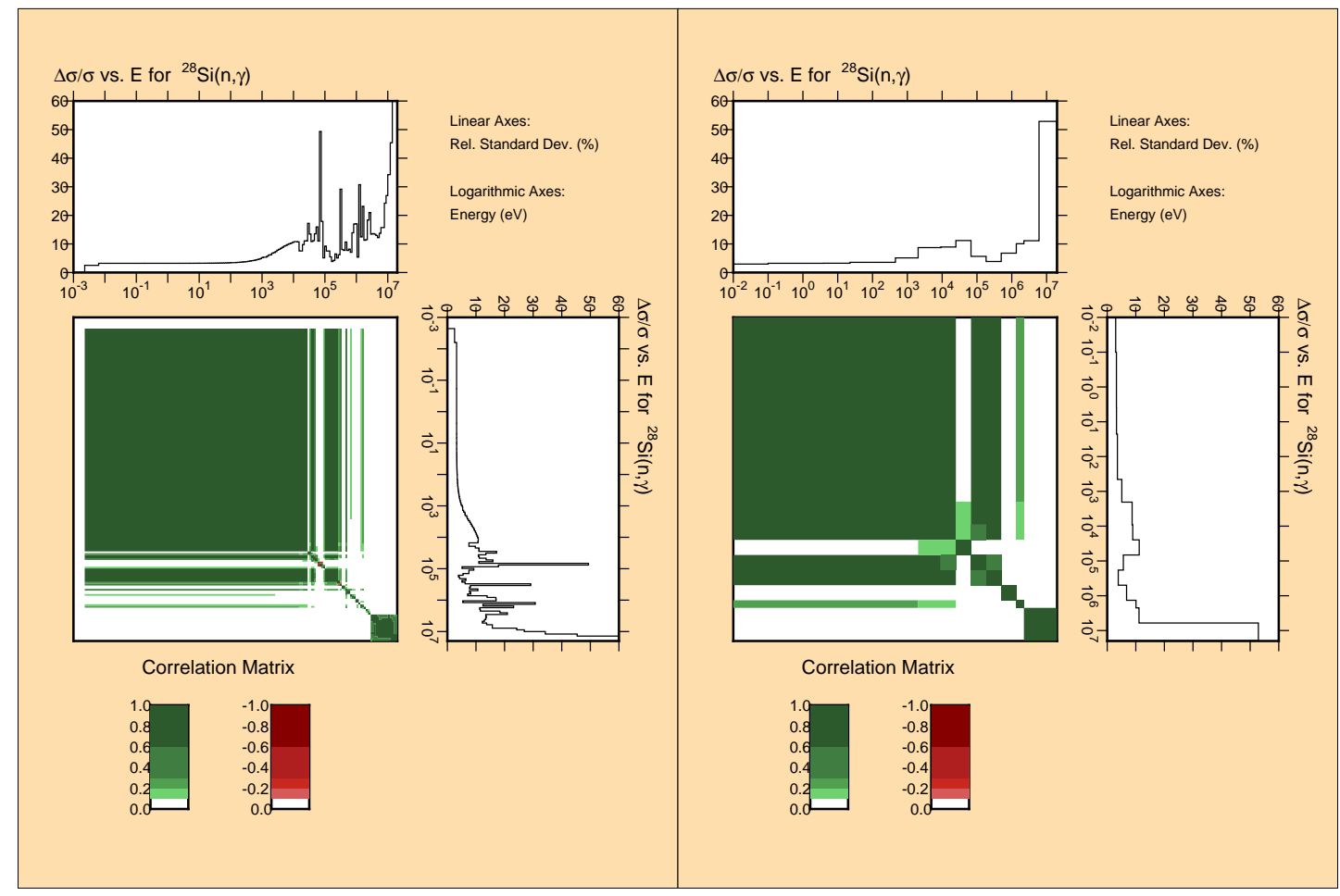

Figure A.19: Correlation and uncertainties in 187 (left) and 15 (right) groups for the ${ }^{28} \mathrm{Si}(\mathrm{n}, \gamma)$ reaction 


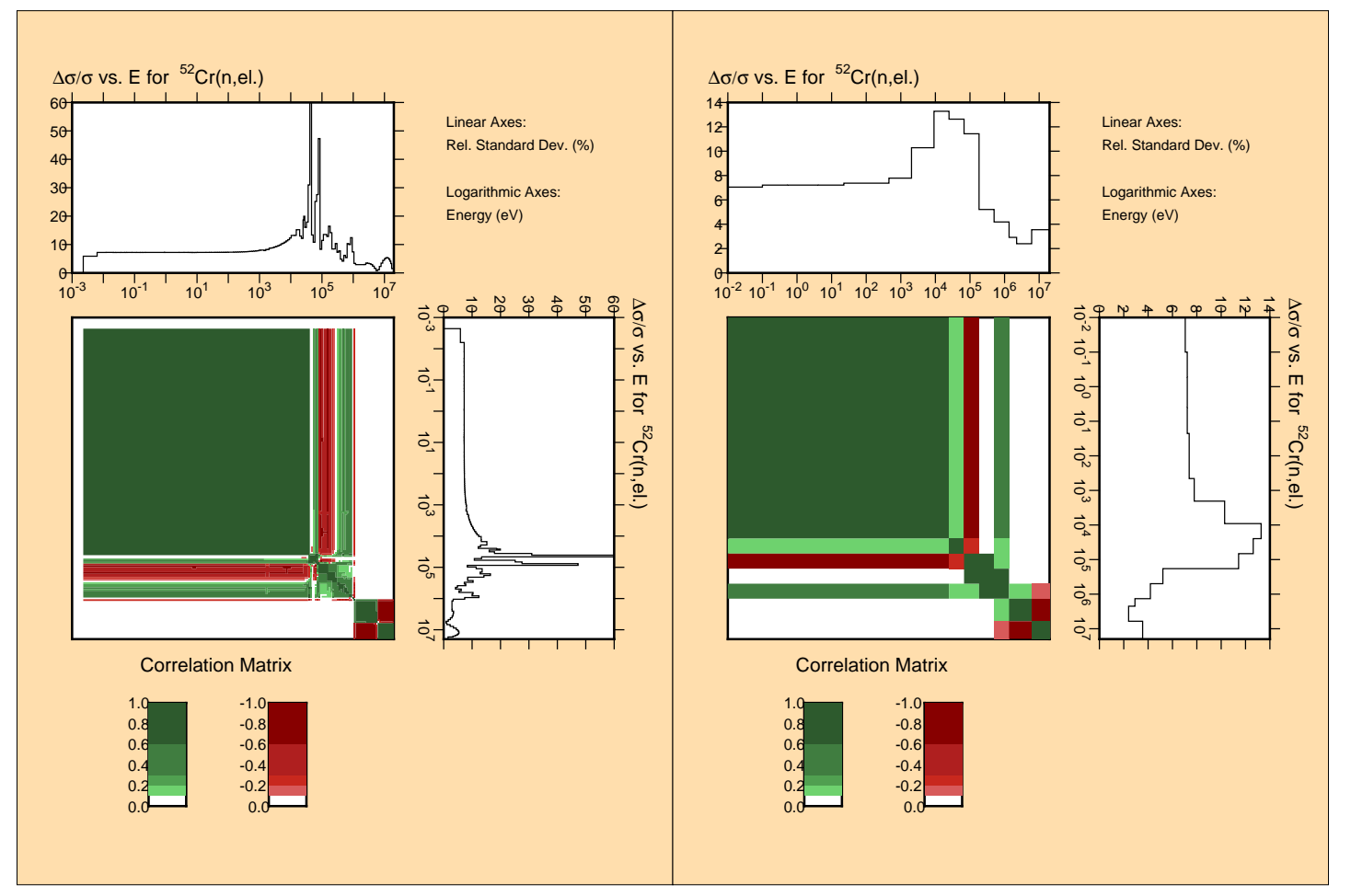

Figure A.20: Correlation and uncertainties in 187 (left) and 15 (right) groups for the ${ }^{52} \mathrm{Cr}(\mathrm{n}, \mathrm{el})$ reaction

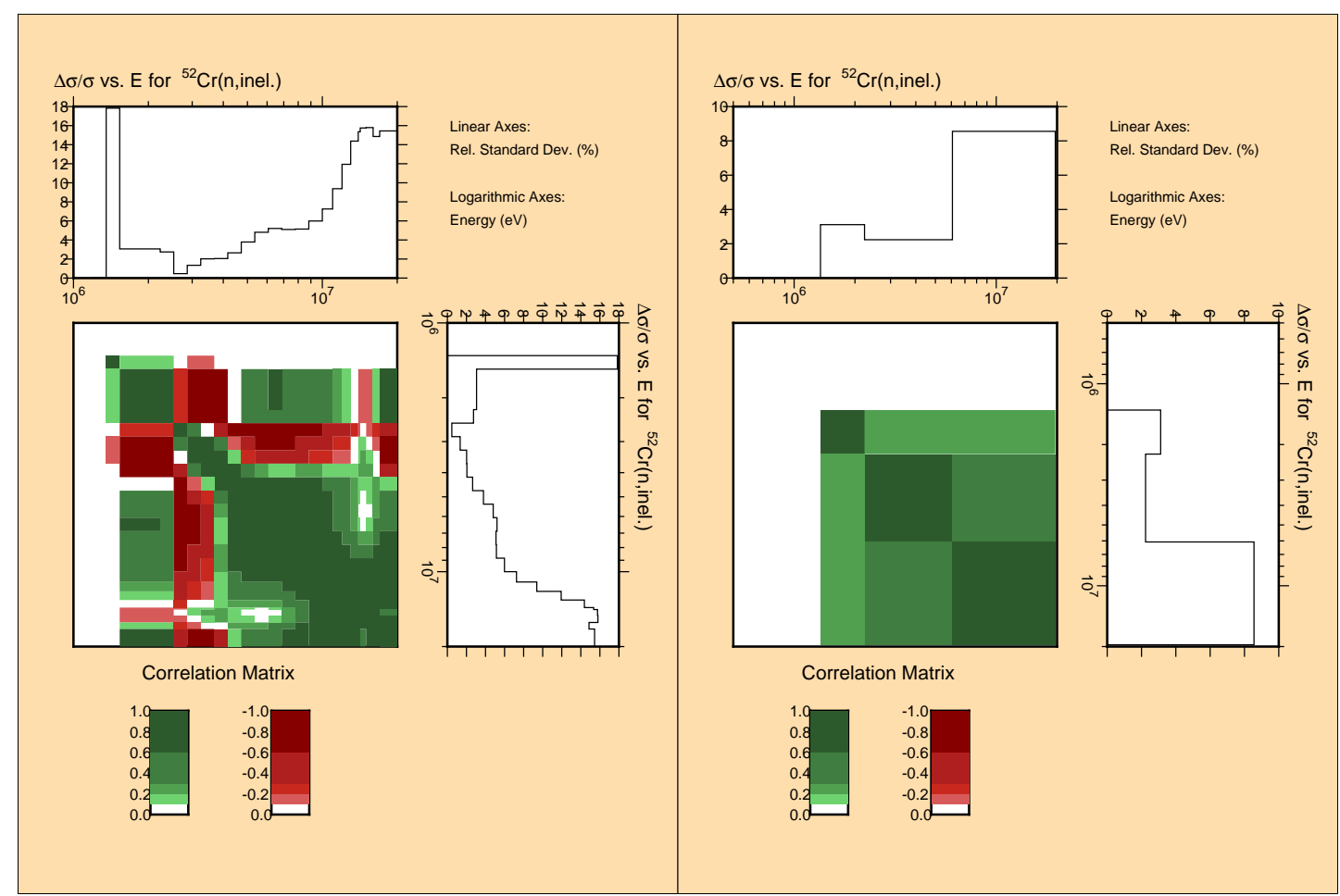

Figure A.21: Correlation and uncertainties in 187 (left) and 15 (right) groups for the ${ }^{52} \mathrm{Cr}\left(\mathrm{n}, \mathrm{n}^{\prime}\right)$ reaction 


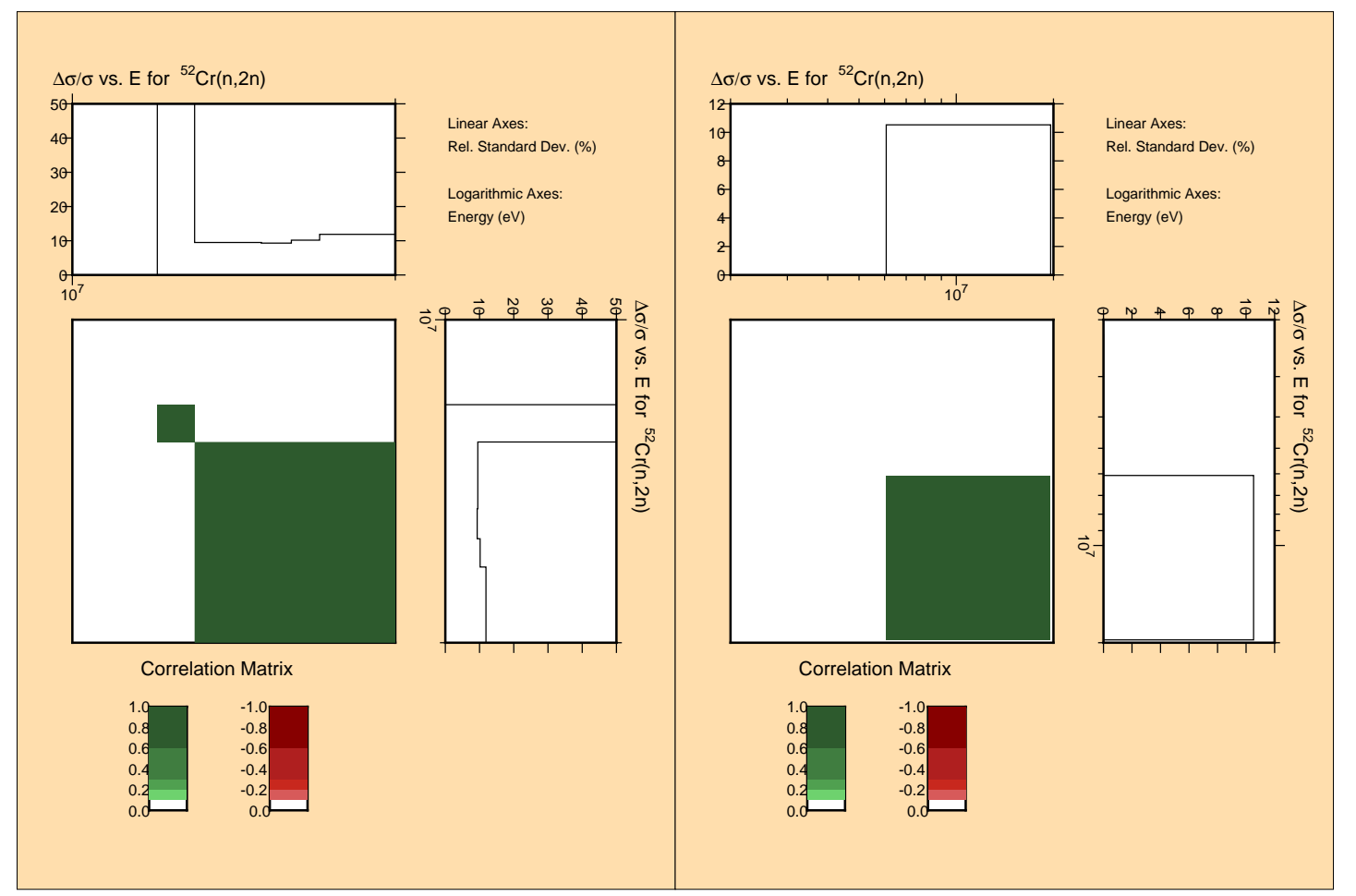

Figure A.22: Correlation and uncertainties in 187 (left) and 15 (right) groups for the ${ }^{52} \mathrm{Cr}(\mathrm{n}, 2 \mathrm{n})$ reaction

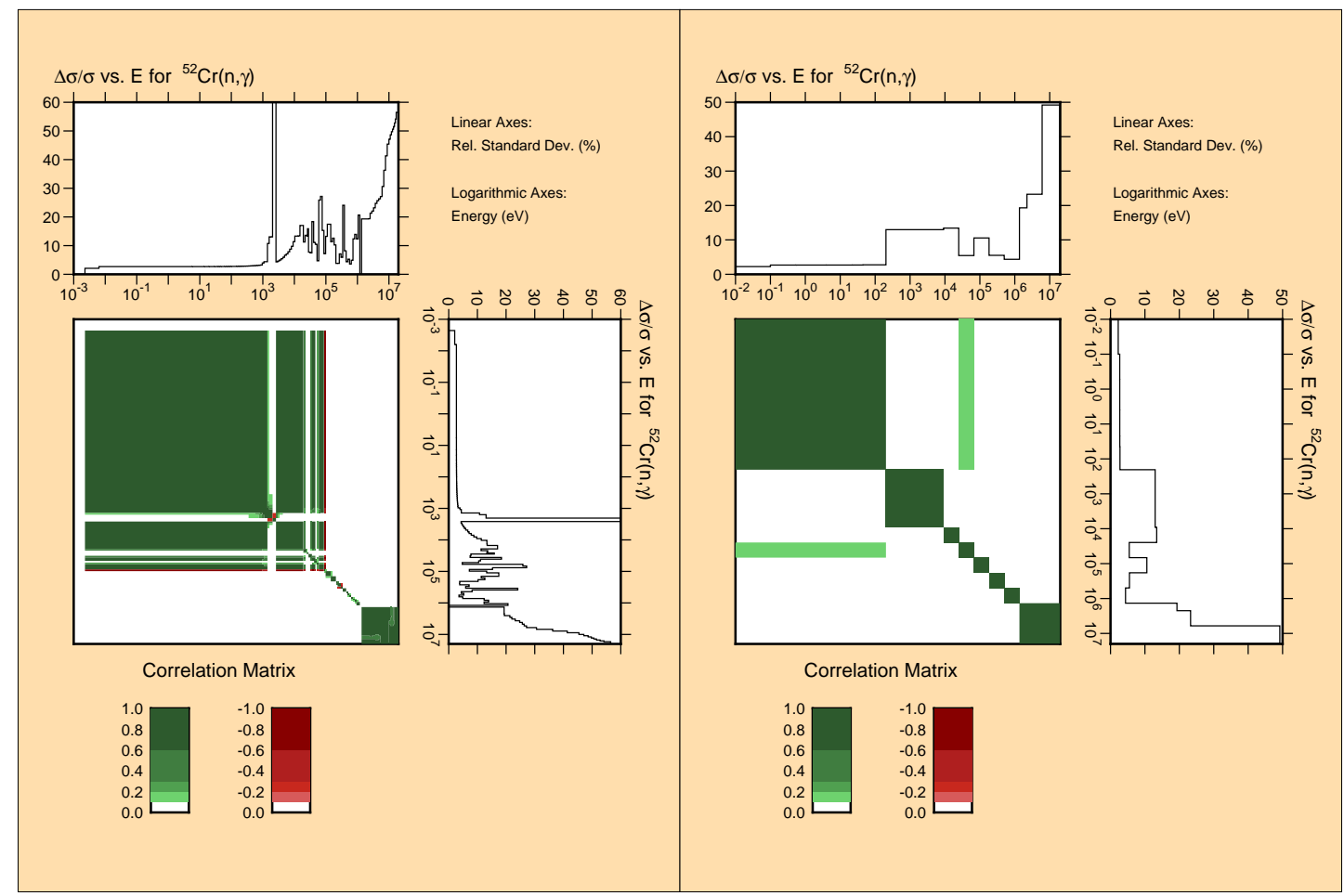

Figure A.23: Correlation and uncertainties in 187 (left) and 15 (right) groups for the ${ }^{52} \mathrm{Cr}(\mathrm{n}, \gamma)$ reaction

D. Rochman et al. 


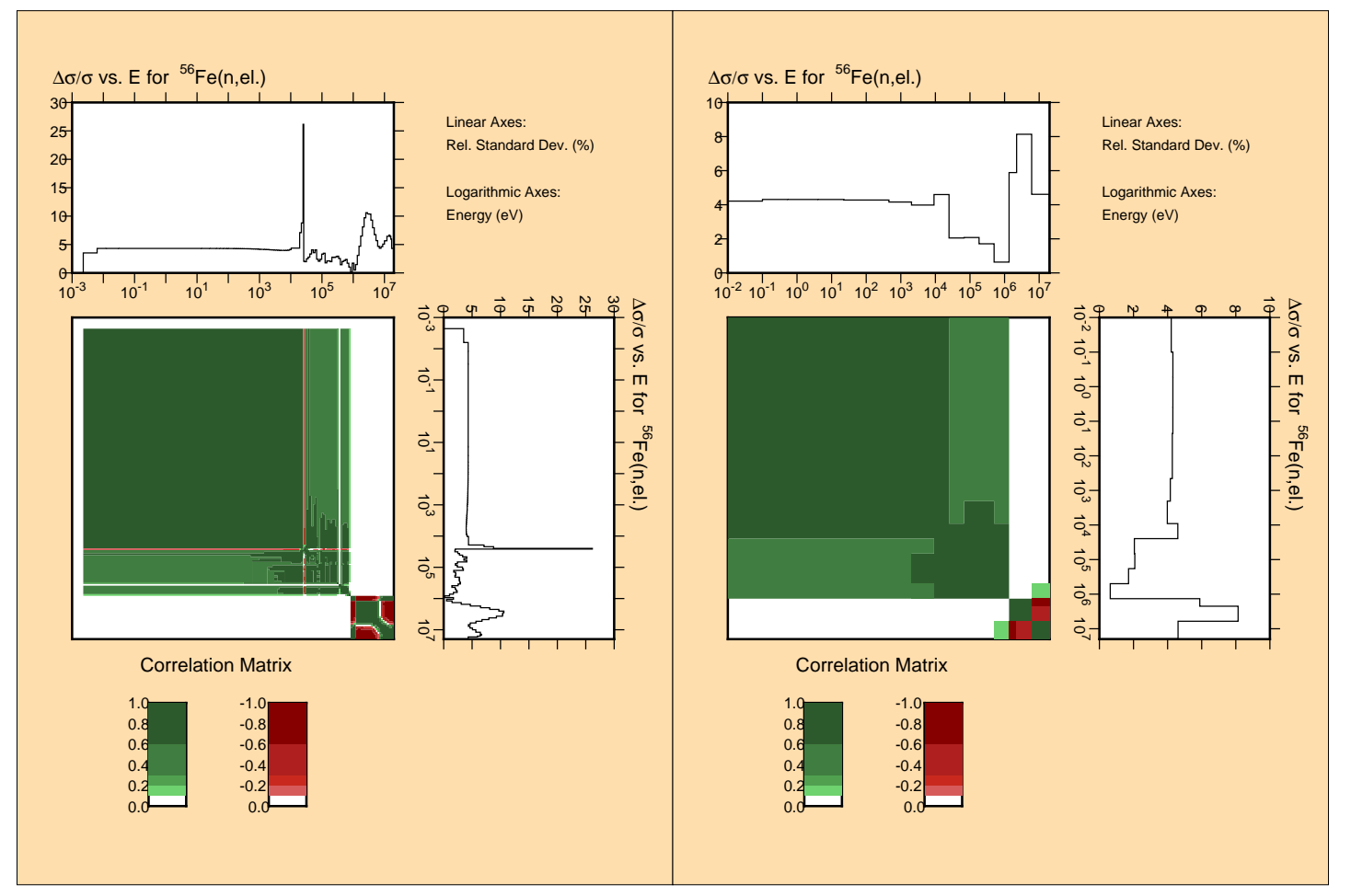

Figure A.24: Correlation and uncertainties in 187 (left) and 15 (right) groups for the ${ }^{56} \mathrm{Fe}(\mathrm{n}, \mathrm{el})$ reaction

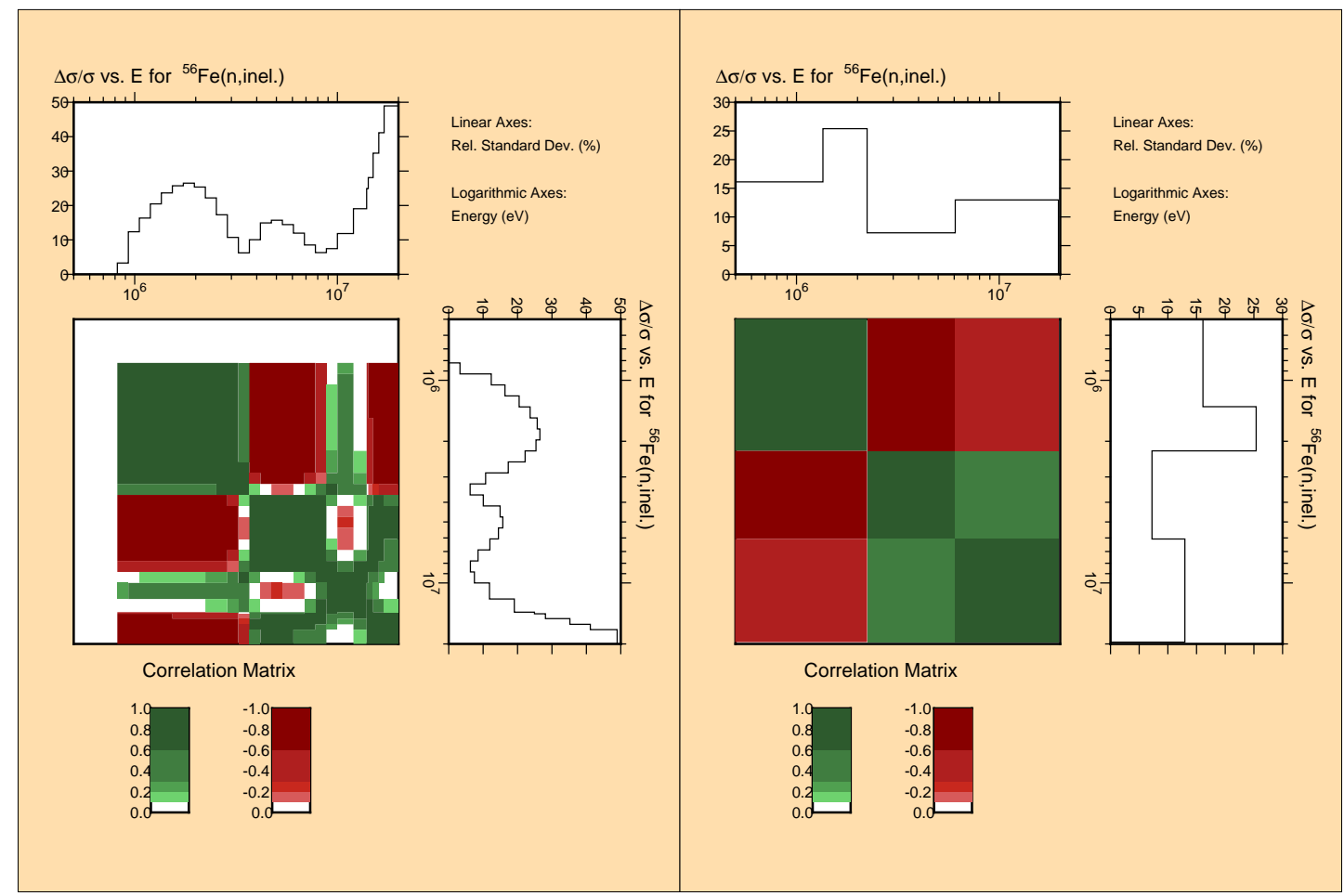

Figure A.25: Correlation and uncertainties in 187 (left) and 15 (right) groups for the ${ }^{56} \mathrm{Fe}\left(\mathrm{n}, \mathrm{n}^{\prime}\right)$ reaction 


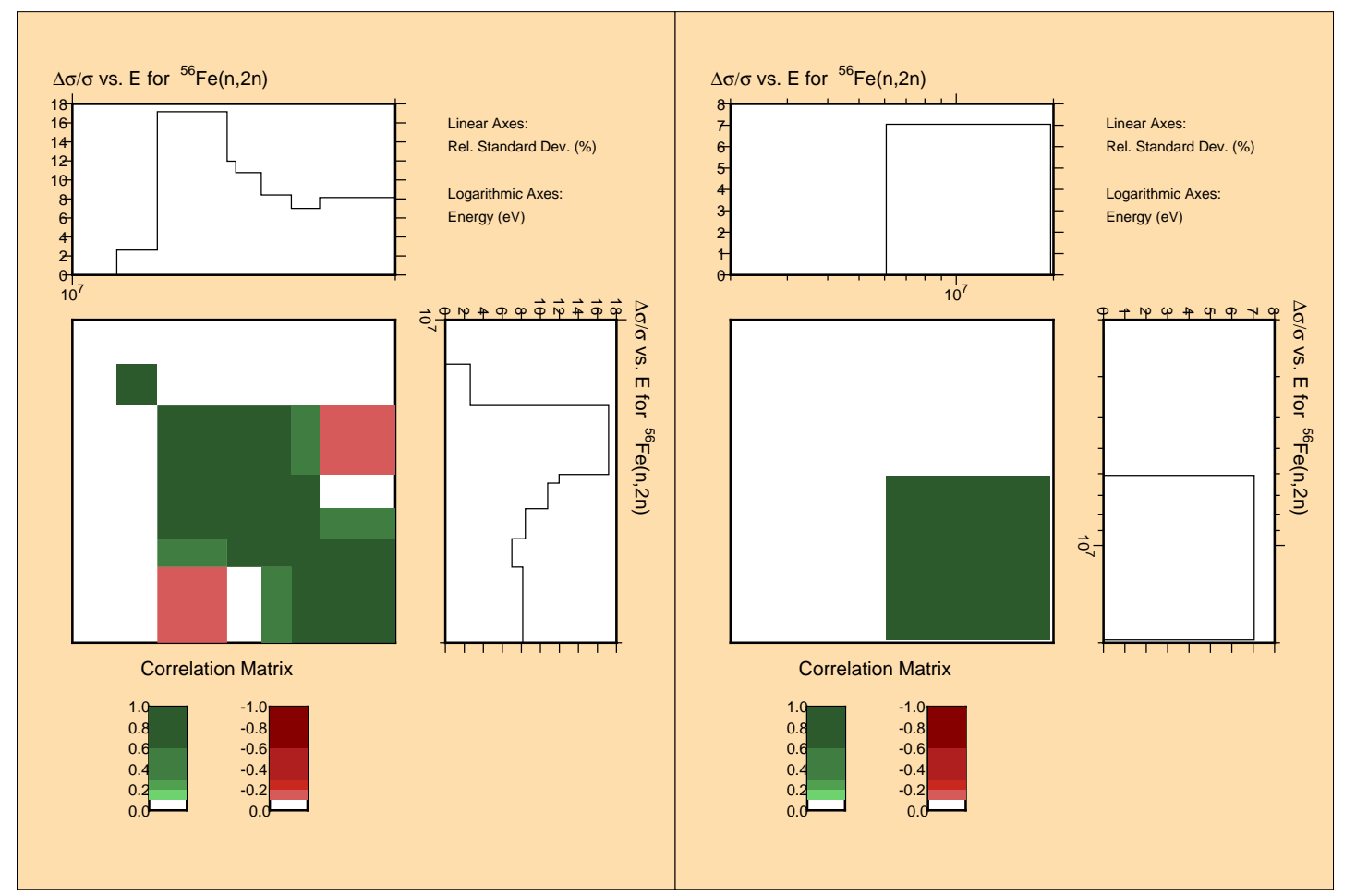

Figure A.26: Correlation and uncertainties in 187 (left) and 15 (right) groups for the ${ }^{56} \mathrm{Fe}(\mathrm{n}, 2 \mathrm{n})$ reaction

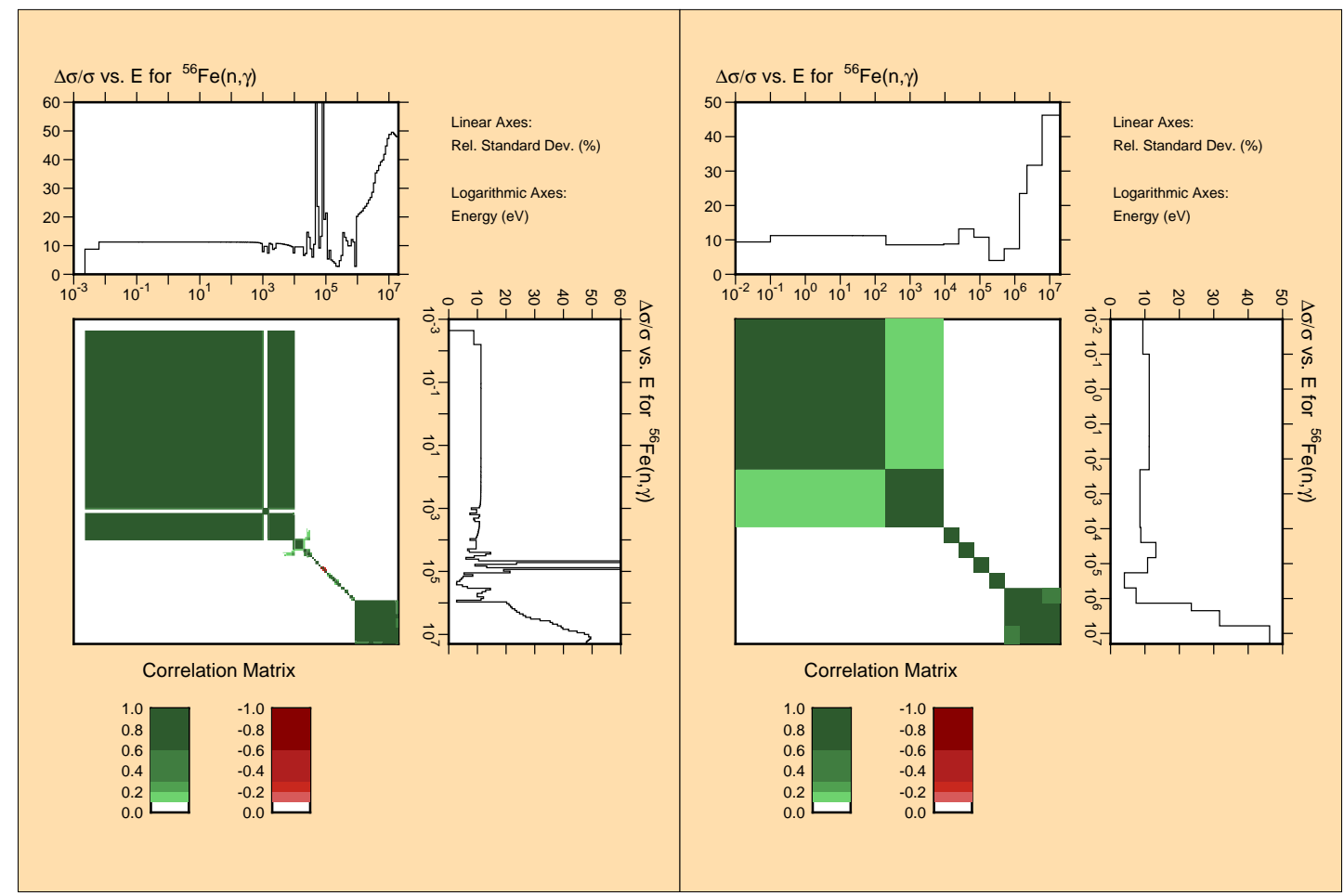

Figure A.27: Correlation and uncertainties in 187 (left) and 15 (right) groups for the ${ }^{56} \mathrm{Fe}(\mathrm{n}, \gamma)$ reaction 


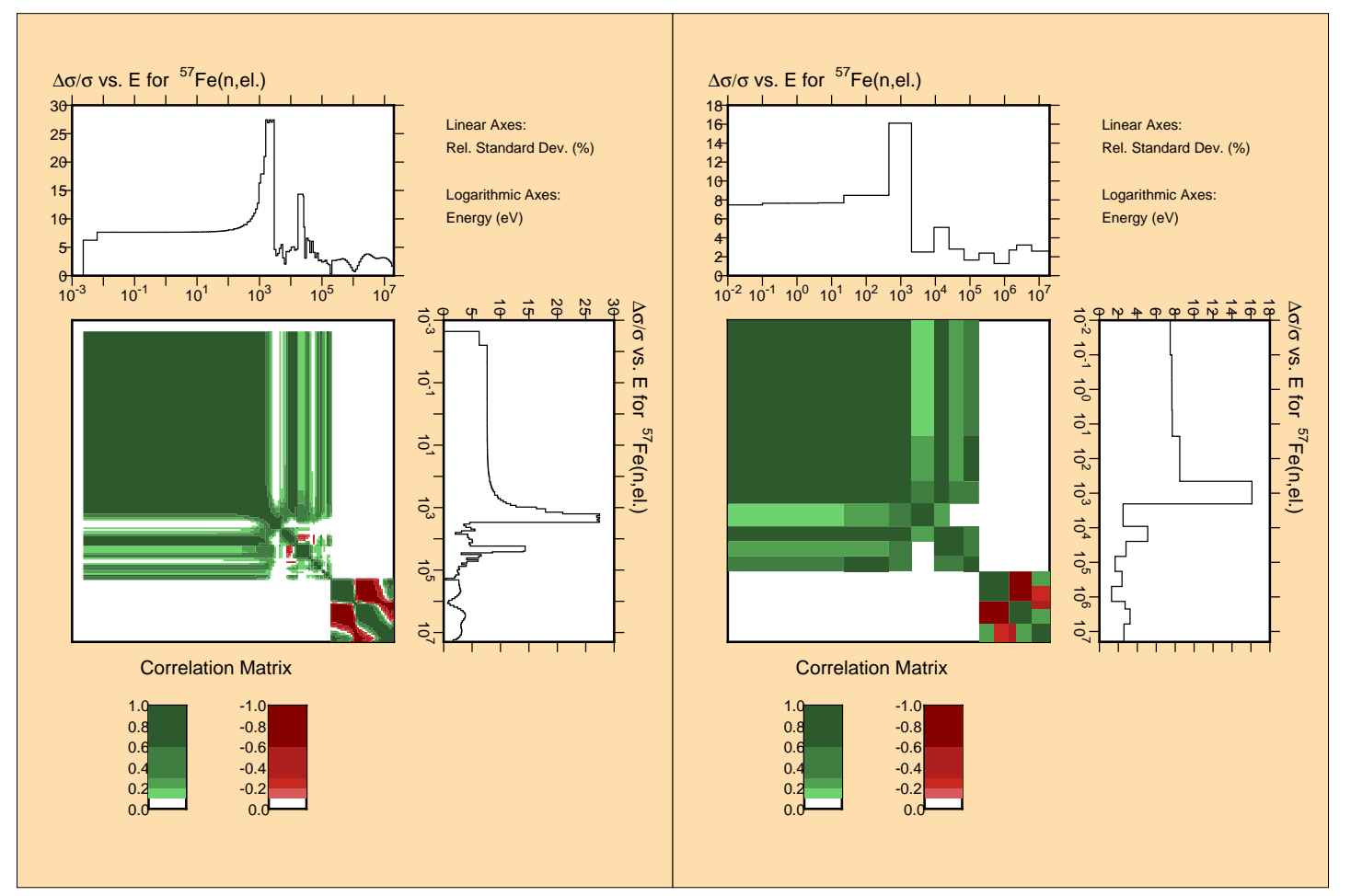

Figure A.28: Correlation and uncertainties in 187 (left) and 15 (right) groups for the ${ }^{57} \mathrm{Fe}(\mathrm{n}, \mathrm{el})$ reaction

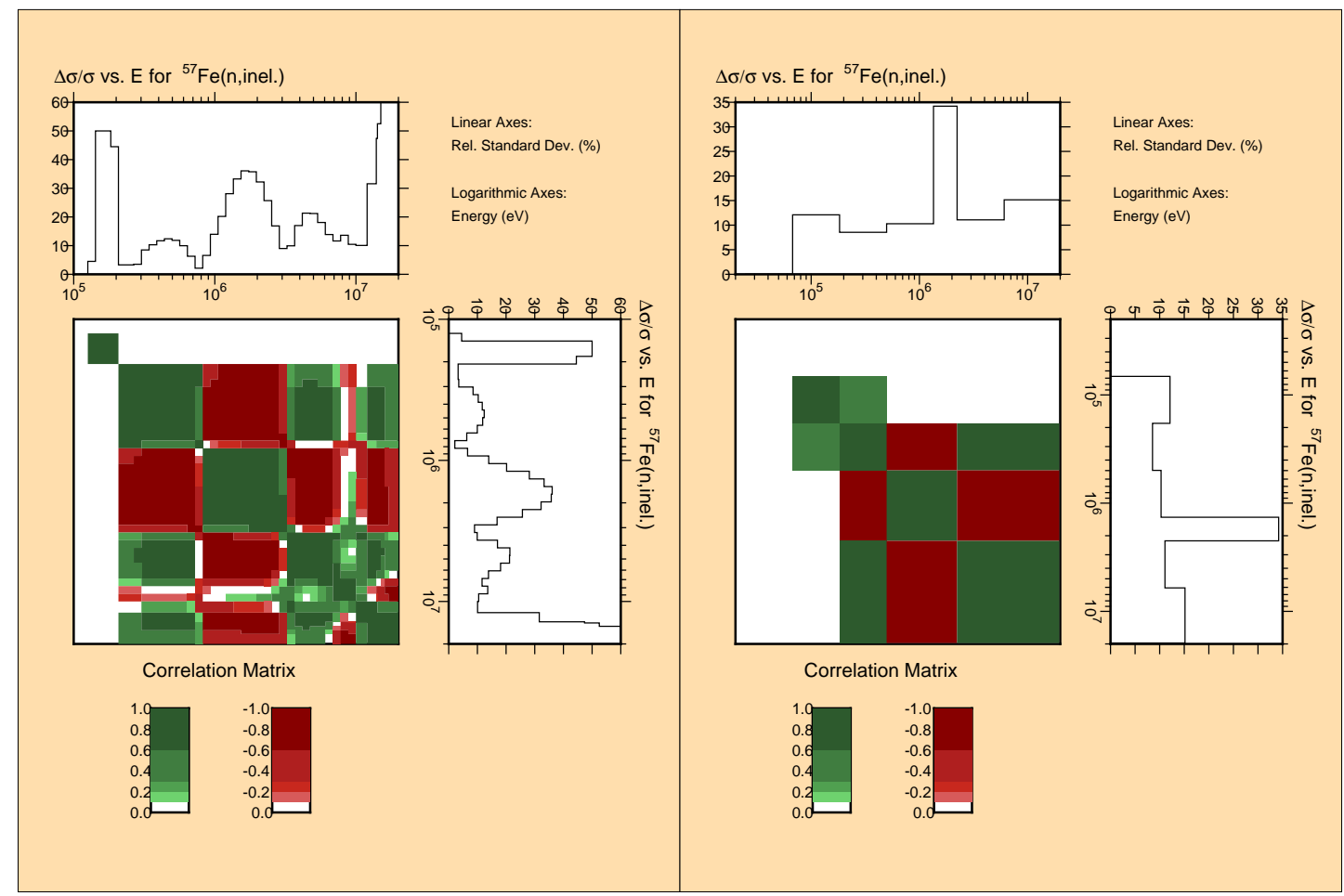

Figure A.29: Correlation and uncertainties in 187 (left) and 15 (right) groups for the ${ }^{57} \mathrm{Fe}\left(\mathrm{n}, \mathrm{n}^{\prime}\right)$ reaction 


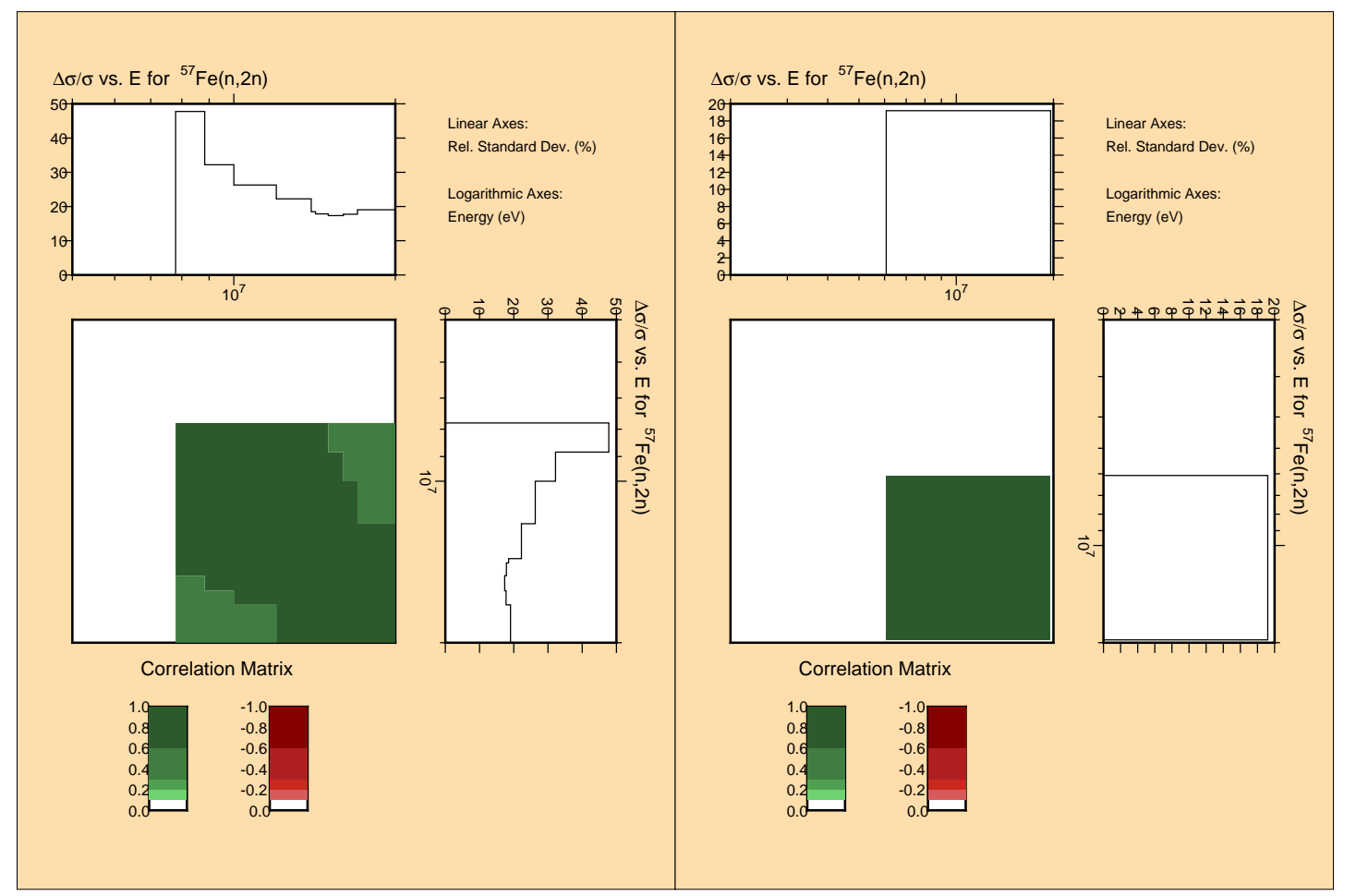

Figure A.30: Correlation and uncertainties in 187 (left) and 15 (right) groups for the ${ }^{57} \mathrm{Fe}(\mathrm{n}, 2 \mathrm{n})$ reaction

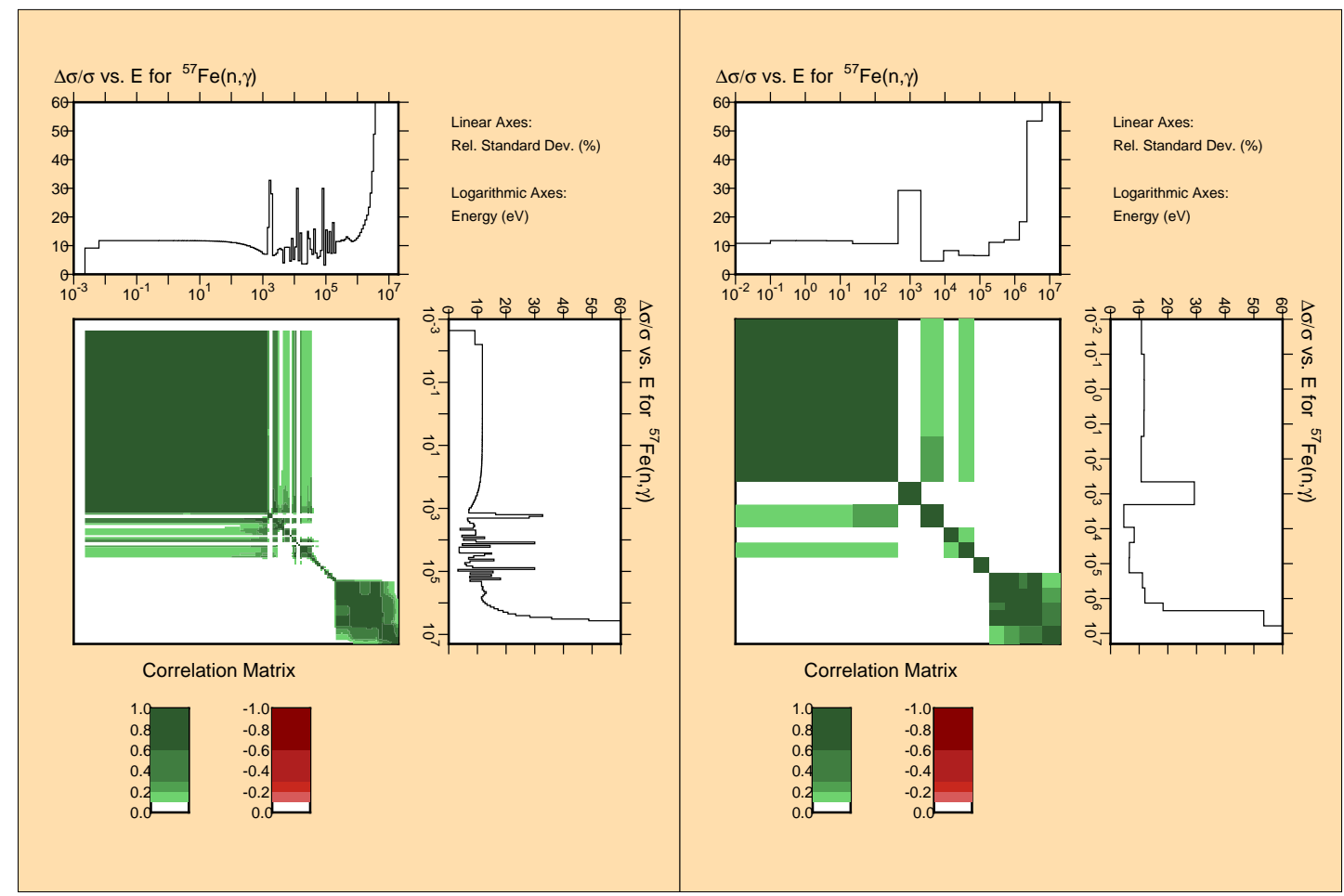

Figure A.31: Correlation and uncertainties in 187 (left) and 15 (right) groups for the ${ }^{57} \mathrm{Fe}(\mathrm{n}, \gamma)$ reaction

D. Rochman et al. 


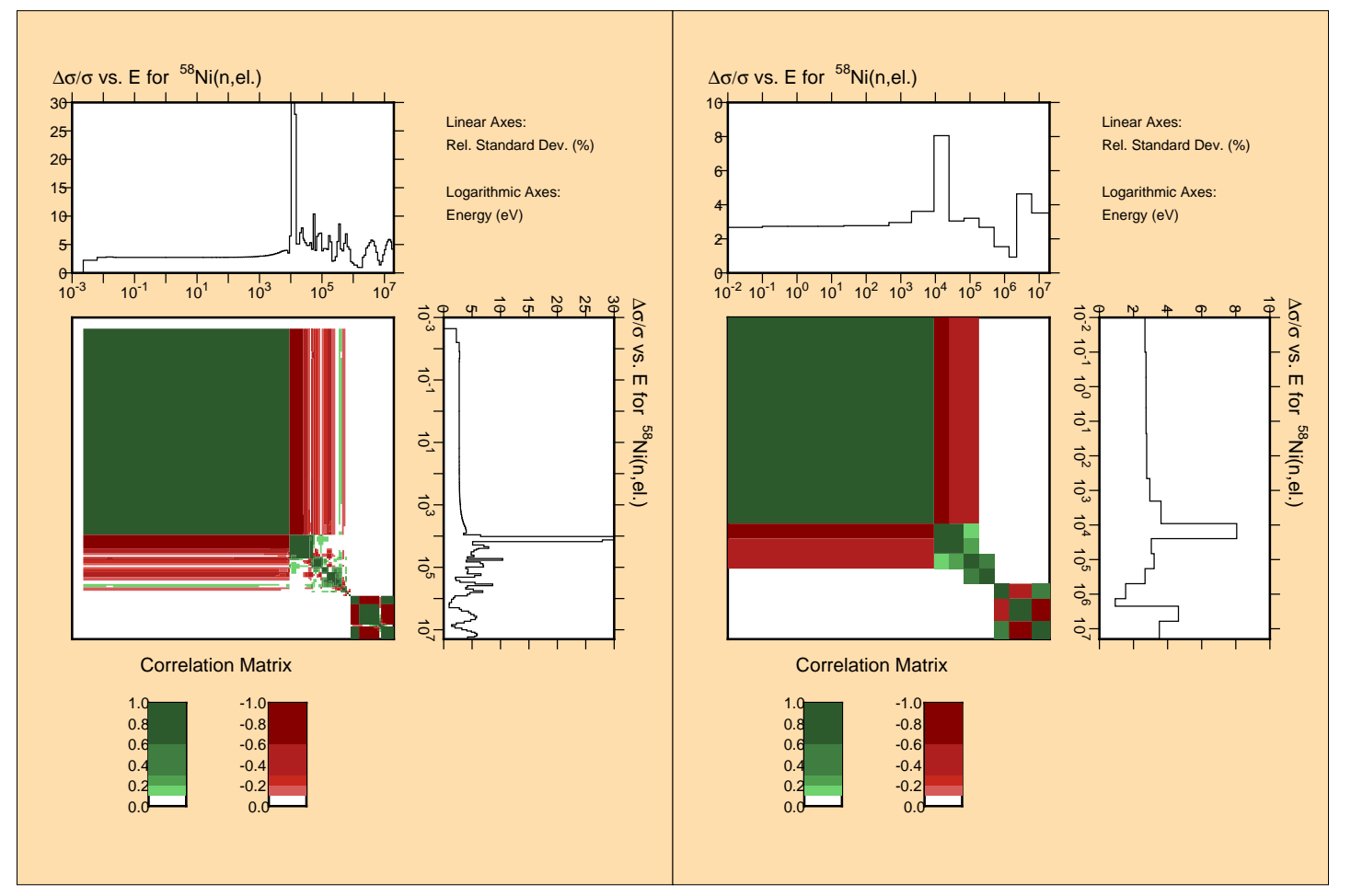

Figure A.32: Correlation and uncertainties in 187 (left) and 15 (right) groups for the ${ }^{58} \mathrm{Ni}(\mathrm{n}, \mathrm{el})$ reaction

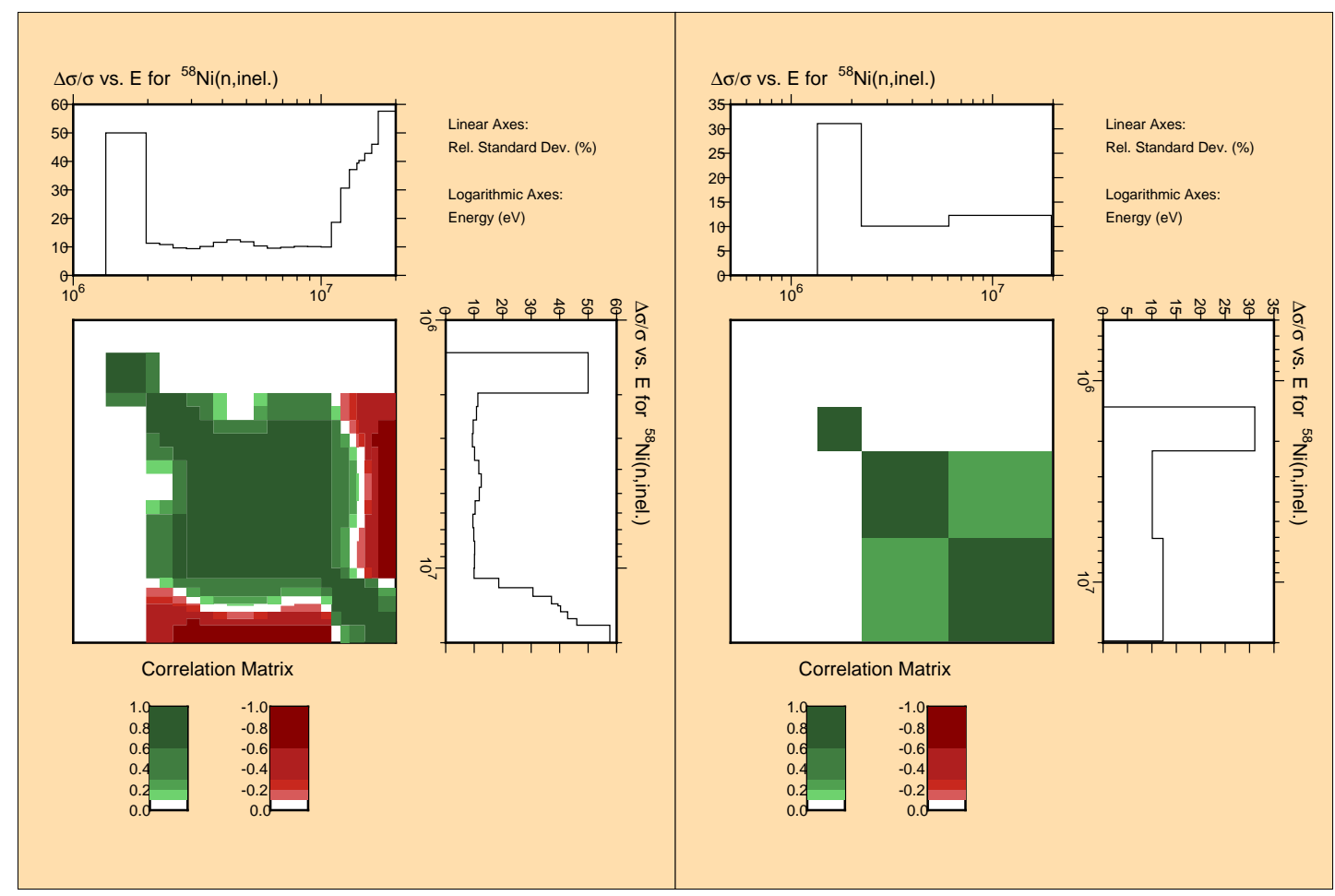

Figure A.33: Correlation and uncertainties in 187 (left) and 15 (right) groups for the ${ }^{58} \mathrm{Ni}\left(\mathrm{n}, \mathrm{n}^{\prime}\right)$ reaction 


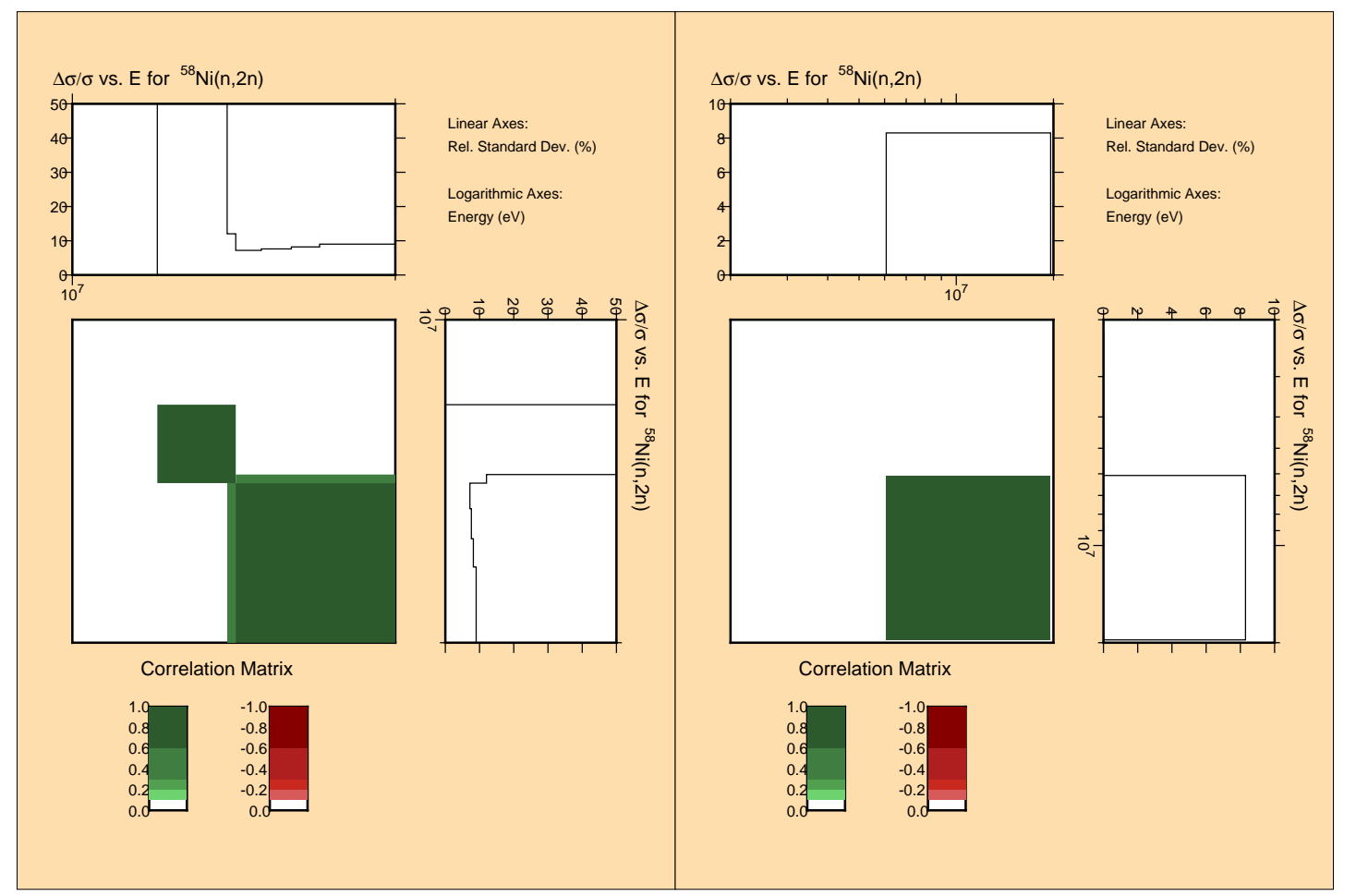

Figure A.34: Correlation and uncertainties in 187 (left) and 15 (right) groups for the ${ }^{58} \mathrm{Ni}(\mathrm{n}, 2 \mathrm{n})$ reaction

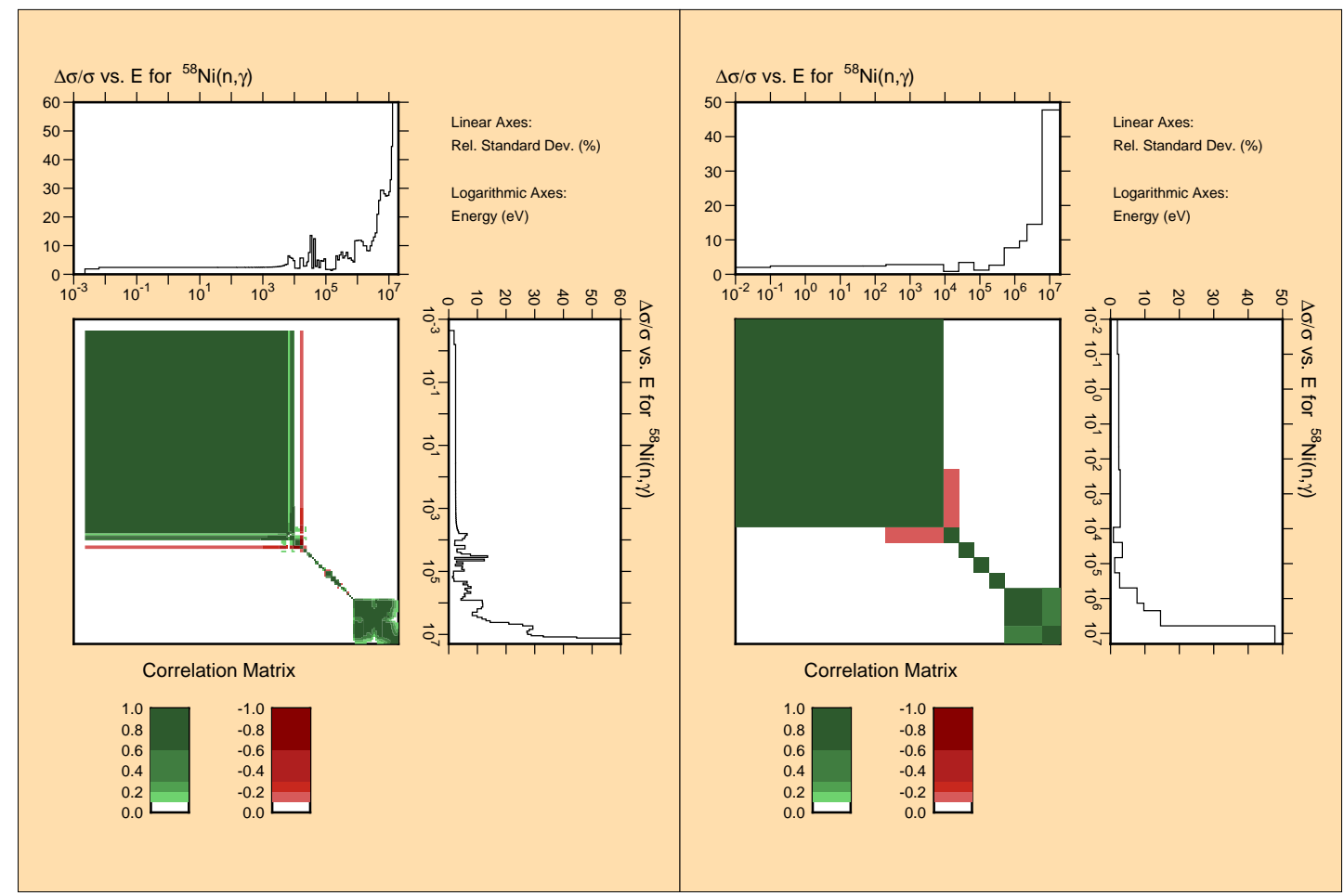

Figure A.35: Correlation and uncertainties in 187 (left) and 15 (right) groups for the ${ }^{58} \mathrm{Ni}(\mathrm{n}, \gamma)$ reaction

D. Rochman et al. 


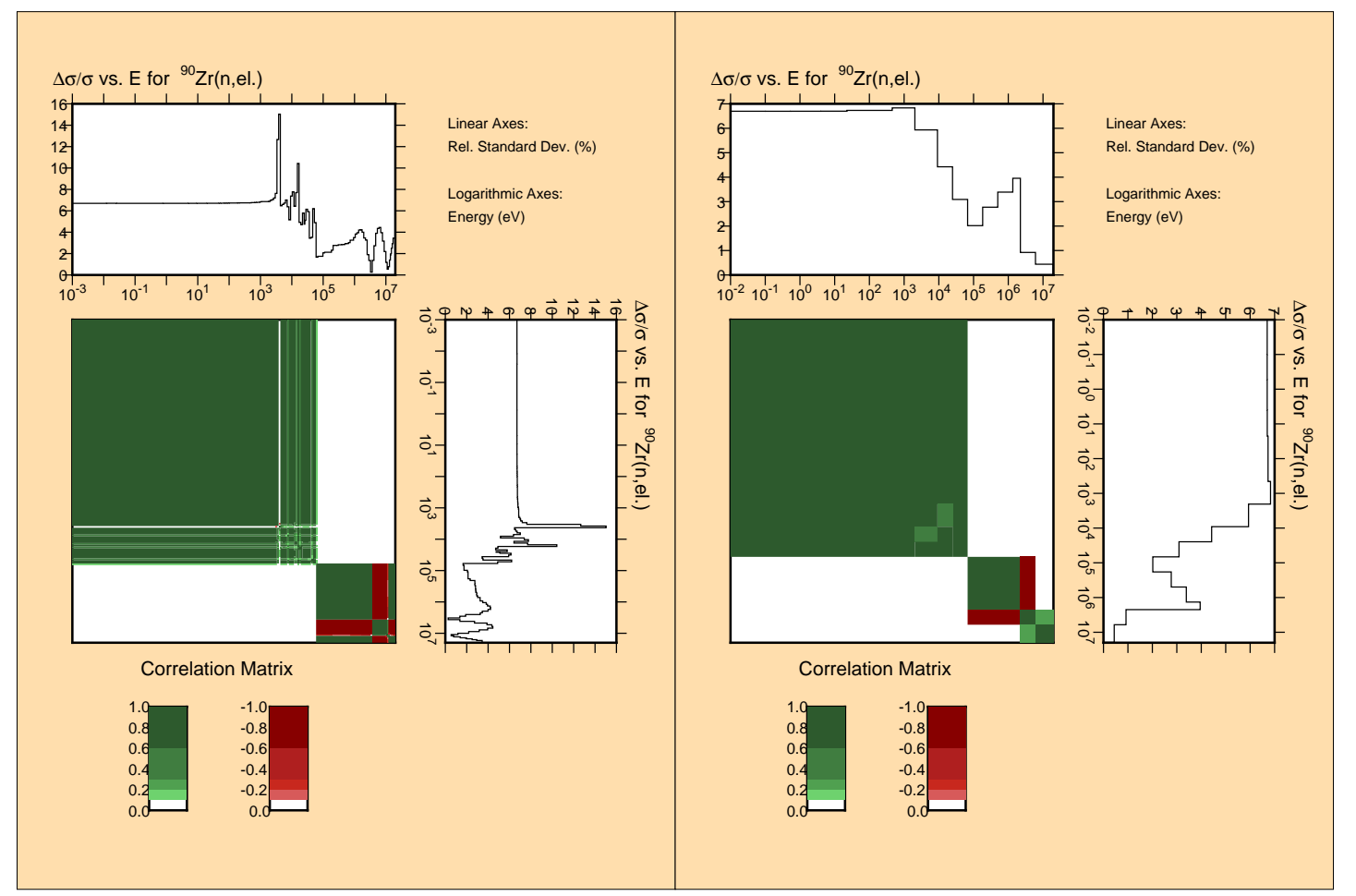

Figure A.36: Correlation and uncertainties in 187 (left) and 15 (right) groups for the ${ }^{90} \mathrm{Zr}(\mathrm{n}, \mathrm{el})$ reaction

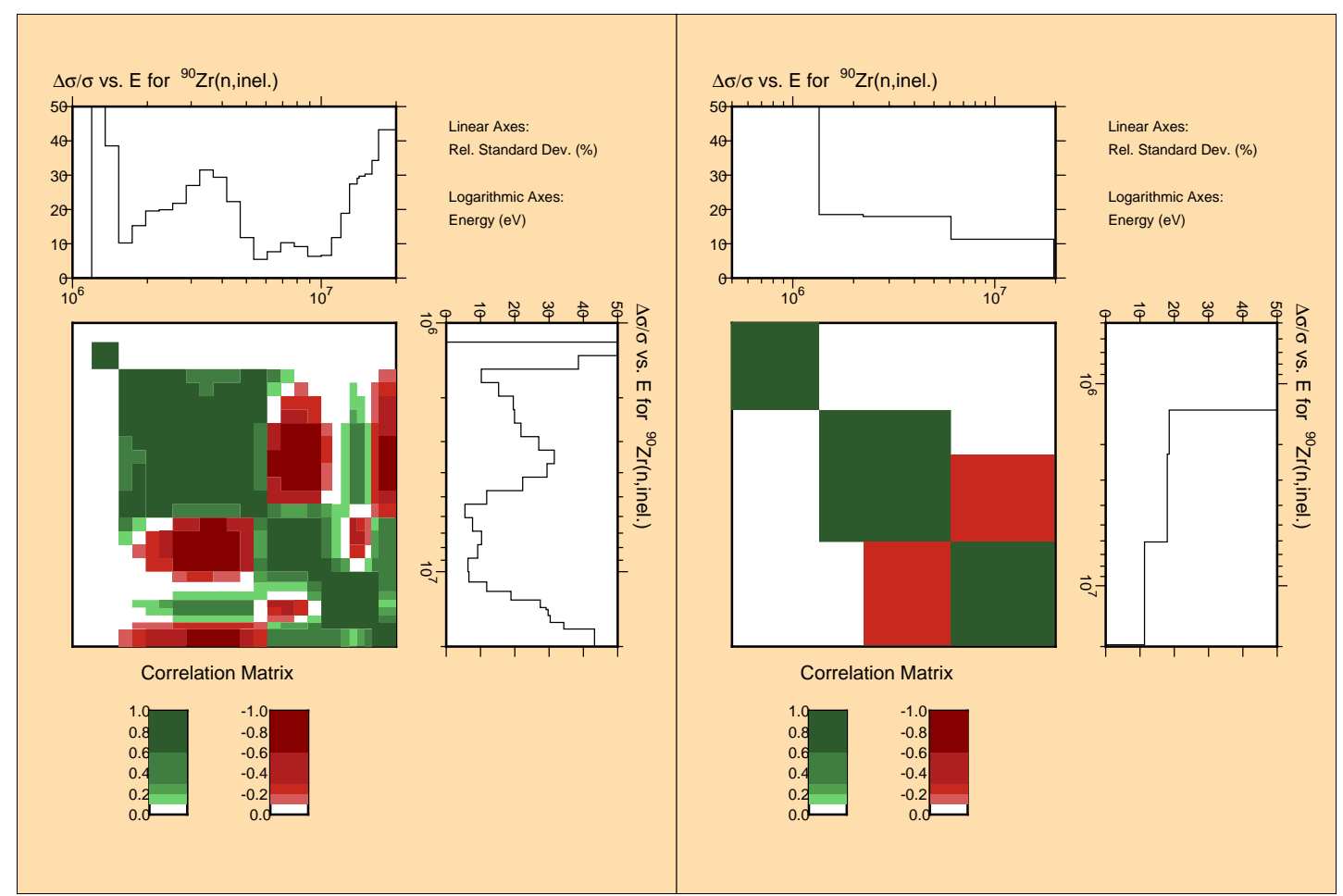

Figure A.37: Correlation and uncertainties in 187 (left) and 15 (right) groups for the ${ }^{90} \mathrm{Zr}\left(\mathrm{n}, \mathrm{n}^{\prime}\right)$ reaction

D. Rochman et al. 


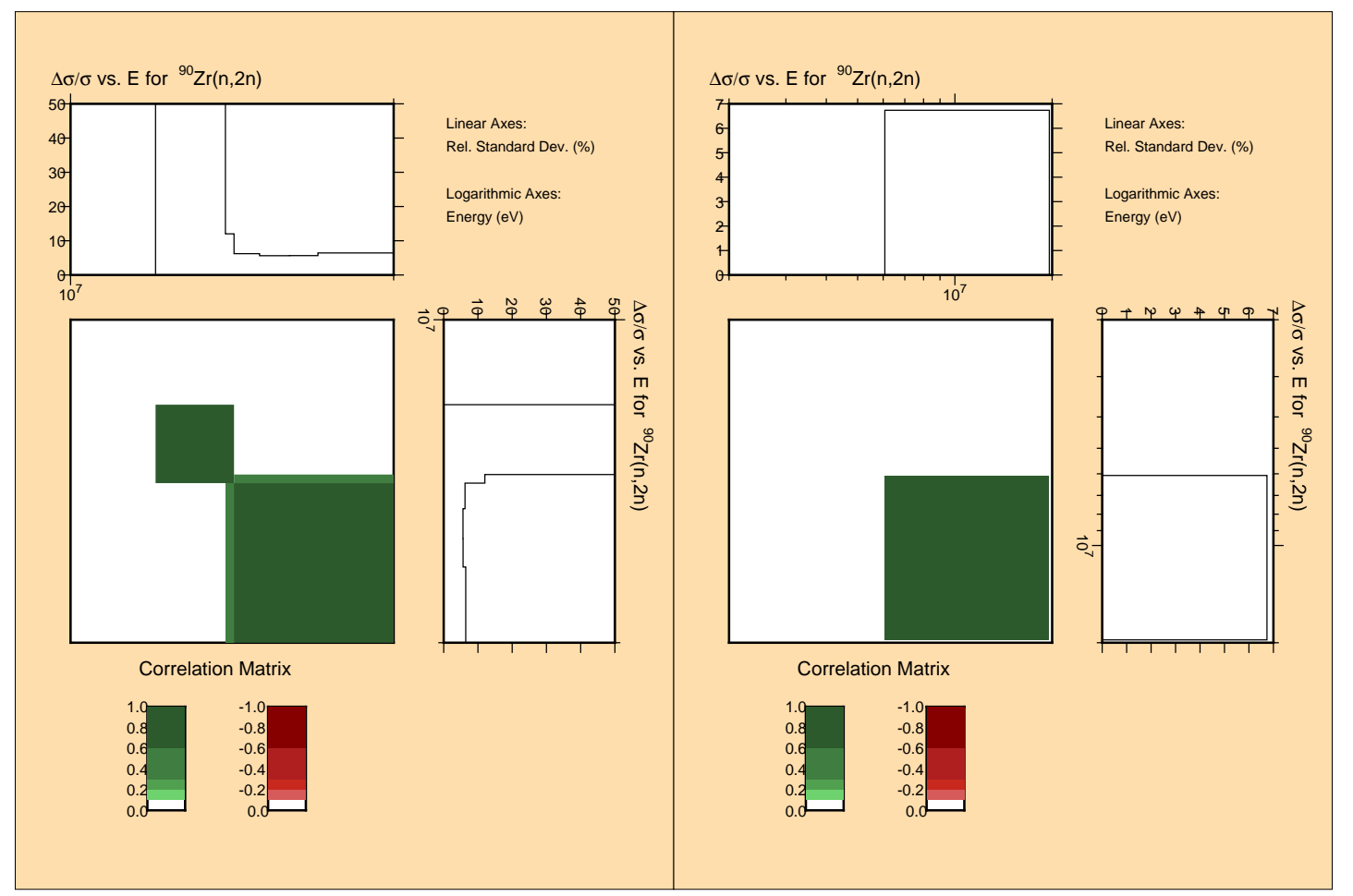

Figure A.38: Correlation and uncertainties in 187 (left) and 15 (right) groups for the ${ }^{90} \mathrm{Zr}(\mathrm{n}, 2 \mathrm{n})$ reaction

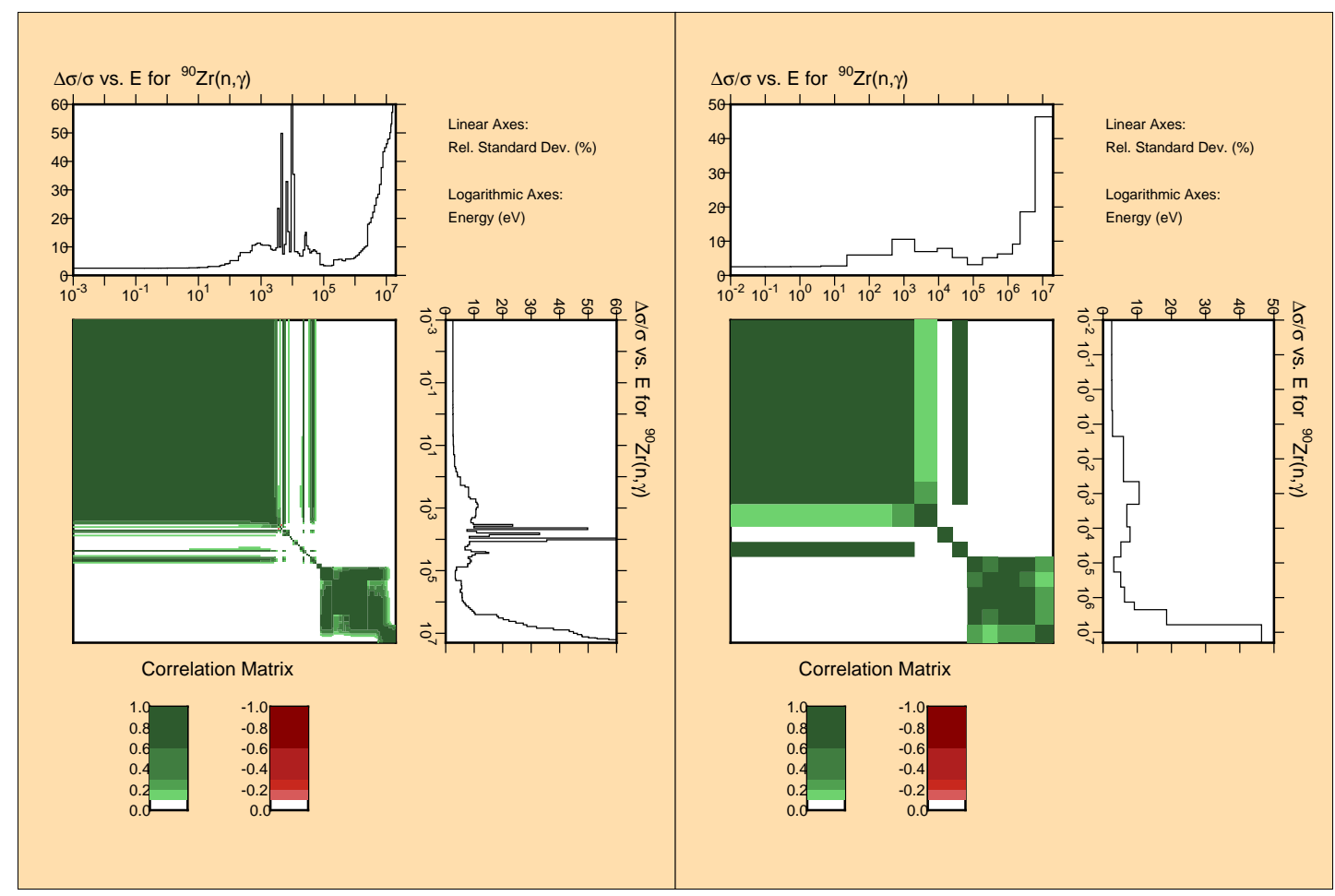

Figure A.39: Correlation and uncertainties in 187 (left) and 15 (right) groups for the ${ }^{90} \mathrm{Zr}(\mathrm{n}, \gamma)$ reaction 


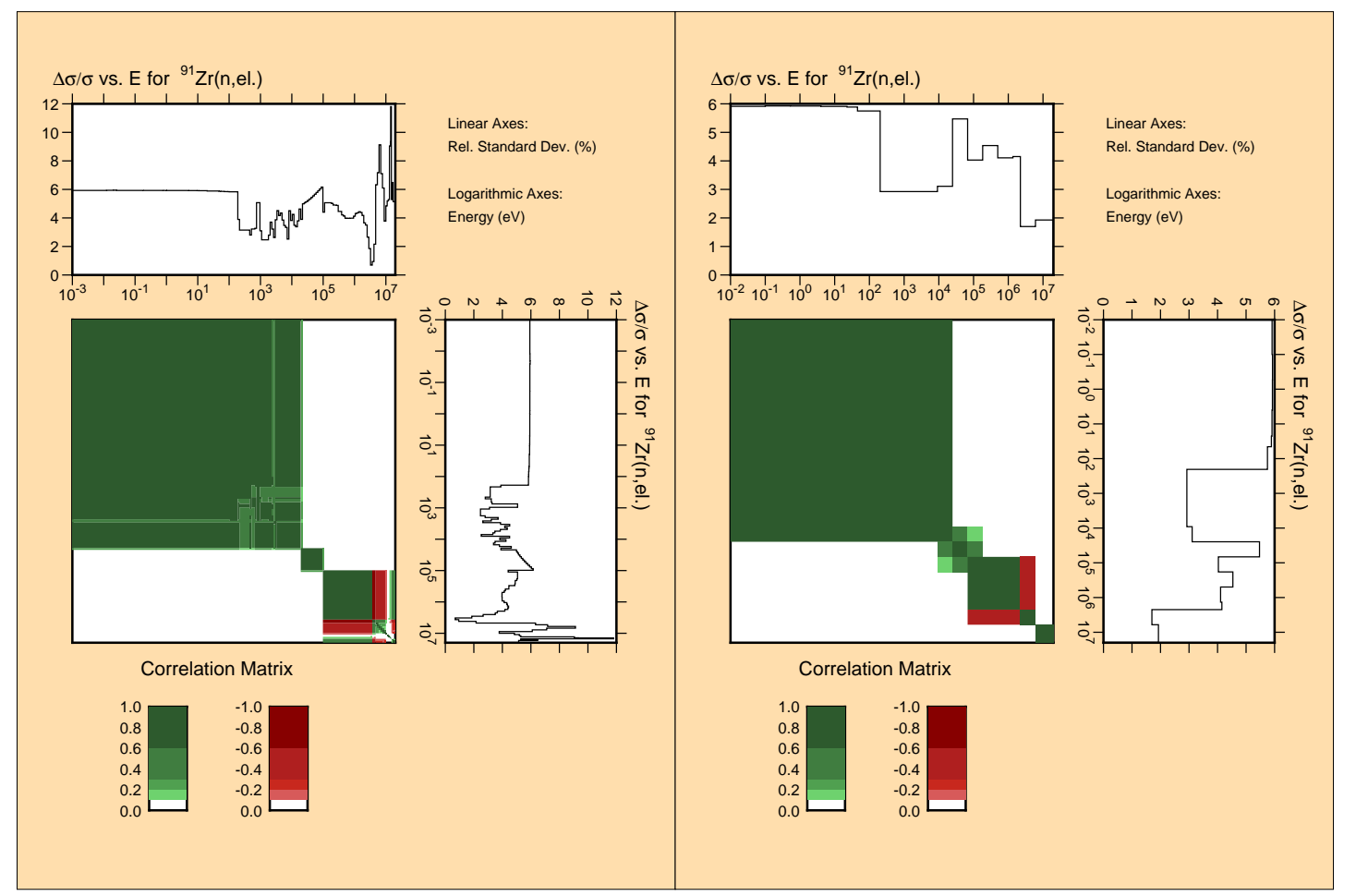

Figure A.40: Correlation and uncertainties in 187 (left) and 15 (right) groups for the ${ }^{91} \mathrm{Zr}(\mathrm{n}, \mathrm{el})$ reaction

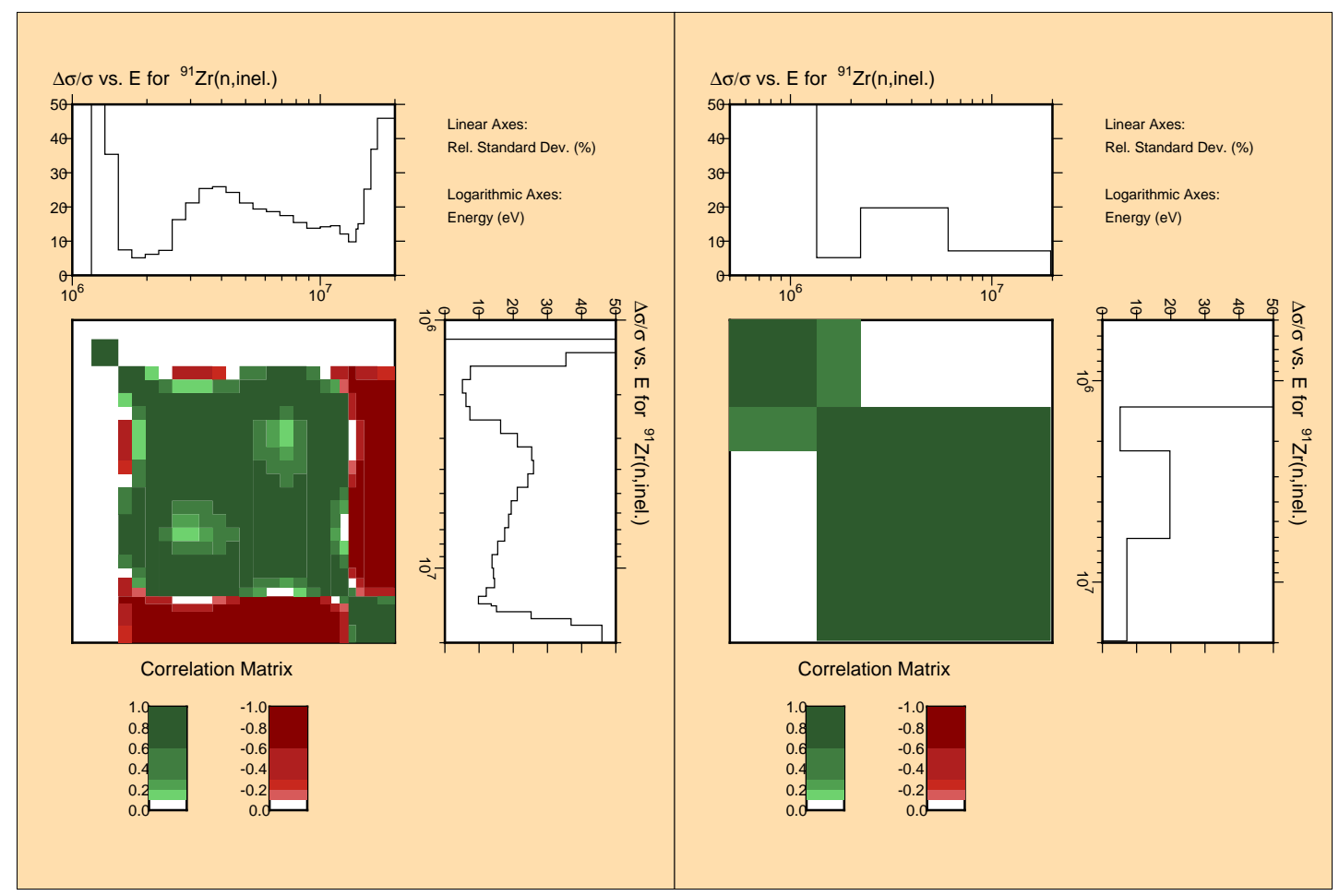

Figure A.41: Correlation and uncertainties in 187 (left) and 15 (right) groups for the ${ }^{91} \mathrm{Zr}\left(\mathrm{n}, \mathrm{n}^{\prime}\right)$ reaction

D. Rochman et al. 


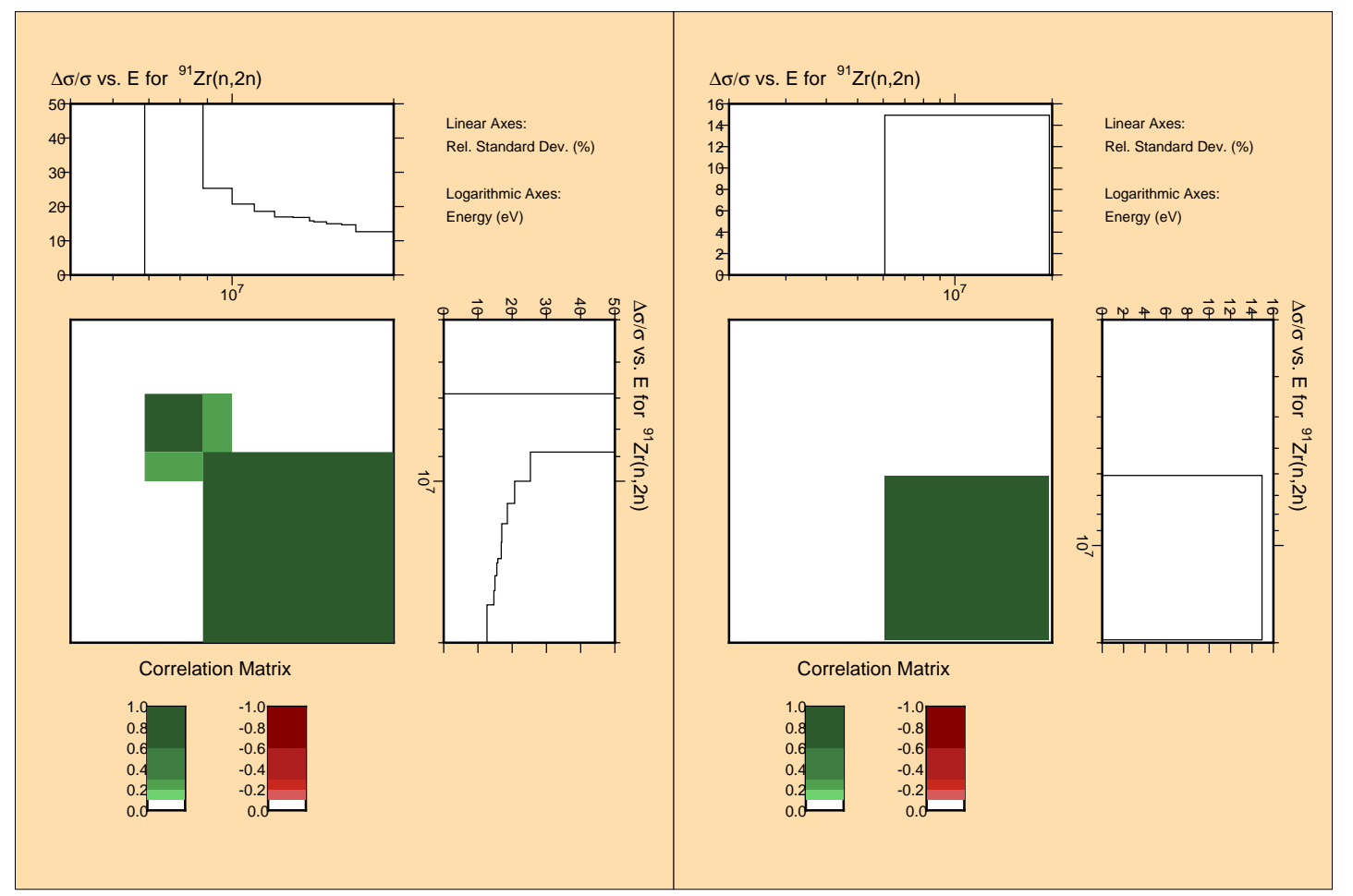

Figure A.42: Correlation and uncertainties in 187 (left) and 15 (right) groups for the ${ }^{91} \mathrm{Zr}(\mathrm{n}, 2 \mathrm{n})$ reaction

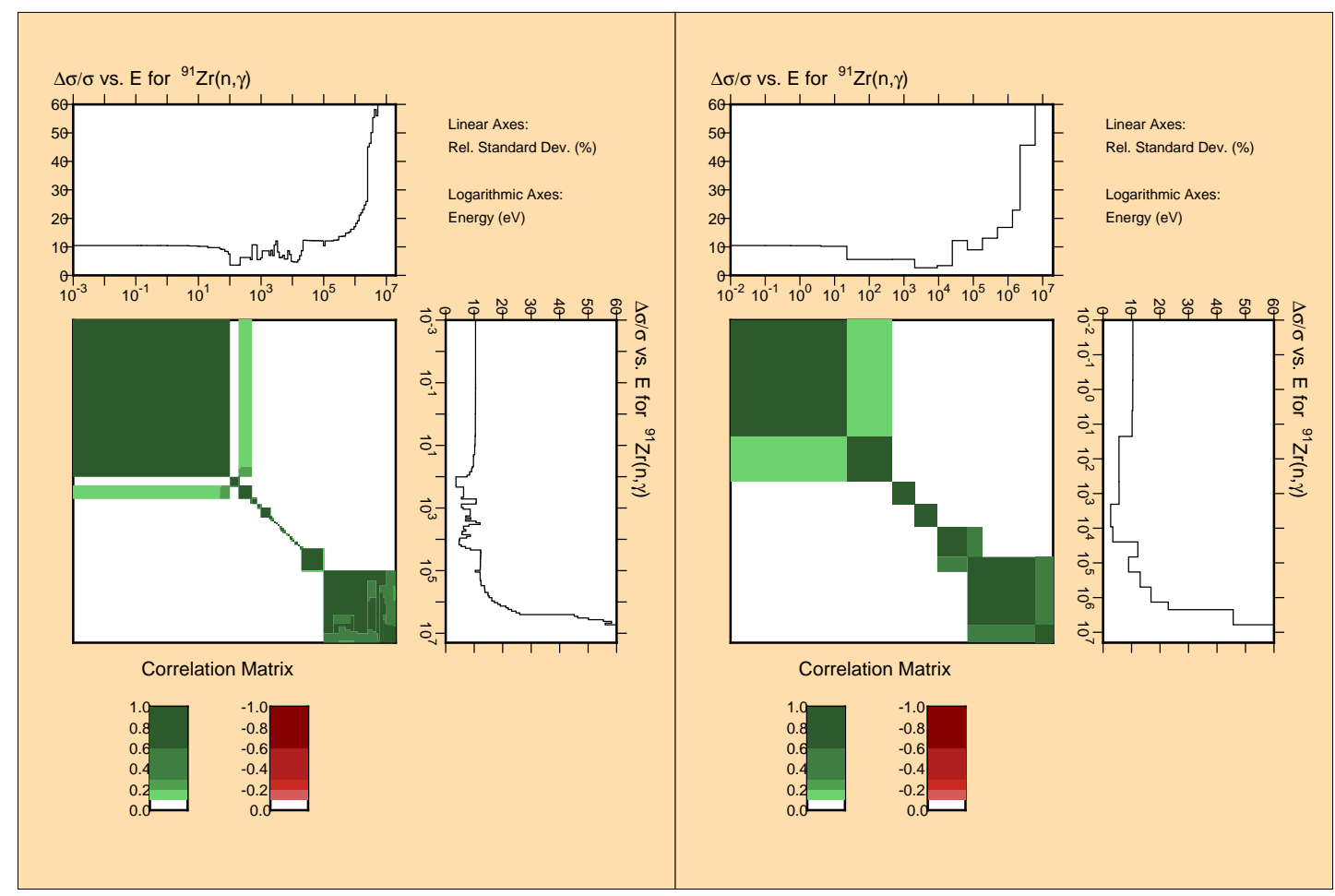

Figure A.43: Correlation and uncertainties in 187 (left) and 15 (right) groups for the ${ }^{91} \mathrm{Zr}(\mathrm{n}, \gamma)$ reaction 


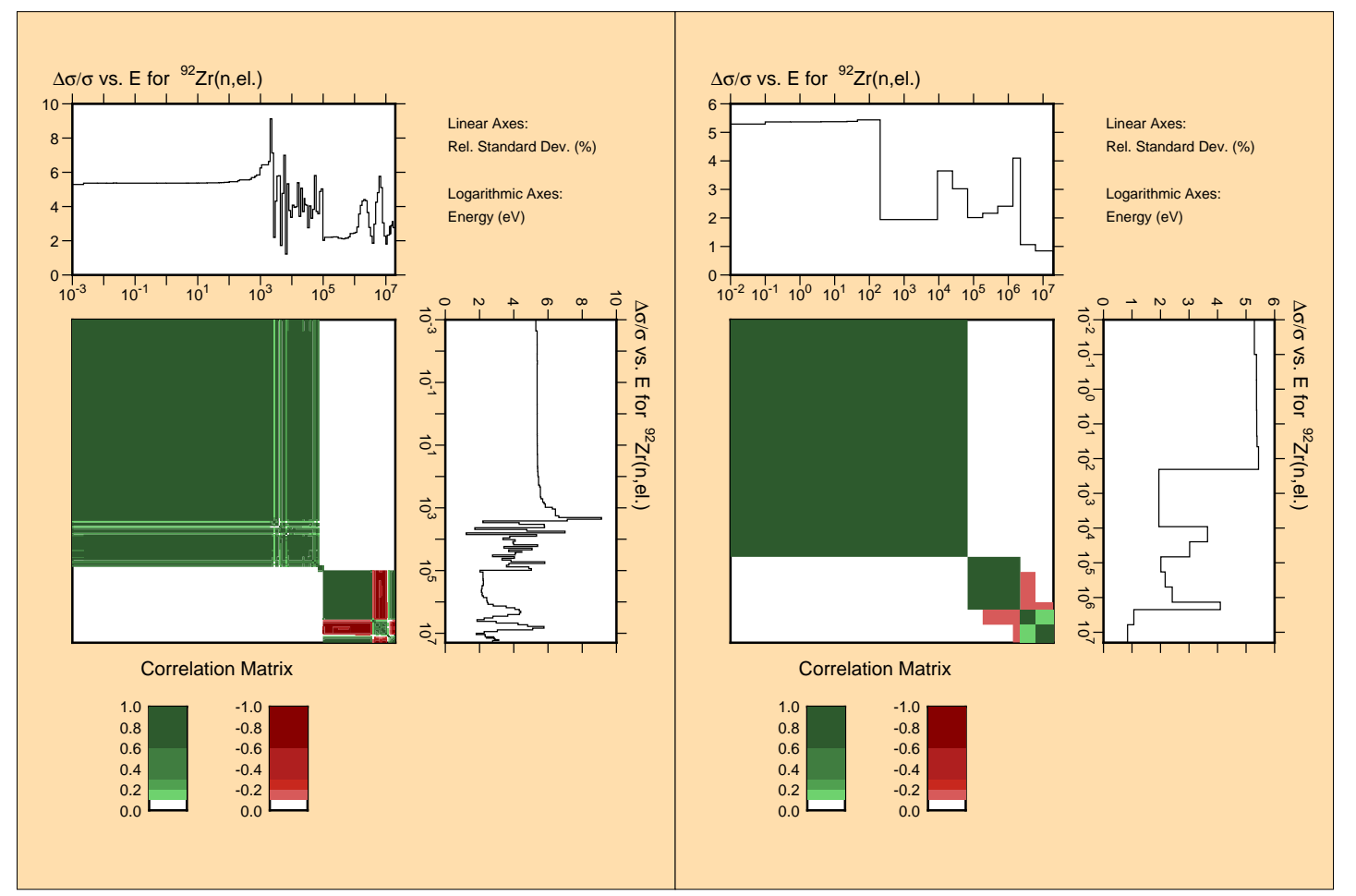

Figure A.44: Correlation and uncertainties in 187 (left) and 15 (right) groups for the ${ }^{92} \mathrm{Zr}(\mathrm{n}, \mathrm{el})$ reaction

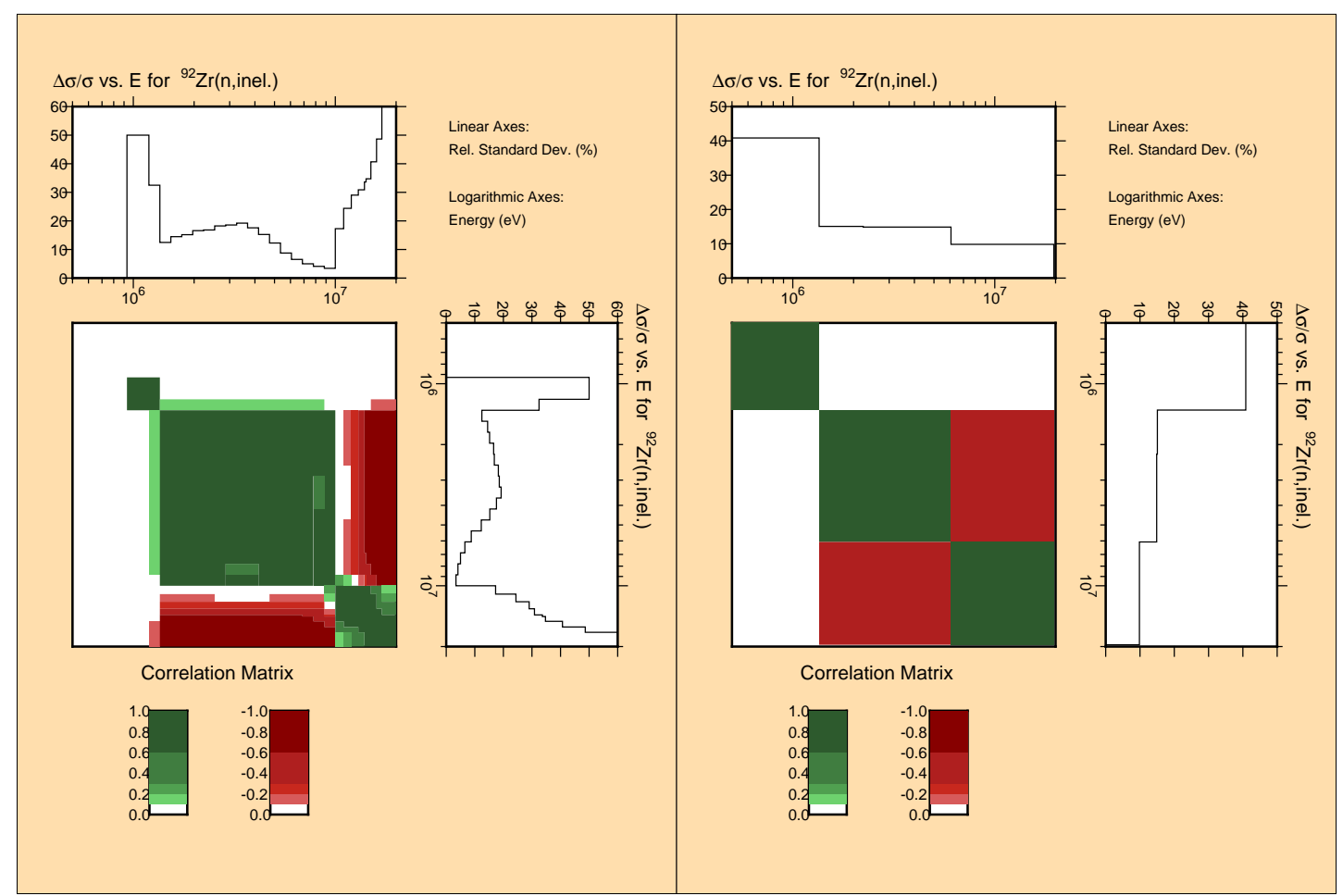

Figure A.45: Correlation and uncertainties in 187 (left) and 15 (right) groups for the ${ }^{92} \mathrm{Zr}\left(\mathrm{n}, \mathrm{n}^{\prime}\right)$ reaction 


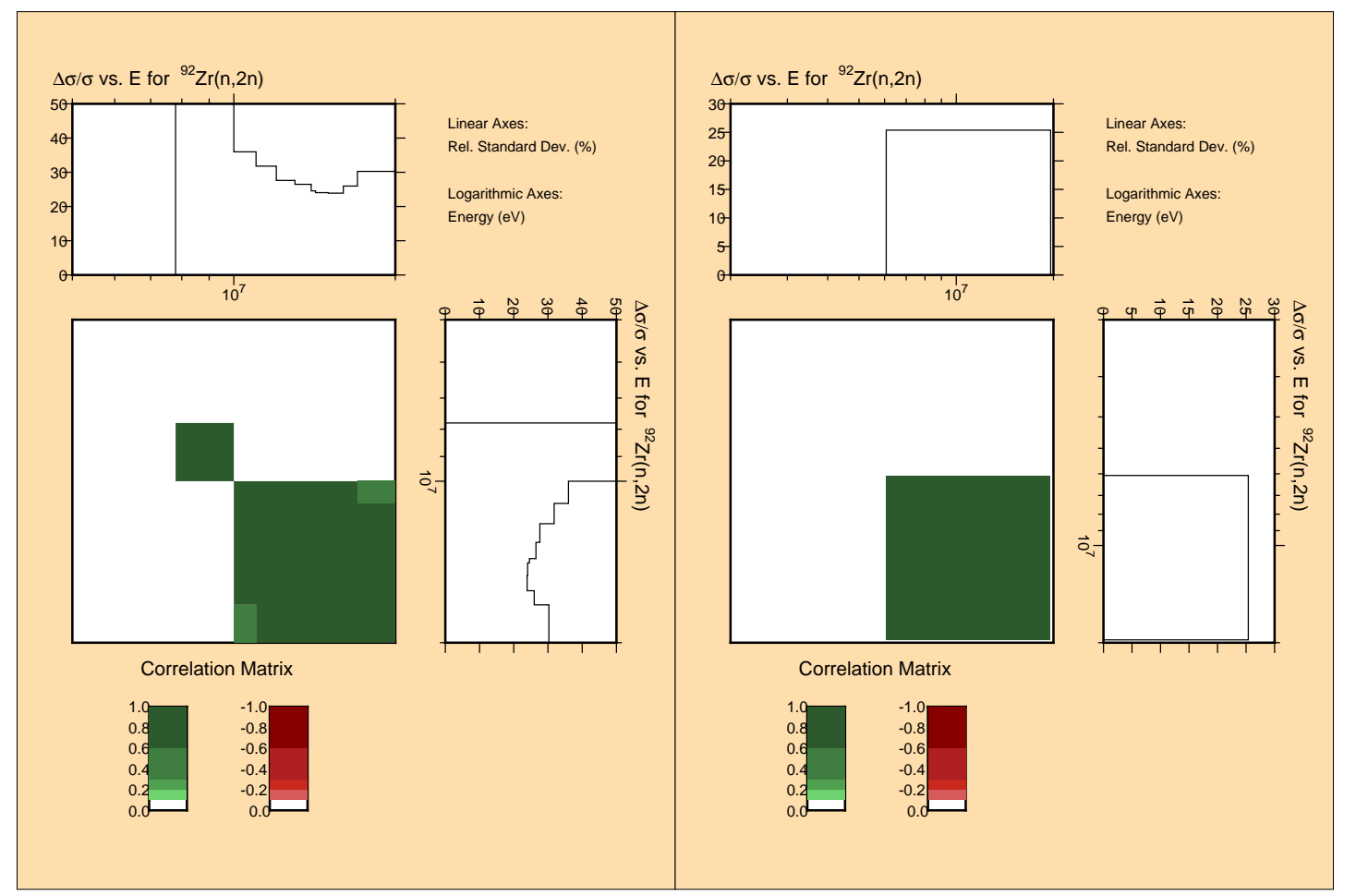

Figure A.46: Correlation and uncertainties in 187 (left) and 15 (right) groups for the ${ }^{92} \mathrm{Zr}(\mathrm{n}, 2 \mathrm{n})$ reaction

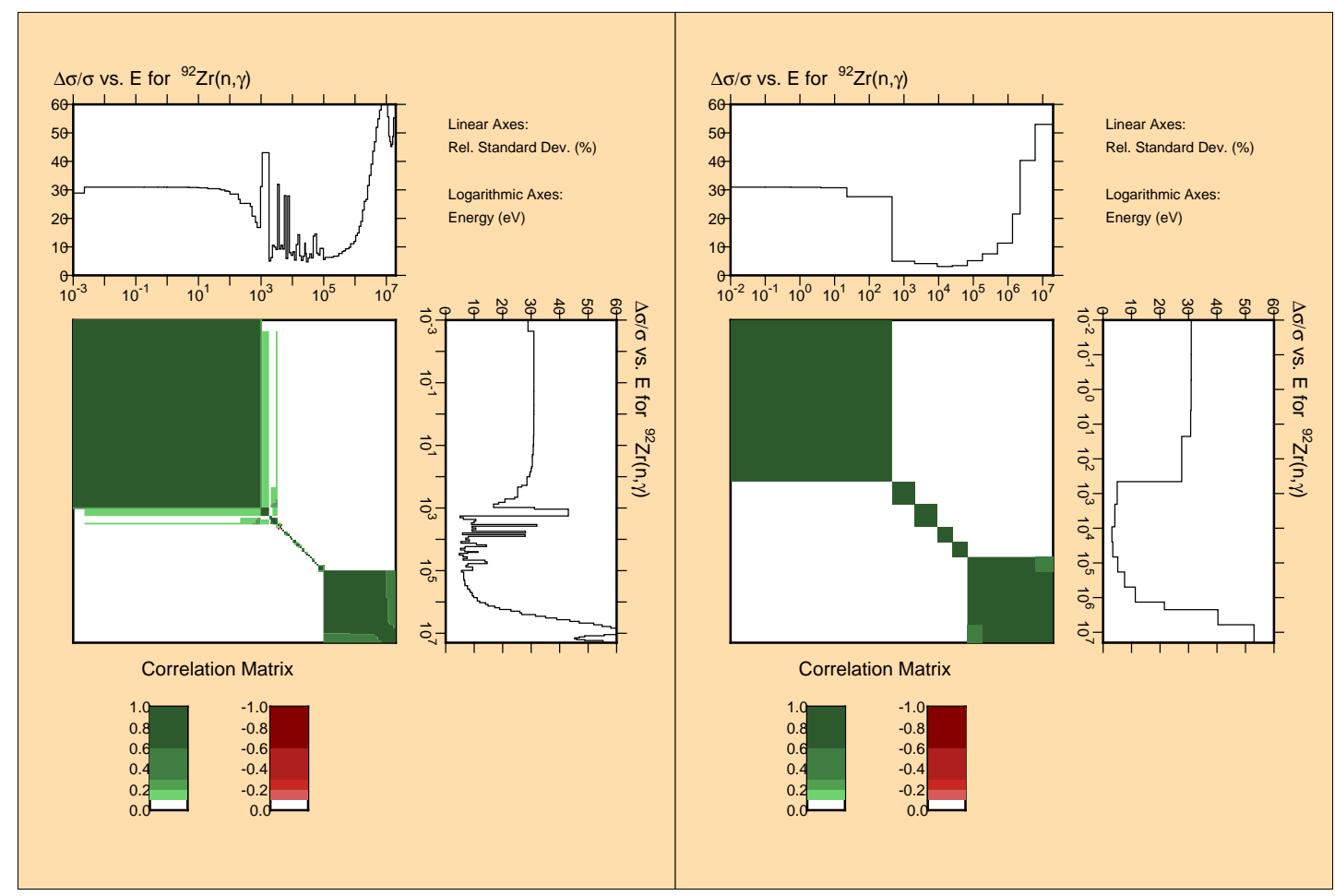

Figure A.47: Correlation and uncertainties in 187 (left) and 15 (right) groups for the ${ }^{92} \mathrm{Zr}(\mathrm{n}, \gamma)$ reaction 


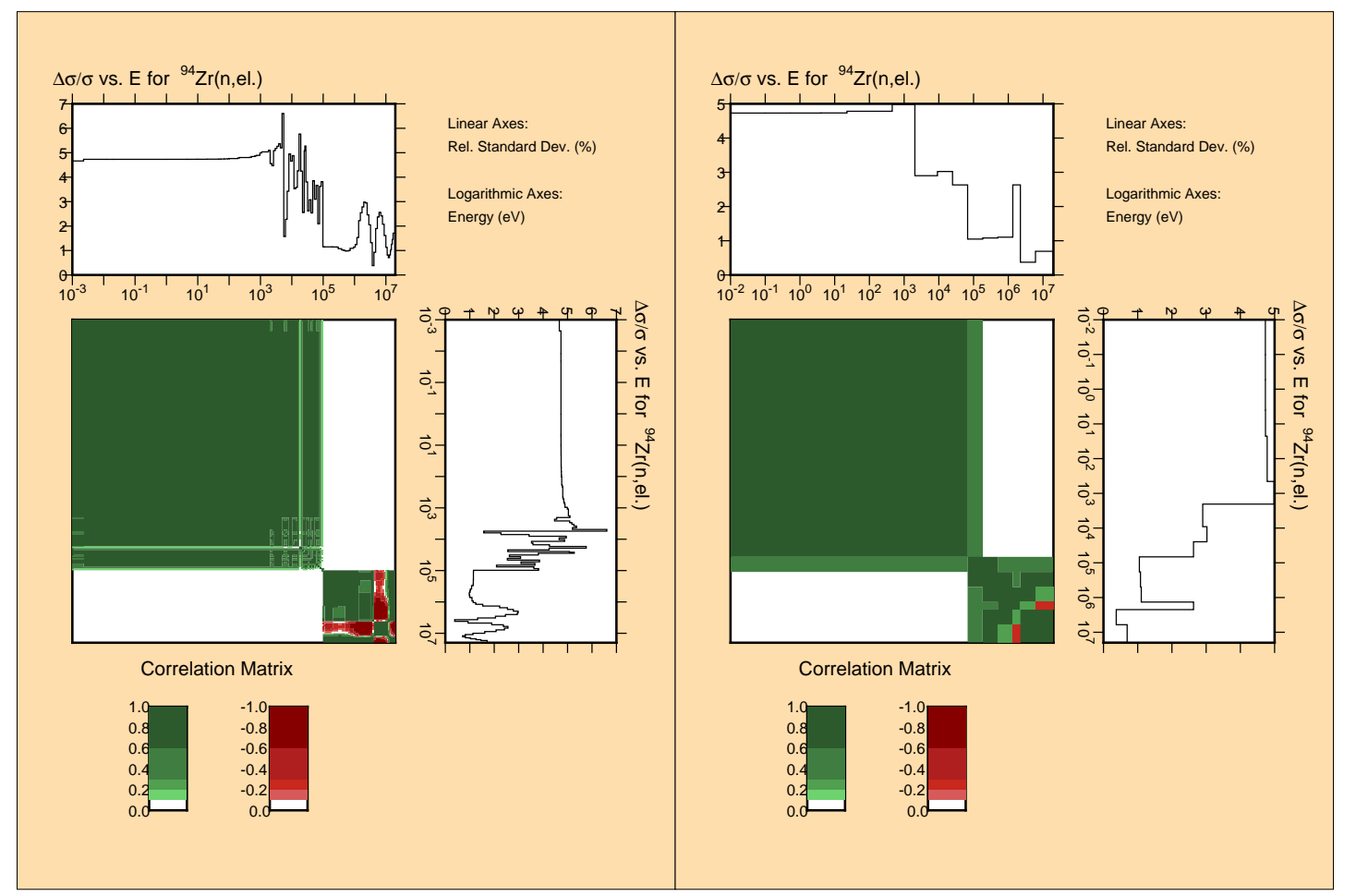

Figure A.48: Correlation and uncertainties in 187 (left) and 15 (right) groups for the ${ }^{94} \mathrm{Zr}(\mathrm{n}, \mathrm{el})$ reaction

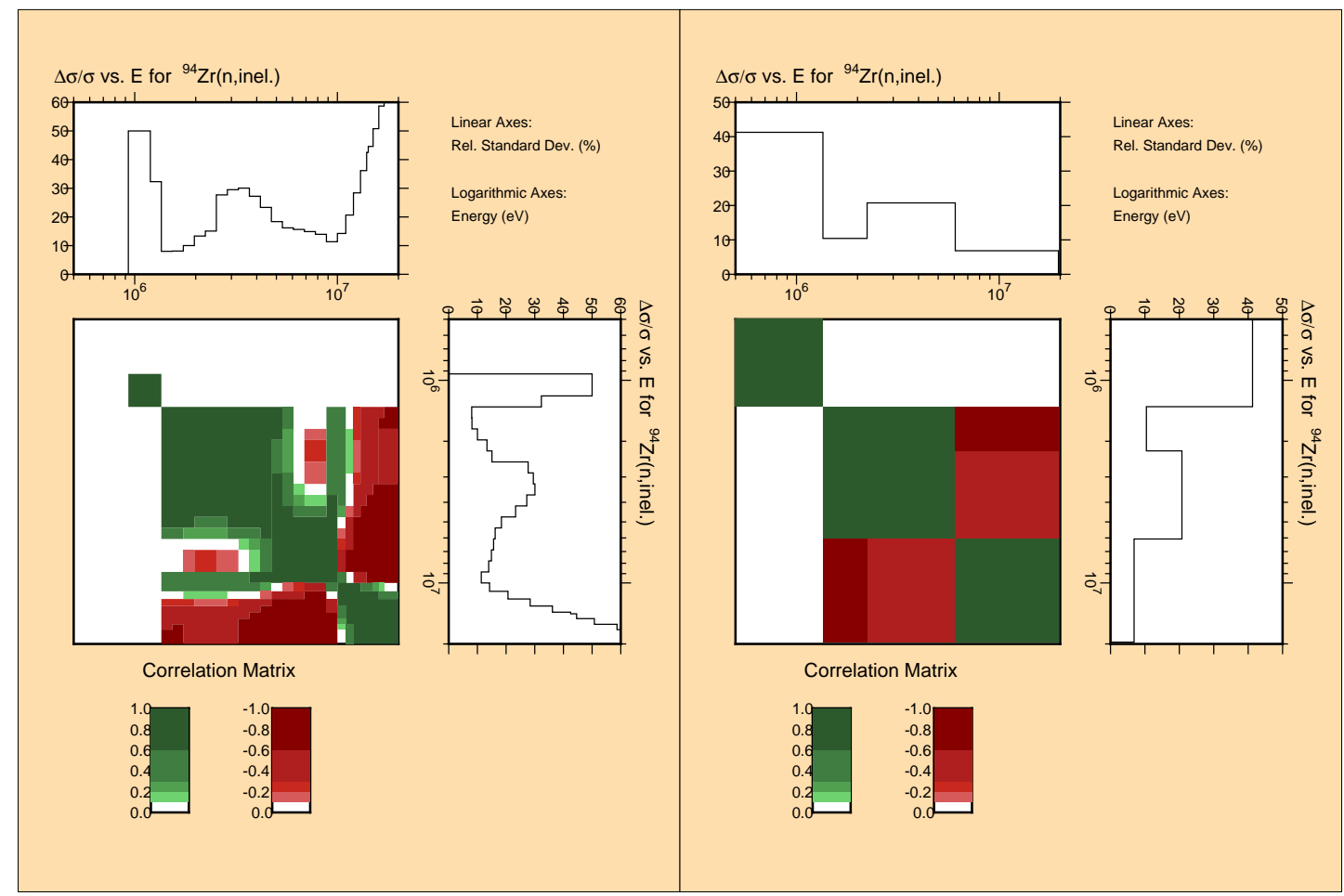

Figure A.49: Correlation and uncertainties in 187 (left) and 15 (right) groups for the ${ }^{94} \mathrm{Zr}\left(\mathrm{n}, \mathrm{n}^{\prime}\right)$ reaction 


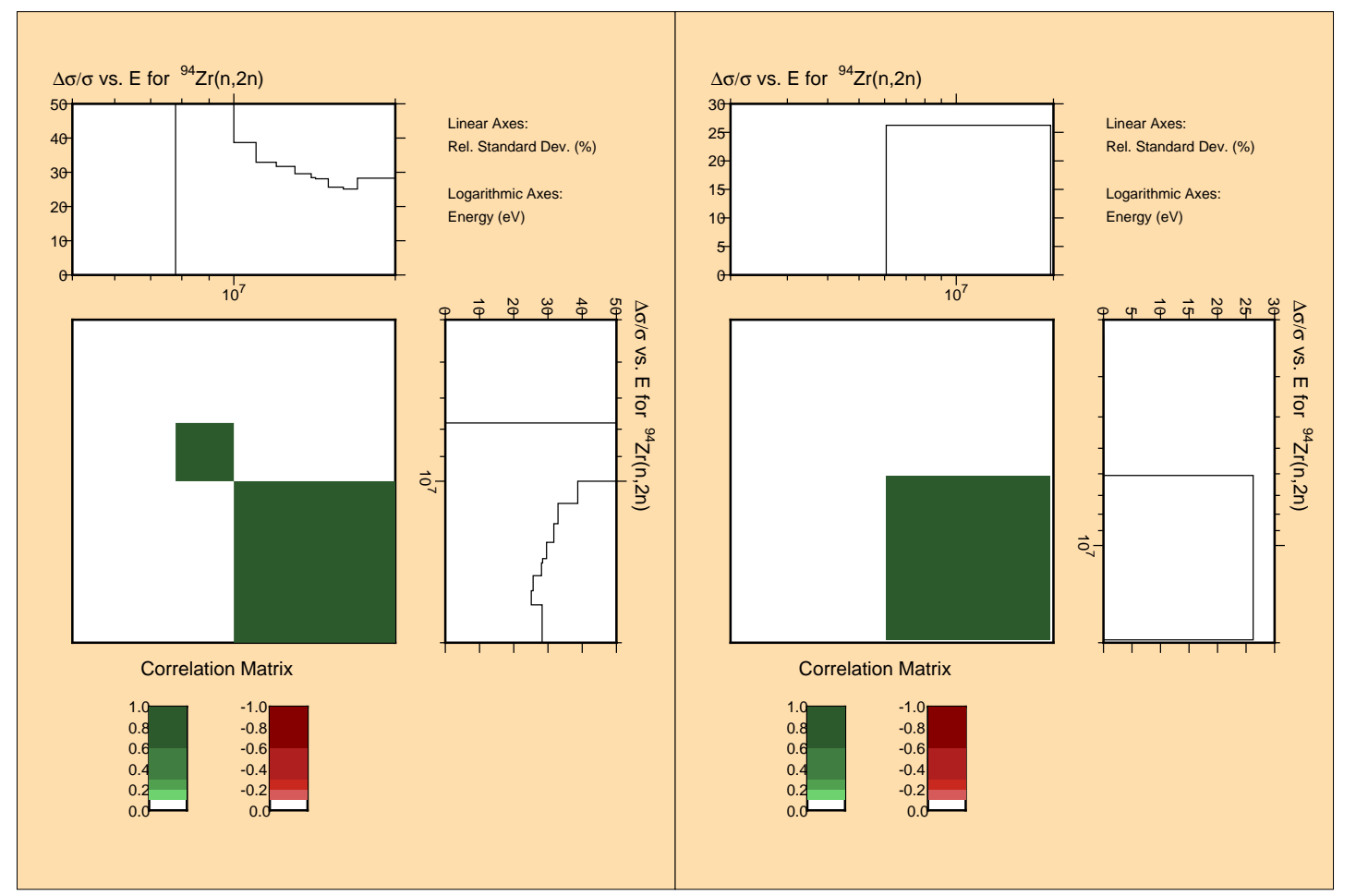

Figure A.50: Correlation and uncertainties in 187 (left) and 15 (right) groups for the ${ }^{94} \mathrm{Zr}(\mathrm{n}, 2 \mathrm{n})$ reaction

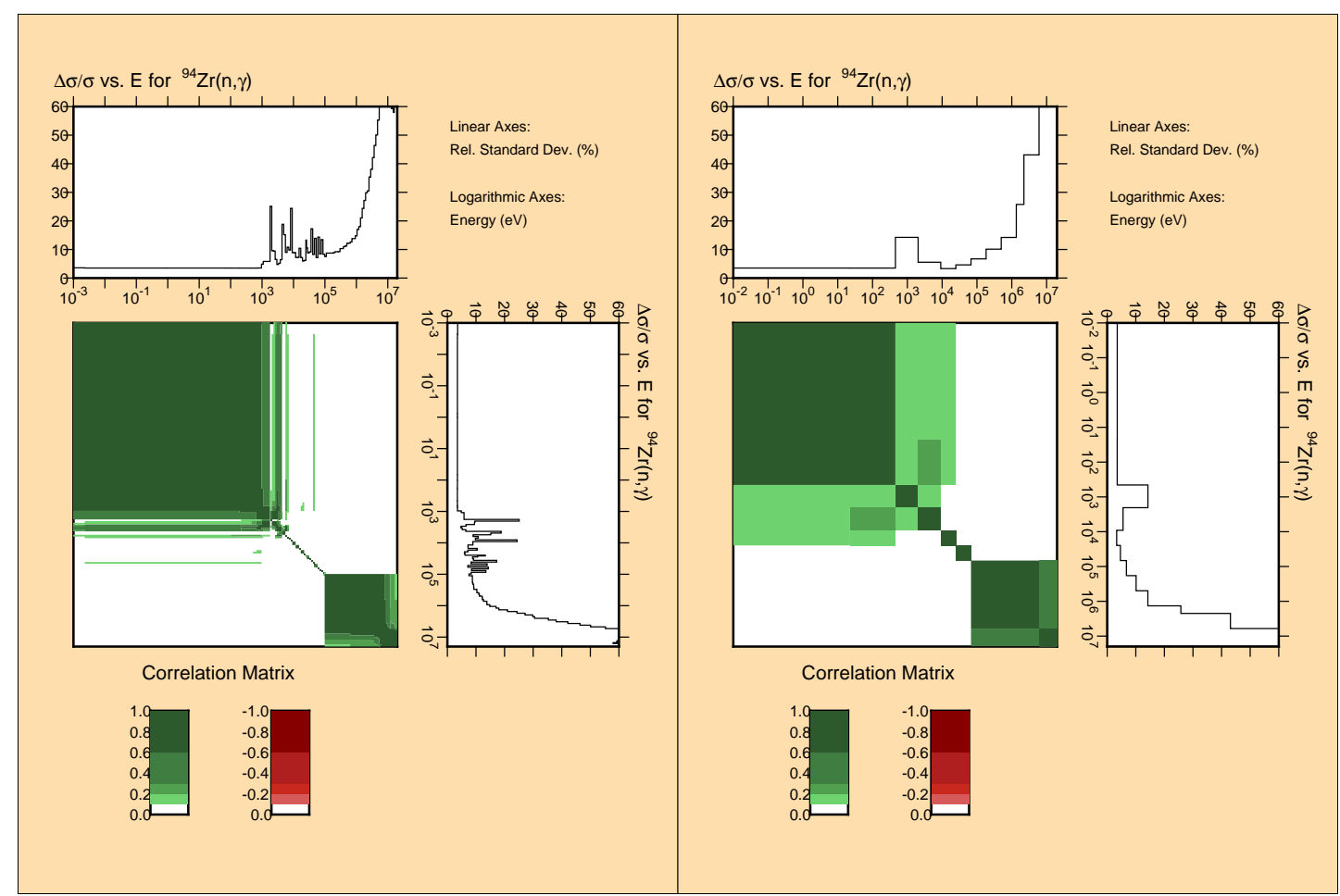

Figure A.51: Correlation and uncertainties in 187 (left) and 15 (right) groups for the ${ }^{94} \mathrm{Zr}(\mathrm{n}, \gamma)$ reaction 


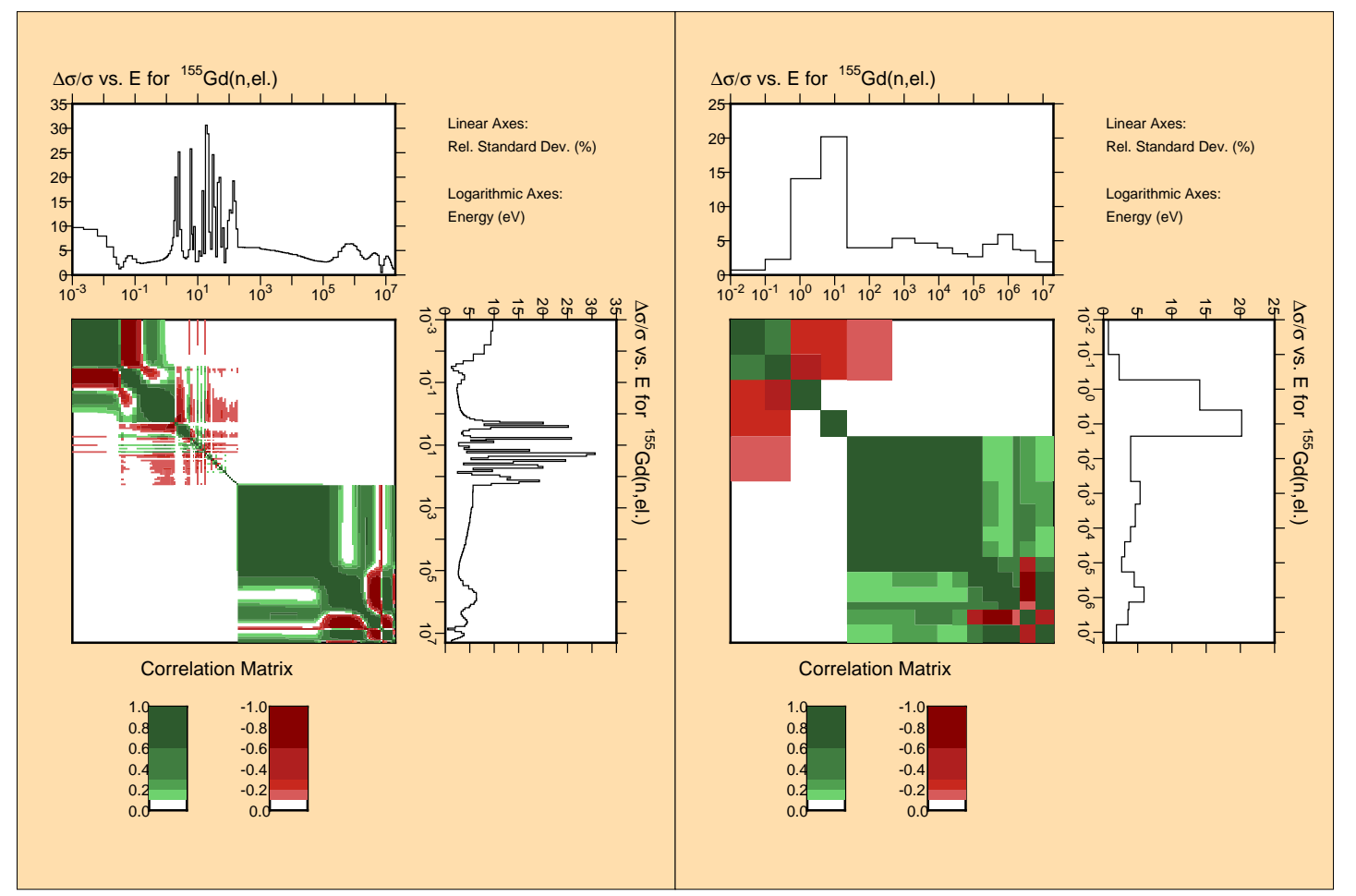

Figure A.52: Correlation and uncertainties in 187 (left) and 15 (right) groups for the ${ }^{155} \mathrm{Gd}(\mathrm{n}, \mathrm{el})$ reaction

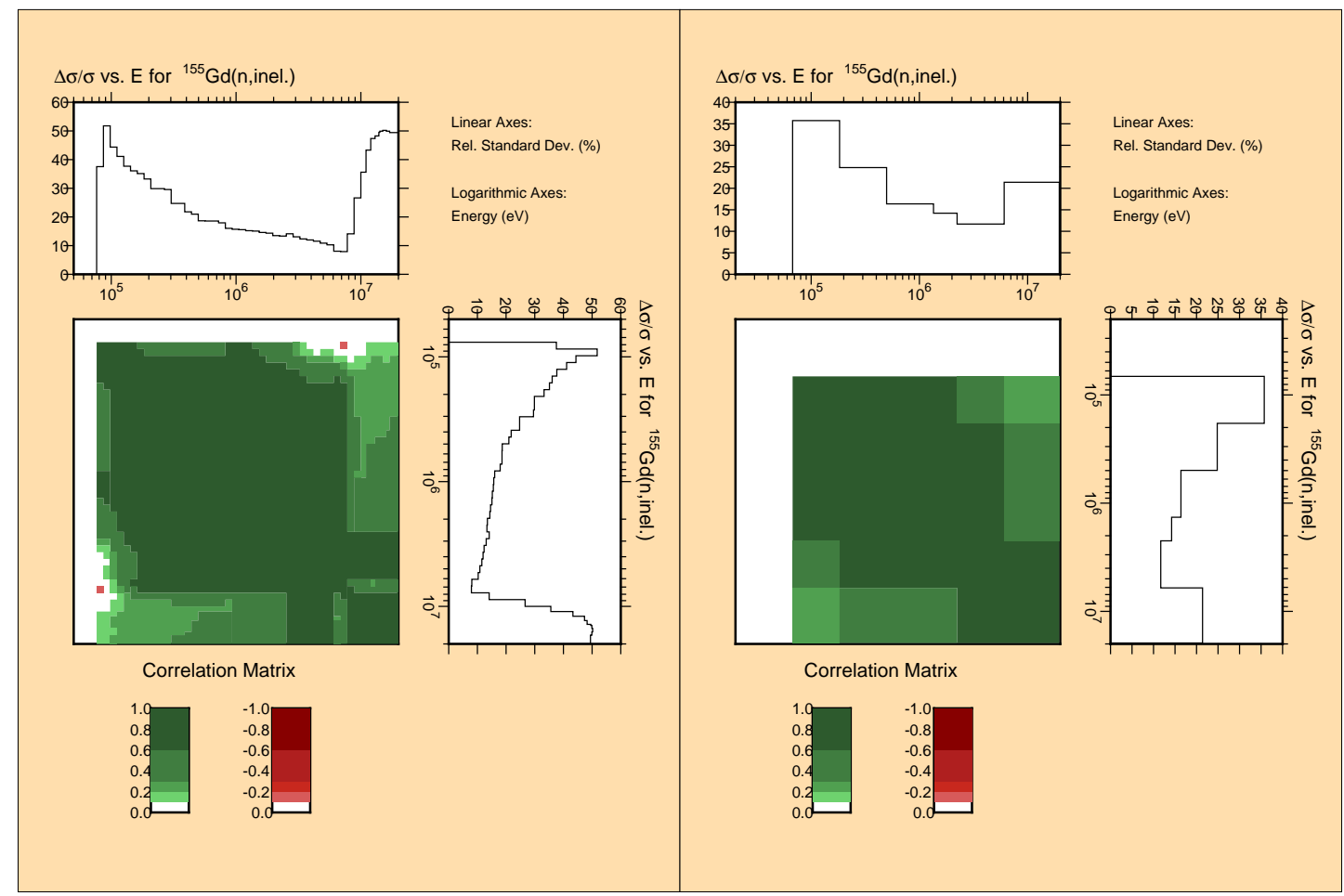

Figure A.53: Correlation and uncertainties in 187 (left) and 15 (right) groups for the ${ }^{155} \mathrm{Gd}\left(\mathrm{n}, \mathrm{n}^{\prime}\right)$ reaction 


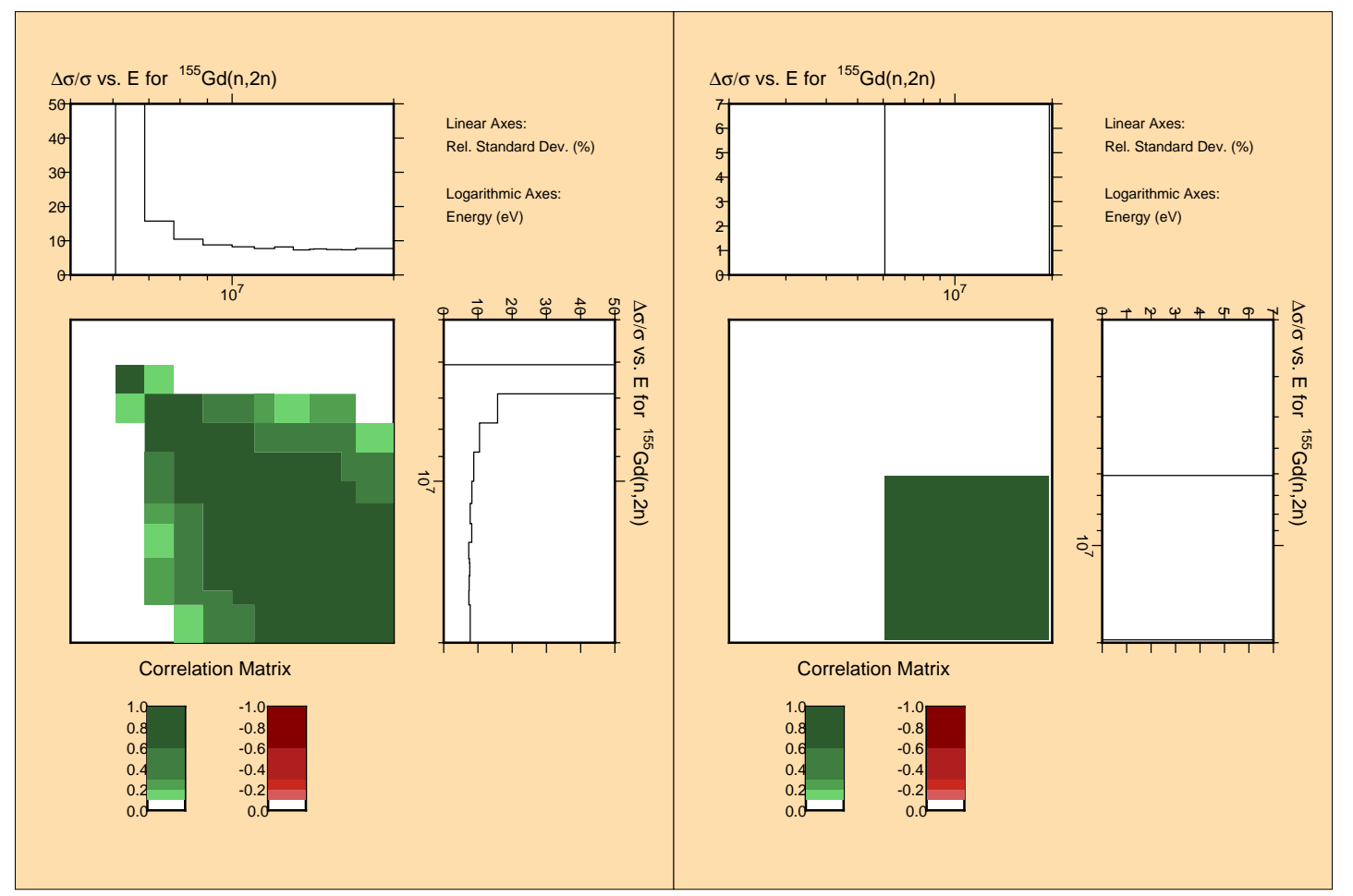

Figure A.54: Correlation and uncertainties in 187 (left) and 15 (right) groups for the ${ }^{155} \mathrm{Gd}(\mathrm{n}, 2 \mathrm{n})$ reaction

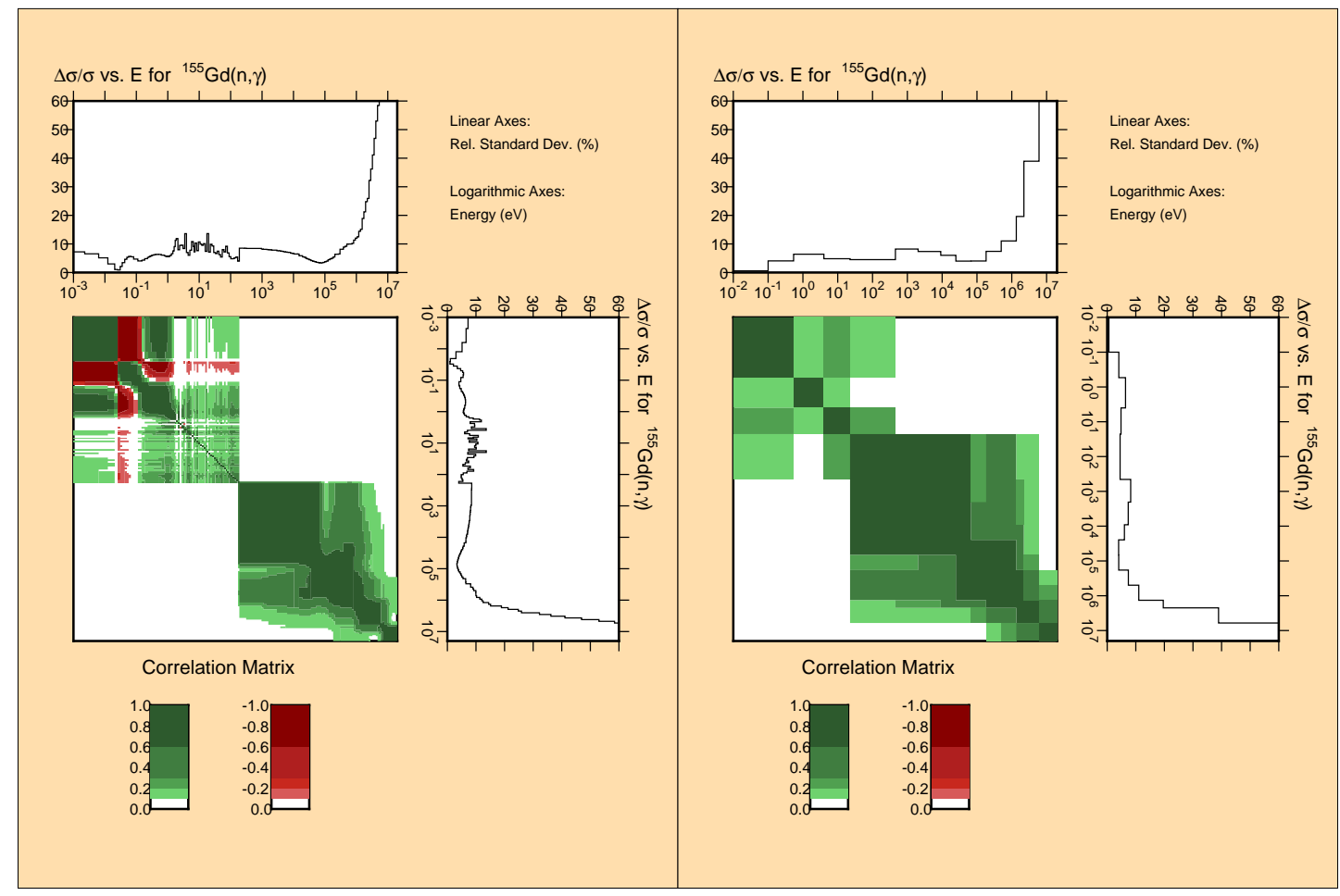

Figure A.55: Correlation and uncertainties in 187 (left) and 15 (right) groups for the ${ }^{155} \mathrm{Gd}(\mathrm{n}, \gamma)$ reaction 


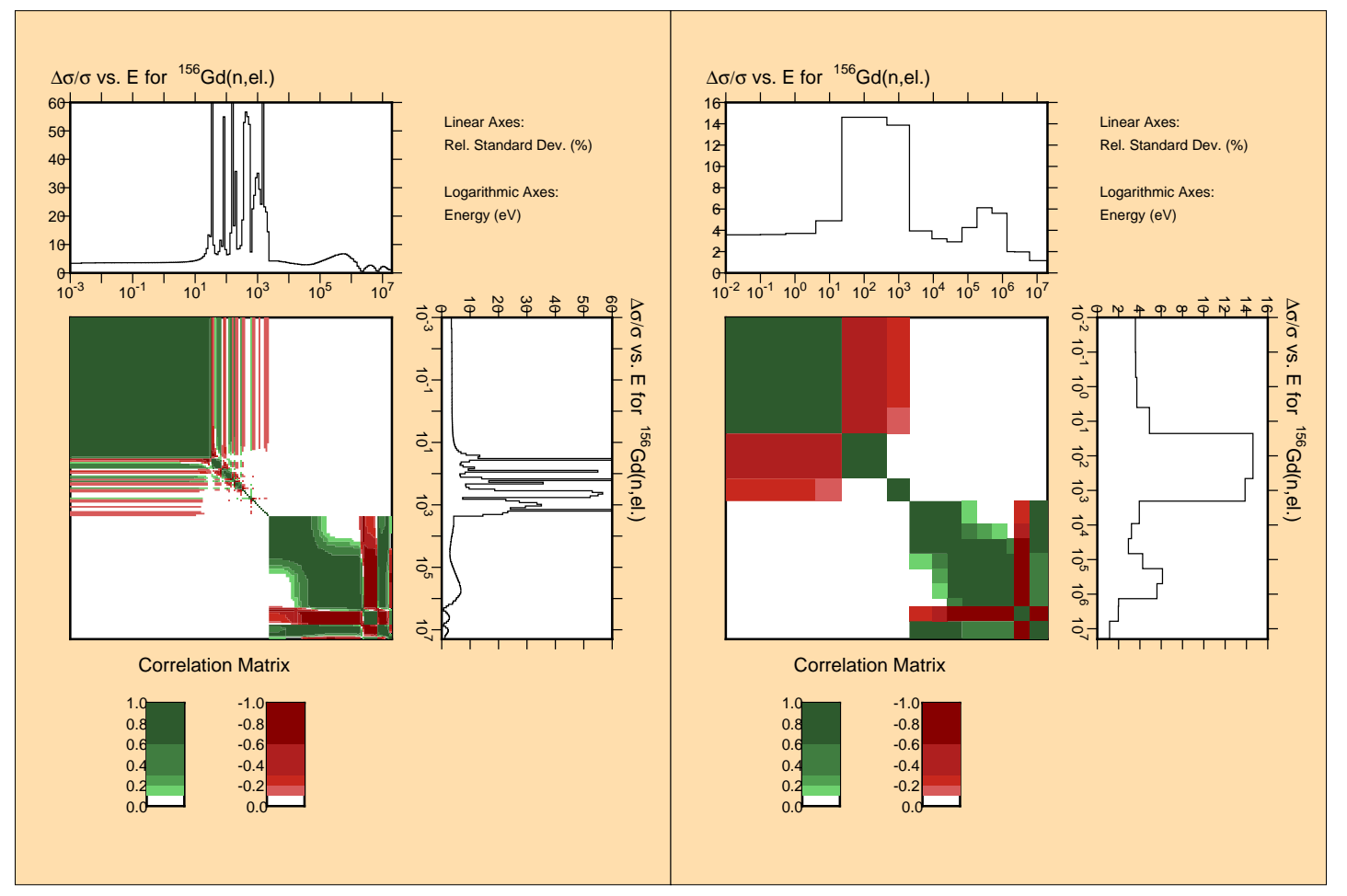

Figure A.56: Correlation and uncertainties in 187 (left) and 15 (right) groups for the ${ }^{156} \mathrm{Gd}(\mathrm{n}, \mathrm{el})$ reaction

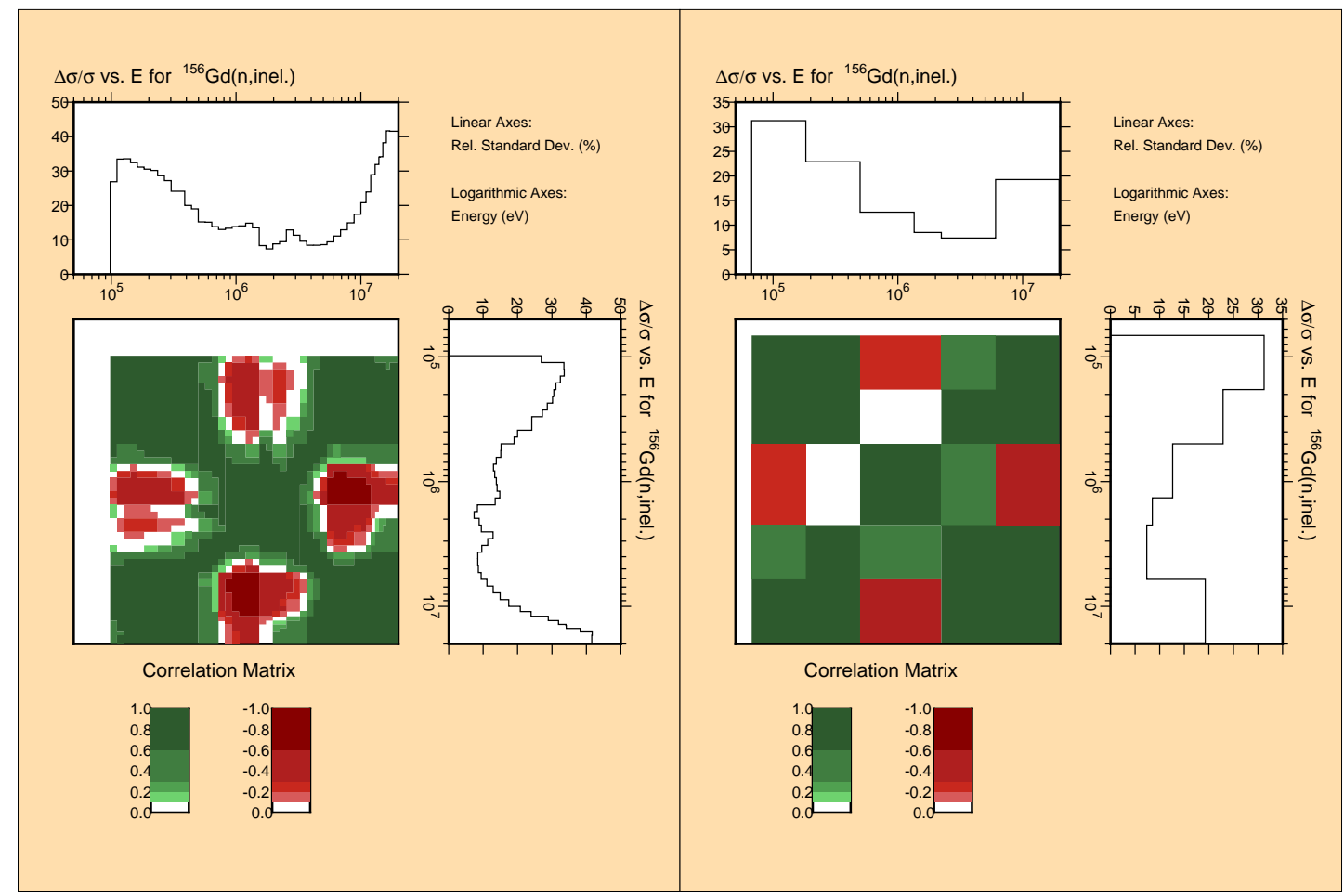

Figure A.57: Correlation and uncertainties in 187 (left) and 15 (right) groups for the ${ }^{156} \mathrm{Gd}\left(\mathrm{n}, \mathrm{n}^{\prime}\right)$ reaction 


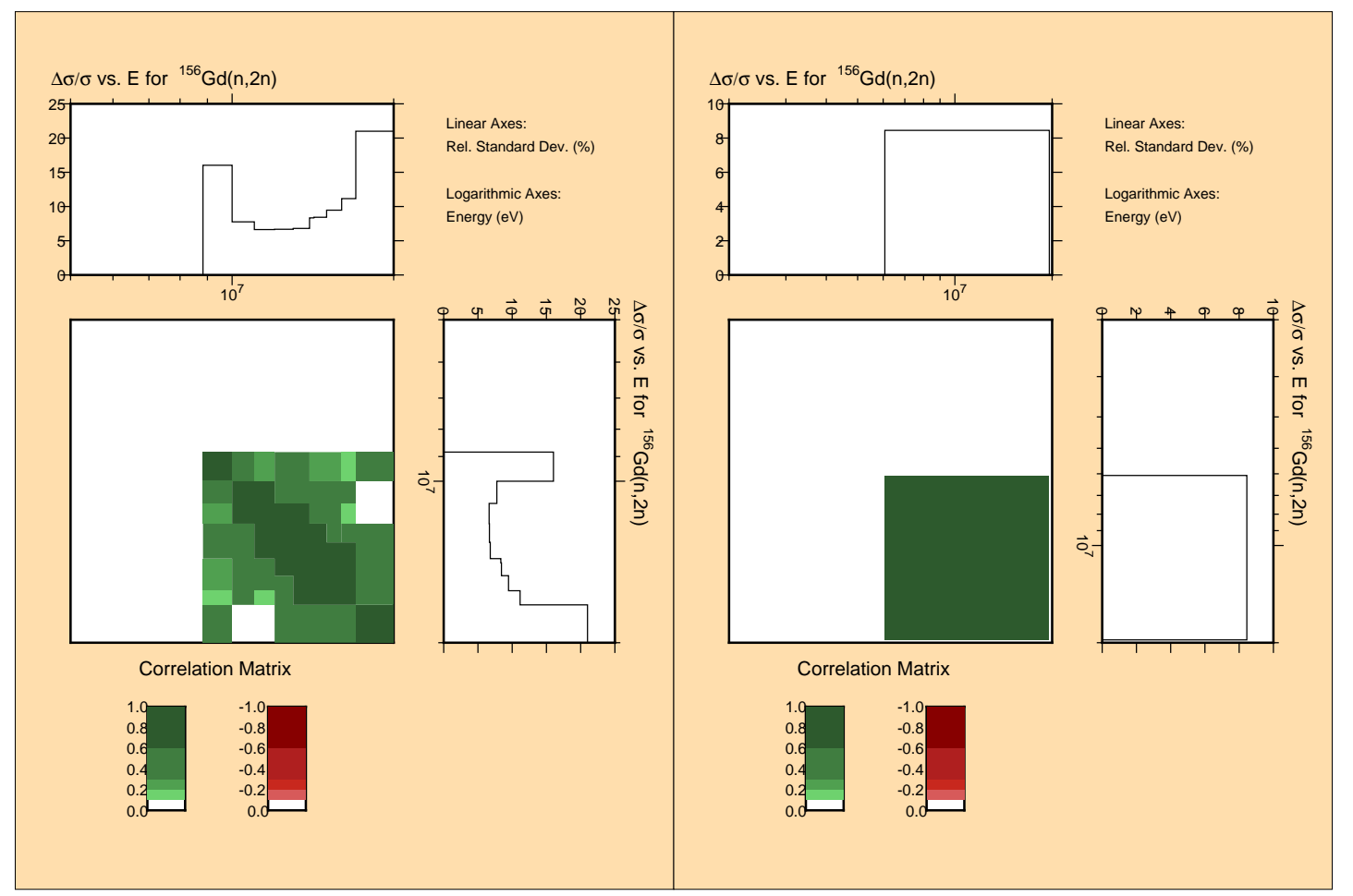

Figure A.58: Correlation and uncertainties in 187 (left) and 15 (right) groups for the ${ }^{156} \mathrm{Gd}(\mathrm{n}, 2 \mathrm{n})$ reaction

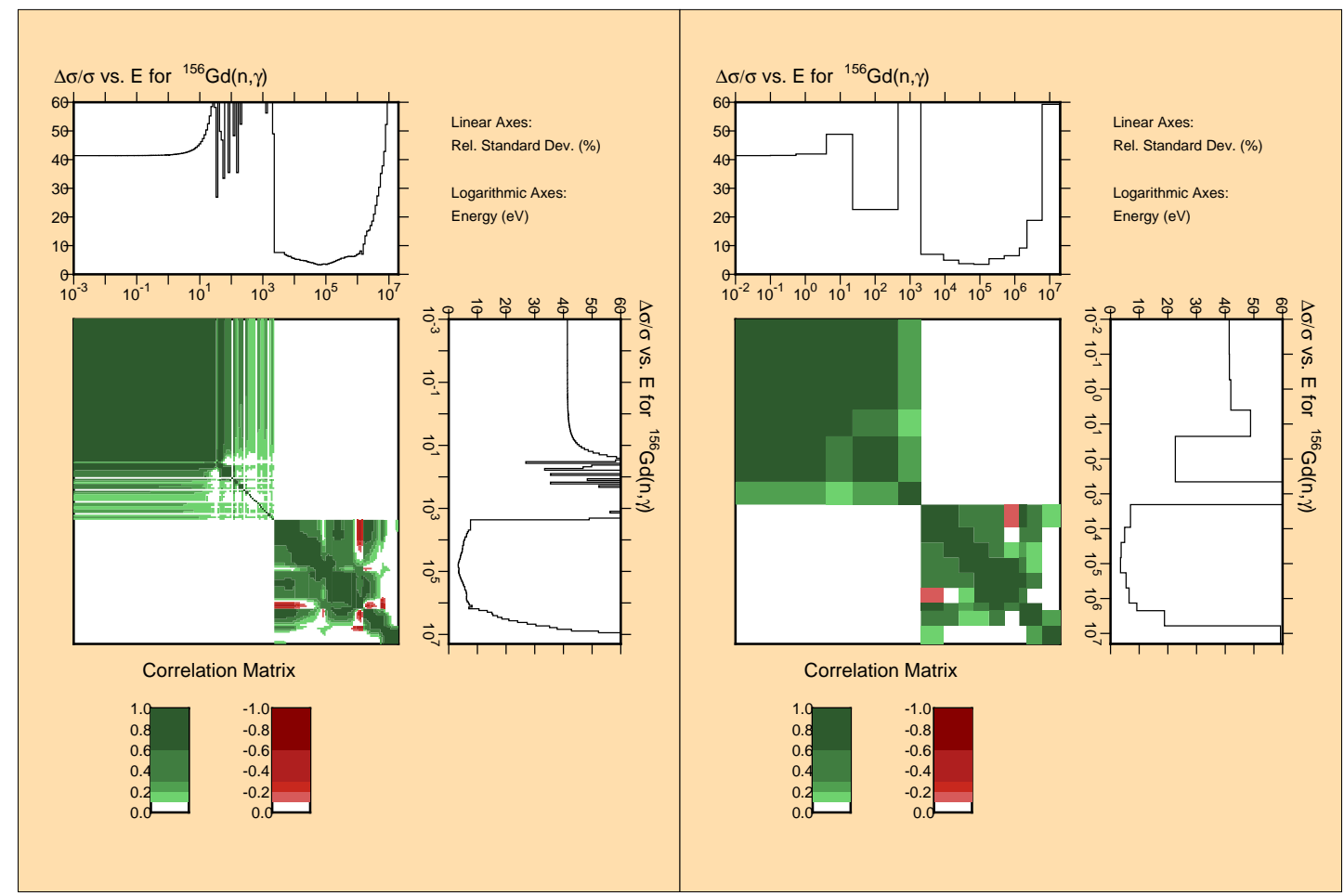

Figure A.59: Correlation and uncertainties in 187 (left) and 15 (right) groups for the ${ }^{156} \mathrm{Gd}(\mathrm{n}, \gamma)$ reaction 


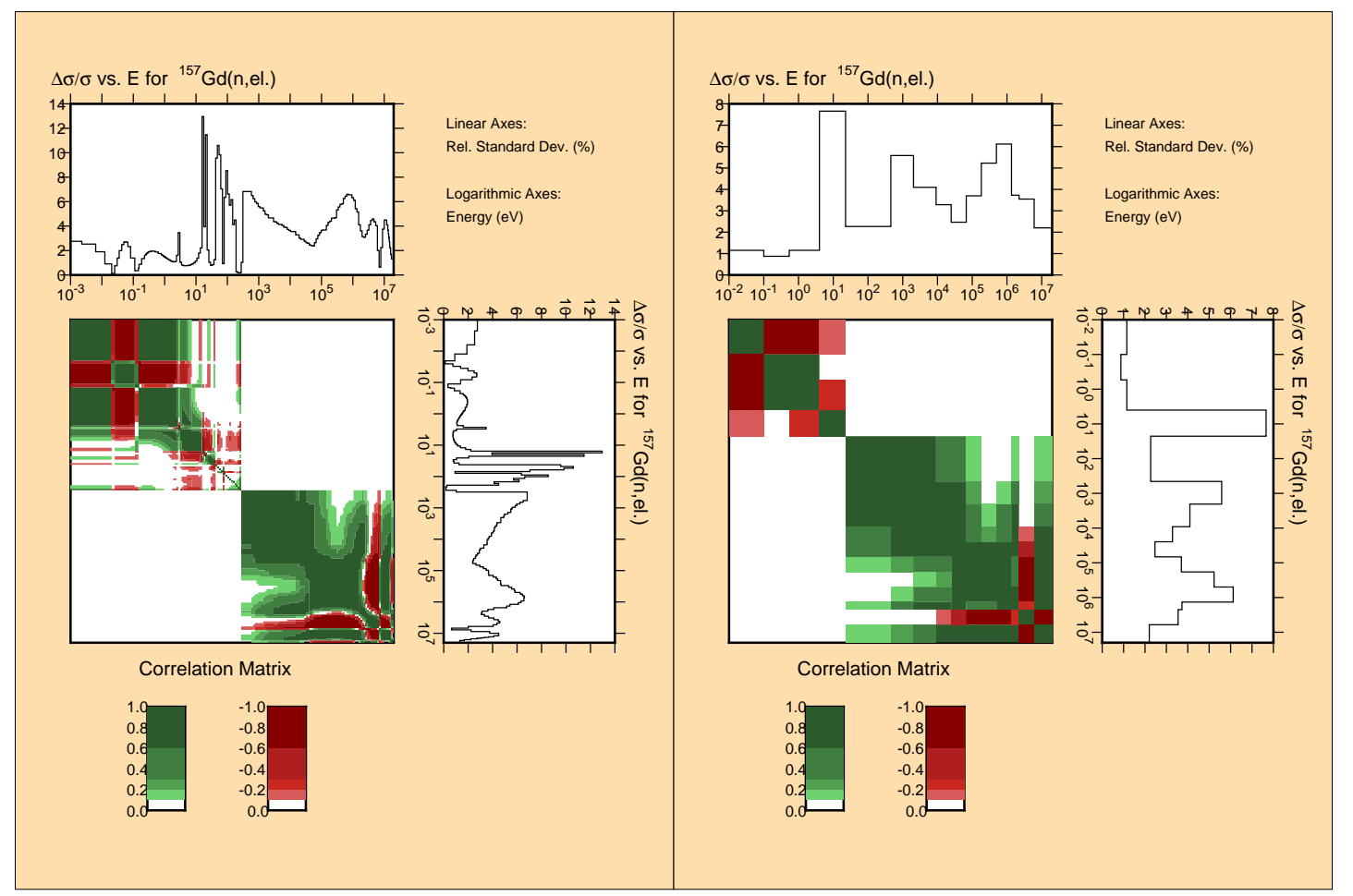

Figure A.60: Correlation and uncertainties in 187 (left) and 15 (right) groups for the ${ }^{157} \mathrm{Gd}(\mathrm{n}, \mathrm{el})$ reaction

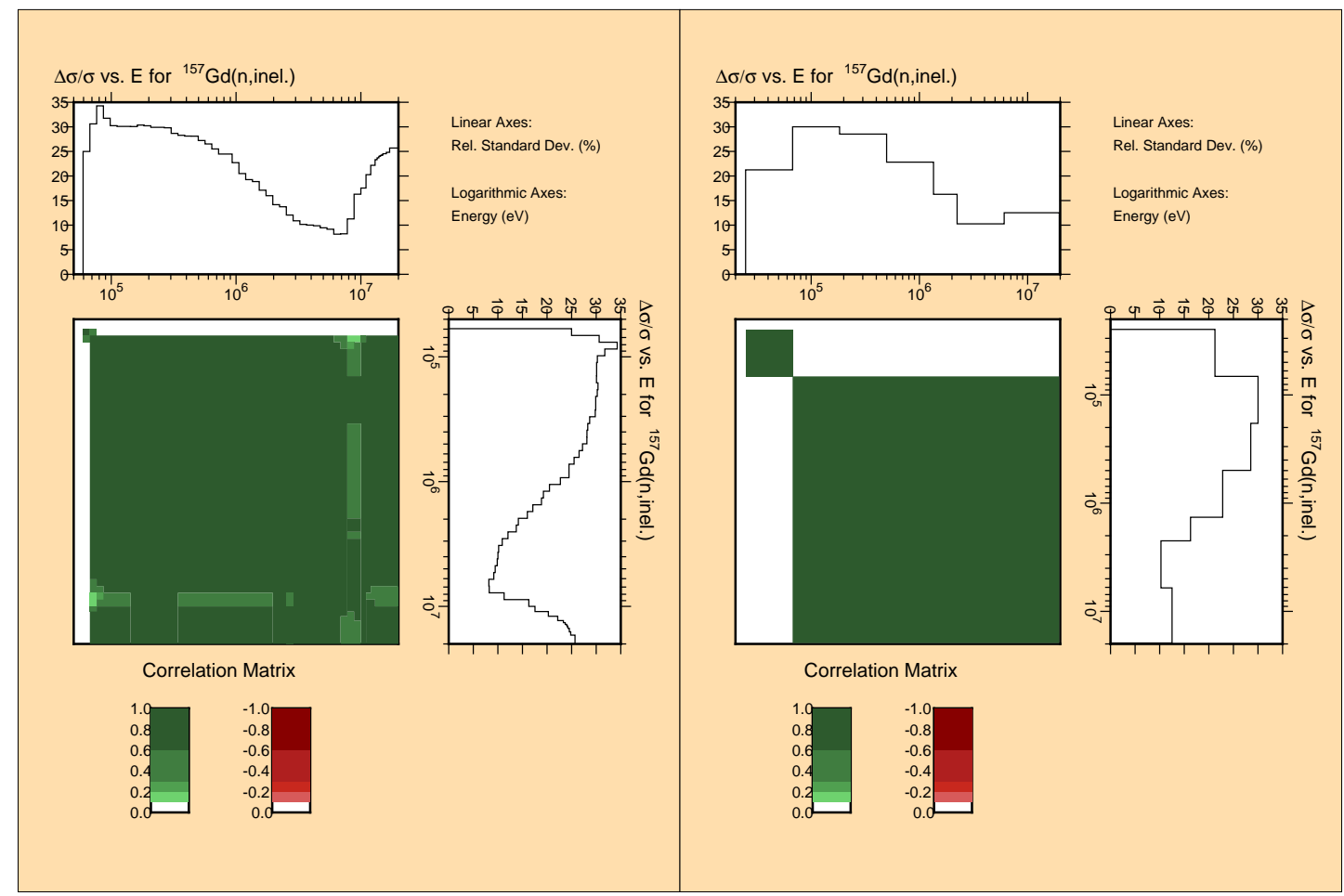

Figure A.61: Correlation and uncertainties in 187 (left) and 15 (right) groups for the ${ }^{157} \mathrm{Gd}\left(\mathrm{n}, \mathrm{n}^{\prime}\right)$ reaction 


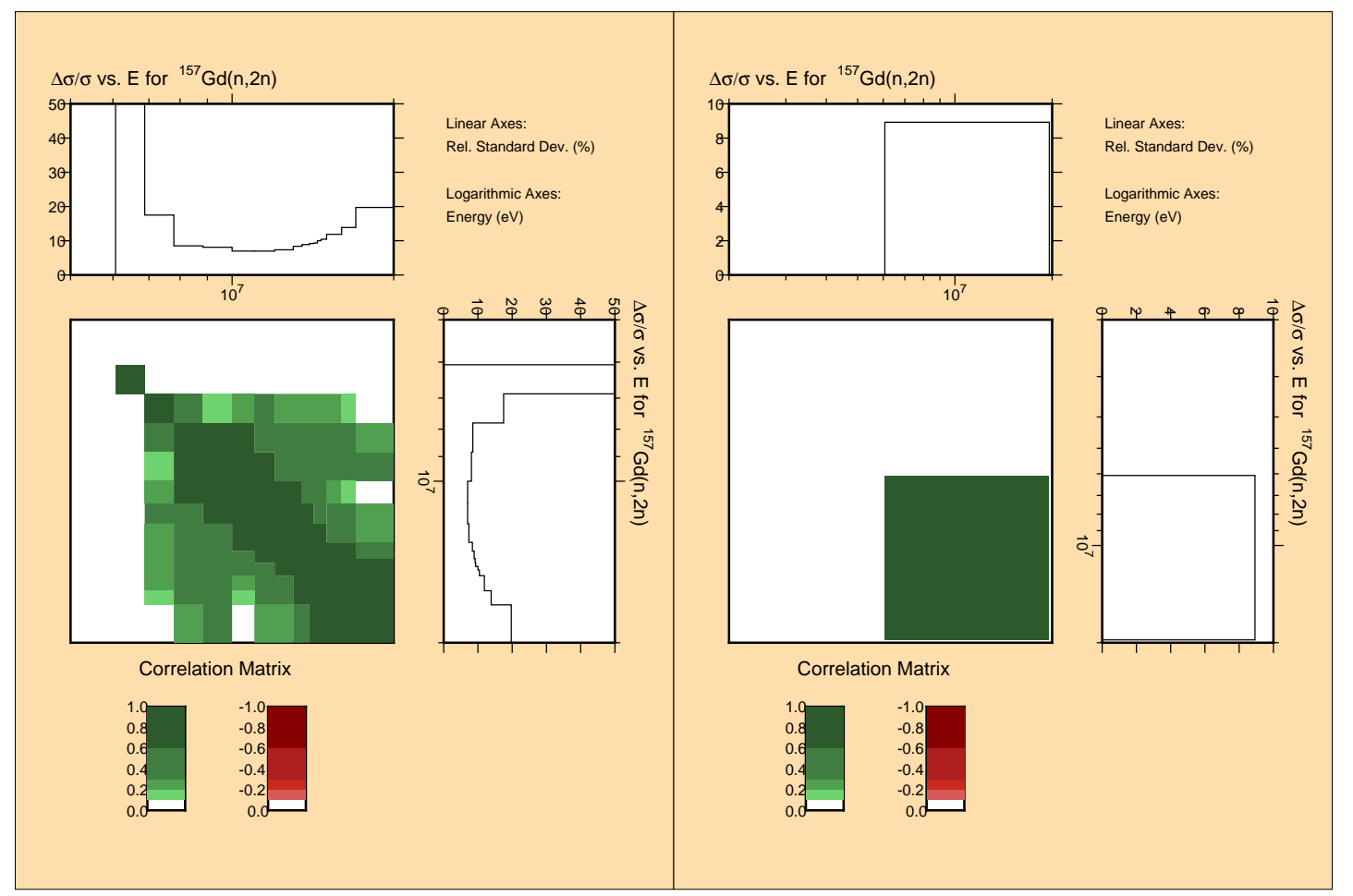

Figure A.62: Correlation and uncertainties in 187 (left) and 15 (right) groups for the ${ }^{157} \mathrm{Gd}(\mathrm{n}, 2 \mathrm{n})$ reaction

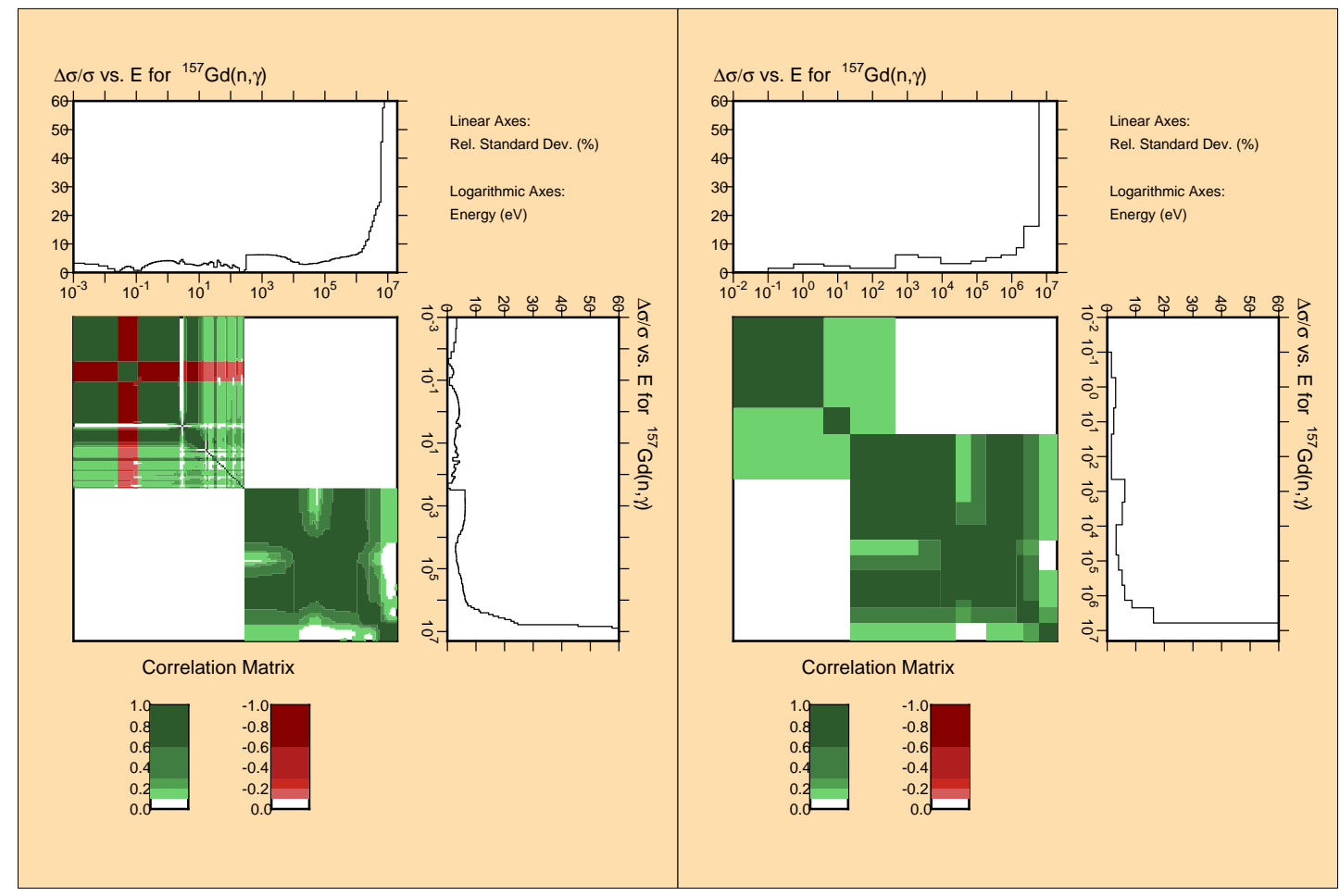

Figure A.63: Correlation and uncertainties in 187 (left) and 15 (right) groups for the ${ }^{157} \mathrm{Gd}(\mathrm{n}, \gamma)$ reaction

D. Rochman et al. 


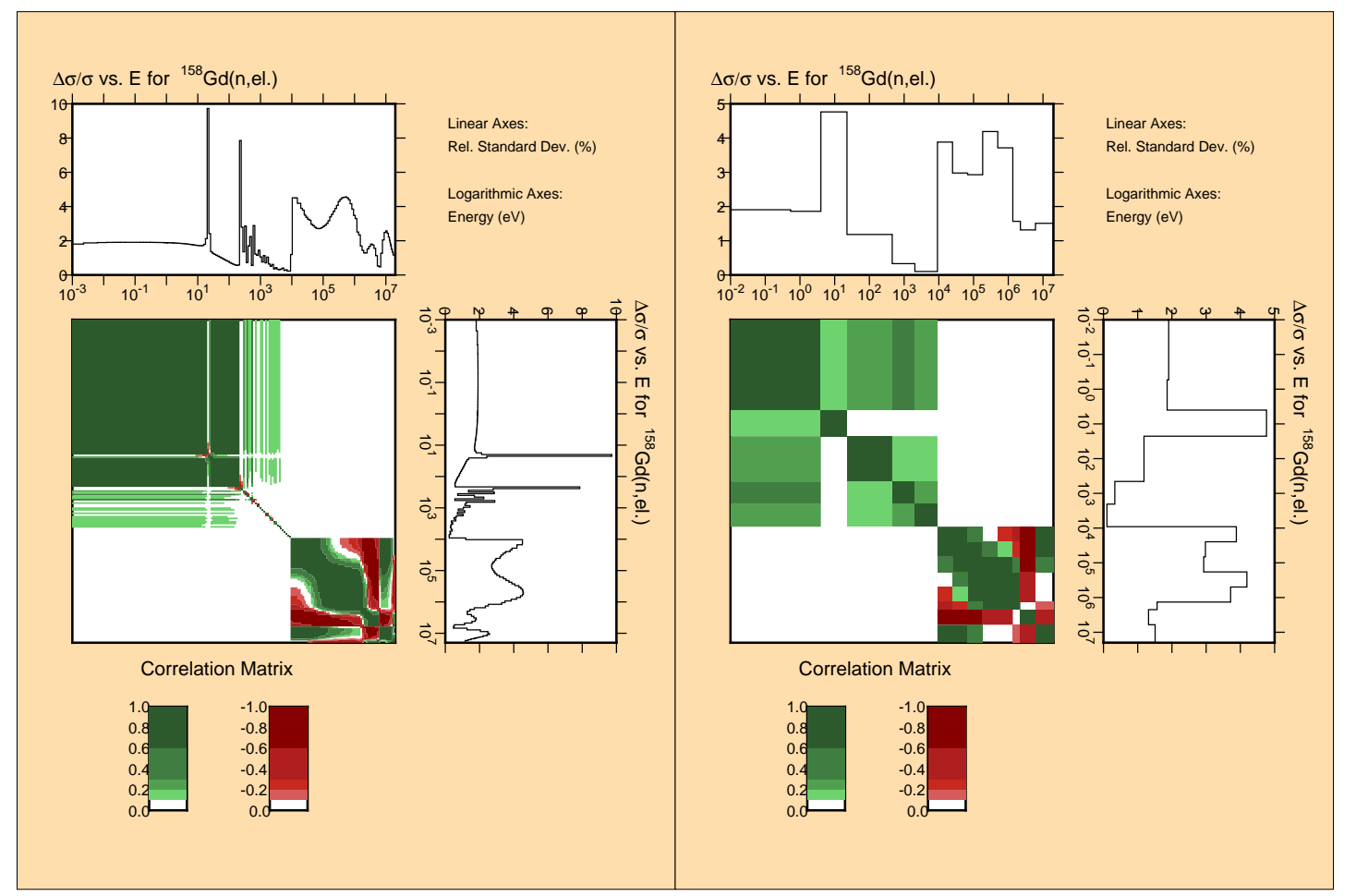

Figure A.64: Correlation and uncertainties in 187 (left) and 15 (right) groups for the ${ }^{158} \mathrm{Gd}(\mathrm{n}, \mathrm{el})$ reaction

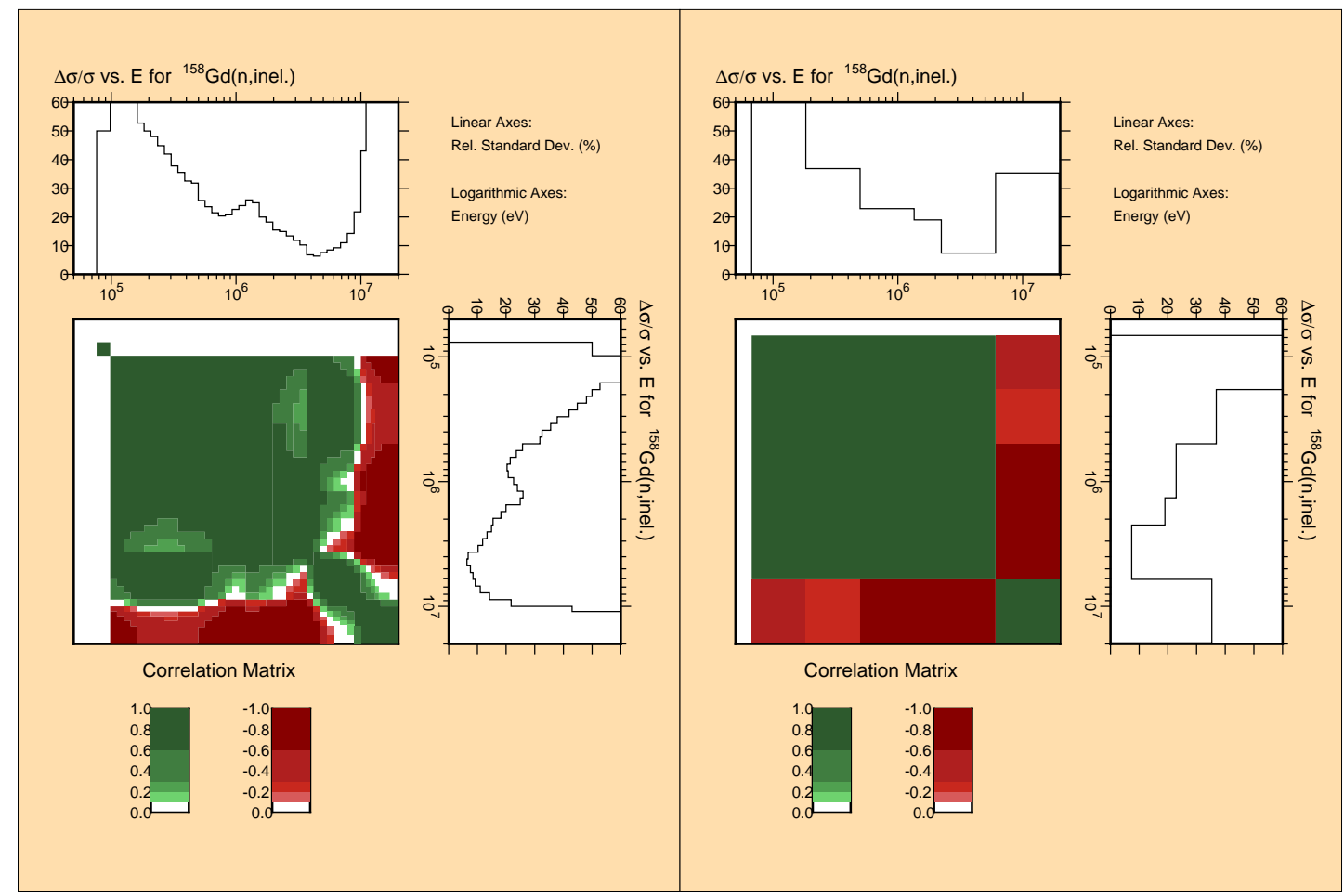

Figure A.65: Correlation and uncertainties in 187 (left) and 15 (right) groups for the ${ }^{158} \mathrm{Gd}\left(\mathrm{n}, \mathrm{n}^{\prime}\right)$ reaction 


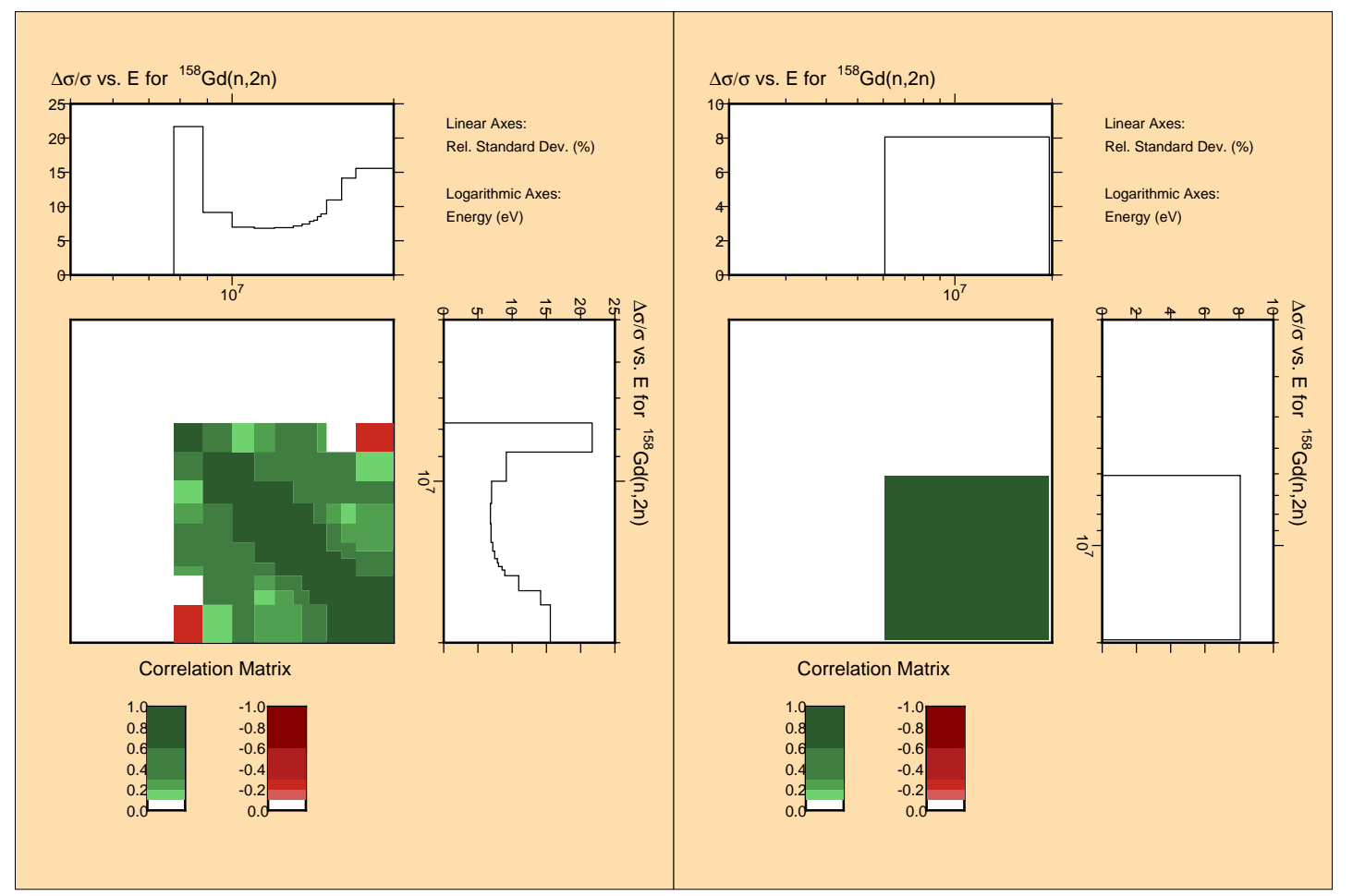

Figure A.66: Correlation and uncertainties in 187 (left) and 15 (right) groups for the ${ }^{158} \mathrm{Gd}(\mathrm{n}, 2 \mathrm{n})$ reaction

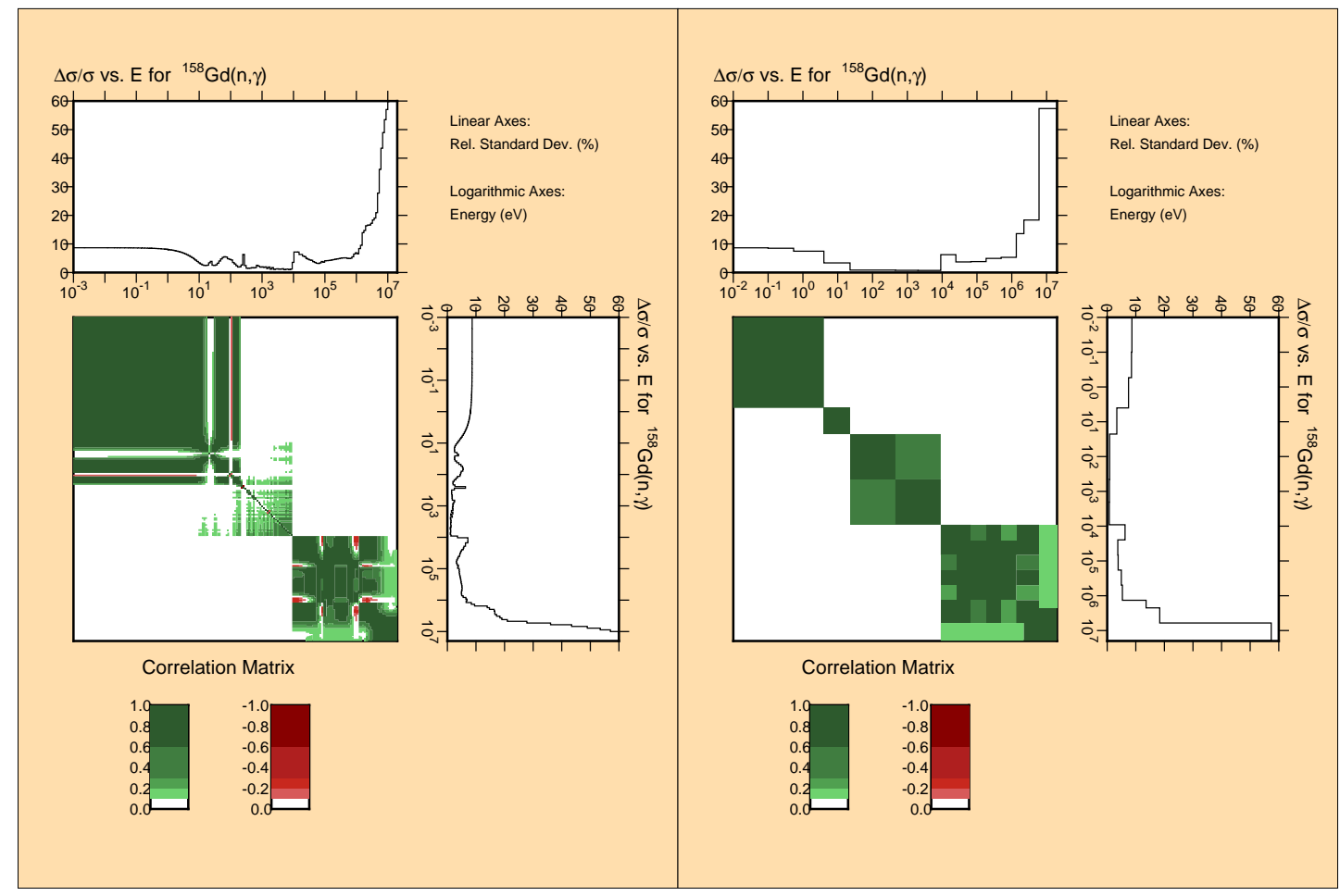

Figure A.67: Correlation and uncertainties in 187 (left) and 15 (right) groups for the ${ }^{158} \mathrm{Gd}(\mathrm{n}, \gamma)$ reaction 


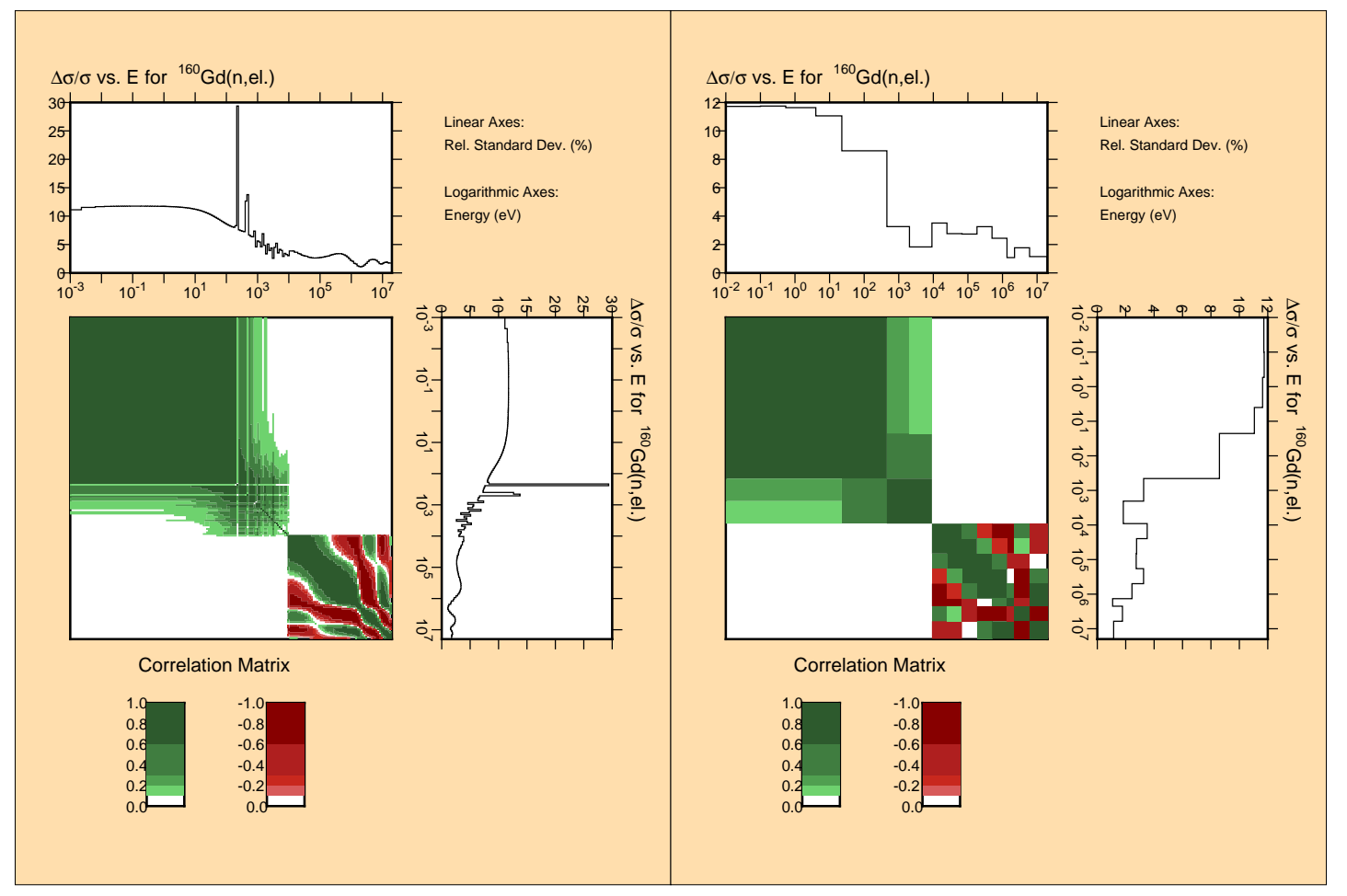

Figure A.68: Correlation and uncertainties in 187 (left) and 15 (right) groups for the ${ }^{160} \mathrm{Gd}(\mathrm{n}, \mathrm{el})$ reaction

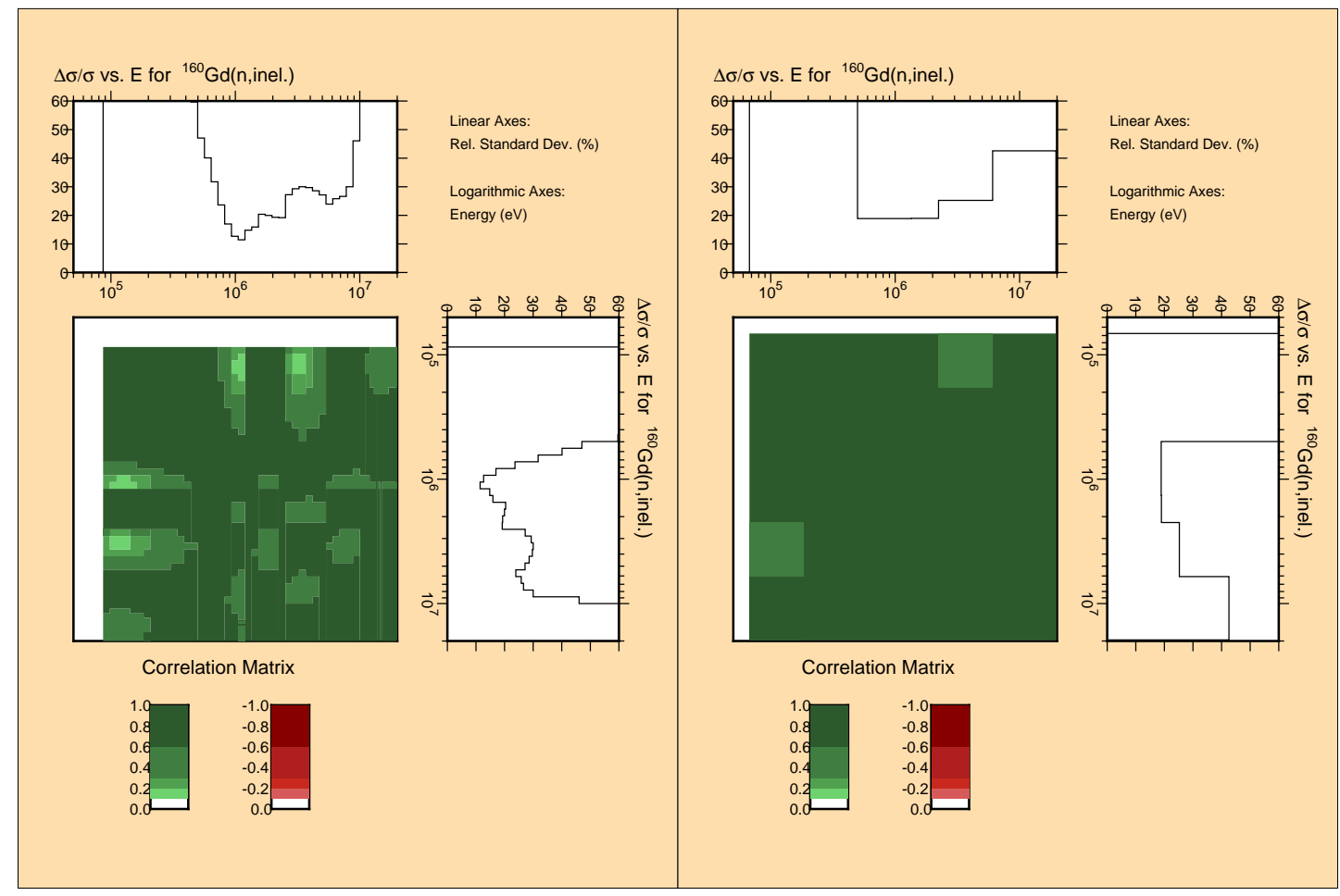

Figure A.69: Correlation and uncertainties in 187 (left) and 15 (right) groups for the ${ }^{160} \mathrm{Gd}\left(\mathrm{n}, \mathrm{n}^{\prime}\right)$ reaction 


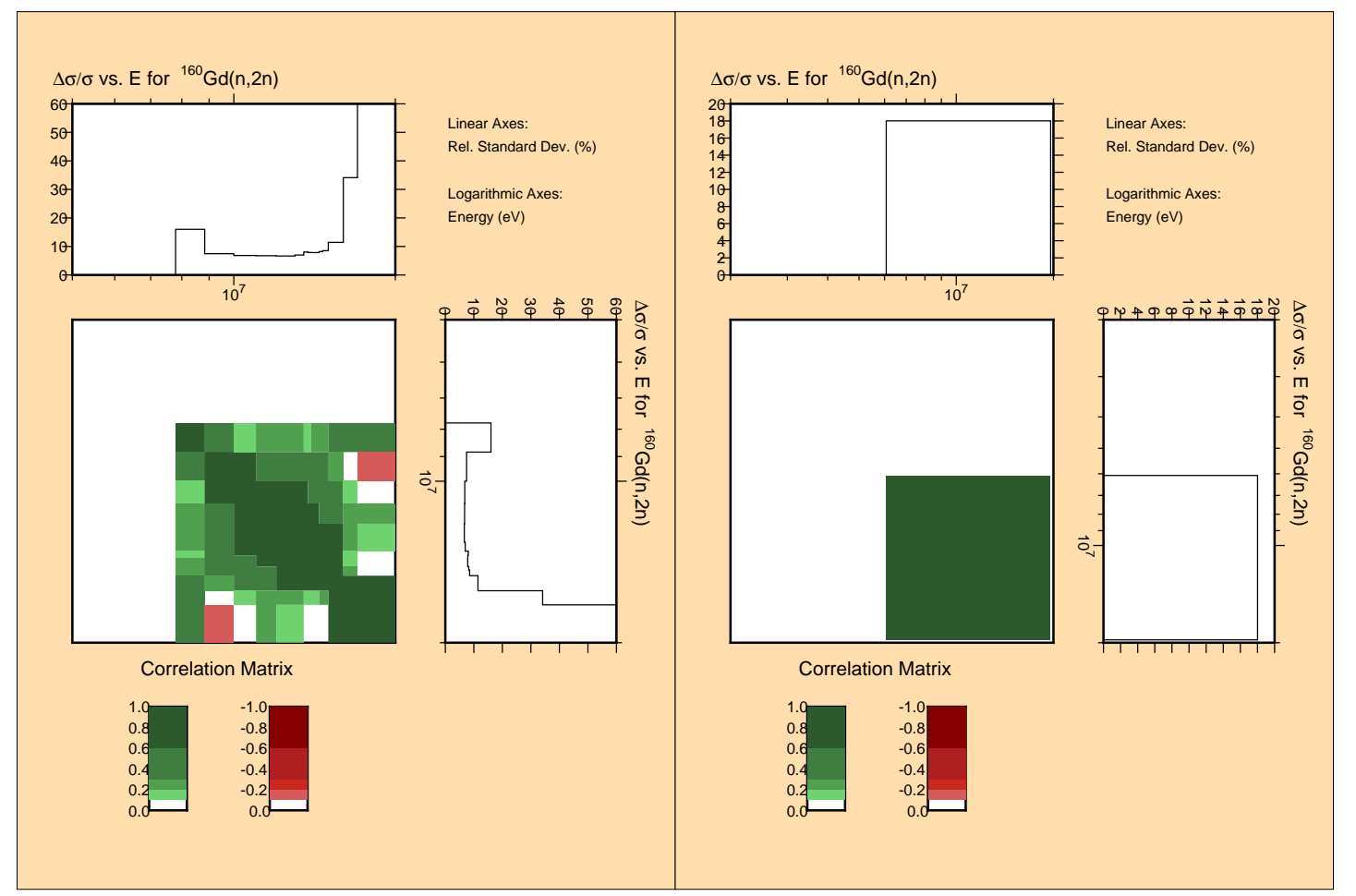

Figure A.70: Correlation and uncertainties in 187 (left) and 15 (right) groups for the ${ }^{160} \mathrm{Gd}(\mathrm{n}, 2 \mathrm{n})$ reaction

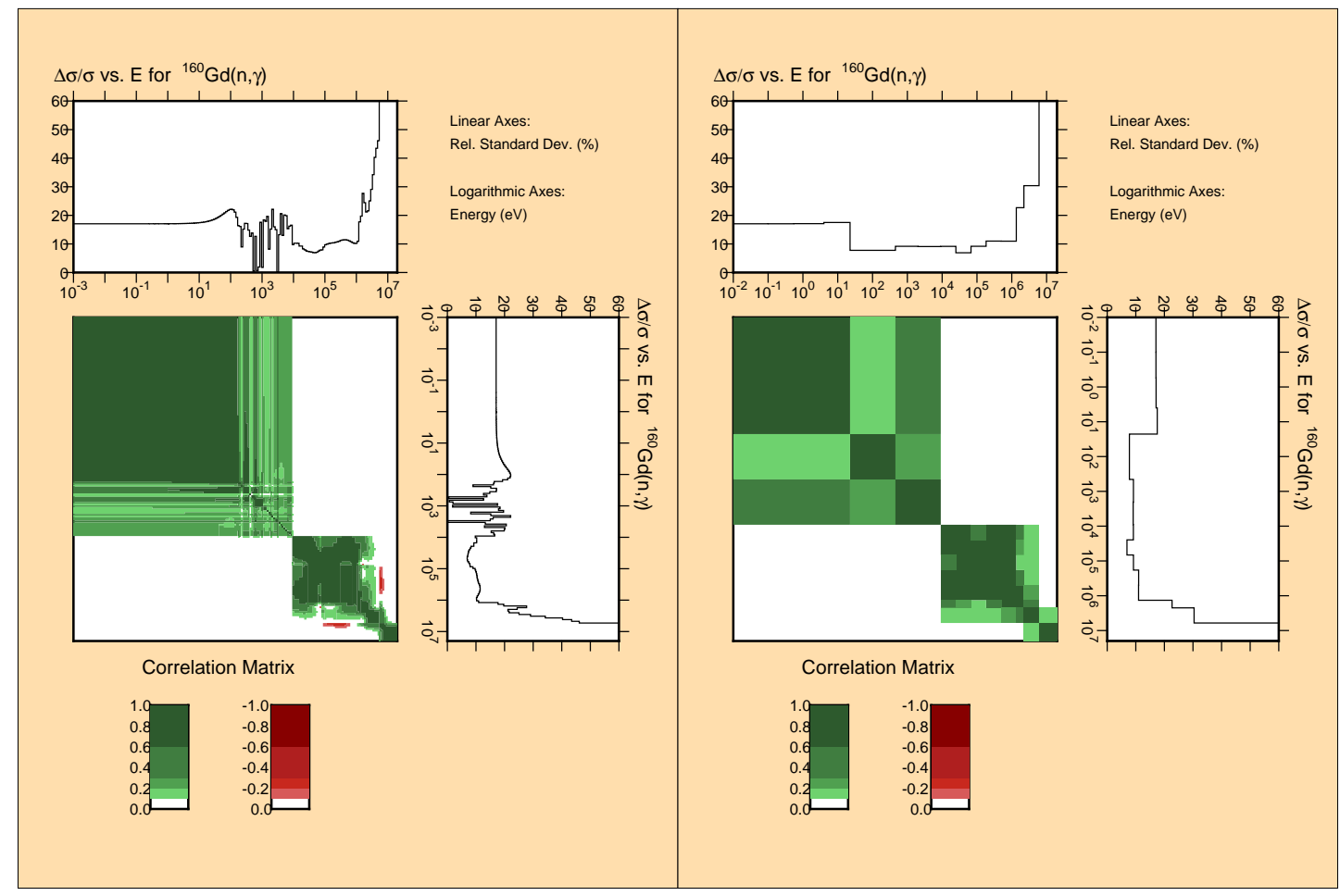

Figure A.71: Correlation and uncertainties in 187 (left) and 15 (right) groups for the ${ }^{160} \mathrm{Gd}(\mathrm{n}, \gamma)$ reaction

D. Rochman et al. 


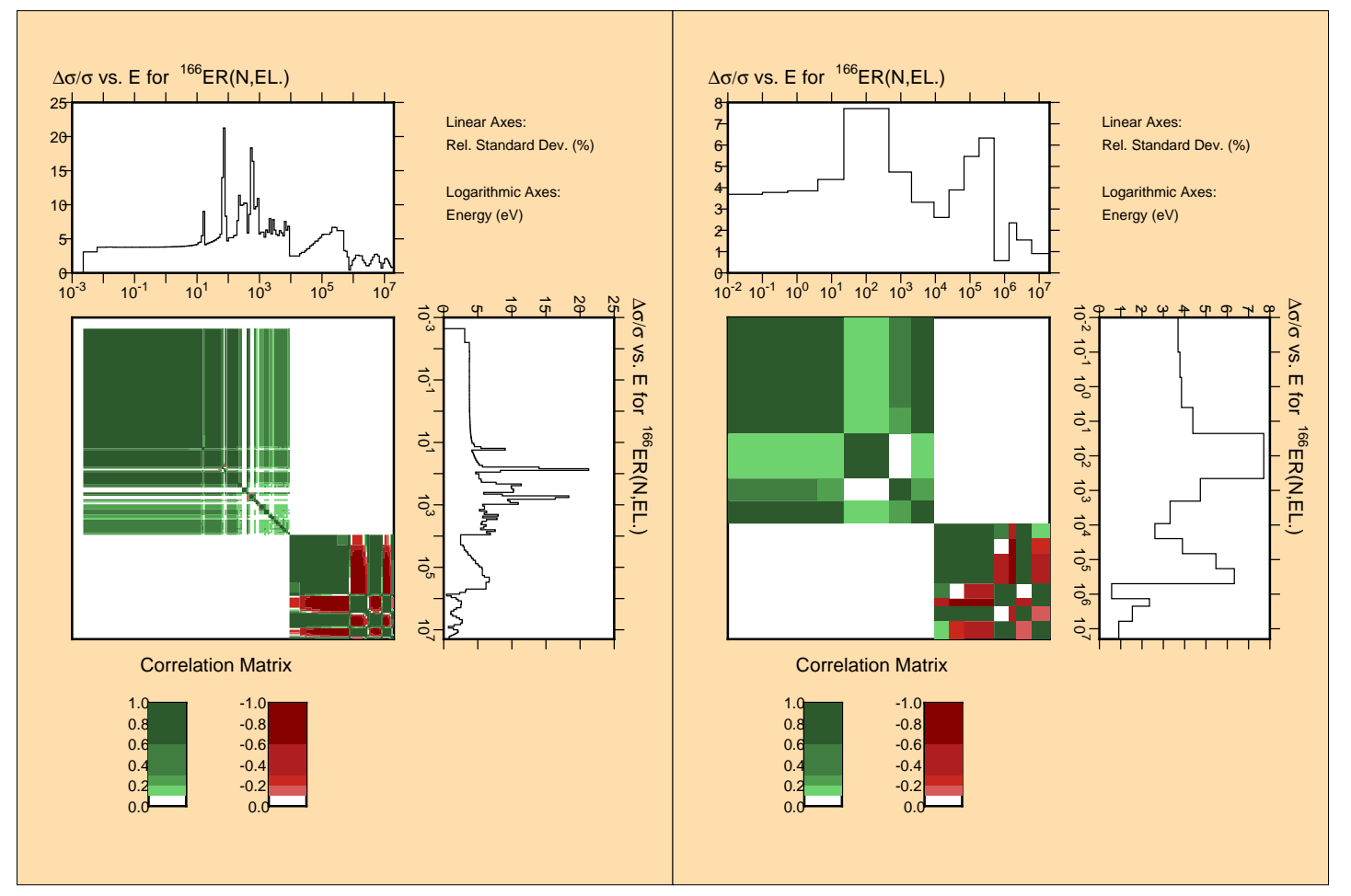

Figure A.72: Correlation and uncertainties in 187 (left) and 15 (right) groups for the ${ }^{166} \operatorname{Er}(n, e l)$ reaction

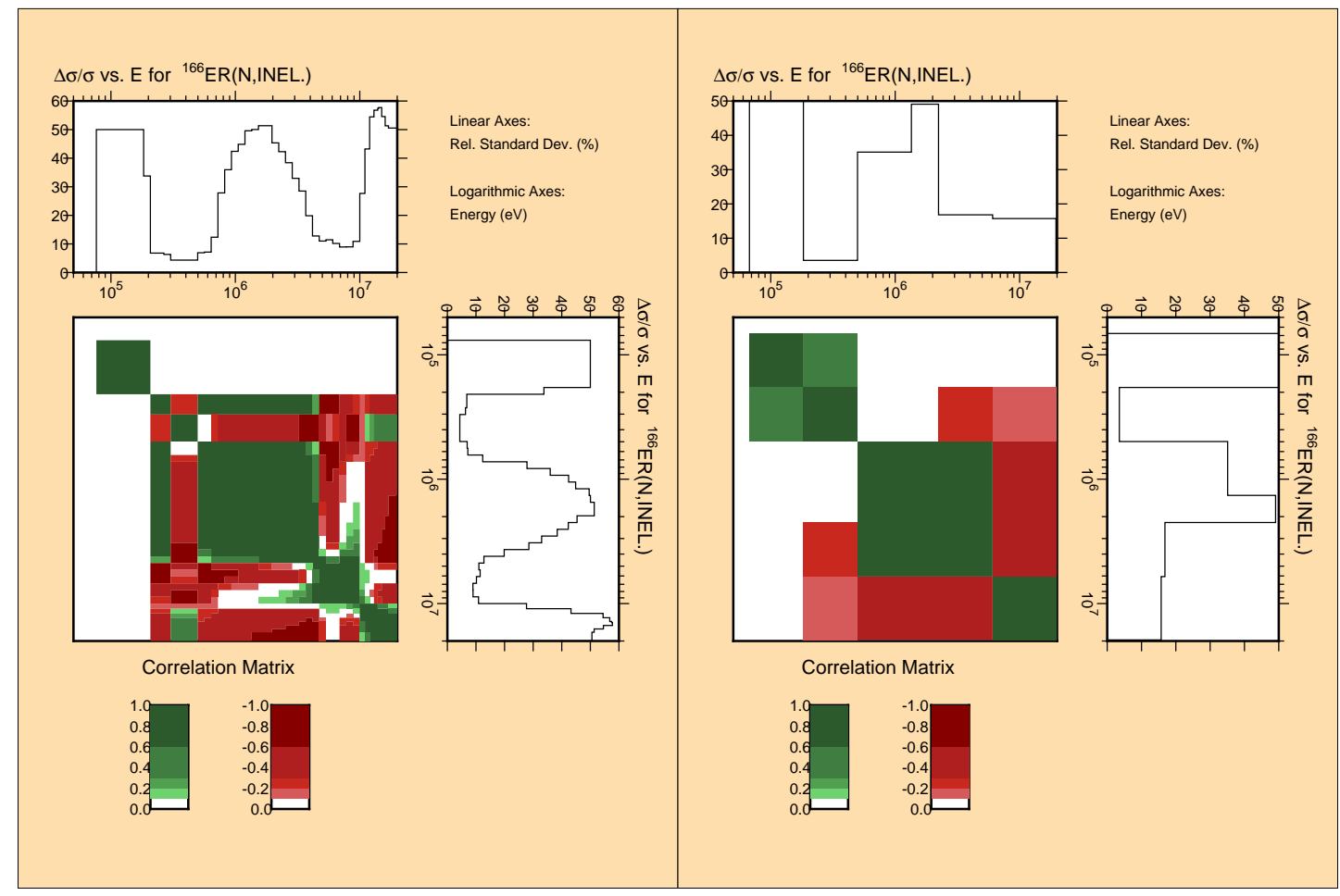

Figure A.73: Correlation and uncertainties in 187 (left) and 15 (right) groups for the ${ }^{166} \operatorname{Er}\left(\mathrm{n}, \mathrm{n}^{\prime}\right)$ reaction 


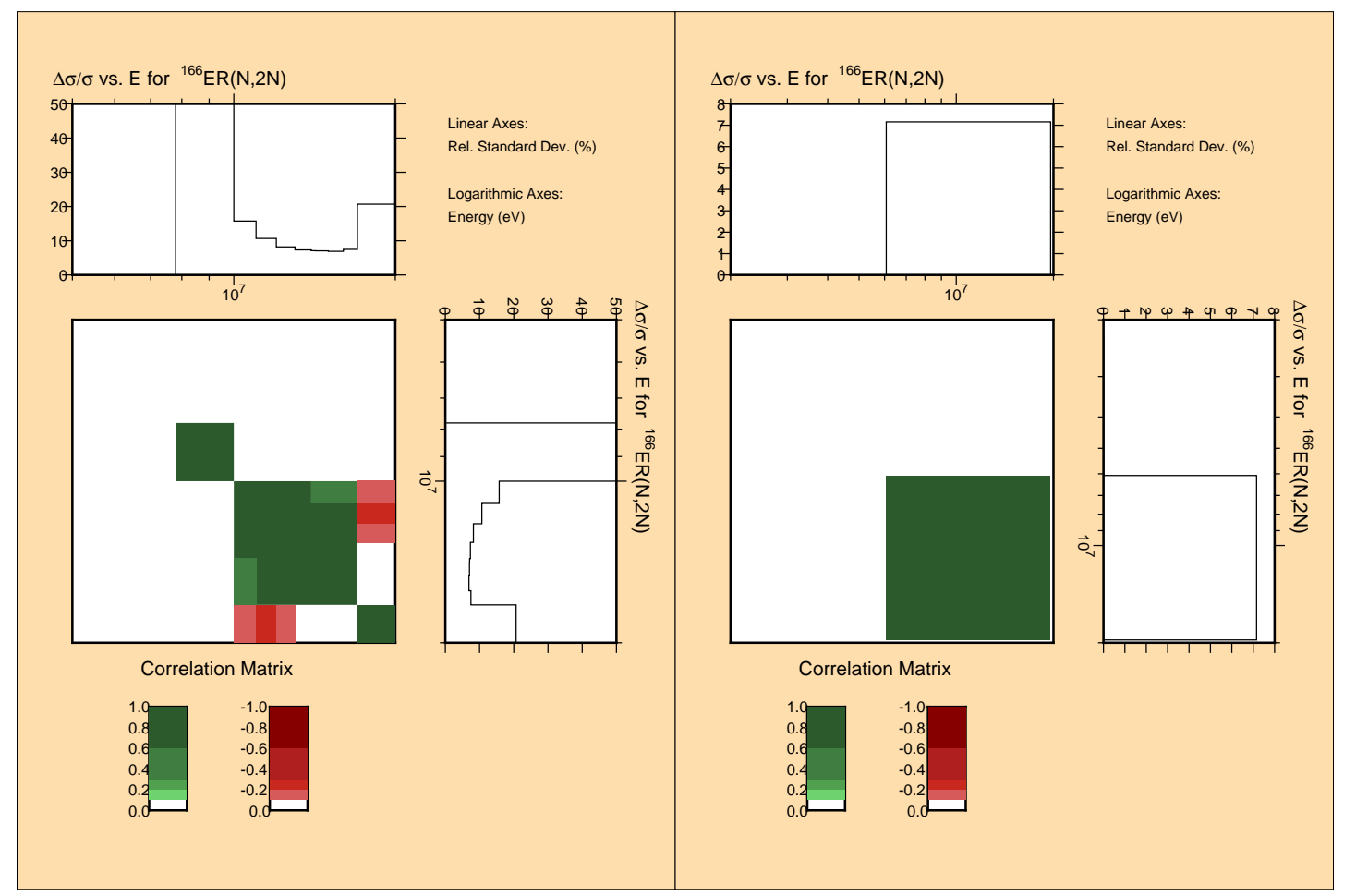

Figure A.74: Correlation and uncertainties in 187 (left) and 15 (right) groups for the ${ }^{166} \operatorname{Er}(\mathrm{n}, 2 \mathrm{n})$ reaction

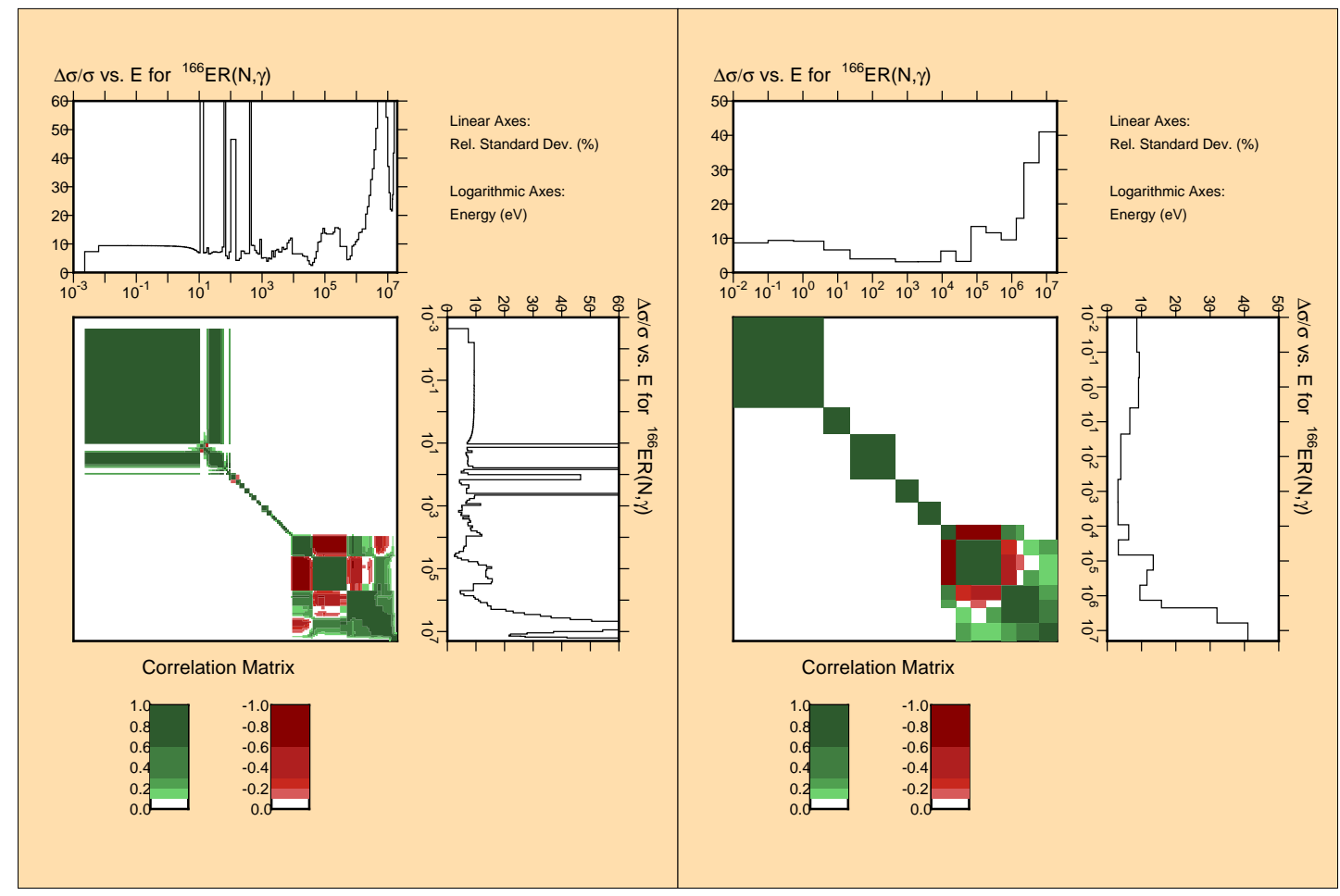

Figure A.75: Correlation and uncertainties in 187 (left) and 15 (right) groups for the ${ }^{166} \operatorname{Er}(\mathrm{n}, \gamma)$ reaction 


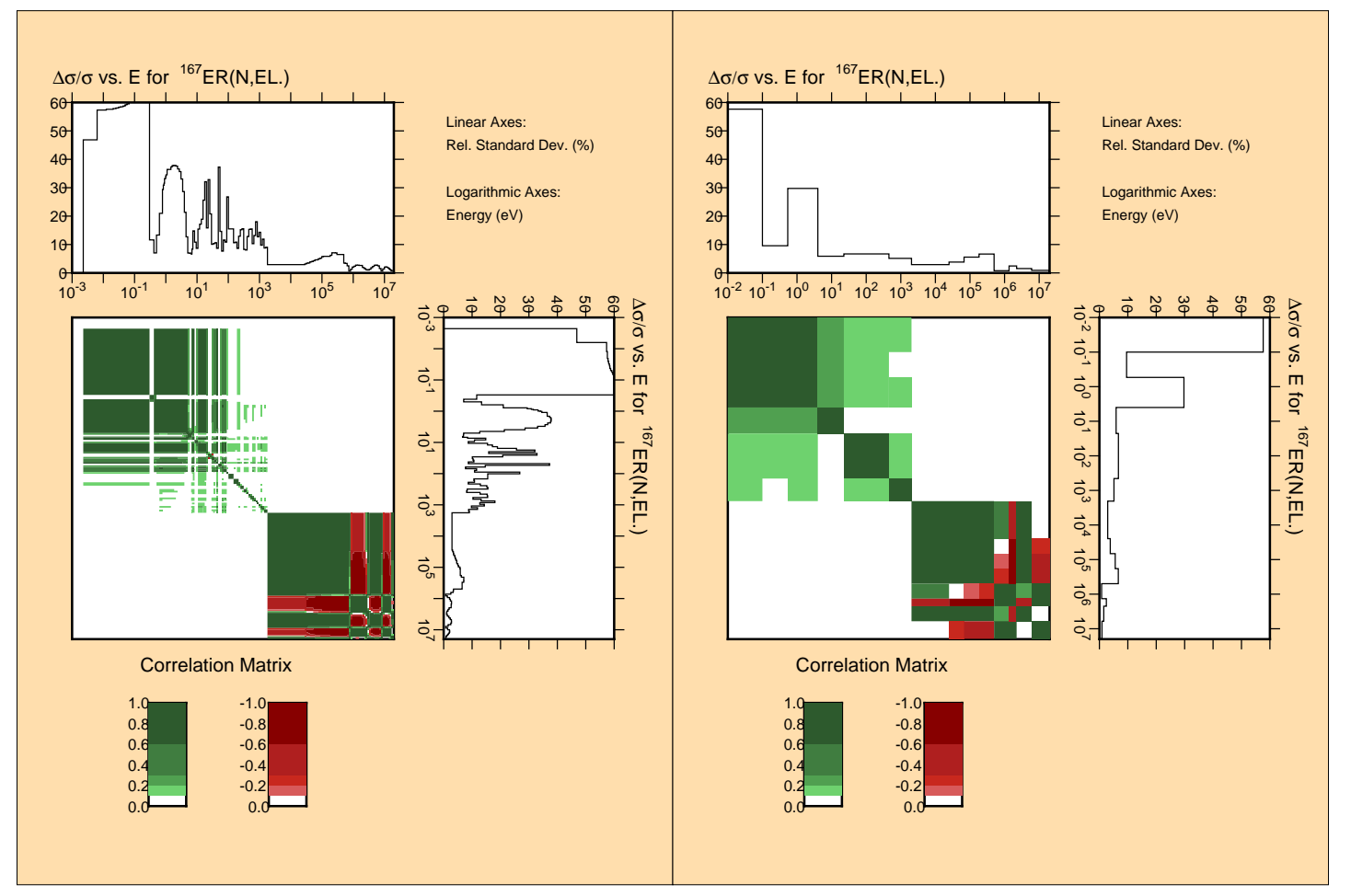

Figure A.76: Correlation and uncertainties in 187 (left) and 15 (right) groups for the ${ }^{167} \operatorname{Er}(\mathrm{n}, \mathrm{el})$ reaction

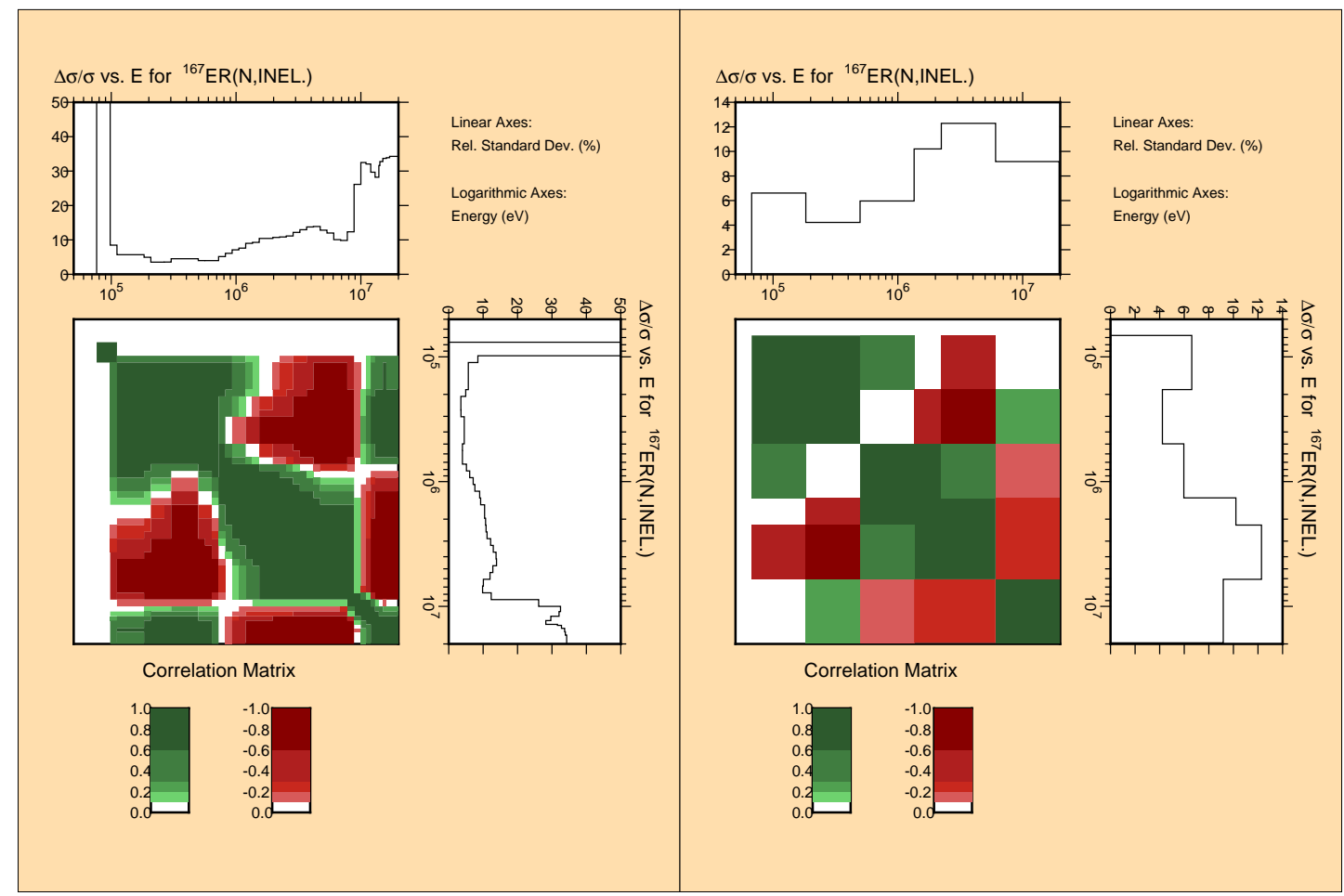

Figure A.77: Correlation and uncertainties in 187 (left) and 15 (right) groups for the ${ }^{167} \operatorname{Er}\left(\mathrm{n}, \mathrm{n}^{\prime}\right)$ reaction 


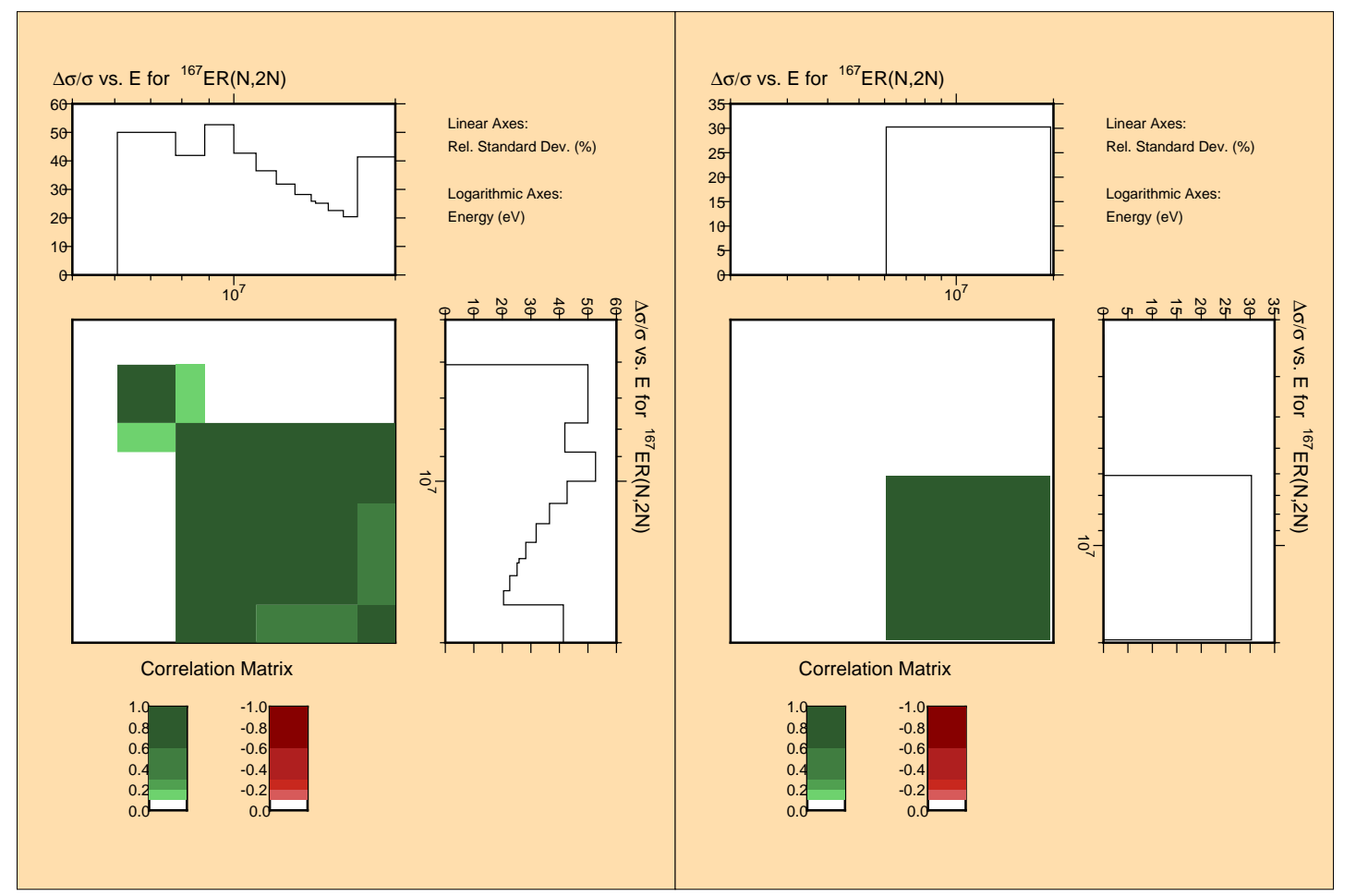

Figure A.78: Correlation and uncertainties in 187 (left) and 15 (right) groups for the ${ }^{167} \operatorname{Er}(\mathrm{n}, 2 \mathrm{n})$ reaction

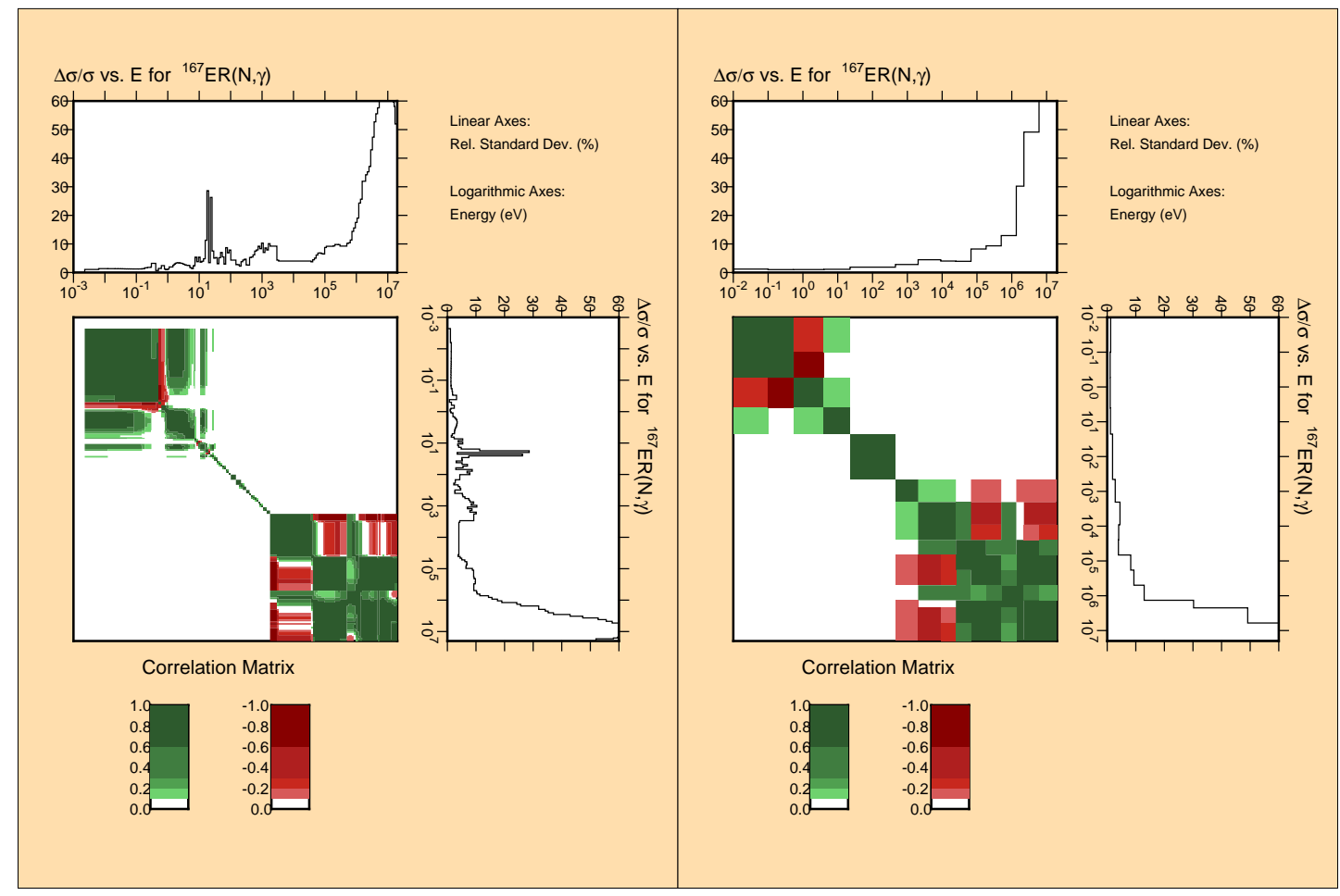

Figure A.79: Correlation and uncertainties in 187 (left) and 15 (right) groups for the ${ }^{167} \operatorname{Er}(\mathrm{n}, \gamma)$ reaction 


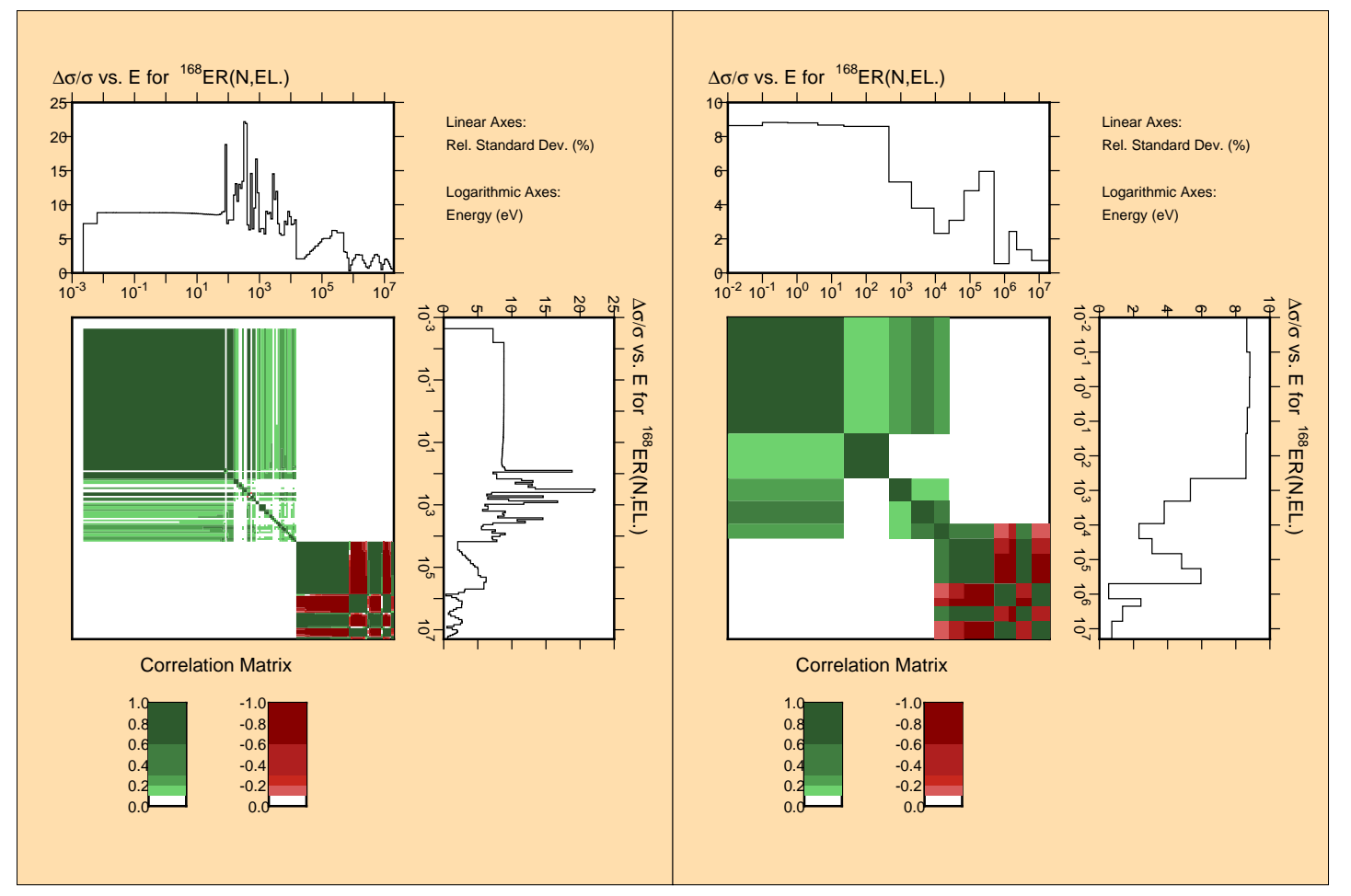

Figure A.80: Correlation and uncertainties in 187 (left) and 15 (right) groups for the ${ }^{168} \operatorname{Er}(\mathrm{n}, \mathrm{el})$ reaction

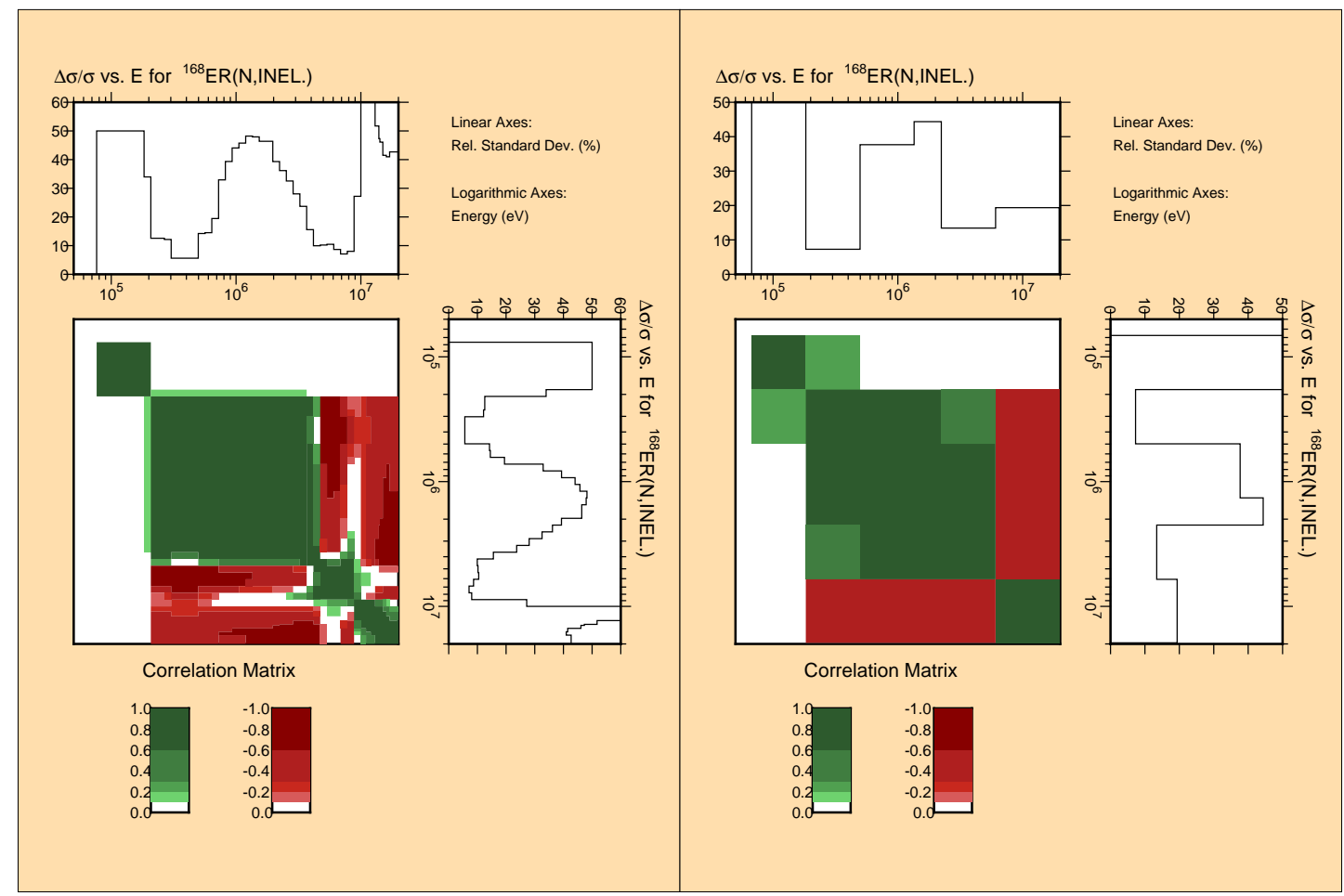

Figure A.81: Correlation and uncertainties in 187 (left) and 15 (right) groups for the ${ }^{168} \operatorname{Er}\left(\mathrm{n}, \mathrm{n}^{\prime}\right)$ reaction 


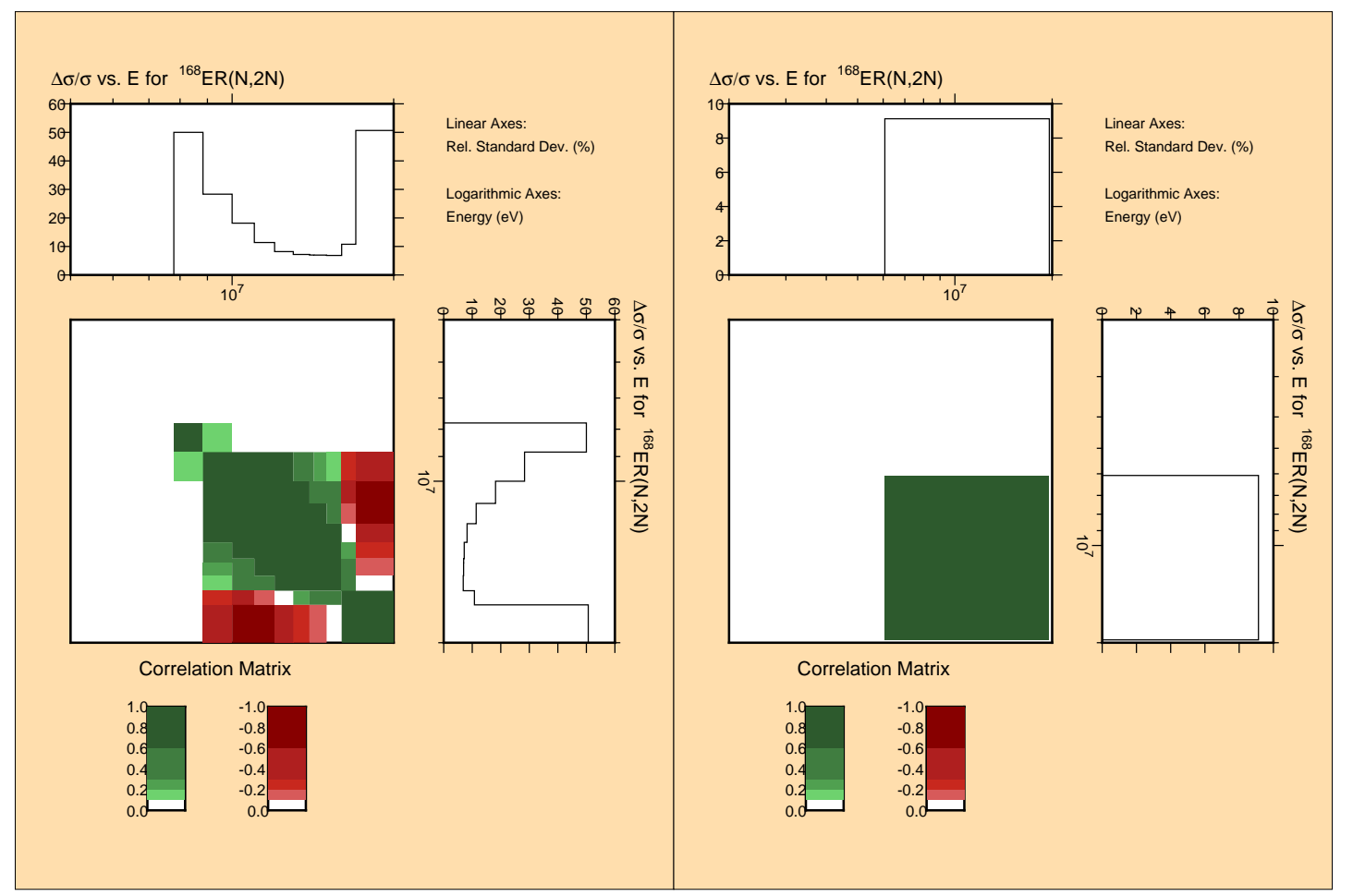

Figure A.82: Correlation and uncertainties in 187 (left) and 15 (right) groups for the ${ }^{168} \operatorname{Er}(\mathrm{n}, 2 \mathrm{n})$ reaction

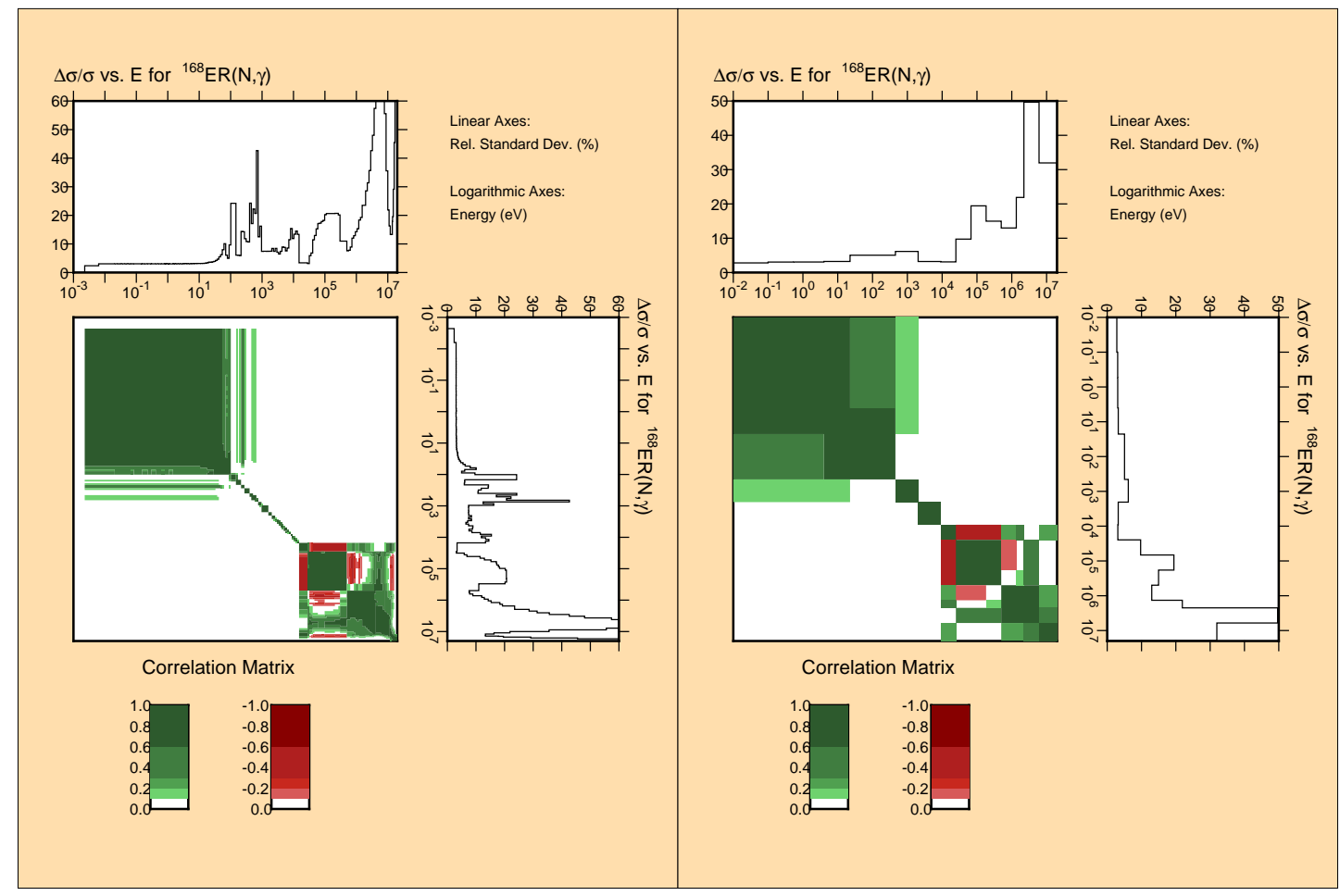

Figure A.83: Correlation and uncertainties in 187 (left) and 15 (right) groups for the ${ }^{168} \operatorname{Er}(\mathrm{n}, \gamma)$ reaction

D. Rochman et al. 


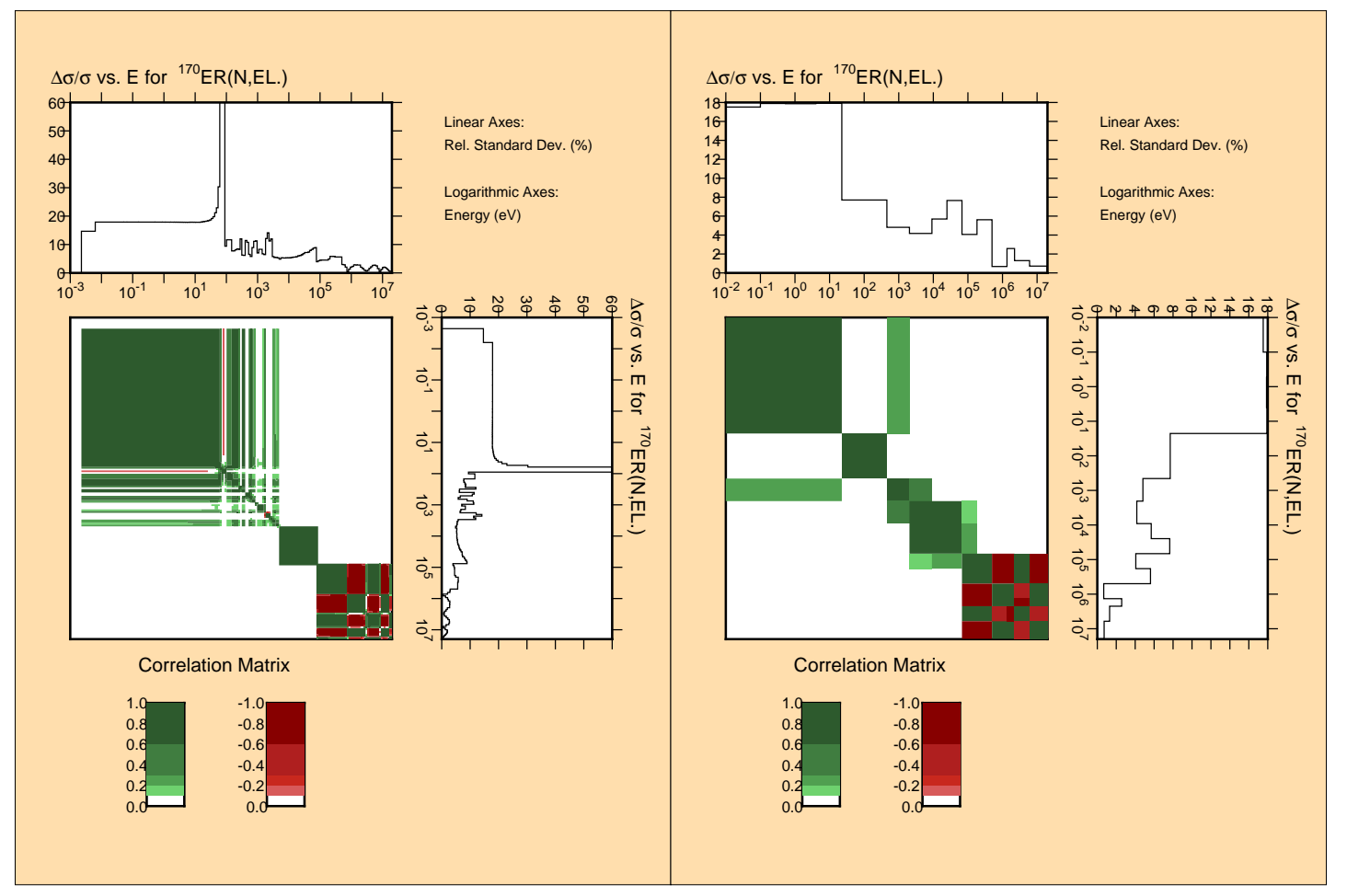

Figure A.84: Correlation and uncertainties in 187 (left) and 15 (right) groups for the ${ }^{170} \operatorname{Er}(n, e l)$ reaction

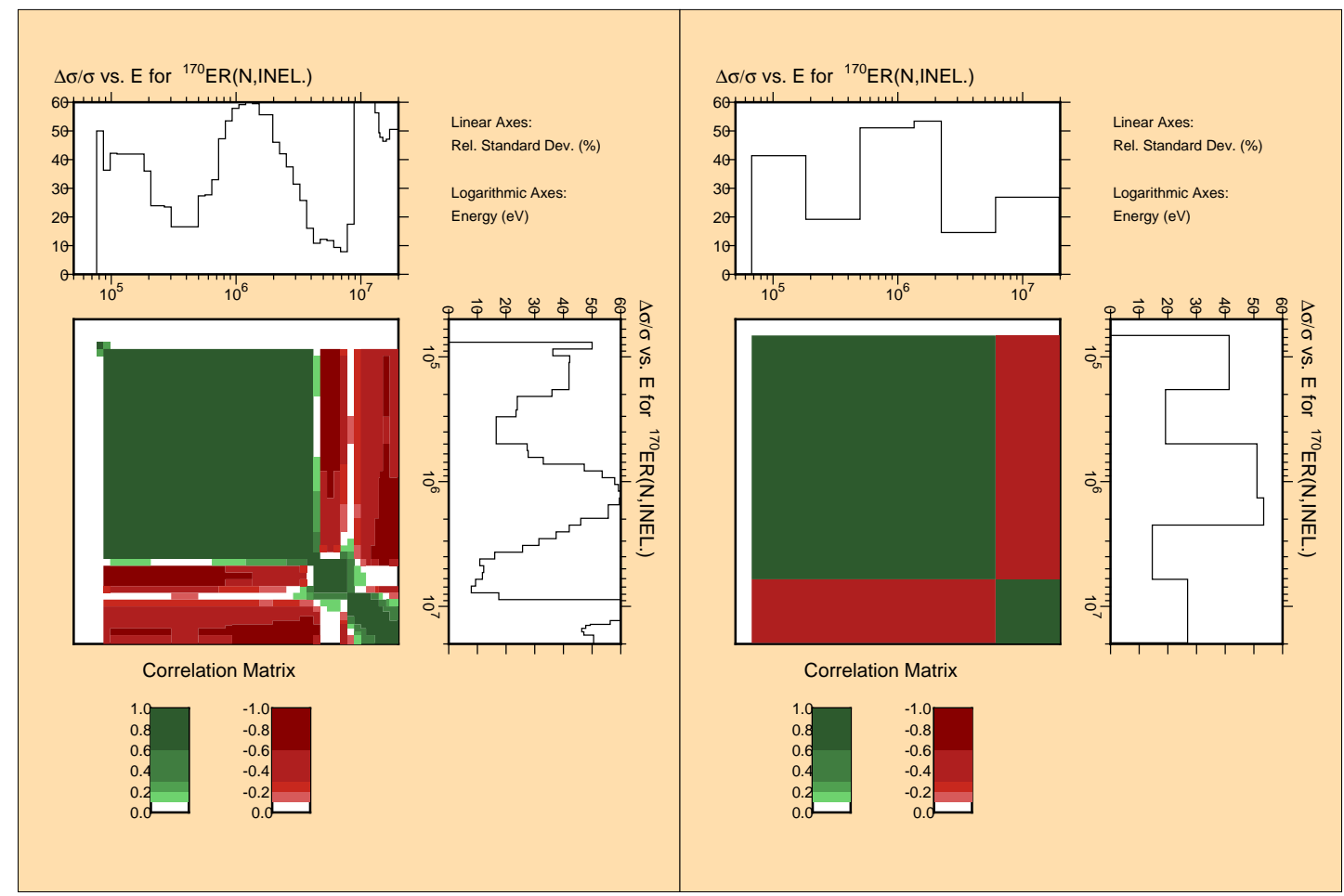

Figure A.85: Correlation and uncertainties in 187 (left) and 15 (right) groups for the ${ }^{170} \operatorname{Er}\left(\mathrm{n}, \mathrm{n}^{\prime}\right)$ reaction 


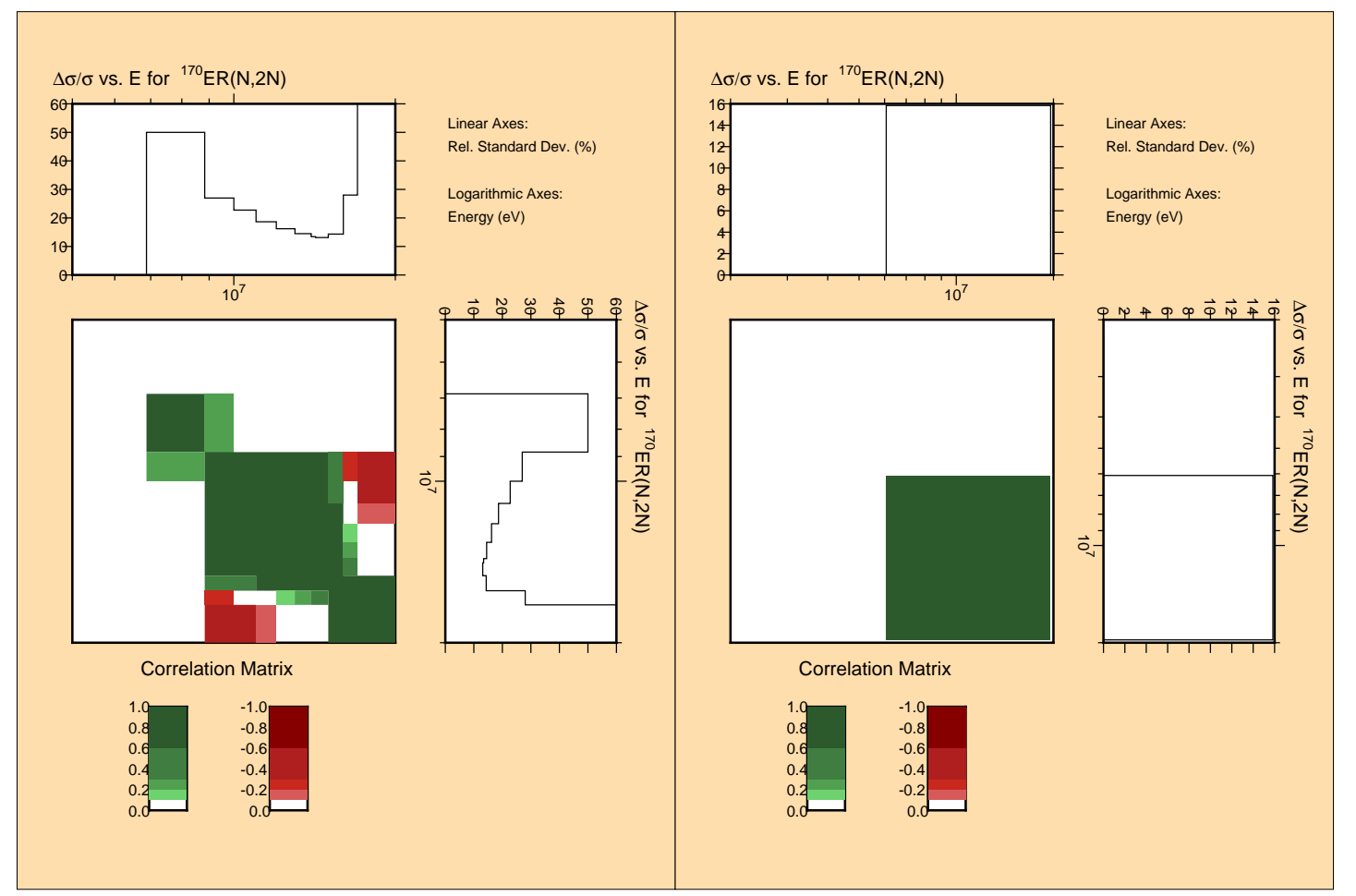

Figure A.86: Correlation and uncertainties in 187 (left) and 15 (right) groups for the ${ }^{170} \operatorname{Er}(\mathrm{n}, 2 \mathrm{n})$ reaction

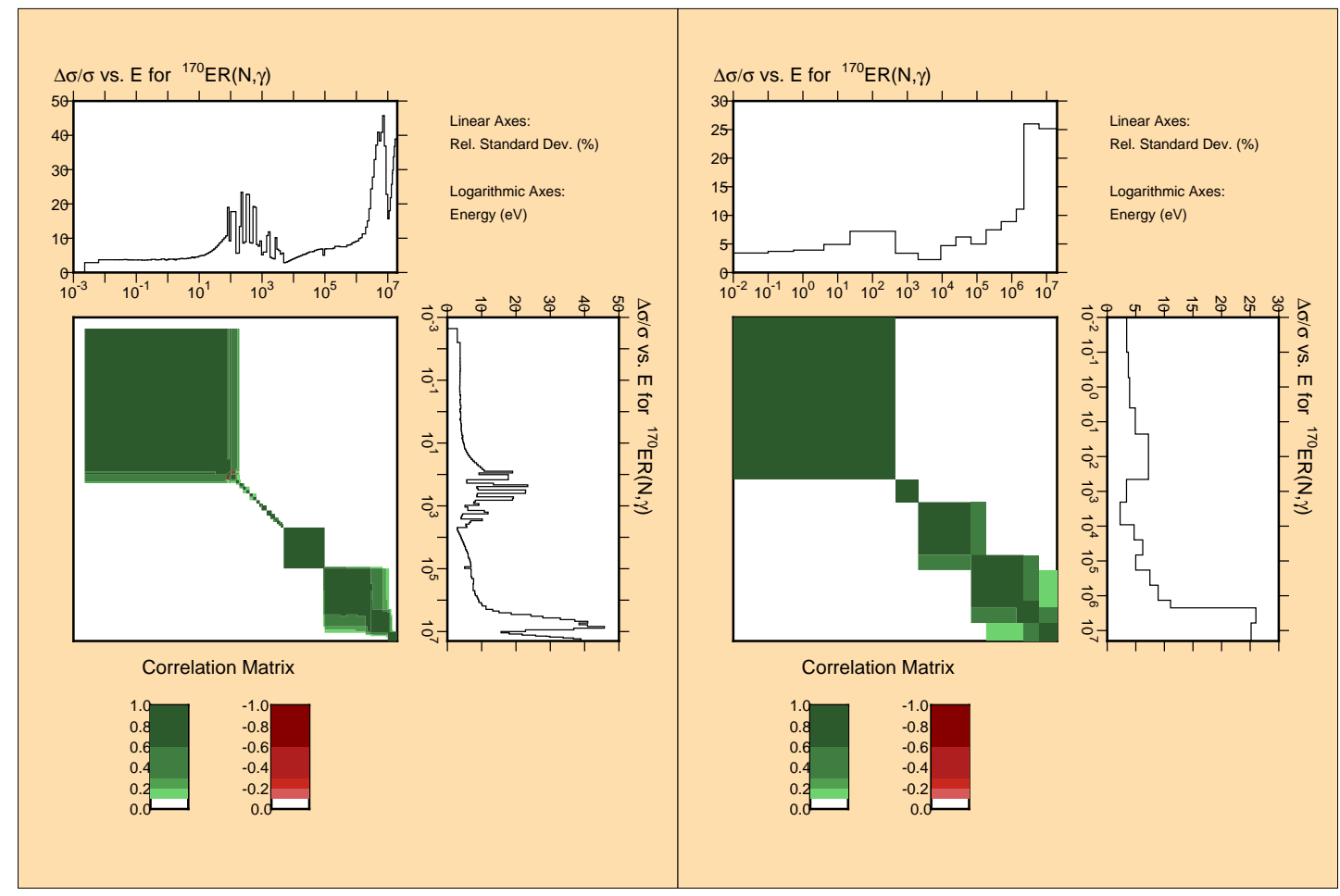

Figure A.87: Correlation and uncertainties in 187 (left) and 15 (right) groups for the ${ }^{170} \operatorname{Er}(\mathrm{n}, \gamma)$ reaction 


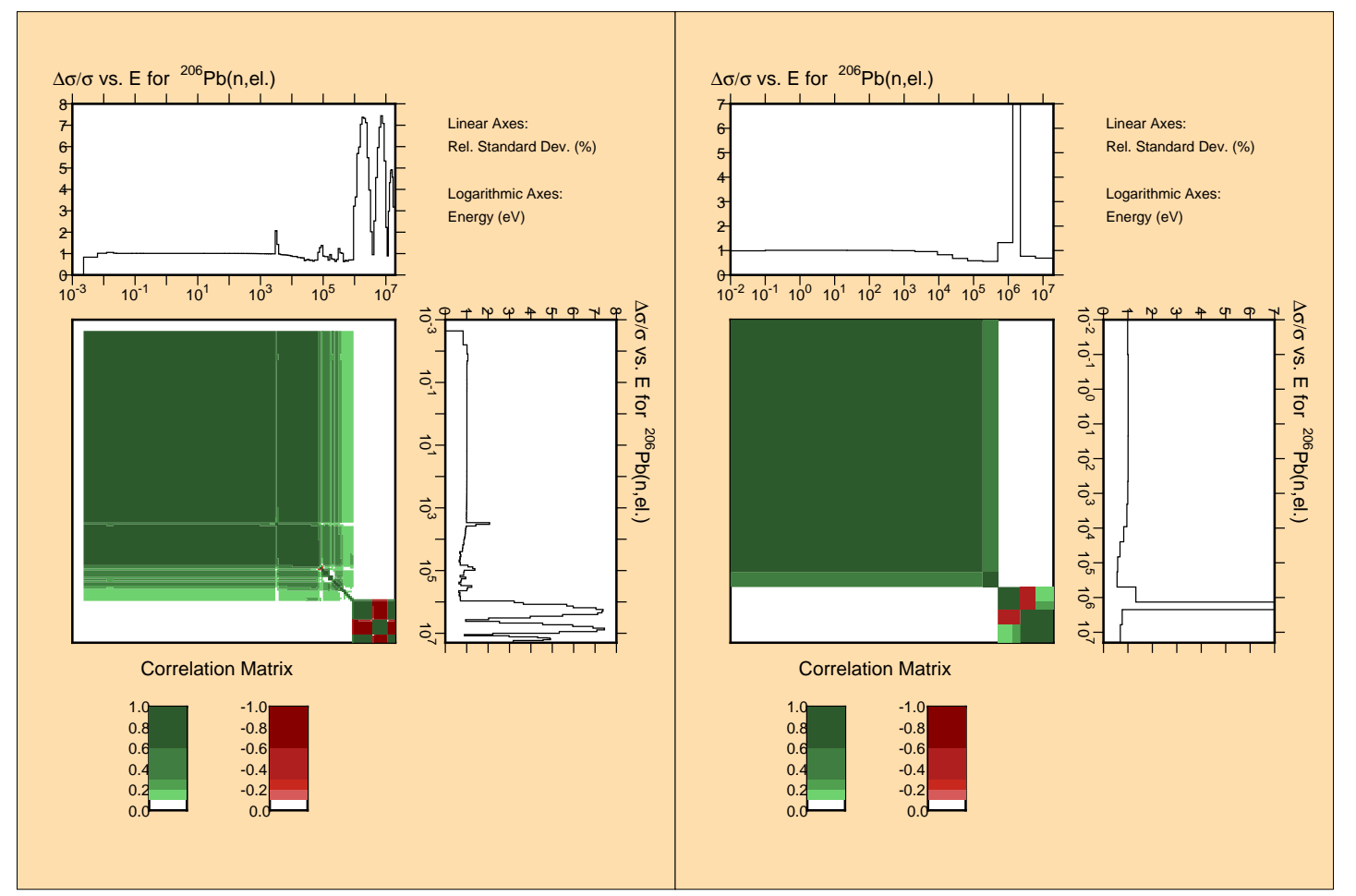

Figure A.88: Correlation and uncertainties in 187 (left) and 15 (right) groups for the ${ }^{206} \mathrm{~Pb}(\mathrm{n}, \mathrm{el})$ reaction

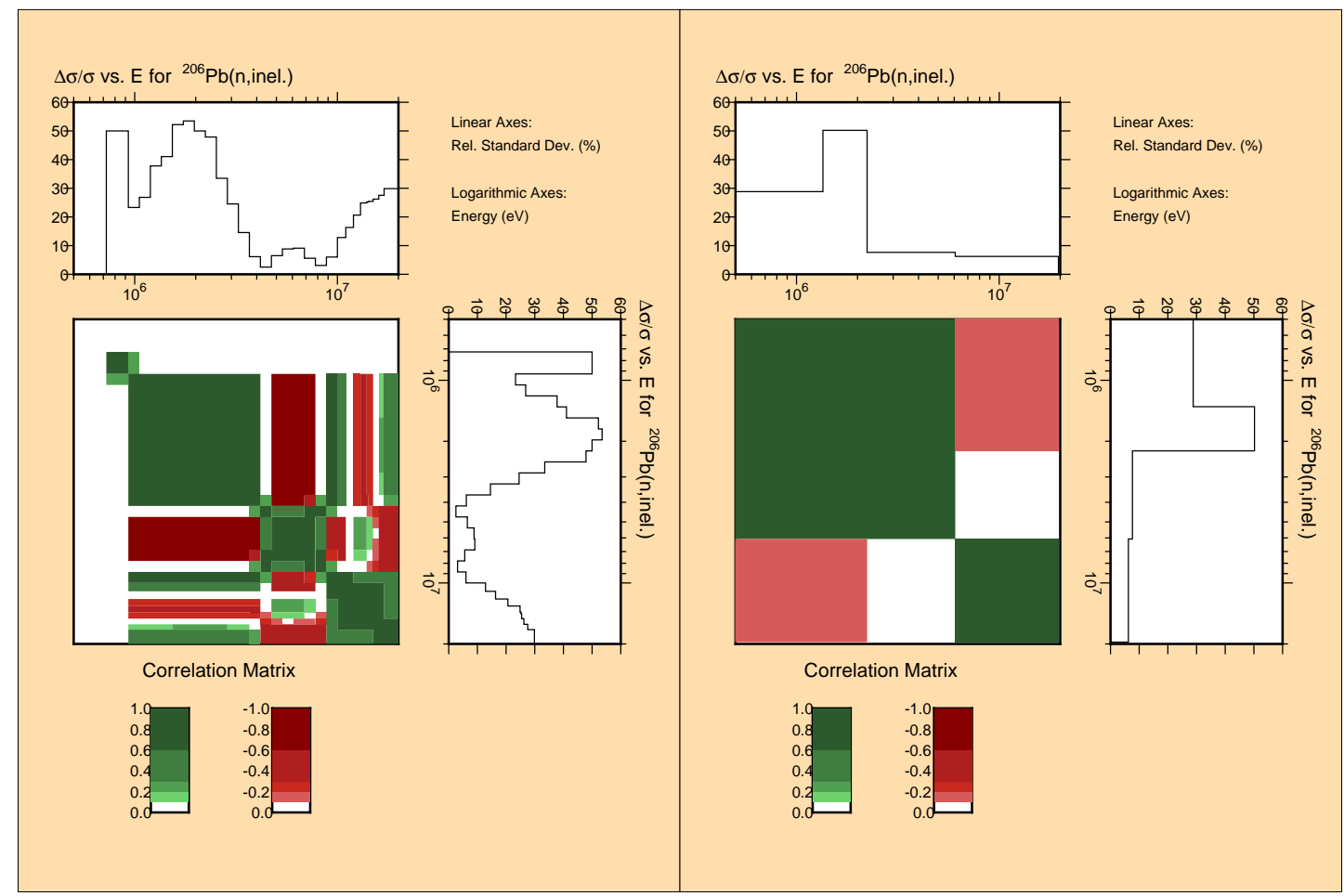

Figure A.89: Correlation and uncertainties in 187 (left) and 15 (right) groups for the ${ }^{206} \mathrm{~Pb}\left(\mathrm{n}, \mathrm{n}^{\prime}\right)$ reaction 


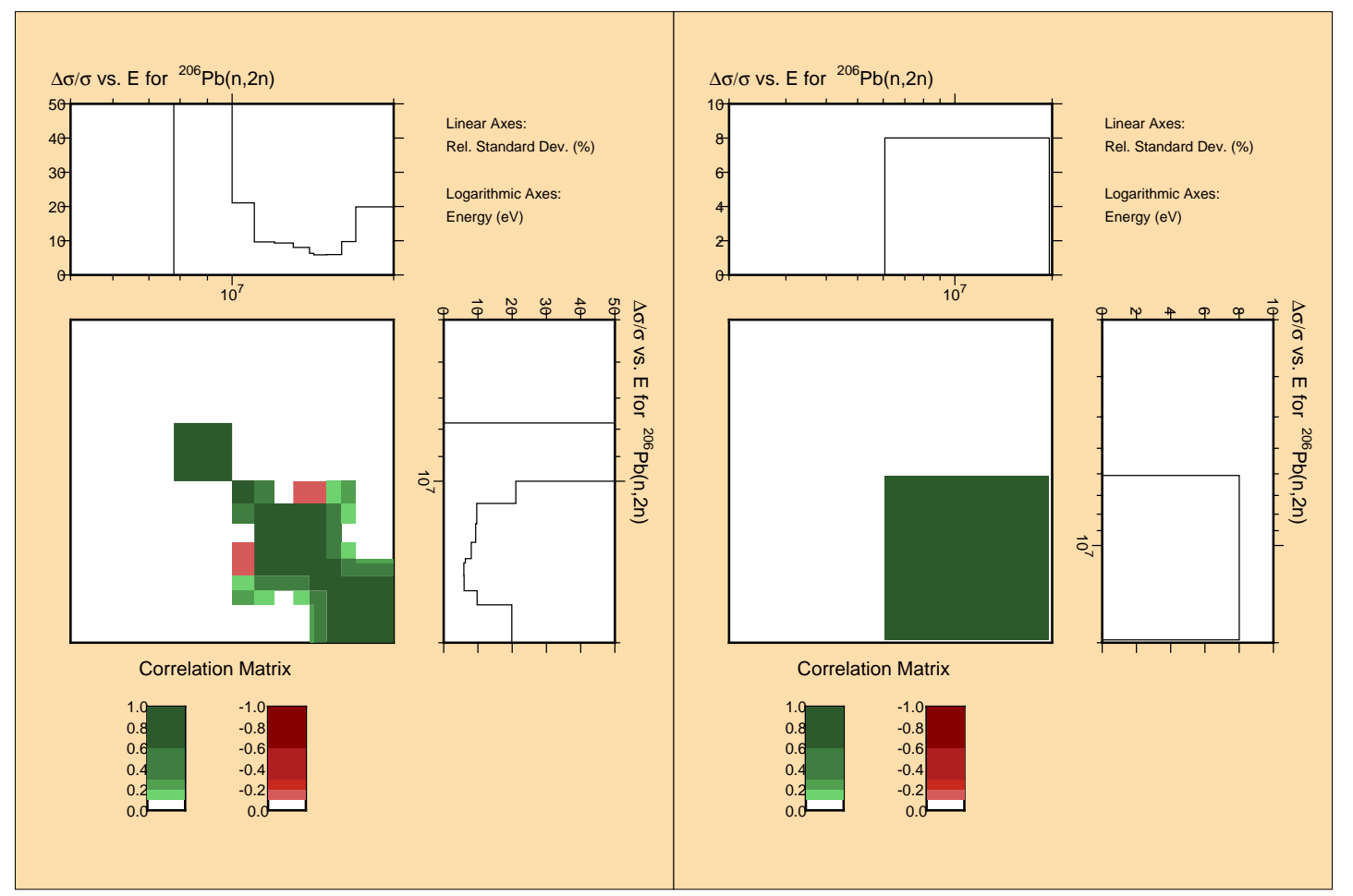

Figure A.90: Correlation and uncertainties in 187 (left) and 15 (right) groups for the ${ }^{206} \mathrm{~Pb}(\mathrm{n}, 2 \mathrm{n})$ reaction

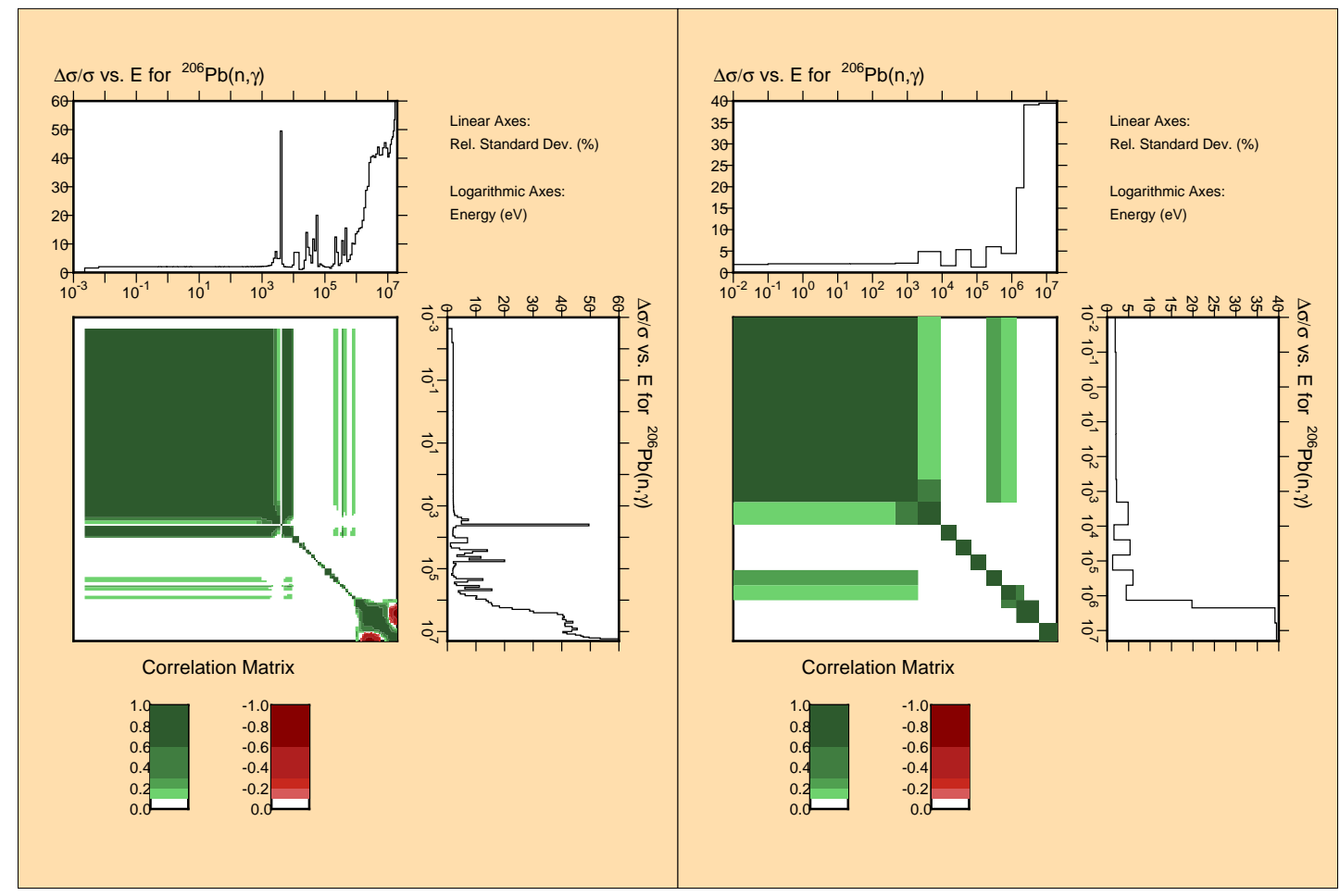

Figure A.91: Correlation and uncertainties in 187 (left) and 15 (right) groups for the ${ }^{206} \mathrm{~Pb}(\mathrm{n}, \gamma)$ reaction

D. Rochman et al. 


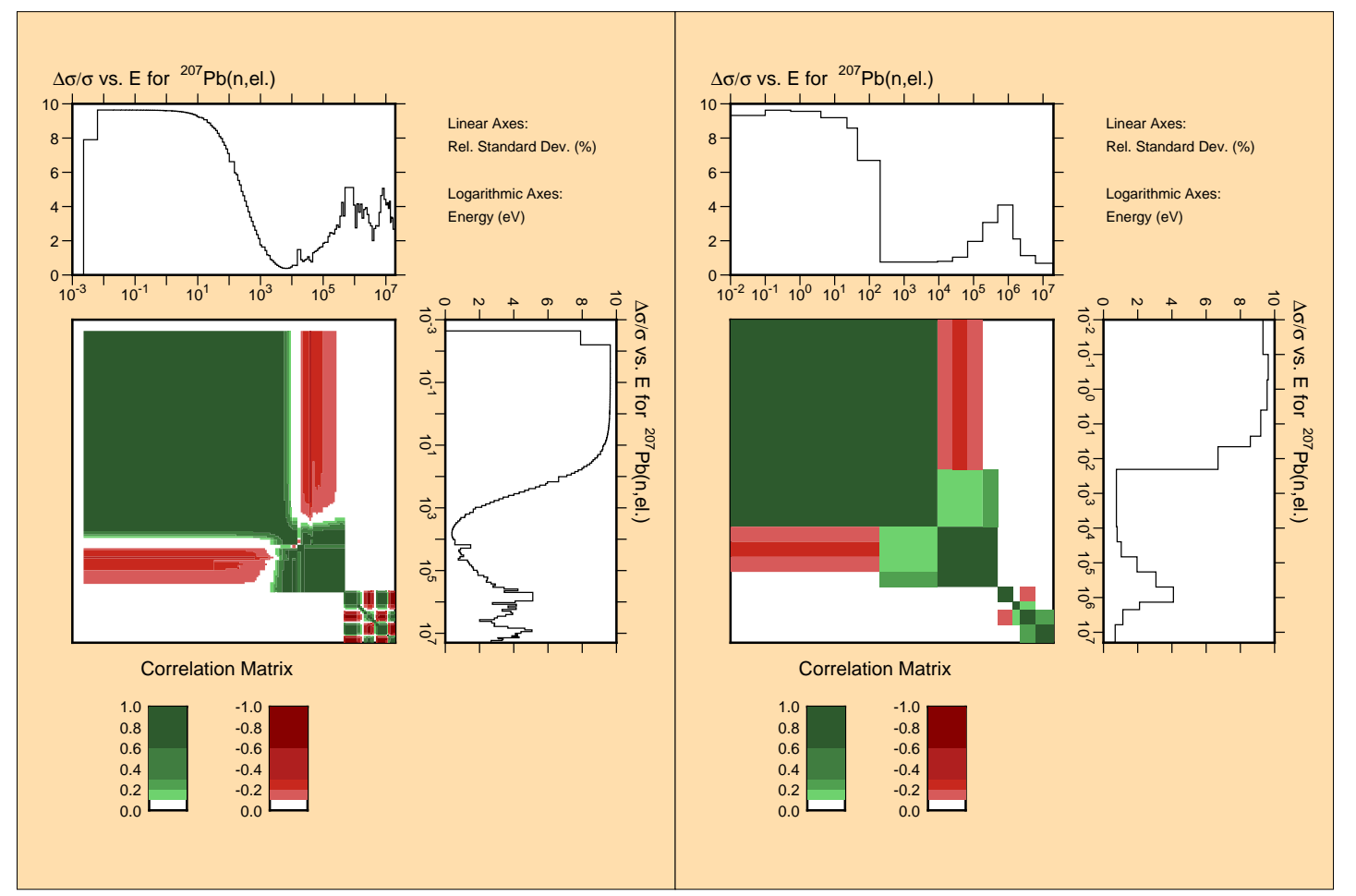

Figure A.92: Correlation and uncertainties in 187 (left) and 15 (right) groups for the ${ }^{207} \mathrm{~Pb}(\mathrm{n}, \mathrm{el})$ reaction

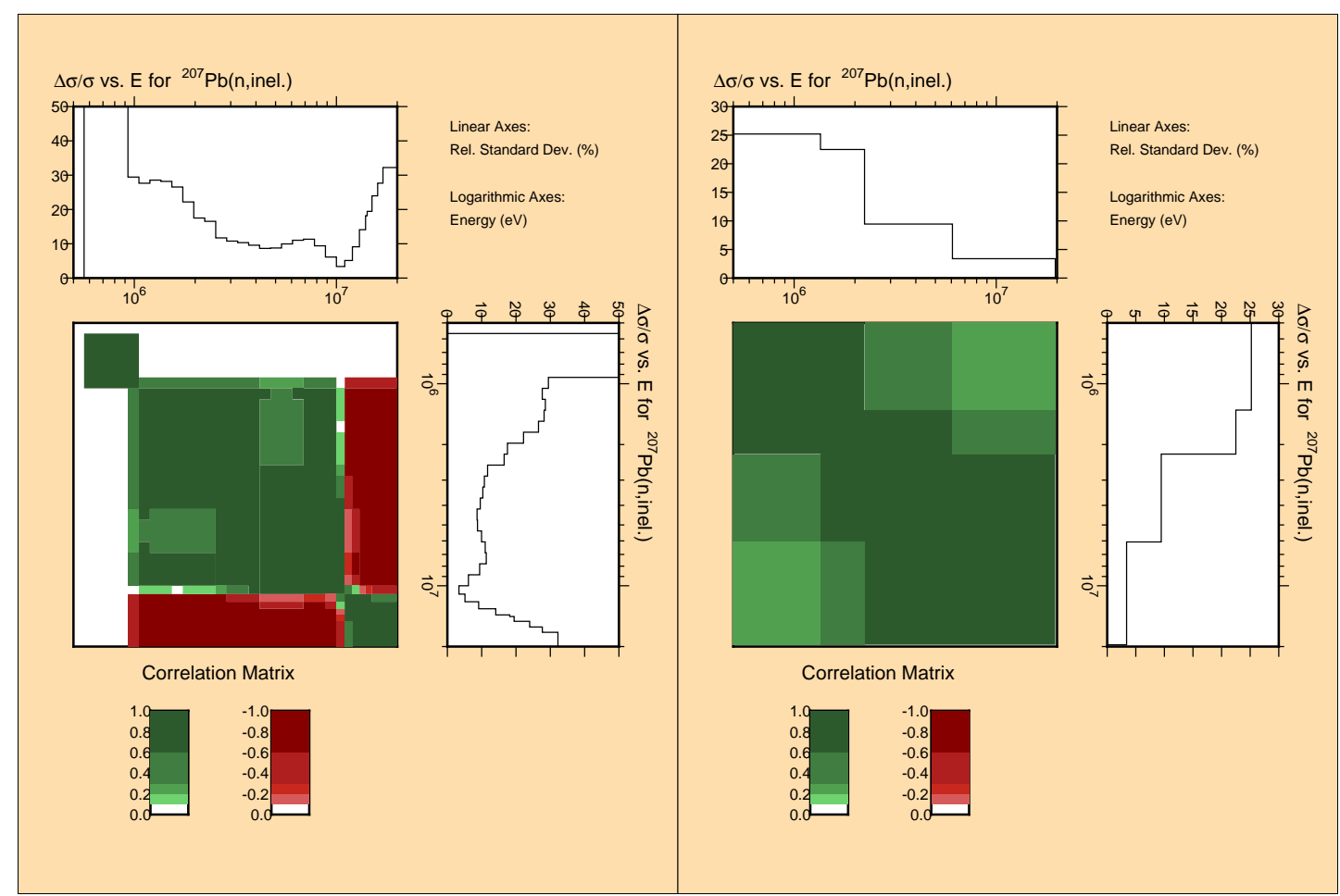

Figure A.93: Correlation and uncertainties in 187 (left) and 15 (right) groups for the ${ }^{207} \mathrm{~Pb}\left(\mathrm{n}, \mathrm{n}^{\prime}\right)$ reaction 


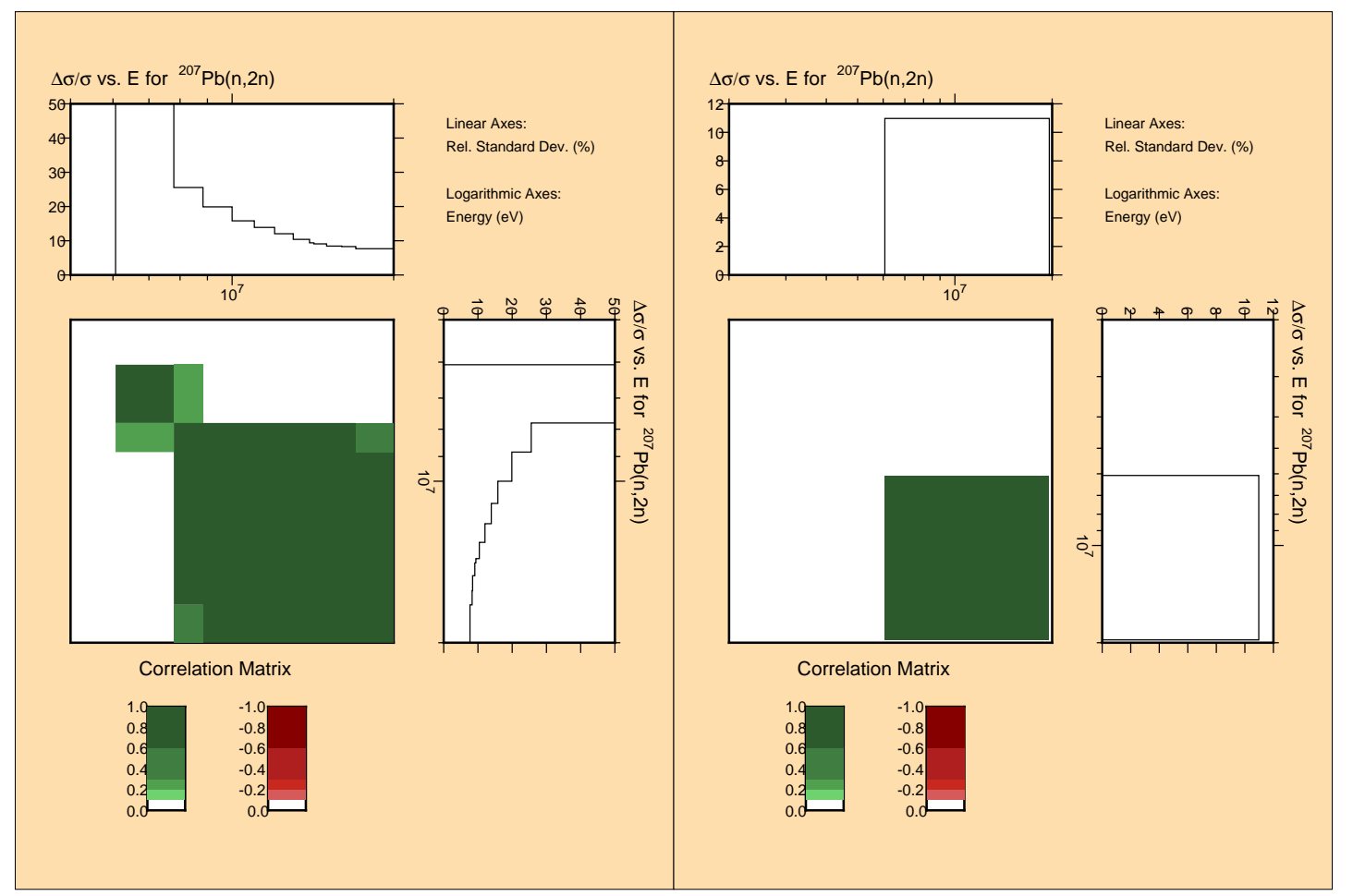

Figure A.94: Correlation and uncertainties in 187 (left) and 15 (right) groups for the ${ }^{207} \mathrm{~Pb}(\mathrm{n}, 2 \mathrm{n})$ reaction

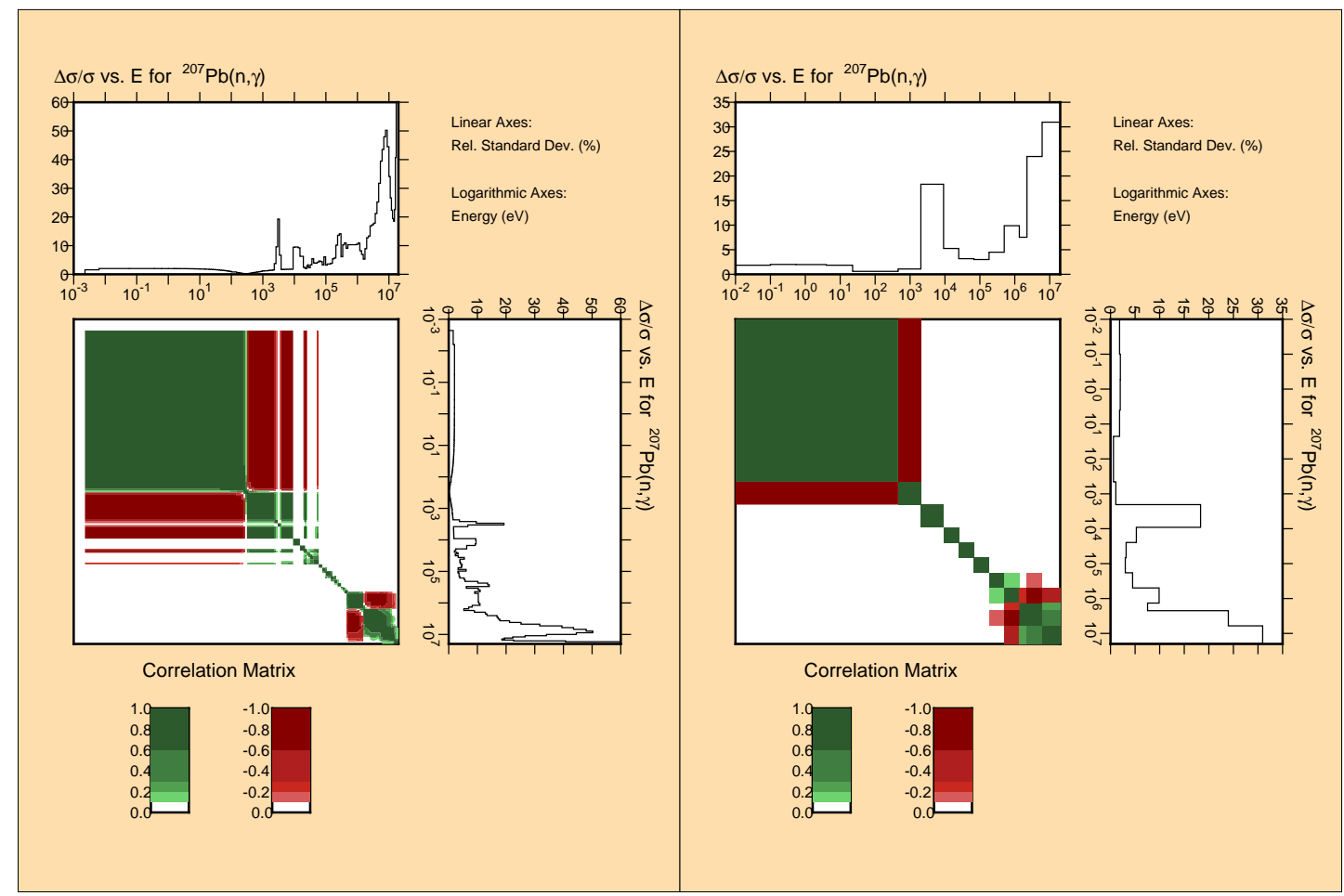

Figure A.95: Correlation and uncertainties in 187 (left) and 15 (right) groups for the ${ }^{207} \mathrm{~Pb}(\mathrm{n}, \gamma)$ reaction 


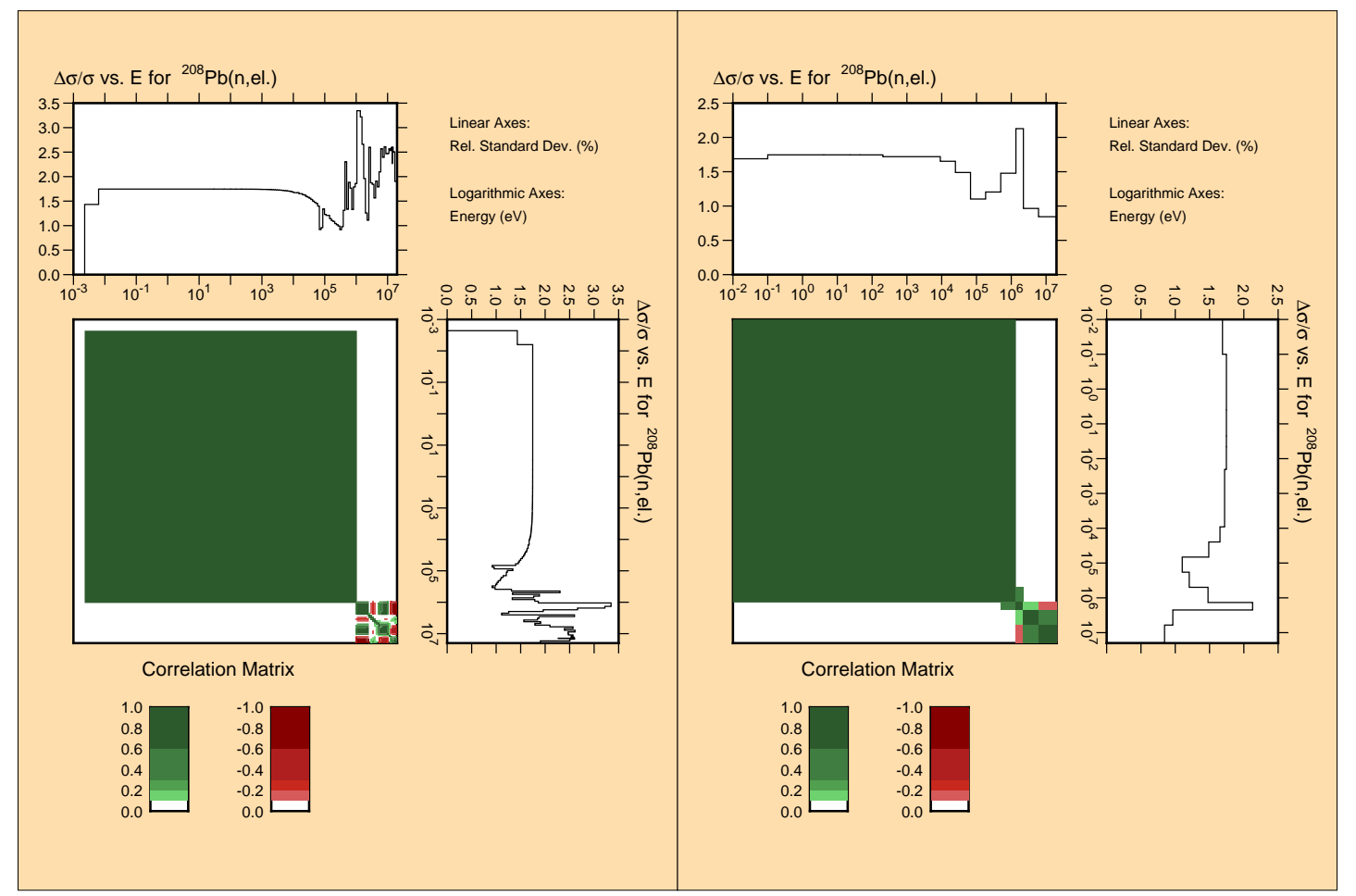

Figure A.96: Correlation and uncertainties in 187 (left) and 15 (right) groups for the ${ }^{208} \mathrm{~Pb}(\mathrm{n}, \mathrm{el})$ reaction

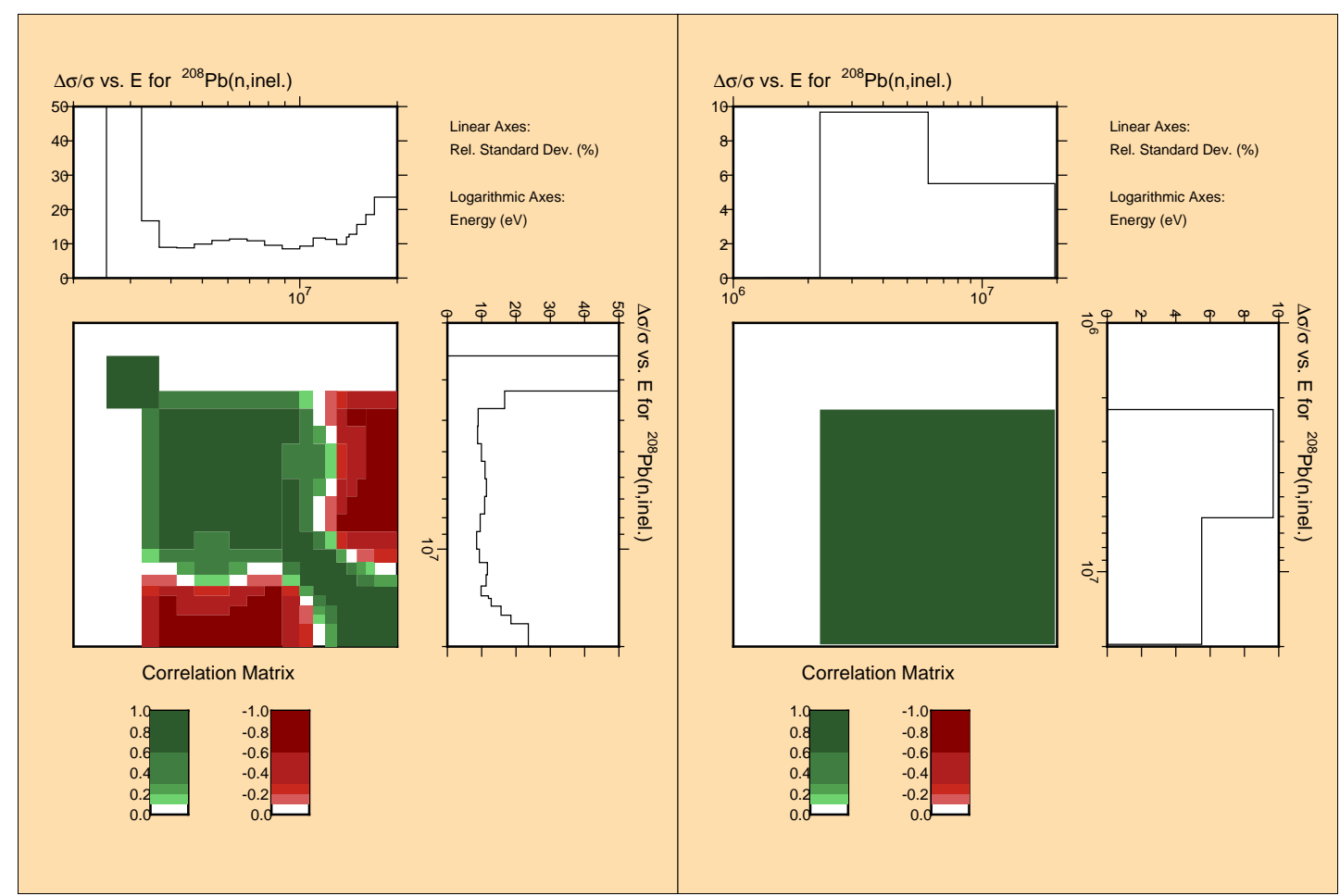

Figure A.97: Correlation and uncertainties in 187 (left) and 15 (right) groups for the ${ }^{208} \mathrm{~Pb}\left(\mathrm{n}, \mathrm{n}^{\prime}\right)$ reaction 


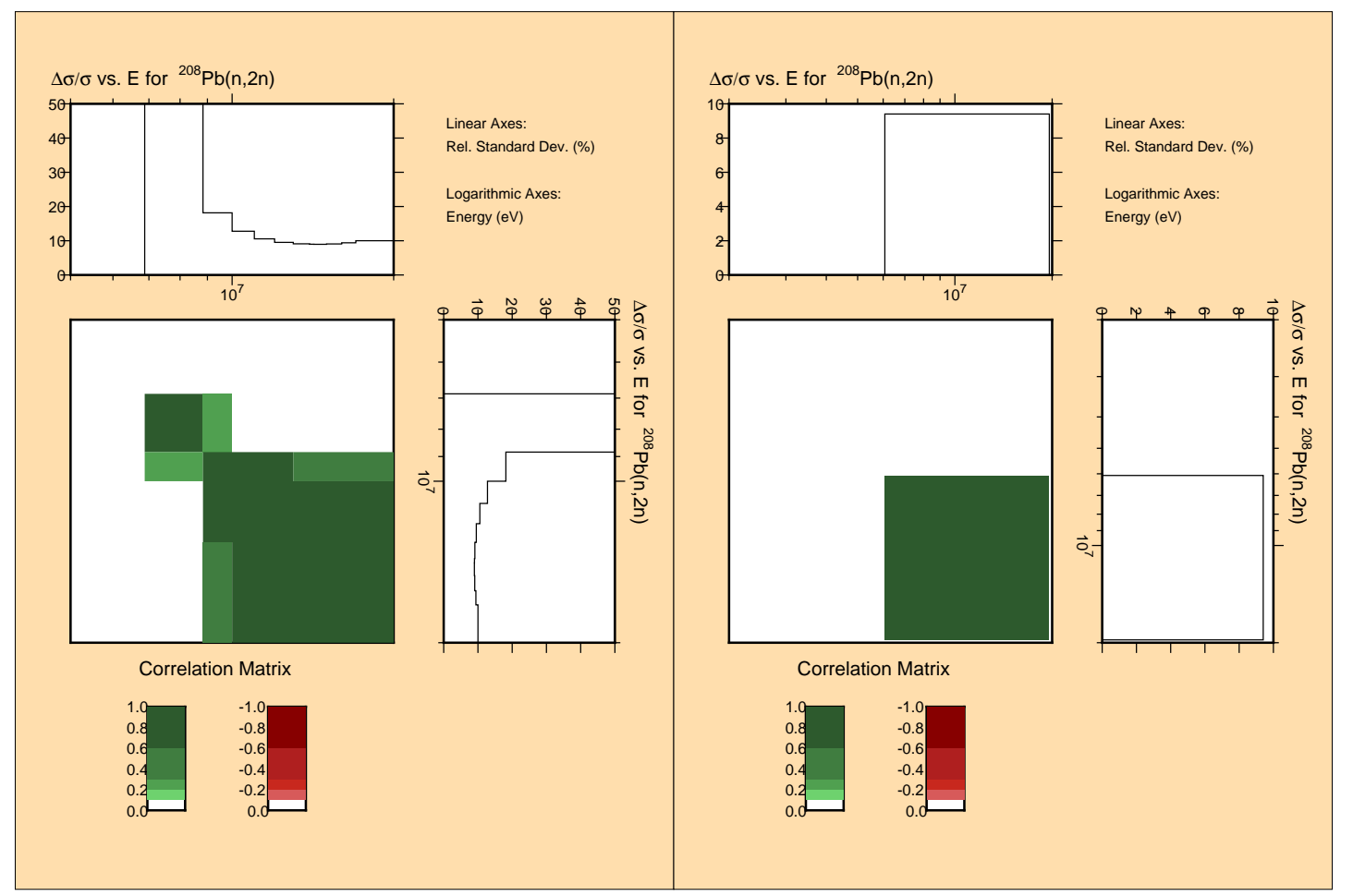

Figure A.98: Correlation and uncertainties in 187 (left) and 15 (right) groups for the ${ }^{208} \mathrm{~Pb}(\mathrm{n}, 2 \mathrm{n})$ reaction

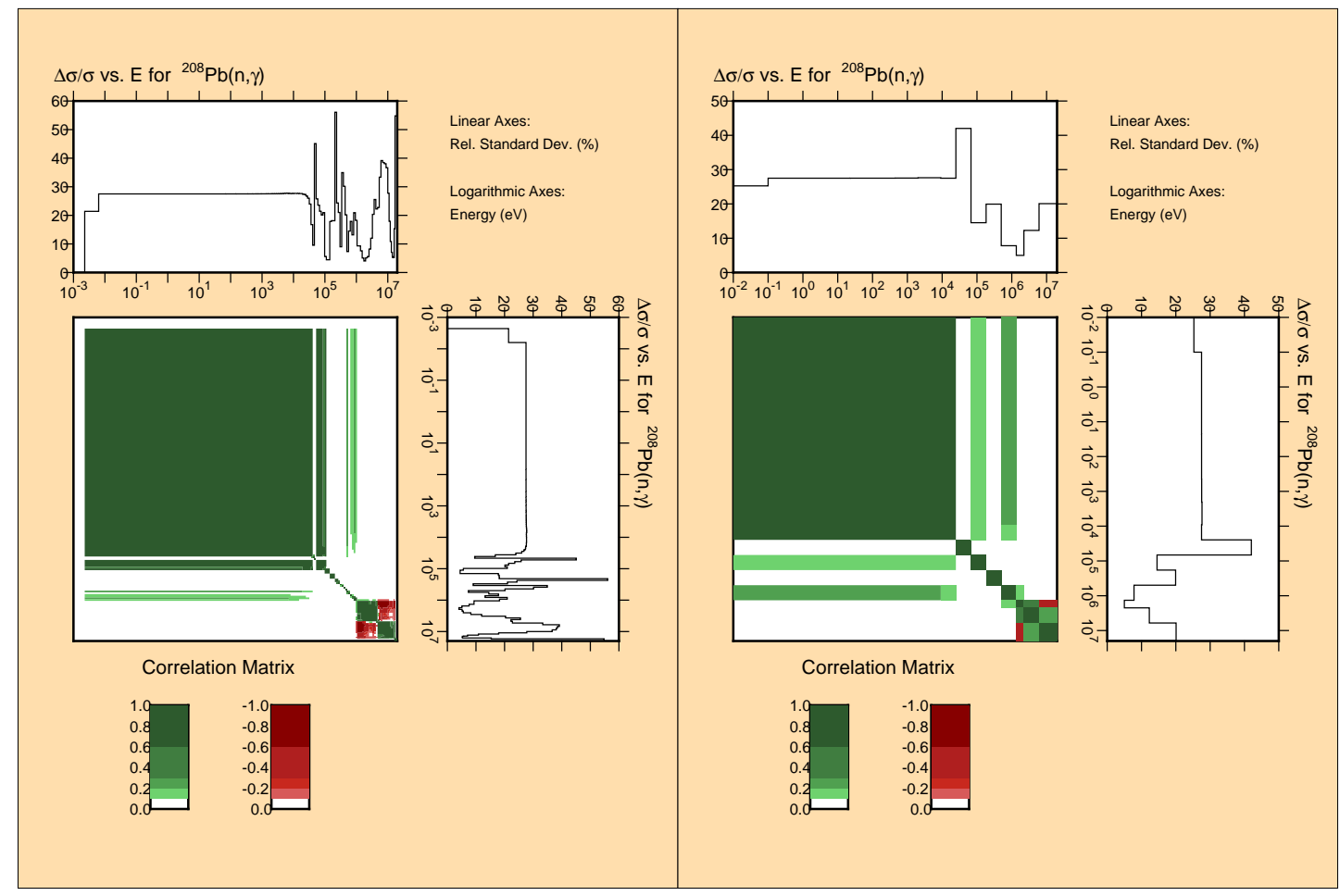

Figure A.99: Correlation and uncertainties in 187 (left) and 15 (right) groups for the ${ }^{208} \mathrm{~Pb}(\mathrm{n}, \gamma)$ reaction 


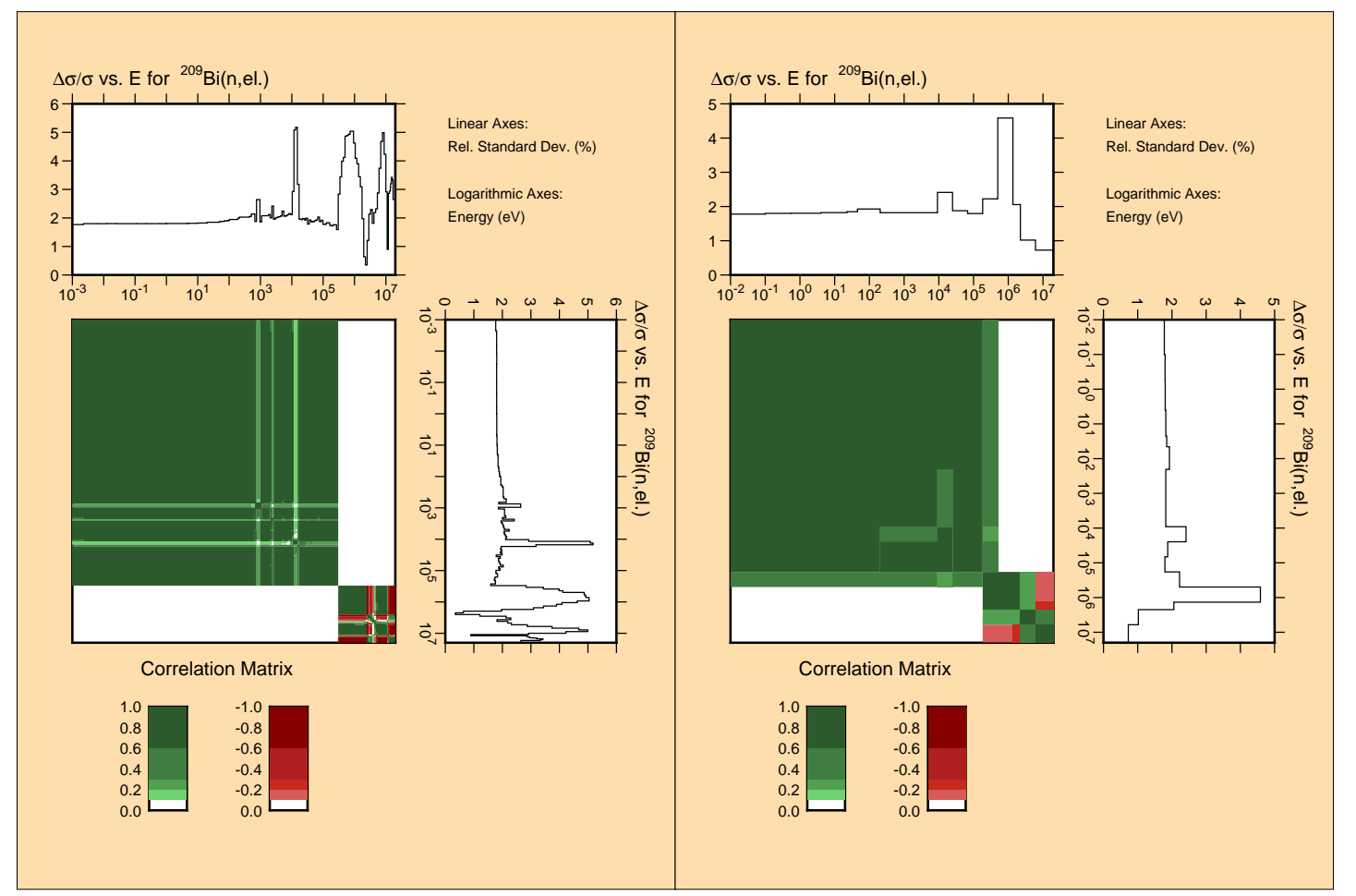

Figure A.100: Correlation and uncertainties in 187 (left) and 15 (right) groups for the ${ }^{209} \mathrm{Bi}(\mathrm{n}, \mathrm{el})$ reaction

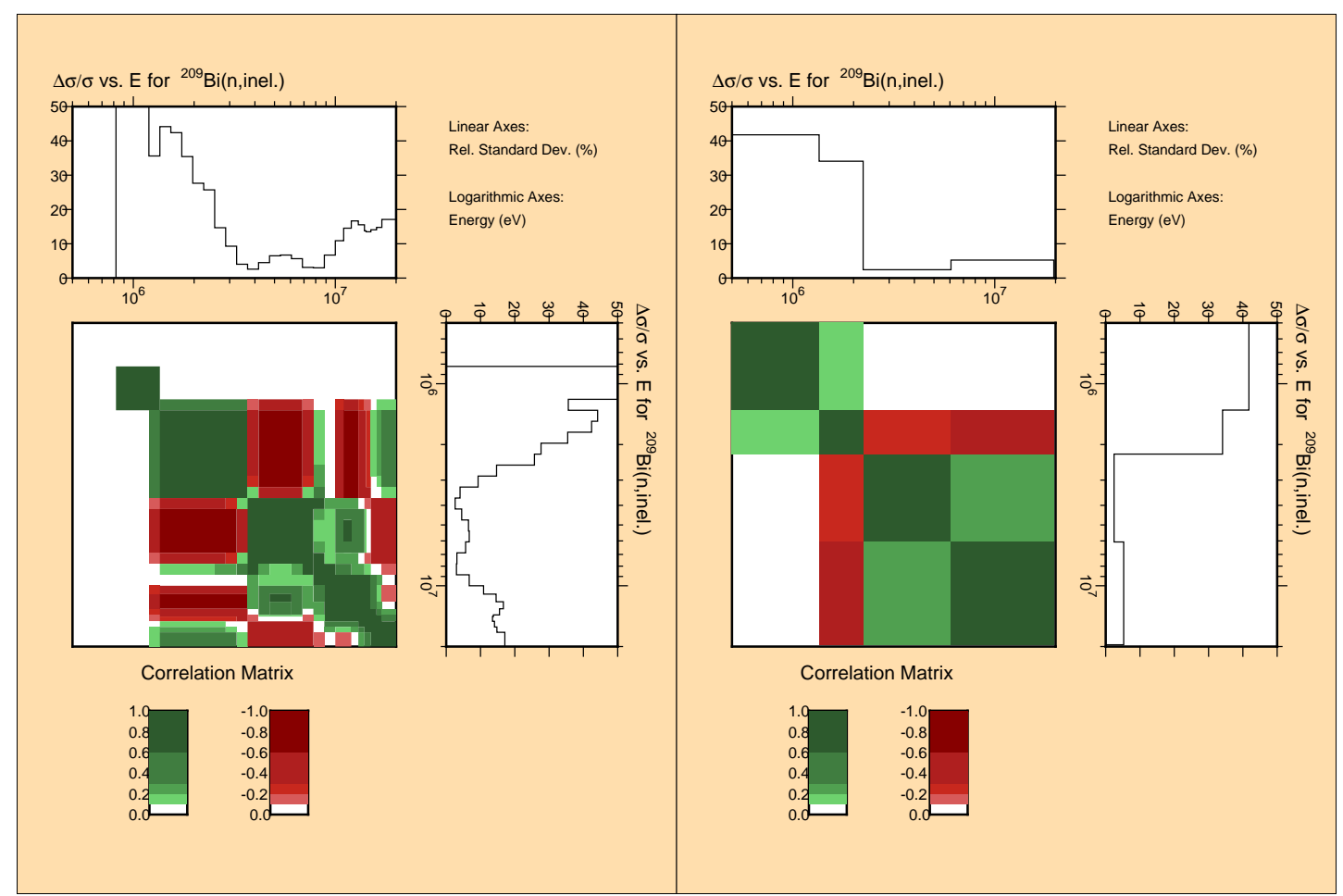

Figure A.101: Correlation and uncertainties in 187 (left) and 15 (right) groups for the ${ }^{209} \mathrm{Bi}\left(\mathrm{n}, \mathrm{n}^{\prime}\right)$ reaction

D. Rochman et al. 


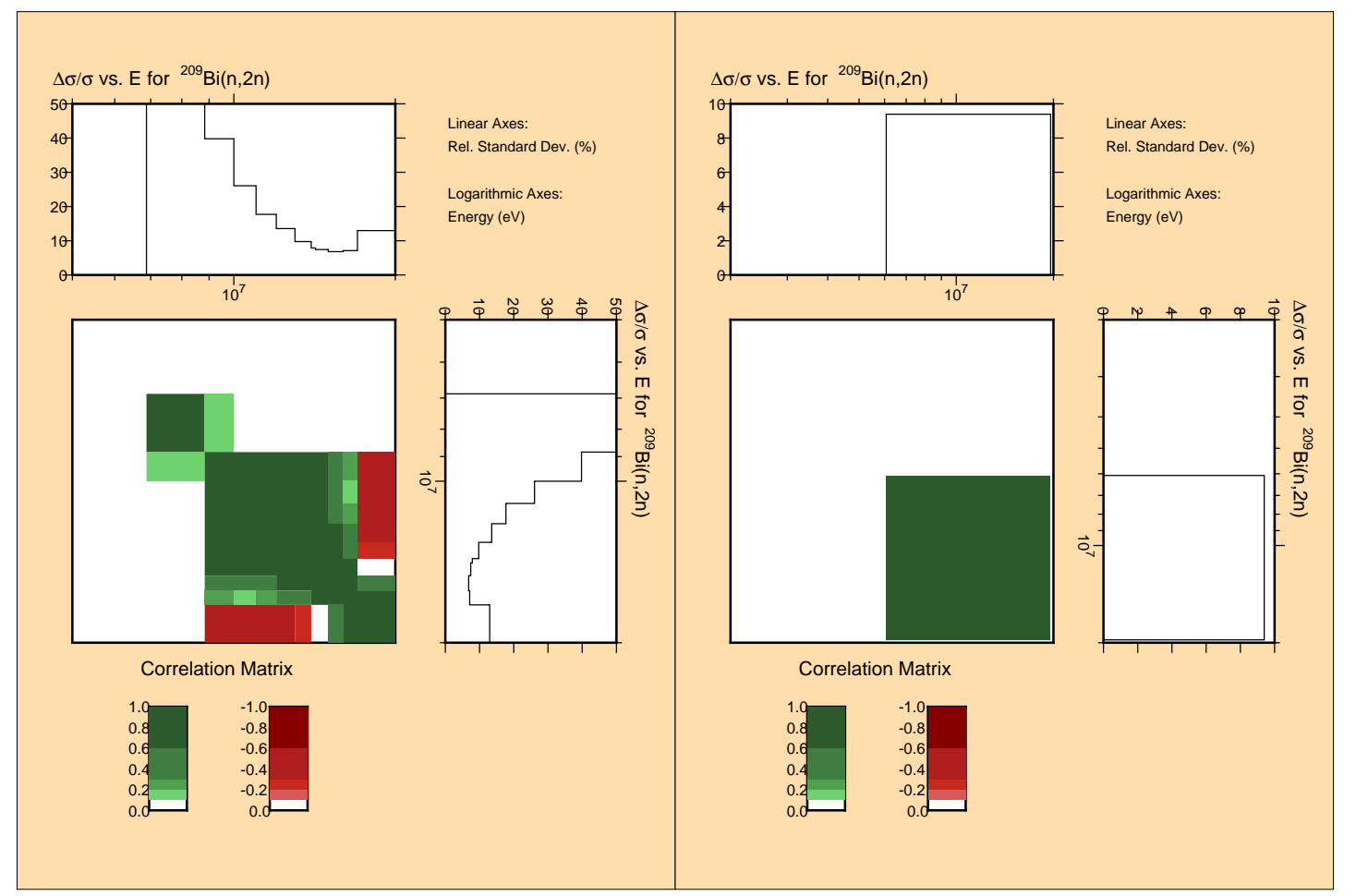

Figure A.102: Correlation and uncertainties in 187 (left) and 15 (right) groups for the ${ }^{209} \mathrm{Bi}(\mathrm{n}, 2 \mathrm{n})$ reaction

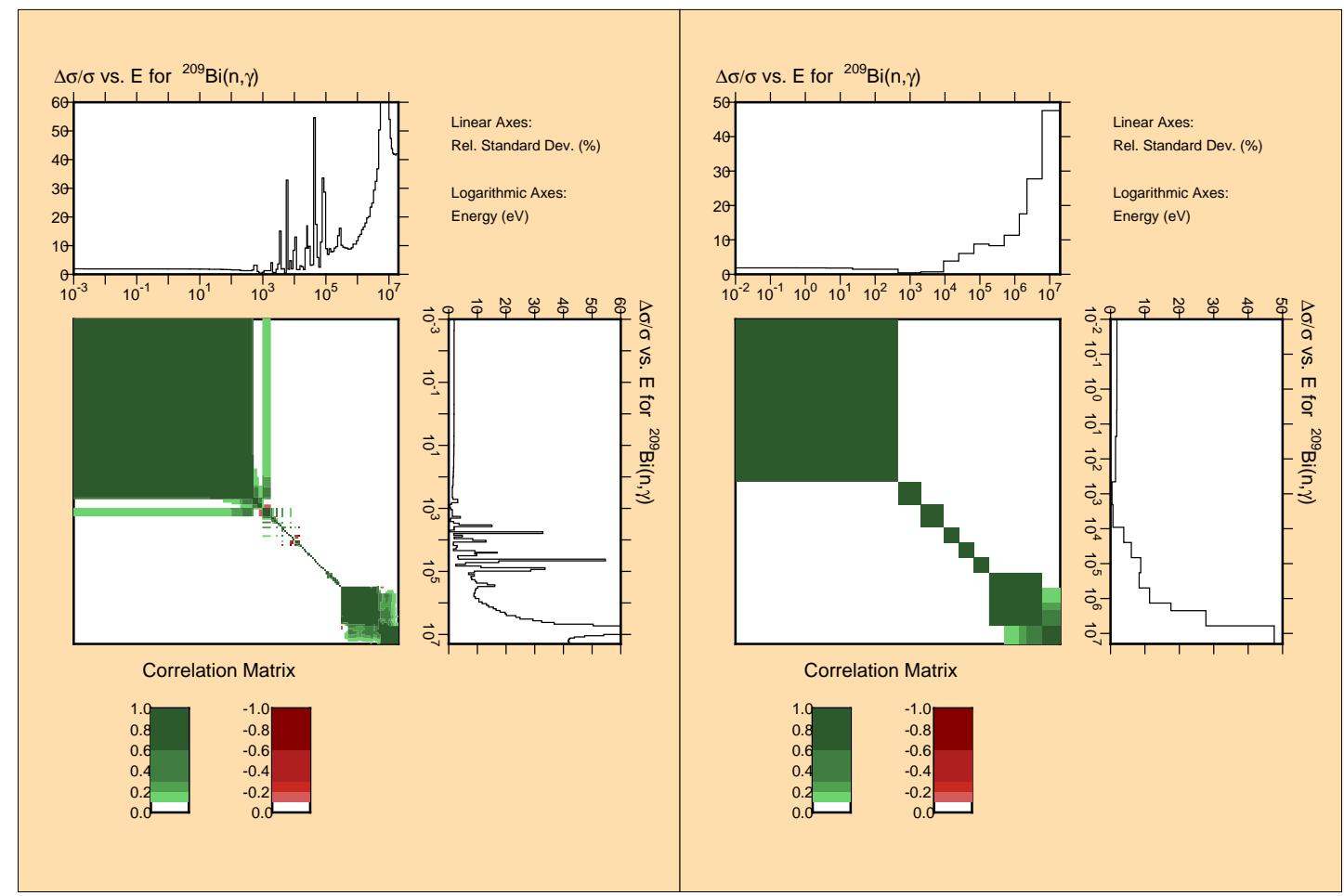

Figure A.103: Correlation and uncertainties in 187 (left) and 15 (right) groups for the ${ }^{209} \mathrm{Bi}(\mathrm{n}, \gamma)$ reaction 


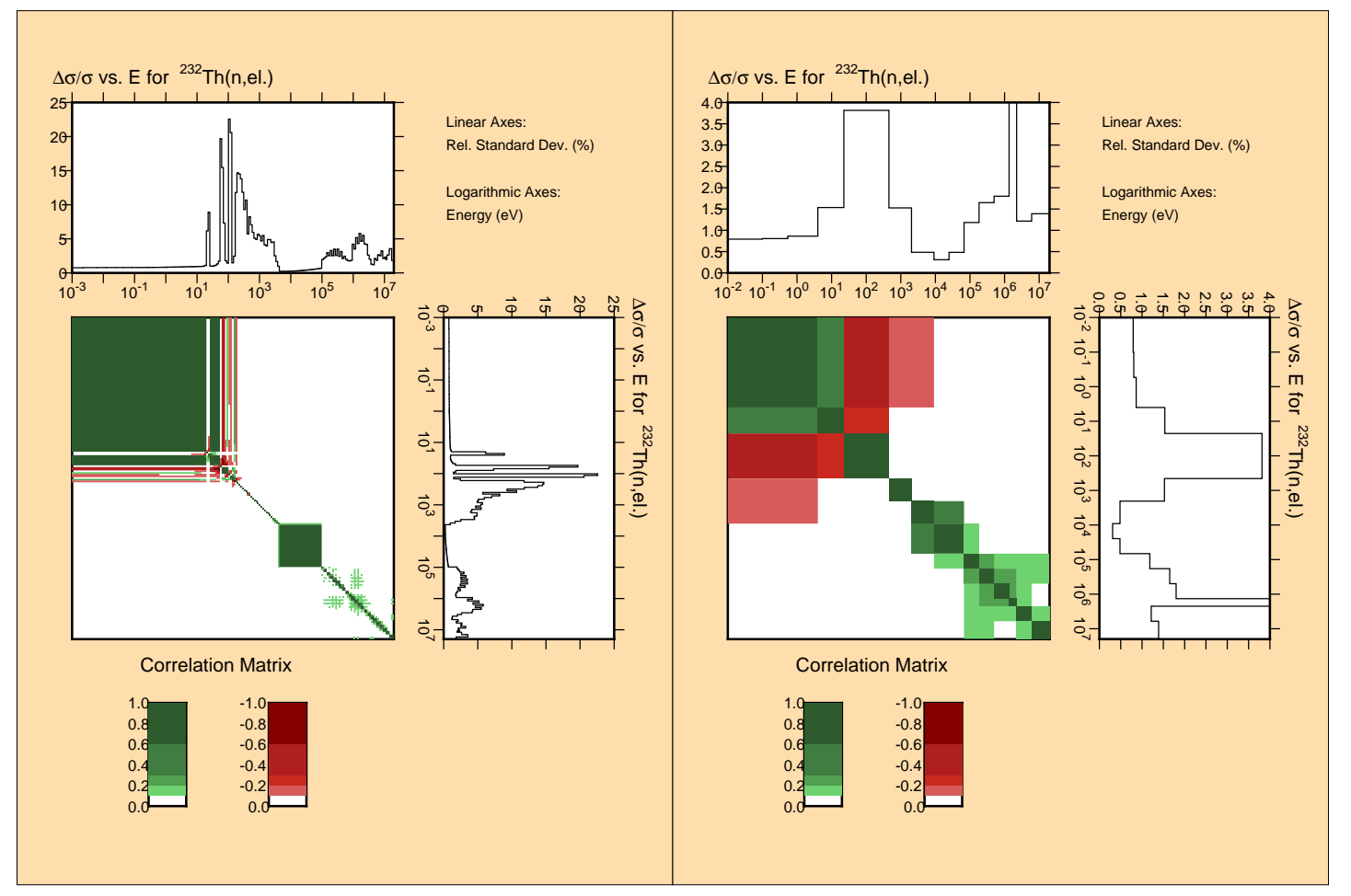

Figure A.104: Correlation and uncertainties in 187 (left) and 15 (right) groups for the ${ }^{232} \mathrm{Th}(\mathrm{n}, \mathrm{el})$ reaction

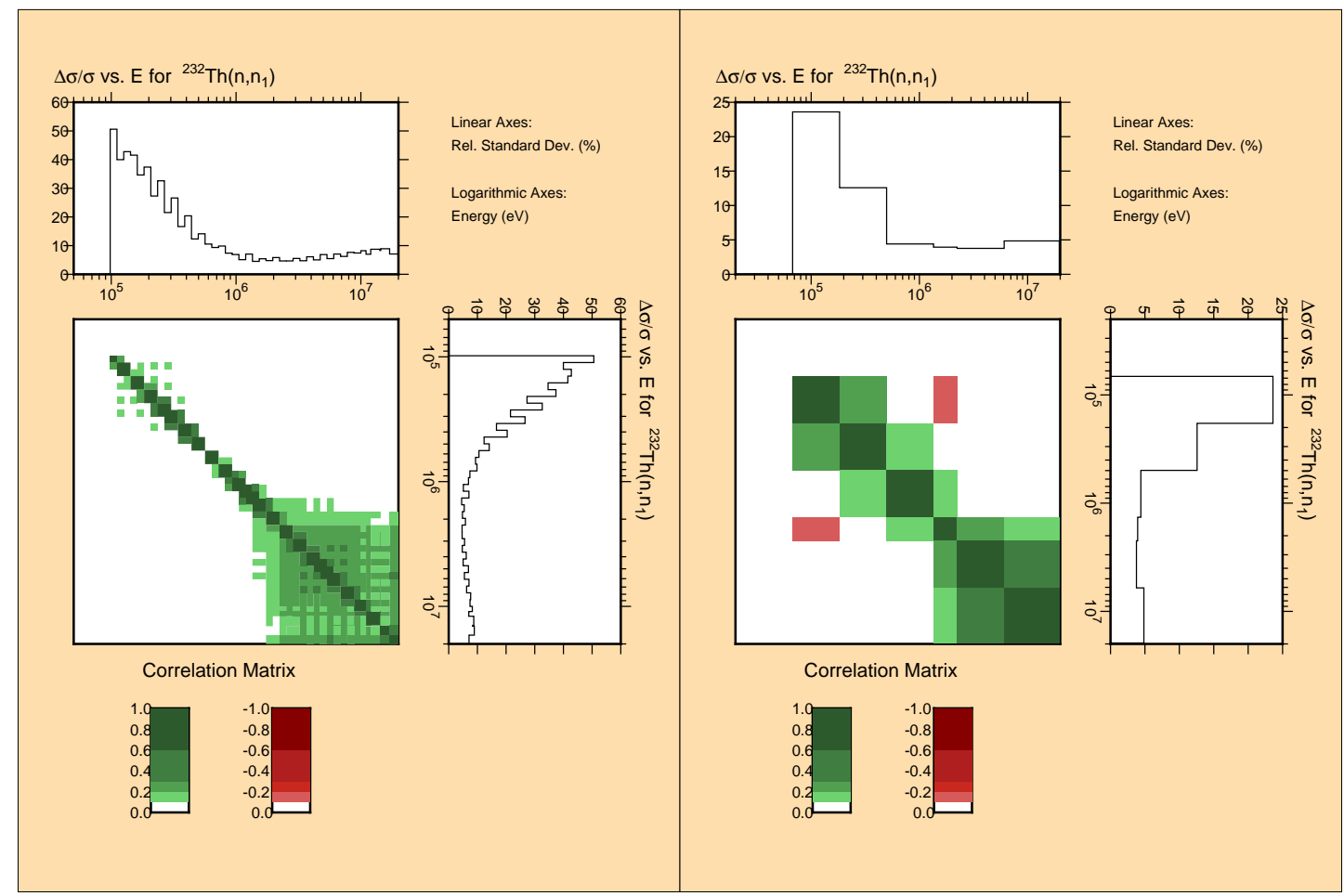

Figure A.105: Correlation and uncertainties in 187 (left) and 15 (right) groups for the ${ }^{232} \mathrm{Th}\left(\mathrm{n}, \mathrm{n}^{\prime}\right)$ reaction 


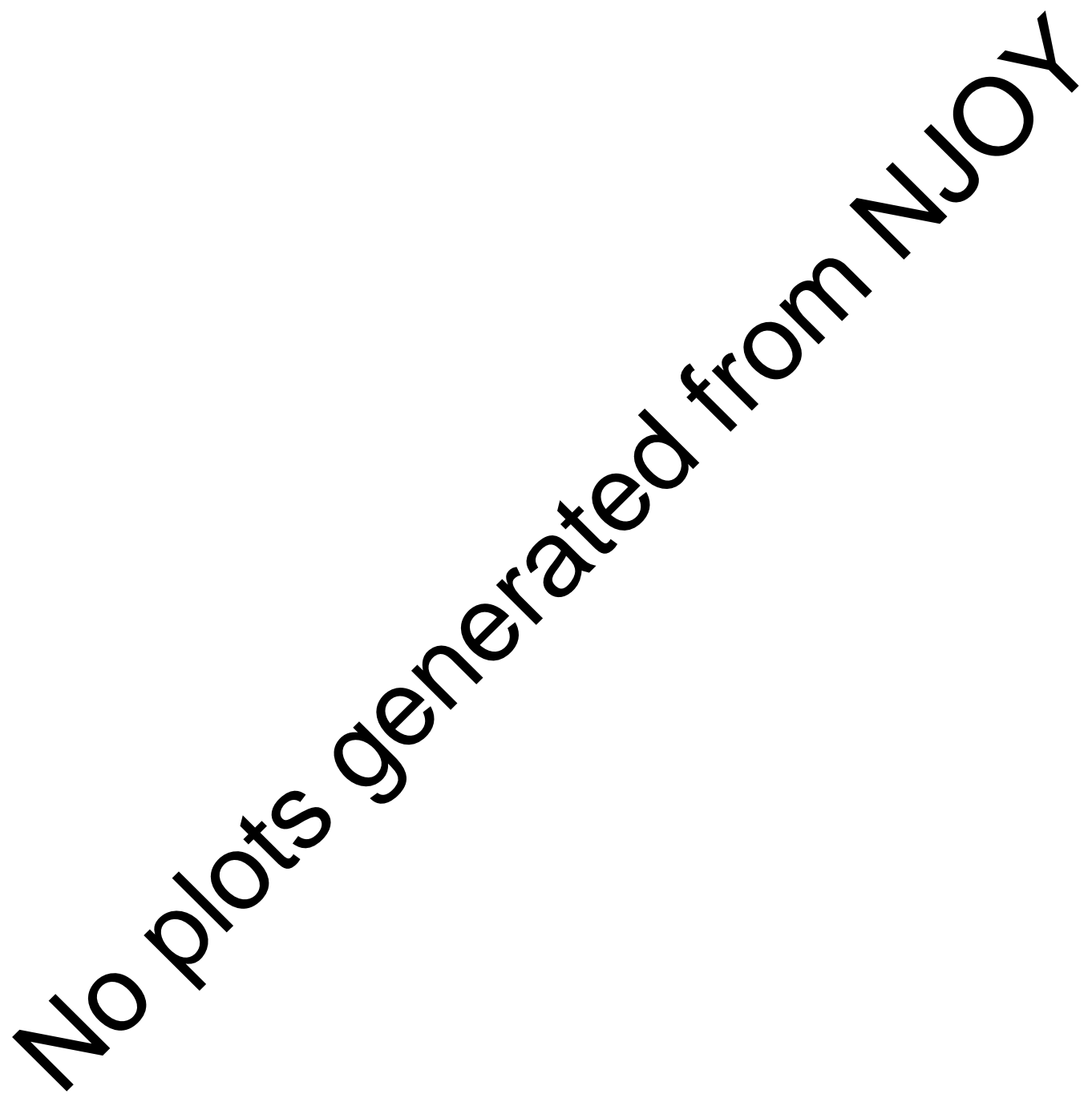

Figure A.106: Correlation and uncertainties in 187 (left) and 15 (right) groups for the ${ }^{232} \mathrm{Th}(\mathrm{n}, 2 \mathrm{n})$ reaction 


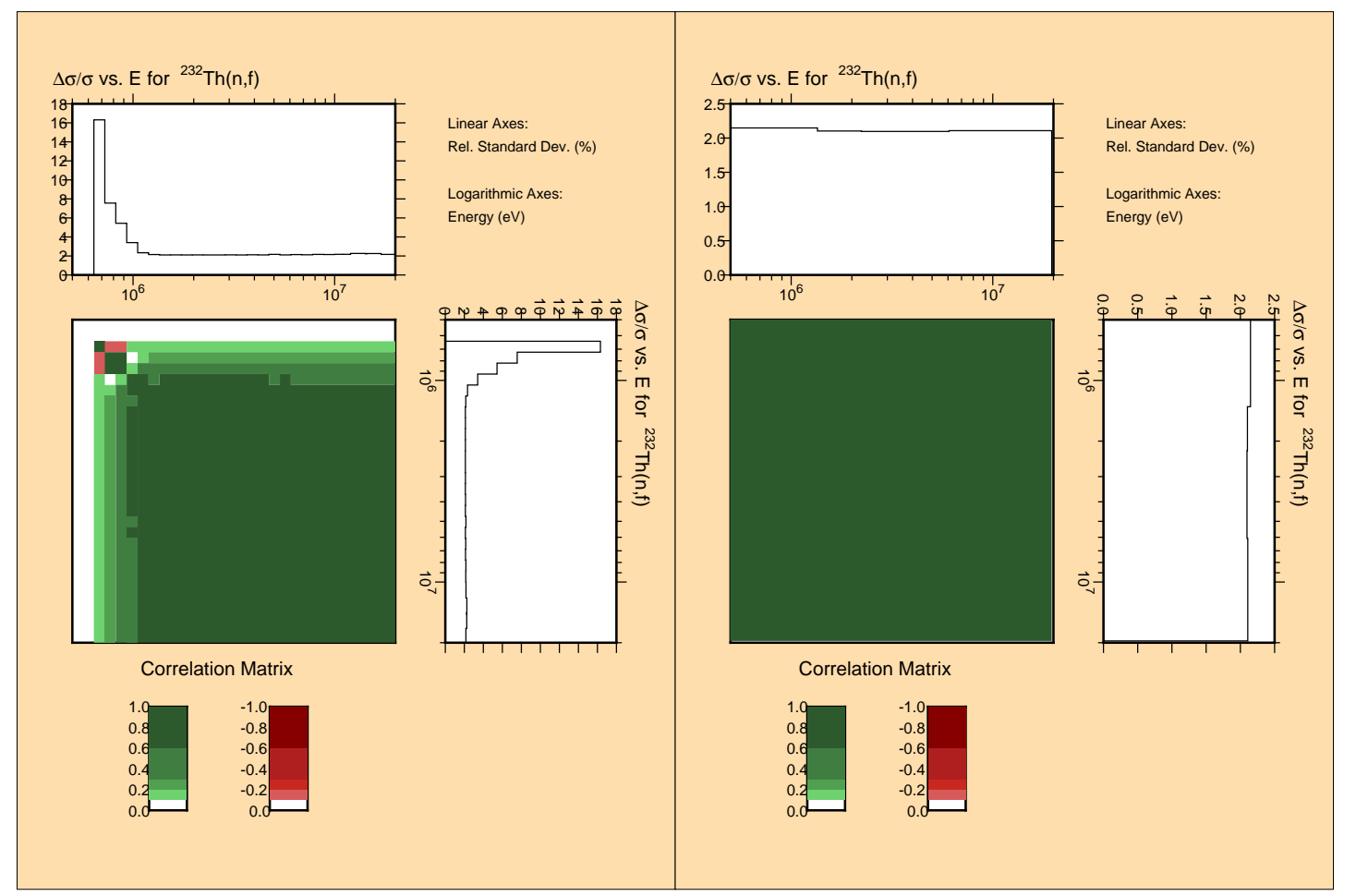

Figure A.107: Correlation and uncertainties in 187 (left) and 15 (right) groups for the ${ }^{232} \mathrm{Th}(\mathrm{n}, \mathrm{f})$ reaction

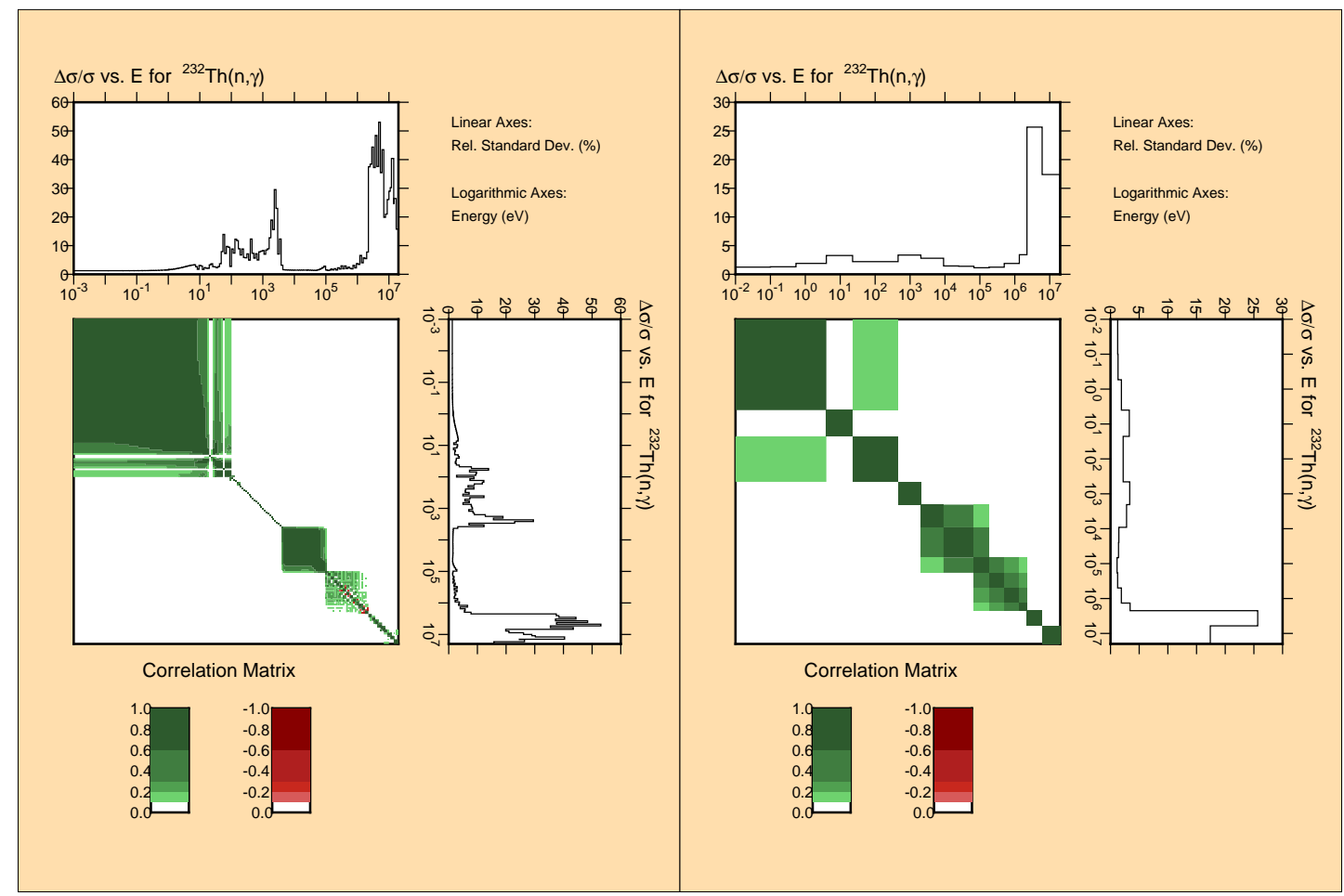

Figure A.108: Correlation and uncertainties in 187 (left) and 15 (right) groups for the ${ }^{232} \mathrm{Th}(\mathrm{n}, \gamma)$ reaction 


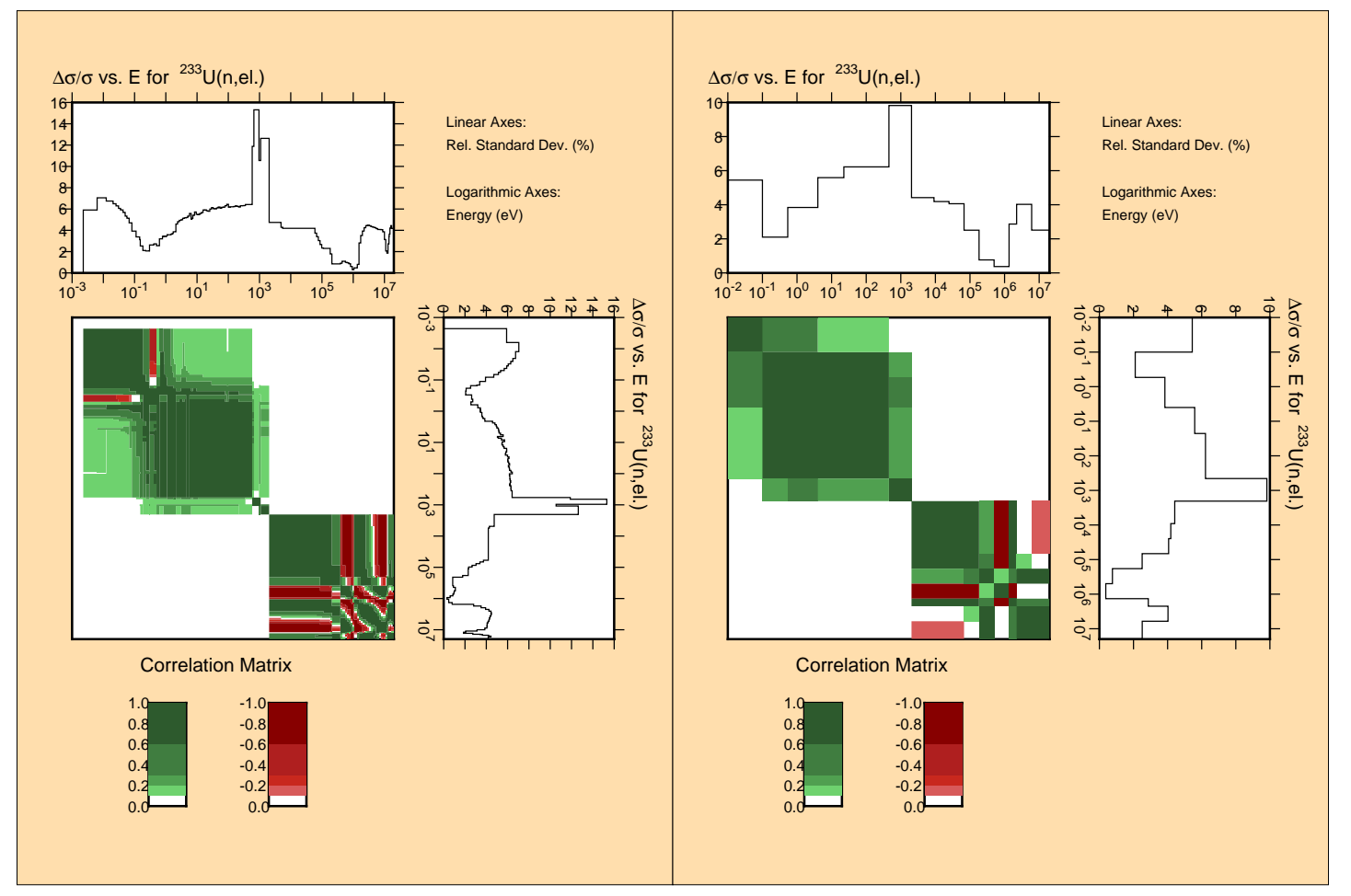

Figure A.109: Correlation and uncertainties in 187 (left) and 15 (right) groups for the ${ }^{233} \mathrm{U}(\mathrm{n}, \mathrm{el})$ reaction

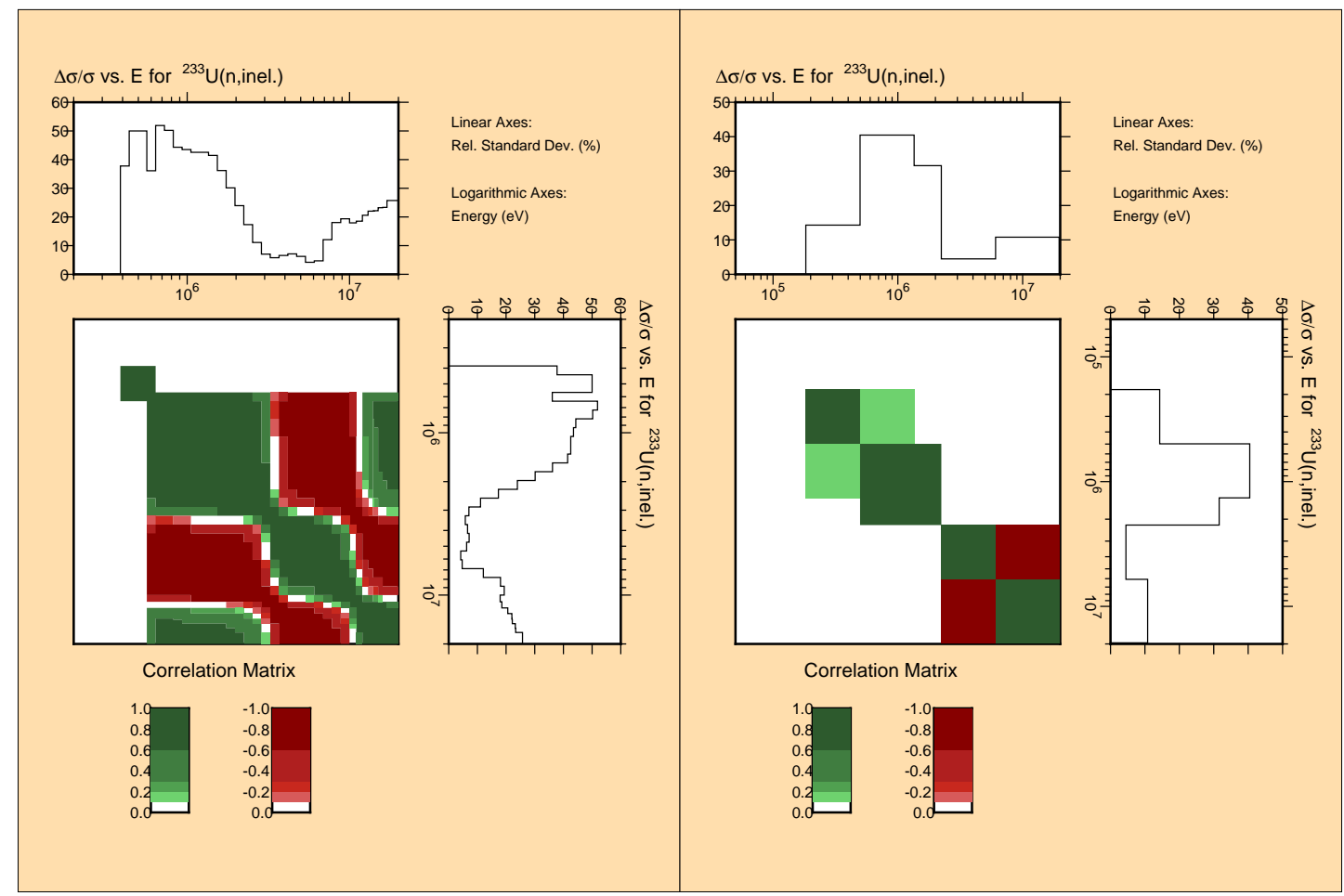

Figure A.110: Correlation and uncertainties in 187 (left) and 15 (right) groups for the ${ }^{233} \mathrm{U}\left(\mathrm{n}, \mathrm{n}^{\prime}\right)$ reaction

D. Rochman et al. 


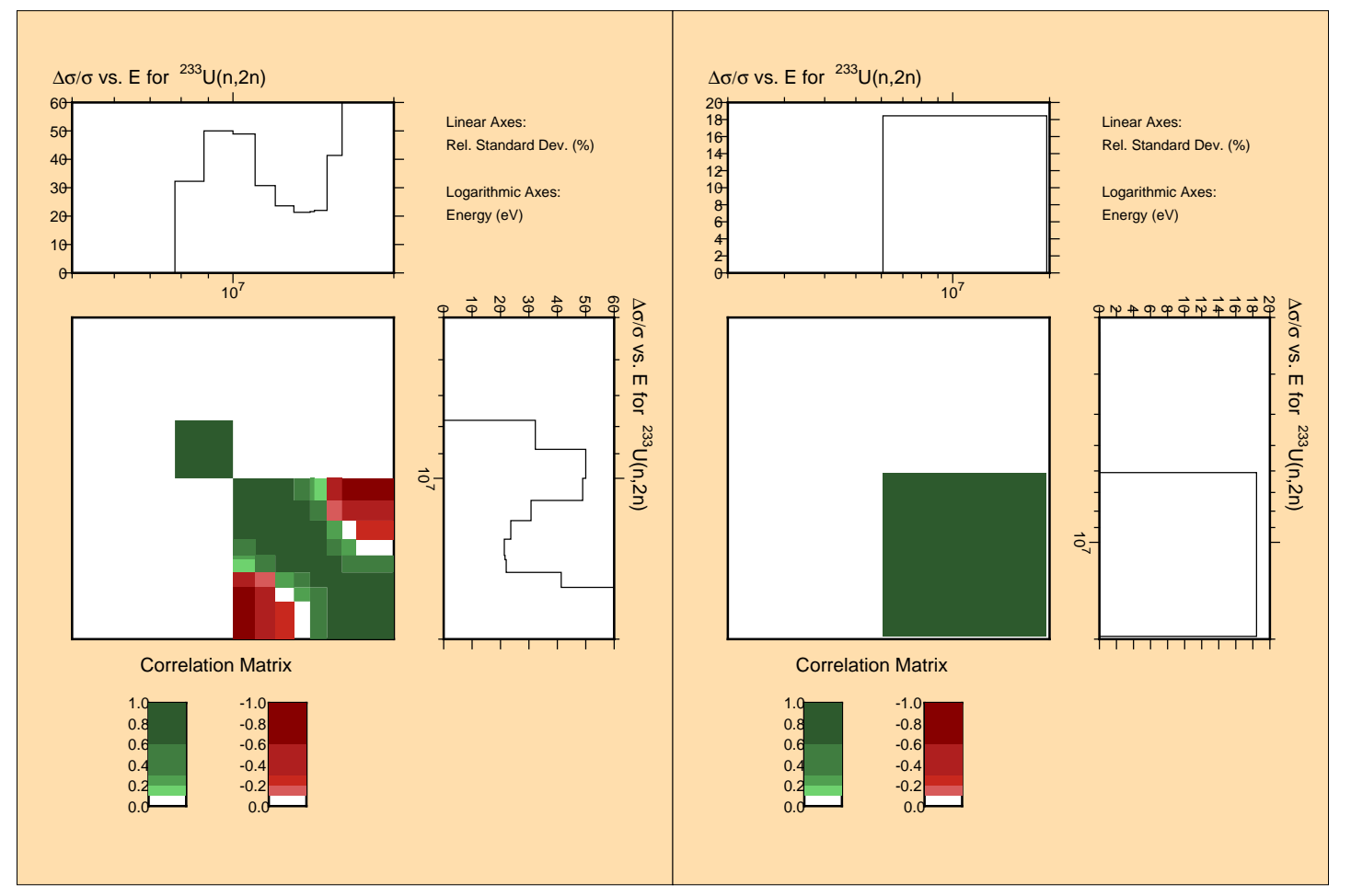

Figure A.111: Correlation and uncertainties in 187 (left) and 15 (right) groups for the ${ }^{233} \mathrm{U}(\mathrm{n}, 2 \mathrm{n})$ reaction

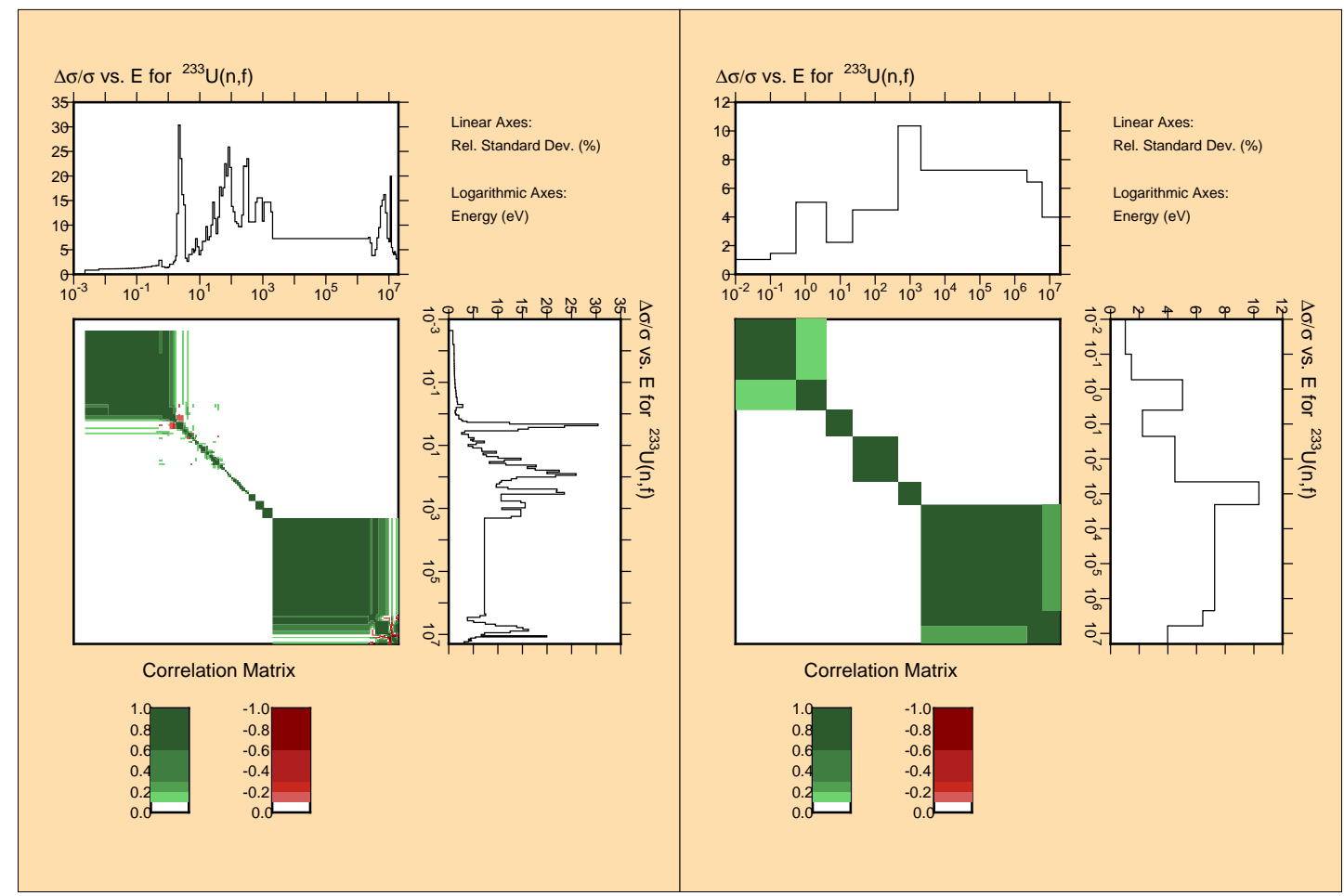

Figure A.112: Correlation and uncertainties in 187 (left) and 15 (right) groups for the ${ }^{233} \mathrm{U}(\mathrm{n}, \mathrm{f})$ reaction

D. Rochman et al. 


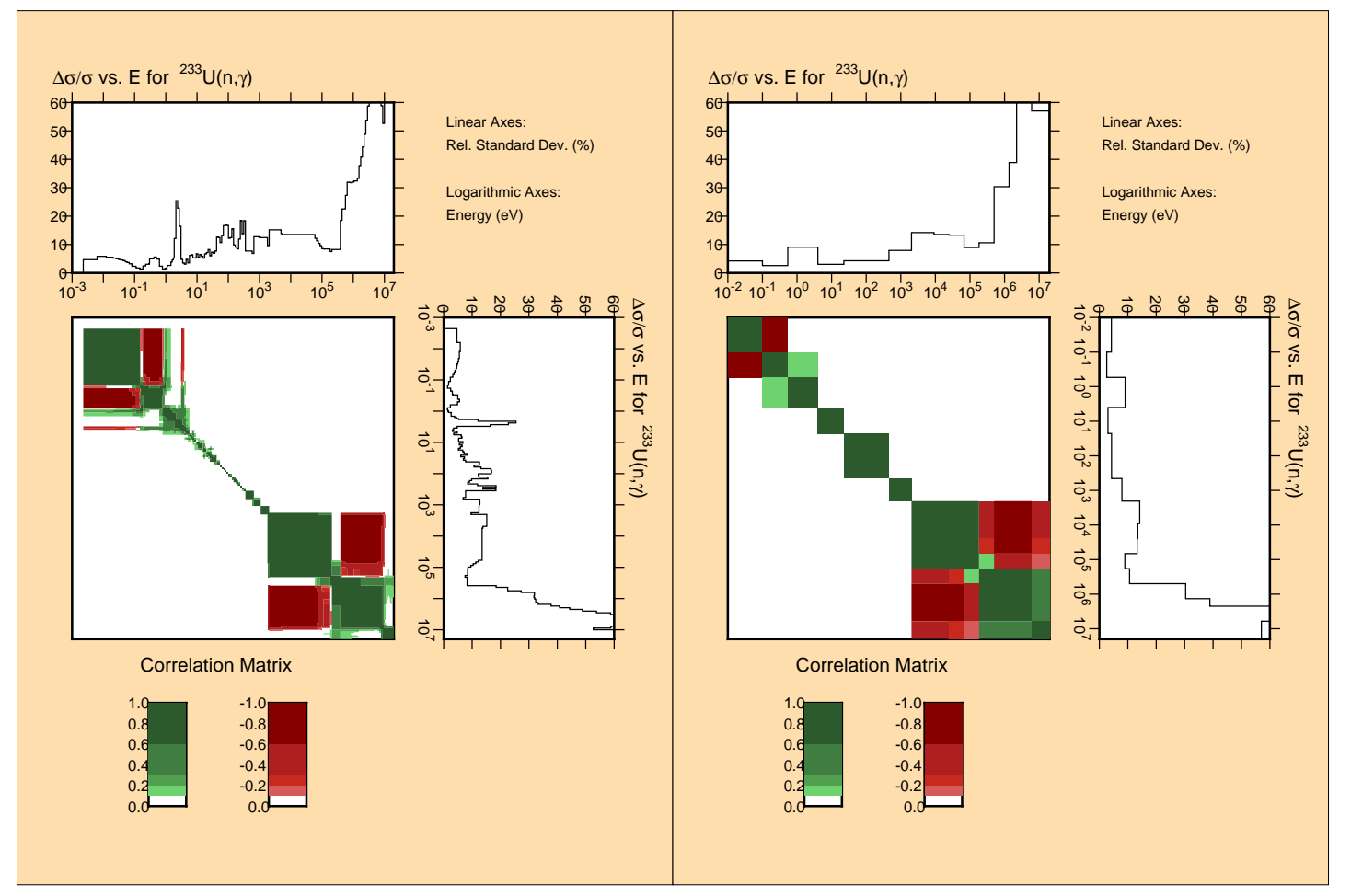

Figure A.113: Correlation and uncertainties in 187 (left) and 15 (right) groups for the ${ }^{233} \mathrm{U}(\mathrm{n}, \gamma)$ reaction

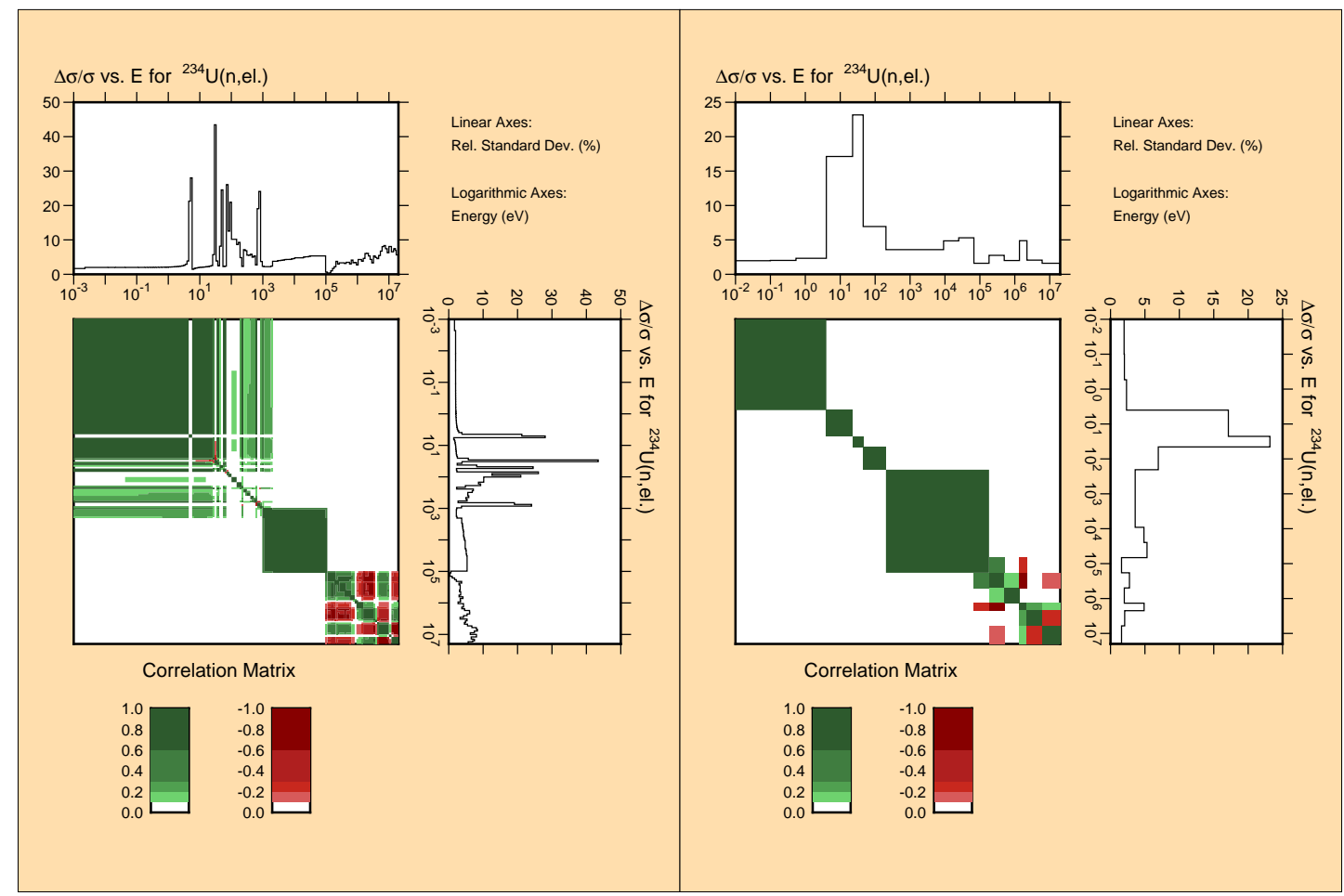

Figure A.114: Correlation and uncertainties in 187 (left) and 15 (right) groups for the ${ }^{234} \mathrm{U}(\mathrm{n}, \mathrm{el})$ reaction 


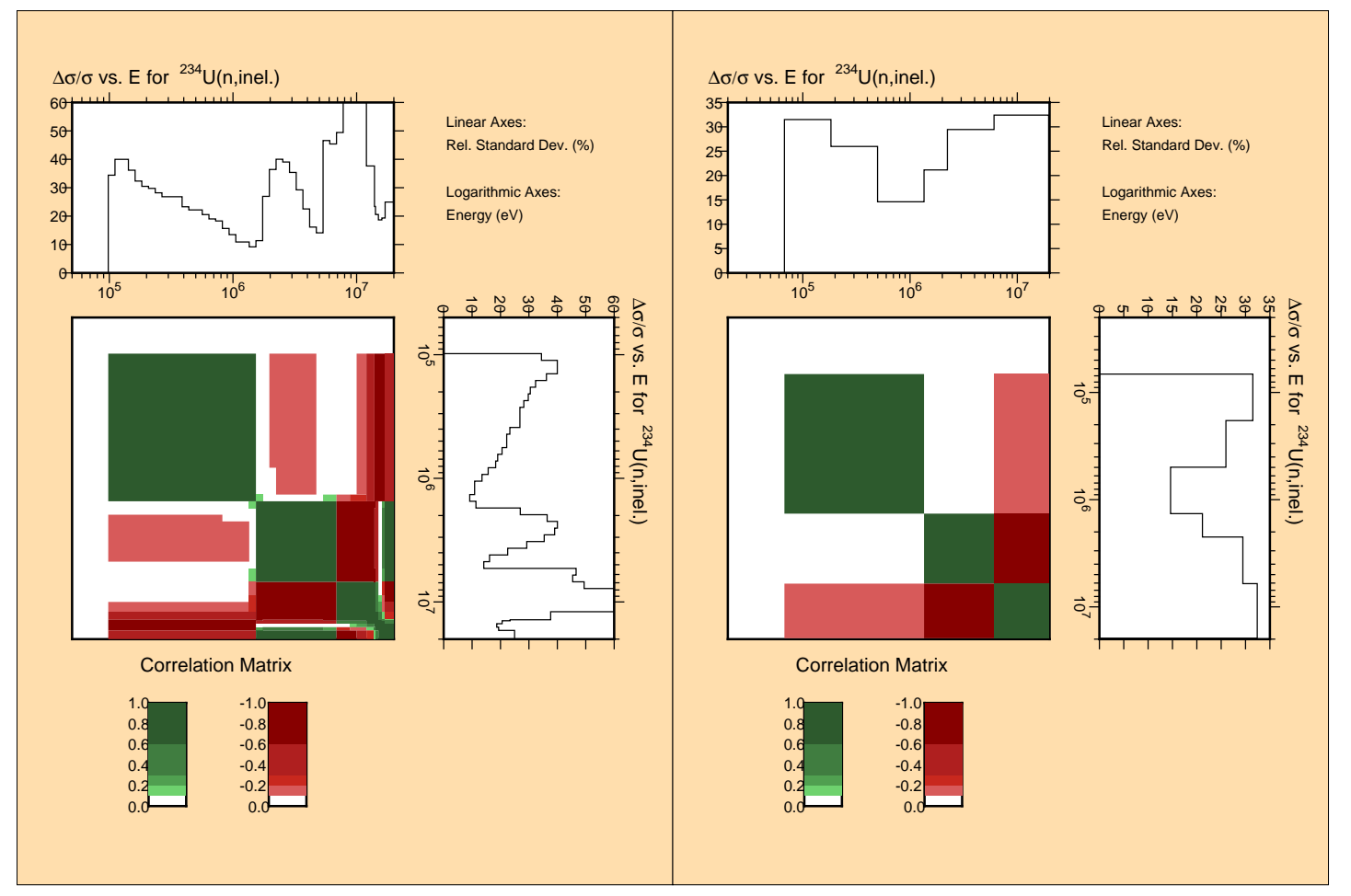

Figure A.115: Correlation and uncertainties in 187 (left) and 15 (right) groups for the ${ }^{234} \mathrm{U}\left(\mathrm{n}, \mathrm{n}^{\prime}\right)$ reaction

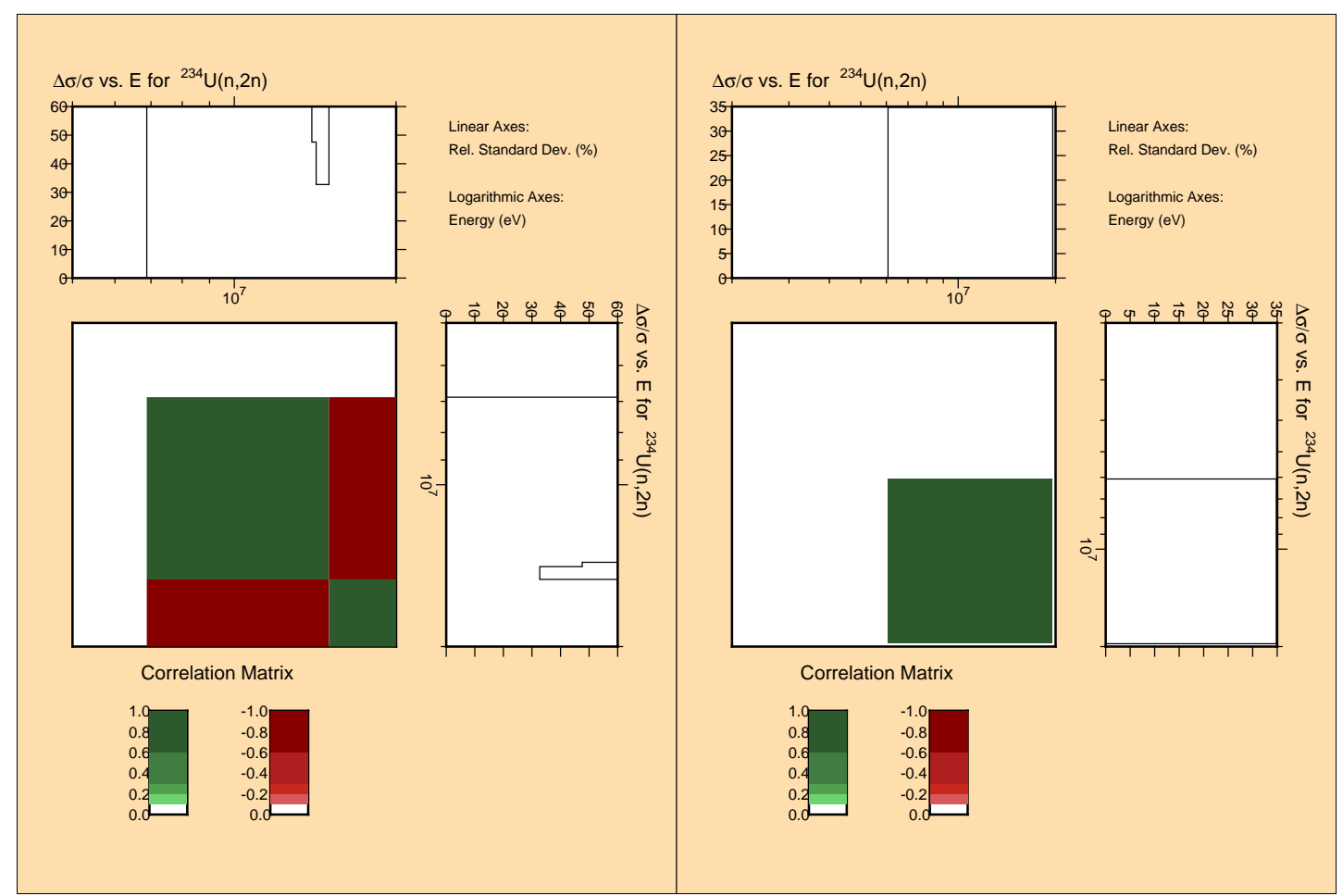

Figure A.116: Correlation and uncertainties in 187 (left) and 15 (right) groups for the ${ }^{234} \mathrm{U}(\mathrm{n}, 2 \mathrm{n})$ reaction 


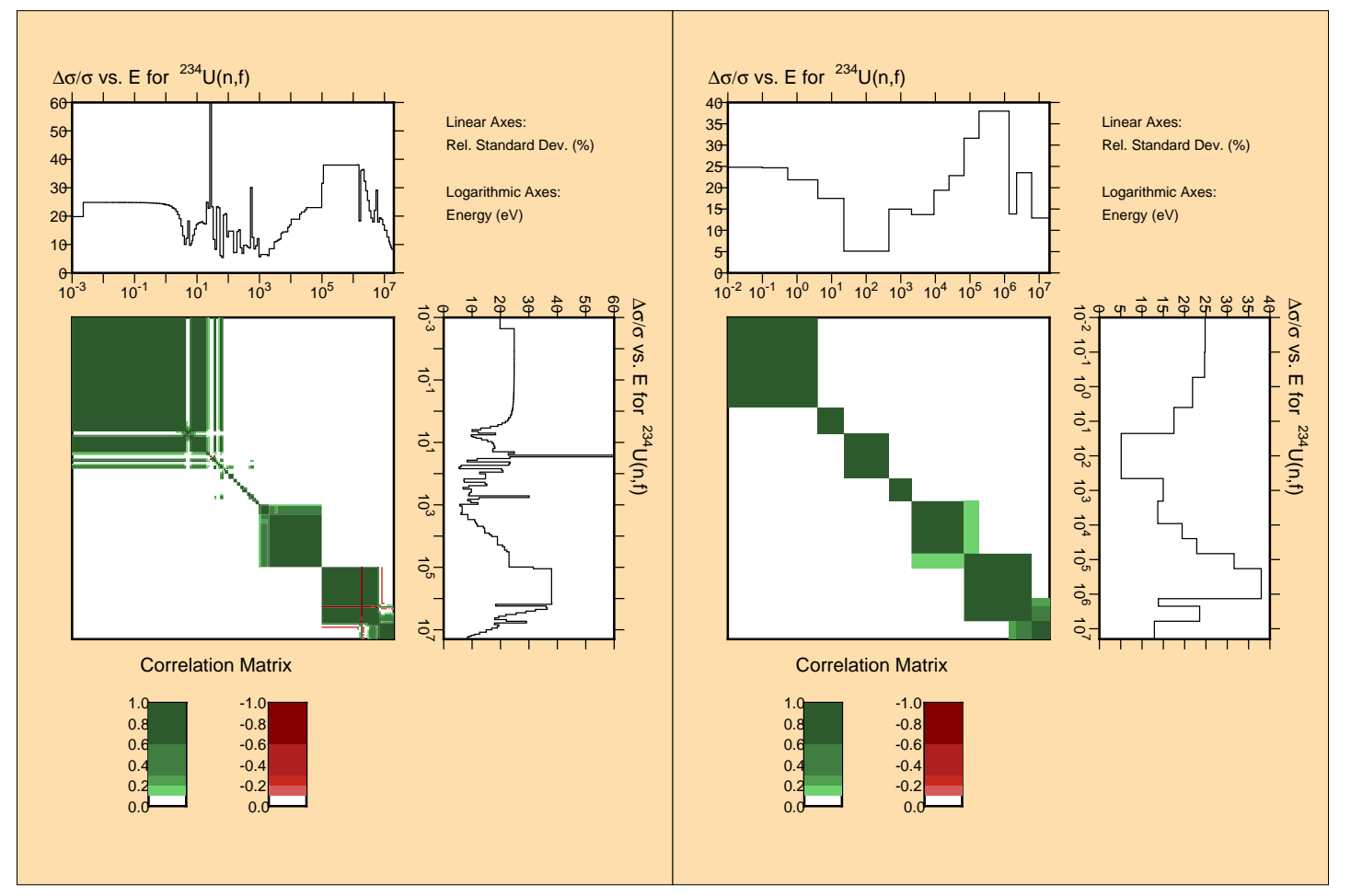

Figure A.117: Correlation and uncertainties in 187 (left) and 15 (right) groups for the ${ }^{234} \mathrm{U}(\mathrm{n}, \mathrm{f})$ reaction

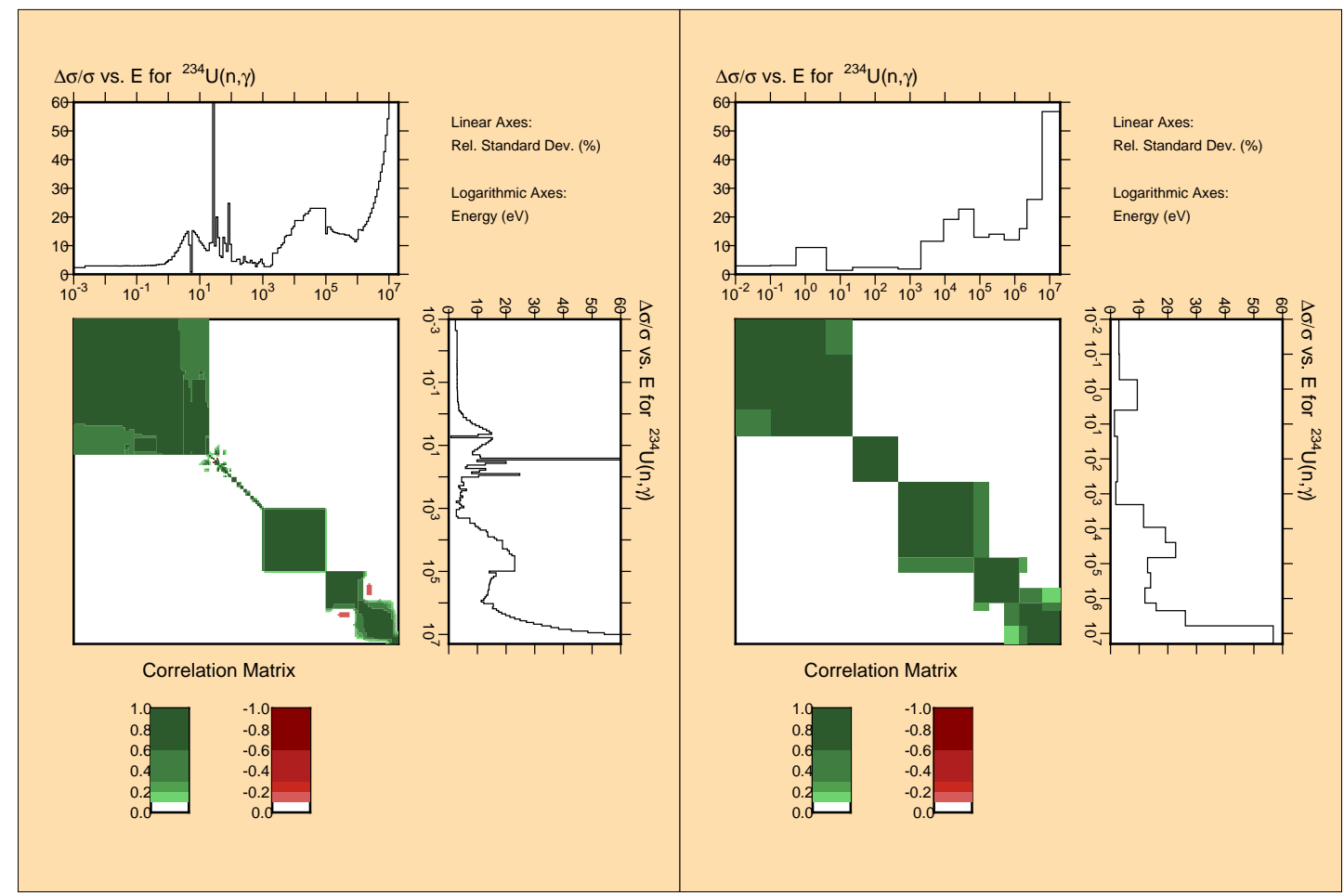

Figure A.118: Correlation and uncertainties in 187 (left) and 15 (right) groups for the ${ }^{234} \mathrm{U}(\mathrm{n}, \gamma)$ reaction 


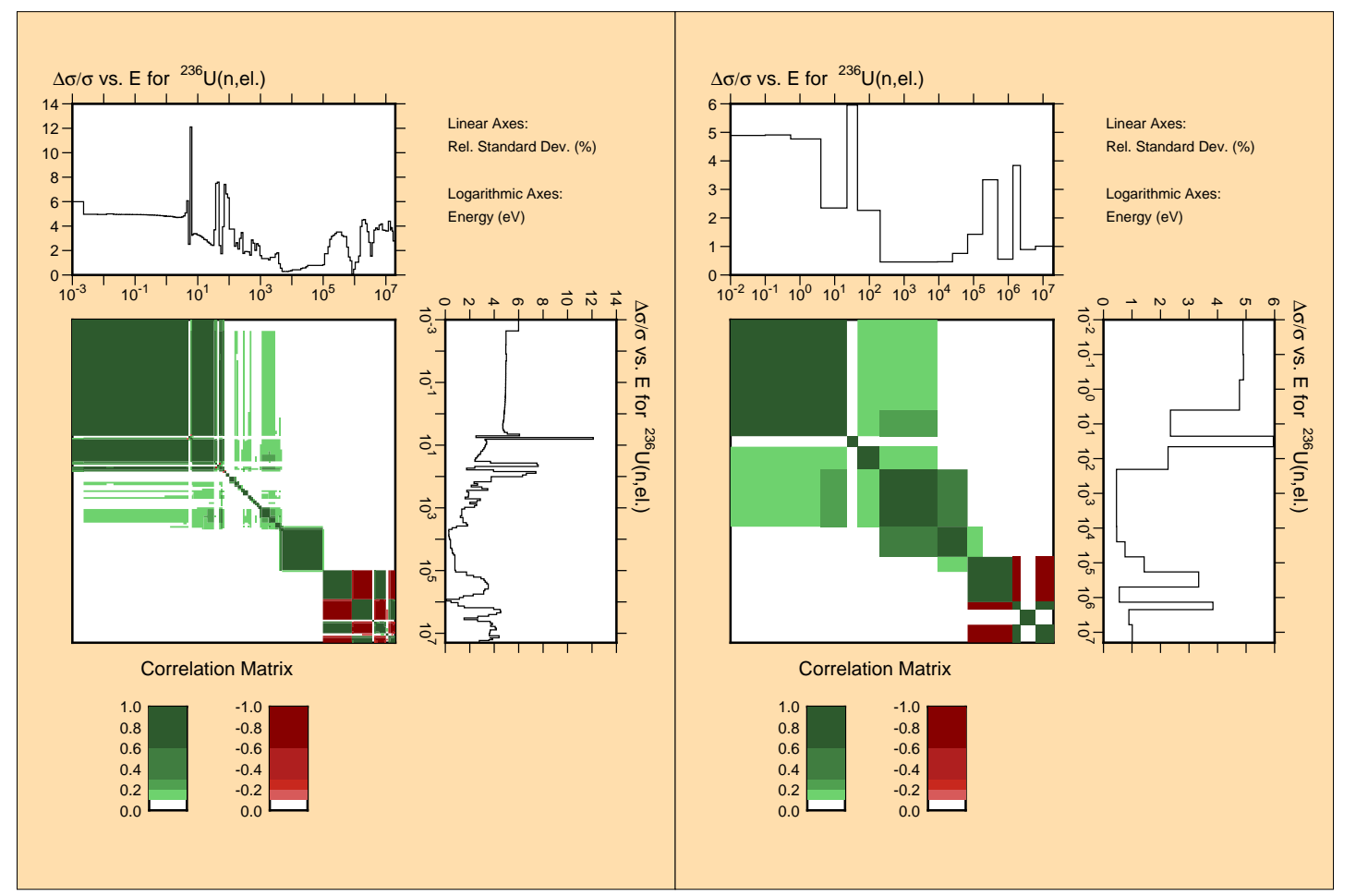

Figure A.119: Correlation and uncertainties in 187 (left) and 15 (right) groups for the ${ }^{236} \mathrm{U}(\mathrm{n}, \mathrm{el})$ reaction

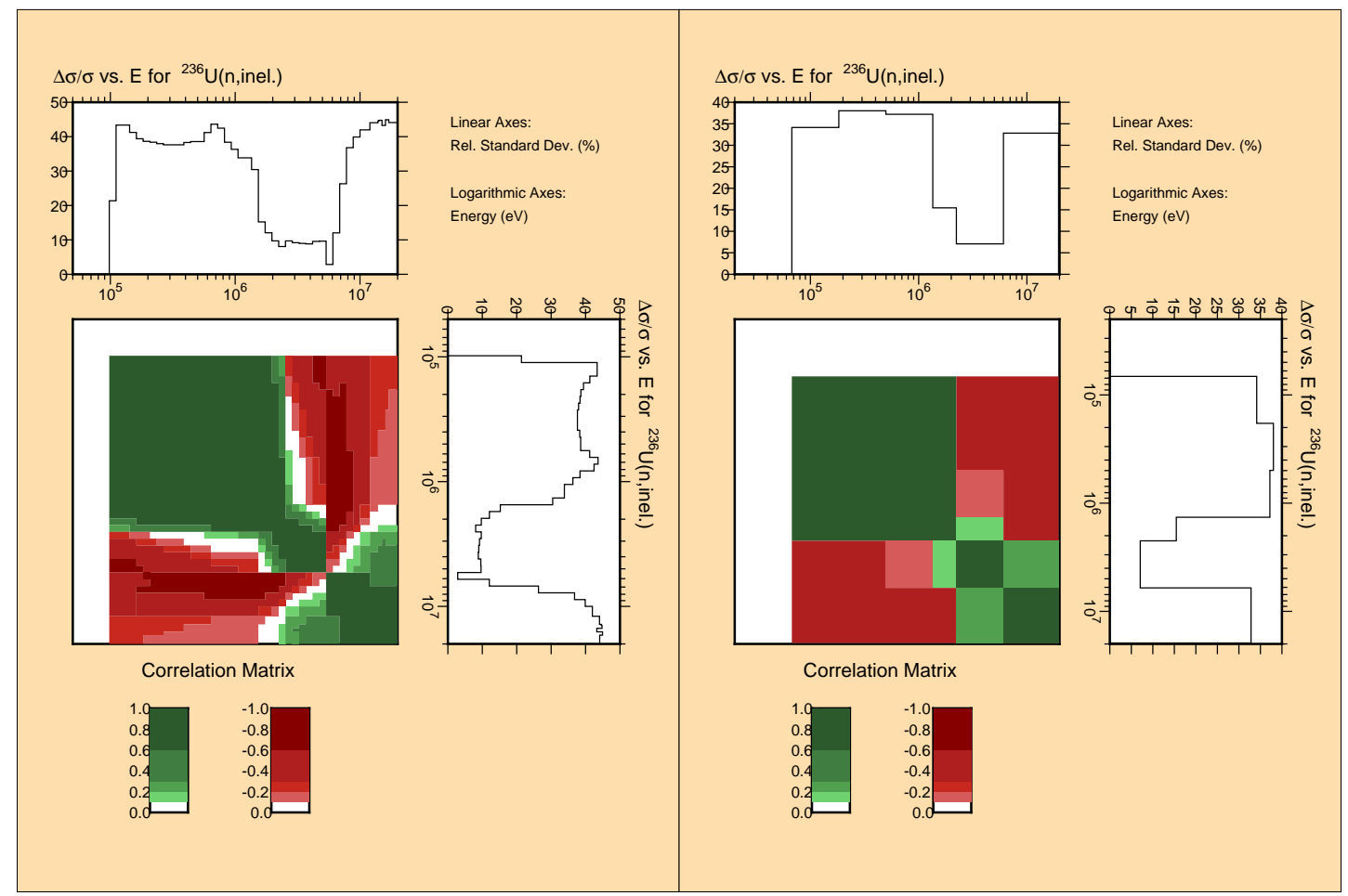

Figure A.120: Correlation and uncertainties in 187 (left) and 15 (right) groups for the ${ }^{236} \mathrm{U}\left(\mathrm{n}, \mathrm{n}^{\prime}\right)$ reaction 


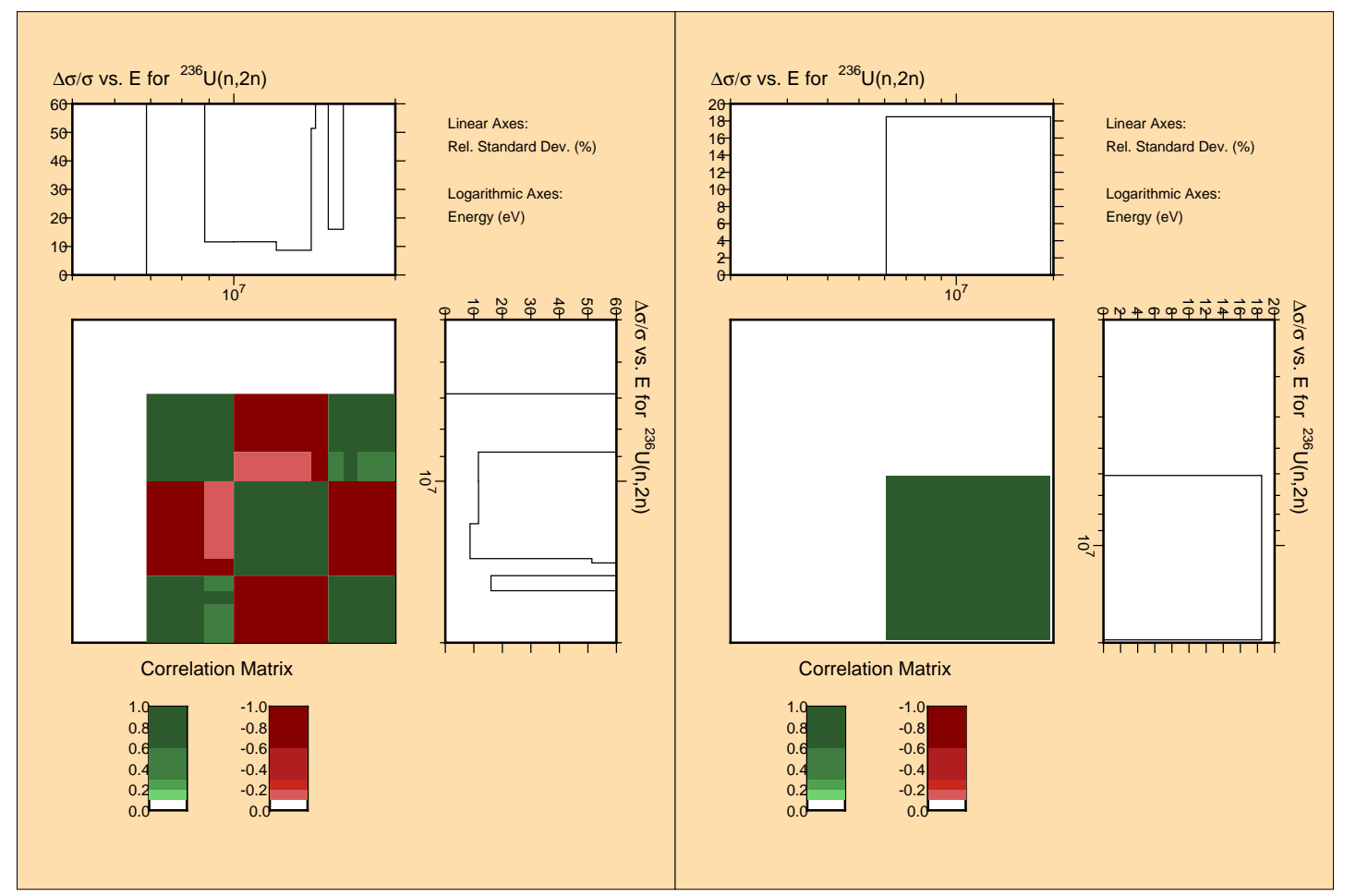

Figure A.121: Correlation and uncertainties in 187 (left) and 15 (right) groups for the ${ }^{236} \mathrm{U}(\mathrm{n}, 2 \mathrm{n})$ reaction

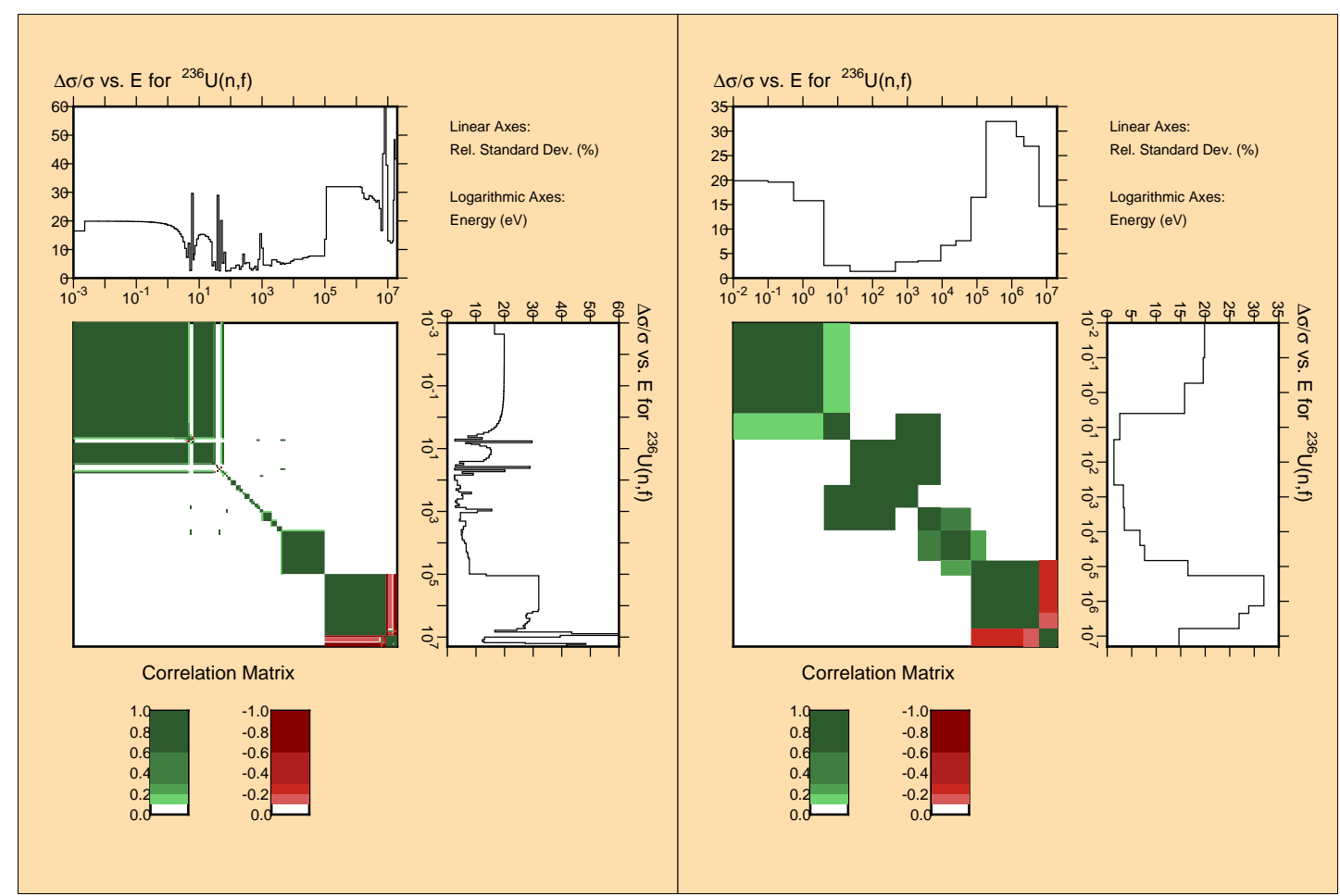

Figure A.122: Correlation and uncertainties in 187 (left) and 15 (right) groups for the ${ }^{236} \mathrm{U}(\mathrm{n}, \mathrm{f})$ reaction 


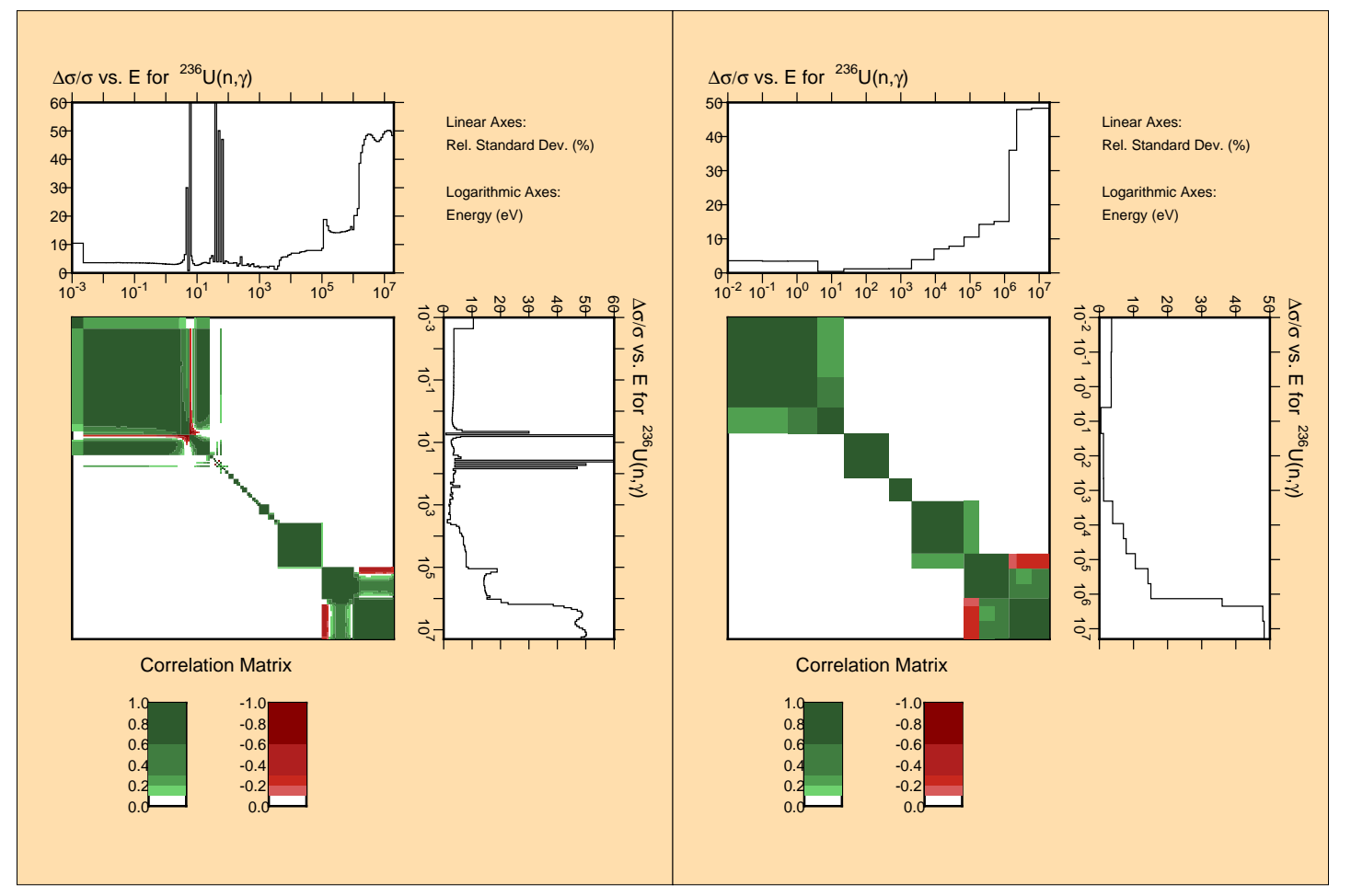

Figure A.123: Correlation and uncertainties in 187 (left) and 15 (right) groups for the ${ }^{236} \mathrm{U}(\mathrm{n}, \gamma)$ reaction

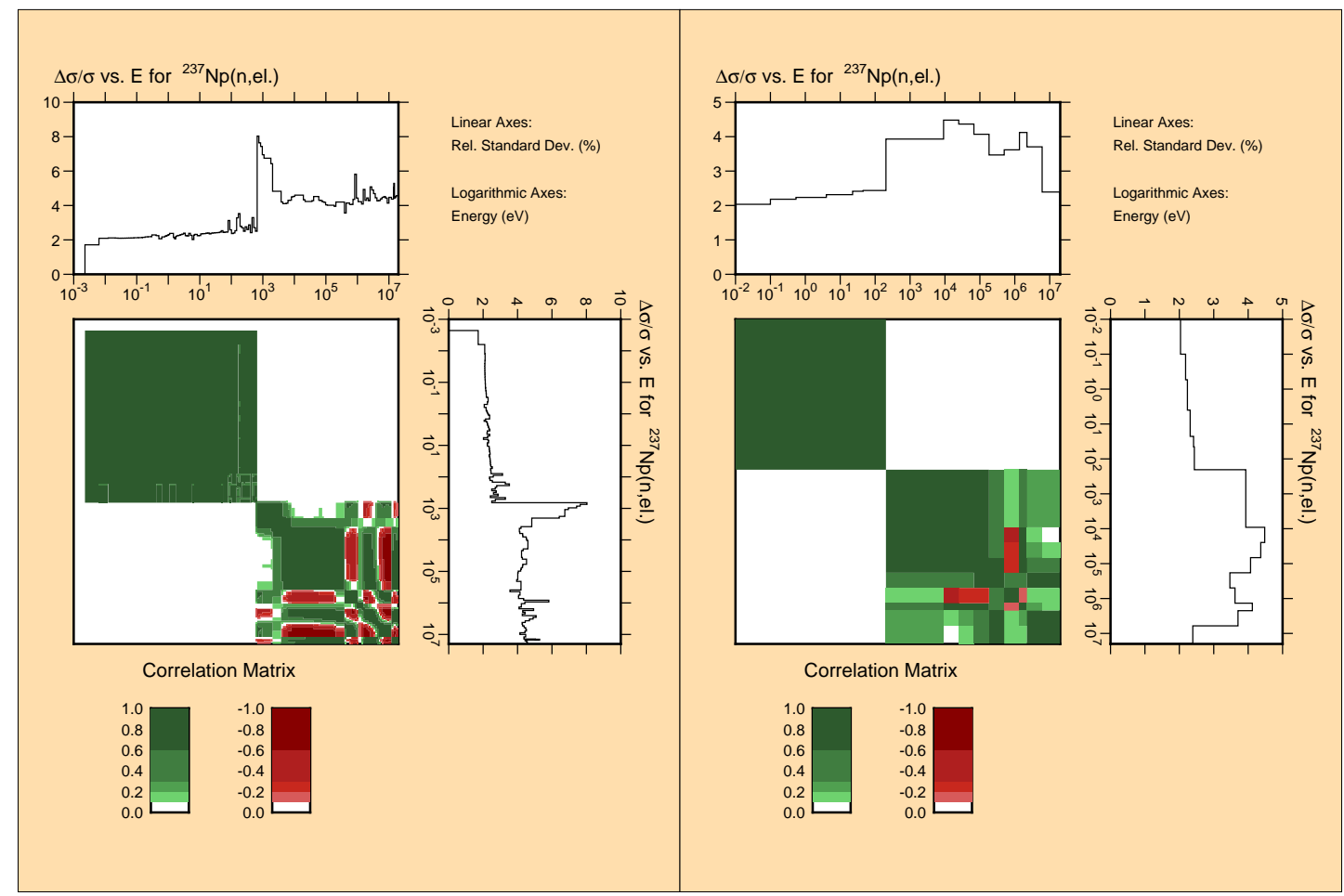

Figure A.124: Correlation and uncertainties in 187 (left) and 15 (right) groups for the ${ }^{237} \mathrm{~Np}(\mathrm{n}, \mathrm{el})$ reaction 


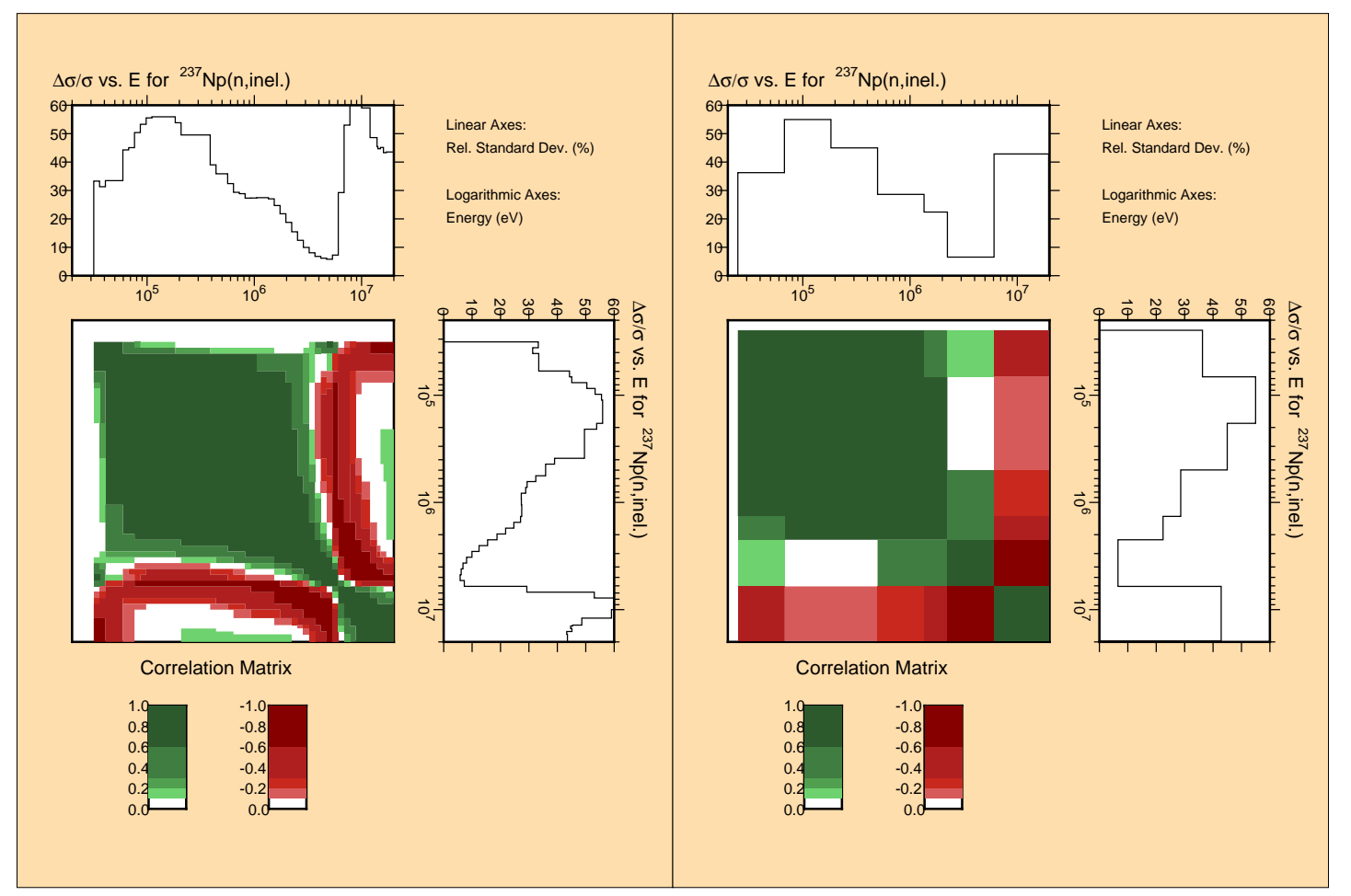

Figure A.125: Correlation and uncertainties in 187 (left) and 15 (right) groups for the ${ }^{237} \mathrm{~Np}\left(\mathrm{n}, \mathrm{n}^{\prime}\right)$ reaction

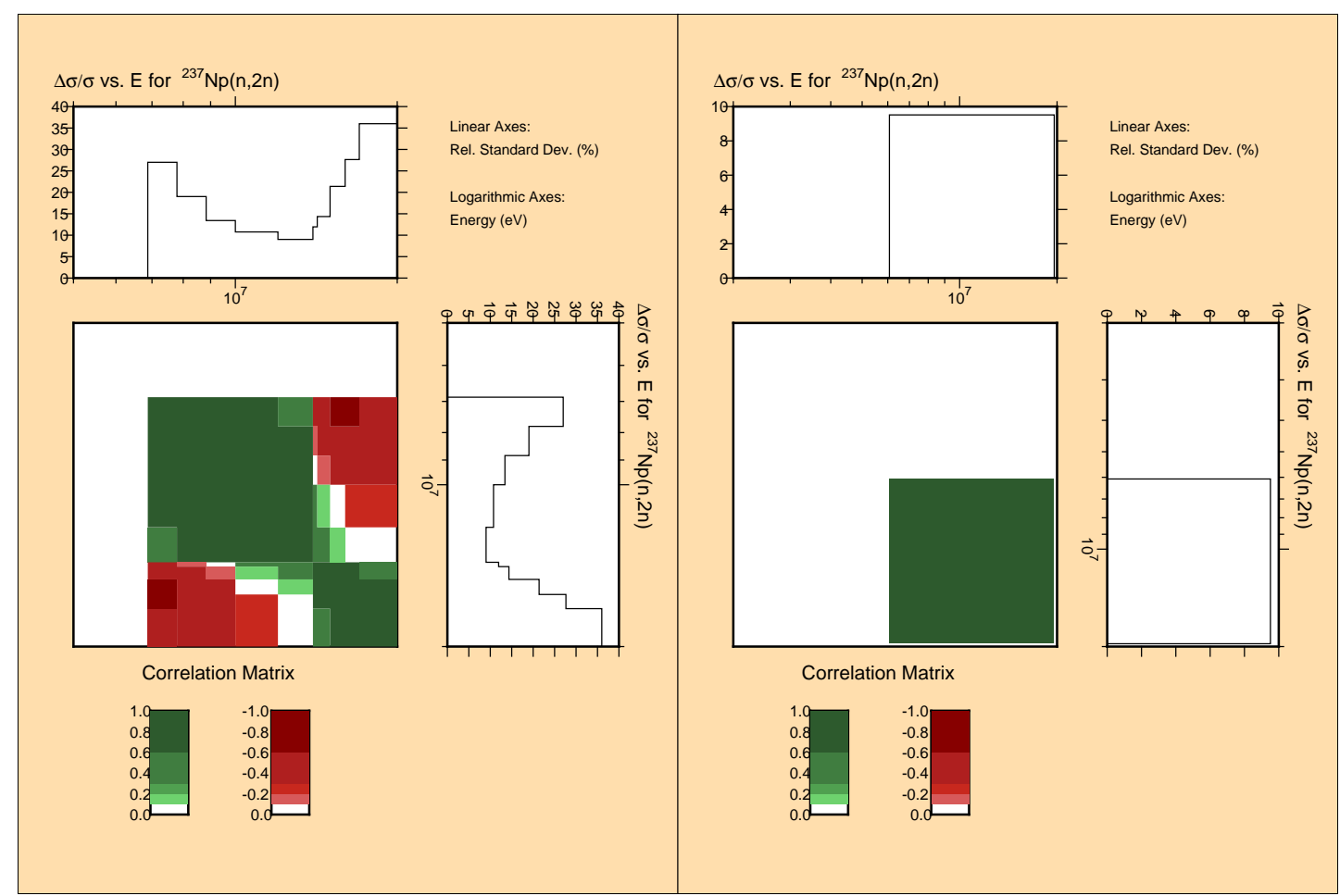

Figure A.126: Correlation and uncertainties in 187 (left) and 15 (right) groups for the ${ }^{237} \mathrm{~Np}(\mathrm{n}, 2 \mathrm{n})$ reaction 


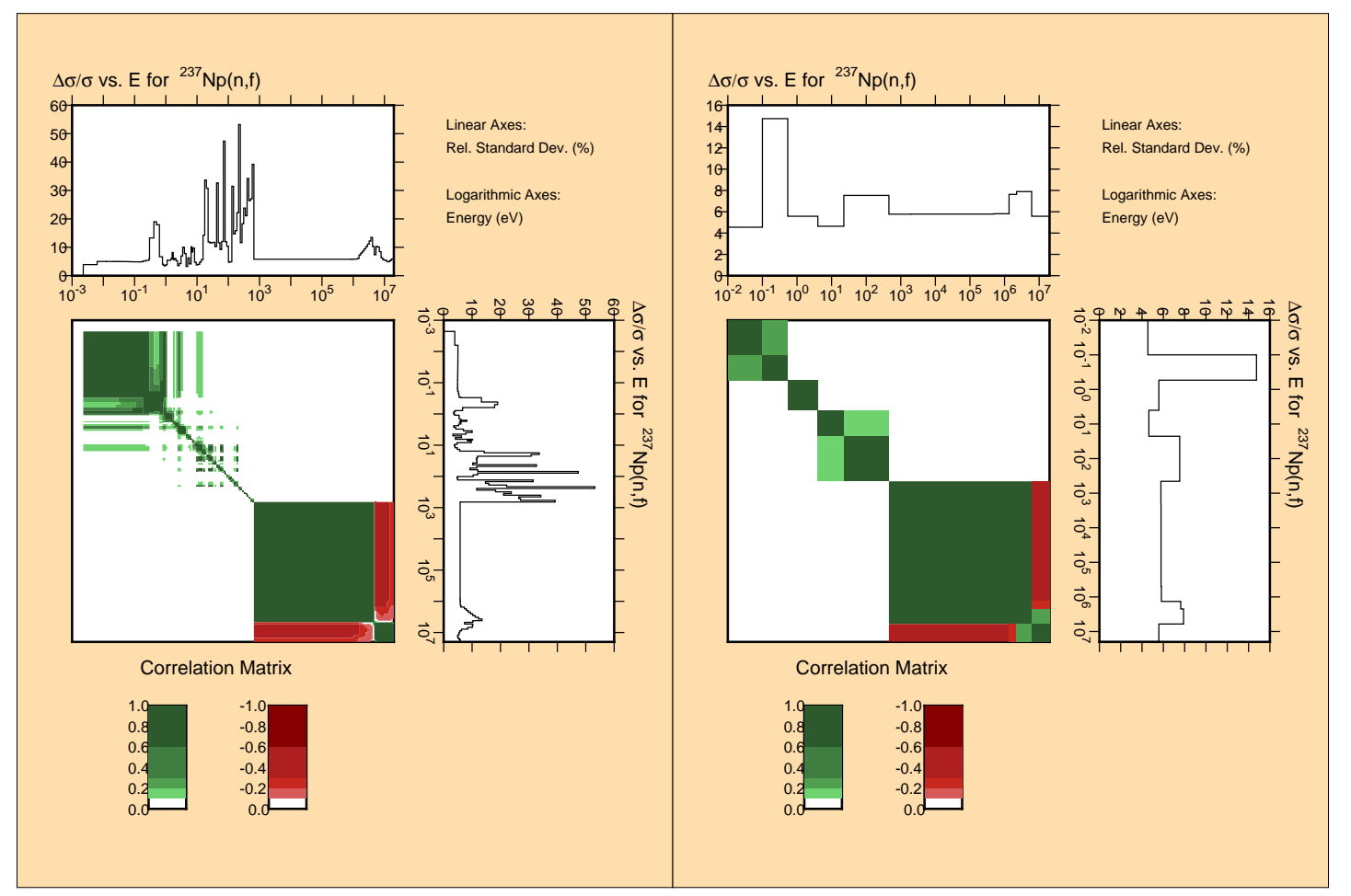

Figure A.127: Correlation and uncertainties in 187 (left) and 15 (right) groups for the ${ }^{237} \mathrm{~Np}(\mathrm{n}, \mathrm{f})$ reaction

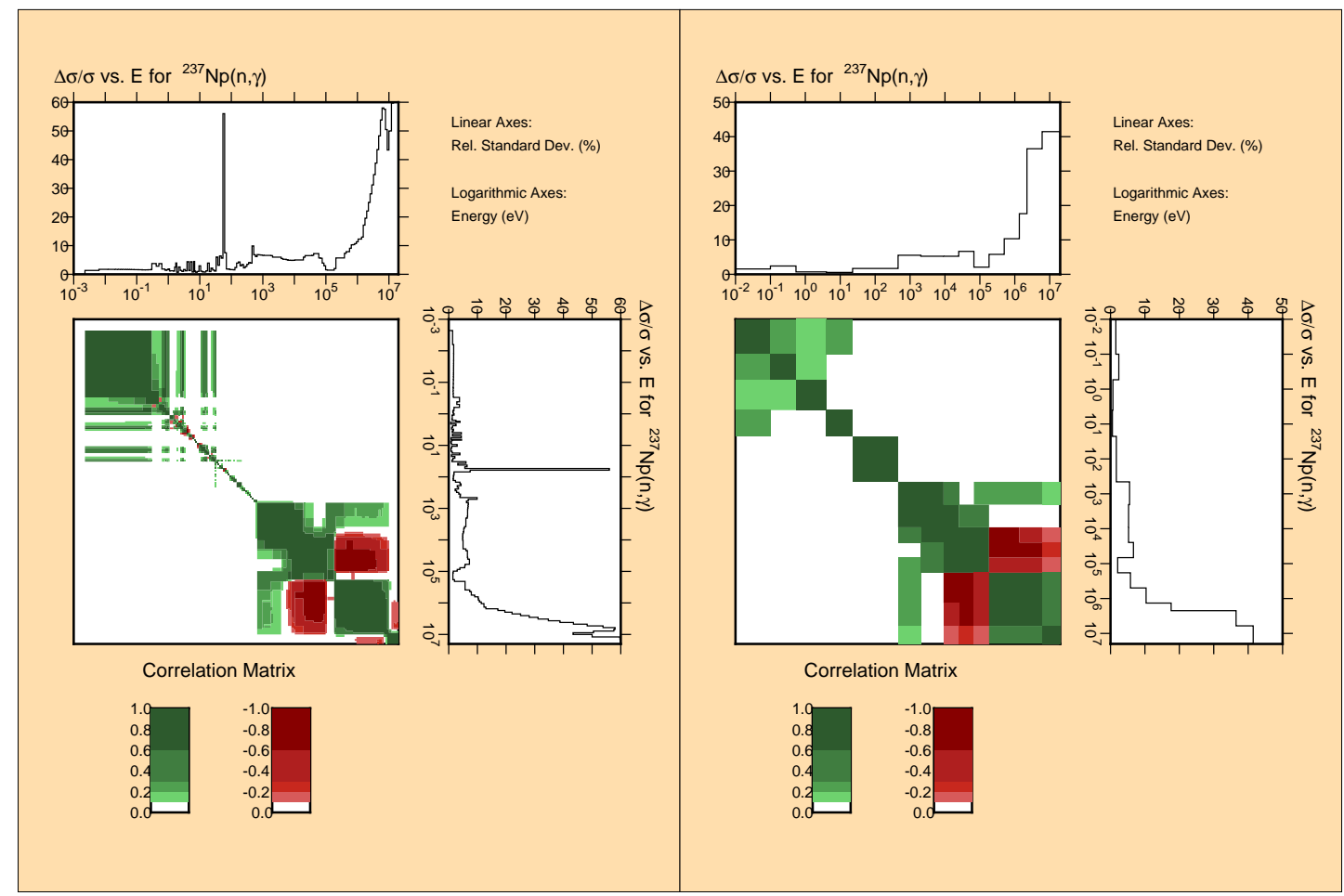

Figure A.128: Correlation and uncertainties in 187 (left) and 15 (right) groups for the ${ }^{237} \mathrm{~Np}(\mathrm{n}, \gamma)$ reaction 


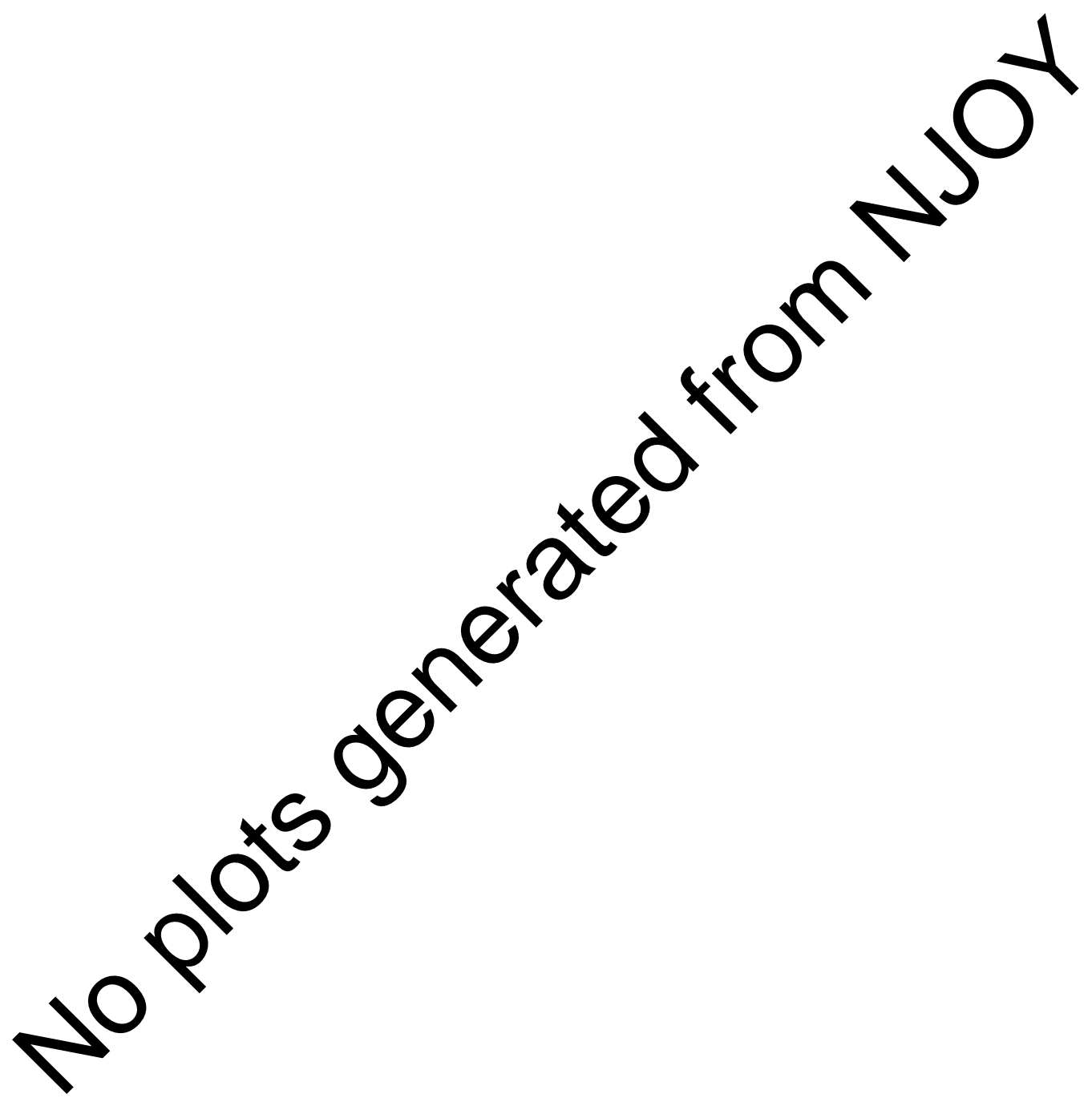

Figure A.129: Correlation and uncertainties in 187 and 15 groups for ${ }^{238} \mathrm{U}$ 


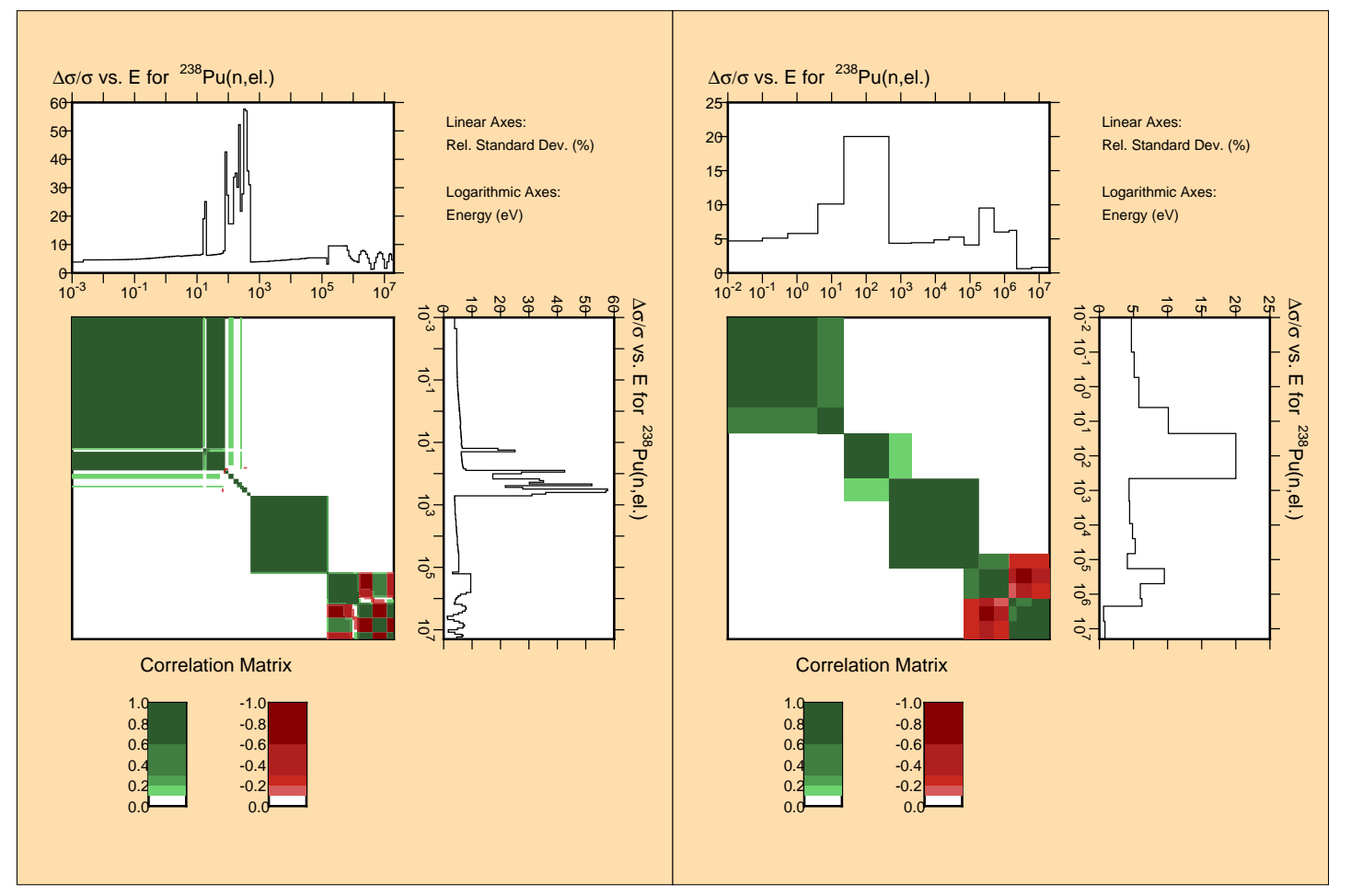

Figure A.130: Correlation and uncertainties in 187 (left) and 15 (right) groups for the ${ }^{238} \mathrm{Pu}(\mathrm{n}, \mathrm{el})$ reaction

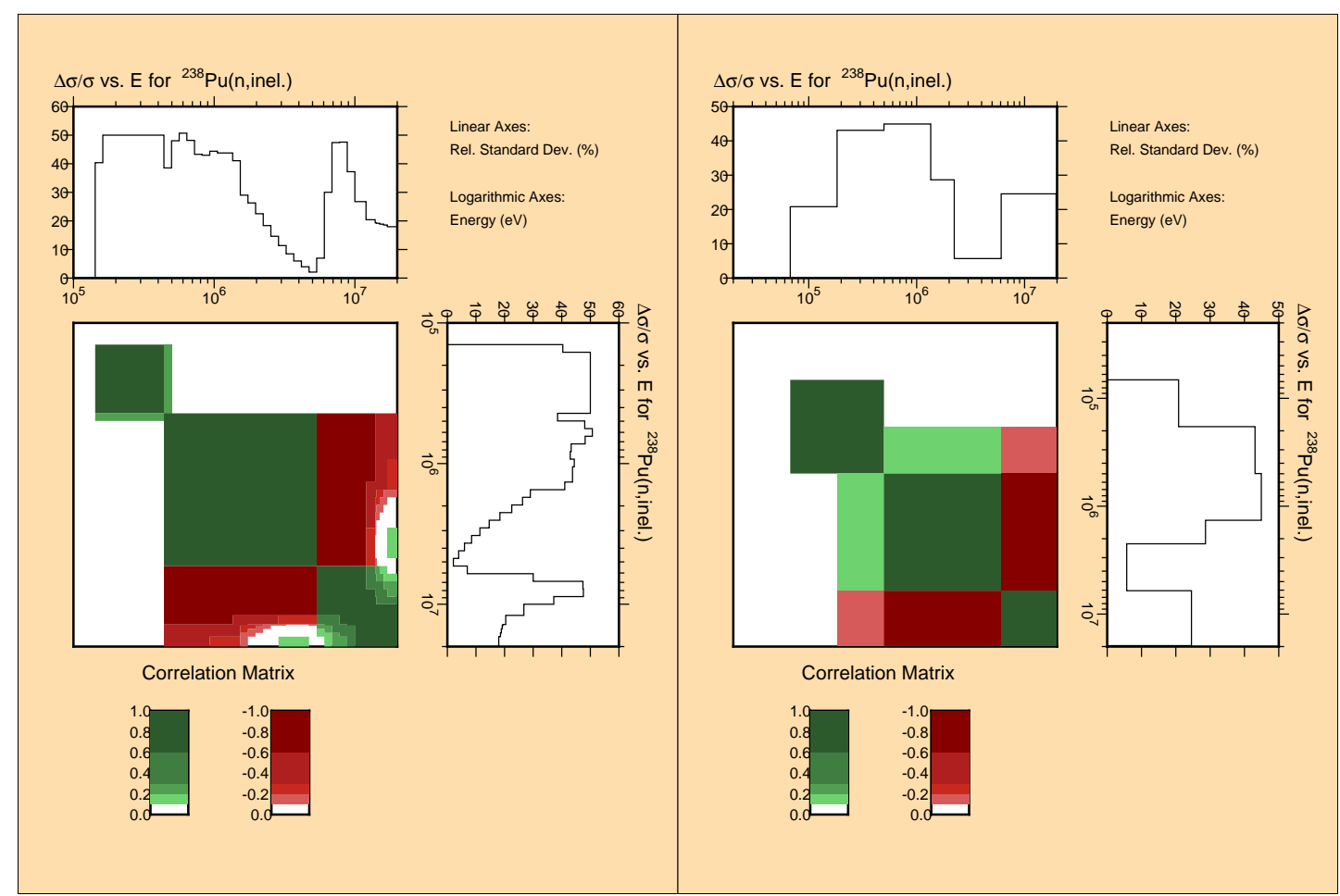

Figure A.131: Correlation and uncertainties in 187 (left) and 15 (right) groups for the ${ }^{238} \mathrm{Pu}\left(\mathrm{n}, \mathrm{n}^{\prime}\right)$ reaction 


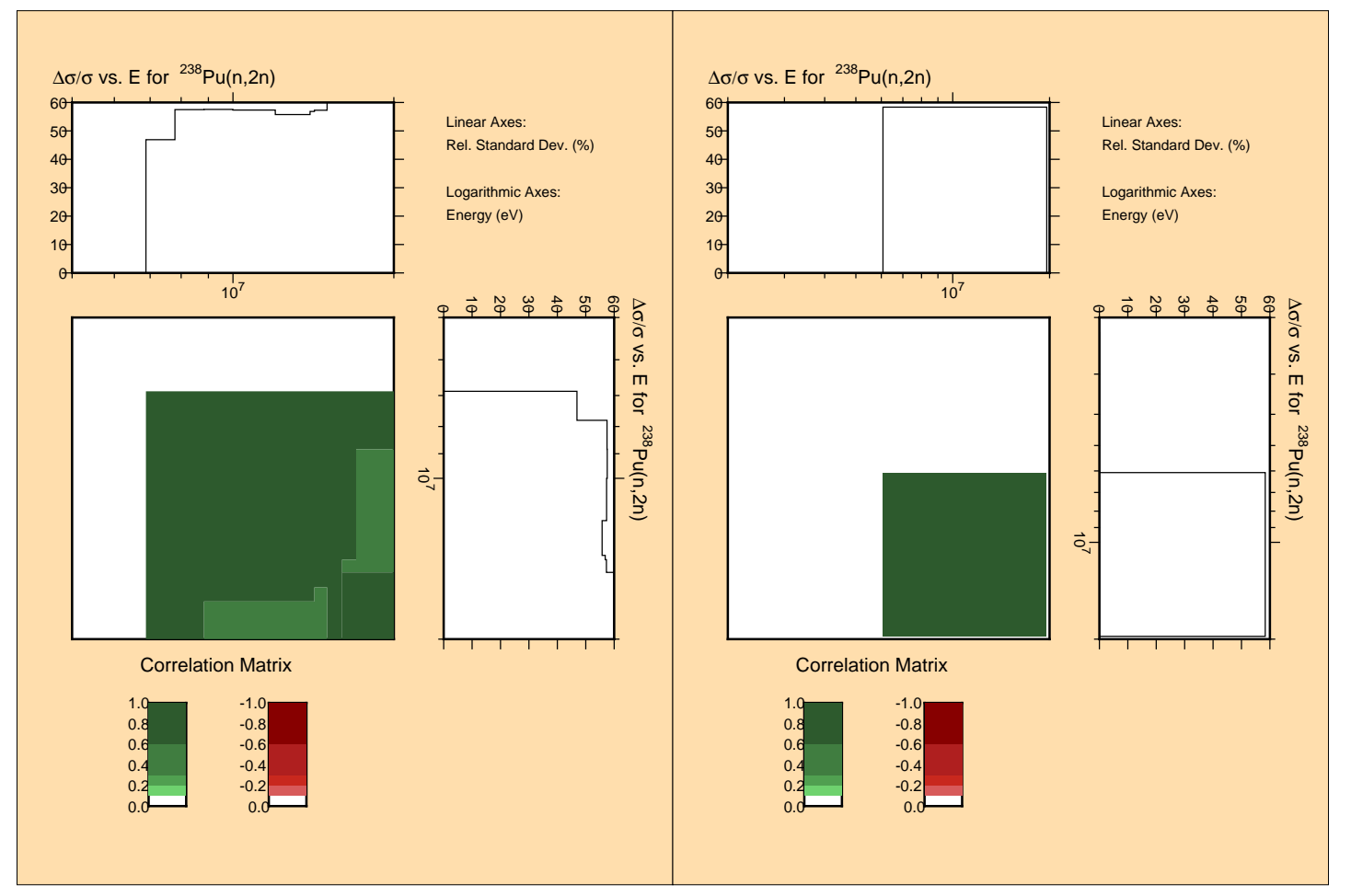

Figure A.132: Correlation and uncertainties in 187 (left) and 15 (right) groups for the ${ }^{238} \mathrm{Pu}(\mathrm{n}, 2 \mathrm{n})$ reaction

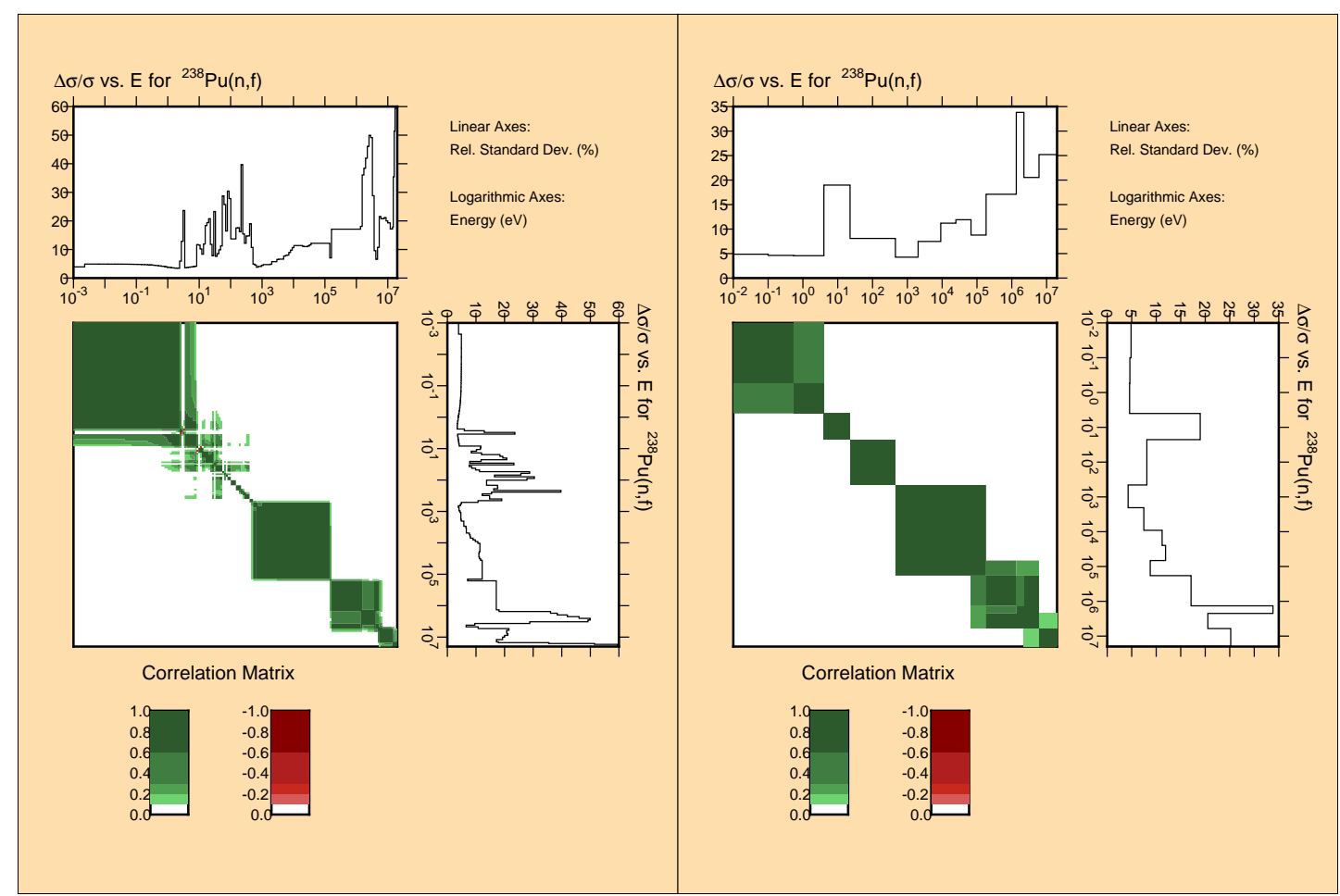

Figure A.133: Correlation and uncertainties in 187 (left) and 15 (right) groups for the ${ }^{238} \mathrm{Pu}(\mathrm{n}, \mathrm{f})$ reaction 


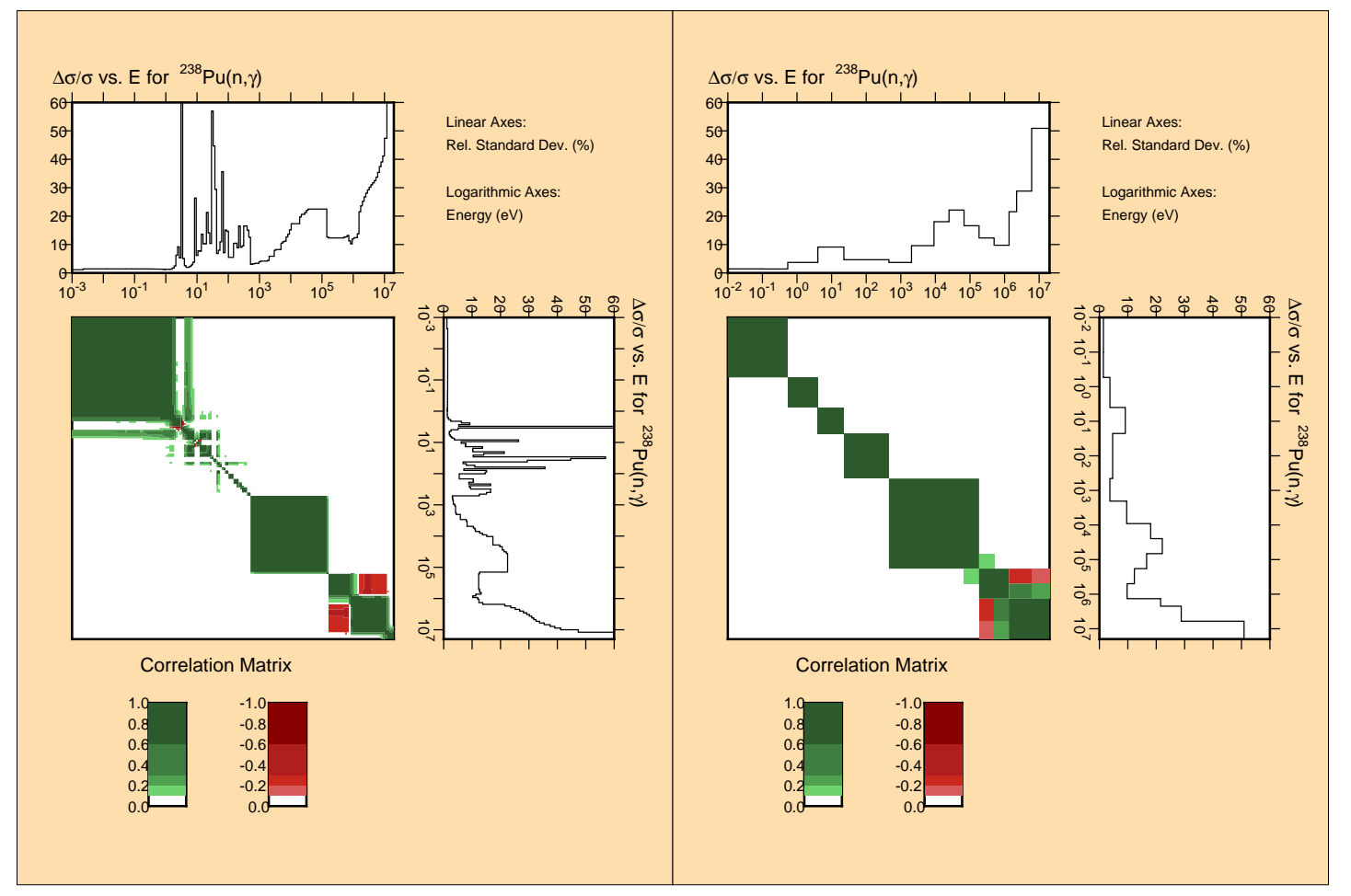

Figure A.134: Correlation and uncertainties in 187 (left) and 15 (right) groups for the ${ }^{238} \mathrm{Pu}(\mathrm{n}, \gamma)$ reaction

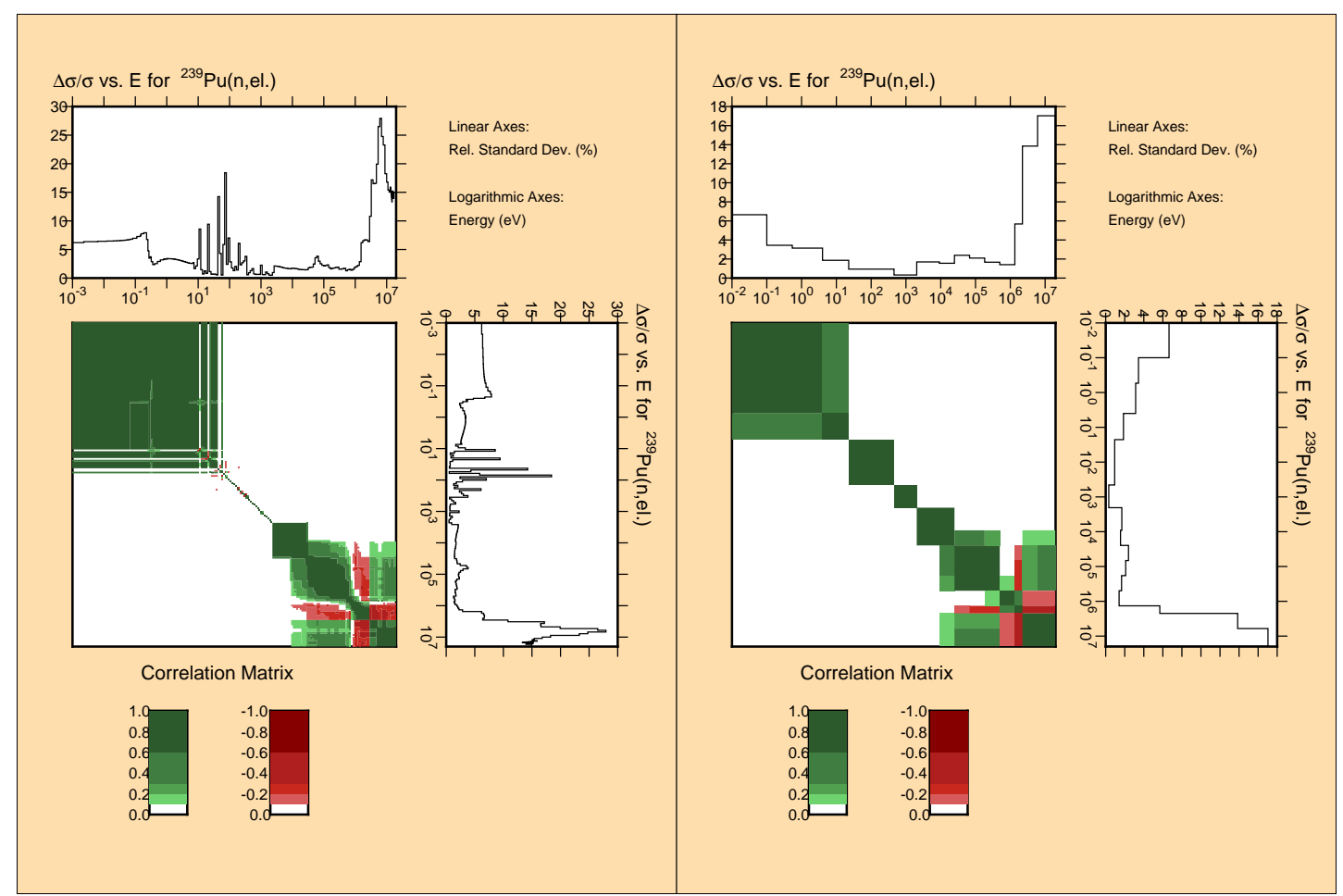

Figure A.135: Correlation and uncertainties in 187 (left) and 15 (right) groups for the ${ }^{239} \mathrm{Pu}(\mathrm{n}, \mathrm{el})$ reaction 


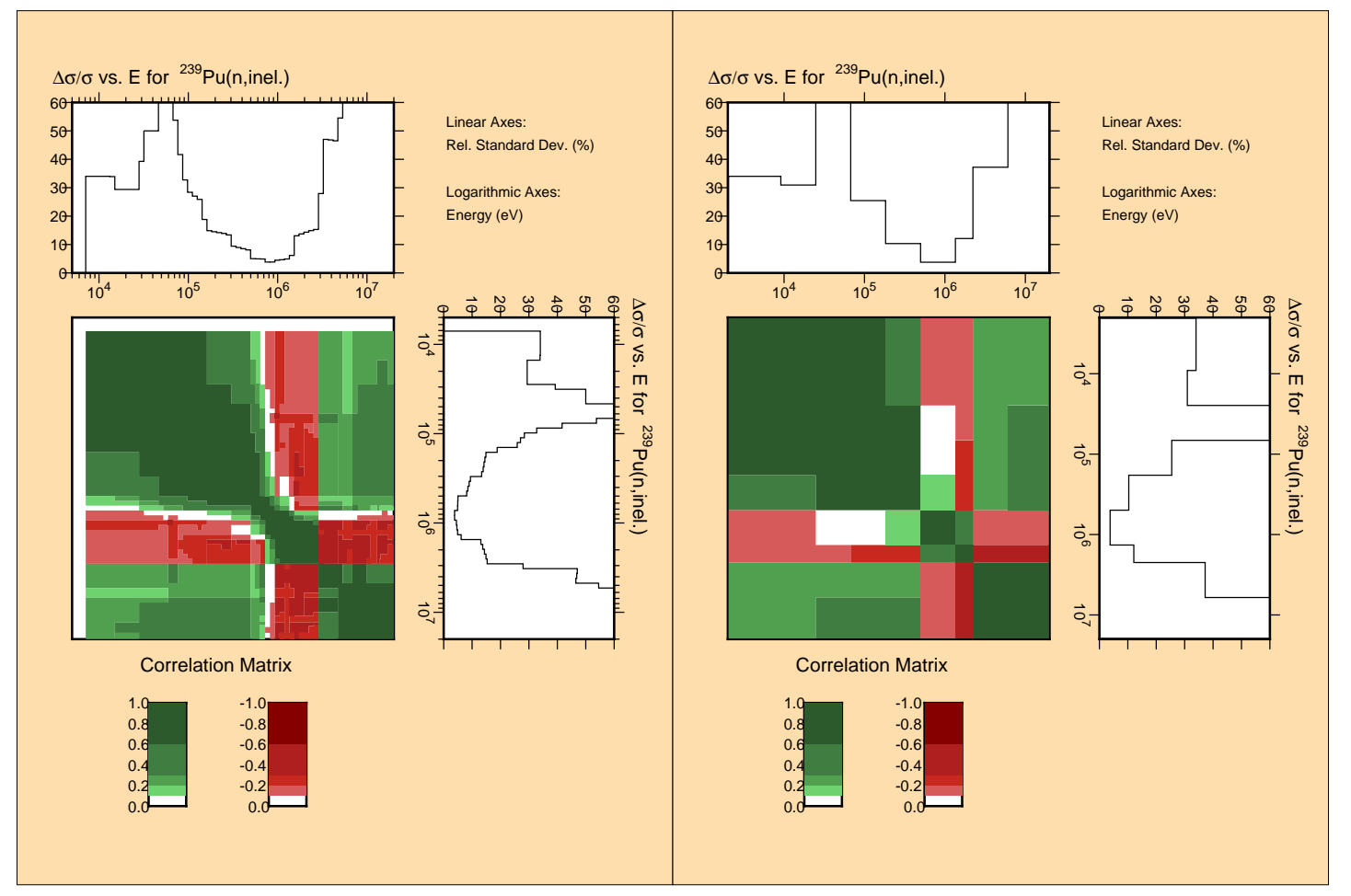

Figure A.136: Correlation and uncertainties in 187 (left) and 15 (right) groups for the ${ }^{239} \mathrm{Pu}\left(\mathrm{n}, \mathrm{n}^{\prime}\right)$ reaction

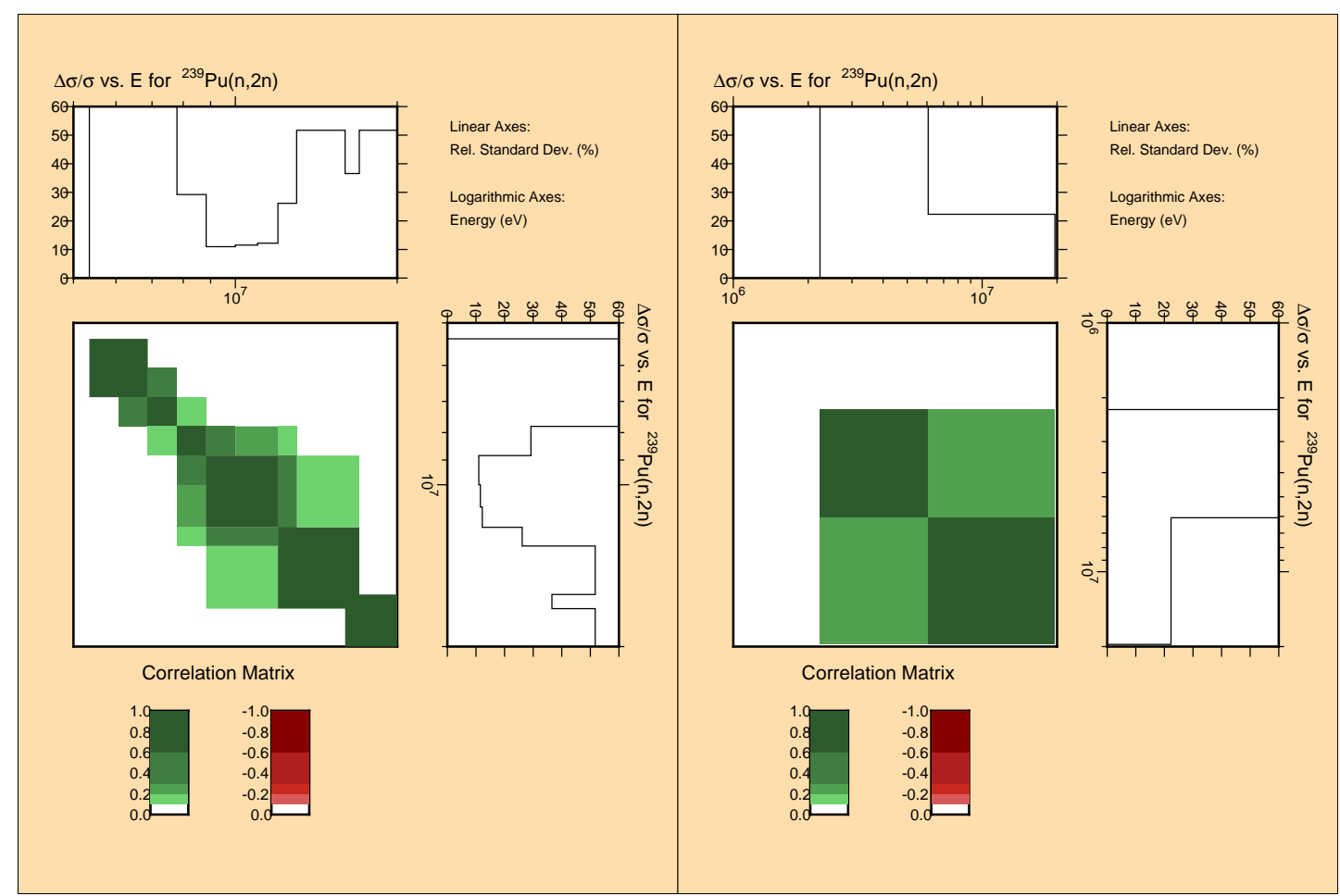

Figure A.137: Correlation and uncertainties in 187 (left) and 15 (right) groups for the ${ }^{239} \mathrm{Pu}(\mathrm{n}, 2 \mathrm{n})$ reaction 


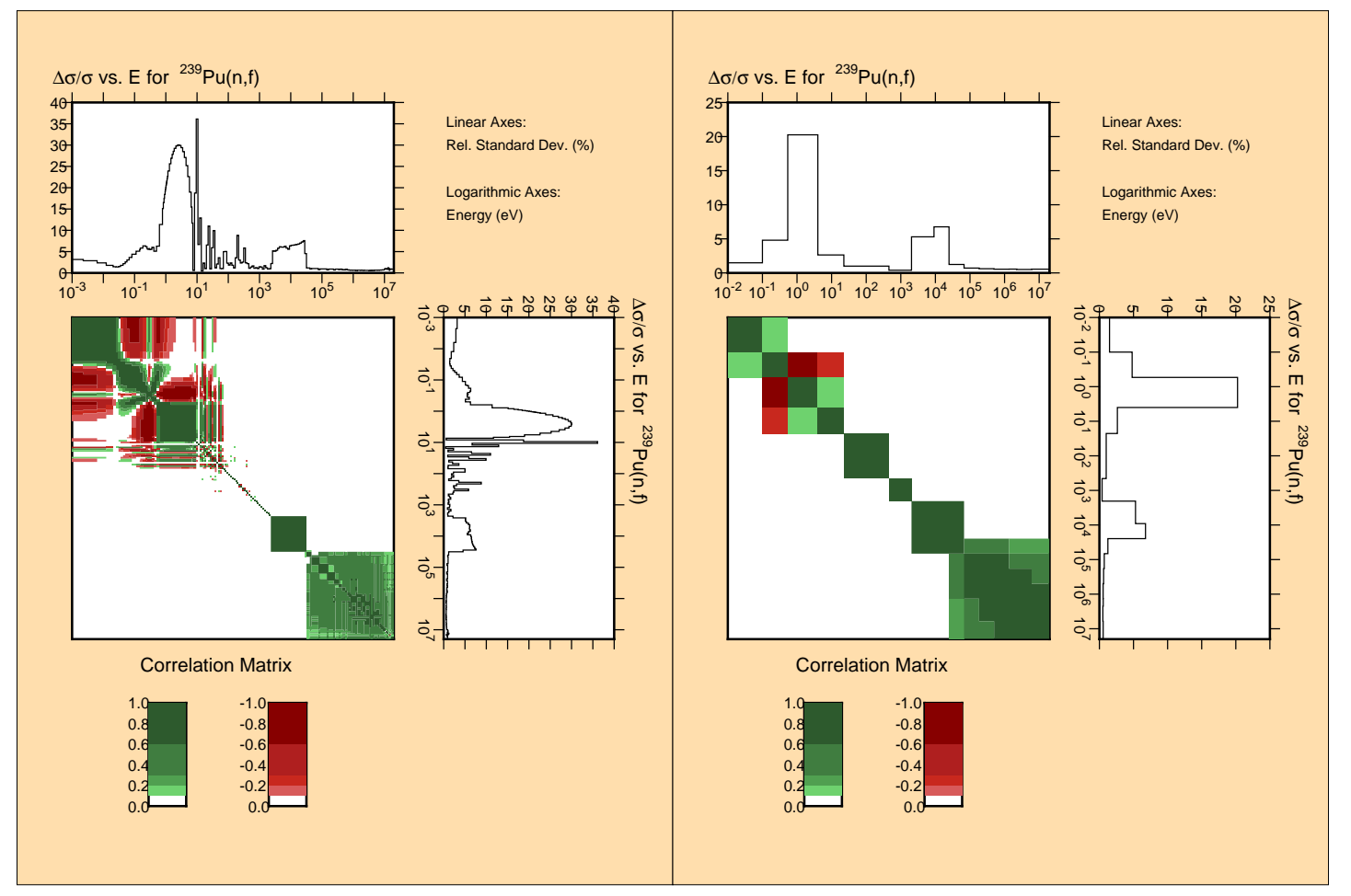

Figure A.138: Correlation and uncertainties in 187 (left) and 15 (right) groups for the ${ }^{239} \mathrm{Pu}(\mathrm{n}, \mathrm{f})$ reaction

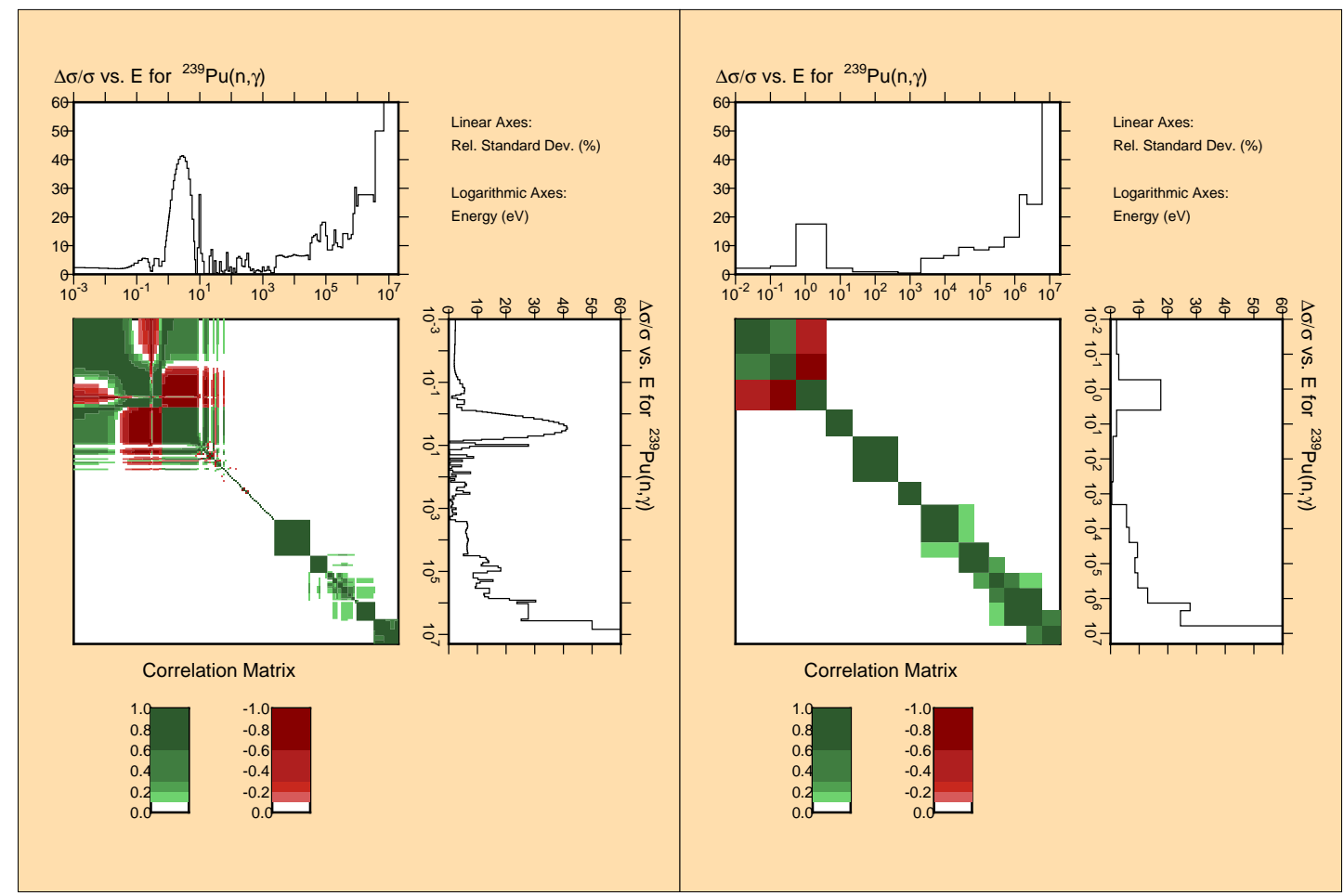

Figure A.139: Correlation and uncertainties in 187 (left) and 15 (right) groups for the ${ }^{239} \mathrm{Pu}(\mathrm{n}, \gamma)$ reaction 


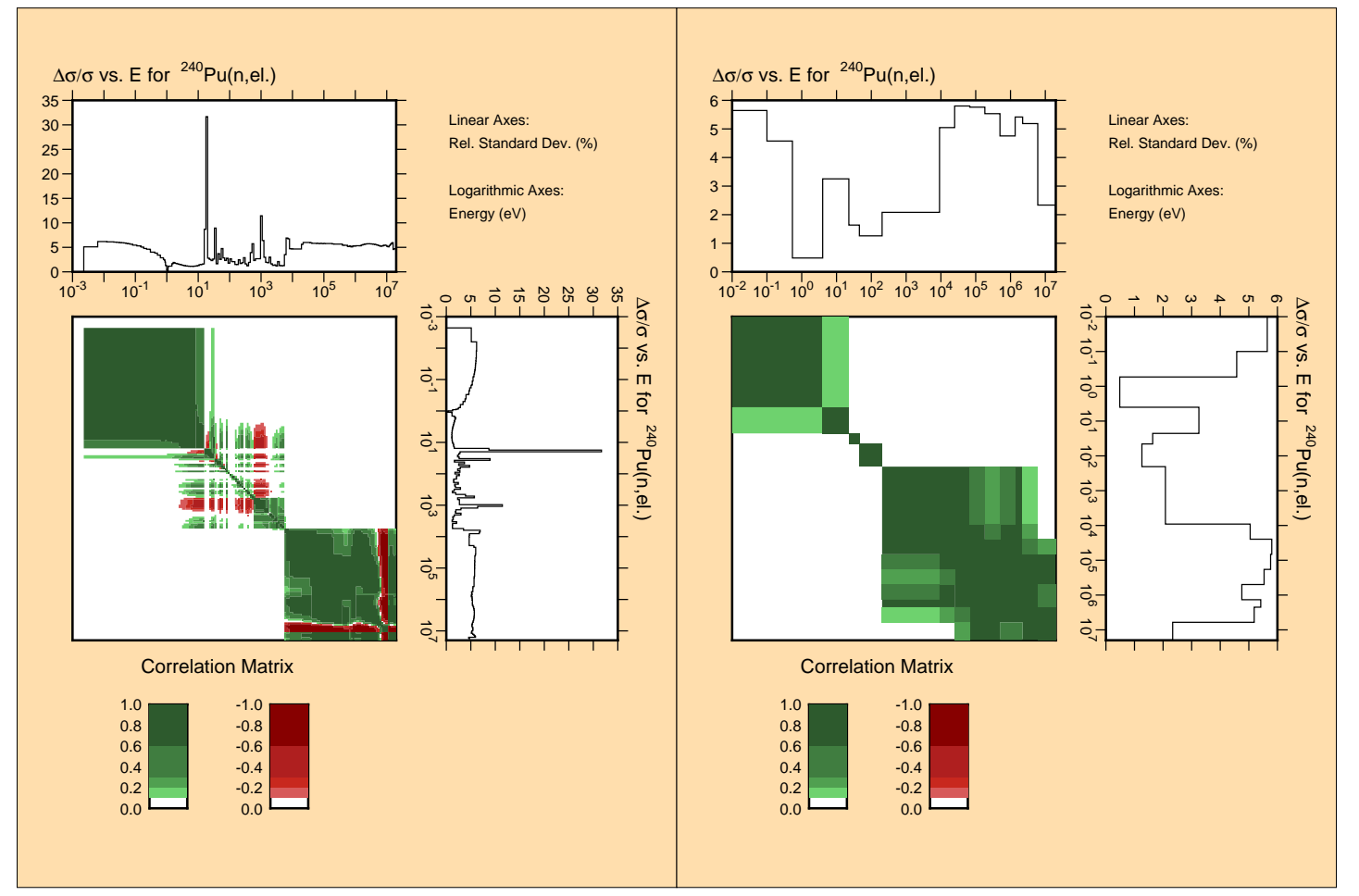

Figure A.140: Correlation and uncertainties in 187 (left) and 15 (right) groups for the ${ }^{240} \mathrm{Pu}(\mathrm{n}, \mathrm{el})$ reaction

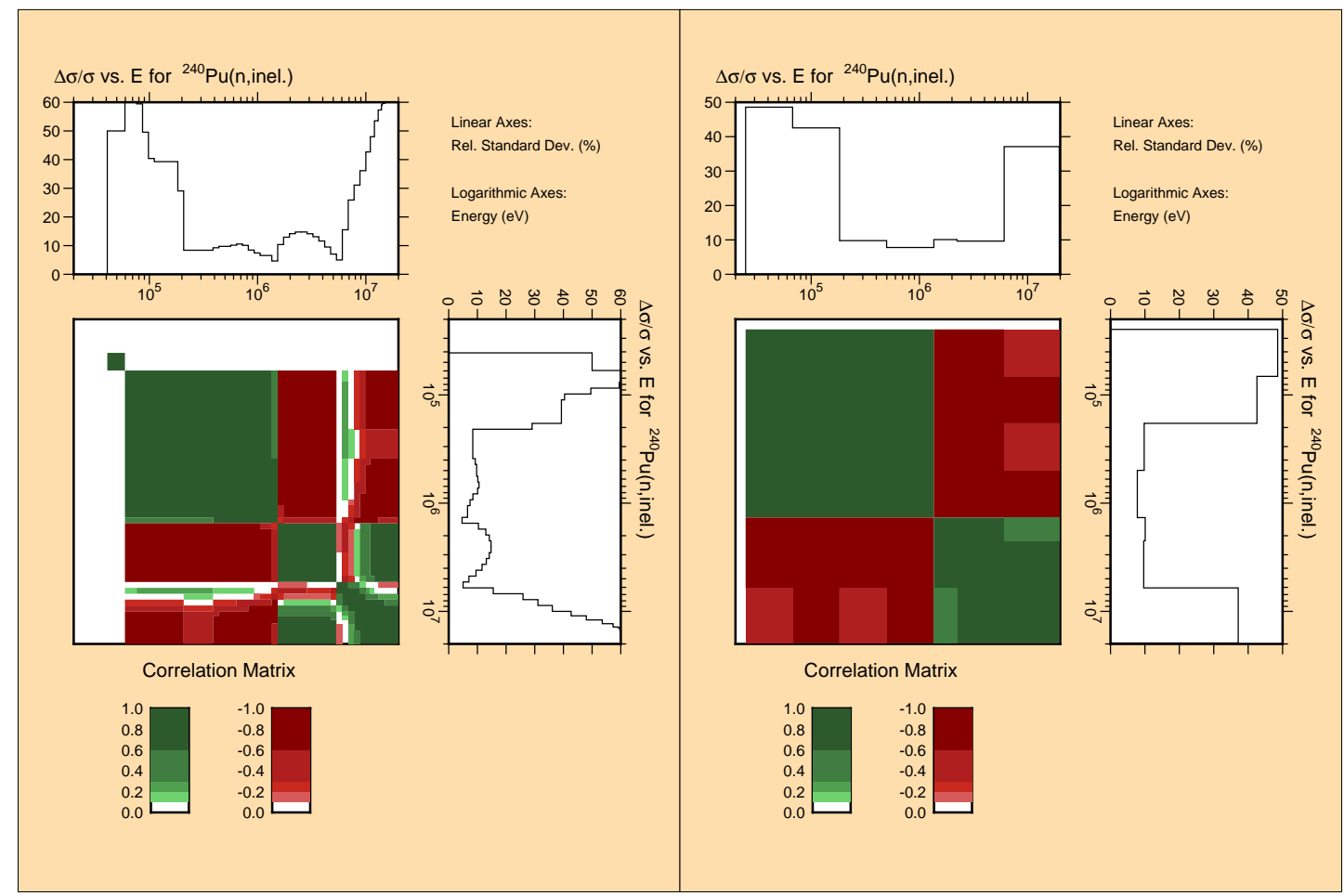

Figure A.141: Correlation and uncertainties in 187 (left) and 15 (right) groups for the ${ }^{240} \mathrm{Pu}\left(\mathrm{n}, \mathrm{n}^{\prime}\right)$ reaction 


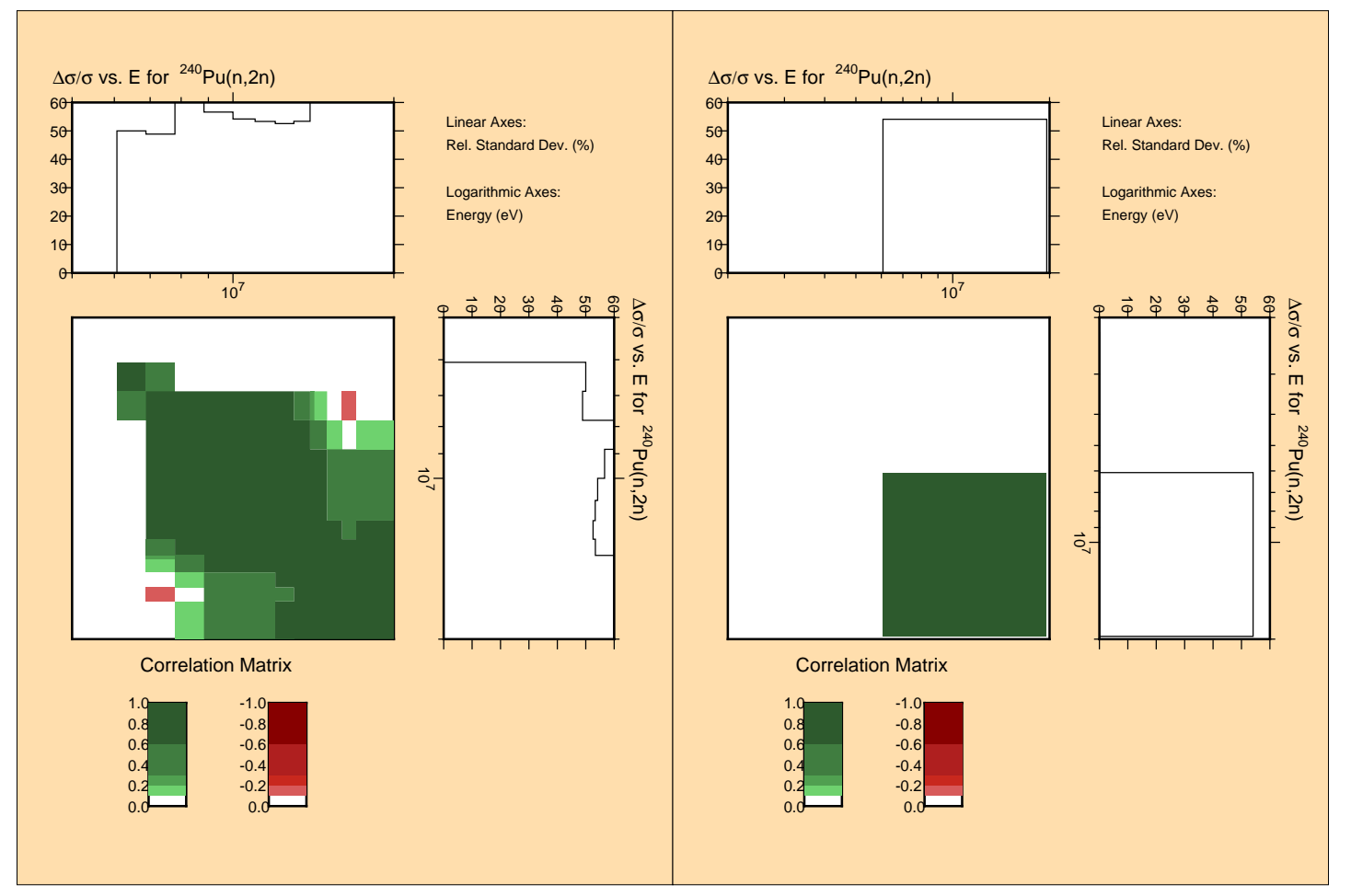

Figure A.142: Correlation and uncertainties in 187 (left) and 15 (right) groups for the ${ }^{240} \mathrm{Pu}(\mathrm{n}, 2 \mathrm{n})$ reaction

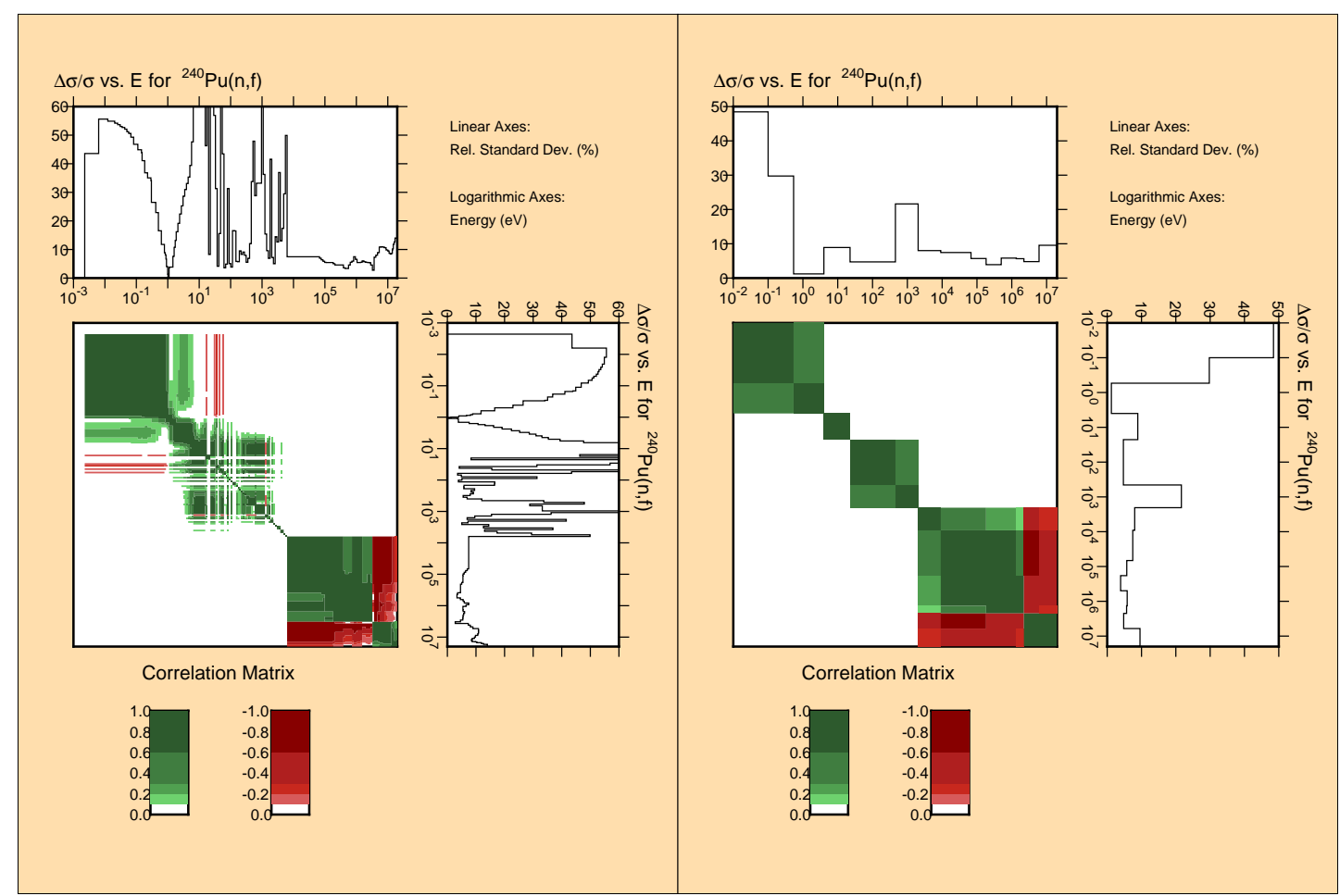

Figure A.143: Correlation and uncertainties in 187 (left) and 15 (right) groups for the ${ }^{240} \mathrm{Pu}(\mathrm{n}, \mathrm{f})$ reaction 


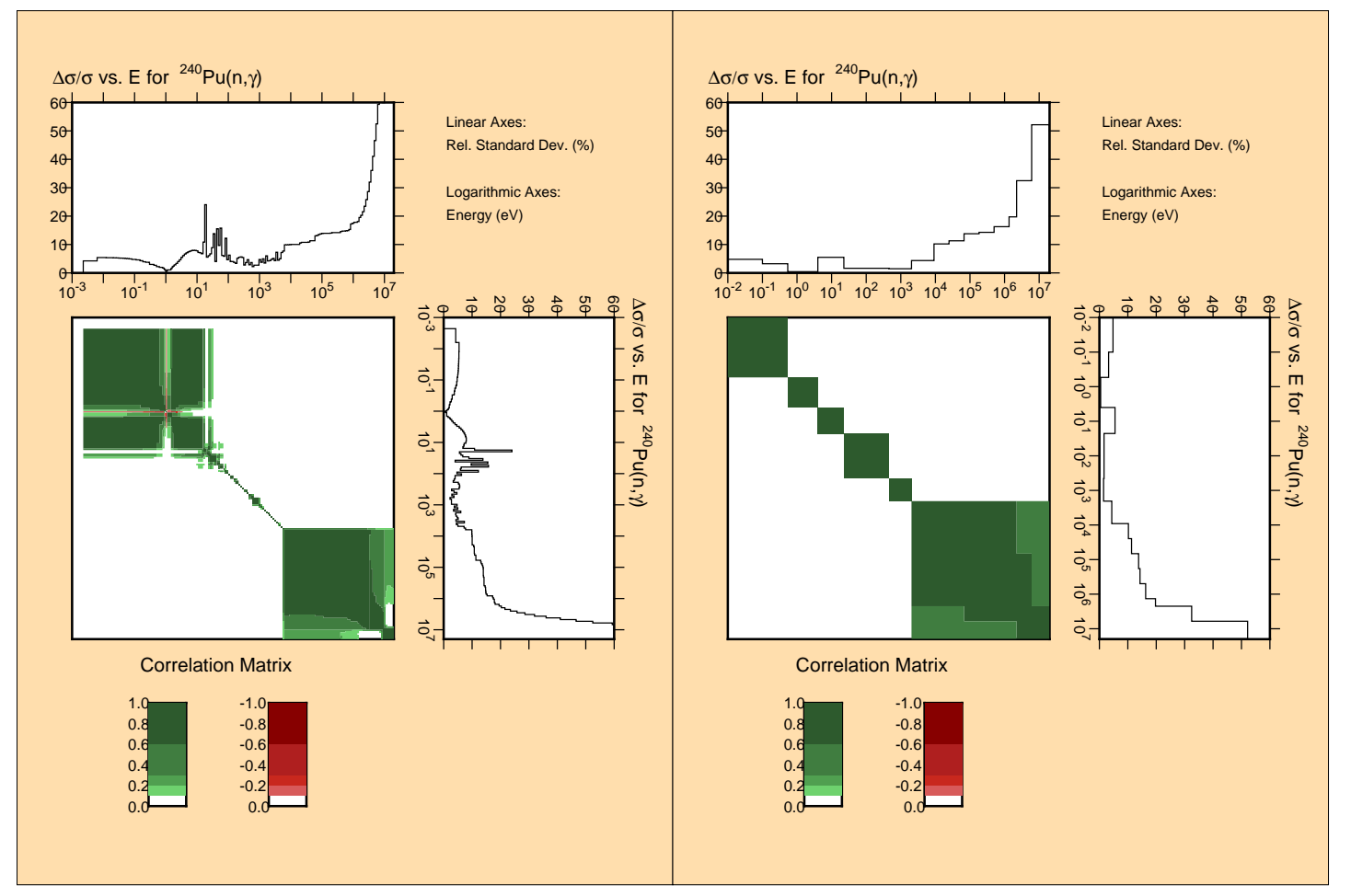

Figure A.144: Correlation and uncertainties in 187 (left) and 15 (right) groups for the ${ }^{240} \mathrm{Pu}(\mathrm{n}, \gamma)$ reaction

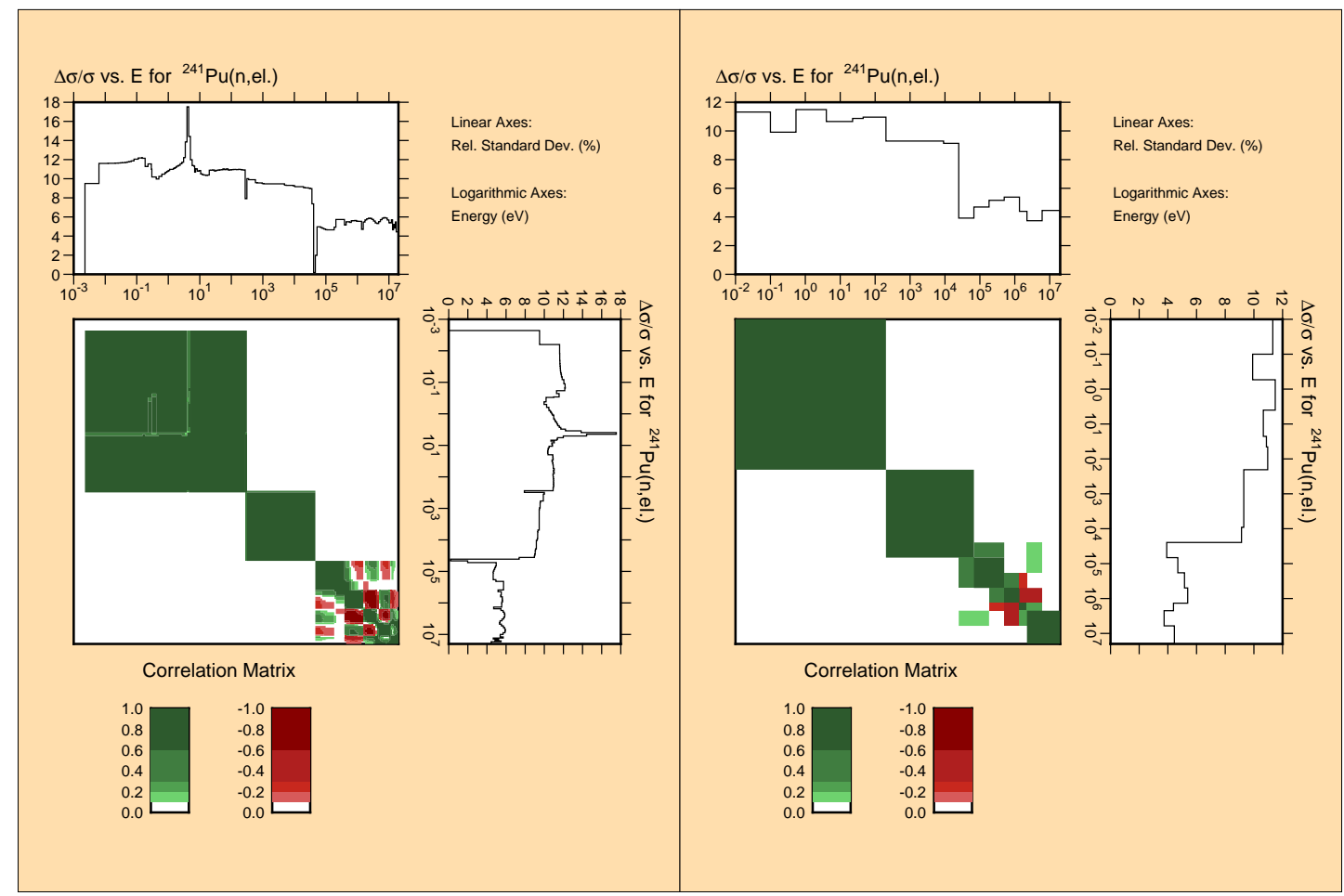

Figure A.145: Correlation and uncertainties in 187 (left) and 15 (right) groups for the ${ }^{241} \mathrm{Pu}(\mathrm{n}, \mathrm{el})$ reaction 


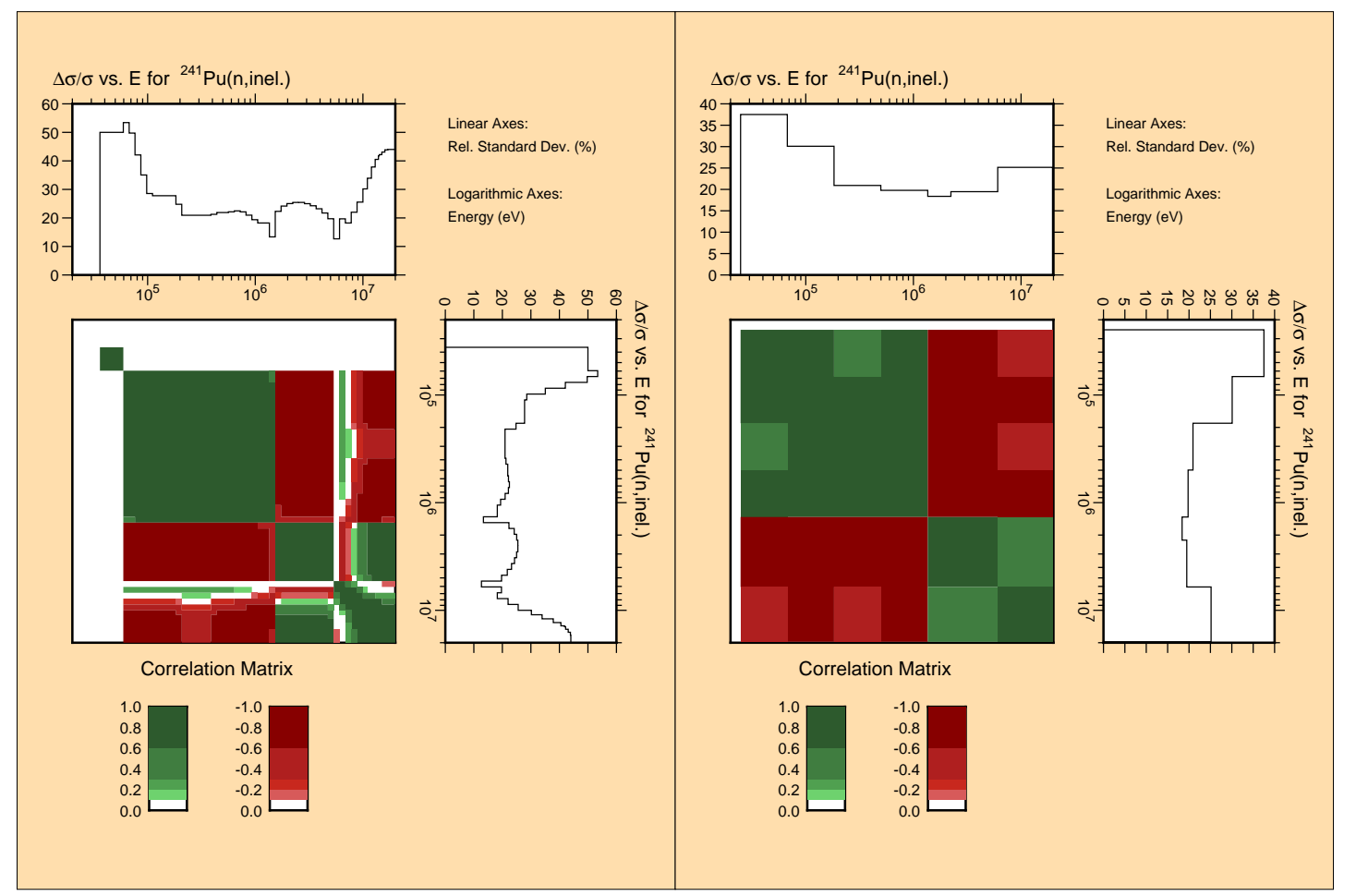

Figure A.146: Correlation and uncertainties in 187 (left) and 15 (right) groups for the ${ }^{241} \mathrm{Pu}\left(\mathrm{n}, \mathrm{n}^{\prime}\right)$ reaction

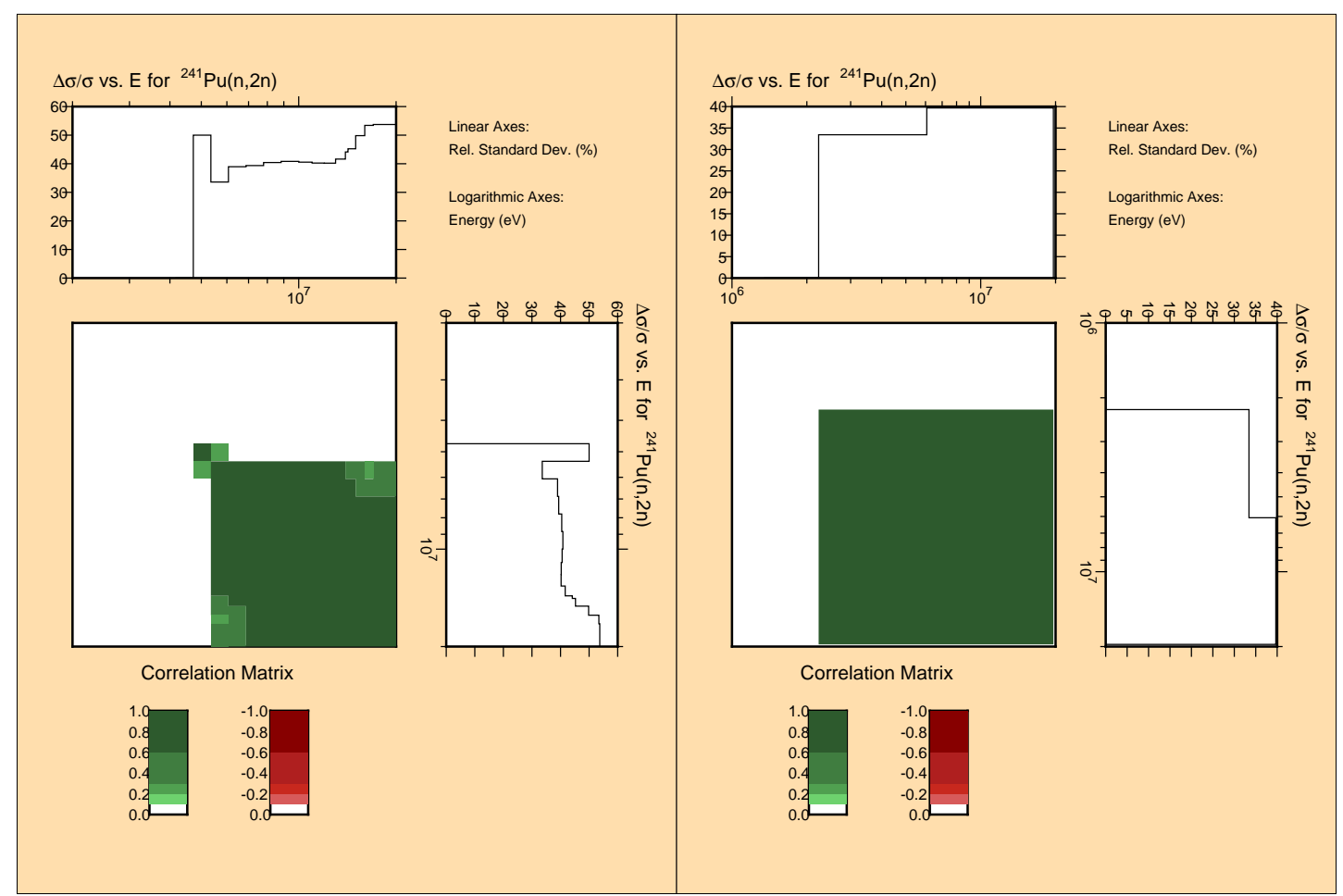

Figure A.147: Correlation and uncertainties in 187 (left) and 15 (right) groups for the ${ }^{241} \mathrm{Pu}(\mathrm{n}, 2 \mathrm{n})$ reaction 


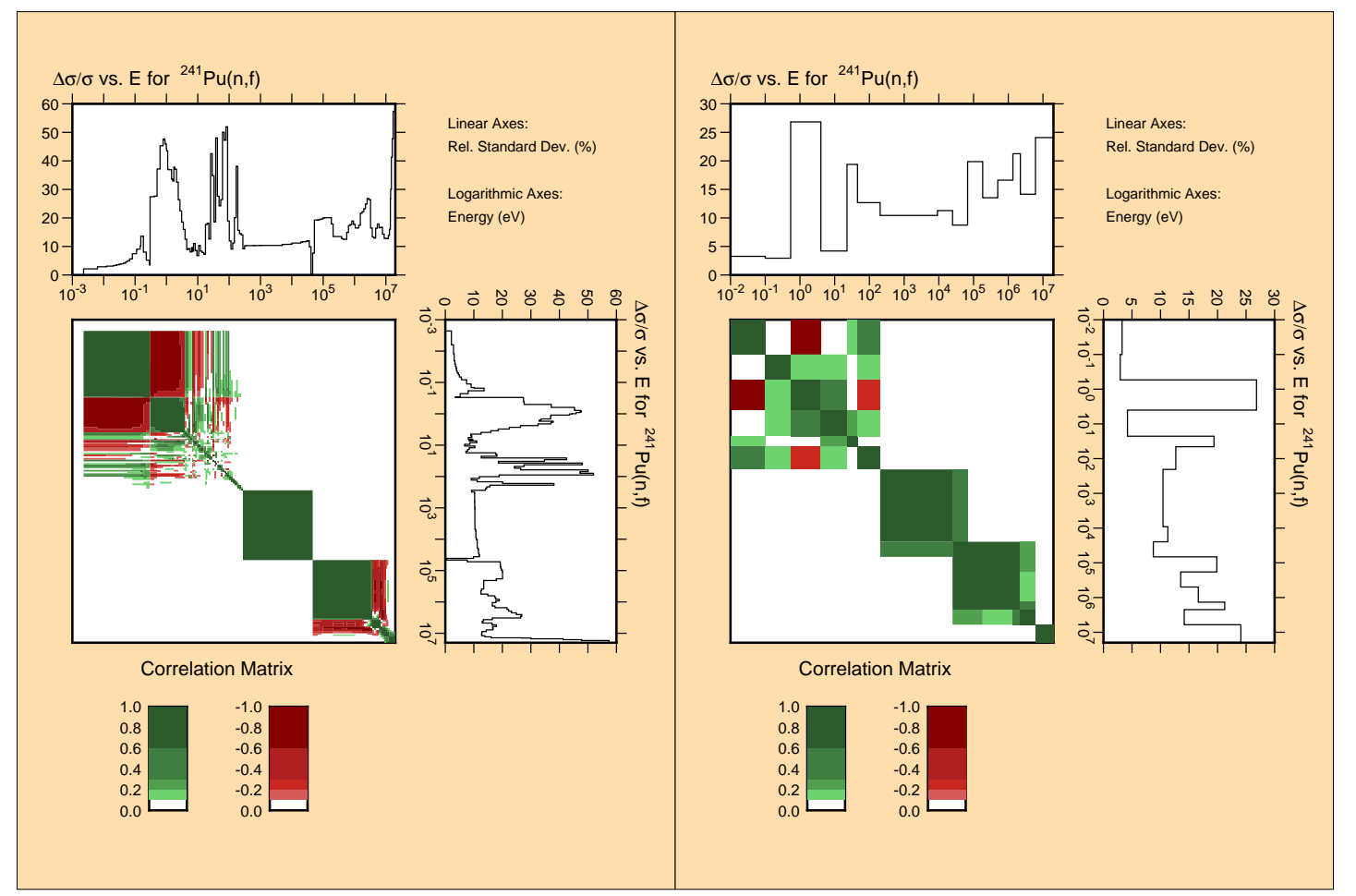

Figure A.148: Correlation and uncertainties in 187 (left) and 15 (right) groups for the ${ }^{241} \mathrm{Pu}(\mathrm{n}, \mathrm{f})$ reaction

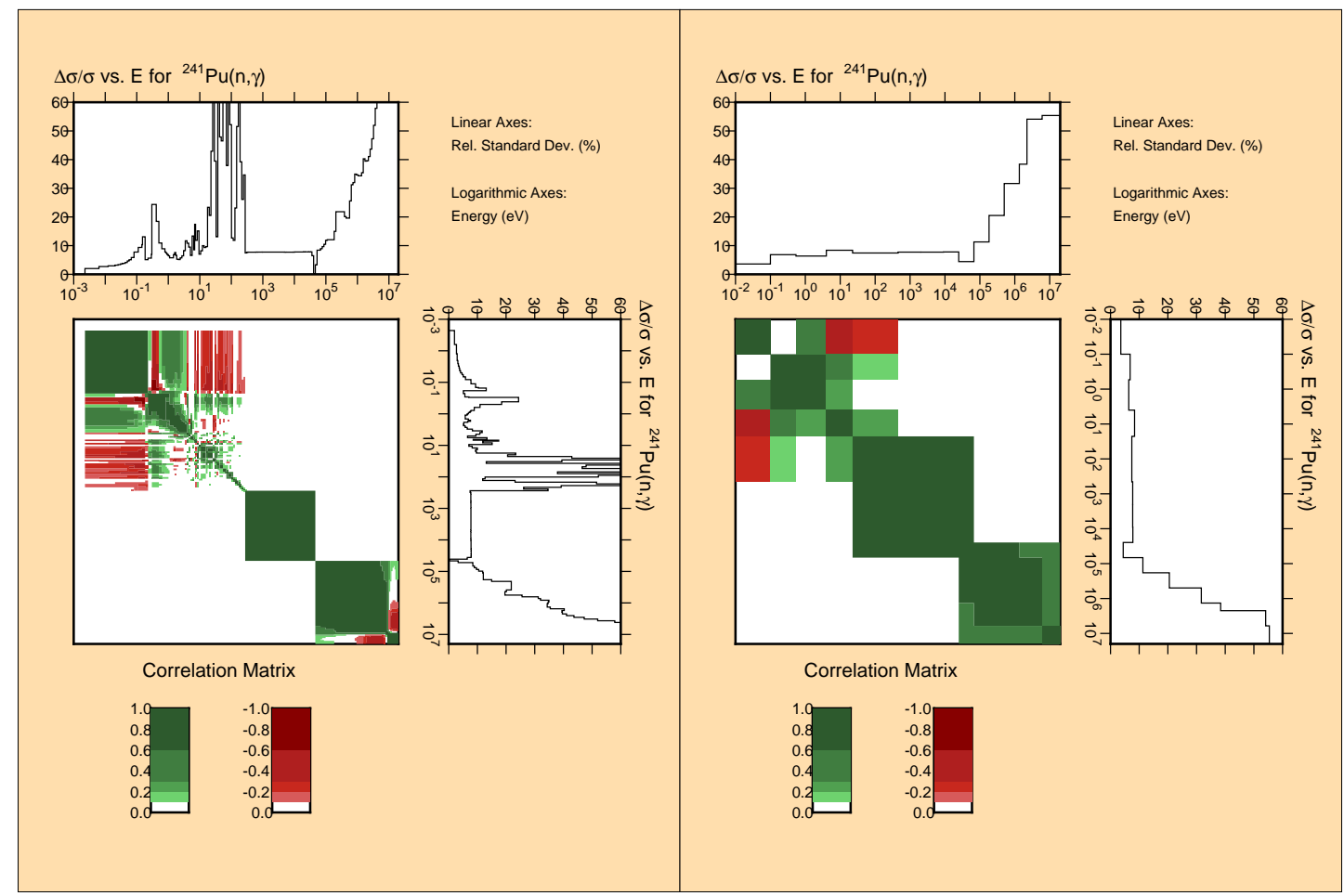

Figure A.149: Correlation and uncertainties in 187 (left) and 15 (right) groups for the ${ }^{241} \mathrm{Pu}(\mathrm{n}, \gamma)$ reaction 


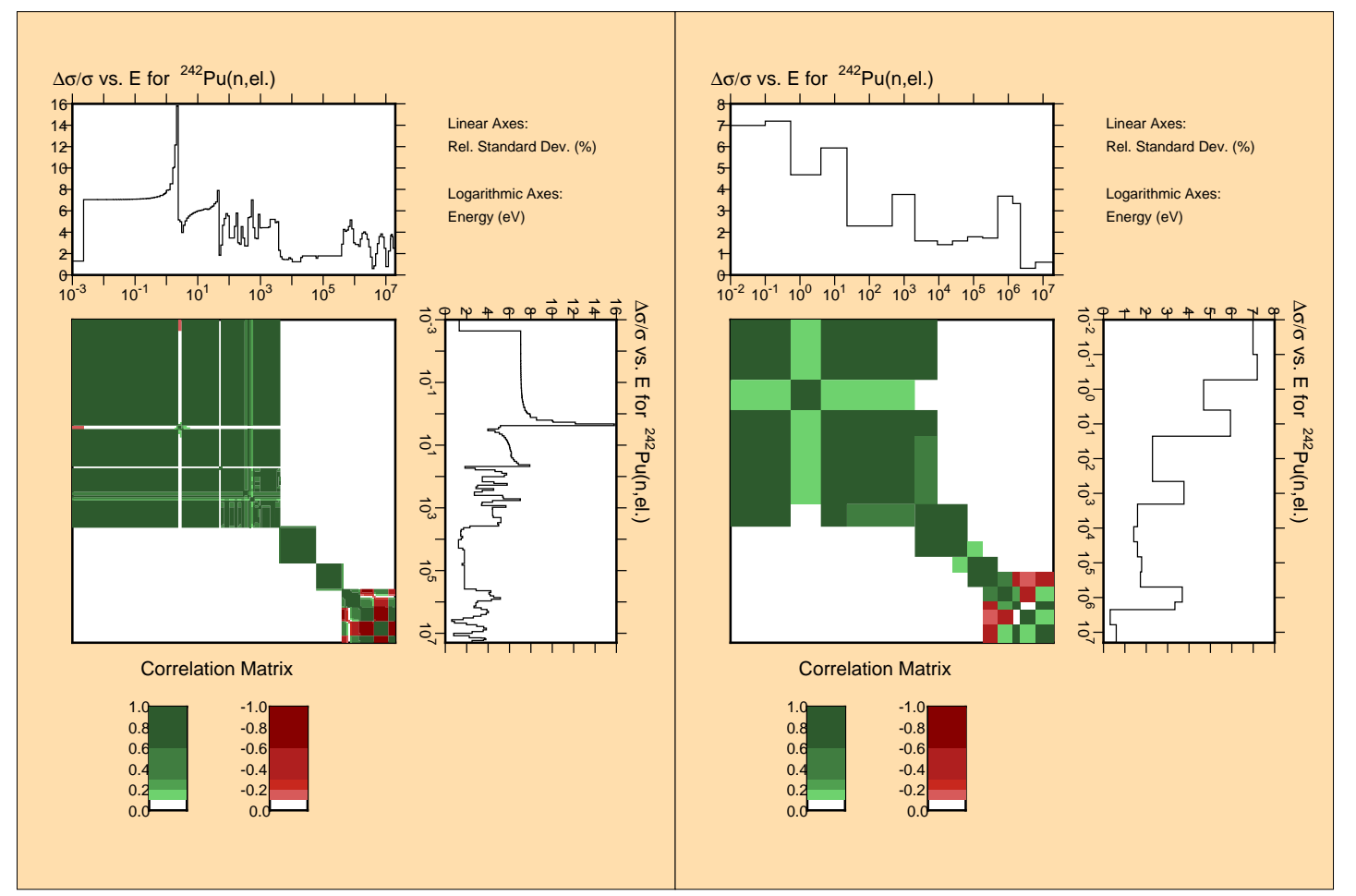

Figure A.150: Correlation and uncertainties in 187 (left) and 15 (right) groups for the ${ }^{242} \mathrm{Pu}(\mathrm{n}, \mathrm{el})$ reaction

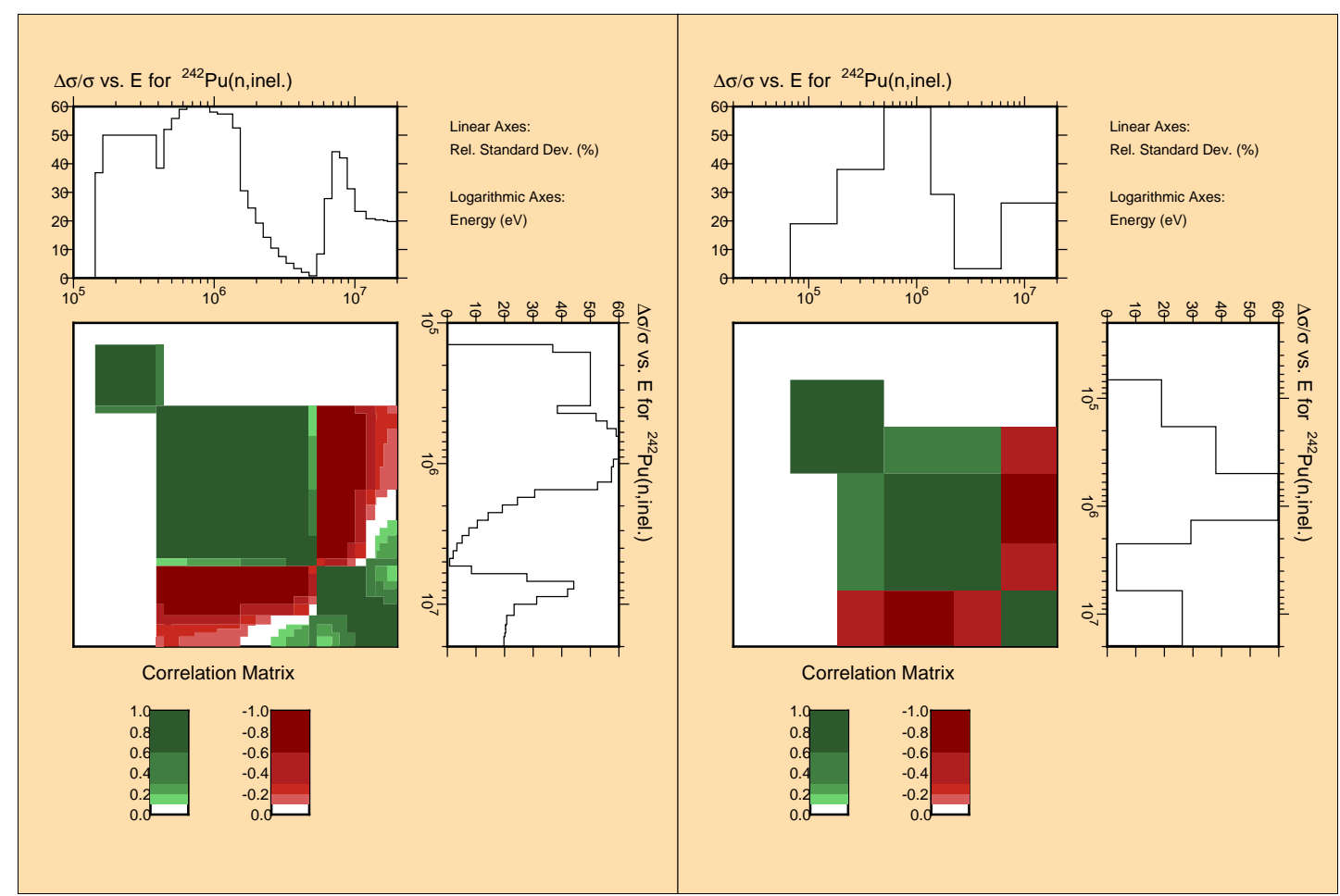

Figure A.151: Correlation and uncertainties in 187 (left) and 15 (right) groups for the ${ }^{242} \mathrm{Pu}\left(\mathrm{n}, \mathrm{n}^{\prime}\right)$ reaction 


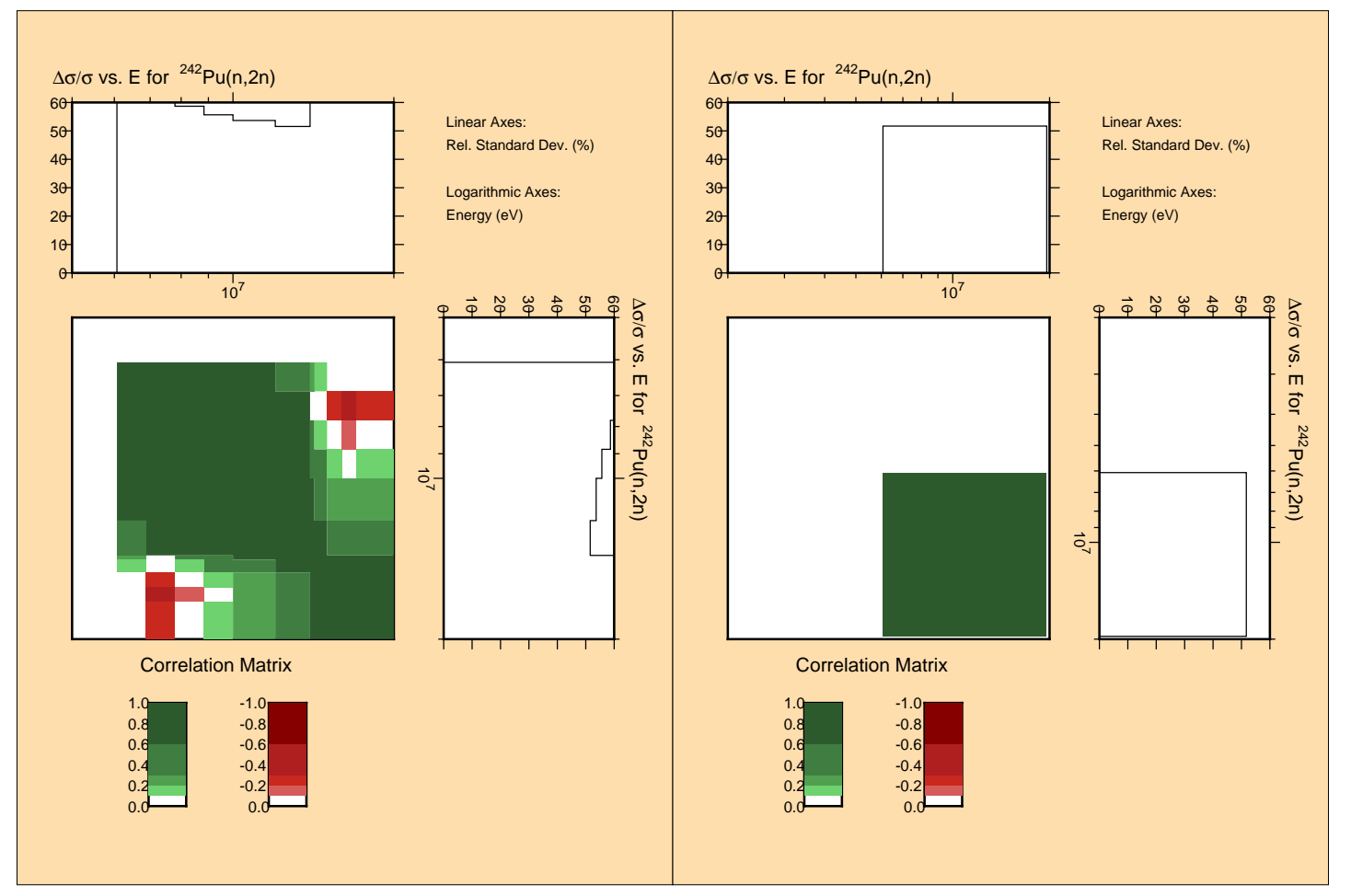

Figure A.152: Correlation and uncertainties in 187 (left) and 15 (right) groups for the ${ }^{242} \mathrm{Pu}(\mathrm{n}, 2 \mathrm{n})$ reaction

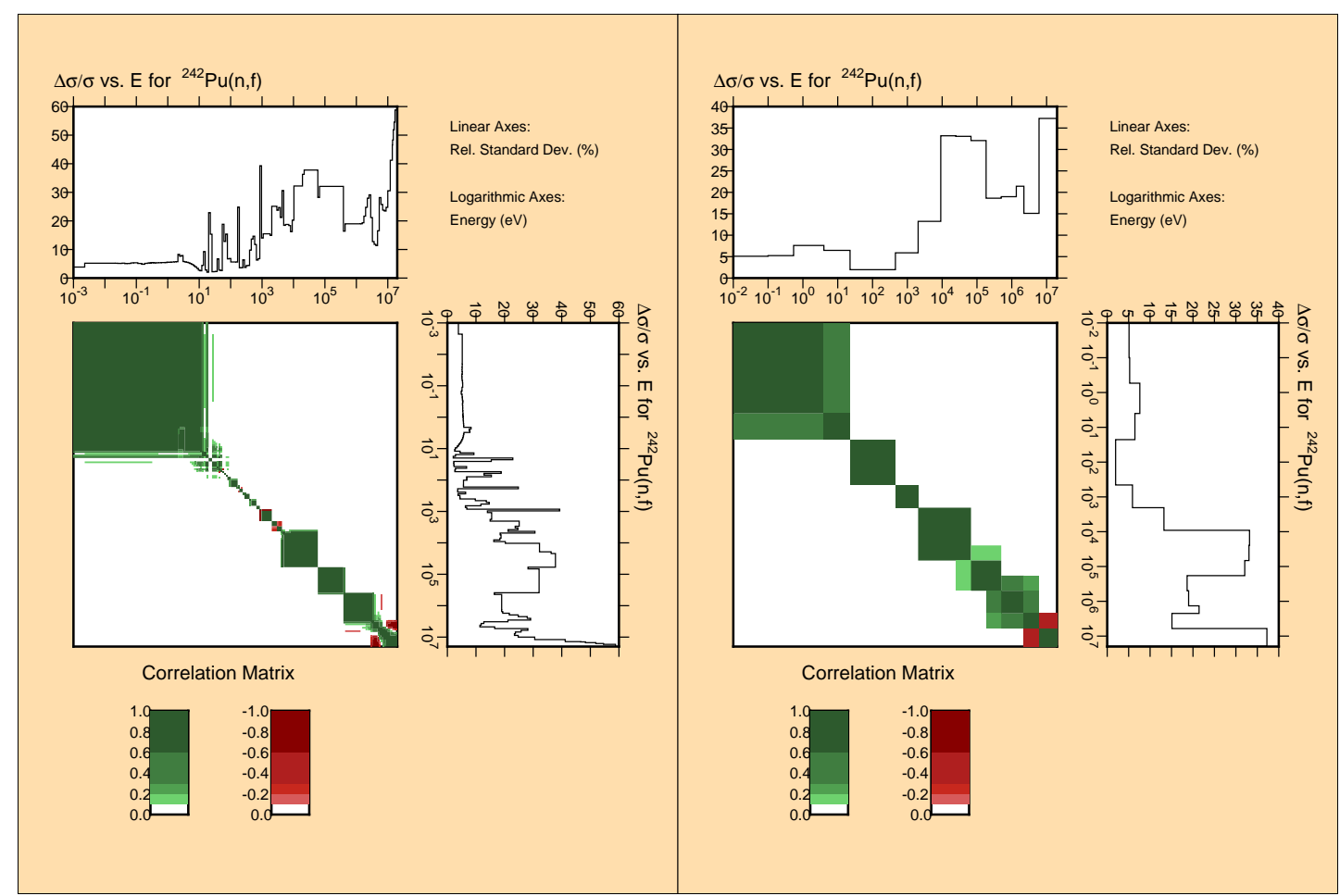

Figure A.153: Correlation and uncertainties in 187 (left) and 15 (right) groups for the ${ }^{242} \mathrm{Pu}(\mathrm{n}, \mathrm{f})$ reaction 


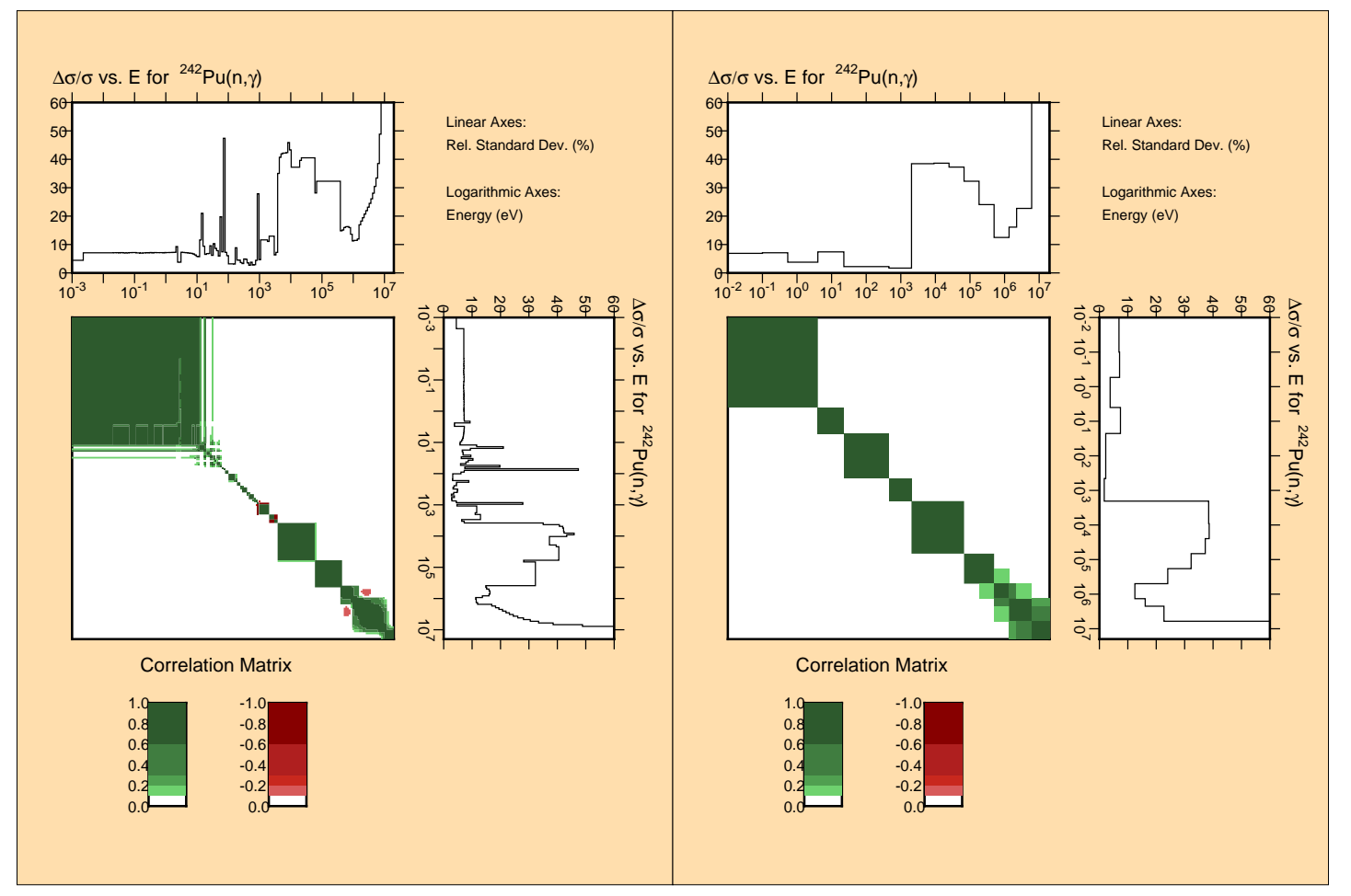

Figure A.154: Correlation and uncertainties in 187 (left) and 15 (right) groups for the ${ }^{242} \mathrm{Pu}(\mathrm{n}, \gamma)$ reaction

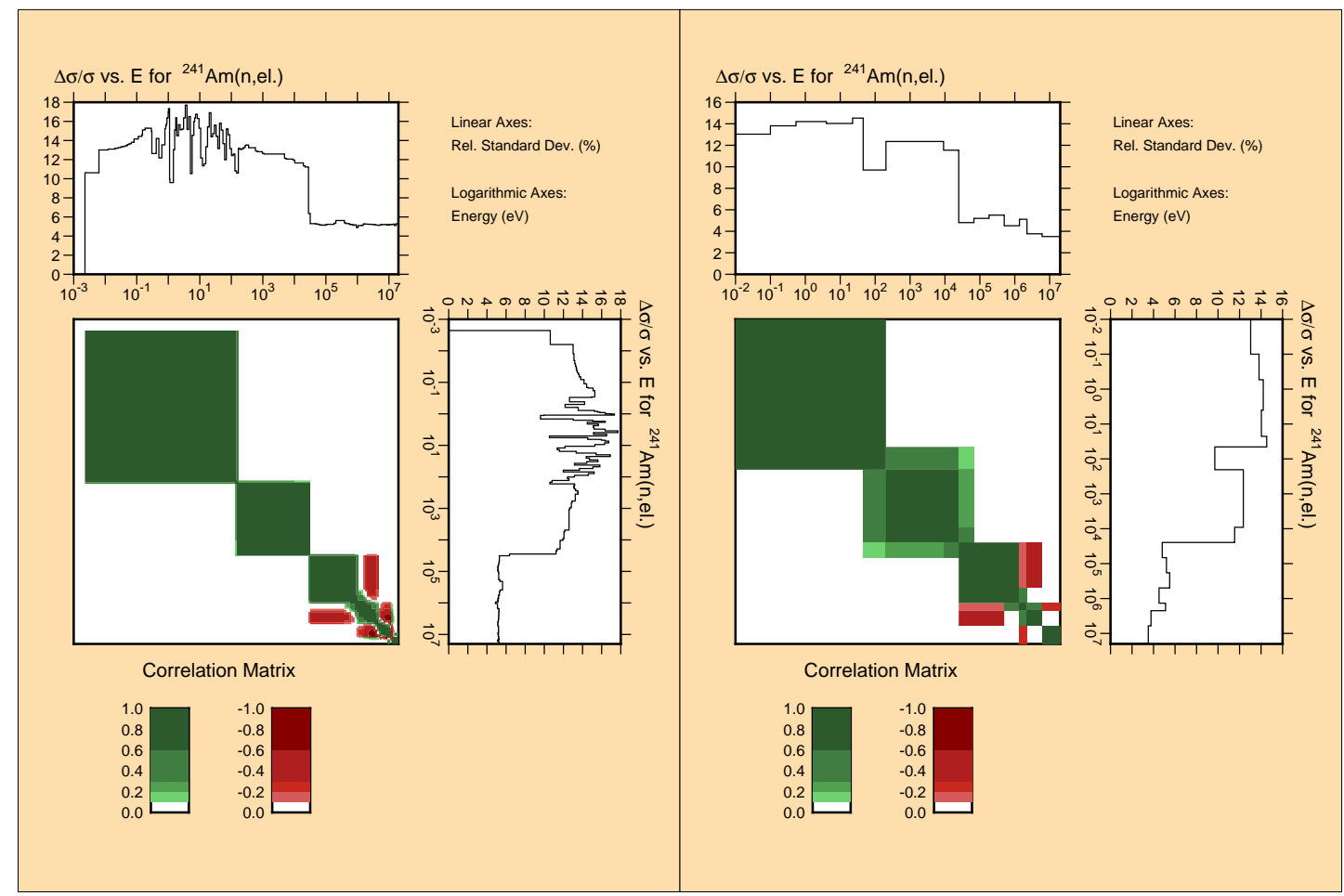

Figure A.155: Correlation and uncertainties in 187 (left) and 15 (right) groups for the ${ }^{241} \mathrm{Am}(\mathrm{n}, \mathrm{el})$ reaction 


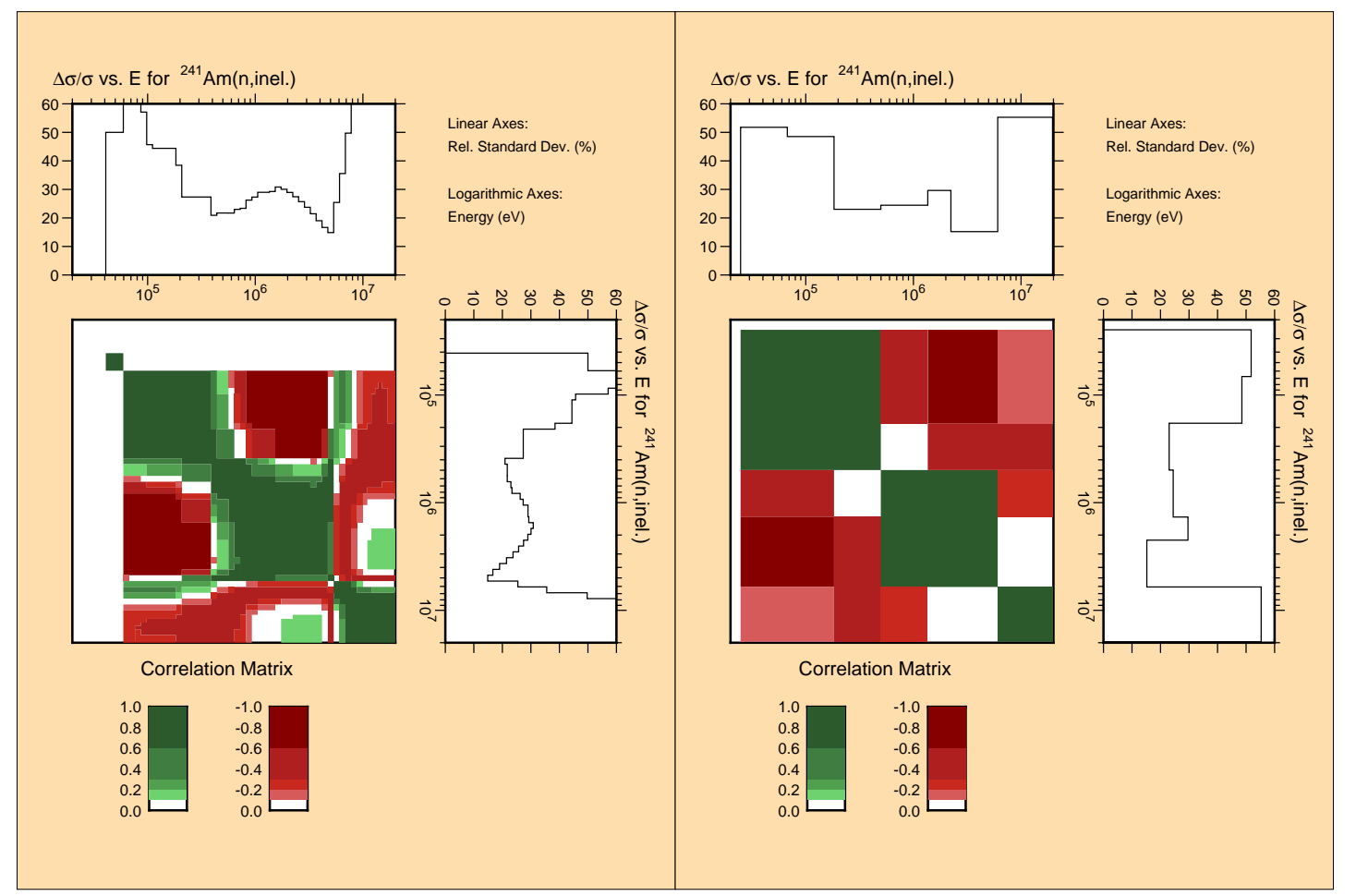

Figure A.156: Correlation and uncertainties in 187 (left) and 15 (right) groups for the ${ }^{241} \mathrm{Am}\left(\mathrm{n}, \mathrm{n}^{\prime}\right)$ reaction

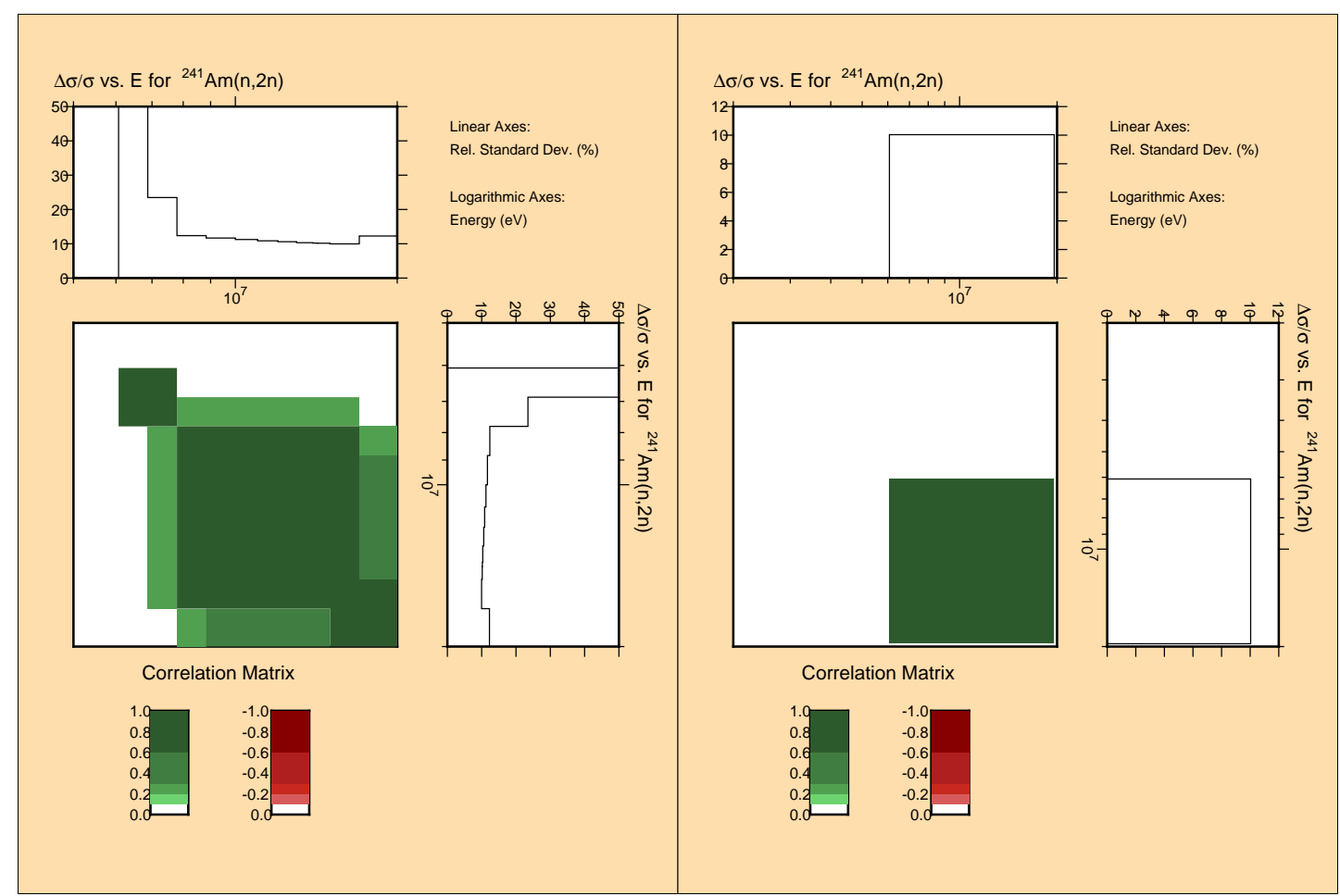

Figure A.157: Correlation and uncertainties in 187 (left) and 15 (right) groups for the ${ }^{241} \mathrm{Am}(\mathrm{n}, 2 \mathrm{n})$ reaction 


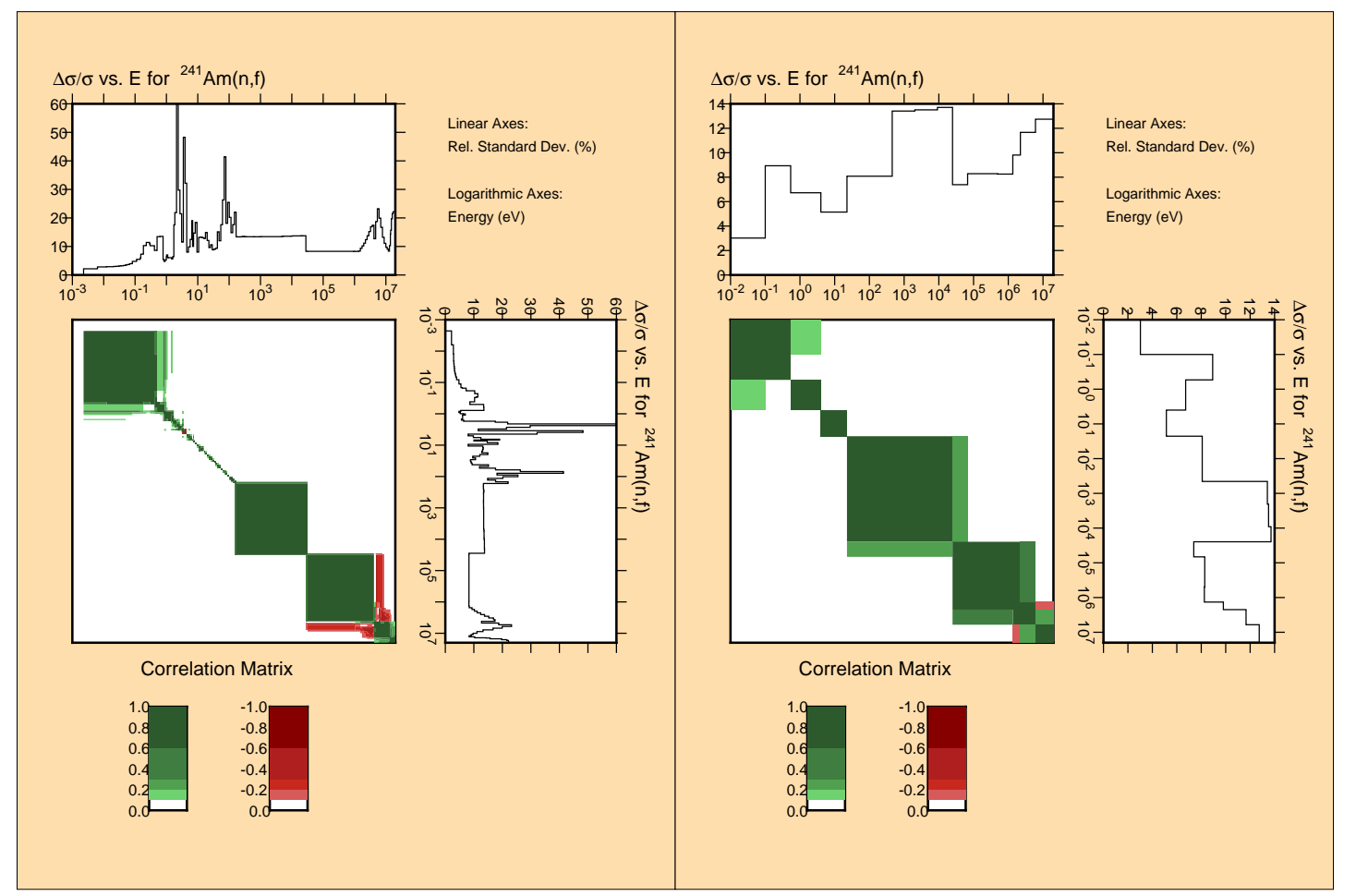

Figure A.158: Correlation and uncertainties in 187 (left) and 15 (right) groups for the ${ }^{241} \mathrm{Am}(\mathrm{n}, \mathrm{f})$ reaction

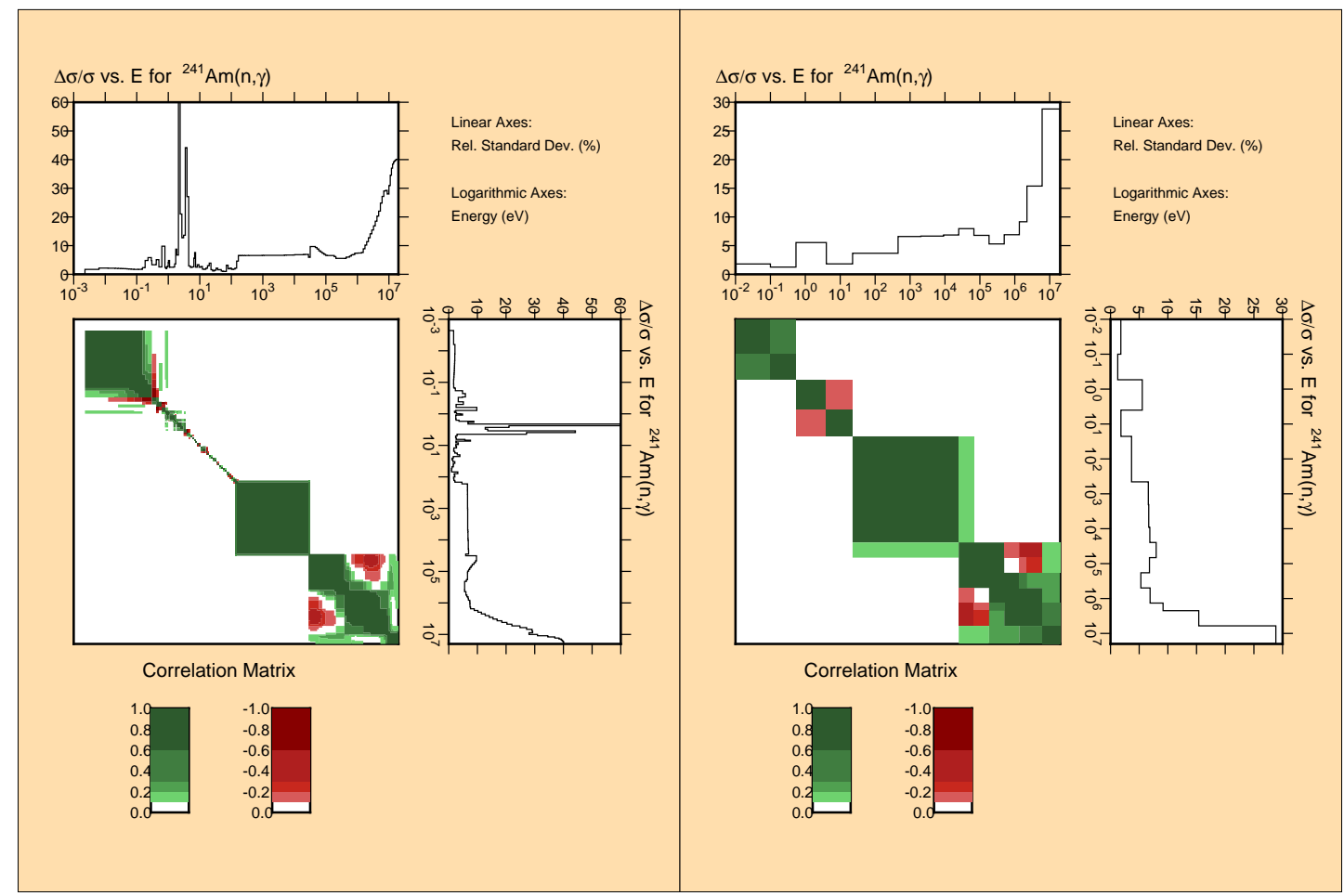

Figure A.159: Correlation and uncertainties in 187 (left) and 15 (right) groups for the ${ }^{241} \mathrm{Am}(\mathrm{n}, \gamma)$ reaction 


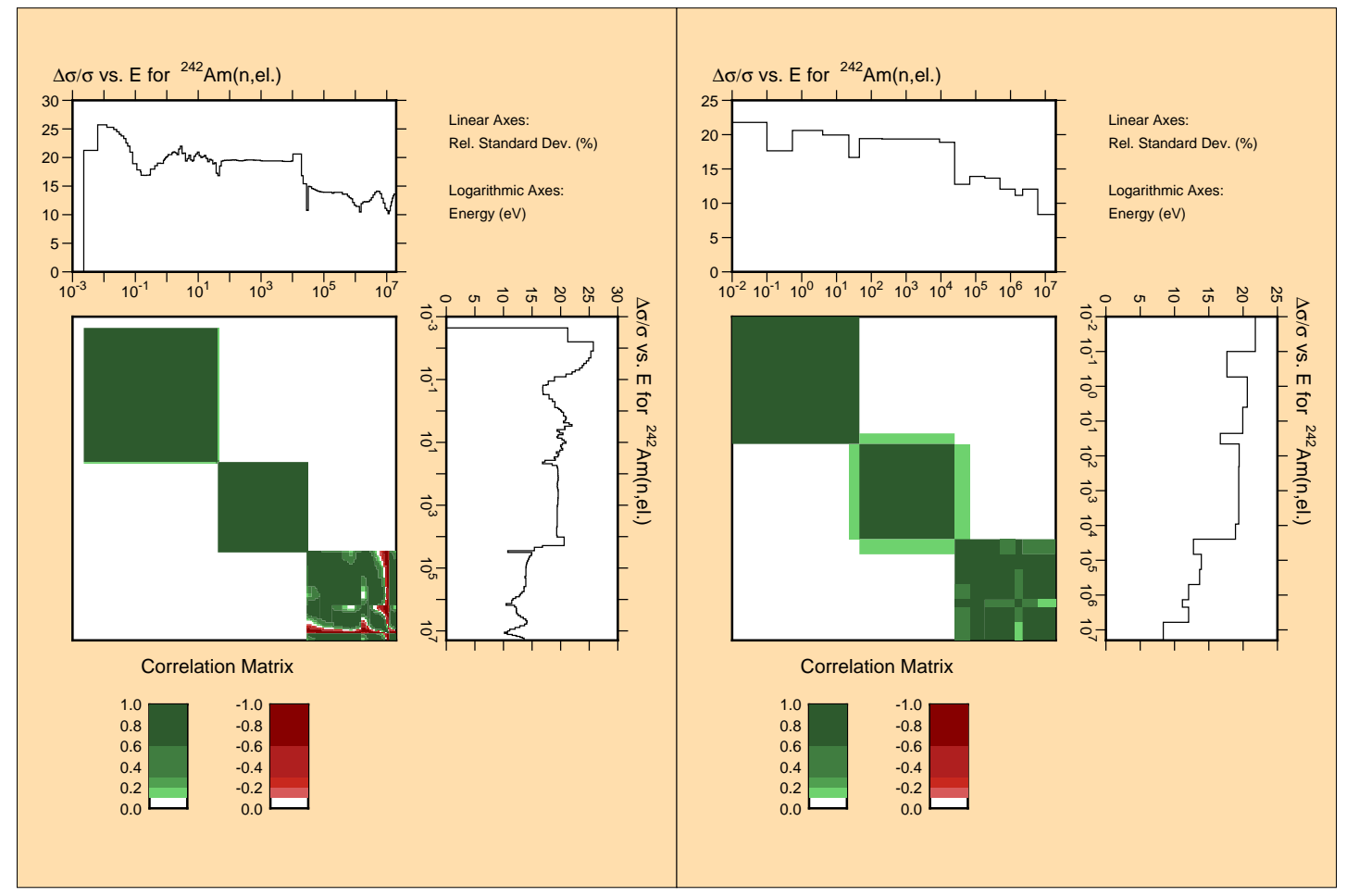

Figure A.160: Correlation and uncertainties in 187 (left) and 15 (right) groups for the ${ }^{242 m} \mathrm{Am}(\mathrm{n}, \mathrm{el})$ reaction

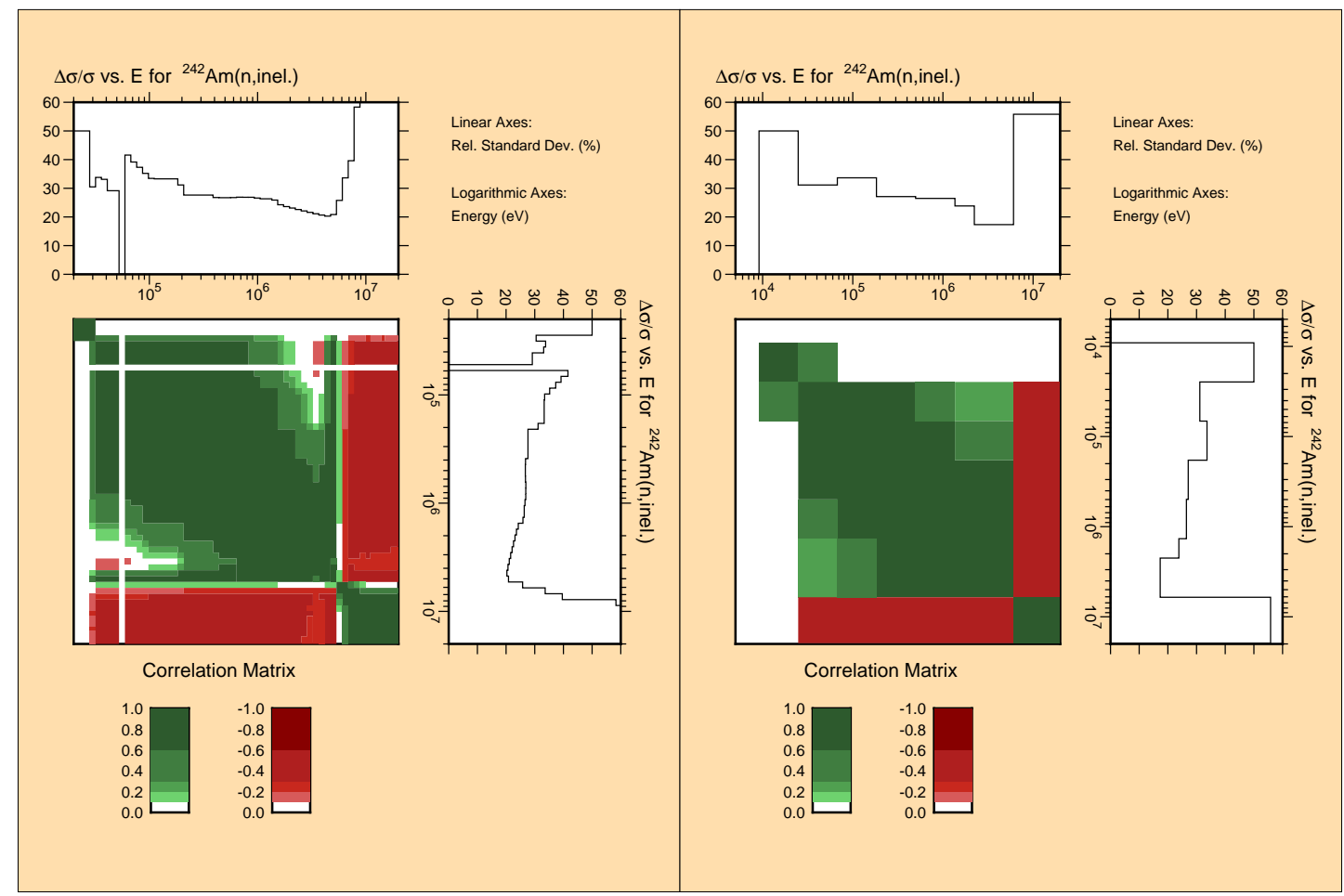

Figure A.161: Correlation and uncertainties in 187 (left) and 15 (right) groups for the ${ }^{242 m} \mathrm{Am}\left(\mathrm{n}, \mathrm{n}^{\prime}\right)$ reaction 


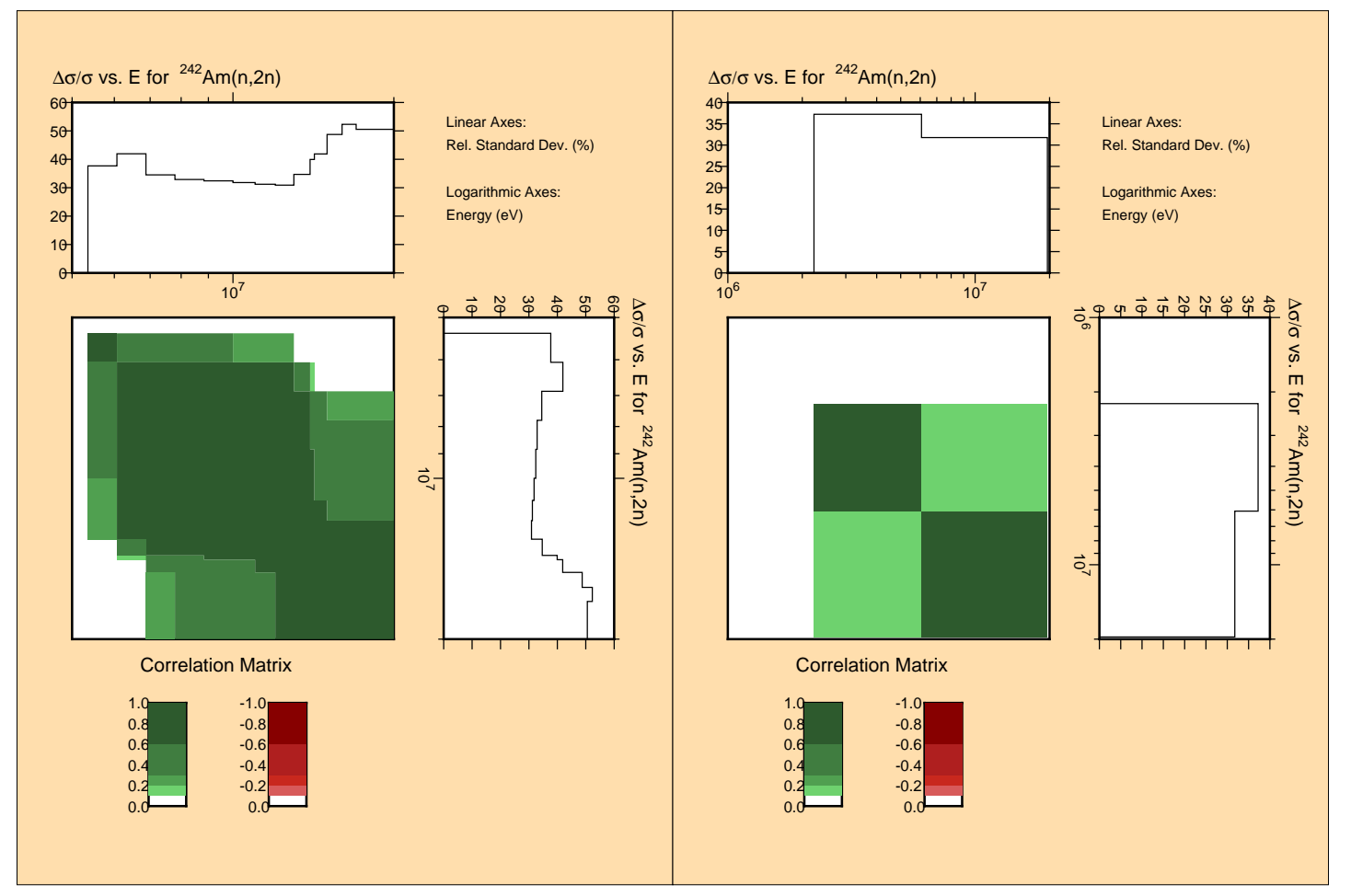

Figure A.162: Correlation and uncertainties in 187 (left) and 15 (right) groups for the ${ }^{242 m} \mathrm{Am}(\mathrm{n}, 2 \mathrm{n})$ reaction

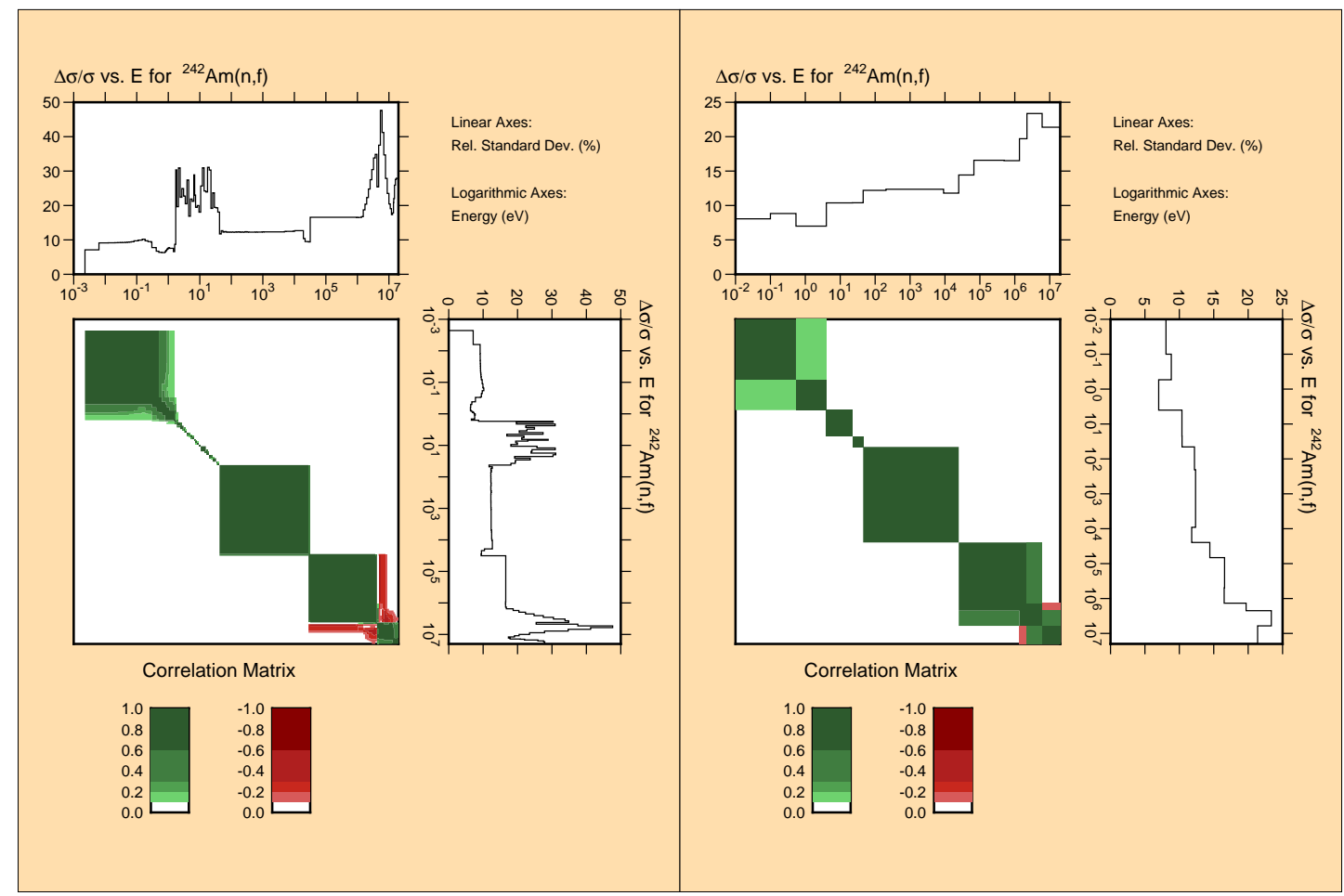

Figure A.163: Correlation and uncertainties in 187 (left) and 15 (right) groups for the ${ }^{242 m} \mathrm{Am}(\mathrm{n}, \mathrm{f})$ reaction 


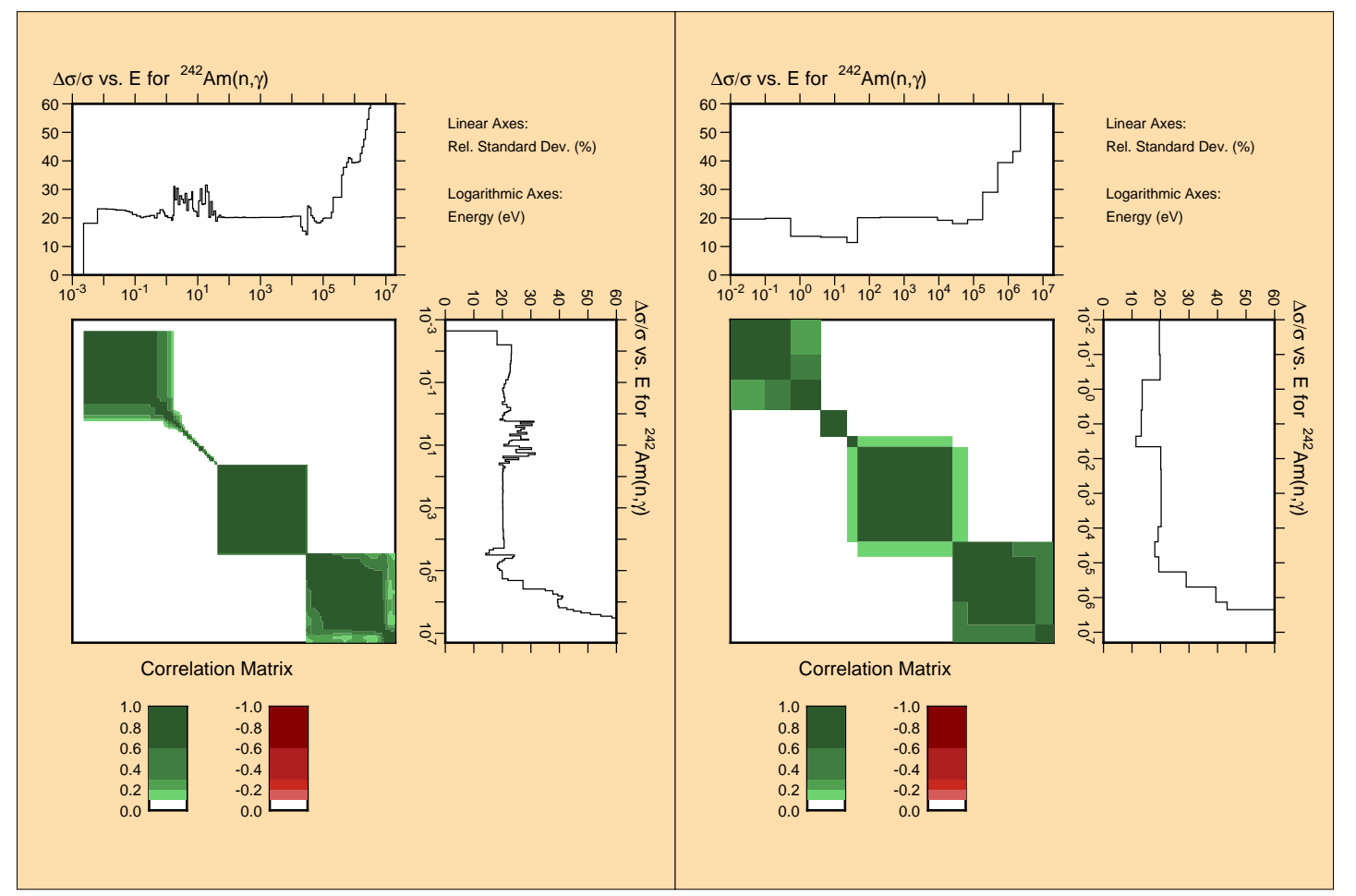

Figure A.164: Correlation and uncertainties in 187 (left) and 15 (right) groups for the ${ }^{242 m} \mathrm{Am}(\mathrm{n}, \gamma)$ reaction

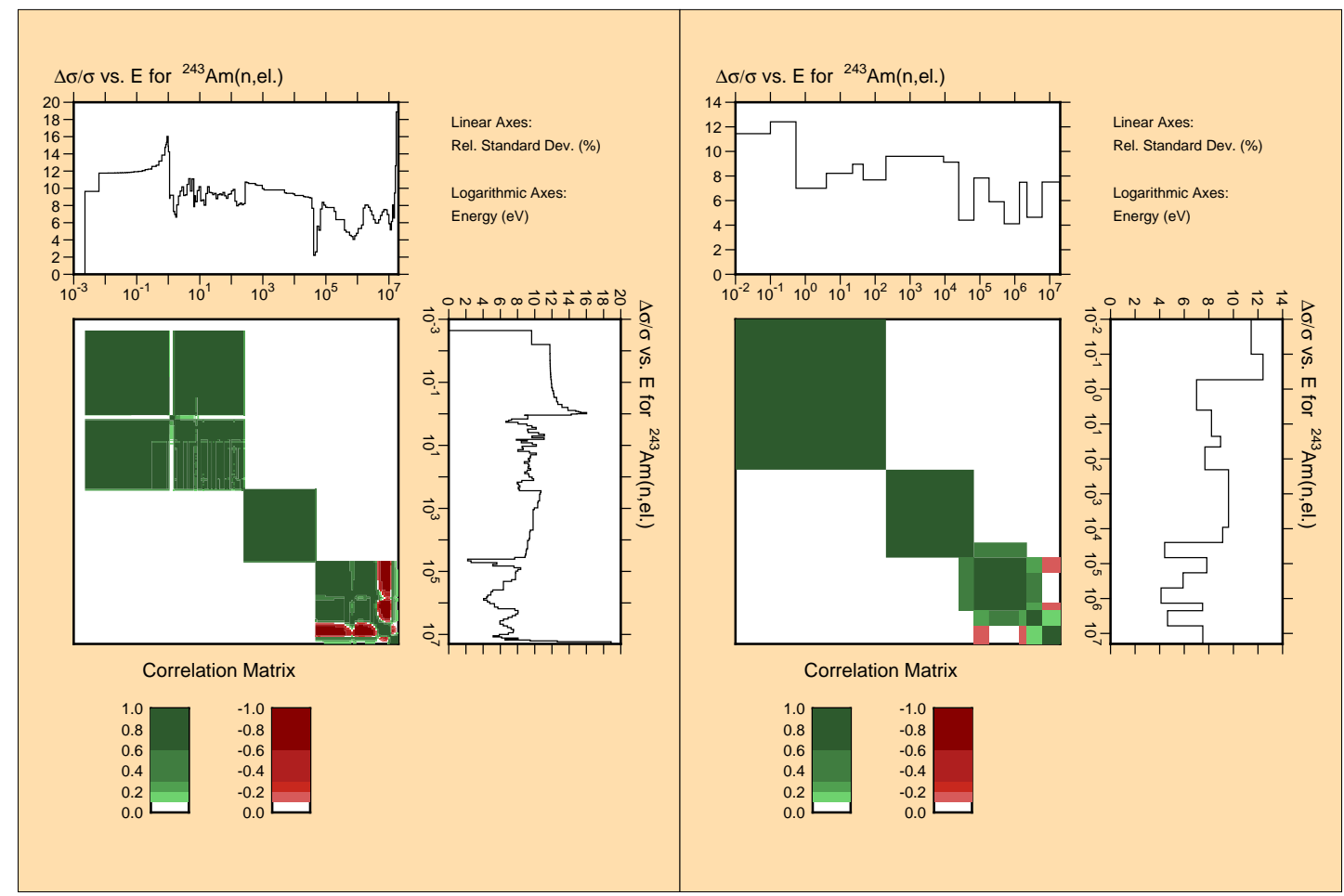

Figure A.165: Correlation and uncertainties in 187 (left) and 15 (right) groups for the ${ }^{243} \mathrm{Am}(\mathrm{n}, \mathrm{el})$ reaction 


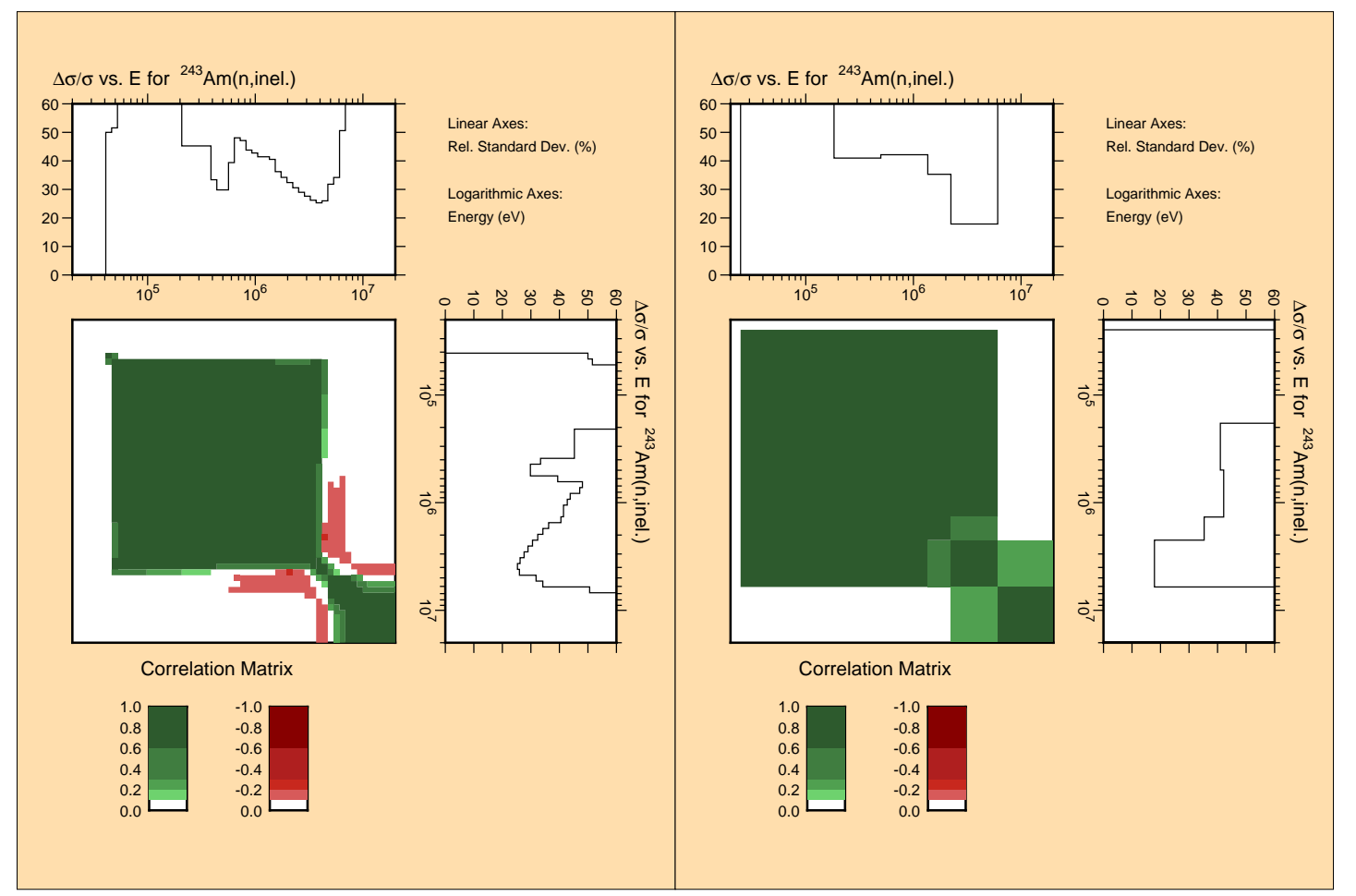

Figure A.166: Correlation and uncertainties in 187 (left) and 15 (right) groups for the ${ }^{243} \mathrm{Am}\left(\mathrm{n}, \mathrm{n}^{\prime}\right)$ reaction

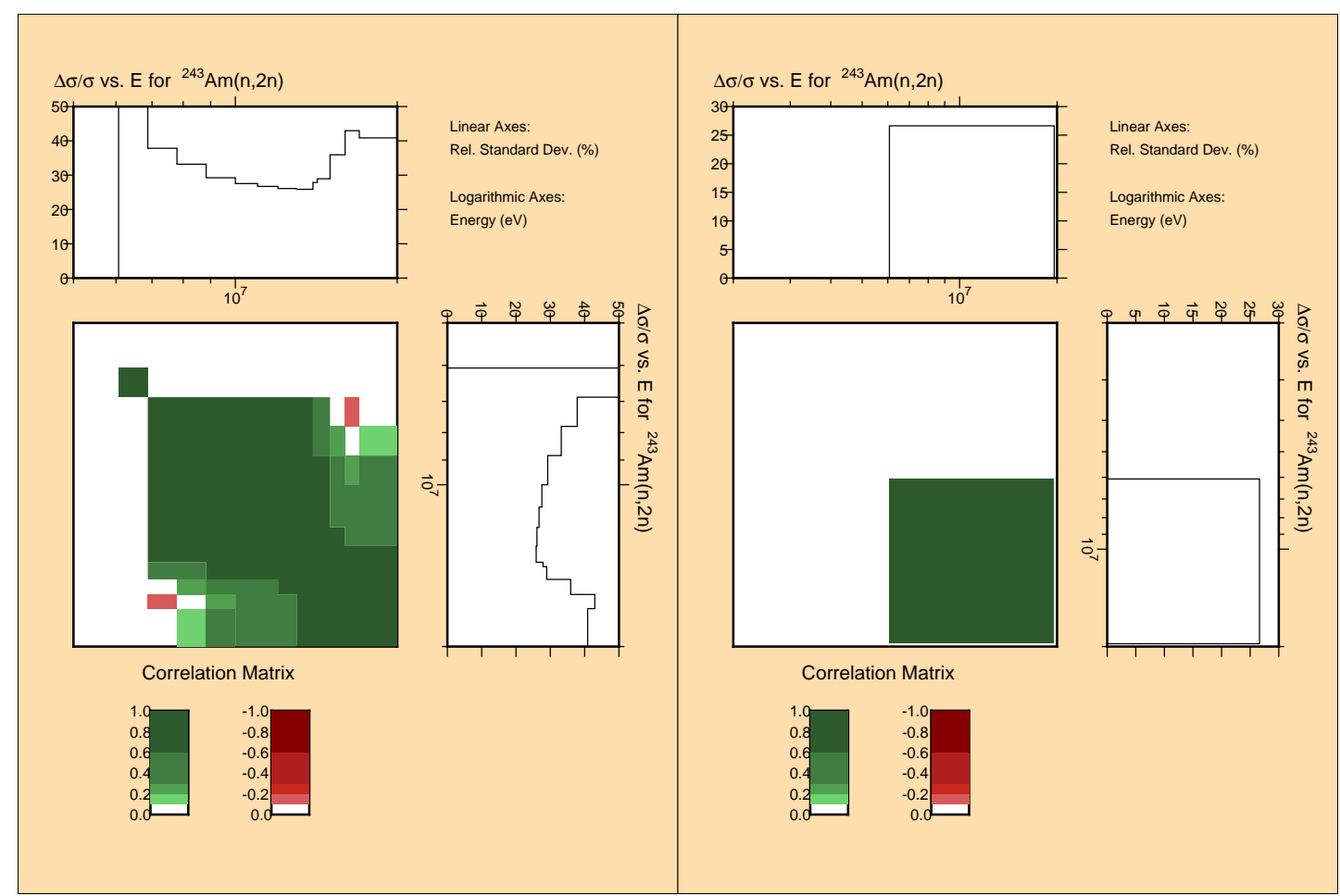

Figure A.167: Correlation and uncertainties in 187 (left) and 15 (right) groups for the ${ }^{243} \mathrm{Am}(\mathrm{n}, 2 \mathrm{n})$ reaction 


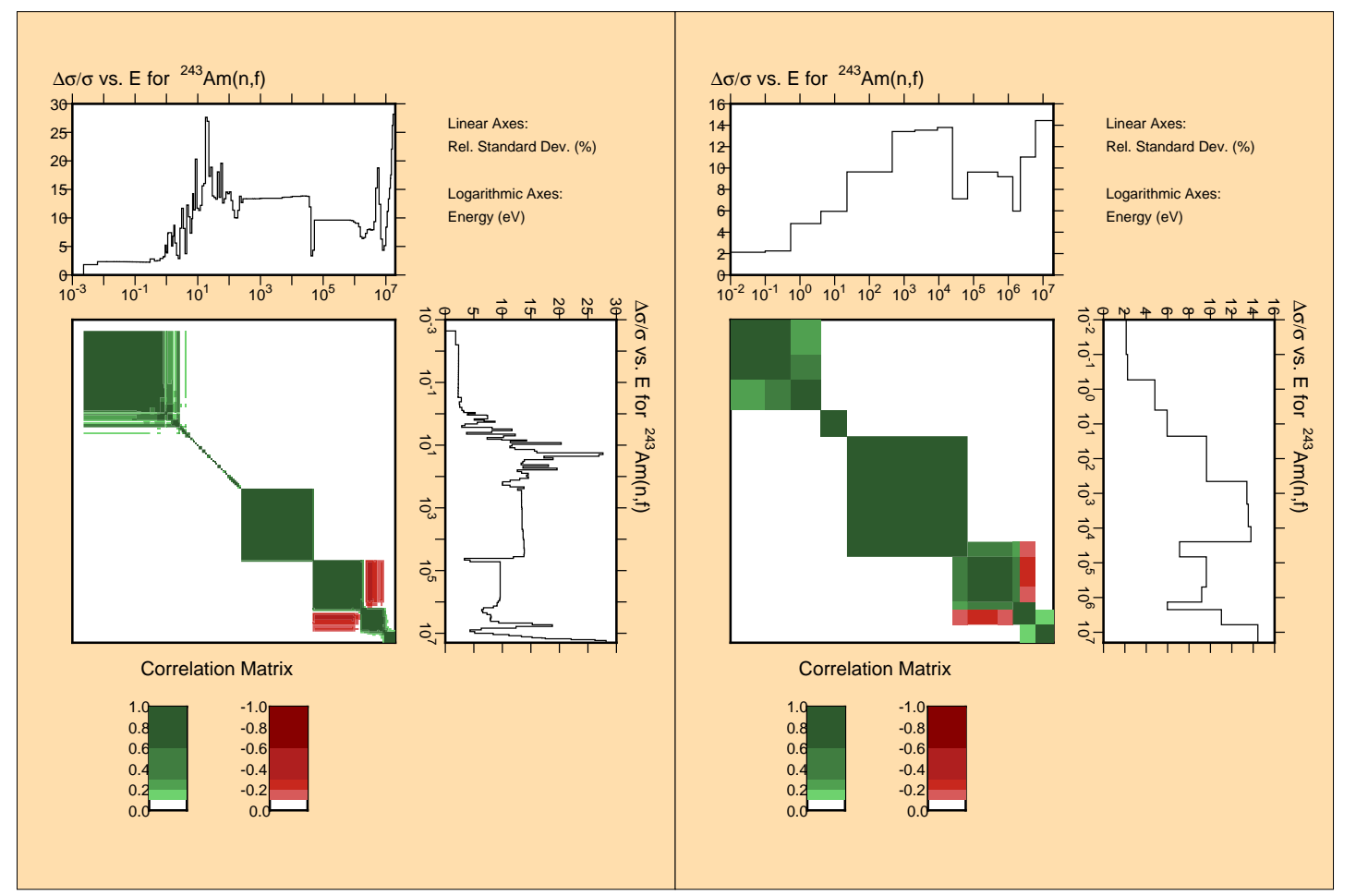

Figure A.168: Correlation and uncertainties in 187 (left) and 15 (right) groups for the ${ }^{243} \mathrm{Am}(\mathrm{n}, \mathrm{f})$ reaction

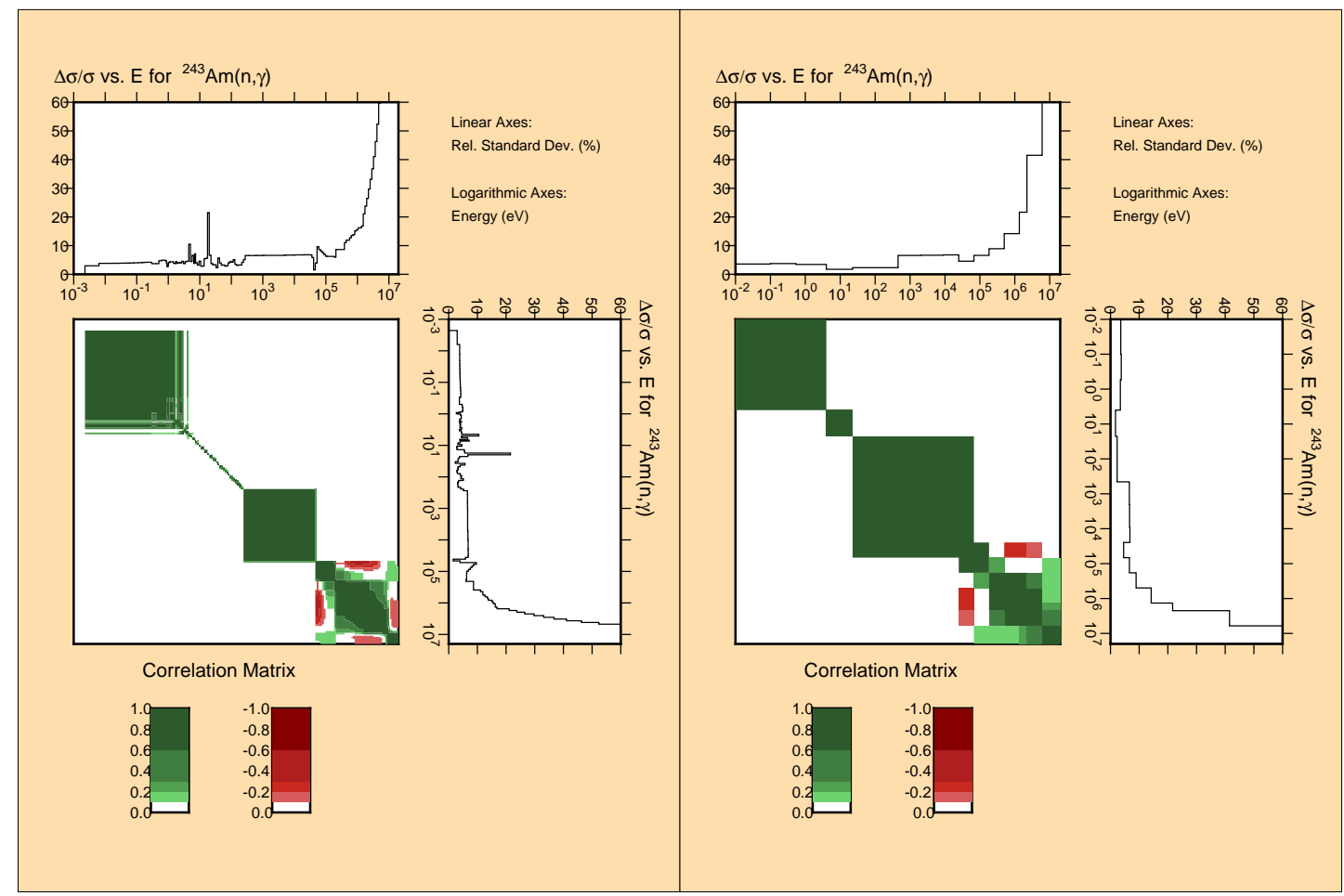

Figure A.169: Correlation and uncertainties in 187 (left) and 15 (right) groups for the ${ }^{243} \mathrm{Am}(\mathrm{n}, \gamma)$ reaction 


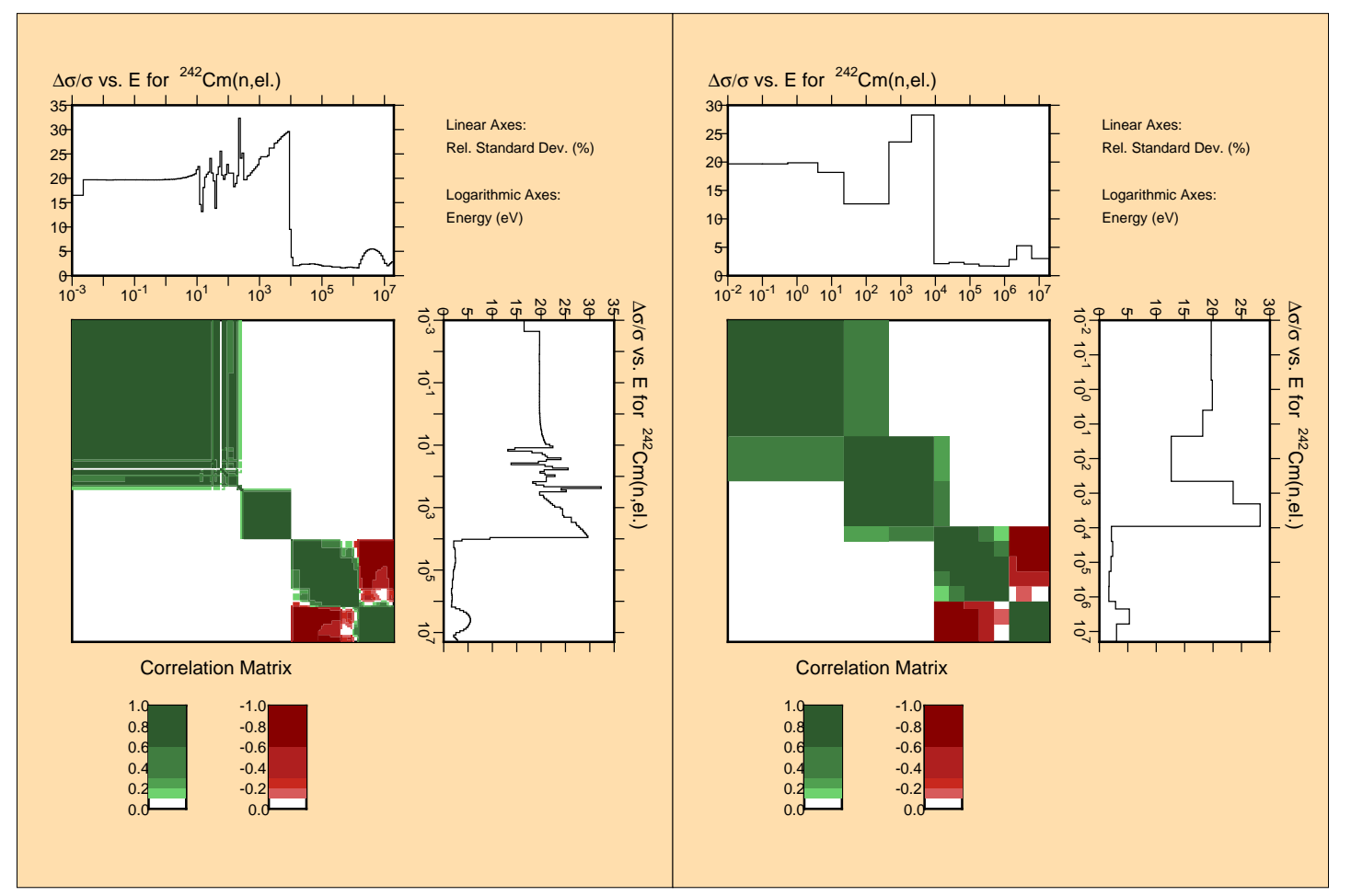

Figure A.170: Correlation and uncertainties in 187 (left) and 15 (right) groups for the ${ }^{242} \mathrm{Cm}(\mathrm{n}, \mathrm{el})$ reaction

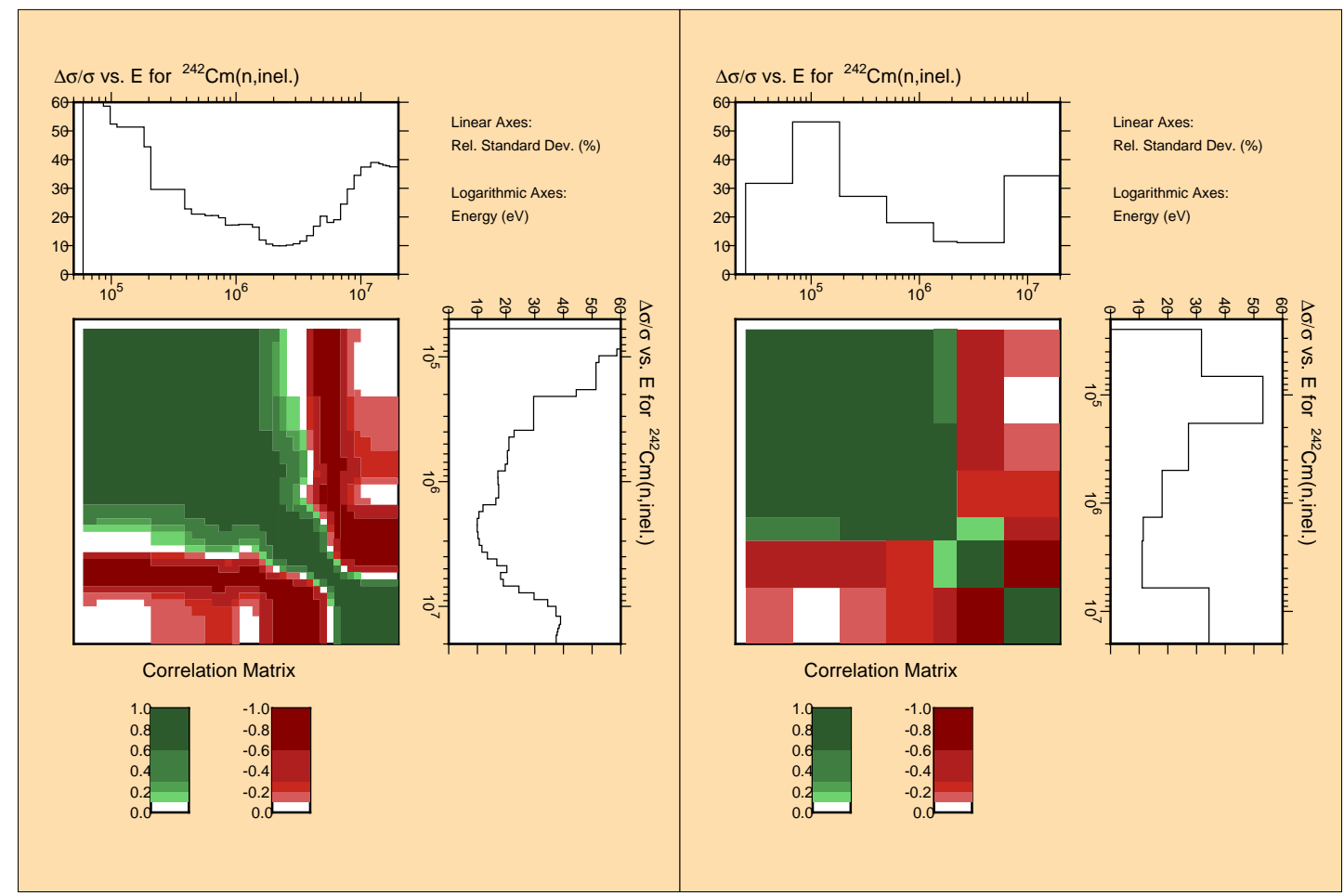

Figure A.171: Correlation and uncertainties in 187 (left) and 15 (right) groups for the ${ }^{242} \mathrm{Cm}\left(\mathrm{n}, \mathrm{n}^{\prime}\right)$ reaction 


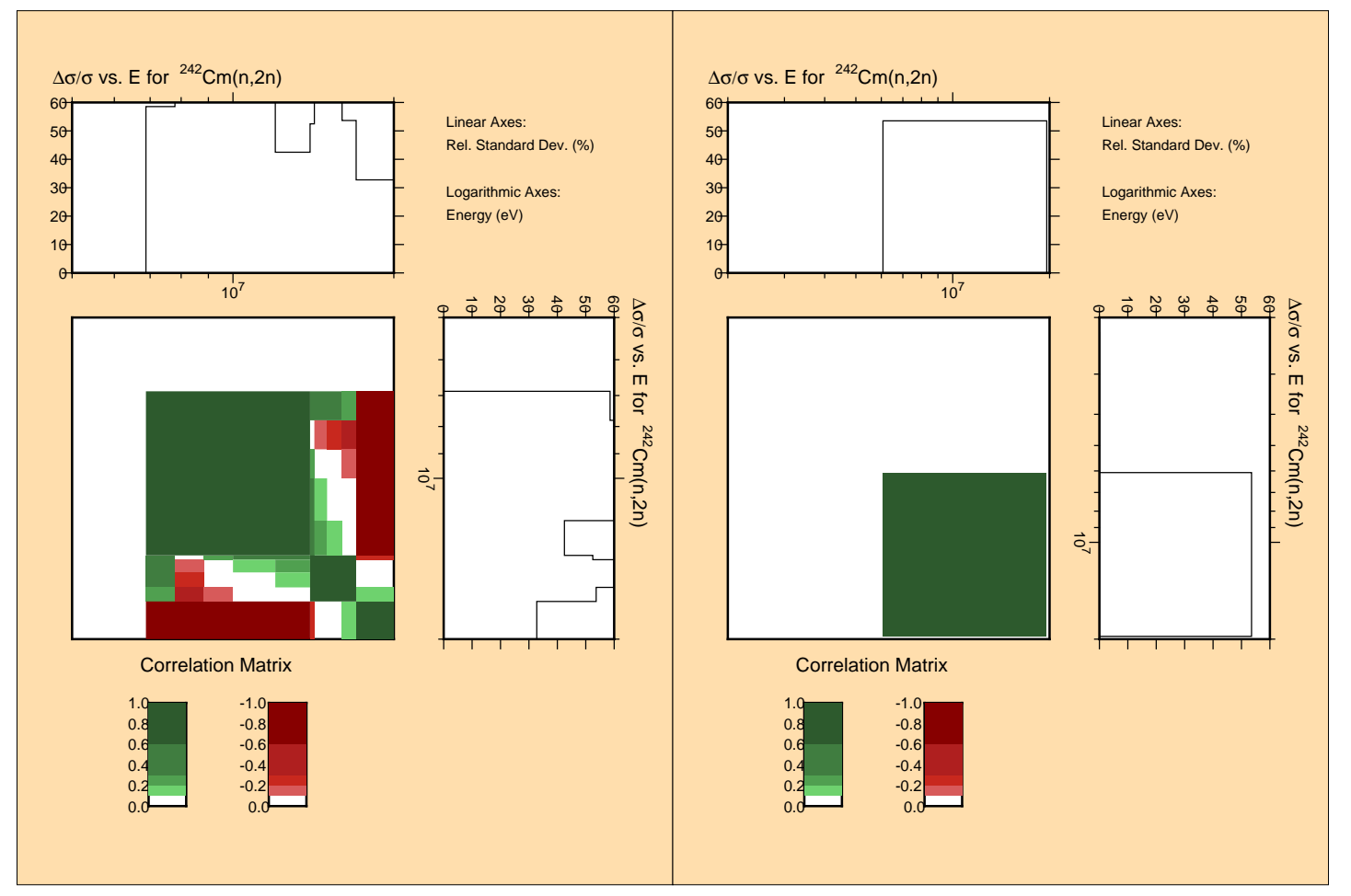

Figure A.172: Correlation and uncertainties in 187 (left) and 15 (right) groups for the ${ }^{242} \mathrm{Cm}(\mathrm{n}, 2 \mathrm{n})$ reaction

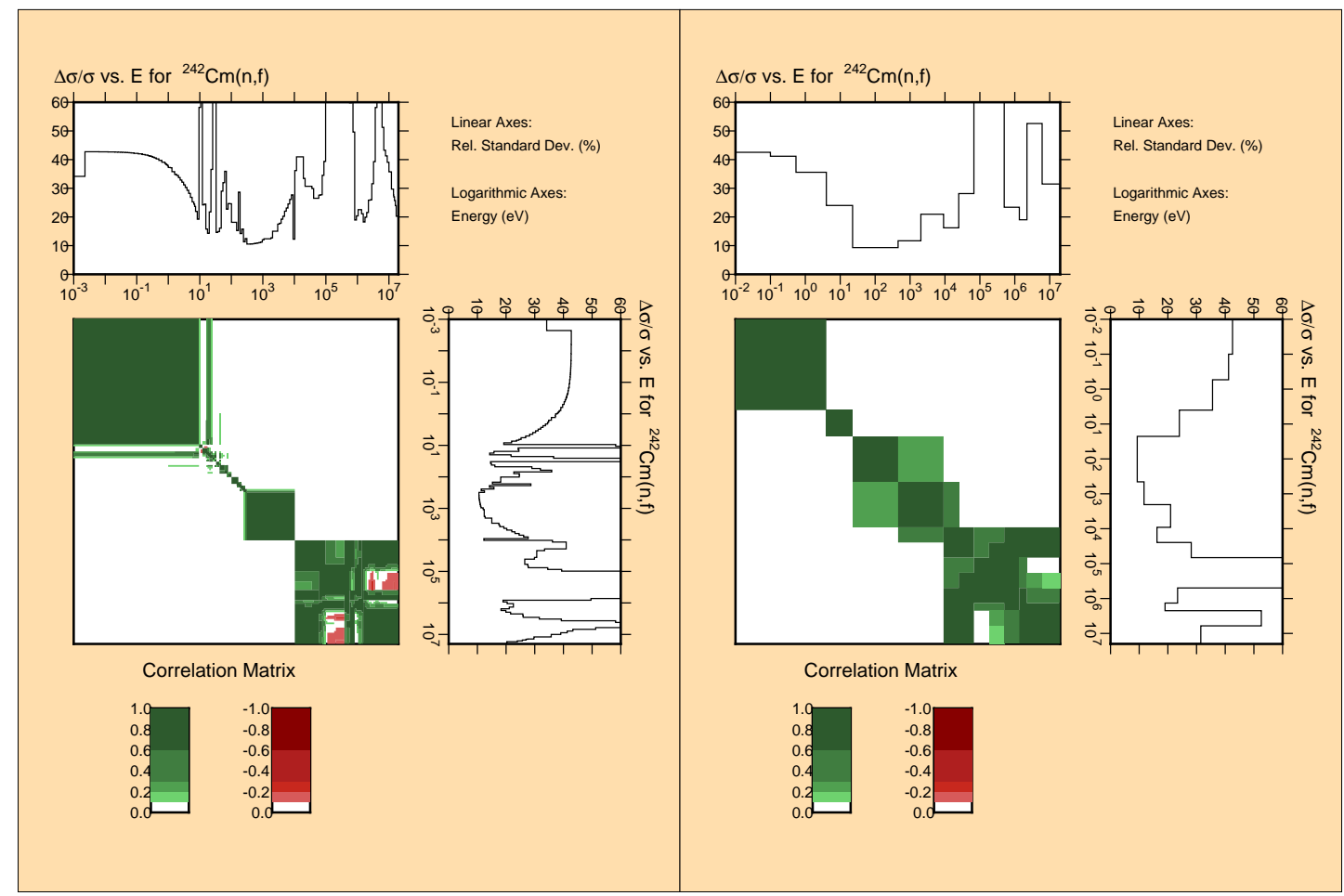

Figure A.173: Correlation and uncertainties in 187 (left) and 15 (right) groups for the ${ }^{242} \mathrm{Cm}(\mathrm{n}, \mathrm{f})$ reaction 


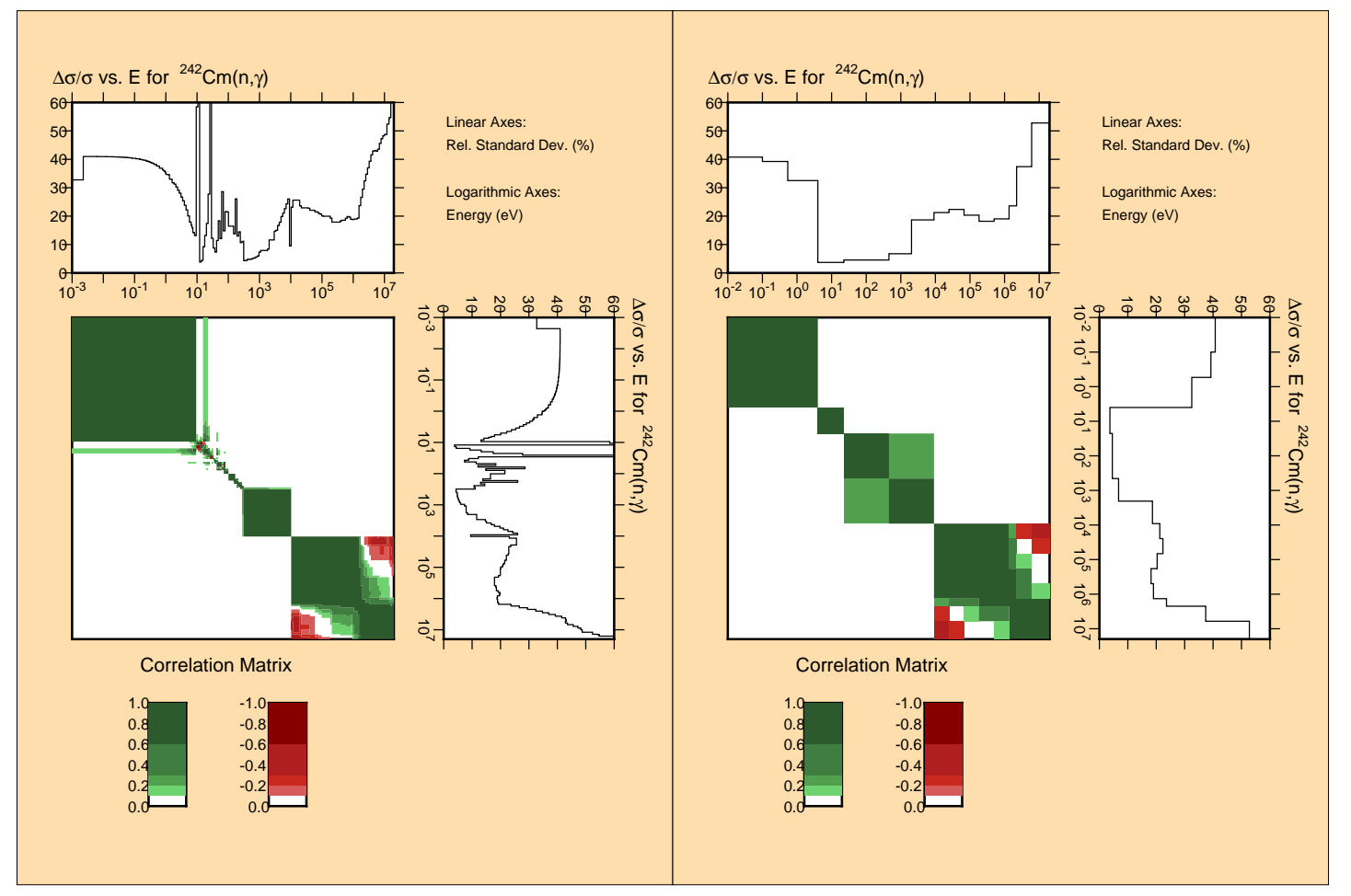

Figure A.174: Correlation and uncertainties in 187 (left) and 15 (right) groups for the ${ }^{242} \mathrm{Cm}(\mathrm{n}, \gamma)$ reaction

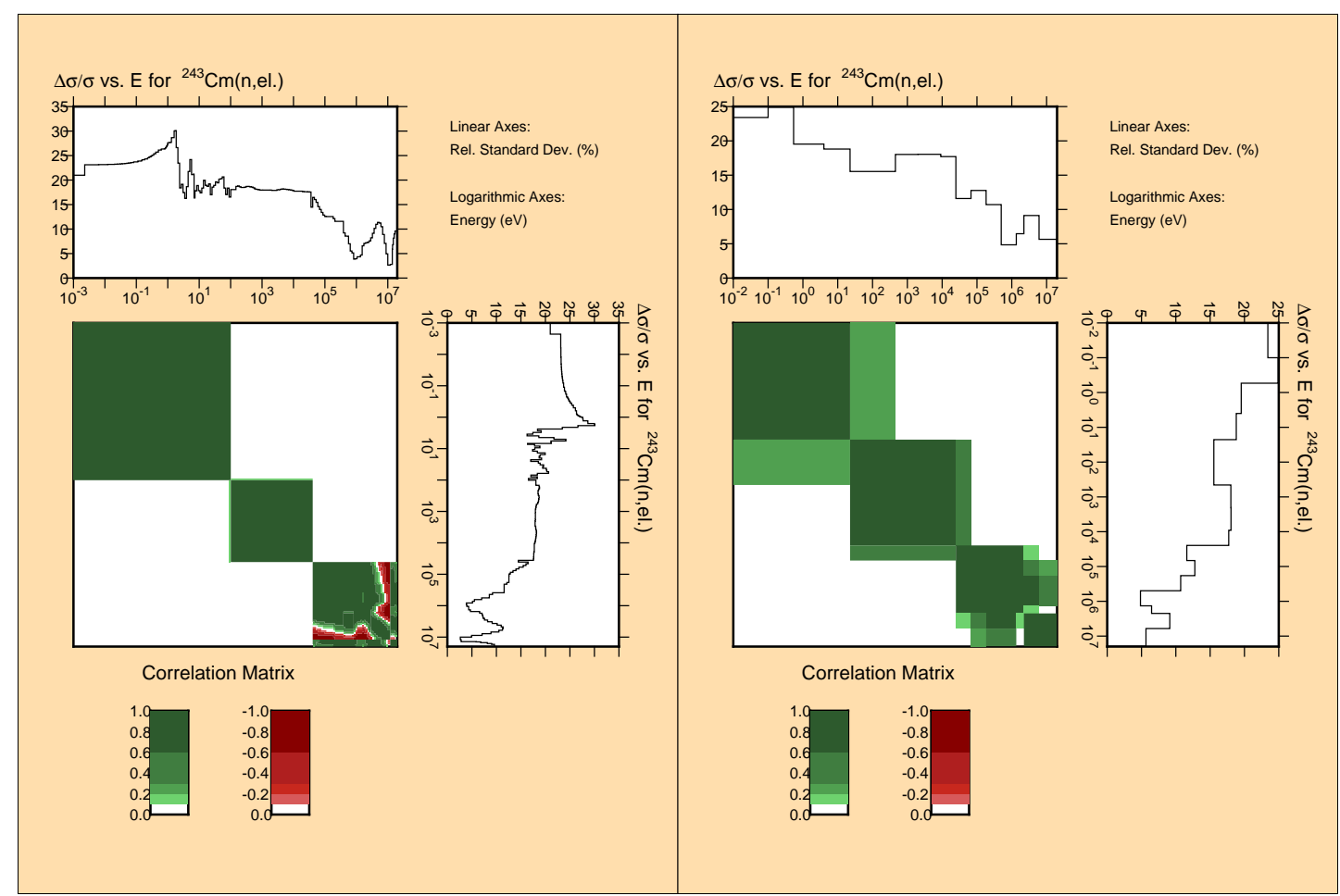

Figure A.175: Correlation and uncertainties in 187 (left) and 15 (right) groups for the ${ }^{243} \mathrm{Cm}(\mathrm{n}, \mathrm{el})$ reaction 


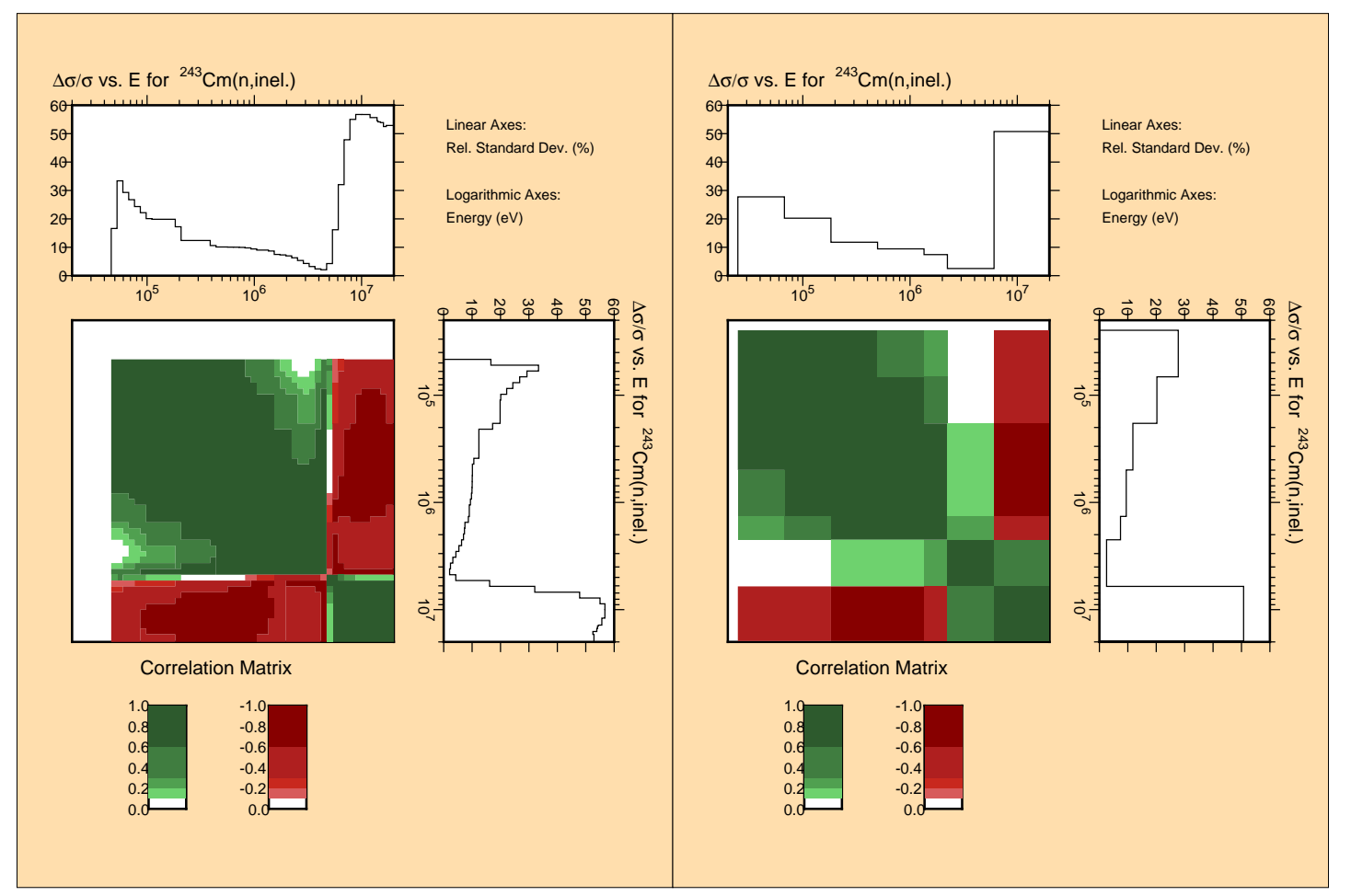

Figure A.176: Correlation and uncertainties in 187 (left) and 15 (right) groups for the ${ }^{243} \mathrm{Cm}\left(\mathrm{n}, \mathrm{n}^{\prime}\right)$ reaction

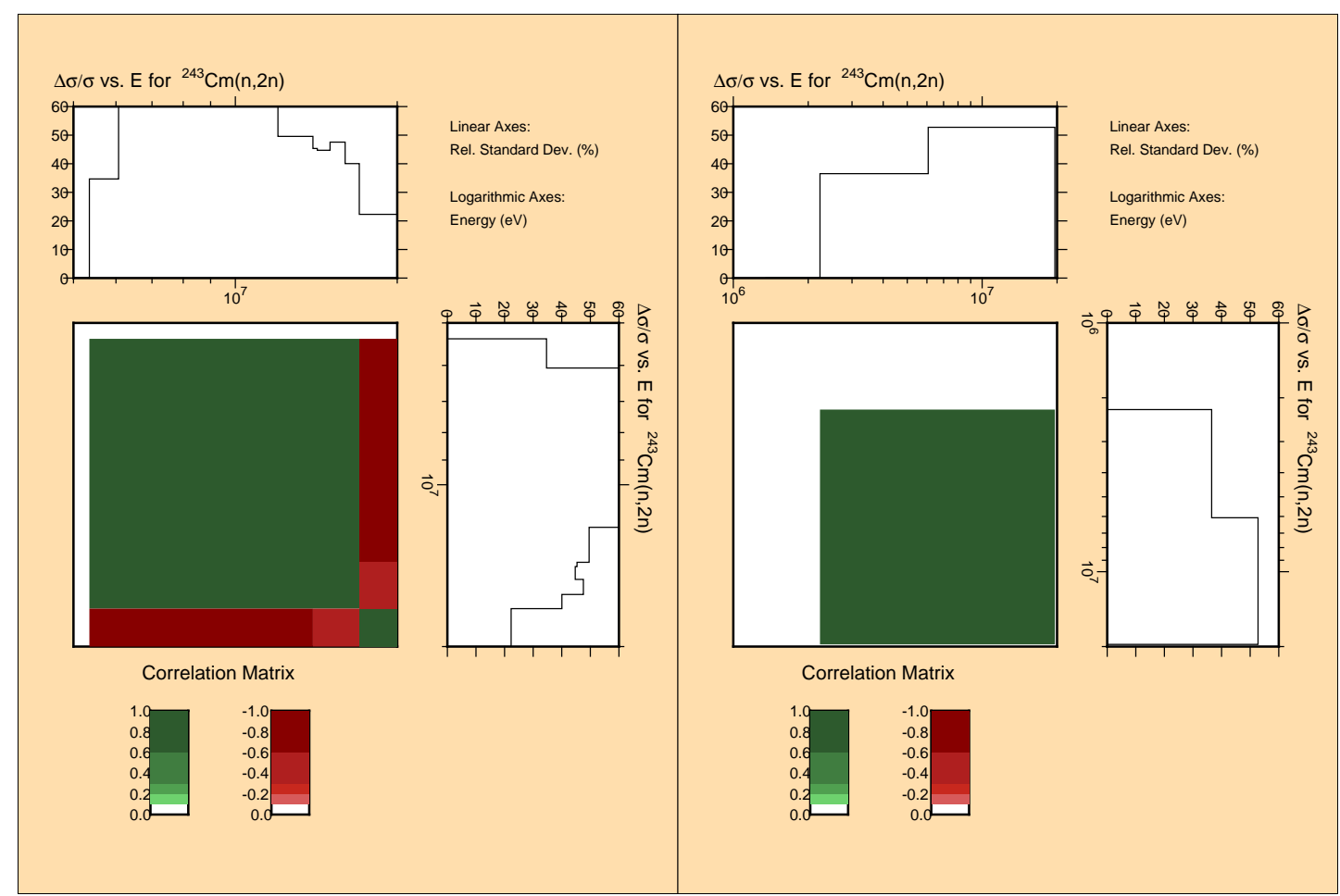

Figure A.177: Correlation and uncertainties in 187 (left) and 15 (right) groups for the ${ }^{243} \mathrm{Cm}(\mathrm{n}, 2 \mathrm{n})$ reaction 


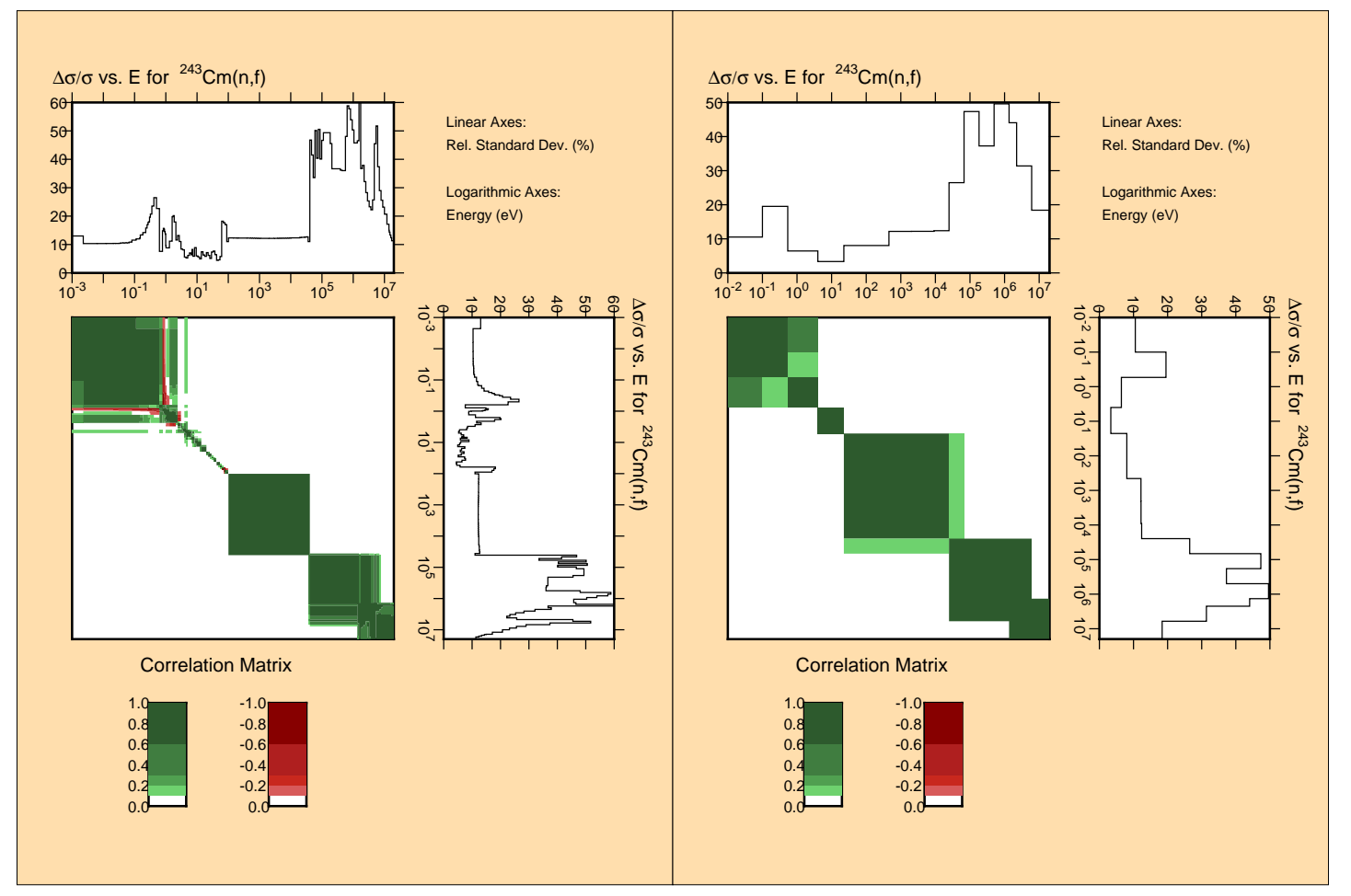

Figure A.178: Correlation and uncertainties in 187 (left) and 15 (right) groups for the ${ }^{243} \mathrm{Cm}(\mathrm{n}, \mathrm{f})$ reaction

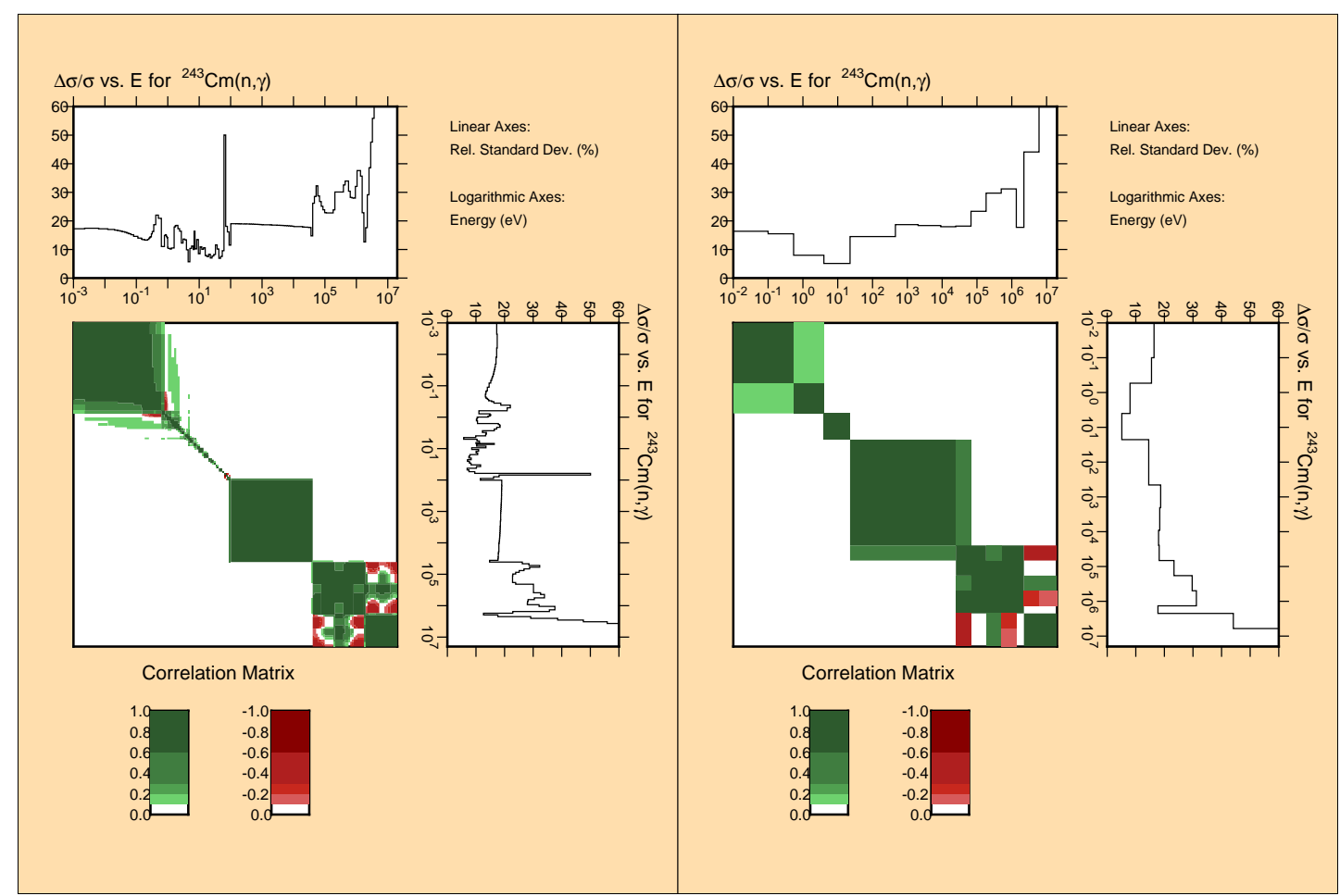

Figure A.179: Correlation and uncertainties in 187 (left) and 15 (right) groups for the ${ }^{243} \mathrm{Cm}(\mathrm{n}, \gamma)$ reaction 


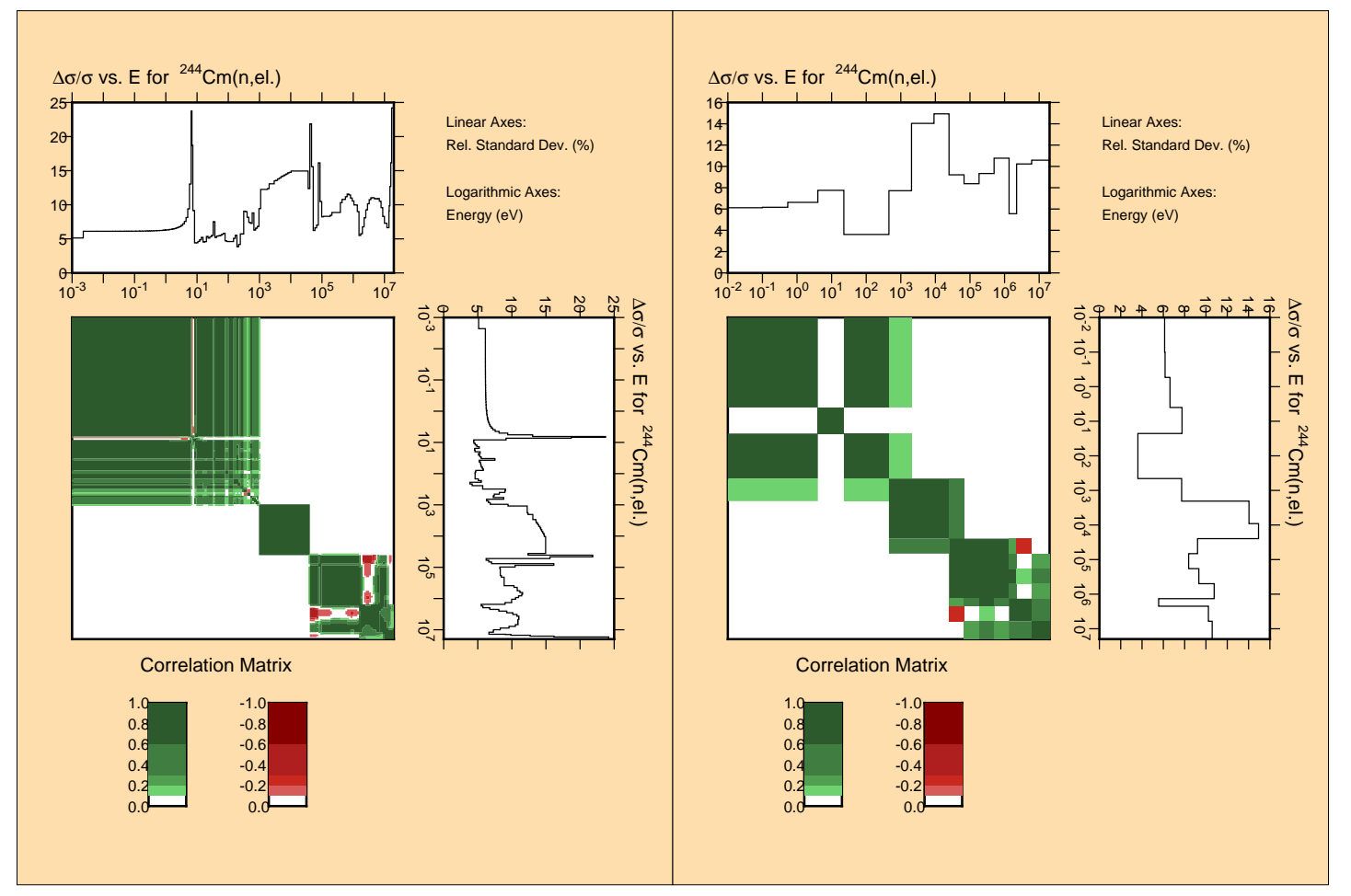

Figure A.180: Correlation and uncertainties in 187 (left) and 15 (right) groups for the ${ }^{244} \mathrm{Cm}(\mathrm{n}, \mathrm{el})$ reaction

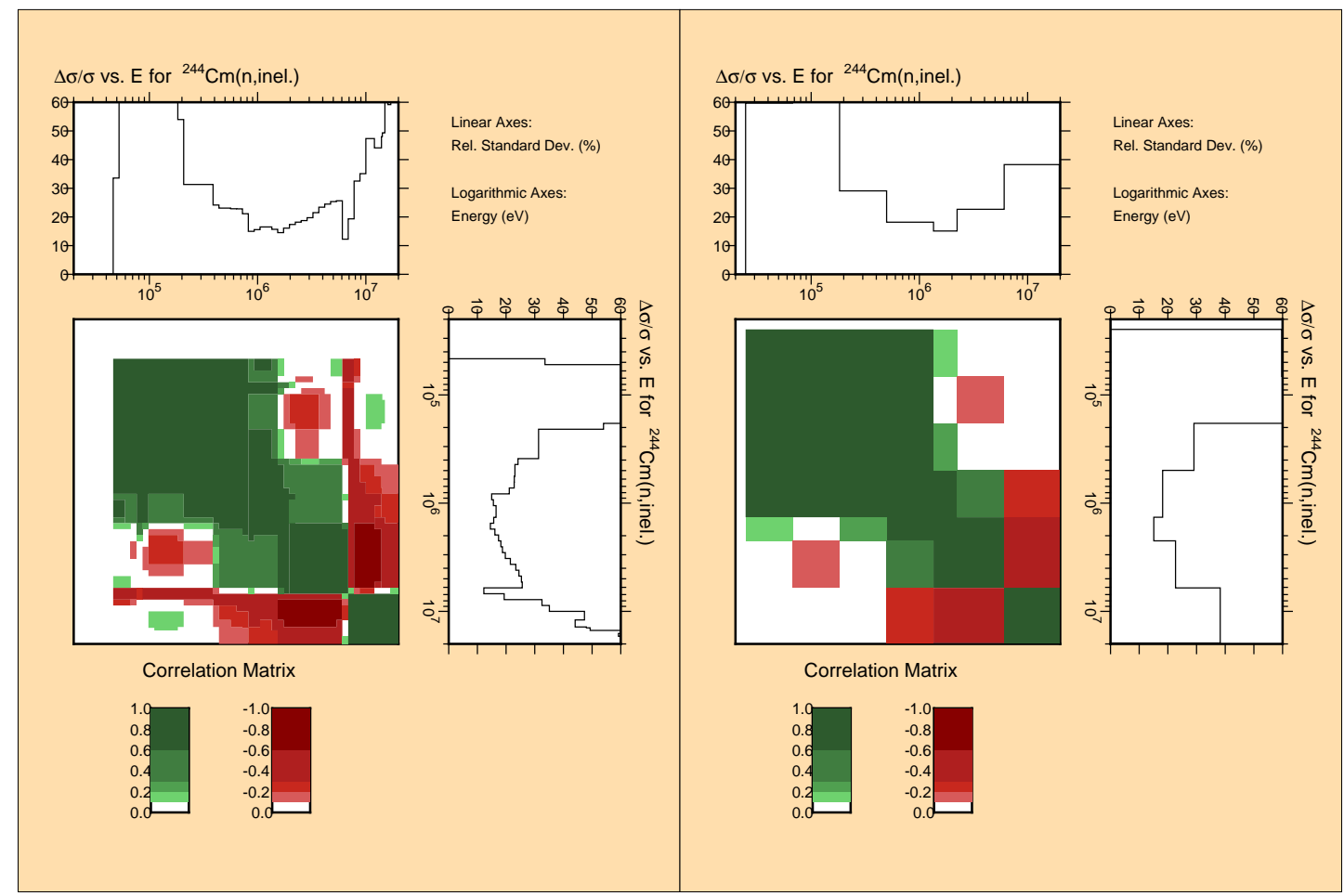

Figure A.181: Correlation and uncertainties in 187 (left) and 15 (right) groups for the ${ }^{244} \mathrm{Cm}\left(\mathrm{n}, \mathrm{n}^{\prime}\right)$ reaction 


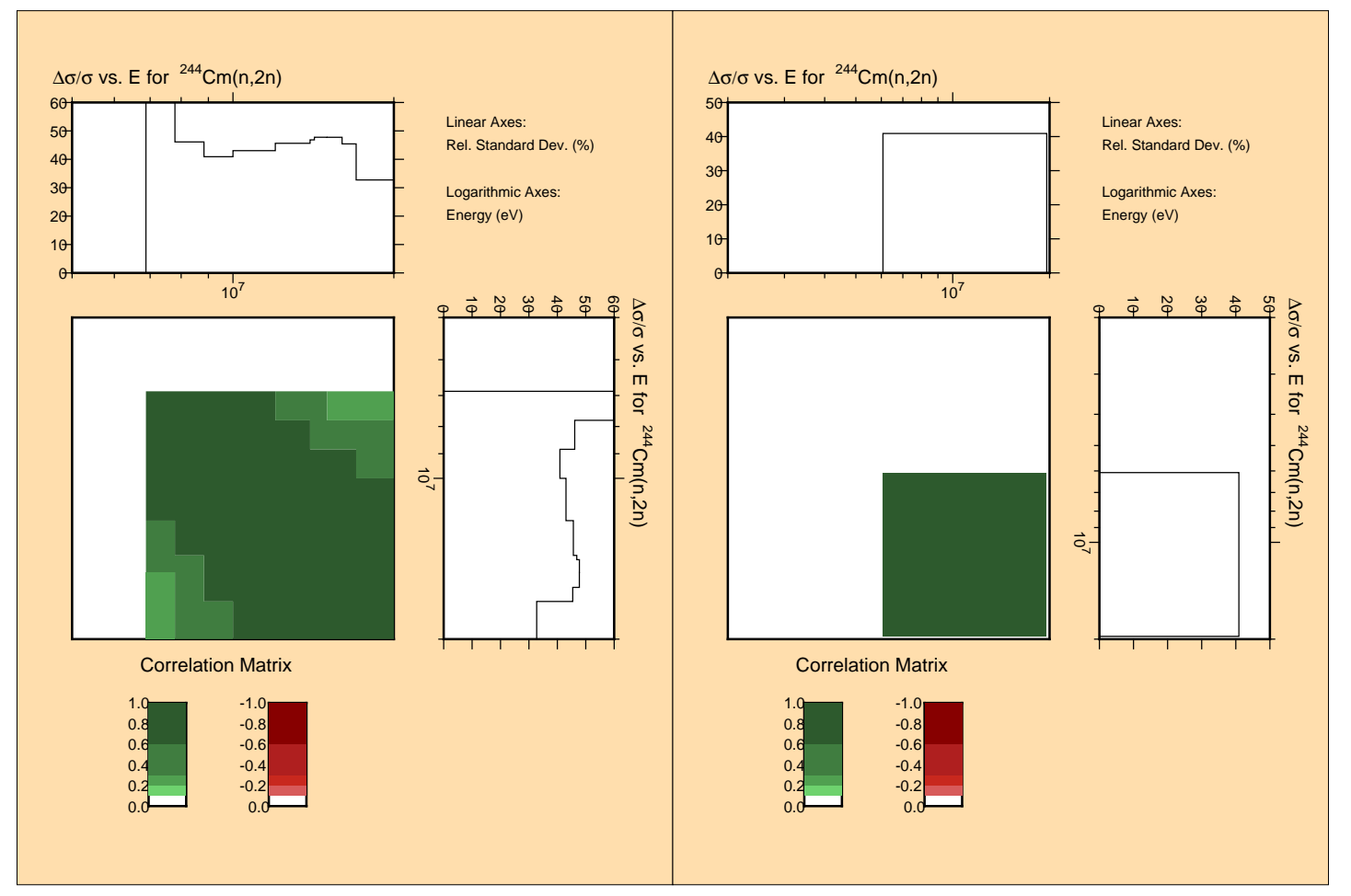

Figure A.182: Correlation and uncertainties in 187 (left) and 15 (right) groups for the ${ }^{244} \mathrm{Cm}(\mathrm{n}, 2 \mathrm{n})$ reaction

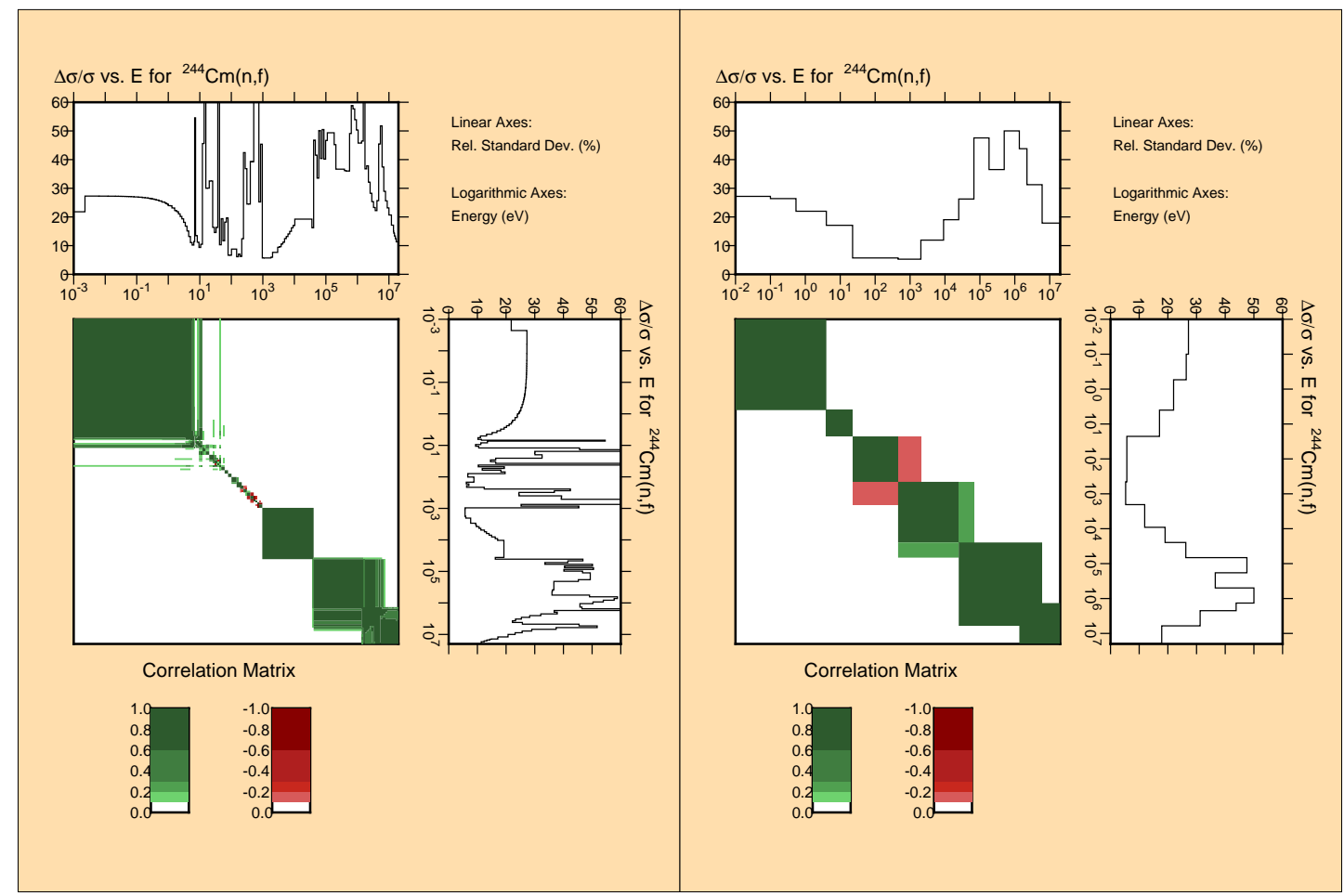

Figure A.183: Correlation and uncertainties in 187 (left) and 15 (right) groups for the ${ }^{244} \mathrm{Cm}(\mathrm{n}, \mathrm{f})$ reaction 


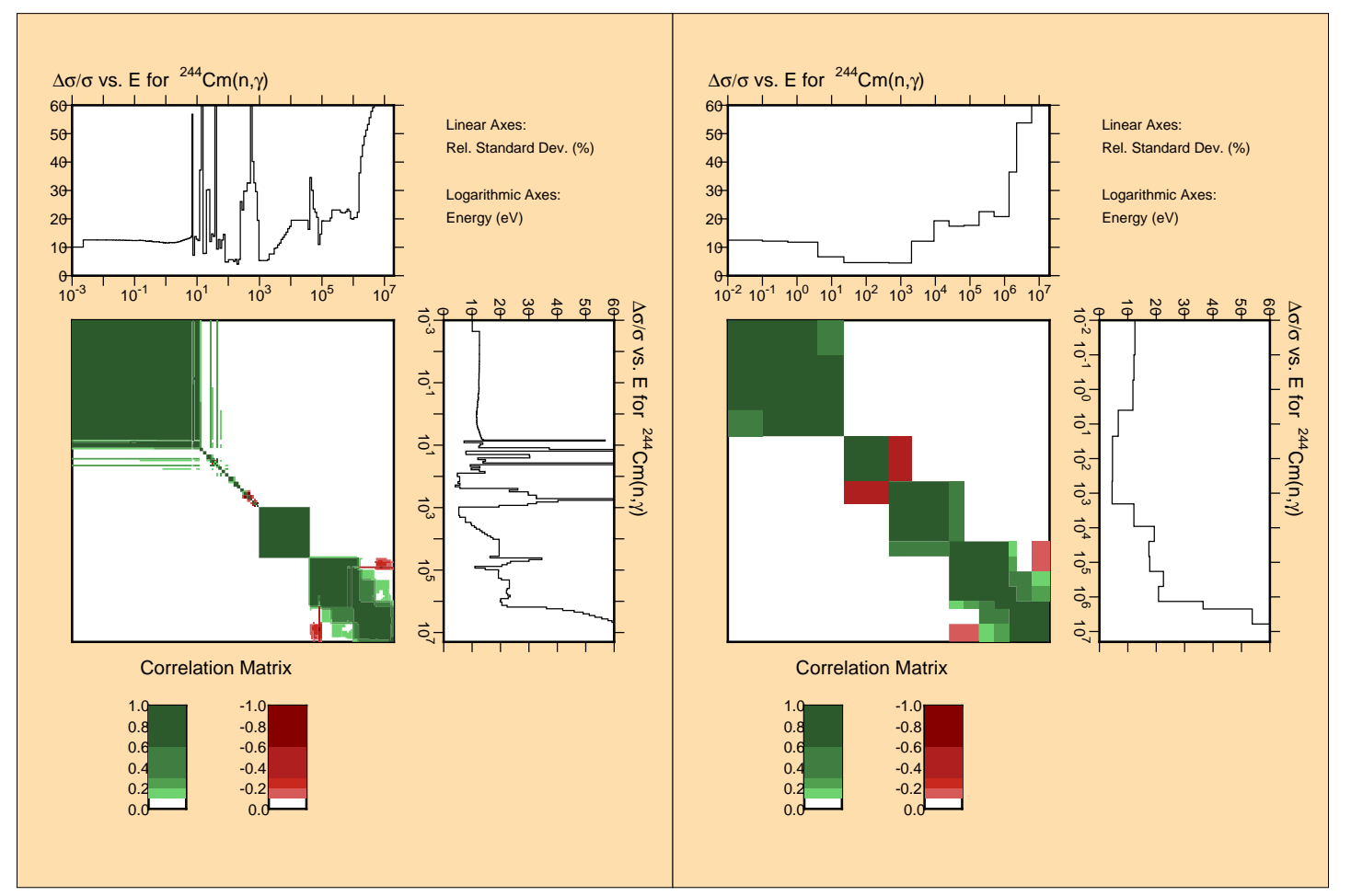

Figure A.184: Correlation and uncertainties in 187 (left) and 15 (right) groups for the ${ }^{244} \mathrm{Cm}(\mathrm{n}, \gamma)$ reaction

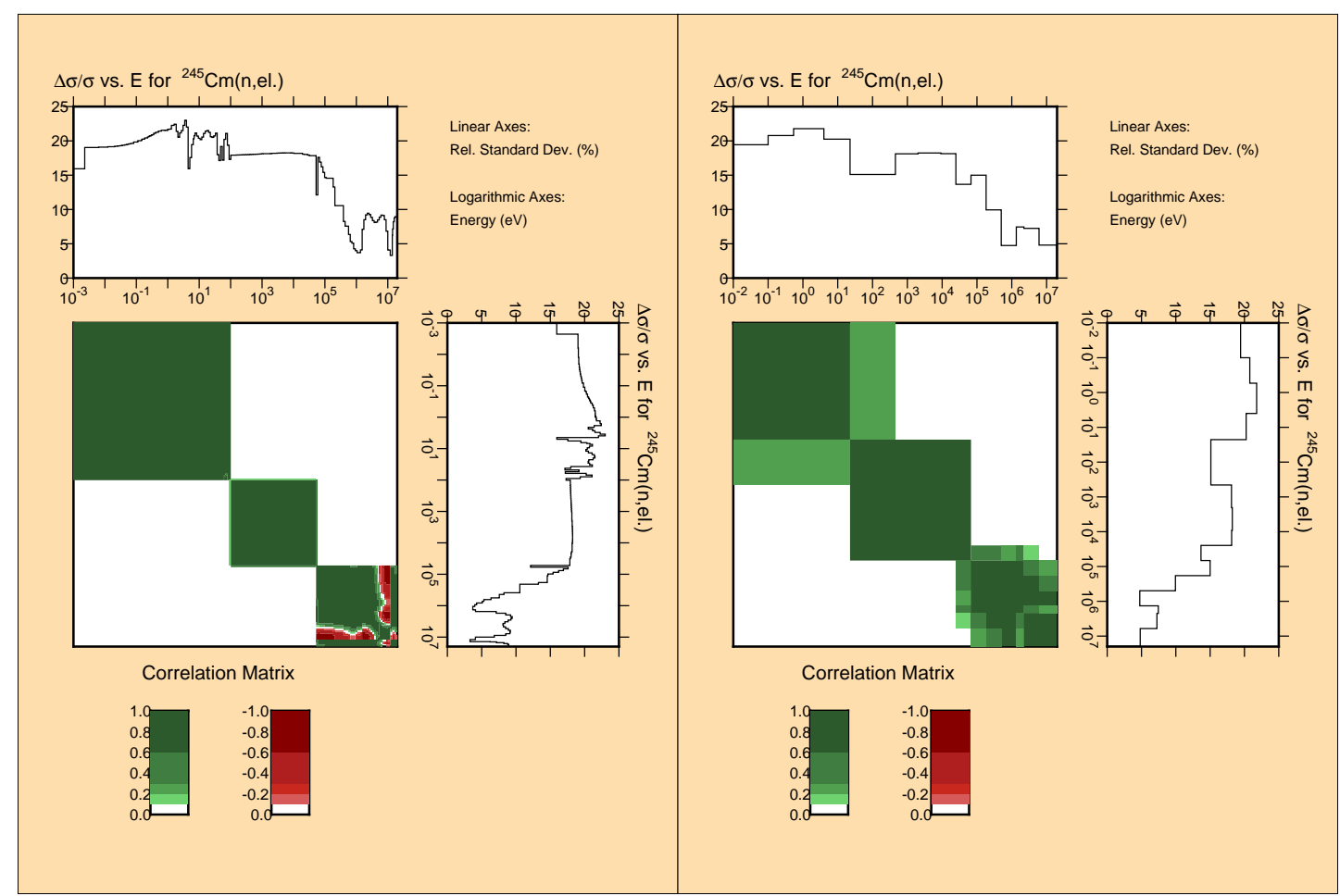

Figure A.185: Correlation and uncertainties in 187 (left) and 15 (right) groups for the ${ }^{245} \mathrm{Cm}(\mathrm{n}, \mathrm{el})$ reaction 


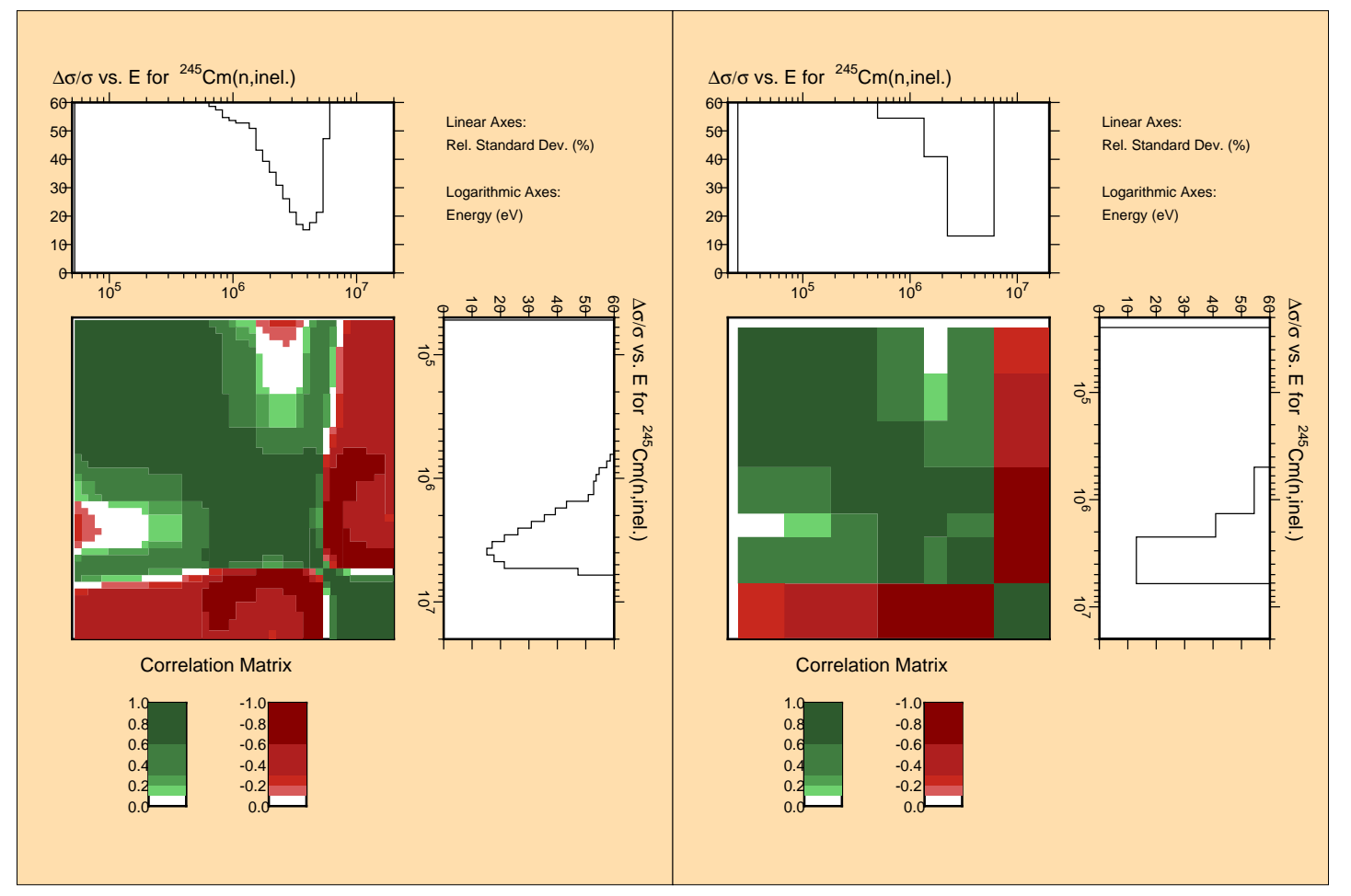

Figure A.186: Correlation and uncertainties in 187 (left) and 15 (right) groups for the ${ }^{245} \mathrm{Cm}\left(\mathrm{n}, \mathrm{n}^{\prime}\right)$ reaction

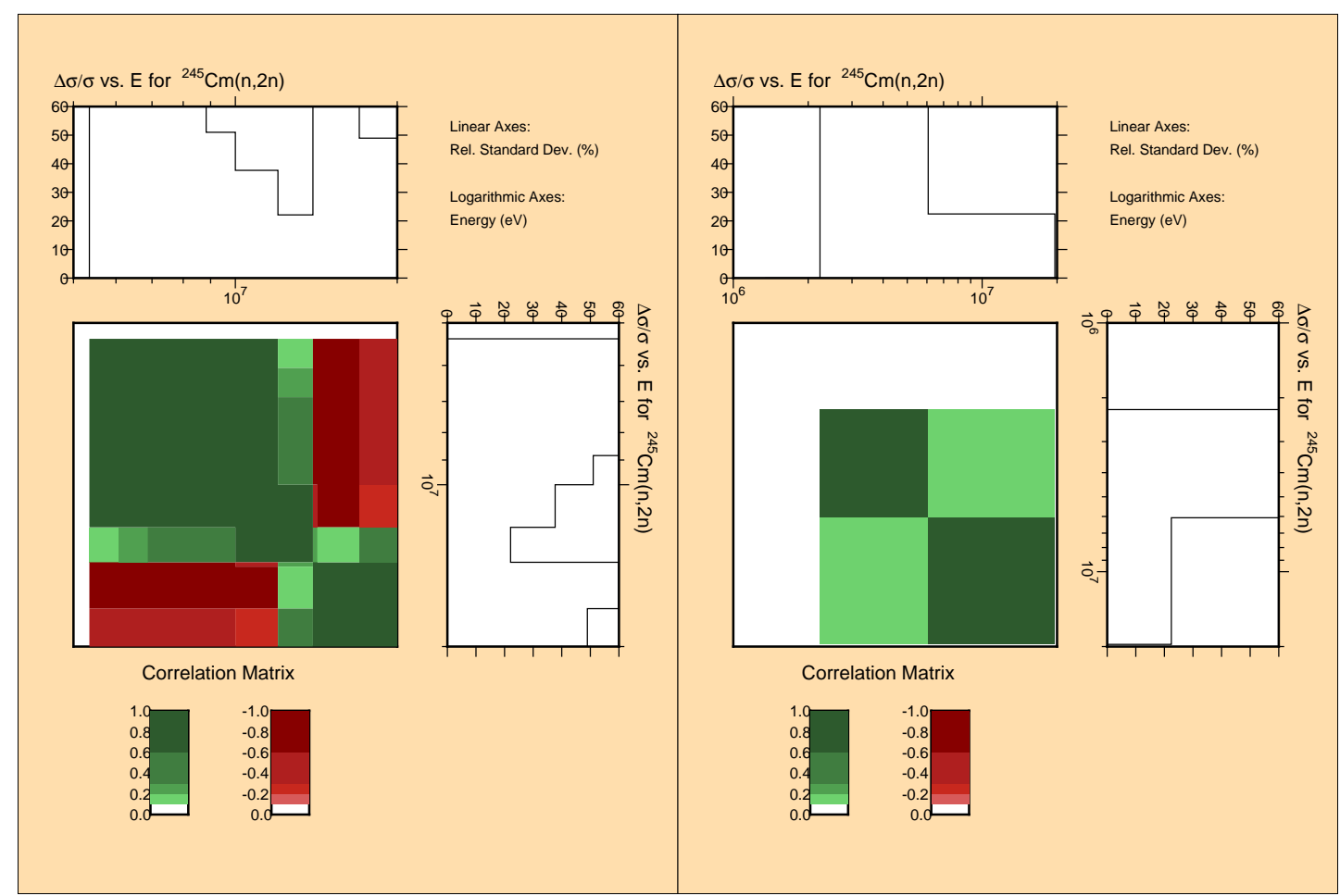

Figure A.187: Correlation and uncertainties in 187 (left) and 15 (right) groups for the ${ }^{245} \mathrm{Cm}(\mathrm{n}, 2 \mathrm{n})$ reaction 


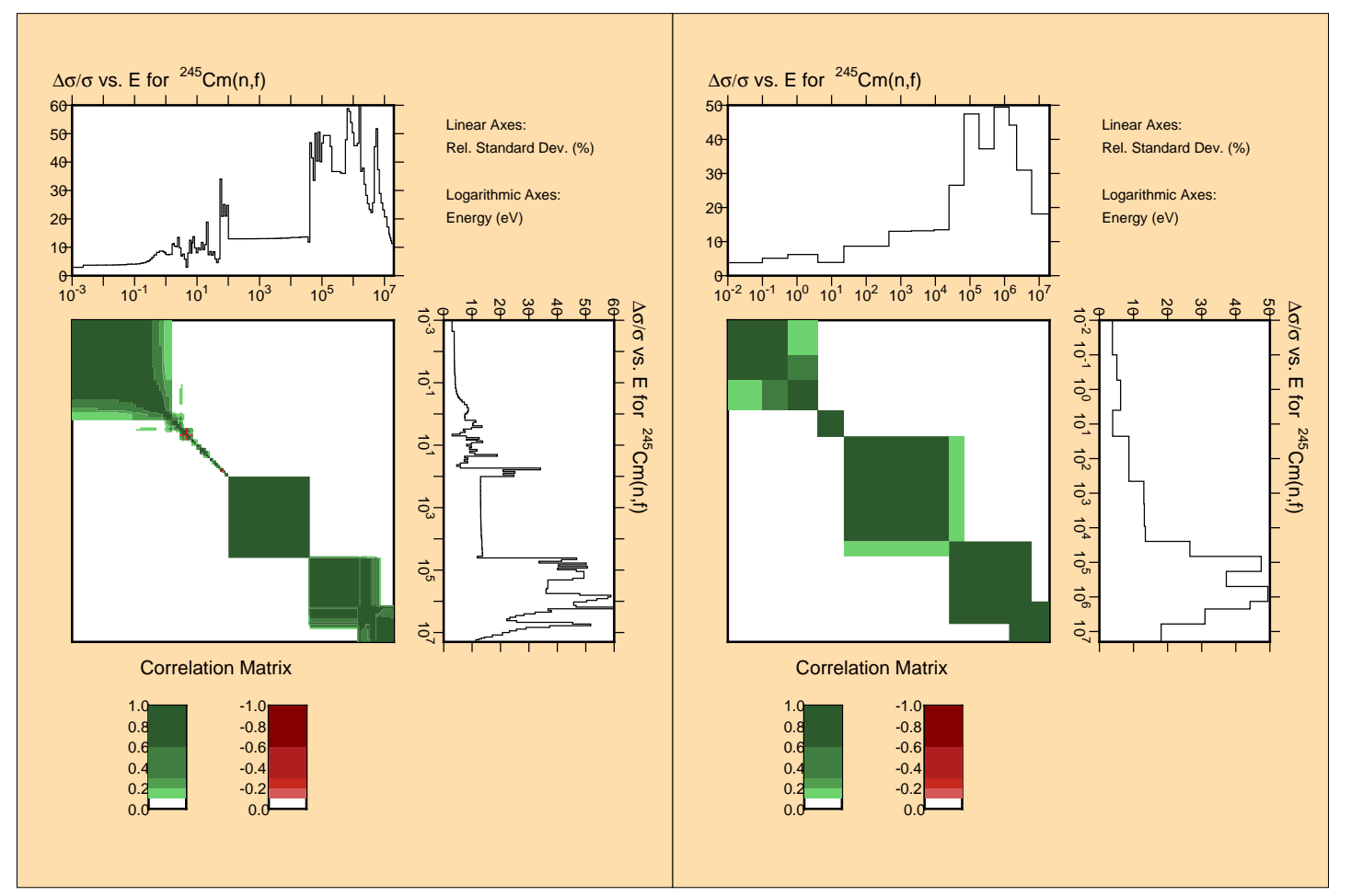

Figure A.188: Correlation and uncertainties in 187 (left) and 15 (right) groups for the ${ }^{245} \mathrm{Cm}(\mathrm{n}, \mathrm{f})$ reaction

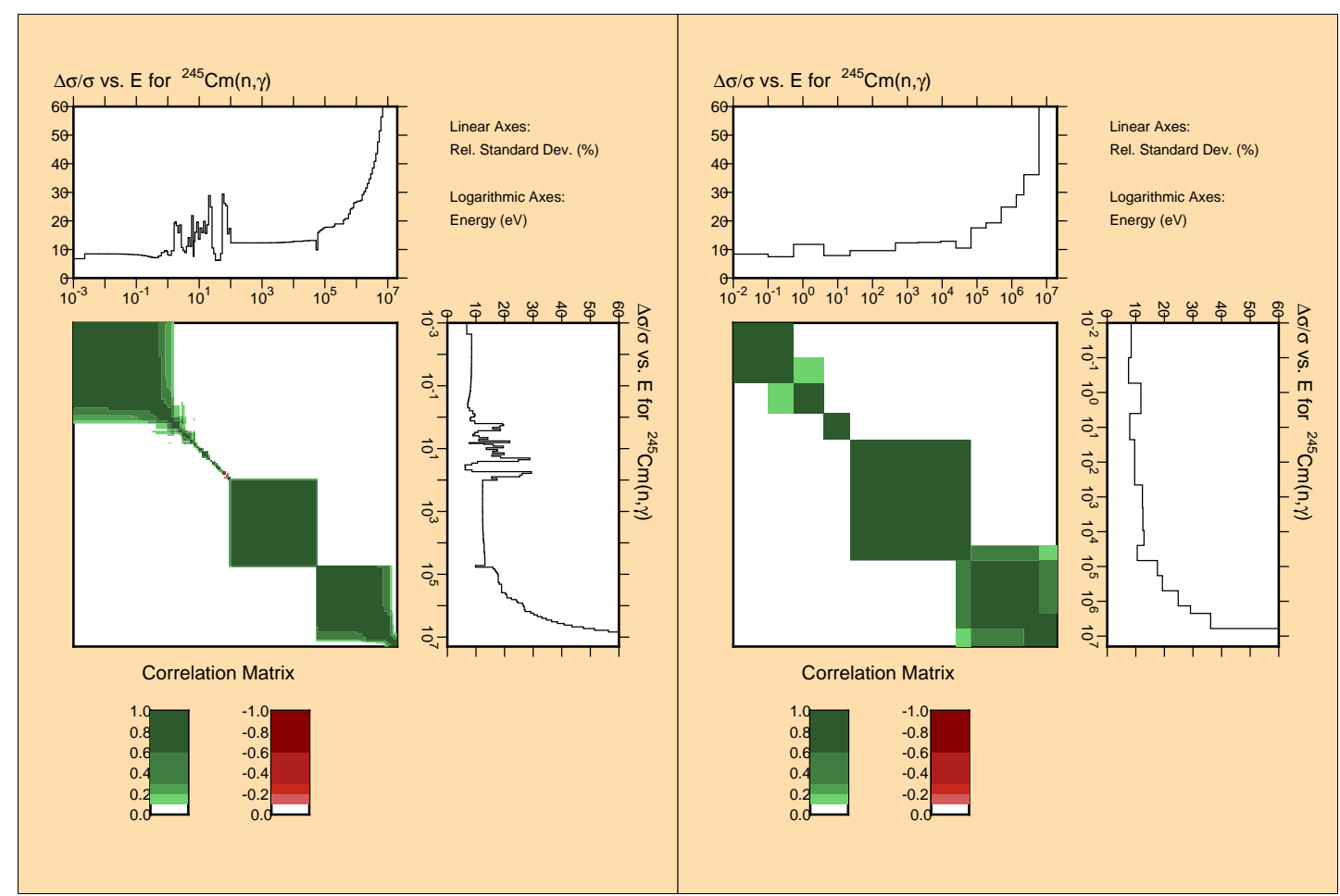

Figure A.189: Correlation and uncertainties in 187 (left) and 15 (right) groups for the ${ }^{245} \mathrm{Cm}(\mathrm{n}, \gamma)$ reaction 


\section{Appendix B}

In the following, numerical tables for the relative cross section uncertainties (relative standard deviations) and correlations (normalized to 1000) are given in the 15-energy group representation.

Table B.1: Definition of the 15-energy groups

\begin{tabular}{|c|c|c|}
\hline \hline Group no. & Energy Max (eV) & Energy Min (eV) \\
\hline 1 & $19.6 \mathrm{E}+07$ & $6.07 \mathrm{E}+06$ \\
2 & $6.07 \mathrm{E}+06$ & $2.23 \mathrm{E}+06$ \\
3 & $2.23 \mathrm{E}+06$ & $1.35 \mathrm{E}+06$ \\
4 & $1.35 \mathrm{E}+06$ & $4.98 \mathrm{E}+05$ \\
5 & $4.98 \mathrm{E}+05$ & $1.83 \mathrm{E}+05$ \\
6 & $1.83 \mathrm{E}+05$ & $6.74 \mathrm{E}+04$ \\
7 & $6.74 \mathrm{E}+04$ & $2.48 \mathrm{E}+04$ \\
8 & $2.48 \mathrm{E}+04$ & $9.12 \mathrm{E}+03$ \\
9 & $9.12 \mathrm{E}+03$ & $2.04 \mathrm{E}+03$ \\
10 & $2.04 \mathrm{E}+03$ & $4.54 \mathrm{E}+02$ \\
11 & $4.54 \mathrm{E}+02$ & $2.26 \mathrm{E}+01$ \\
12 & $2.26 \mathrm{E}+01$ & $4.00 \mathrm{E}+00$ \\
13 & $4.00 \mathrm{E}+00$ & $5.40 \mathrm{E}-01$ \\
14 & $5.40 \mathrm{E}-01$ & $1.00 \mathrm{E}-01$ \\
15 & $1.00 \mathrm{E}-01$ & $1.00 \mathrm{E}-05$ \\
\hline \hline
\end{tabular}


Table B.2: Relative uncertainty and correlation (normalized to 1000) for ${ }^{1} \mathrm{H}(\mathrm{n}, \mathrm{el})$

\begin{tabular}{|c|c|c|c|c|c|c|c|c|c|c|c|c|c|c|c|c|}
\hline 1 & $7.6426 \mathrm{E}-03$ & 1000 & 931 & 931 & 613 & 218 & 157 & -108 & -108 & -108 & -105 & -18 & -18 & -18 & -18 & -18 \\
\hline 2 & $8.7000 \mathrm{E}-03$ & 931 & 1000 & 1000 & 727 & 327 & 248 & -115 & -115 & -115 & -113 & -23 & -23 & -23 & -23 & -23 \\
\hline 3 & $8.7000 \mathrm{E}-03$ & 931 & 1000 & 1000 & 727 & 327 & 248 & -115 & -115 & -115 & -113 & -23 & -23 & -23 & -23 & -23 \\
\hline 4 & $6.2479 \mathrm{E}-03$ & 613 & 727 & 727 & 1000 & 887 & 821 & 190 & 190 & 190 & 176 & -63 & -63 & -63 & -63 & -6 \\
\hline 5 & $7.0000 \mathrm{E}-03$ & 218 & 327 & 327 & 887 & 1000 & 962 & 339 & 339 & 339 & 318 & -71 & -71 & -71 & -71 & -7 \\
\hline 6 & $5.5057 \mathrm{E}-03$ & 157 & 248 & 248 & 821 & 962 & 1000 & 584 & 584 & 584 & 565 & 39 & 39 & 39 & 39 & \\
\hline 7 & $5.0000 \mathrm{E}-03$ & -108 & -115 & -115 & 190 & 339 & 584 & 1000 & 1000 & 1000 & 995 & 344 & 344 & 344 & 344 & 34 \\
\hline 8 & $5.0000 \mathrm{E}-03$ & -108 & -115 & -115 & 190 & 339 & 584 & 1000 & 1000 & 1000 & 995 & 344 & 344 & 344 & 344 & 34 \\
\hline 9 & $5.0000 \mathrm{E}-03$ & -108 & -115 & -115 & 190 & 339 & 584 & 1000 & 1000 & 1000 & 995 & 344 & 344 & 344 & 344 & 34 \\
\hline 10 & $3.4069 \mathrm{E}-03$ & -105 & -113 & -113 & 176 & 318 & 565 & 995 & 995 & 995 & 1000 & 432 & 432 & 432 & 432 & 14 \\
\hline 11 & $1.0000 \mathrm{E}-03$ & -18 & -23 & -23 & -63 & -71 & 39 & 344 & 344 & 344 & 432 & 1000 & 1000 & 1000 & 1000 & 100 \\
\hline 12 & $1.0000 \mathrm{E}-03$ & -18 & -23 & -23 & -63 & -71 & 39 & 344 & 344 & 344 & 432 & 1000 & 1000 & 1000 & 1000 & 100 \\
\hline 13 & $1.0000 \mathrm{E}-03$ & -18 & -23 & -23 & -63 & -71 & 39 & 344 & 344 & 344 & 432 & 1000 & 1000 & 1000 & 1000 & 100 \\
\hline 14 & $1.0000 \mathrm{E}-03$ & -18 & -23 & -23 & -63 & -71 & 39 & 344 & 344 & 344 & 432 & 1000 & 1000 & 1000 & 1000 & 100 \\
\hline 15 & $1.0000 \mathrm{E}-03$ & -18 & -23 & -23 & -63 & -71 & 39 & 344 & 344 & 344 & 432 & 1000 & 1000 & 1000 & 1000 & 100 \\
\hline
\end{tabular}

Table B.3: Relative uncertainty and correlation (normalized to 1000) for ${ }^{1} \mathrm{H}(\mathrm{n}, \gamma)$

\begin{tabular}{|c|c|c|c|c|c|c|c|c|c|c|c|c|c|c|c|c|}
\hline 1 & 1. $9557 \mathrm{E}-02$ & 1000 & 829 & 698 & 633 & 564 & 526 & 514 & 514 & 514 & 514 & 511 & 511 & 511 & 511 & 511 \\
\hline 2 & 1.6979E-02 & 829 & 1000 & 899 & 847 & 782 & 712 & 644 & 580 & 540 & 511 & 508 & 508 & 508 & 508 & 508 \\
\hline 3 & $1.5991 \mathrm{E}-02$ & 698 & 899 & 1000 & 958 & 901 & 847 & 797 & 724 & 636 & 535 & 500 & 500 & 500 & 500 & \\
\hline 4 & $1.3866 \mathrm{E}-02$ & 633 & 847 & 958 & 1000 & 976 & 919 & 870 & 812 & 715 & 610 & 513 & 505 & 505 & 505 & 505 \\
\hline 5 & 1. 2533E-02 & 564 & 782 & 901 & 976 & 1000 & 966 & 917 & 868 & 787 & 672 & 545 & 502 & 502 & 502 & 502 \\
\hline 6 & $1.1510 \mathrm{E}-02$ & 526 & 712 & 847 & 919 & 966 & 1000 & 975 & 928 & 861 & 756 & 616 & 562 & 562 & 562 & 562 \\
\hline 7 & $9.9502 \mathrm{E}-03$ & 514 & 644 & 797 & 870 & 917 & 975 & 1000 & 978 & 913 & 828 & 682 & 626 & 626 & 626 & 626 \\
\hline 8 & $8.5361 \mathrm{E}-03$ & 514 & 580 & 724 & 812 & 868 & 928 & 978 & 1000 & 961 & 880 & 745 & 673 & 673 & 673 & 673 \\
\hline 9 & $7.1380 \mathrm{E}-03$ & 514 & 540 & 636 & 715 & 787 & 861 & 913 & 961 & 1000 & 953 & 849 & 791 & 791 & 791 & 79 \\
\hline 10 & $5.5692 \mathrm{E}-03$ & 514 & 511 & 535 & 610 & 672 & 756 & 828 & 880 & 953 & 1000 & 967 & 953 & 953 & 953 & 953 \\
\hline 11 & $5.0000 \mathrm{E}-03$ & 511 & 508 & 500 & 513 & 545 & 616 & 682 & 745 & 849 & 967 & 1000 & 1000 & 1000 & 1000 & 1000 \\
\hline 12 & $5.0000 \mathrm{E}-03$ & 511 & 508 & 500 & 505 & 502 & 562 & 626 & 673 & 791 & 953 & 1000 & 1000 & 1000 & 1000 & 100 \\
\hline 13 & $5.0000 \mathrm{E}-03$ & 511 & 508 & 500 & 505 & 502 & 562 & 626 & 673 & 791 & 953 & 1000 & 1000 & 1000 & 1000 & 100 \\
\hline 14 & $5.0000 \mathrm{E}-03$ & 511 & 508 & 500 & 505 & 502 & 562 & 626 & 673 & 791 & 953 & 1000 & 1000 & 1000 & 1000 & 100 \\
\hline 15 & $5.0000 \mathrm{E}-03$ & 511 & 508 & 500 & 505 & 502 & 562 & 626 & 673 & 791 & 953 & 1000 & 1000 & 1000 & 1000 & 100 \\
\hline
\end{tabular}


Table B.4: Relative uncertainty and correlation (normalized to 1000$)$ for ${ }^{16} \mathrm{O}(\mathrm{n}, \mathrm{el})$

\begin{tabular}{|c|c|c|c|c|c|c|c|c|c|c|c|c|c|c|c|c|}
\hline 1 & $8.4609 \mathrm{E}-01$ & 1000 & 813 & 808 & 722 & 673 & 761 & 699 & 701 & 726 & 728 & 728 & 728 & 728 & 728 & 727 \\
\hline 2 & $5.4924 \mathrm{E}-01$ & 813 & 1000 & 925 & 790 & 728 & 814 & 732 & 734 & 758 & 760 & 760 & 760 & 762 & 762 & \\
\hline 3 & 1.2181E-01 & 808 & 925 & 1000 & 783 & 646 & 701 & 597 & 598 & 627 & 629 & 630 & 630 & 631 & 631 & 632 \\
\hline 4 & $1.4348 \mathrm{E}-02$ & 722 & 790 & 783 & 1000 & 911 & 880 & 576 & 577 & 608 & 611 & 611 & 611 & 612 & 612 & \\
\hline 5 & 1.6793E-02 & 673 & 728 & 646 & 911 & 1000 & 944 & 576 & 577 & 606 & 609 & 609 & 609 & 610 & 610 & 611 \\
\hline 6 & 1. 6809E-02 & 761 & 814 & 701 & 880 & 944 & 1000 & 814 & 815 & 835 & 836 & 837 & 837 & 837 & 837 & 838 \\
\hline 7 & $2.3574 \mathrm{E}-02$ & 699 & 732 & 597 & 576 & 576 & 814 & 1000 & 1000 & 999 & 998 & 998 & 998 & 999 & 999 & 999 \\
\hline 8 & $2.3506 \mathrm{E}-02$ & 701 & 734 & 598 & 577 & 577 & 815 & 1000 & 1000 & 999 & 999 & 999 & 998 & 999 & 999 & 999 \\
\hline 9 & $2.2365 \mathrm{E}-02$ & 726 & 758 & 627 & 608 & 606 & 835 & 999 & 999 & 1000 & 1000 & 1000 & 1000 & 1000 & 1000 & 1000 \\
\hline 10 & 2. 2270E-02 & 728 & 760 & 629 & 611 & 609 & 836 & 998 & 999 & 1000 & 1000 & 1000 & 1000 & 1000 & 1000 & 1000 \\
\hline 11 & $2.2249 \mathrm{E}-02$ & 728 & 760 & 630 & 611 & 609 & 837 & 998 & 999 & 1000 & 1000 & 1000 & 1000 & 1000 & 1000 & 1000 \\
\hline 12 & $2.2244 \mathrm{E}-02$ & 728 & 760 & 630 & 611 & 609 & 837 & 998 & 998 & 1000 & 1000 & 1000 & 1000 & 1000 & 1000 & 1000 \\
\hline 13 & $2.2285 \mathrm{E}-02$ & 728 & 762 & 631 & 612 & 610 & 837 & 999 & 999 & 1000 & 1000 & 1000 & 1000 & 1000 & 1000 & 1000 \\
\hline 14 & $2.2287 \mathrm{E}-02$ & 728 & 762 & 631 & 612 & 610 & 837 & 999 & 999 & 1000 & 1000 & 1000 & 1000 & 1000 & 1000 & 1000 \\
\hline 15 & 1.9971E-02 & 727 & 763 & 632 & 613 & 611 & 838 & 999 & 999 & 1000 & 1000 & 1000 & 1000 & 1000 & 1000 & 1000 \\
\hline
\end{tabular}

Table B.5: Relative uncertainty and correlation (normalized to 1000) for ${ }^{16} \mathrm{O}\left(\mathrm{n}, \mathrm{n}^{\prime}\right)$

group rel.s.d.

1 1.0000E-00 1000

Table B.6: Relative uncertainty (relative standard deviation) and correlation (normalized to 1000) for ${ }^{16} \mathrm{O}(\mathrm{n}, 2 \mathrm{n})$

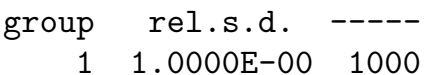


Table B.7: Relative uncertainty (relative standard deviation) and correlation (normalized to 1000) for ${ }^{16} \mathrm{O}(\mathrm{n}, \gamma)$

\begin{tabular}{|c|c|c|c|c|c|c|c|c|c|c|c|c|c|c|c|c|}
\hline & 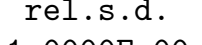 & & & & & & & & & & & & & & & \\
\hline 1 & $1.0000 \mathrm{E}-00$ & 1000 & 77 & 2 & -3 & -8 & -11 & -32 & -30 & -6 & -1 & 0 & 0 & 0 & 0 & \\
\hline 2 & $1.0000 \mathrm{E}-00$ & 77 & 1000 & 24 & -52 & -105 & -149 & -422 & -398 & -76 & -17 & -4 & -5 & 0 & -4 & \\
\hline 3 & $1.0000 \mathrm{E}-00$ & 2 & 24 & 1000 & 37 & -12 & -18 & -64 & -60 & -8 & -3 & 0 & -1 & 0 & -1 & \\
\hline 4 & $1.0000 \mathrm{E}-00$ & -3 & -52 & 37 & 1000 & 627 & 584 & -510 & -491 & -315 & -115 & -85 & -214 & -69 & -171 & \\
\hline 5 & $8.1814 \mathrm{E}-01$ & -8 & -105 & -12 & 627 & 1000 & 995 & -197 & -202 & -385 & -158 & -131 & -326 & -105 & -259 & \\
\hline 6 & $6.9631 \mathrm{E}-01$ & -11 & -149 & -18 & 584 & 995 & 1000 & -98 & -103 & -318 & -99 & -75 & -269 & -49 & -202 & \\
\hline 7 & $4.7272 \mathrm{E}-01$ & -32 & -422 & -64 & -510 & -197 & -98 & 1000 & 997 & 712 & 599 & 573 & 608 & 565 & 598 & \\
\hline 8 & $2.8207 \mathrm{E}-01$ & -30 & -398 & -60 & -491 & -202 & -103 & 997 & 1000 & 762 & 660 & 635 & 666 & 627 & 658 & \\
\hline 9 & 1. $2096 \mathrm{E}-01$ & -6 & -76 & -8 & -315 & -385 & -318 & 712 & 762 & 1000 & 961 & 950 & 988 & 941 & 979 & \\
\hline 10 & $9.3567 \mathrm{E}-02$ & -1 & -17 & -3 & -115 & -158 & -99 & 599 & 660 & 961 & 1000 & 999 & 985 & 998 & 994 & \\
\hline 11 & $1.0420 \mathrm{E}-01$ & 0 & -4 & 0 & -85 & -131 & -75 & 573 & 635 & 950 & 999 & 1000 & 979 & 1000 & 991 & \\
\hline 12 & 1. $1285 \mathrm{E}-01$ & 0 & -5 & -1 & -214 & -326 & -269 & 608 & 666 & 988 & 985 & 979 & 1000 & 973 & 998 & \\
\hline 13 & $1.0624 \mathrm{E}-01$ & 0 & 0 & 0 & -69 & -105 & -49 & 565 & 627 & 941 & 998 & 1000 & 973 & 1000 & 987 & \\
\hline 14 & 1. $1027 \mathrm{E}-01$ & 0 & -4 & -1 & -171 & -259 & -202 & 598 & 658 & 979 & 994 & 991 & 998 & 987 & 1000 & \\
\hline 15 & $8.0044 \mathrm{E}-02$ & 0 & 1 & 0 & 53 & 80 & 132 & 509 & 571 & 866 & 970 & 977 & 914 & 983 & 940 & 10 \\
\hline
\end{tabular}

Table B.8: Relative uncertainty and correlation (normalized to 1000 ) for ${ }^{19} \mathrm{~F}(\mathrm{n}, \mathrm{el})$

\begin{tabular}{|c|c|c|c|c|c|c|c|c|c|c|c|c|c|c|c|c|}
\hline 1 & $8.7062 \mathrm{E}-02$ & 1000 & -156 & -44 & 0 & 0 & 0 & 0 & 0 & 0 & 0 & 0 & 0 & 0 & 0 & 0 \\
\hline 2 & $8.1205 E-02$ & -156 & 1000 & 666 & 0 & 0 & 0 & 0 & 0 & 0 & 0 & 0 & 0 & 0 & 0 & 0 \\
\hline 3 & $2.1189 \mathrm{E}-02$ & -44 & 666 & 1000 & 612 & 585 & 572 & 582 & 586 & 586 & 586 & 586 & 586 & 586 & 586 & 586 \\
\hline 4 & 1. $6474 \mathrm{E}-02$ & 0 & 0 & 612 & 1000 & 725 & 704 & 723 & 730 & 731 & 731 & 731 & 731 & 731 & 731 & 731 \\
\hline 5 & $1.0212 \mathrm{E}-02$ & 0 & 0 & 585 & 725 & 1000 & 905 & 936 & 945 & 947 & 948 & 948 & 948 & 948 & 948 & 948 \\
\hline 6 & $1.0828 \mathrm{E}-02$ & 0 & 0 & 572 & 704 & 905 & 1000 & 992 & 993 & 993 & 992 & 992 & 992 & 992 & 992 & 992 \\
\hline 7 & $9.6832 \mathrm{E}-03$ & 0 & 0 & 582 & 723 & 936 & 992 & 1000 & 996 & 995 & 995 & 995 & 995 & 995 & 995 & 995 \\
\hline 8 & $1.6768 \mathrm{E}-02$ & 0 & 0 & 586 & 730 & 945 & 993 & 996 & 1000 & 1000 & 1000 & 1000 & 1000 & 1000 & 1000 & 1000 \\
\hline 9 & $2.0521 \mathrm{E}-02$ & 0 & 0 & 586 & 731 & 947 & 993 & 995 & 1000 & 1000 & 1000 & 1000 & 1000 & 1000 & 1000 & 1000 \\
\hline 10 & $2.0502 \mathrm{E}-02$ & 0 & 0 & 586 & 731 & 948 & 992 & 995 & 1000 & 1000 & 1000 & 1000 & 1000 & 1000 & 1000 & 1000 \\
\hline 11 & $2.0502 \mathrm{E}-02$ & 0 & 0 & 586 & 731 & 948 & 992 & 995 & 1000 & 1000 & 1000 & 1000 & 1000 & 1000 & 1000 & 1000 \\
\hline 12 & $2.0486 \mathrm{E}-02$ & 0 & 0 & 586 & 731 & 948 & 992 & 995 & 1000 & 1000 & 1000 & 1000 & 1000 & 1000 & 1000 & 1000 \\
\hline 13 & $2.0496 \mathrm{E}-02$ & 0 & 0 & 586 & 731 & 948 & 992 & 995 & 1000 & 1000 & 1000 & 1000 & 1000 & 1000 & 1000 & 1000 \\
\hline 14 & $2.0493 \mathrm{E}-02$ & 0 & 0 & 586 & 731 & 948 & 992 & 995 & 1000 & 1000 & 1000 & 1000 & 1000 & 1000 & 1000 & 1000 \\
\hline 15 & 1.9990E-02 & 0 & 0 & 586 & 731 & 948 & 992 & 995 & 1000 & 1000 & 1000 & 1000 & 1000 & 1000 & 1000 & 1000 \\
\hline
\end{tabular}

Table B.9: Relative uncertainty and correlation (normalized to 1000) for ${ }^{19} \mathrm{~F}\left(\mathrm{n}, \mathrm{n}^{\prime}\right)$

$\begin{array}{ccrrrrr}\text { group } & \text { rel.s.d. } & ---1 & -- & & & \\ 1 & 4.5447 \mathrm{E}-02 & 1000 & -918 & 58 & 137 & -346 \\ 2 & 9.1245 \mathrm{E}-02 & -918 & 1000 & 60 & -26 & 484 \\ 3 & 7.3010 \mathrm{E}-02 & 58 & 60 & 1000 & 996 & 903 \\ 4 & 2.2031 \mathrm{E}-01 & 137 & -26 & 996 & 1000 & 862 \\ 5 & 1.5884 \mathrm{E}-01 & -346 & 484 & 903 & 862 & 1000\end{array}$


Table B.10: Relative uncertainty (relative standard deviation) and correlation (normalized to 1000$)$ for ${ }^{19} \mathrm{~F}(\mathrm{n}, 2 \mathrm{n})$

group rel.s.d

$1 \quad 7.2027 \mathrm{E}-02 \quad 1000$

Table B.11: Relative uncertainty (relative standard deviation) and correlation (normalized to 1000) for ${ }^{19} \mathrm{~F}(\mathrm{n}, \gamma)$

\begin{tabular}{|c|c|c|c|c|c|c|c|c|c|c|c|c|c|c|c|c|}
\hline & & & & & & & & & & & & & & & & \\
\hline 1 & $1.5863 \mathrm{E}-01$ & 1000 & 567 & 203 & 0 & 0 & 0 & 0 & 0 & 0 & 0 & 0 & 0 & 0 & 0 & 0 \\
\hline 2 & $1.5422 \mathrm{E}-01$ & 567 & 1000 & 413 & 0 & 0 & 0 & 0 & 0 & 0 & 0 & 0 & 0 & 0 & 0 & 0 \\
\hline 3 & $8.4973 \mathrm{E}-02$ & 203 & 413 & 1000 & -474 & -5 & -4 & 0 & -11 & -125 & -148 & -149 & -149 & -149 & -149 & -149 \\
\hline 4 & $5.1389 \mathrm{E}-02$ & 0 & 0 & -474 & 1000 & -706 & -5 & 0 & -7 & -77 & -91 & -91 & -91 & -91 & -91 & -91 \\
\hline 5 & $6.1347 \mathrm{E}-02$ & 0 & 0 & -5 & -706 & 1000 & 12 & 0 & 18 & 194 & 229 & 229 & 229 & 230 & 230 & 230 \\
\hline 6 & 1.9967E-02 & 0 & 0 & -4 & -5 & 12 & 1000 & 0 & 9 & 92 & 104 & 104 & 104 & 104 & 104 & 105 \\
\hline 7 & $2.8853 \mathrm{E}-02$ & 0 & 0 & 0 & 0 & 0 & 0 & 1000 & 923 & 188 & 167 & 167 & 167 & 167 & 167 & 167 \\
\hline 8 & $2.5526 \mathrm{E}-02$ & 0 & 0 & -11 & -7 & 18 & 9 & 923 & 1000 & 462 & 394 & 393 & 392 & 392 & 392 & 392 \\
\hline 9 & 4.3913E-02 & 0 & 0 & -125 & -77 & 194 & 92 & 188 & 462 & 1000 & 982 & 982 & 981 & 981 & 981 & 981 \\
\hline 10 & $6.0451 \mathrm{E}-02$ & 0 & 0 & -148 & -91 & 229 & 104 & 167 & 394 & 982 & 1000 & 1000 & 1000 & 1000 & 1000 & 1000 \\
\hline 11 & $6.0899 \mathrm{E}-02$ & 0 & 0 & -149 & -91 & 229 & 104 & 167 & 393 & 982 & 1000 & 1000 & 1000 & 1000 & 1000 & 1000 \\
\hline 12 & $6.1027 \mathrm{E}-02$ & 0 & 0 & -149 & -91 & 229 & 104 & 167 & 392 & 981 & 1000 & 1000 & 1000 & 1000 & 1000 & 1000 \\
\hline 13 & $6.1089 \mathrm{E}-02$ & 0 & 0 & -149 & -91 & 230 & 104 & 167 & 392 & 981 & 1000 & 1000 & 1000 & 1000 & 1000 & 1000 \\
\hline 14 & $6.1100 \mathrm{E}-02$ & 0 & 0 & -149 & -91 & 230 & 104 & 167 & 392 & 981 & 1000 & 1000 & 1000 & 1000 & 1000 & 1000 \\
\hline 15 & $5.5540 \mathrm{E}-02$ & 0 & 0 & -149 & -91 & 230 & 105 & 167 & 392 & 981 & 1000 & 1000 & 1000 & 1000 & 1000 & 1000 \\
\hline
\end{tabular}

Table B.12: Relative uncertainty (relative standard deviation) and correlation (normalized to 1000) for ${ }^{13} \mathrm{Na}(\mathrm{n}, \mathrm{el})$

\begin{tabular}{|c|c|c|c|c|c|c|c|c|c|c|c|c|c|c|c|c|}
\hline 1 & 1.8014E-02 & 1000 & -786 & -612 & -570 & 0 & 0 & 0 & 0 & 0 & 0 & 0 & 0 & 0 & 0 & 0 \\
\hline 2 & $4.6200 \mathrm{E}-02$ & -786 & 1000 & 970 & 932 & 0 & 0 & 0 & 0 & 0 & 0 & 0 & 0 & 0 & 0 & \\
\hline 3 & $3.7221 \mathrm{E}-02$ & -612 & 970 & 1000 & 968 & 0 & 0 & 0 & 0 & 0 & 0 & 0 & 0 & 0 & 0 & 0 \\
\hline 4 & $3.0063 E-02$ & -570 & 932 & 968 & 1000 & 6 & 12 & 14 & 4 & 0 & 102 & 104 & 104 & 104 & 105 & 104 \\
\hline 5 & $3.3068 \mathrm{E}-02$ & 0 & 0 & 0 & 6 & 1000 & 962 & 932 & 948 & 129 & 530 & 567 & 575 & 580 & 581 & 581 \\
\hline 6 & $3.2536 \mathrm{E}-02$ & 0 & 0 & 0 & 12 & 962 & 1000 & 972 & 976 & 140 & 548 & 586 & 594 & 599 & 600 & 600 \\
\hline 7 & $2.3817 \mathrm{E}-02$ & 0 & 0 & 0 & 14 & 932 & 972 & 1000 & 935 & 161 & 538 & 573 & 581 & 586 & 587 & 587 \\
\hline 8 & $2.8713 \mathrm{E}-02$ & 0 & 0 & 0 & 4 & 948 & 976 & 935 & 1000 & 282 & 627 & 659 & 666 & 671 & 672 & 672 \\
\hline 9 & 3. 2297E-02 & 0 & 0 & 0 & 0 & 129 & 140 & 161 & 282 & 1000 & 774 & 744 & 737 & 733 & 733 & 732 \\
\hline 10 & $4.9344 \mathrm{E}-02$ & 0 & 0 & 0 & 102 & 530 & 548 & 538 & 627 & 774 & 1000 & 999 & 998 & 997 & 997 & 997 \\
\hline 11 & $4.7574 \mathrm{E}-02$ & 0 & 0 & 0 & 104 & 567 & 586 & 573 & 659 & 744 & 999 & 1000 & 1000 & 1000 & 1000 & 1000 \\
\hline 12 & $4.7254 \mathrm{E}-02$ & 0 & 0 & 0 & 104 & 575 & 594 & 581 & 666 & 737 & 998 & 1000 & 1000 & 1000 & 1000 & 1000 \\
\hline 13 & $4.7056 \mathrm{E}-02$ & 0 & 0 & 0 & 104 & 580 & 599 & 586 & 671 & 733 & 997 & 1000 & 1000 & 1000 & 1000 & 1000 \\
\hline 14 & $4.7012 \mathrm{E}-02$ & 0 & 0 & 0 & 105 & 581 & 600 & 587 & 672 & 733 & 997 & 1000 & 1000 & 1000 & 1000 & 1000 \\
\hline 15 & $4.5935 \mathrm{E}-02$ & 0 & 0 & 0 & 104 & 581 & 600 & 587 & 672 & 732 & 997 & 1000 & 1000 & 1000 & 1000 & 1000 \\
\hline
\end{tabular}


Table B.13: Relative uncertainty (relative standard deviation) and correlation (normalized to 1000) for ${ }^{13} \mathrm{Na}\left(\mathrm{n}, \mathrm{n}^{\prime}\right)$

$\begin{array}{rrrrrrr}\text { grp } & \text { rel.s.d. } & ----1 & -160 & 0 \\ 1 & 1.8790 \mathrm{E}-01 & 1000 & 299 & 234 & 160 & \\ 2 & 8.8682 \mathrm{E}-02 & 299 & 1000 & 596 & 315 & 0 \\ 3 & 1.2562 \mathrm{E}-01 & 234 & 596 & 1000 & 941 & 0 \\ 4 & 2.8004 \mathrm{E}-01 & 160 & 315 & 941 & 1000 & 147 \\ 5 & 5.0000 \mathrm{E}-01 & 0 & 0 & 0 & 147 & 1000\end{array}$

Table B.14: Relative uncertainty (relative standard deviation) and correlation (normalized to 1000$)$ for ${ }^{13} \mathrm{Na}(\mathrm{n}, 2 \mathrm{n})$

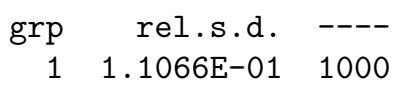

Table B.15: Relative uncertainty (relative standard deviation) and correlation (normalized to 1000) for ${ }^{13} \mathrm{Na}(\mathrm{n}, \gamma)$

\begin{tabular}{|c|c|c|c|c|c|c|c|c|c|c|c|c|c|c|c|c|}
\hline 1 & $4.6437 \mathrm{E}-01$ & 1000 & 479 & 452 & -331 & 0 & 0 & 0 & 0 & 0 & 0 & 0 & 0 & 0 & 0 & 0 \\
\hline 2 & $2.4326 \mathrm{E}-01$ & 479 & 1000 & 510 & -688 & 0 & 0 & 0 & 0 & 0 & 0 & 0 & 0 & 0 & 0 & 0 \\
\hline 3 & $1.7026 \mathrm{E}-02$ & 452 & 510 & 1000 & -109 & 0 & 0 & 0 & 0 & 0 & 0 & 0 & 0 & 0 & 0 & 0 \\
\hline 4 & $7.4439 \mathrm{E}-02$ & -331 & -688 & -109 & 1000 & 5 & 0 & 0 & 14 & 0 & 3 & 3 & 3 & 3 & 3 & 3 \\
\hline 5 & $6.8142 \mathrm{E}-02$ & 0 & 0 & 0 & 5 & 1000 & 10 & 5 & 254 & 6 & 46 & 48 & 49 & 49 & 49 & 50 \\
\hline 6 & $2.3586 \mathrm{E}-01$ & 0 & 0 & 0 & 0 & 10 & 1000 & 2 & 13 & 0 & 2 & 2 & 2 & 3 & 2 & 2 \\
\hline 7 & $6.7867 \mathrm{E}-02$ & 0 & 0 & 0 & 0 & 5 & 2 & 1000 & 351 & 5 & 33 & 35 & 36 & 36 & 36 & 36 \\
\hline 8 & $6.6348 \mathrm{E}-02$ & 0 & 0 & 0 & 14 & 254 & 13 & 351 & 1000 & 154 & 417 & 425 & 428 & 429 & 429 & 430 \\
\hline 9 & 1. $1771 \mathrm{E}-02$ & 0 & 0 & 0 & 0 & 6 & 0 & 5 & 154 & 1000 & 506 & 499 & 502 & 501 & 501 & 505 \\
\hline 10 & $2.2758 \mathrm{E}-02$ & 0 & 0 & 0 & 3 & 46 & 2 & 33 & 417 & 506 & 1000 & 1000 & 1000 & 1000 & 1000 & 997 \\
\hline 11 & $2.2978 \mathrm{E}-02$ & 0 & 0 & 0 & 3 & 48 & 2 & 35 & 425 & 499 & 1000 & 1000 & 1000 & 1000 & 1000 & 997 \\
\hline 12 & $2.2889 \mathrm{E}-02$ & 0 & 0 & 0 & 3 & 49 & 2 & 36 & 428 & 502 & 1000 & 1000 & 1000 & 1000 & 1000 & 997 \\
\hline 13 & $2.2894 \mathrm{E}-02$ & 0 & 0 & 0 & 3 & 49 & 3 & 36 & 429 & 501 & 1000 & 1000 & 1000 & 1000 & 1000 & 997 \\
\hline 14 & $2.2920 \mathrm{E}-02$ & 0 & 0 & 0 & 3 & 49 & 2 & 36 & 429 & 501 & 1000 & 1000 & 1000 & 1000 & 1000 & 997 \\
\hline 15 & $2.0664 \mathrm{E}-02$ & 0 & 0 & 0 & 3 & 50 & 2 & 36 & 430 & 505 & 997 & 997 & 997 & 997 & 997 & 1000 \\
\hline
\end{tabular}


Table B.16: Relative uncertainty (relative standard deviation) and correlation (normalized to 1000) for ${ }^{27} \mathrm{Al}(\mathrm{n}, \mathrm{el})$

\begin{tabular}{|c|c|c|c|c|c|c|c|c|c|c|c|c|c|c|c|c|}
\hline 1 & $1.0350 \mathrm{E}-02$ & 1000 & 535 & 991 & 662 & 0 & 0 & 0 & 0 & 0 & 0 & 0 & 0 & 0 & 0 & 0 \\
\hline 2 & $2.1948 \mathrm{E}-02$ & 535 & 1000 & 629 & 298 & 0 & 0 & 0 & 0 & 0 & 0 & 0 & 0 & 0 & 0 & 0 \\
\hline 3 & $1.7778 \mathrm{E}-02$ & 991 & 629 & 1000 & 652 & 0 & 0 & 0 & 0 & 0 & 0 & 0 & 0 & 0 & 0 & 0 \\
\hline 4 & 1. $5522 \mathrm{E}-02$ & 662 & 298 & 652 & 1000 & 26 & 6 & -48 & 88 & 1 & -14 & -17 & -17 & -17 & -17 & -17 \\
\hline 5 & 1.9805E-02 & 0 & 0 & 0 & 26 & 1000 & 553 & 249 & 606 & 535 & 533 & 530 & 529 & 529 & 529 & 529 \\
\hline 6 & $1.7577 \mathrm{E}-02$ & 0 & 0 & 0 & 6 & 553 & 1000 & 540 & 347 & 319 & 318 & 316 & 316 & 316 & 316 & 316 \\
\hline 7 & $2.4883 \mathrm{E}-02$ & 0 & 0 & 0 & -48 & 249 & 540 & 1000 & 567 & 387 & 388 & 386 & 386 & 386 & 386 & 386 \\
\hline 8 & $2.5094 \mathrm{E}-02$ & 0 & 0 & 0 & 88 & 606 & 347 & 567 & 1000 & 862 & 863 & 858 & 857 & 857 & 857 & 857 \\
\hline 9 & $9.8364 \mathrm{E}-03$ & 0 & 0 & 0 & 1 & 535 & 319 & 387 & 862 & 1000 & 968 & 968 & 968 & 968 & 967 & 968 \\
\hline 10 & $7.3725 \mathrm{E}-03$ & 0 & 0 & 0 & -14 & 533 & 318 & 388 & 863 & 968 & 1000 & 1000 & 1000 & 1000 & 1000 & 1000 \\
\hline 11 & $6.3439 \mathrm{E}-03$ & 0 & 0 & 0 & -17 & 530 & 316 & 386 & 858 & 968 & 1000 & 1000 & 1000 & 1000 & 1000 & 1000 \\
\hline 12 & $6.1203 E-03$ & 0 & 0 & 0 & -17 & 529 & 316 & 386 & 857 & 968 & 1000 & 1000 & 1000 & 1000 & 1000 & 1000 \\
\hline 13 & $6.1097 \mathrm{E}-03$ & 0 & 0 & 0 & -17 & 529 & 316 & 386 & 857 & 968 & 1000 & 1000 & 1000 & 1000 & 1000 & 1000 \\
\hline 14 & $6.1077 \mathrm{E}-03$ & 0 & 0 & 0 & -17 & 529 & 316 & 386 & 857 & 967 & 1000 & 1000 & 1000 & 1000 & 1000 & 1000 \\
\hline 15 & $5.9526 \mathrm{E}-03$ & 0 & 0 & 0 & -17 & 529 & 316 & 386 & 857 & 968 & 1000 & 1000 & 1000 & 1000 & 1000 & 1000 \\
\hline
\end{tabular}

Table B.17: Relative uncertainty (relative standard deviation) and correlation (normalized to 1000) for ${ }^{27} \mathrm{Al}\left(\mathrm{n}, \mathrm{n}^{\prime}\right)$

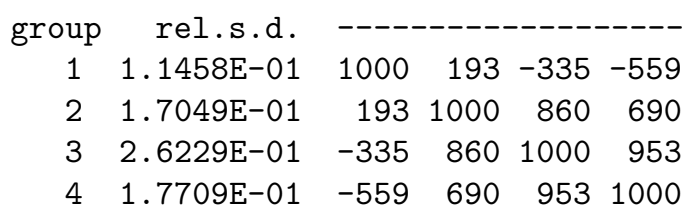

Table B.18: Relative uncertainty (relative standard deviation) and correlation (normalized to 1000) for ${ }^{27} \mathrm{Al}(\mathrm{n}, 2 \mathrm{n})$

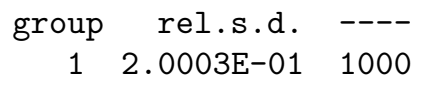


Table B.19: Relative uncertainty (relative standard deviation) and correlation (normalized to 1000) for ${ }^{27} \mathrm{Al}(\mathrm{n}, \gamma)$

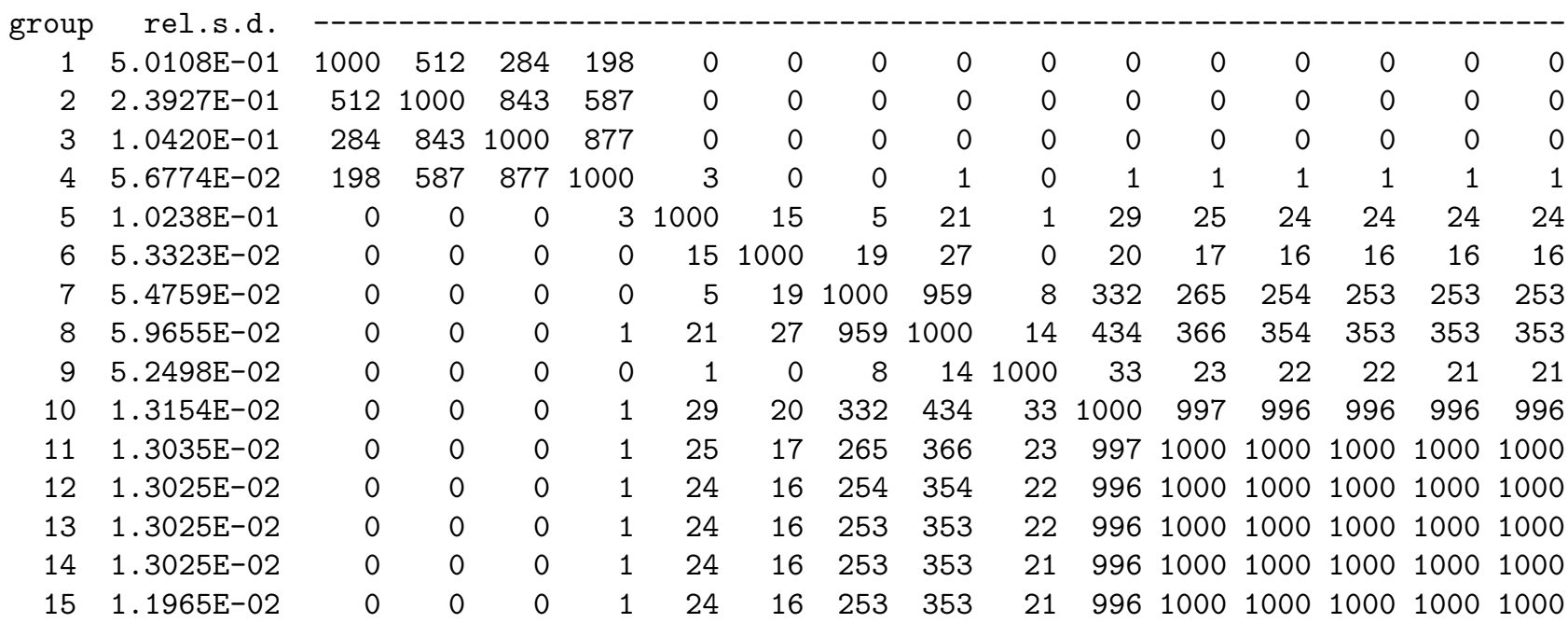

Table B.20: Relative uncertainty (relative standard deviation) and correlation (normalized to 1000) for ${ }^{28} \mathrm{Si}(\mathrm{n}, \mathrm{el})$

\begin{tabular}{|c|c|c|c|c|c|c|c|c|c|c|c|c|c|c|c|c|}
\hline 1 & $6.9408 \mathrm{E}-03$ & 1000 & 921 & 0 & 0 & 0 & 0 & 0 & 0 & 0 & 0 & 0 & 0 & 0 & 0 & \\
\hline 2 & $2.7714 \mathrm{E}-02$ & 921 & 1000 & 18 & 18 & 29 & 7 & 10 & 23 & 24 & 25 & 25 & 25 & 24 & 25 & 24 \\
\hline 3 & 1. $6639 \mathrm{E}-02$ & 0 & 18 & 1000 & 890 & 810 & 460 & 393 & 847 & 853 & 856 & 856 & 856 & 857 & 856 & 857 \\
\hline 4 & $1.4323 E-02$ & 0 & 18 & 890 & 1000 & 846 & 469 & 411 & 877 & 885 & 887 & 887 & 888 & 888 & 888 & 888 \\
\hline 5 & $1.0782 \mathrm{E}-02$ & 0 & 29 & 810 & 846 & 1000 & 552 & 464 & 944 & 952 & 954 & 955 & 955 & 954 & 955 & 955 \\
\hline 6 & $2.9655 \mathrm{E}-02$ & 0 & 7 & 460 & 469 & 552 & 1000 & 280 & 392 & 397 & 399 & 400 & 400 & 400 & 400 & 400 \\
\hline 7 & 4.2997E-02 & 0 & 10 & 393 & 411 & 464 & 280 & 1000 & 256 & 292 & 303 & 305 & 306 & 306 & 306 & 306 \\
\hline 8 & $4.1810 \mathrm{E}-02$ & 0 & 23 & 847 & 877 & 944 & 392 & 256 & 1000 & 999 & 999 & 999 & 999 & 998 & 999 & 999 \\
\hline 9 & $3.6216 \mathrm{E}-02$ & 0 & 24 & 853 & 885 & 952 & 397 & 292 & 999 & 1000 & 1000 & 1000 & 1000 & 1000 & 1000 & 1000 \\
\hline 10 & $3.2309 \mathrm{E}-02$ & 0 & 25 & 856 & 887 & 954 & 399 & 303 & 999 & 1000 & 1000 & 1000 & 1000 & 1000 & 1000 & 1000 \\
\hline 11 & $3.0323 E-02$ & 0 & 25 & 856 & 887 & 955 & 400 & 305 & 999 & 1000 & 1000 & 1000 & 1000 & 1000 & 1000 & 1000 \\
\hline 12 & $2.9729 \mathrm{E}-02$ & 0 & 25 & 856 & 888 & 955 & 400 & 306 & 999 & 1000 & 1000 & 1000 & 1000 & 1000 & 1000 & 1000 \\
\hline 13 & 2.9697E-02 & 0 & 24 & 857 & 888 & 954 & 400 & 306 & 998 & 1000 & 1000 & 1000 & 1000 & 1000 & 1000 & 1000 \\
\hline 14 & 2. $9693 \mathrm{E}-02$ & 0 & 25 & 856 & 888 & 955 & 400 & 306 & 999 & 1000 & 1000 & 1000 & 1000 & 1000 & 1000 & 1000 \\
\hline 15 & $2.8957 \mathrm{E}-02$ & 0 & 24 & 857 & 888 & 955 & 400 & 306 & 999 & 1000 & 1000 & 1000 & 1000 & 1000 & 1000 & 1000 \\
\hline
\end{tabular}

Table B.21: Relative uncertainty (relative standard deviation) and correlation (normalized to 1000) for ${ }^{28} \mathrm{Si}\left(\mathrm{n}, \mathrm{n}^{\prime}\right)$

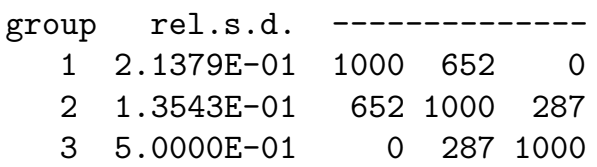


Table B.22: Relative uncertainty (relative standard deviation) and correlation (normalized to 1000) for ${ }^{28} \mathrm{Si}(\mathrm{n}, 2 \mathrm{n})$

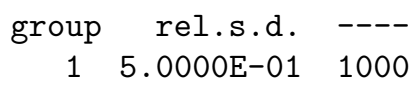

Table B.23: Relative uncertainty (relative standard deviation) and correlation (normalized to 1000) for ${ }^{28} \mathrm{Si}(\mathrm{n}, \gamma)$

\begin{tabular}{|c|c|c|c|c|c|c|c|c|c|c|c|c|c|c|c|c|}
\hline & & & & & & & & & & & & & & & & \\
\hline 1 & & & & 0 & 0 & 0 & & 0 & 0 & & & 0 & 0 & 0 & & \\
\hline 2 & $1.1119 \mathrm{E}-01$ & 684 & 1000 & 4 & 0 & 0 & & 0 & 2 & 2 & 2 & & 2 & 2 & 2 & \\
\hline 3 & $1.0068 \mathrm{E}-01$ & 0 & 4 & 1000 & 46 & 48 & 15 & 10 & 172 & 197 & 204 & 206 & 207 & 207 & 207 & 207 \\
\hline 4 & $6.7724 \mathrm{E}-02$ & 0 & 0 & 46 & 1000 & 40 & 8 & 4 & 64 & 72 & 74 & 74 & 75 & 75 & 75 & \\
\hline 5 & $3.8611 \mathrm{E}-02$ & 0 & 0 & 48 & 40 & 1000 & 430 & 51 & 677 & 694 & 693 & 693 & 693 & 693 & 693 & 693 \\
\hline 6 & 5.648 & 0 & c & 15 & 8 & 430 & 1000 & 43 & 91 & & 602 & 601 & 601 & 601 & 1 & 60 \\
\hline 7 & 1.1193 & 0 & 0 & 1( & & 5 & 43 & 1000 & 116 & & 100 & 99 & 99 & 99 & 9 & 9 \\
\hline 8 & $8.9262 \mathrm{E}-02$ & 0 & 2 & 172 & 64 & 677 & 591 & 116 & 1000 & 973 & 972 & 972 & 972 & 972 & 972 & 972 \\
\hline 9 & $8.7148 \mathrm{E}-02$ & 0 & 2 & 197 & 72 & 694 & 603 & 103 & 973 & 1000 & 1000 & 1000 & 1000 & 1000 & 1000 & 1000 \\
\hline 10 & 5.116 & 0 & 2 & 204 & 74 & 693 & 602 & 100 & 972 & 1000 & 1000 & 1000 & 1000 & 1000 & 1000 & 1000 \\
\hline 11 & 3.565 & 0 & 2 & 206 & 4 & 693 & 601 & 99 & 972 & 00 & 1000 & 1000 & 1000 & 1000 & 1000 & 1000 \\
\hline 12 & 3.24 & & & $20^{\circ}$ & & & & 9 & 972 & & 10 & 10 & 1000 & 1000 & 1000 & 100 \\
\hline 1 & $3.22^{\prime}$ & & & 20 & & & & & 97 & & & & & 1000 & & \\
\hline 1 & 3.2246 & 0 & 2 & 207 & & & & & 972 & & & 1000 & 1000 & 1000 & 1000 & 100 \\
\hline 15 & $2.9619 \mathrm{E}-02$ & 0 & 2 & 207 & 75 & 693 & 601 & 99 & 972 & 1000 & 1000 & 1000 & 1000 & 1000 & 1000 & 100 \\
\hline
\end{tabular}


Table B.24: Relative uncertainty (relative standard deviation) and correlation (normalized to 1000) for ${ }^{52} \mathrm{Cr}(\mathrm{n}, \mathrm{el})$

\begin{tabular}{|c|c|c|c|c|c|c|c|c|c|c|c|c|c|c|c|c|}
\hline & & & & & & & & & & & & & & & & \\
\hline 1 & $3.5494 \mathrm{E}-02$ & 1000 & -952 & -988 & -150 & 0 & 0 & 0 & 0 & 0 & 0 & 0 & 0 & 0 & 0 & 0 \\
\hline 2 & $2.3991 \mathrm{E}-02$ & -952 & 1000 & 988 & 150 & 0 & 0 & 0 & 0 & 0 & 0 & 0 & 0 & 0 & 0 & \\
\hline 3 & $2.9194 \mathrm{E}-02$ & -988 & 988 & 1000 & 152 & 0 & 0 & 0 & 0 & 0 & 0 & 0 & 0 & 0 & 0 & \\
\hline 4 & $4.1864 \mathrm{E}-02$ & -150 & 150 & 152 & 1000 & 650 & 184 & 159 & 462 & 453 & 449 & 456 & 454 & 454 & 457 & 456 \\
\hline 5 & $5.2121 \mathrm{E}-02$ & 0 & 0 & 0 & 650 & 1000 & 619 & 7 & 27 & 18 & 21 & 22 & 21 & 23 & 22 & 22 \\
\hline 6 & 1. $1430 \mathrm{E}-01$ & 0 & 0 & 0 & 184 & 619 & 1000 & -248 & -621 & -632 & -621 & -628 & -629 & -627 & -627 & -628 \\
\hline 7 & 1. $2631 \mathrm{E}-01$ & 0 & 0 & 0 & 159 & 7 & -248 & 1000 & 141 & 177 & 185 & 190 & 190 & 190 & 190 & 190 \\
\hline 8 & 1.3279E-01 & 0 & 0 & 0 & 462 & 27 & -621 & 141 & 1000 & 999 & 984 & 997 & 996 & 996 & 996 & 996 \\
\hline 9 & $1.0284 \mathrm{E}-01$ & 0 & 0 & 0 & 453 & 18 & -632 & 177 & 999 & 1000 & 988 & 999 & 999 & 998 & 999 & 999 \\
\hline 10 & $7.7853 \mathrm{E}-02$ & 0 & 0 & 0 & 449 & 21 & -621 & 185 & 984 & 988 & 1000 & 984 & 984 & 984 & 984 & 984 \\
\hline 11 & $7.3730 \mathrm{E}-02$ & 0 & 0 & 0 & 456 & 22 & -628 & 190 & 997 & 999 & 984 & 1000 & 1000 & 1000 & 1000 & 1000 \\
\hline 12 & $7.2146 \mathrm{E}-02$ & 0 & 0 & 0 & 454 & 21 & -629 & 190 & 996 & 999 & 984 & 1000 & 1000 & 1000 & 1000 & 1000 \\
\hline 13 & $7.2151 \mathrm{E}-02$ & 0 & 0 & 0 & 454 & 23 & -627 & 190 & 996 & 998 & 984 & 1000 & 1000 & 1000 & 1000 & 1000 \\
\hline 14 & $7.2146 \mathrm{E}-02$ & 0 & 0 & 0 & 457 & 22 & -627 & 190 & 996 & 999 & 984 & 1000 & 1000 & 1000 & 1000 & 1000 \\
\hline 15 & $7.0489 \mathrm{E}-02$ & 0 & 0 & 0 & 456 & 22 & -628 & 190 & 996 & 999 & 984 & 1000 & 1000 & 1000 & 1000 & 1000 \\
\hline
\end{tabular}

Table B.25: Relative uncertainty (relative standard deviation) and correlation (normalized to 1000) for ${ }^{52} \mathrm{Cr}\left(\mathrm{n}, \mathrm{n}^{\prime}\right)$

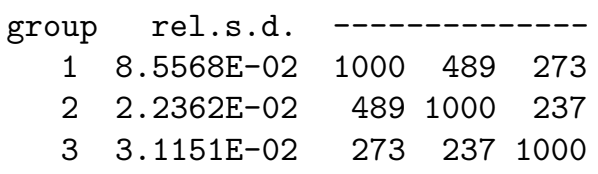

Table B.26: Relative uncertainty (relative standard deviation) and correlation (normalized to 1000) for ${ }^{52} \mathrm{Cr}(\mathrm{n}, 2 \mathrm{n})$

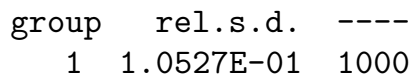


Table B.27: Relative uncertainty (relative standard deviation) and correlation (normalized to 1000) for ${ }^{52} \mathrm{Cr}(\mathrm{n}, \gamma)$

\begin{tabular}{|c|c|c|c|c|c|c|c|c|c|c|c|c|c|c|c|c|}
\hline 1 & $4.9198 \mathrm{E}-01$ & 1000 & 652 & 627 & 0 & 0 & 0 & 0 & 0 & 0 & 0 & 0 & 0 & 0 & 0 & 0 \\
\hline 2 & $2.3267 \mathrm{E}-01$ & 652 & 1000 & 941 & 0 & 0 & 0 & 0 & 0 & 0 & 0 & 0 & 0 & 0 & 0 & 0 \\
\hline 3 & $1.9312 \mathrm{E}-01$ & 627 & 941 & 1000 & 0 & 0 & 0 & 0 & 0 & 0 & 0 & 0 & 0 & 0 & 0 & 0 \\
\hline 4 & $4.3632 \mathrm{E}-02$ & 0 & 0 & 0 & 1000 & 0 & 0 & 0 & 0 & 0 & 1 & 1 & 1 & 1 & 1 & \\
\hline 5 & $5.5101 \mathrm{E}-02$ & 0 & 0 & 0 & 0 & 1000 & 45 & 3 & 0 & 0 & 13 & 13 & 13 & 13 & 13 & 13 \\
\hline 6 & $1.0558 \mathrm{E}-01$ & 0 & 0 & 0 & 0 & 45 & 1000 & -11 & -1 & 0 & -45 & -45 & -45 & -45 & -45 & -45 \\
\hline 7 & $5.4476 \mathrm{E}-02$ & 0 & 0 & 0 & 0 & 3 & -11 & 1000 & 7 & 0 & 195 & 194 & 194 & 194 & 194 & 194 \\
\hline 8 & 1.3423E-01 & 0 & 0 & 0 & 0 & 0 & -1 & 7 & 1000 & 0 & 27 & 27 & 27 & 27 & 27 & 27 \\
\hline 9 & 1. $2972 \mathrm{E}-01$ & 0 & 0 & 0 & 0 & 0 & 0 & 0 & 0 & 1000 & 74 & 67 & 66 & 65 & 65 & 65 \\
\hline 10 & $2.7479 \mathrm{E}-02$ & 0 & 0 & 0 & 1 & 13 & -45 & 195 & 27 & 74 & 1000 & 1000 & 1000 & 1000 & 1000 & 1000 \\
\hline 11 & $2.7012 \mathrm{E}-02$ & 0 & 0 & 0 & 1 & 13 & -45 & 194 & 27 & 67 & 1000 & 1000 & 1000 & 1000 & 1000 & 1000 \\
\hline 12 & $2.6894 \mathrm{E}-02$ & 0 & 0 & 0 & 1 & 13 & -45 & 194 & 27 & 66 & 1000 & 1000 & 1000 & 1000 & 1000 & 1000 \\
\hline 13 & $2.6838 \mathrm{E}-02$ & 0 & 0 & 0 & 1 & 13 & -45 & 194 & 27 & 65 & 1000 & 1000 & 1000 & 1000 & 1000 & 1000 \\
\hline 14 & $2.6828 \mathrm{E}-02$ & 0 & 0 & 0 & 1 & 13 & -45 & 194 & 27 & 65 & 1000 & 1000 & 1000 & 1000 & 1000 & 1000 \\
\hline 15 & $2.2404 \mathrm{E}-02$ & 0 & 0 & 0 & 1 & 13 & -45 & 194 & 27 & 65 & 1000 & 1000 & 1000 & 1000 & 1000 & 1000 \\
\hline
\end{tabular}

Table B.28: Relative uncertainty (relative standard deviation) and correlation (normalized to 1000) for ${ }^{56} \mathrm{Fe}(\mathrm{n}, \mathrm{el})$

\begin{tabular}{|c|c|c|c|c|c|c|c|c|c|c|c|c|c|c|c|c|}
\hline & & & & & & & & & & & & & & & & \\
\hline 1 & $4.6128 \mathrm{E}-02$ & 1000 & -524 & -730 & 123 & 0 & 0 & 0 & 0 & 0 & 0 & 0 & 0 & 0 & 0 & 0 \\
\hline 2 & $8.1354 \mathrm{E}-02$ & -524 & 1000 & 964 & 2 & 0 & 0 & 0 & 0 & 0 & 0 & 0 & 0 & 0 & 0 & 0 \\
\hline 3 & $5.8876 \mathrm{E}-02$ & -730 & 964 & 1000 & -36 & 0 & 0 & 0 & 0 & 0 & 0 & 0 & 0 & 0 & 0 & 0 \\
\hline 4 & $6.3516 \mathrm{E}-03$ & 123 & 2 & -36 & 1000 & 835 & 845 & 619 & 771 & 599 & 463 & 419 & 408 & 408 & 408 & 408 \\
\hline 5 & $1.7092 \mathrm{E}-02$ & 0 & 0 & 0 & 835 & 1000 & 867 & 641 & 800 & 630 & 494 & 451 & 439 & 439 & 439 & 439 \\
\hline 6 & $2.0771 \mathrm{E}-02$ & 0 & 0 & 0 & 845 & 867 & 1000 & 700 & 869 & 706 & 571 & 528 & 516 & 516 & 516 & 516 \\
\hline 7 & $2.0507 \mathrm{E}-02$ & 0 & 0 & 0 & 619 & 641 & 700 & 1000 & 724 & 586 & 512 & 486 & 479 & 478 & 478 & 478 \\
\hline 8 & $4.5987 \mathrm{E}-02$ & 0 & 0 & 0 & 771 & 800 & 869 & 724 & 1000 & 951 & 878 & 850 & 842 & 842 & 842 & 842 \\
\hline 9 & $3.9829 \mathrm{E}-02$ & 0 & 0 & 0 & 599 & 630 & 706 & 586 & 951 & 1000 & 982 & 969 & 965 & 965 & 965 & 965 \\
\hline 10 & $4.1599 \mathrm{E}-02$ & 0 & 0 & 0 & 463 & 494 & 571 & 512 & 878 & 982 & 1000 & 998 & 997 & 997 & 997 & 997 \\
\hline 11 & $4.2760 \mathrm{E}-02$ & 0 & 0 & 0 & 419 & 451 & 528 & 486 & 850 & 969 & 998 & 1000 & 1000 & 1000 & 1000 & 1000 \\
\hline 12 & $4.3085 E-02$ & 0 & 0 & 0 & 408 & 439 & 516 & 479 & 842 & 965 & 997 & 1000 & 1000 & 1000 & 1000 & 1000 \\
\hline 13 & $4.3100 \mathrm{E}-02$ & 0 & 0 & 0 & 408 & 439 & 516 & 478 & 842 & 965 & 997 & 1000 & 1000 & 1000 & 1000 & 1000 \\
\hline 14 & $4.3102 \mathrm{E}-02$ & 0 & 0 & 0 & 408 & 439 & 516 & 478 & 842 & 965 & 997 & 1000 & 1000 & 1000 & 1000 & 1000 \\
\hline 15 & $4.2135 \mathrm{E}-02$ & 0 & 0 & 0 & 408 & 439 & 516 & 478 & 842 & 965 & 997 & 1000 & 1000 & 1000 & 1000 & 1000 \\
\hline
\end{tabular}


Table B.29: Relative uncertainty (relative standard deviation) and correlation (normalized to 1000) for ${ }^{56} \mathrm{Fe}\left(\mathrm{n}, \mathrm{n}^{\prime}\right)$

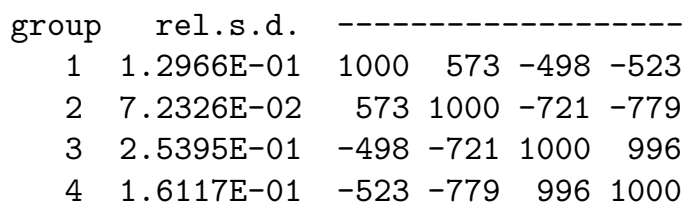

Table B.30: Relative uncertainty (relative standard deviation) and correlation (normalized to 1000) for ${ }^{56} \mathrm{Fe}(\mathrm{n}, 2 \mathrm{n})$

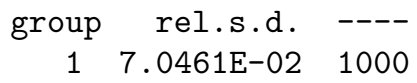


Table B.31: Relative uncertainty (relative standard deviation) and correlation (normalized to 1000) for ${ }^{56} \mathrm{Fe}(\mathrm{n}, \gamma)$

\begin{tabular}{|c|c|c|c|c|c|c|c|c|c|c|c|c|c|c|c|c|}
\hline & 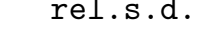 & & & & & & & & & & & & & & & \\
\hline 1 & $4.6237 \mathrm{E}-01$ & 1000 & 693 & 691 & 555 & 0 & 0 & 0 & 0 & 0 & 0 & 0 & 0 & 0 & 0 & 0 \\
\hline 2 & $3.1689 \mathrm{E}-01$ & 693 & 1000 & 994 & 824 & 0 & 0 & 0 & 0 & 0 & 0 & 0 & 0 & 0 & 0 & 0 \\
\hline 3 & $2.3483 E-01$ & 691 & 994 & 1000 & 831 & 0 & 0 & 0 & 0 & 0 & 0 & 0 & 0 & 0 & 0 & 0 \\
\hline 4 & $7.4291 \mathrm{E}-02$ & 555 & 824 & 831 & 1000 & 4 & 0 & 0 & 0 & 0 & 0 & 0 & 0 & 0 & 0 & 0 \\
\hline 5 & $4.0225 E-02$ & 0 & 0 & 0 & 4 & 1000 & 8 & 0 & 0 & 0 & 0 & 0 & 0 & 0 & 0 & 0 \\
\hline 6 & $1.0773 \mathrm{E}-01$ & 0 & 0 & 0 & 0 & 8 & 1000 & 0 & 0 & 0 & 1 & 1 & 1 & 1 & 1 & 1 \\
\hline 7 & 1.3189E-01 & 0 & 0 & 0 & 0 & 0 & 0 & 1000 & 8 & 3 & 8 & 8 & 8 & 8 & 8 & 8 \\
\hline 8 & $8.8106 \mathrm{E}-02$ & 0 & 0 & 0 & 0 & 0 & 0 & 8 & 1000 & 3 & 13 & 13 & 13 & 13 & 13 & 13 \\
\hline 9 & $8.5613 \mathrm{E}-02$ & 0 & 0 & 0 & 0 & 0 & 0 & 3 & 3 & 1000 & 196 & 195 & 195 & 195 & 195 & 195 \\
\hline 10 & 1. $1233 \mathrm{E}-01$ & 0 & 0 & 0 & 0 & 0 & 1 & 8 & 13 & 196 & 1000 & 1000 & 1000 & 1000 & 1000 & 1000 \\
\hline 11 & $1.1248 \mathrm{E}-01$ & 0 & 0 & 0 & 0 & 0 & 1 & 8 & 13 & 195 & 1000 & 1000 & 1000 & 1000 & 1000 & 1000 \\
\hline 12 & $1.1252 \mathrm{E}-01$ & 0 & 0 & 0 & 0 & 0 & 1 & 8 & 13 & 195 & 1000 & 1000 & 1000 & 1000 & 1000 & 1000 \\
\hline 13 & 1. $1254 \mathrm{E}-01$ & 0 & 0 & 0 & 0 & 0 & 1 & 8 & 13 & 195 & 1000 & 1000 & 1000 & 1000 & 1000 & 1000 \\
\hline 14 & $1.1254 \mathrm{E}-01$ & 0 & 0 & 0 & 0 & 0 & 1 & 8 & 13 & 195 & 1000 & 1000 & 1000 & 1000 & 1000 & 1000 \\
\hline 15 & $9.3990 \mathrm{E}-02$ & 0 & 0 & 0 & 0 & 0 & 1 & 8 & 13 & 195 & 1000 & 1000 & 1000 & 1000 & 1000 & 1000 \\
\hline
\end{tabular}

Table B.32: Relative uncertainty (relative standard deviation) and correlation (normalized to 1000) for ${ }^{57} \mathrm{Fe}(\mathrm{n}, \mathrm{el})$

\begin{tabular}{|c|c|c|c|c|c|c|c|c|c|c|c|c|c|c|c|c|}
\hline 1 & $2.5930 \mathrm{E}-02$ & 1000 & 262 & -409 & -284 & 251 & 0 & 0 & 0 & 0 & 0 & 0 & 0 & 0 & 0 & 0 \\
\hline 2 & $3.2359 \mathrm{E}-02$ & 262 & 1000 & 773 & -1000 & -868 & 0 & 0 & 0 & 0 & 0 & 0 & 0 & 0 & 0 & 0 \\
\hline 3 & $2.7113 \mathrm{E}-02$ & -409 & 773 & 1000 & -758 & -986 & 0 & 0 & 0 & 0 & 0 & 0 & 0 & 0 & 0 & 0 \\
\hline 4 & 1. $2838 \mathrm{E}-02$ & $-284-$ & -1000 & -758 & 1000 & 856 & 0 & 0 & 0 & 0 & 0 & 0 & 0 & 0 & 0 & 0 \\
\hline 5 & $2.3875 \mathrm{E}-02$ & 251 & -868 & -986 & 856 & 1000 & 6 & 2 & 4 & 0 & 6 & 7 & 7 & 7 & 7 & 7 \\
\hline 6 & $1.6545 \mathrm{E}-02$ & 0 & 0 & 0 & 0 & 6 & 1000 & 421 & 351 & 36 & 563 & 601 & 593 & 592 & 592 & 592 \\
\hline 7 & $2.8087 \mathrm{E}-02$ & 0 & 0 & 0 & 0 & 2 & 421 & 1000 & 662 & 3 & 550 & 289 & 248 & 246 & 246 & 246 \\
\hline 8 & $5.0996 \mathrm{E}-02$ & 0 & 0 & 0 & 0 & 4 & 351 & 662 & 1000 & 255 & 814 & 689 & 655 & 654 & 654 & 654 \\
\hline 9 & $2.5017 \mathrm{E}-02$ & 0 & 0 & 0 & 0 & 0 & 36 & 3 & 255 & 1000 & 543 & 226 & 190 & 188 & 188 & 188 \\
\hline 10 & 1. $6108 \mathrm{E}-01$ & 0 & 0 & 0 & 0 & 6 & 563 & 550 & 814 & 543 & 1000 & 834 & 801 & 799 & 799 & 799 \\
\hline 11 & $8.4843 E-02$ & 0 & 0 & 0 & 0 & 7 & 601 & 289 & 689 & 226 & 834 & 1000 & 998 & 998 & 998 & 998 \\
\hline 12 & $7.6912 \mathrm{E}-02$ & 0 & 0 & 0 & 0 & 7 & 593 & 248 & 655 & 190 & 801 & 998 & 1000 & 1000 & 1000 & 1000 \\
\hline 13 & $7.6546 \mathrm{E}-02$ & 0 & 0 & 0 & 0 & 7 & 592 & 246 & 654 & 188 & 799 & 998 & 1000 & 1000 & 1000 & 1000 \\
\hline 14 & $7.6486 \mathrm{E}-02$ & 0 & 0 & 0 & 0 & 7 & 592 & 246 & 654 & 188 & 799 & 998 & 1000 & 1000 & 1000 & 1000 \\
\hline 15 & $7.4759 \mathrm{E}-02$ & 0 & 0 & 0 & 0 & 7 & 592 & 246 & 654 & 188 & 799 & 998 & 1000 & 1000 & 1000 & 1000 \\
\hline
\end{tabular}


Table B.33: Relative uncertainty (relative standard deviation) and correlation (normalized to 1000) for ${ }^{57} \mathrm{Fe}\left(\mathrm{n}, \mathrm{n}^{\prime}\right)$

$\begin{array}{crrrrrrr}\text { group } & \text { rel.s.d. } & -------------------- \\ 1 & 1.5151 \mathrm{E}-01 & 1000 & 724 & -771 & -803 & 699 & 0 \\ 2 & 1.1076 \mathrm{E}-01 & 724 & 1000 & -718 & -825 & 679 & 0 \\ 3 & 3.4206 \mathrm{E}-01 & -771 & -718 & 1000 & 977 & -904 & 0 \\ 4 & 1.0285 \mathrm{E}-01 & -803 & -825 & 977 & 1000 & -863 & 0 \\ 5 & 8.5437 \mathrm{E}-02 & 699 & 679 & -904 & -863 & 1000 & 360 \\ 6 & 1.2097 \mathrm{E}-01 & 0 & 0 & 0 & 0 & 360 & 1000\end{array}$

Table B.34: Relative uncertainty (relative standard deviation) and correlation (normalized to 1000) for ${ }^{57} \mathrm{Fe}(\mathrm{n}, 2 \mathrm{n})$

$\underset{1}{\operatorname{group}} \begin{array}{rr}\text { rel.s.d. } & ---- \\ 1.9201 \mathrm{E}-01 & 1000\end{array}$ 
Table B.35: Relative uncertainty (relative standard deviation) and correlation (normalized to 1000) for ${ }^{57} \mathrm{Fe}(\mathrm{n}, \gamma)$

\begin{tabular}{|c|c|c|c|c|c|c|c|c|c|c|c|c|c|c|c|c|}
\hline 1 & $8.5378 \mathrm{E}-01$ & 1000 & 429 & 322 & 271 & 124 & 0 & 0 & 0 & 0 & 0 & 0 & 0 & 0 & 0 & 0 \\
\hline 2 & $5.3455 \mathrm{E}-01$ & 429 & 1000 & 839 & 900 & 724 & 0 & 0 & 0 & 0 & 0 & 0 & 0 & 0 & 0 & 0 \\
\hline 3 & $1.8328 \mathrm{E}-01$ & 322 & 839 & 1000 & 896 & 477 & 0 & 0 & 0 & 0 & 0 & 0 & 0 & 0 & 0 & 0 \\
\hline 4 & 1. $1992 \mathrm{E}-01$ & 271 & 900 & 896 & 1000 & 813 & 0 & 0 & 0 & 0 & 0 & 0 & 0 & 0 & 0 & \\
\hline 5 & 1. 1143E-01 & 124 & 724 & 477 & 813 & 1000 & 8 & 0 & 0 & 0 & 0 & 0 & 0 & 0 & 0 & 0 \\
\hline 6 & $6.5066 \mathrm{E}-02$ & 0 & 0 & 0 & 0 & 8 & 1000 & 15 & 5 & 2 & 1 & 18 & 16 & 16 & 16 & 16 \\
\hline 7 & $6.5987 \mathrm{E}-02$ & 0 & 0 & 0 & 0 & 0 & 15 & 1000 & 143 & 18 & 9 & 173 & 153 & 151 & 151 & 151 \\
\hline 8 & $8.2655 \mathrm{E}-02$ & 0 & 0 & 0 & 0 & 0 & 5 & 143 & 1000 & 26 & 3 & 58 & 51 & 51 & 51 & 51 \\
\hline 9 & $4.6370 \mathrm{E}-02$ & 0 & 0 & 0 & 0 & 0 & 2 & 18 & 26 & 1000 & 16 & 206 & 174 & 172 & 172 & 172 \\
\hline 10 & $2.9239 \mathrm{E}-01$ & 0 & 0 & 0 & 0 & 0 & 1 & 9 & 3 & 16 & 1000 & 37 & 34 & 33 & 34 & 34 \\
\hline 11 & $1.0687 \mathrm{E}-01$ & 0 & 0 & 0 & 0 & 0 & 18 & 173 & 58 & 206 & 37 & 1000 & 998 & 998 & 998 & 998 \\
\hline 12 & $1.1673 \mathrm{E}-01$ & 0 & 0 & 0 & 0 & 0 & 16 & 153 & 51 & 174 & 34 & 998 & 1000 & 1000 & 1000 & 1000 \\
\hline 13 & 1. 1733E-01 & 0 & 0 & 0 & 0 & 0 & 16 & 151 & 51 & 172 & 33 & 998 & 1000 & 1000 & 1000 & 1000 \\
\hline 14 & $1.1743 \mathrm{E}-01$ & 0 & 0 & 0 & 0 & 0 & 16 & 151 & 51 & 172 & 34 & 998 & 1000 & 1000 & 1000 & 1000 \\
\hline 15 & $1.0789 \mathrm{E}-01$ & 0 & 0 & 0 & 0 & 0 & 16 & 151 & 51 & 172 & 34 & 998 & 1000 & 1000 & 1000 & 1000 \\
\hline
\end{tabular}

Table B.36: Relative uncertainty (relative standard deviation) and correlation (normalized to 1000) for ${ }^{58} \mathrm{Ni}(\mathrm{n}, \mathrm{el})$

\begin{tabular}{|c|c|c|c|c|c|c|c|c|c|c|c|c|c|c|c|c|}
\hline & & & & & & & & & & & & & & & & \\
\hline 1 & $3.5160 \mathrm{E}-02$ & 1000 & -934 & -999 & 538 & 0 & 0 & 0 & 0 & 0 & 0 & 0 & 0 & 0 & 0 & 0 \\
\hline 2 & $4.6361 \mathrm{E}-02$ & -934 & 1000 & 950 & -557 & 0 & 0 & 0 & 0 & 0 & 0 & 0 & 0 & 0 & 0 & 0 \\
\hline 3 & $9.2900 \mathrm{E}-03$ & -999 & 950 & 1000 & -545 & 0 & 0 & 0 & 0 & 0 & 0 & 0 & 0 & 0 & 0 & 0 \\
\hline 4 & $1.5393 \mathrm{E}-02$ & 538 & -557 & -545 & 1000 & 74 & 75 & 19 & 11 & -22 & -34 & -36 & -36 & -36 & -37 & -37 \\
\hline 5 & $2.6769 \mathrm{E}-02$ & 0 & 0 & 0 & 74 & 1000 & 517 & 87 & 57 & -36 & -40 & -38 & -39 & -39 & -39 & -42 \\
\hline 6 & $3.2103 E-02$ & 0 & 0 & 0 & 75 & 517 & 1000 & 244 & 128 & -405 & -412 & -415 & -417 & -417 & -417 & -418 \\
\hline 7 & $3.0459 \mathrm{E}-02$ & 0 & 0 & 0 & 19 & 87 & 244 & 1000 & 852 & -552 & -532 & -523 & -519 & -519 & -519 & -519 \\
\hline 8 & $8.0544 E-02$ & 0 & 0 & 0 & 11 & 57 & 128 & 852 & 1000 & -820 & -805 & -797 & -794 & -794 & -794 & -794 \\
\hline 9 & $3.6133 \mathrm{E}-02$ & 0 & 0 & 0 & -22 & -36 & -405 & -552 & -820 & 1000 & 999 & 999 & 999 & 999 & 999 & 998 \\
\hline 10 & $2.9583 \mathrm{E}-02$ & 0 & 0 & 0 & -34 & -40 & -412 & -532 & -805 & 999 & 1000 & 1000 & 1000 & 1000 & 1000 & 1000 \\
\hline 11 & $2.7718 \mathrm{E}-02$ & 0 & 0 & 0 & -36 & -38 & -415 & -523 & -797 & 999 & 1000 & 1000 & 1000 & 1000 & 1000 & 1000 \\
\hline 12 & $2.7358 \mathrm{E}-02$ & 0 & 0 & 0 & -36 & -39 & -417 & -519 & -794 & 999 & 1000 & 1000 & 1000 & 1000 & 1000 & 1000 \\
\hline 13 & $2.7341 \mathrm{E}-02$ & 0 & 0 & 0 & -36 & -39 & -417 & -519 & -794 & 999 & 1000 & 1000 & 1000 & 1000 & 1000 & 1000 \\
\hline 14 & $2.7338 \mathrm{E}-02$ & 0 & 0 & 0 & -37 & -39 & -417 & -519 & -794 & 999 & 1000 & 1000 & 1000 & 1000 & 1000 & 1000 \\
\hline 15 & $2.6717 \mathrm{E}-02$ & 0 & 0 & 0 & -37 & -42 & -418 & -519 & -794 & 998 & 1000 & 1000 & 1000 & 1000 & 1000 & 1000 \\
\hline
\end{tabular}


Table B.37: Relative uncertainty (relative standard deviation) and correlation (normalized to 1000) for ${ }^{58} \mathrm{Ni}\left(\mathrm{n}, \mathrm{n}^{\prime}\right)$

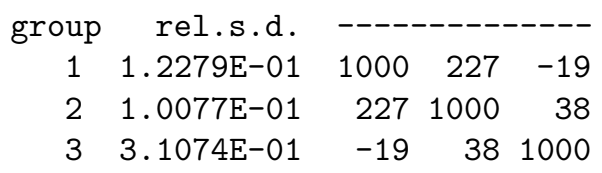

Table B.38: Relative uncertainty (relative standard deviation) and correlation (normalized to 1000) for ${ }^{58} \mathrm{Ni}(\mathrm{n}, 2 \mathrm{n})$

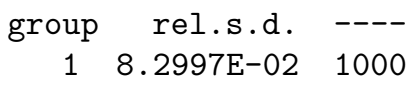

Table B.39: Relative uncertainty (relative standard deviation) and correlation (normalized to 1000) for ${ }^{58} \mathrm{Ni}(\mathrm{n}, \gamma)$

\begin{tabular}{|c|c|c|c|c|c|c|c|c|c|c|c|c|c|c|c|c|}
\hline 1 & $4.7760 \mathrm{E}-01$ & 1000 & 359 & 448 & 527 & 0 & 0 & 0 & 0 & 0 & 0 & 0 & 0 & 0 & 0 & 0 \\
\hline 2 & $1.4538 \mathrm{E}-01$ & 359 & 1000 & 965 & 782 & 0 & 0 & 0 & 0 & 0 & 0 & 0 & 0 & 0 & 0 & 0 \\
\hline 3 & $9.6815 \mathrm{E}-02$ & 448 & 965 & 1000 & 915 & 0 & 0 & 0 & 0 & 0 & 0 & 0 & 0 & 0 & 0 & 0 \\
\hline 4 & $7.7071 \mathrm{E}-02$ & 527 & 782 & 915 & 1000 & -3 & 0 & 0 & 0 & 0 & 0 & 0 & 0 & 0 & 0 & 0 \\
\hline 5 & $2.6492 \mathrm{E}-02$ & 0 & 0 & 0 & -3 & 1000 & 9 & 0 & 0 & 0 & 0 & 0 & 0 & 0 & 0 & 0 \\
\hline 6 & 1.2123E-02 & 0 & 0 & 0 & 0 & 9 & 1000 & 5 & 1 & 7 & 8 & 8 & 8 & 8 & 8 & 8 \\
\hline 7 & $3.4419 \mathrm{E}-02$ & 0 & 0 & 0 & 0 & 0 & 5 & 1000 & -12 & 12 & 11 & 11 & 11 & 11 & 11 & 11 \\
\hline 8 & $8.3326 \mathrm{E}-03$ & 0 & 0 & 0 & 0 & 0 & 1 & -12 & 1000 & -200 & -78 & -76 & -75 & -75 & -75 & -75 \\
\hline 9 & $2.8227 \mathrm{E}-02$ & 0 & 0 & 0 & 0 & 0 & 7 & 12 & -200 & 1000 & 836 & 834 & 833 & 832 & 832 & 832 \\
\hline 10 & $2.4064 \mathrm{E}-02$ & 0 & 0 & 0 & 0 & 0 & 8 & 11 & -78 & 836 & 1000 & 1000 & 1000 & 1000 & 1000 & 1000 \\
\hline 11 & $2.4036 \mathrm{E}-02$ & 0 & 0 & 0 & 0 & 0 & 8 & 11 & -76 & 834 & 1000 & 1000 & 1000 & 1000 & 1000 & 1000 \\
\hline 12 & $2.4028 \mathrm{E}-02$ & 0 & 0 & 0 & 0 & 0 & 8 & 11 & -75 & 833 & 1000 & 1000 & 1000 & 1000 & 1000 & 1000 \\
\hline 13 & $2.4024 \mathrm{E}-02$ & 0 & 0 & 0 & 0 & 0 & 8 & 11 & -75 & 832 & 1000 & 1000 & 1000 & 1000 & 1000 & 1000 \\
\hline 14 & $2.4024 \mathrm{E}-02$ & 0 & 0 & 0 & 0 & 0 & 8 & 11 & -75 & 832 & 1000 & 1000 & 1000 & 1000 & 1000 & 1000 \\
\hline 15 & $2.2070 \mathrm{E}-02$ & 0 & 0 & 0 & 0 & 0 & 8 & 11 & -75 & 832 & 1000 & 1000 & 1000 & 1000 & 1000 & 1000 \\
\hline
\end{tabular}


Table B.40: Relative uncertainty (relative standard deviation) and correlation (normalized to 1000) for ${ }^{90} \mathrm{Zr}(\mathrm{n}, \mathrm{el})$

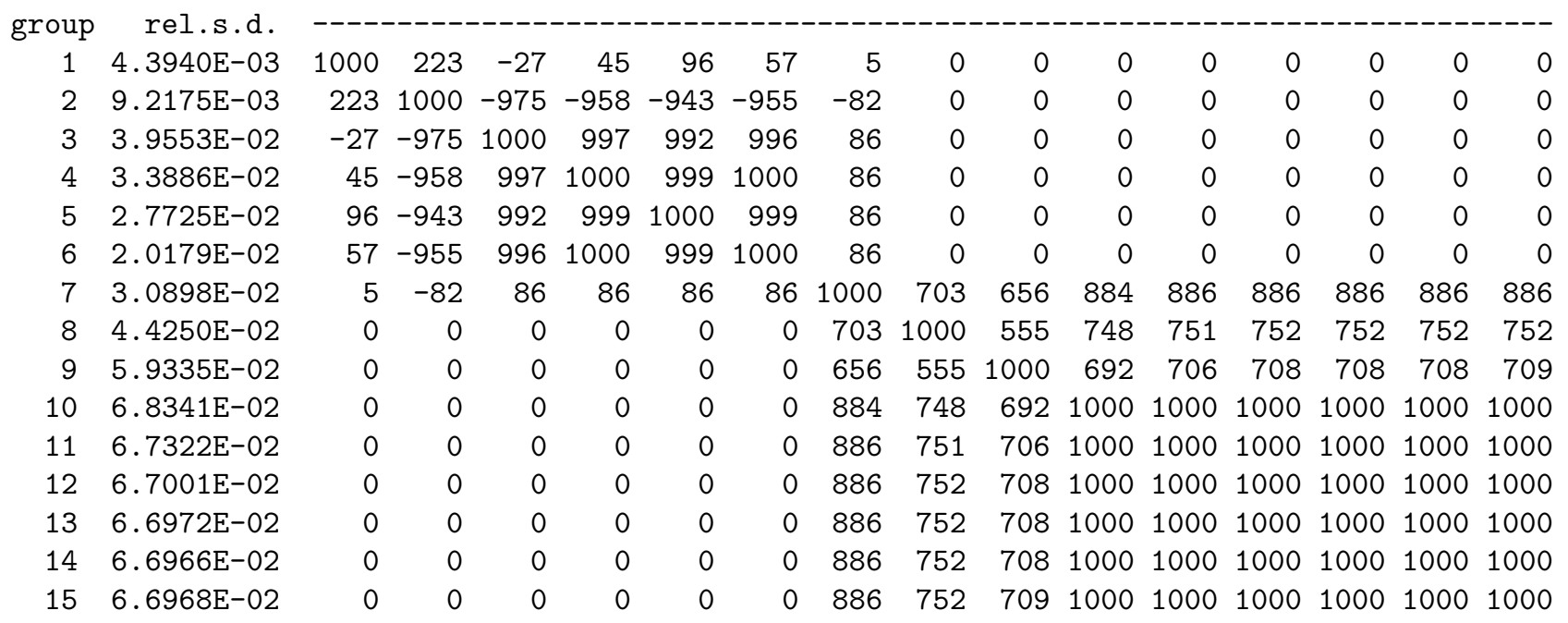

Table B.41: Relative uncertainty (relative standard deviation) and correlation (normalized to 1000) for ${ }^{90} \operatorname{Zr}\left(\mathrm{n}, \mathrm{n}^{\prime}\right)$

$\begin{array}{crrrrr}\text { group } & \text { rel.s.d. } & ---1 & & & \\ 1 & 1.1322 \mathrm{E}-01 & 1000 & -202 & -71 & 0 \\ 2 & 1.7958 \mathrm{E}-01 & -202 & 1000 & 797 & 0 \\ 3 & 1.8523 \mathrm{E}-01 & -71 & 797 & 1000 & 1 \\ 4 & 5.0000 \mathrm{E}-01 & 0 & 0 & 1 & 1000\end{array}$

Table B.42: Relative uncertainty (relative standard deviation) and correlation (normalized to 1000) for ${ }^{90} \operatorname{Zr}(\mathrm{n}, 2 \mathrm{n})$

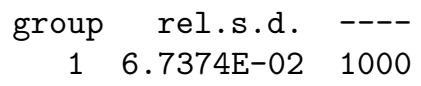


Table B.43: Relative uncertainty (relative standard deviation) and correlation (normalized to 1000) for ${ }^{90} \operatorname{Zr}(\mathrm{n}, \gamma)$

\begin{tabular}{|c|c|c|c|c|c|c|c|c|c|c|c|c|c|c|c|c|}
\hline 1 & $4.6363 \mathrm{E}-01$ & 1000 & 270 & 230 & 220 & 129 & 233 & 0 & 0 & 0 & 0 & 0 & 0 & 0 & 0 & 0 \\
\hline 2 & $1.8586 \mathrm{E}-01$ & 270 & 1000 & 902 & 856 & 456 & 932 & 0 & 0 & 0 & 0 & 0 & 0 & 0 & 0 & 0 \\
\hline 3 & $9.1445 \mathrm{E}-02$ & 230 & 902 & 1000 & 995 & 794 & 920 & 0 & 0 & 0 & 0 & 0 & 0 & 0 & 0 & 0 \\
\hline 4 & $6.2638 \mathrm{E}-02$ & 220 & 856 & 995 & 1000 & 849 & 893 & 0 & 0 & 0 & 0 & 0 & 0 & 0 & 0 & 0 \\
\hline 5 & $5.1576 \mathrm{E}-02$ & 129 & 456 & 794 & 849 & 1000 & 585 & 0 & 0 & 0 & 0 & 0 & 0 & 0 & 0 & 0 \\
\hline 6 & $3.1315 \mathrm{E}-02$ & 233 & 932 & 920 & 893 & 585 & 1000 & 43 & 0 & 0 & 4 & 4 & 4 & 4 & 4 & 4 \\
\hline 7 & $5.2022 \mathrm{E}-02$ & 0 & 0 & 0 & 0 & 0 & 43 & 1000 & 4 & 1 & 657 & 707 & 695 & 691 & 690 & 690 \\
\hline 8 & $7.8934 \mathrm{E}-02$ & 0 & 0 & 0 & 0 & 0 & 0 & 4 & 1000 & 1 & 79 & 79 & 76 & 76 & 76 & 76 \\
\hline 9 & $6.9585 \mathrm{E}-02$ & 0 & 0 & 0 & 0 & 0 & 0 & 1 & 1 & 1000 & 270 & 178 & 160 & 159 & 158 & 158 \\
\hline 10 & $1.0547 \mathrm{E}-01$ & 0 & 0 & 0 & 0 & 0 & 4 & 657 & 79 & 270 & 1000 & 978 & 950 & 944 & 943 & 943 \\
\hline 11 & $5.9502 \mathrm{E}-02$ & 0 & 0 & 0 & 0 & 0 & 4 & 707 & 79 & 178 & 978 & 1000 & 987 & 984 & 983 & 983 \\
\hline 12 & $2.7477 \mathrm{E}-02$ & 0 & 0 & 0 & 0 & 0 & 4 & 695 & 76 & 160 & 950 & 987 & 1000 & 1000 & 1000 & 1000 \\
\hline 13 & $2.5599 \mathrm{E}-02$ & 0 & 0 & 0 & 0 & 0 & 4 & 691 & 76 & 159 & 944 & 984 & 1000 & 1000 & 1000 & 1000 \\
\hline 14 & $2.5260 \mathrm{E}-02$ & 0 & 0 & 0 & 0 & 0 & 4 & 690 & 76 & 158 & 943 & 983 & 1000 & 1000 & 1000 & 1000 \\
\hline 15 & $2.5212 \mathrm{E}-02$ & 0 & 0 & 0 & 0 & 0 & 4 & 690 & 76 & 158 & 943 & 983 & 1000 & 1000 & 1000 & 1000 \\
\hline
\end{tabular}

Table B.44: Relative uncertainty (relative standard deviation) and correlation (normalized to 1000) for ${ }^{91} \mathrm{Zr}(\mathrm{n}, \mathrm{el})$

\begin{tabular}{|c|c|c|c|c|c|c|c|c|c|c|c|c|c|c|c|c|}
\hline 1 & 1. $9273 \mathrm{E}-02$ & 1000 & 60 & 5 & 9 & 9 & 4 & 0 & 0 & 0 & 0 & 0 & 0 & 0 & 0 & 0 \\
\hline 2 & 1.6980E-02 & 60 & 1000 & -377 & -373 & -373 & -343 & 0 & 0 & 0 & 0 & 0 & 0 & 0 & 0 & 0 \\
\hline 3 & $4.1518 \mathrm{E}-02$ & 5 & -377 & 1000 & 1000 & 1000 & 909 & 0 & 0 & 0 & 0 & 0 & 0 & 0 & 0 & 0 \\
\hline 4 & $4.1066 \mathrm{E}-02$ & 9 & -373 & 1000 & 1000 & 1000 & 909 & 0 & 0 & 0 & 0 & 0 & 0 & 0 & 0 & 0 \\
\hline 5 & $4.5372 \mathrm{E}-02$ & 9 & -373 & 1000 & 1000 & 1000 & 909 & 0 & 0 & 0 & 0 & 0 & 0 & 0 & 0 & 0 \\
\hline 6 & $4.0291 \mathrm{E}-02$ & 4 & -343 & 909 & 909 & 909 & 1000 & 416 & 190 & 0 & 0 & 0 & 0 & 0 & 0 & 0 \\
\hline 7 & $5.4711 \mathrm{E}-02$ & 0 & 0 & 0 & 0 & 0 & 416 & 1000 & 457 & 0 & 0 & 0 & 0 & 0 & 0 & 0 \\
\hline 8 & $3.1094 \mathrm{E}-02$ & 0 & 0 & 0 & 0 & 0 & 190 & 457 & 1000 & 870 & 727 & 697 & 690 & 685 & 684 & 684 \\
\hline 9 & $2.9240 \mathrm{E}-02$ & 0 & 0 & 0 & 0 & 0 & 0 & 0 & 870 & 1000 & 874 & 846 & 839 & 834 & 833 & 833 \\
\hline 10 & $5.7502 \mathrm{E}-02$ & 0 & 0 & 0 & 0 & 0 & 0 & 0 & 727 & 874 & 1000 & 998 & 997 & 996 & 996 & 996 \\
\hline 11 & $5.8877 \mathrm{E}-02$ & 0 & 0 & 0 & 0 & 0 & 0 & 0 & 697 & 846 & 998 & 1000 & 1000 & 1000 & 1000 & 1000 \\
\hline 12 & $5.9097 \mathrm{E}-02$ & 0 & 0 & 0 & 0 & 0 & 0 & 0 & 690 & 839 & 997 & 1000 & 1000 & 1000 & 1000 & 1000 \\
\hline 13 & $5.9238 \mathrm{E}-02$ & 0 & 0 & 0 & 0 & 0 & 0 & 0 & 685 & 834 & 996 & 1000 & 1000 & 1000 & 1000 & 1000 \\
\hline 14 & $5.9267 \mathrm{E}-02$ & 0 & 0 & 0 & 0 & 0 & 0 & 0 & 684 & 833 & 996 & 1000 & 1000 & 1000 & 1000 & 1000 \\
\hline 15 & $5.9121 \mathrm{E}-02$ & 0 & 0 & 0 & 0 & 0 & 0 & 0 & 684 & 833 & 996 & 1000 & 1000 & 1000 & 1000 & 1000 \\
\hline
\end{tabular}


Table B.45: Relative uncertainty (relative standard deviation) and correlation (normalized to 1000) for ${ }^{91} \mathrm{Zr}\left(\mathrm{n}, \mathrm{n}^{\prime}\right)$

$\begin{array}{crrrrr}\text { group } & \text { rel.s.d. } & ---------------- \\ 1 & 7.1601 \mathrm{E}-02 & 1000 & 783 & 909 & 0 \\ 2 & 1.9747 \mathrm{E}-01 & 783 & 1000 & 732 & 0 \\ 3 & 5.1818 \mathrm{E}-02 & 909 & 732 & 1000 & 335 \\ 4 & 5.0000 \mathrm{E}-01 & 0 & 0 & 335 & 1000\end{array}$

Table B.46: Relative uncertainty (relative standard deviation) and correlation (normalized to 1000) for ${ }^{91} \operatorname{Zr}(\mathrm{n}, 2 \mathrm{n})$

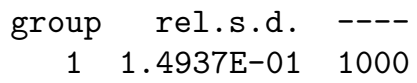


Table B.47: Relative uncertainty (relative standard deviation) and correlation (normalized to 1000) for ${ }^{91} \operatorname{Zr}(\mathrm{n}, \gamma)$

\begin{tabular}{|c|c|c|c|c|c|c|c|c|c|c|c|c|c|c|c|c|}
\hline & & & & & & & & & & & & & & & & \\
\hline 1 & $6.6620 \mathrm{E}-01$ & 1000 & 527 & 526 & 484 & 481 & 481 & 0 & 0 & 0 & 0 & 0 & 0 & 0 & 0 & 0 \\
\hline 2 & $4.5685 \mathrm{E}-01$ & 527 & 1000 & 841 & 694 & 603 & 681 & 0 & 0 & 0 & 0 & 0 & 0 & 0 & 0 & 0 \\
\hline 3 & $2.2891 \mathrm{E}-01$ & 526 & 841 & 1000 & 973 & 935 & 873 & 0 & 0 & 0 & 0 & 0 & 0 & 0 & 0 & 0 \\
\hline 4 & $1.6826 \mathrm{E}-01$ & 484 & 694 & 973 & 1000 & 988 & 871 & 0 & 0 & 0 & 0 & 0 & 0 & 0 & 0 & 0 \\
\hline 5 & 1. 3033E-01 & 481 & 603 & 935 & 988 & 1000 & 861 & 0 & 0 & 0 & 0 & 0 & 0 & 0 & 0 & \\
\hline 6 & $8.9648 \mathrm{E}-02$ & 481 & 681 & 873 & 871 & 861 & 1000 & 463 & 378 & 0 & 0 & 0 & 0 & 0 & 0 & \\
\hline 7 & 1. $2212 \mathrm{E}-01$ & 0 & 0 & 0 & 0 & 0 & 463 & 1000 & 816 & 0 & 0 & 0 & 0 & 0 & 0 & \\
\hline 8 & $3.4218 \mathrm{E}-02$ & 0 & 0 & 0 & 0 & 0 & 378 & 816 & 1000 & 18 & 0 & 0 & 1 & 1 & 1 & \\
\hline 9 & $2.6629 \mathrm{E}-02$ & 0 & 0 & 0 & 0 & 0 & 0 & 0 & 18 & 1000 & 2 & 0 & 10 & 10 & 10 & 10 \\
\hline 10 & $5.6153 \mathrm{E}-02$ & 0 & 0 & 0 & 0 & 0 & 0 & 0 & 0 & 2 & 1000 & 2 & 44 & 42 & 42 & 42 \\
\hline 11 & $5.5842 \mathrm{E}-02$ & 0 & 0 & 0 & 0 & 0 & 0 & 0 & 0 & 0 & 2 & 1000 & 146 & 132 & 129 & 129 \\
\hline 12 & $1.0200 \mathrm{E}-01$ & 0 & 0 & 0 & 0 & 0 & 0 & 0 & 1 & 10 & 44 & 146 & 1000 & 1000 & 1000 & 1000 \\
\hline 13 & $1.0424 \mathrm{E}-01$ & 0 & 0 & 0 & 0 & 0 & 0 & 0 & 1 & 10 & 42 & 132 & 1000 & 1000 & 1000 & 1000 \\
\hline 14 & $1.0464 \mathrm{E}-01$ & 0 & 0 & 0 & 0 & 0 & 0 & 0 & 1 & 10 & 42 & 129 & 1000 & 1000 & 1000 & 1000 \\
\hline 15 & $1.0469 \mathrm{E}-01$ & 0 & 0 & 0 & 0 & 0 & 0 & 0 & 1 & 10 & 42 & 129 & 1000 & 1000 & 1000 & 1000 \\
\hline
\end{tabular}

Table B.48: Relative uncertainty (relative standard deviation) and correlation (normalized to 1000) for ${ }^{92} \mathrm{Zr}(\mathrm{n}, \mathrm{el})$

\begin{tabular}{|c|c|c|c|c|c|c|c|c|c|c|c|c|c|c|c|c|}
\hline 1 & $8.4469 \mathrm{E}-03$ & 1000 & 177 & -163 & -94 & -56 & -64 & 0 & 0 & 0 & 0 & 0 & 0 & 0 & 0 & 0 \\
\hline 2 & $1.0650 \mathrm{E}-02$ & 177 & 1000 & -159 & -127 & -108 & -95 & 0 & 0 & 0 & 0 & 0 & 0 & 0 & 0 & \\
\hline 3 & $4.0974 \mathrm{E}-02$ & -163 & -159 & 1000 & 991 & 979 & 784 & 0 & 0 & 0 & 0 & 0 & 0 & 0 & 0 & \\
\hline 4 & $2.4110 \mathrm{E}-02$ & -94 & -127 & 991 & 1000 & 997 & 794 & 0 & 0 & 0 & 0 & 0 & 0 & 0 & 0 & \\
\hline 5 & $2.1634 \mathrm{E}-02$ & -56 & -108 & 979 & 997 & 1000 & 793 & 0 & 0 & 0 & 0 & 0 & 0 & 0 & 0 & \\
\hline 6 & $2.0122 \mathrm{E}-02$ & -64 & -95 & 784 & 794 & 793 & 1000 & 59 & 58 & 52 & 58 & 58 & 58 & 58 & 58 & 58 \\
\hline 7 & $3.0220 \mathrm{E}-02$ & 0 & 0 & 0 & 0 & 0 & 59 & 1000 & 911 & 827 & 915 & 913 & 913 & 912 & 912 & 912 \\
\hline 8 & $3.6488 \mathrm{E}-02$ & 0 & 0 & 0 & 0 & 0 & 58 & 911 & 1000 & 880 & 967 & 965 & 965 & 964 & 964 & 964 \\
\hline 9 & $1.9428 \mathrm{E}-02$ & 0 & 0 & 0 & 0 & 0 & 52 & 827 & 880 & 1000 & 867 & 867 & 867 & 867 & 867 & 866 \\
\hline 10 & $5.4372 \mathrm{E}-02$ & 0 & 0 & 0 & 0 & 0 & 58 & 915 & 967 & 867 & 1000 & 1000 & 1000 & 1000 & 1000 & 999 \\
\hline 11 & $5.3846 \mathrm{E}-02$ & 0 & 0 & 0 & 0 & 0 & 58 & 913 & 965 & 867 & 1000 & 1000 & 1000 & 1000 & 1000 & 999 \\
\hline 12 & $5.3737 \mathrm{E}-02$ & 0 & 0 & 0 & 0 & 0 & 58 & 913 & 965 & 867 & 1000 & 1000 & 1000 & 1000 & 1000 & 999 \\
\hline 13 & $5.3669 \mathrm{E}-02$ & 0 & 0 & 0 & 0 & 0 & 58 & 912 & 964 & 867 & 1000 & 1000 & 1000 & 1000 & 1000 & 999 \\
\hline 14 & $5.3657 \mathrm{E}-02$ & 0 & 0 & 0 & 0 & 0 & 58 & 912 & 964 & 867 & 1000 & 1000 & 1000 & 1000 & 1000 & 999 \\
\hline 15 & $5.2909 \mathrm{E}-02$ & 0 & 0 & 0 & 0 & 0 & 58 & 912 & 964 & 866 & 999 & 999 & 999 & 999 & 999 & 1000 \\
\hline
\end{tabular}

Table B.49: Relative uncertainty (relative standard deviation) and correlation (normalized to 1000) for ${ }^{92} \operatorname{Zr}\left(\mathrm{n}, \mathrm{n}^{\prime}\right)$

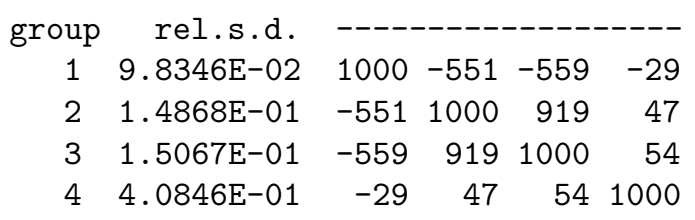


Table B.50: Relative uncertainty (relative standard deviation) and correlation (normalized to 1000) for ${ }^{92} \mathrm{Zr}(\mathrm{n}, 2 \mathrm{n})$

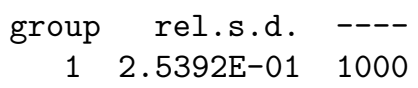

Table B.51: Relative uncertainty (relative standard deviation) and correlation (normalized to 1000) for ${ }^{92} \operatorname{Zr}(\mathrm{n}, \gamma)$

\begin{tabular}{|c|c|c|c|c|c|c|c|c|c|c|c|c|c|c|c|c|}
\hline 1 & $5.2994 \mathrm{E}-01$ & 1000 & 728 & 684 & 682 & 627 & 556 & 0 & 0 & 0 & 0 & 0 & 0 & 0 & 0 & 0 \\
\hline 2 & $4.0323 E-01$ & 728 & 1000 & 987 & 980 & 886 & 787 & 0 & 0 & 0 & 0 & 0 & 0 & 0 & 0 & 0 \\
\hline 3 & $2.1532 \mathrm{E}-01$ & 684 & 987 & 1000 & 999 & 943 & 827 & 0 & 0 & 0 & 0 & 0 & 0 & 0 & 0 & 0 \\
\hline 4 & $1.1310 \mathrm{E}-01$ & 682 & 980 & 999 & 1000 & 958 & 837 & 0 & 0 & 0 & 0 & 0 & 0 & 0 & 0 & 0 \\
\hline 5 & $7.5513 \mathrm{E}-02$ & 627 & 886 & 943 & 958 & 1000 & 855 & 0 & 0 & 0 & 0 & 0 & 0 & 0 & 0 & 0 \\
\hline 6 & $5.1549 \mathrm{E}-02$ & 556 & 787 & 827 & 837 & 855 & 1000 & 0 & 0 & 0 & 0 & 0 & 0 & 0 & 0 & 0 \\
\hline 7 & $3.4165 \mathrm{E}-02$ & 0 & 0 & 0 & 0 & 0 & 0 & 1000 & -2 & 0 & 1 & 5 & 4 & 4 & 4 & 4 \\
\hline 8 & $3.1066 \mathrm{E}-02$ & 0 & 0 & 0 & 0 & 0 & 0 & -2 & 1000 & 4 & 0 & 3 & 2 & 2 & 2 & 2 \\
\hline 9 & $4.1304 \mathrm{E}-02$ & 0 & 0 & 0 & 0 & 0 & 0 & 0 & 4 & 1000 & 23 & 70 & 52 & 52 & 51 & 51 \\
\hline 10 & $4.9555 \mathrm{E}-02$ & 0 & 0 & 0 & 0 & 0 & 0 & 1 & 0 & 23 & 1000 & 55 & 54 & 54 & 54 & 54 \\
\hline 11 & $2.7610 \mathrm{E}-01$ & 0 & 0 & 0 & 0 & 0 & 0 & 5 & 3 & 70 & 55 & 1000 & 1000 & 1000 & 1000 & 1000 \\
\hline 12 & $3.0749 \mathrm{E}-01$ & 0 & 0 & 0 & 0 & 0 & 0 & 4 & 2 & 52 & 54 & 1000 & 1000 & 1000 & 1000 & 1000 \\
\hline 13 & $3.0925 \mathrm{E}-01$ & 0 & 0 & 0 & 0 & 0 & 0 & 4 & 2 & 52 & 54 & 1000 & 1000 & 1000 & 1000 & 1000 \\
\hline 14 & $3.0958 \mathrm{E}-01$ & 0 & 0 & 0 & 0 & 0 & 0 & 4 & 2 & 51 & 54 & 1000 & 1000 & 1000 & 1000 & 1000 \\
\hline 15 & $3.0962 \mathrm{E}-01$ & 0 & 0 & 0 & 0 & 0 & 0 & 4 & 2 & 51 & 54 & 1000 & 1000 & 1000 & 1000 & 1000 \\
\hline
\end{tabular}


Table B.52: Relative uncertainty (relative standard deviation) and correlation (normalized to 1000) for ${ }^{94} \mathrm{Zr}(\mathrm{n}, \mathrm{el})$

\begin{tabular}{|c|c|c|c|c|c|c|c|c|c|c|c|c|c|c|c|c|}
\hline & & & & & & & & & & & & & & & & \\
\hline 1 & $7.9147 \mathrm{E}-03$ & 1000 & 881 & -250 & 234 & 652 & 368 & 0 & 0 & 0 & 0 & 0 & 0 & 0 & 0 & 0 \\
\hline 2 & $3.7286 \mathrm{E}-03$ & 881 & 1000 & 205 & 642 & 920 & 565 & 0 & 0 & 0 & 0 & 0 & 0 & 0 & 0 & 0 \\
\hline 3 & $2.6317 \mathrm{E}-02$ & -250 & 205 & 1000 & 880 & 559 & 414 & 0 & 0 & 0 & 0 & 0 & 0 & 0 & 0 & \\
\hline 4 & 1. 1043E-02 & 234 & 642 & 880 & 1000 & 886 & 599 & 0 & 0 & 0 & 0 & 0 & 0 & 0 & 0 & \\
\hline 5 & $1.0811 \mathrm{E}-02$ & 652 & 920 & 559 & 886 & 1000 & 641 & 0 & 0 & 0 & 0 & 0 & 0 & 0 & 0 & \\
\hline 6 & $1.0484 \mathrm{E}-02$ & 368 & 565 & 414 & 599 & 641 & 1000 & 416 & 392 & 496 & 510 & 511 & 512 & 512 & 512 & 512 \\
\hline 7 & $2.6312 \mathrm{E}-02$ & 0 & 0 & 0 & 0 & 0 & 416 & 1000 & 760 & 924 & 941 & 941 & 941 & 941 & 941 & 941 \\
\hline 8 & $3.0231 \mathrm{E}-02$ & 0 & 0 & 0 & 0 & 0 & 392 & 760 & 1000 & 727 & 753 & 755 & 755 & 755 & 755 & 755 \\
\hline 9 & $2.9003 E-02$ & 0 & 0 & 0 & 0 & 0 & 496 & 924 & 727 & 1000 & 979 & 980 & 980 & 980 & 980 & 980 \\
\hline 10 & $4.9857 \mathrm{E}-02$ & 0 & 0 & 0 & 0 & 0 & 510 & 941 & 753 & 979 & 1000 & 1000 & 1000 & 1000 & 1000 & 1000 \\
\hline 11 & $4.7830 \mathrm{E}-02$ & 0 & 0 & 0 & 0 & 0 & 511 & 941 & 755 & 980 & 1000 & 1000 & 1000 & 1000 & 1000 & 1000 \\
\hline 12 & $4.7337 \mathrm{E}-02$ & 0 & 0 & 0 & 0 & 0 & 512 & 941 & 755 & 980 & 1000 & 1000 & 1000 & 1000 & 1000 & 1000 \\
\hline 13 & $4.7312 \mathrm{E}-02$ & 0 & 0 & 0 & 0 & 0 & 512 & 941 & 755 & 980 & 1000 & 1000 & 1000 & 1000 & 1000 & 1000 \\
\hline 14 & $4.7307 \mathrm{E}-02$ & 0 & 0 & 0 & 0 & 0 & 512 & 941 & 755 & 980 & 1000 & 1000 & 1000 & 1000 & 1000 & 1000 \\
\hline 15 & $4.7305 \mathrm{E}-02$ & 0 & 0 & 0 & 0 & 0 & 512 & 941 & 755 & 980 & 1000 & 1000 & 1000 & 1000 & 1000 & 1000 \\
\hline
\end{tabular}

Table B.53: Relative uncertainty (relative standard deviation) and correlation (normalized to 1000) for ${ }^{94} \operatorname{Zr}\left(\mathrm{n}, \mathrm{n}^{\prime}\right)$

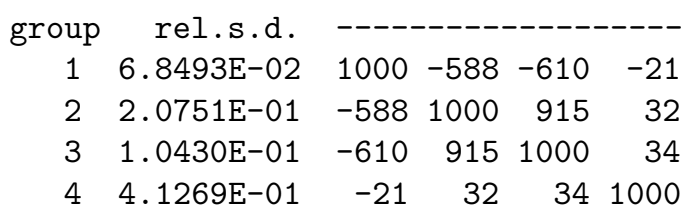

Table B.54: Relative uncertainty (relative standard deviation) and correlation (normalized to 1000) for ${ }^{94} \mathrm{Zr}(\mathrm{n}, 2 \mathrm{n})$

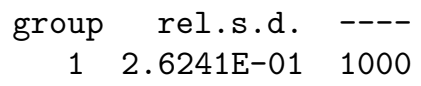


Table B.55: Relative uncertainty (relative standard deviation) and correlation (normalized to 1000) for ${ }^{94} \operatorname{Zr}(\mathrm{n}, \gamma)$

\begin{tabular}{|c|c|c|c|c|c|c|c|c|c|c|c|c|c|c|c|c|}
\hline 1 & $6.3780 \mathrm{E}-01$ & 1000 & 510 & 408 & 410 & 374 & 370 & 0 & 0 & 0 & 0 & 0 & 0 & 0 & 0 & 0 \\
\hline 2 & $4.3099 \mathrm{E}-01$ & 510 & 1000 & 967 & 965 & 876 & 863 & 0 & 0 & 0 & 0 & 0 & 0 & 0 & 0 & 0 \\
\hline 3 & $2.5760 \mathrm{E}-01$ & 408 & 967 & 1000 & 1000 & 961 & 943 & 0 & 0 & 0 & 0 & 0 & 0 & 0 & 0 & 0 \\
\hline 4 & 1. $4216 \mathrm{E}-01$ & 410 & 965 & 1000 & 1000 & 964 & 946 & 0 & 0 & 0 & 0 & 0 & 0 & 0 & 0 & 0 \\
\hline 5 & $1.0107 \mathrm{E}-01$ & 374 & 876 & 961 & 964 & 1000 & 978 & 0 & 0 & 0 & 0 & 0 & 0 & 0 & 0 & 0 \\
\hline 6 & $6.7134 \mathrm{E}-02$ & 370 & 863 & 943 & 946 & 978 & 1000 & 2 & 0 & 0 & 3 & 18 & 17 & 17 & 17 & 17 \\
\hline 7 & $4.6161 \mathrm{E}-02$ & 0 & 0 & 0 & 0 & 0 & 2 & 1000 & -3 & 0 & 17 & 96 & 90 & 90 & 90 & 90 \\
\hline 8 & $3.3109 \mathrm{E}-02$ & 0 & 0 & 0 & 0 & 0 & 0 & -3 & 1000 & 0 & 27 & 141 & 130 & 129 & 129 & 129 \\
\hline 9 & $5.5444 \mathrm{E}-02$ & 0 & 0 & 0 & 0 & 0 & 0 & 0 & 0 & 1000 & 122 & 231 & 196 & 195 & 194 & 194 \\
\hline 10 & 1. $4242 \mathrm{E}-01$ & 0 & 0 & 0 & 0 & 0 & 3 & 17 & 27 & 122 & 1000 & 186 & 171 & 170 & 170 & 170 \\
\hline 11 & $3.4990 \mathrm{E}-02$ & 0 & 0 & 0 & 0 & 0 & 18 & 96 & 141 & 231 & 186 & 1000 & 998 & 998 & 998 & 998 \\
\hline 12 & $3.5139 \mathrm{E}-02$ & 0 & 0 & 0 & 0 & 0 & 17 & 90 & 130 & 196 & 171 & 998 & 1000 & 1000 & 1000 & 1000 \\
\hline 13 & $3.5145 E-02$ & 0 & 0 & 0 & 0 & 0 & 17 & 90 & 129 & 195 & 170 & 998 & 1000 & 1000 & 1000 & 1000 \\
\hline 14 & $3.5148 \mathrm{E}-02$ & 0 & 0 & 0 & 0 & 0 & 17 & 90 & 129 & 194 & 170 & 998 & 1000 & 1000 & 1000 & 1000 \\
\hline 15 & $3.5148 \mathrm{E}-02$ & 0 & 0 & 0 & 0 & 0 & 17 & 90 & 129 & 194 & 170 & 998 & 1000 & 1000 & 1000 & 1000 \\
\hline
\end{tabular}

Table B.56: Relative uncertainty (relative standard deviation) and correlation (normalized to 1000) for ${ }^{155} \mathrm{Gd}(\mathrm{n}, \mathrm{el})$

\begin{tabular}{|c|c|c|c|c|c|c|c|c|c|c|c|c|c|c|c|c|}
\hline 1 & 1.8949E-02 & 1000 & -552 & 823 & 913 & 761 & 440 & 177 & 188 & 206 & 214 & 179 & 0 & 0 & 0 & 0 \\
\hline 2 & $3.5794 \mathrm{E}-02$ & -552 & 1000 & -136 & -775 & -861 & -317 & 263 & 317 & 304 & 283 & 229 & 0 & 0 & 0 & 0 \\
\hline 3 & $3.7113 \mathrm{E}-02$ & 823 & -136 & 1000 & 729 & 479 & 396 & 412 & 464 & 481 & 480 & 397 & 0 & 0 & 0 & 0 \\
\hline 4 & $5.9260 \mathrm{E}-02$ & 913 & -775 & 729 & 1000 & 915 & 513 & 121 & 113 & 133 & 147 & 126 & 0 & 0 & 0 & 0 \\
\hline 5 & $4.4883 E-02$ & 761 & -861 & 479 & 915 & 1000 & 713 & 238 & 193 & 208 & 228 & 197 & 0 & 0 & 0 & \\
\hline 6 & $2.6606 \mathrm{E}-02$ & 440 & -317 & 396 & 513 & 713 & 1000 & 826 & 781 & 786 & 801 & 675 & 0 & 0 & 0 & \\
\hline 7 & $3.1003 E-02$ & 177 & 263 & 412 & 121 & 238 & 826 & 1000 & 995 & 994 & 996 & 833 & 0 & 0 & 0 & \\
\hline 8 & $3.9527 \mathrm{E}-02$ & 188 & 317 & 464 & 113 & 193 & 781 & 995 & 1000 & 1000 & 999 & 835 & 0 & 0 & 0 & \\
\hline 9 & $4.6530 \mathrm{E}-02$ & 206 & 304 & 481 & 133 & 208 & 786 & 994 & 1000 & 1000 & 1000 & 835 & 0 & 0 & 0 & \\
\hline 10 & $5.3490 \mathrm{E}-02$ & 214 & 283 & 480 & 147 & 228 & 801 & 996 & 999 & 1000 & 1000 & 836 & 0 & 0 & 0 & 0 \\
\hline 11 & $3.9706 \mathrm{E}-02$ & 179 & 229 & 397 & 126 & 197 & 675 & 833 & 835 & 835 & 836 & 1000 & 76 & -11 & -124 & -163 \\
\hline 12 & $2.0192 \mathrm{E}-01$ & 0 & 0 & 0 & 0 & 0 & 0 & 0 & 0 & 0 & 0 & 76 & 1000 & -51 & -267 & -255 \\
\hline 13 & $1.4064 \mathrm{E}-01$ & 0 & 0 & 0 & 0 & 0 & 0 & 0 & 0 & 0 & 0 & -11 & -51 & 1000 & -396 & -297 \\
\hline 14 & $2.2869 \mathrm{E}-02$ & 0 & 0 & 0 & 0 & 0 & 0 & 0 & 0 & 0 & 0 & -124 & -267 & -396 & 1000 & 415 \\
\hline 15 & $7.2057 \mathrm{E}-03$ & 0 & 0 & 0 & 0 & 0 & 0 & 0 & 0 & 0 & 0 & -163 & -255 & -297 & 415 & 1000 \\
\hline
\end{tabular}


Table B.57: Relative uncertainty (relative standard deviation) and correlation (normalized to 1000$)$ for ${ }^{155} \mathrm{Gd}\left(\mathrm{n}, \mathrm{n}^{\prime}\right)$

$\begin{array}{crrrrrrr}\text { group } & \text { rel.s.d. } & ----1-100 & 844 & 474 & 428 & 406 & 294 \\ 1 & 2.1397 \mathrm{E}-01 & 1000 & 84 & \\ 2 & 1.1682 \mathrm{E}-01 & 844 & 1000 & 840 & 775 & 768 & 560 \\ 3 & 1.4204 \mathrm{E}-01 & 474 & 840 & 1000 & 977 & 889 & 784 \\ 4 & 1.6372 \mathrm{E}-01 & 428 & 775 & 977 & 1000 & 910 & 887 \\ 5 & 2.4813 \mathrm{E}-01 & 406 & 768 & 889 & 910 & 1000 & 887 \\ 6 & 3.5739 \mathrm{E}-01 & 294 & 560 & 784 & 887 & 887 & 1000\end{array}$

Table B.58: Relative uncertainty (relative standard deviation) and correlation (normalized to 1000$)$ for ${ }^{155} \mathrm{Gd}(\mathrm{n}, 2 \mathrm{n})$

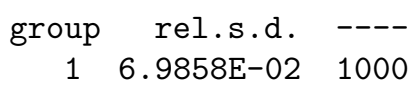

Table B.59: Relative uncertainty (relative standard deviation) and correlation (normalized to 1000) for ${ }^{155} \mathrm{Gd}(\mathrm{n}, \gamma)$

\begin{tabular}{|c|c|c|c|c|c|c|c|c|c|c|c|c|c|c|c|c|}
\hline & & & & & & & & & & & & & & & & \\
\hline 1 & $6.9293 \mathrm{E}-01$ & 1000 & 351 & 346 & 243 & 179 & 93 & 84 & 97 & 84 & 63 & 50 & 0 & 0 & 0 & 0 \\
\hline 2 & $3.8939 \mathrm{E}-01$ & 351 & 1000 & 942 & 524 & 334 & 202 & 180 & 188 & 161 & 126 & 105 & 0 & 0 & 0 & \\
\hline 3 & $1.9609 \mathrm{E}-01$ & 346 & 942 & 1000 & 773 & 604 & 368 & 316 & 326 & 276 & 212 & 174 & 0 & 0 & 0 & \\
\hline 4 & 1. 1043E-01 & 243 & 524 & 773 & 1000 & 956 & 676 & 606 & 576 & 494 & 402 & 341 & 0 & 0 & 0 & \\
\hline 5 & 7.3997E-02 & 179 & 334 & 604 & 956 & 1000 & 834 & 675 & 556 & 457 & 368 & 313 & 0 & 0 & 0 & \\
\hline 6 & $4.0313 \mathrm{E}-02$ & 93 & 202 & 368 & 676 & 834 & 1000 & 725 & 434 & 326 & 274 & 241 & 0 & 0 & 0 & \\
\hline 7 & 3.9933E-02 & 84 & 180 & 316 & 606 & 675 & 725 & 1000 & 921 & 877 & 859 & 789 & 0 & 0 & 0 & \\
\hline 8 & $6.0197 \mathrm{E}-02$ & 97 & 188 & 326 & 576 & 556 & 434 & 921 & 1000 & 993 & 977 & 896 & 0 & 0 & 0 & \\
\hline 9 & $7.3531 \mathrm{E}-02$ & 84 & 161 & 276 & 494 & 457 & 326 & 877 & 993 & 1000 & 994 & 914 & 0 & 0 & 0 & \\
\hline 10 & $8.2123 \mathrm{E}-02$ & 63 & 126 & 212 & 402 & 368 & 274 & 859 & 977 & 994 & 1000 & 923 & 0 & 0 & 0 & \\
\hline 11 & $4.5092 \mathrm{E}-02$ & 50 & 105 & 174 & 341 & 313 & 241 & 789 & 896 & 914 & 923 & 1000 & 215 & 87 & 122 & 124 \\
\hline 12 & $4.8302 \mathrm{E}-02$ & 0 & 0 & 0 & 0 & 0 & 0 & 0 & 0 & 0 & 0 & 215 & 1000 & 101 & 216 & 219 \\
\hline 13 & $6.4045 \mathrm{E}-02$ & 0 & 0 & 0 & 0 & 0 & 0 & 0 & 0 & 0 & 0 & 87 & 101 & 1000 & 111 & 109 \\
\hline 14 & $4.0659 \mathrm{E}-02$ & 0 & 0 & 0 & 0 & 0 & 0 & 0 & 0 & 0 & 0 & 122 & 216 & 111 & 1000 & 604 \\
\hline 15 & $5.8790 \mathrm{E}-03$ & 0 & 0 & 0 & 0 & 0 & 0 & 0 & 0 & 0 & 0 & 124 & 219 & 109 & 604 & 1000 \\
\hline
\end{tabular}


Table B.60: Relative uncertainty (relative standard deviation) and correlation (normalized to 1000) for ${ }^{156} \mathrm{Gd}(\mathrm{n}, \mathrm{el})$

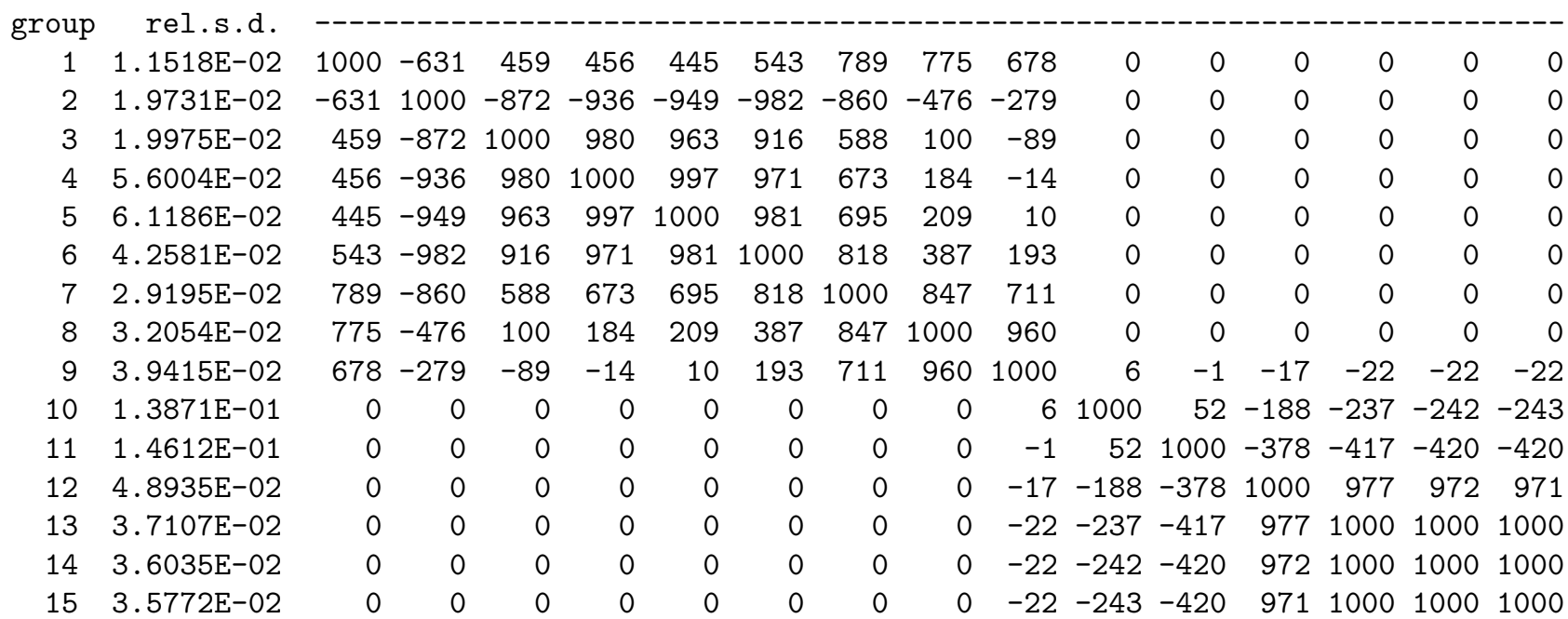

Table B.61: Relative uncertainty (relative standard deviation) and correlation (normalized to 1000$)$ for ${ }^{156} \mathrm{Gd}\left(\mathrm{n}, \mathrm{n}^{\prime}\right)$

$\begin{array}{crrrrrrr}\text { group } & \text { rel.s.d. } & -----1 & ---1 & \\ 1 & 1.9267 \mathrm{E}-01 & 1000 & 627 & -382 & -407 & 818 & 854 \\ 2 & 7.3738 \mathrm{E}-02 & 627 & 1000 & 426 & 384 & 675 & 481 \\ 3 & 8.5051 \mathrm{E}-02 & -382 & 426 & 1000 & 942 & -65 & -277 \\ 4 & 1.2635 \mathrm{E}-01 & -407 & 384 & 942 & 1000 & 43 & -216 \\ 5 & 2.2892 \mathrm{E}-01 & 818 & 675 & -65 & 43 & 1000 & 933 \\ 6 & 3.1240 \mathrm{E}-01 & 854 & 481 & -277 & -216 & 933 & 1000\end{array}$

Table B.62: Relative uncertainty (relative standard deviation) and correlation (normalized to 1000) for ${ }^{156} \mathrm{Gd}(\mathrm{n}, 2 \mathrm{n})$

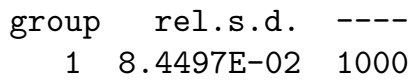


Table B.63: Relative uncertainty (relative standard deviation) and correlation (normalized to 1000) for ${ }^{156} \mathrm{Gd}(\mathrm{n}, \gamma)$

\begin{tabular}{|c|c|c|c|c|c|c|c|c|c|c|c|c|c|c|c|c|}
\hline 1 & $5.9279 \mathrm{E}-01$ & 1000 & 246 & 82 & -51 & 26 & 86 & 20 & 15 & 122 & 0 & 0 & 0 & 0 & 0 & 0 \\
\hline 2 & $1.8813 \mathrm{E}-01$ & 246 & 1000 & 643 & -24 & 403 & 197 & 140 & 327 & 567 & 0 & 0 & 0 & 0 & 0 & \\
\hline 3 & $9.1730 \mathrm{E}-02$ & 82 & 643 & 1000 & 333 & 874 & 466 & 272 & 508 & 803 & 0 & 0 & 0 & 0 & 0 & \\
\hline 4 & $6.4751 \mathrm{E}-02$ & -51 & -24 & 333 & 1000 & 705 & 614 & 198 & -18 & -113 & 0 & 0 & 0 & 0 & 0 & \\
\hline 5 & $5.4368 \mathrm{E}-02$ & 26 & 403 & 874 & 705 & 1000 & 740 & 469 & 507 & 584 & 0 & 0 & 0 & 0 & 0 & \\
\hline 6 & $3.4844 \mathrm{E}-02$ & 86 & 197 & 466 & 614 & 740 & 1000 & 711 & 475 & 424 & 0 & 0 & 0 & 0 & 0 & \\
\hline 7 & $3.7041 \mathrm{E}-02$ & 20 & 140 & 272 & 198 & 469 & 711 & 1000 & 885 & 404 & 0 & 0 & 0 & 0 & 0 & \\
\hline 8 & $4.9178 \mathrm{E}-02$ & 15 & 327 & 508 & -18 & 507 & 475 & 885 & 1000 & 636 & 0 & 0 & 0 & 0 & 0 & \\
\hline 9 & $6.9698 \mathrm{E}-02$ & 122 & 567 & 803 & -113 & 584 & 424 & 404 & 636 & 1000 & 29 & 42 & 30 & 38 & 38 & 9 \\
\hline 10 & $6.2960 \mathrm{E}-01$ & 0 & 0 & 0 & 0 & 0 & 0 & 0 & 0 & 29 & 1000 & 231 & 176 & 238 & 246 & 247 \\
\hline 11 & $2.2602 \mathrm{E}-01$ & 0 & 0 & 0 & 0 & 0 & 0 & 0 & 0 & 42 & 231 & 1000 & 417 & 615 & 637 & 640 \\
\hline 12 & $4.8836 \mathrm{E}-01$ & 0 & 0 & 0 & 0 & 0 & 0 & 0 & 0 & 30 & 176 & 417 & 1000 & 957 & 946 & 945 \\
\hline 13 & $4.1958 \mathrm{E}-01$ & 0 & 0 & 0 & 0 & 0 & 0 & 0 & 0 & 38 & 238 & 615 & 957 & 1000 & 999 & 999 \\
\hline 14 & $4.1455 \mathrm{E}-01$ & 0 & 0 & 0 & 0 & 0 & 0 & 0 & 0 & 38 & 246 & 637 & 946 & 999 & 1000 & 1000 \\
\hline 15 & $4.1394 \mathrm{E}-01$ & 0 & 0 & 0 & 0 & 0 & 0 & 0 & 0 & 39 & 247 & 640 & 945 & 999 & 1000 & 1000 \\
\hline
\end{tabular}

Table B.64: Relative uncertainty (relative standard deviation) and correlation (normalized to 1000) for ${ }^{157} \mathrm{Gd}(\mathrm{n}, \mathrm{el})$

$\begin{array}{rr}\text { group } & \text { rel.s.d. } \\ 1 & 2.2013 \mathrm{E}-02 \\ 2 & 3.5479 \mathrm{E}-02 \\ 3 & 3.7286 \mathrm{E}-02 \\ 4 & 6.1210 \mathrm{E}-02 \\ 5 & 5.2282 \mathrm{E}-02 \\ 6 & 3.6991 \mathrm{E}-02 \\ 7 & 2.4665 \mathrm{E}-02 \\ 8 & 3.2861 \mathrm{E}-02 \\ 9 & 4.0973 \mathrm{E}-02 \\ 10 & 5.5839 \mathrm{E}-02 \\ 11 & 2.2659 \mathrm{E}-02 \\ 12 & 7.6579 \mathrm{E}-02 \\ 13 & 1.1525 \mathrm{E}-02 \\ 14 & 8.7352 \mathrm{E}-03 \\ 15 & 1.1516 \mathrm{E}-02\end{array}$

$\begin{array}{rrrrrrrrrrrrrrr}1000 & -616 & 848 & 895 & 693 & 745 & 773 & 646 & 513 & 250 & 102 & 0 & 0 & 0 & 0 \\ -616 & 1000 & -274 & -863 & -991 & -948 & -593 & -123 & -17 & 17 & 23 & 0 & 0 & 0 & 0 \\ 848 & -274 & 1000 & 721 & 376 & 498 & 776 & 868 & 735 & 372 & 162 & 0 & 0 & 0 & 0 \\ 895 & -863 & 721 & 1000 & 912 & 945 & 837 & 547 & 404 & 194 & 79 & 0 & 0 & 0 & 0 \\ 693 & -991 & 376 & 912 & 1000 & 980 & 687 & 246 & 142 & 89 & 54 & 0 & 0 & 0 & 0 \\ 745 & -948 & 498 & 945 & 980 & 1000 & 817 & 427 & 333 & 260 & 184 & 0 & 0 & 0 & 0 \\ 773 & -593 & 776 & 837 & 687 & 817 & 1000 & 863 & 813 & 681 & 499 & 0 & 0 & 0 & 0 \\ 646 & -123 & 868 & 547 & 246 & 427 & 863 & 1000 & 972 & 768 & 540 & 0 & 0 & 0 & 0 \\ 513 & -17 & 735 & 404 & 142 & 333 & 813 & 972 & 1000 & 891 & 674 & 0 & 0 & 0 & 0 \\ 250 & 17 & 372 & 194 & 89 & 260 & 681 & 768 & 891 & 1000 & 844 & 0 & 0 & 0 & 0 \\ 102 & 23 & 162 & 79 & 54 & 184 & 499 & 540 & 674 & 844 & 1000 & 48 & -52 & 22 & -74 \\ 0 & 0 & 0 & 0 & 0 & 0 & 0 & 0 & 0 & 0 & 48 & 1000 & -260 & -39 & -103 \\ 0 & 0 & 0 & 0 & 0 & 0 & 0 & 0 & 0 & 0 & -52 & -260 & 1000 & 889 & -848 \\ 0 & 0 & 0 & 0 & 0 & 0 & 0 & 0 & 0 & 0 & 22 & -39 & 889 & 1000 & -911 \\ 0 & 0 & 0 & 0 & 0 & 0 & 0 & 0 & 0 & 0 & -74 & -103 & -848 & -911 & 1000\end{array}$


Table B.65: Relative uncertainty (relative standard deviation) and correlation (normalized to 1000) for ${ }^{157} \mathrm{Gd}\left(\mathrm{n}, \mathrm{n}^{\prime}\right)$

\begin{tabular}{|c|c|c|c|c|c|c|c|c|}
\hline & & & & & & & & \\
\hline 1 & 1. $2519 \mathrm{E}-01$ & 1000 & 954 & 888 & 841 & 887 & 862 & 0 \\
\hline 2 & $1.0263 \mathrm{E}-01$ & 954 & 1000 & 972 & 945 & 973 & 953 & 0 \\
\hline 3 & 1. $6275 \mathrm{E}-01$ & 888 & 972 & 1000 & 994 & 985 & 975 & 0 \\
\hline 4 & $2.2817 \mathrm{E}-01$ & 841 & 945 & 994 & 1000 & 978 & 975 & 0 \\
\hline 5 & $2.8527 \mathrm{E}-01$ & 887 & 973 & 985 & 978 & 1000 & 995 & 0 \\
\hline 6 & $3.0009 \mathrm{E}-01$ & 862 & 953 & 975 & 975 & 995 & 1000 & 16 \\
\hline 7 & $2.1247 \mathrm{E}-01$ & 0 & 0 & 0 & 0 & 0 & 16 & 1000 \\
\hline
\end{tabular}

Table B.66: Relative uncertainty (relative standard deviation) and correlation (normalized to 1000) for ${ }^{157} \mathrm{Gd}(\mathrm{n}, 2 \mathrm{n})$

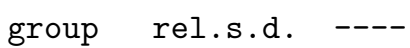

Table B.67: Relative uncertainty (relative standard deviation) and correlation (normalized to 1000) for ${ }^{157} \mathrm{Gd}(\mathrm{n}, \gamma)$

\begin{tabular}{|c|c|c|c|c|c|c|c|c|c|c|c|c|c|c|c|c|}
\hline & & & & & & & & & & & & & & & & \\
\hline 1 & $6.9267 \mathrm{E}-01$ & 1000 & 248 & 146 & 114 & 102 & 81 & 61 & 110 & 126 & 120 & 107 & 0 & 0 & 0 & 0 \\
\hline 2 & 1. $6182 \mathrm{E}-01$ & 248 & 1000 & 900 & 520 & 434 & 359 & 247 & 424 & 453 & 432 & 386 & 0 & 0 & 0 & 0 \\
\hline 3 & $8.6661 \mathrm{E}-02$ & 146 & 900 & 1000 & 829 & 761 & 657 & 485 & 748 & 748 & 698 & 620 & 0 & 0 & 0 & 0 \\
\hline 4 & $6.1284 \mathrm{E}-02$ & 114 & 520 & 829 & 1000 & 985 & 898 & 694 & 953 & 861 & 779 & 688 & 0 & 0 & 0 & 0 \\
\hline 5 & $5.2001 \mathrm{E}-02$ & 102 & 434 & 761 & 985 & 1000 & 956 & 795 & 977 & 800 & 692 & 604 & 0 & 0 & 0 & \\
\hline 6 & $3.9712 \mathrm{E}-02$ & 81 & 359 & 657 & 898 & 956 & 1000 & 922 & 938 & 599 & 455 & 382 & 0 & 0 & 0 & \\
\hline 7 & $3.1151 \mathrm{E}-02$ & 61 & 247 & 485 & 694 & 795 & 922 & 1000 & 836 & 376 & 197 & 137 & 0 & 0 & 0 & \\
\hline 8 & $3.1137 \mathrm{E}-02$ & 110 & 424 & 748 & 953 & 977 & 938 & 836 & 1000 & 819 & 699 & 605 & 0 & 0 & 0 & \\
\hline 9 & $5.2698 \mathrm{E}-02$ & 126 & 453 & 748 & 861 & 800 & 599 & 376 & 819 & 1000 & 982 & 882 & 0 & 0 & 0 & \\
\hline 10 & $6.1777 \mathrm{E}-02$ & 120 & 432 & 698 & 779 & 692 & 455 & 197 & 699 & 982 & 1000 & 906 & 0 & 0 & 0 & 0 \\
\hline 11 & $1.4940 \mathrm{E}-02$ & 107 & 386 & 620 & 688 & 604 & 382 & 137 & 605 & 882 & 906 & 1000 & 121 & 135 & 134 & 134 \\
\hline 12 & $2.2932 \mathrm{E}-02$ & 0 & 0 & 0 & 0 & 0 & 0 & 0 & 0 & 0 & 0 & 121 & 1000 & 148 & 176 & 176 \\
\hline 13 & $2.9582 \mathrm{E}-02$ & 0 & 0 & 0 & 0 & 0 & 0 & 0 & 0 & 0 & 0 & 135 & 148 & 1000 & 601 & 603 \\
\hline 14 & $1.4931 \mathrm{E}-02$ & 0 & 0 & 0 & 0 & 0 & 0 & 0 & 0 & 0 & 0 & 134 & 176 & 601 & 1000 & 988 \\
\hline 15 & 1.9788E-03 & 0 & 0 & 0 & 0 & 0 & 0 & 0 & 0 & 0 & 0 & 134 & 176 & 603 & 988 & 1000 \\
\hline
\end{tabular}


Table B.68: Relative uncertainty (relative standard deviation) and correlation (normalized to 1000) for ${ }^{158} \mathrm{Gd}(\mathrm{n}, \mathrm{el})$

\begin{tabular}{|c|c|c|c|c|c|c|c|c|c|c|c|c|c|c|c|c|}
\hline 1 & 1.5091E-02 & 1000 & -544 & -178 & -27 & 65 & 349 & 681 & 713 & 0 & 0 & 0 & 0 & 0 & 0 & 0 \\
\hline 2 & 1. $3165 \mathrm{E}-02$ & -544 & 1000 & 59 & -424 & -586 & -870 & -924 & -754 & 0 & 0 & 0 & 0 & 0 & 0 & \\
\hline 3 & $1.5672 \mathrm{E}-02$ & -178 & 59 & 1000 & 864 & 755 & 420 & -293 & -598 & 0 & 0 & 0 & 0 & 0 & 0 & 侟 \\
\hline 4 & $3.7149 \mathrm{E}-02$ & -27 & -424 & 864 & 1000 & 982 & 805 & 158 & -211 & 0 & 0 & 0 & 0 & 0 & 0 & \\
\hline 5 & $4.1906 \mathrm{E}-02$ & 65 & -586 & 755 & 982 & 1000 & 899 & 328 & -38 & 0 & 0 & 0 & 0 & 0 & 0 & \\
\hline 6 & $2.9287 \mathrm{E}-02$ & 349 & -870 & 420 & 805 & 899 & 1000 & 708 & 402 & 0 & 0 & 0 & 0 & 0 & 0 & \\
\hline 7 & $2.9787 \mathrm{E}-02$ & 681 & -924 & -293 & 158 & 328 & 708 & 1000 & 931 & 0 & 0 & 0 & 0 & 0 & 0 & \\
\hline 8 & $3.8826 \mathrm{E}-02$ & 713 & -754 & -598 & -211 & -38 & 402 & 931 & 1000 & 0 & 0 & 0 & 0 & 0 & 0 & 0 \\
\hline 9 & $1.0181 \mathrm{E}-03$ & 0 & 0 & 0 & 0 & 0 & 0 & 0 & 0 & 1000 & 208 & 132 & 73 & 294 & 295 & 295 \\
\hline 10 & $3.3109 \mathrm{E}-03$ & 0 & 0 & 0 & 0 & 0 & 0 & 0 & 0 & 208 & 1000 & 149 & 86 & 340 & 341 & 342 \\
\hline 11 & 1. 1836E-02 & 0 & 0 & 0 & 0 & 0 & 0 & 0 & 0 & 132 & 149 & 1000 & 86 & 265 & 267 & 267 \\
\hline 12 & $4.7644 \mathrm{E}-02$ & 0 & 0 & 0 & 0 & 0 & 0 & 0 & 0 & 73 & 86 & 86 & 1000 & 130 & 141 & 142 \\
\hline 13 & $1.8599 \mathrm{E}-02$ & 0 & 0 & 0 & 0 & 0 & 0 & 0 & 0 & 294 & 340 & 265 & 130 & 1000 & 1000 & 1000 \\
\hline 14 & 1. $9051 \mathrm{E}-02$ & 0 & 0 & 0 & 0 & 0 & 0 & 0 & 0 & 295 & 341 & 267 & 141 & 1000 & 1000 & 1000 \\
\hline 15 & $1.9051 \mathrm{E}-02$ & 0 & 0 & 0 & 0 & 0 & 0 & 0 & 0 & 295 & 342 & 267 & 142 & 1000 & 1000 & 1000 \\
\hline
\end{tabular}

Table B.69: Relative uncertainty (relative standard deviation) and correlation (normalized to 1000) for ${ }^{158} \mathrm{Gd}\left(\mathrm{n}, \mathrm{n}^{\prime}\right)$

\begin{tabular}{|c|c|c|c|c|c|c|c|}
\hline & & & & & & & \\
\hline 1 & $3.5335 \mathrm{E}-01$ & 1000 & -737 & -800 & -738 & -207 & -413 \\
\hline 2 & $7.3864 \mathrm{E}-02$ & -737 & 1000 & 965 & 953 & 798 & 918 \\
\hline 3 & 1.8975E-01 & -800 & 965 & 1000 & 994 & 742 & 836 \\
\hline 4 & $2.2898 \mathrm{E}-01$ & -738 & 953 & 994 & 1000 & 791 & 855 \\
\hline 5 & $3.6884 \mathrm{E}-01$ & -207 & 798 & 742 & 791 & 1000 & 957 \\
\hline 6 & $6.0905 \mathrm{E}-01$ & -413 & 918 & 836 & 855 & 957 & 1000 \\
\hline
\end{tabular}


Table B.70: Relative uncertainty (relative standard deviation) and correlation (normalized to 1000) for ${ }^{158} \mathrm{Gd}(\mathrm{n}, 2 \mathrm{n})$

$\begin{array}{crr}\text { group } & \text { rel.s.d. } & ---- \\ 1 & 8.0655 \mathrm{E}-02 & 1000\end{array}$

Table B.71: Relative uncertainty (relative standard deviation) and correlation (normalized to 1000) for ${ }^{158} \mathrm{Gd}(\mathrm{n}, \gamma)$

\begin{tabular}{|c|c|c|c|c|c|c|c|c|c|c|c|c|c|c|c|c|}
\hline & & & & & & & & & & & & & & & & \\
\hline 1 & $5.7369 \mathrm{E}-01$ & 1000 & 634 & 175 & 138 & 167 & 150 & 161 & 127 & 0 & 0 & 0 & 0 & 0 & 0 & \\
\hline 2 & $1.8366 \mathrm{E}-01$ & 634 & 1000 & 869 & 267 & 659 & 392 & 714 & 825 & 0 & 0 & 0 & 0 & 0 & 0 & \\
\hline 3 & $1.3597 \mathrm{E}-01$ & 175 & 869 & 1000 & 282 & 757 & 433 & 830 & 979 & 0 & 0 & 0 & 0 & 0 & 0 & \\
\hline 4 & $5.3119 \mathrm{E}-02$ & 138 & 267 & 282 & 1000 & 835 & 981 & 732 & 280 & 0 & 0 & 0 & 0 & 0 & 0 & \\
\hline 5 & $4.9415 \mathrm{E}-02$ & 167 & 659 & 757 & 835 & 1000 & 916 & 980 & 760 & 0 & 0 & 0 & 0 & 0 & 0 & \\
\hline 6 & $3.8243 \mathrm{E}-02$ & 150 & 392 & 433 & 981 & 916 & 1000 & 845 & 446 & 0 & 0 & 0 & 0 & 0 & 0 & \\
\hline 7 & $3.7062 \mathrm{E}-02$ & 161 & 714 & 830 & 732 & 980 & 845 & 1000 & 855 & 0 & 0 & 0 & 0 & 0 & 0 & \\
\hline 8 & $6.2387 \mathrm{E}-02$ & 127 & 825 & 979 & 280 & 760 & 446 & 855 & 1000 & 3 & 3 & 2 & 0 & 0 & 0 & \\
\hline 9 & $7.3012 \mathrm{E}-03$ & 0 & 0 & 0 & 0 & 0 & 0 & 0 & 3 & 1000 & 744 & 451 & 48 & 85 & 78 & \\
\hline 10 & $7.7374 \mathrm{E}-03$ & 0 & 0 & 0 & 0 & 0 & 0 & 0 & 3 & 744 & 1000 & 366 & 41 & 45 & 39 & \\
\hline 11 & $8.5340 \mathrm{E}-03$ & 0 & 0 & 0 & 0 & 0 & 0 & 0 & 2 & 451 & 366 & 1000 & 20 & -32 & -39 & \\
\hline 12 & 3. $3634 \mathrm{E}-02$ & 0 & 0 & 0 & 0 & 0 & 0 & 0 & 0 & 48 & 41 & 20 & 1000 & 11 & 5 & \\
\hline 13 & $7.4563 \mathrm{E}-02$ & 0 & 0 & 0 & 0 & 0 & 0 & 0 & 0 & 85 & 45 & -32 & 11 & 1000 & 999 & \\
\hline 14 & $8.4897 \mathrm{E}-02$ & 0 & 0 & 0 & 0 & 0 & 0 & 0 & 0 & 78 & 39 & -39 & 5 & 999 & 1000 & \\
\hline 15 & $8.6402 \mathrm{E}-02$ & 0 & 0 & 0 & 0 & 0 & 0 & 0 & 0 & 78 & 38 & -40 & 4 & 999 & 1000 & 10 \\
\hline
\end{tabular}

Table B.72: Relative uncertainty (relative standard deviation) and correlation (normalized to 1000) for ${ }^{160} \mathrm{Gd}(\mathrm{n}, \mathrm{el})$

\begin{tabular}{|c|c|c|c|c|c|c|c|c|c|c|c|c|c|c|c|c|}
\hline 1 & 1 & 1000 & 711 & & 611 & 326 & 01 & 100 & -585 & 0 & 0 & 0 & 0 & 0 & 0 & 0 \\
\hline $\begin{array}{l}1 \\
2\end{array}$ & $\begin{array}{l}1.1504 \mathrm{E}-02 \\
1.7699 \mathrm{~F}-02\end{array}$ & $\begin{array}{l}1000 \\
-711\end{array}$ & $\begin{array}{l}-711 \\
1000\end{array}$ & $\begin{array}{r}142 \\
-557\end{array}$ & $\begin{array}{r}641 \\
-922\end{array}$ & $\begin{array}{r}336 \\
-785\end{array}$ & $\begin{array}{r}-84 \\
-427\end{array}$ & $\begin{array}{r}-488 \\
135\end{array}$ & 429 & 0 & 0 & 0 & 0 & 0 & 0 & 0 \\
\hline 3 & $1.0794 \mathrm{E}-02$ & 742 & -557 & 1000 & 406 & -49 & -497 & -724 & -630 & 0 & 0 & 0 & 0 & 0 & 0 & 0 \\
\hline 4 & $2.4398 \mathrm{E}-02$ & 641 & -922 & 406 & 1000 & 873 & 447 & -242 & -611 & 0 & 0 & 0 & 0 & 0 & 0 & 0 \\
\hline 5 & $3.2568 \mathrm{E}-02$ & 336 & -785 & -49 & 873 & 1000 & 822 & 235 & -210 & 0 & 0 & 0 & 0 & 0 & 0 & \\
\hline 6 & $2.7378 \mathrm{E}-02$ & -84 & -427 & -497 & 447 & 822 & 1000 & 743 & 370 & 0 & 0 & 0 & 0 & 0 & 0 & 0 \\
\hline 7 & $2.7660 \mathrm{E}-02$ & -488 & 135 & -724 & -242 & 235 & 743 & 1000 & 894 & 0 & 0 & 0 & 0 & 0 & 0 & 0 \\
\hline 8 & $3.5116 \mathrm{E}-02$ & -585 & 429 & -630 & -611 & -210 & 370 & 894 & 1000 & 16 & 13 & 11 & 4 & 4 & 3 & 3 \\
\hline 9 & 1.8298E-02 & 0 & 0 & 0 & 0 & 0 & 0 & 0 & 16 & 1000 & 711 & 576 & 198 & 149 & 140 & 139 \\
\hline 10 & $3.2626 \mathrm{E}-02$ & 0 & 0 & 0 & 0 & 0 & 0 & 0 & 13 & 711 & 1000 & 597 & 270 & 223 & 214 & 213 \\
\hline 11 & $8.5995 \mathrm{E}-02$ & 0 & 0 & 0 & 0 & 0 & 0 & 0 & 11 & 576 & 597 & 1000 & 661 & 626 & 620 & 619 \\
\hline 12 & 1. $1058 \mathrm{E}-01$ & 0 & 0 & 0 & 0 & 0 & 0 & 0 & 4 & 198 & 270 & 661 & 1000 & 998 & 997 & 997 \\
\hline 13 & $1.1638 \mathrm{E}-01$ & 0 & 0 & 0 & 0 & 0 & 0 & 0 & 4 & 149 & 223 & 626 & 998 & 1000 & 1000 & 1000 \\
\hline 14 & $1.1749 \mathrm{E}-01$ & 0 & 0 & 0 & 0 & 0 & 0 & 0 & 3 & 140 & 214 & 620 & 997 & 1000 & 1000 & 1000 \\
\hline 15 & 1. $1724 \mathrm{E}-01$ & 0 & 0 & 0 & 0 & 0 & 0 & 0 & 3 & 139 & 213 & 619 & 997 & 1000 & 1000 & 1000 \\
\hline
\end{tabular}


Table B.73: Relative uncertainty (relative standard deviation) and correlation (normalized to 1000$)$ for ${ }^{160} \mathrm{Gd}\left(\mathrm{n}, \mathrm{n}^{\prime}\right)$

$\begin{array}{crrrrrrr}\text { group } & \text { rel.s.d. } & -----1 & ----1 \\ 1 & 4.2576 \mathrm{E}-01 & 1000 & 872 & 845 & 836 & 897 & 770 \\ 2 & 2.5237 \mathrm{E}-01 & 872 & 1000 & 659 & 872 & 698 & 453 \\ 3 & 1.8958 \mathrm{E}-01 & 845 & 659 & 1000 & 859 & 985 & 915 \\ 4 & 1.8881 \mathrm{E}-01 & 836 & 872 & 859 & 1000 & 835 & 605 \\ 5 & 6.9410 \mathrm{E}-01 & 897 & 698 & 985 & 835 & 1000 & 941 \\ 6 & 9.1341 \mathrm{E}-01 & 770 & 453 & 915 & 605 & 941 & 1000\end{array}$

Table B.74: Relative uncertainty (relative standard deviation) and correlation (normalized to 1000$)$ for ${ }^{160} \mathrm{Gd}(\mathrm{n}, 2 \mathrm{n})$

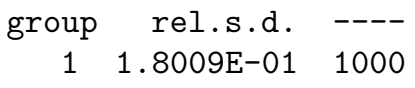

Table B.75: Relative uncertainty (relative standard deviation) and correlation (normalized to 1000) for ${ }^{160} \mathrm{Gd}(\mathrm{n}, \gamma)$

\begin{tabular}{|c|c|c|c|c|c|c|c|c|c|c|c|c|c|c|c|c|}
\hline & & & & & & & & & & & & & & & & \\
\hline 1 & $7.8617 \mathrm{E}-01$ & 1000 & 105 & 34 & 13 & -16 & 2 & 17 & -9 & 0 & 0 & 0 & 0 & 0 & 0 & 0 \\
\hline 2 & $3.0383 \mathrm{E}-01$ & 105 & 1000 & 424 & 250 & 141 & 112 & 120 & 130 & 0 & 0 & 0 & 0 & 0 & 0 & 0 \\
\hline 3 & $2.2679 \mathrm{E}-01$ & 34 & 424 & 1000 & 716 & 316 & 132 & 215 & 436 & 0 & 0 & 0 & 0 & 0 & 0 & \\
\hline 4 & $1.0964 \mathrm{E}-01$ & 13 & 250 & 716 & 1000 & 858 & 771 & 778 & 741 & 0 & 0 & 0 & 0 & 0 & 0 & \\
\hline 5 & $1.0994 \mathrm{E}-01$ & -16 & 141 & 316 & 858 & 1000 & 917 & 812 & 736 & 0 & 0 & 0 & 0 & 0 & 0 & \\
\hline 6 & $9.1784 \mathrm{E}-02$ & 2 & 112 & 132 & 771 & 917 & 1000 & 883 & 551 & 0 & 0 & 0 & 0 & 0 & 0 & \\
\hline 7 & $6.9101 \mathrm{E}-02$ & 17 & 120 & 215 & 778 & 812 & 883 & 1000 & 769 & 0 & 0 & 0 & 0 & 0 & 0 & \\
\hline 8 & $9.1480 \mathrm{E}-02$ & -9 & 130 & 436 & 741 & 736 & 551 & 769 & 1000 & 14 & 12 & 5 & 7 & 7 & 7 & \\
\hline 9 & $9.0872 \mathrm{E}-02$ & 0 & 0 & 0 & 0 & 0 & 0 & 0 & 14 & 1000 & 649 & 269 & 406 & 404 & 403 & 403 \\
\hline 10 & $9.1724 \mathrm{E}-02$ & 0 & 0 & 0 & 0 & 0 & 0 & 0 & 12 & 649 & 1000 & 207 & 317 & 322 & 322 & 322 \\
\hline 11 & $7.7606 \mathrm{E}-02$ & 0 & 0 & 0 & 0 & 0 & 0 & 0 & 5 & 269 & 207 & 1000 & 165 & 153 & 151 & 151 \\
\hline 12 & $1.7505 \mathrm{E}-01$ & 0 & 0 & 0 & 0 & 0 & 0 & 0 & 7 & 406 & 317 & 165 & 1000 & 993 & 990 & 989 \\
\hline 13 & $1.7096 \mathrm{E}-01$ & 0 & 0 & 0 & 0 & 0 & 0 & 0 & 7 & 404 & 322 & 153 & 993 & 1000 & 1000 & 1000 \\
\hline 14 & $1.7050 \mathrm{E}-01$ & 0 & 0 & 0 & 0 & 0 & 0 & 0 & 7 & 403 & 322 & 151 & 990 & 1000 & 1000 & 1000 \\
\hline 15 & $1.7046 \mathrm{E}-01$ & 0 & 0 & 0 & 0 & 0 & 0 & 0 & 7 & 403 & 322 & 151 & 989 & 1000 & 1000 & 1000 \\
\hline
\end{tabular}


Table B.76: Relative uncertainty (relative standard deviation) and correlation (normalized to 1000) for ${ }^{166} \operatorname{Er}(\mathrm{n}, \mathrm{el})$

\begin{tabular}{|c|c|c|c|c|c|c|c|c|c|c|c|c|c|c|c|c|}
\hline 1 & $9.0954 \mathrm{E}-03$ & 1000 & -101 & 847 & 955 & -567 & -452 & -255 & 199 & 3 & 0 & 0 & 0 & 0 & 0 & 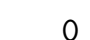 \\
\hline 2 & 1. $5457 \mathrm{E}-02$ & -101 & 1000 & -584 & 68 & 869 & 929 & 987 & 952 & 10 & 0 & 0 & 0 & 0 & 0 & \\
\hline 3 & $2.3493 E-02$ & 847 & -584 & 1000 & 766 & -909 & -843 & -706 & -310 & -2 & 0 & 0 & 0 & 0 & 0 & 0 \\
\hline 4 & $5.7351 \mathrm{E}-03$ & 955 & 68 & 766 & 1000 & -429 & -302 & -91 & 367 & 5 & 0 & 0 & 0 & 0 & 0 & \\
\hline 5 & $6.3308 \mathrm{E}-02$ & -567 & 869 & -909 & -429 & 1000 & 990 & 937 & 678 & 6 & 0 & 0 & 0 & 0 & 0 & \\
\hline 6 & $5.4685 \mathrm{E}-02$ & -452 & 929 & -843 & -302 & 990 & 1000 & 976 & 773 & 7 & 0 & 0 & 0 & 0 & 0 & \\
\hline 7 & $3.8960 \mathrm{E}-02$ & -255 & 987 & -706 & -91 & 937 & 976 & 1000 & 892 & 9 & 0 & 0 & 0 & 0 & 0 & \\
\hline 8 & $2.6039 \mathrm{E}-02$ & 199 & 952 & -310 & 367 & 678 & 773 & 892 & 1000 & 10 & 0 & 0 & 0 & 0 & 0 & 0 \\
\hline 9 & $3.3172 \mathrm{E}-02$ & 3 & 10 & -2 & 5 & 6 & 7 & 9 & 10 & 1000 & 249 & 118 & 613 & 696 & 696 & 696 \\
\hline 10 & $4.7363 \mathrm{E}-02$ & 0 & 0 & 0 & 0 & 0 & 0 & 0 & 0 & 249 & 1000 & 51 & 274 & 315 & 315 & 316 \\
\hline 11 & $7.7131 \mathrm{E}-02$ & 0 & 0 & 0 & 0 & 0 & 0 & 0 & 0 & 118 & 51 & 1000 & 108 & 130 & 131 & 131 \\
\hline 12 & $4.3852 \mathrm{E}-02$ & 0 & 0 & 0 & 0 & 0 & 0 & 0 & 0 & 613 & 274 & 108 & 1000 & 875 & 876 & 876 \\
\hline 13 & $3.8516 \mathrm{E}-02$ & 0 & 0 & 0 & 0 & 0 & 0 & 0 & 0 & 696 & 315 & 130 & 875 & 1000 & 1000 & 1000 \\
\hline 14 & $3.7787 \mathrm{E}-02$ & 0 & 0 & 0 & 0 & 0 & 0 & 0 & 0 & 696 & 315 & 131 & 876 & 1000 & 1000 & 1000 \\
\hline 15 & $3.6898 \mathrm{E}-02$ & 0 & 0 & 0 & 0 & 0 & 0 & 0 & 0 & 696 & 316 & 131 & 876 & 1000 & 1000 & 1000 \\
\hline
\end{tabular}

Table B.77: Relative uncertainty (relative standard deviation) and correlation (normalized to 1000) for ${ }^{166} \operatorname{Er}\left(\mathrm{n}, \mathrm{n}^{\prime}\right)$

$\begin{array}{crrrrrrr}\text { group } & \text { rel.s.d. } & ----140 & \\ 1 & 1.5730 \mathrm{E}-01 & 1000 & -406 & -480 & -491 & -147 & 0 \\ 2 & 1.6822 \mathrm{E}-01 & -406 & 1000 & 872 & 808 & -293 & 0 \\ 3 & 4.9076 \mathrm{E}-01 & -480 & 872 & 1000 & 991 & -16 & 0 \\ 4 & 3.5105 \mathrm{E}-01 & -491 & 808 & 991 & 1000 & 19 & 0 \\ 5 & 3.5375 \mathrm{E}-02 & -147 & -293 & -16 & 19 & 1000 & 481 \\ 6 & 5.0000 \mathrm{E}-01 & 0 & 0 & 0 & 0 & 481 & 1000\end{array}$

Table B.78: Relative uncertainty (relative standard deviation) and correlation (normalized to 1000) for ${ }^{166} \operatorname{Er}(\mathrm{n}, 2 \mathrm{n})$

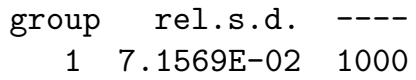


Table B.79: Relative uncertainty (relative standard deviation) and correlation (normalized to 1000) for ${ }^{166} \operatorname{Er}(\mathrm{n}, \gamma)$

\begin{tabular}{|c|c|c|c|c|c|c|c|c|c|c|c|c|c|c|c|c|}
\hline 1 & $4.1002 E-01$ & 1000 & 563 & 355 & 273 & 186 & 148 & 231 & -83 & -3 & 0 & 0 & 0 & 0 & 0 & 0 \\
\hline 2 & $3.2002 \mathrm{E}-01$ & 563 & 1000 & 893 & 781 & 214 & 94 & 192 & -25 & -1 & 0 & 0 & 0 & 0 & 0 & 0 \\
\hline 3 & $1.5819 \mathrm{E}-01$ & 355 & 893 & 1000 & 953 & -18 & -145 & 21 & 226 & 7 & 0 & 0 & 0 & 0 & 0 & 0 \\
\hline 4 & $9.5264 \mathrm{E}-02$ & 273 & 781 & 953 & 1000 & -319 & -439 & -252 & 498 & 17 & 0 & 0 & 0 & 0 & 0 & 0 \\
\hline 5 & 1. 1585E-01 & 186 & 214 & -18 & -319 & 1000 & 989 & 838 & -961 & -33 & 0 & 0 & 0 & 0 & 0 & 0 \\
\hline 6 & $1.3425 \mathrm{E}-01$ & 148 & 94 & -145 & -439 & 989 & 1000 & 867 & -962 & -33 & 0 & 0 & 0 & 0 & 0 & 0 \\
\hline 7 & $3.2366 \mathrm{E}-02$ & 231 & 192 & 21 & -252 & 838 & 867 & 1000 & -697 & -25 & 0 & 0 & 0 & 0 & 0 & 0 \\
\hline 8 & $6.2564 \mathrm{E}-02$ & -83 & -25 & 226 & 498 & -961 & -962 & -697 & 1000 & 34 & 0 & 0 & 0 & 0 & 0 & \\
\hline 9 & $3.1506 \mathrm{E}-02$ & -3 & -1 & 7 & 17 & -33 & -33 & -25 & 34 & 1000 & 8 & 0 & 0 & 1 & 1 & 1 \\
\hline 10 & $3.1343 E-02$ & 0 & 0 & 0 & 0 & 0 & 0 & 0 & 0 & 8 & 1000 & 0 & 0 & 4 & 4 & \\
\hline 11 & $3.9710 \mathrm{E}-02$ & 0 & 0 & 0 & 0 & 0 & 0 & 0 & 0 & 0 & 0 & 1000 & 1 & 32 & 29 & 29 \\
\hline 12 & $6.5909 \mathrm{E}-02$ & 0 & 0 & 0 & 0 & 0 & 0 & 0 & 0 & 0 & 0 & 1 & 1000 & 70 & 56 & 55 \\
\hline 13 & $9.1360 \mathrm{E}-02$ & 0 & 0 & 0 & 0 & 0 & 0 & 0 & 0 & 1 & 4 & 32 & 70 & 1000 & 1000 & 1000 \\
\hline 14 & $9.3643 \mathrm{E}-02$ & 0 & 0 & 0 & 0 & 0 & 0 & 0 & 0 & 1 & 4 & 29 & 56 & 1000 & 1000 & 1000 \\
\hline 15 & $8.6272 \mathrm{E}-02$ & 0 & 0 & 0 & 0 & 0 & 0 & 0 & 0 & 1 & 4 & 29 & 55 & 1000 & 1000 & 1000 \\
\hline
\end{tabular}

Table B.80: Relative uncertainty (relative standard deviation) and correlation (normalized to 1000) for ${ }^{167} \operatorname{Er}(\mathrm{n}, \mathrm{el})$

\begin{tabular}{|c|c|c|c|c|c|c|c|c|c|c|c|c|c|c|c|c|}
\hline 1 & $9.0334 \mathrm{E}-03$ & 1000 & -83 & 865 & 928 & -543 & -436 & -228 & 29 & 29 & 0 & 0 & 0 & 0 & 0 & 0 \\
\hline 2 & $1.5371 \mathrm{E}-02$ & -83 & 1000 & -534 & 223 & 875 & 929 & 989 & 993 & 993 & 14 & 0 & 0 & 0 & 0 & 0 \\
\hline 3 & $2.4493 \mathrm{E}-02$ & 865 & -534 & 1000 & 704 & -877 & -809 & -655 & -435 & -435 & -6 & 0 & 0 & 0 & 0 & 0 \\
\hline 4 & $7.7613 \mathrm{E}-03$ & 928 & 223 & 704 & 1000 & -276 & -152 & 74 & 332 & 332 & 5 & 0 & 0 & 0 & 0 & 0 \\
\hline 5 & $6.6492 \mathrm{E}-02$ & -543 & 875 & -877 & -276 & 1000 & 992 & 938 & 814 & 814 & 12 & 0 & 0 & 0 & 0 & 0 \\
\hline 6 & $5.5658 \mathrm{E}-02$ & -436 & 929 & -809 & -152 & 992 & 1000 & 974 & 881 & 881 & 13 & 0 & 0 & 0 & 0 & 0 \\
\hline 7 & $3.8210 \mathrm{E}-02$ & -228 & 989 & -655 & 74 & 938 & 974 & 1000 & 965 & 965 & 14 & 0 & 0 & 0 & 0 & 0 \\
\hline 8 & $2.9233 E-02$ & 29 & 993 & -435 & 332 & 814 & 881 & 965 & 1000 & 1000 & 14 & 0 & 0 & 0 & 0 & 0 \\
\hline 9 & $2.9233 \mathrm{E}-02$ & 29 & 993 & -435 & 332 & 814 & 881 & 965 & 1000 & 1000 & 14 & 0 & 0 & 0 & 0 & 0 \\
\hline 10 & $5.1232 \mathrm{E}-02$ & 0 & 14 & -6 & 5 & 12 & 13 & 14 & 14 & 14 & 1000 & 141 & 59 & 132 & 86 & 128 \\
\hline 11 & $6.6925 \mathrm{E}-02$ & 0 & 0 & 0 & 0 & 0 & 0 & 0 & 0 & 0 & 141 & 1000 & 47 & 138 & 123 & 137 \\
\hline 12 & $5.8774 \mathrm{E}-02$ & 0 & 0 & 0 & 0 & 0 & 0 & 0 & 0 & 0 & 59 & 47 & 1000 & 271 & 250 & 248 \\
\hline 13 & $2.9747 \mathrm{E}-01$ & 0 & 0 & 0 & 0 & 0 & 0 & 0 & 0 & 0 & 132 & 138 & 271 & 1000 & 955 & 999 \\
\hline 14 & $9.5673 \mathrm{E}-02$ & 0 & 0 & 0 & 0 & 0 & 0 & 0 & 0 & 0 & 86 & 123 & 250 & 955 & 1000 & 957 \\
\hline 15 & $5.7646 \mathrm{E}-01$ & 0 & 0 & 0 & 0 & 0 & 0 & 0 & 0 & 0 & 128 & 137 & 248 & 999 & 957 & 1000 \\
\hline
\end{tabular}


Table B.81: Relative uncertainty (relative standard deviation) and correlation (normalized to 1000) for ${ }^{167} \operatorname{Er}\left(\mathrm{n}, \mathrm{n}^{\prime}\right)$

\begin{tabular}{|c|c|c|c|c|c|c|c|}
\hline & & & & & & & \\
\hline 1 & $9.1742 \mathrm{E}-02$ & 1000 & -244 & -249 & -200 & 242 & 50 \\
\hline 2 & 1. $2285 \mathrm{E}-01$ & -244 & 1000 & 805 & 307 & -934 & -459 \\
\hline 3 & $1.0202 \mathrm{E}-01$ & -249 & 805 & 1000 & 810 & -552 & -3 \\
\hline 4 & $5.9663 \mathrm{E}-02$ & -200 & 307 & 810 & 1000 & 39 & 433 \\
\hline 5 & $4.2220 \mathrm{E}-02$ & 242 & -934 & -552 & 39 & 1000 & 622 \\
\hline 6 & $6.6124 \mathrm{E}-02$ & 50 & -459 & -3 & 433 & 622 & 1000 \\
\hline
\end{tabular}

Table B.82: Relative uncertainty (relative standard deviation) and correlation (normalized to 1000) for ${ }^{167} \operatorname{Er}(n, 2 n)$

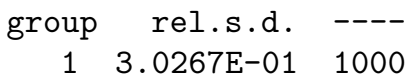

Table B.83: Relative uncertainty (relative standard deviation) and correlation (normalized to 1000) for ${ }^{167} \operatorname{Er}(\mathrm{n}, \gamma)$

\begin{tabular}{|c|c|c|c|c|c|c|c|c|c|c|c|c|c|c|c|c|}
\hline & & & & & & & & & & & & & & & & \\
\hline 1 & $6.7606 \mathrm{E}-01$ & 1000 & 896 & 849 & 248 & 869 & 927 & 580 & -238 & -406 & -149 & 0 & 0 & 0 & 0 & 0 \\
\hline 2 & $4.9140 \mathrm{E}-01$ & 896 & 1000 & 966 & 531 & 992 & 952 & 635 & -147 & -313 & -134 & 0 & 0 & 0 & 0 & \\
\hline 3 & $3.0210 \mathrm{E}-01$ & 849 & 966 & 1000 & 620 & 939 & 927 & 809 & 91 & -88 & -107 & 0 & 0 & 0 & 0 & \\
\hline 4 & 1. 2929E-01 & 248 & 531 & 620 & 1000 & 510 & 296 & 595 & 561 & 496 & 42 & 0 & 0 & 0 & 0 & \\
\hline 5 & $9.3342 \mathrm{E}-02$ & 869 & 992 & 939 & 510 & 1000 & 942 & 563 & -222 & -379 & -139 & 0 & 0 & 0 & 0 & \\
\hline 6 & $8.2282 \mathrm{E}-02$ & 927 & 952 & 927 & 296 & 942 & 1000 & 646 & -227 & -409 & -157 & 0 & 0 & 0 & 0 & \\
\hline 7 & $3.9195 \mathrm{E}-02$ & 580 & 635 & 809 & 595 & 563 & 646 & 1000 & 587 & 417 & -25 & 0 & 0 & 0 & 0 & \\
\hline 8 & $4.0110 \mathrm{E}-02$ & -238 & -147 & 91 & 561 & -222 & -227 & 587 & 1000 & 981 & 139 & 0 & 0 & 0 & 0 & \\
\hline 9 & $4.4682 \mathrm{E}-02$ & -406 & -313 & -88 & 496 & -379 & -409 & 417 & 981 & 1000 & 162 & 0 & 0 & 0 & 0 & \\
\hline 10 & $2.8073 \mathrm{E}-02$ & -149 & -134 & -107 & 42 & -139 & -157 & -25 & 139 & 162 & 1000 & 0 & 0 & 0 & 0 & \\
\hline 11 & $1.8761 \mathrm{E}-02$ & 0 & 0 & 0 & 0 & 0 & 0 & 0 & 0 & 0 & 0 & 1000 & 57 & 43 & 7 & 84 \\
\hline 12 & $1.1266 \mathrm{E}-02$ & 0 & 0 & 0 & 0 & 0 & 0 & 0 & 0 & 0 & 0 & 57 & 1000 & 127 & 14 & 125 \\
\hline 13 & $1.0355 \mathrm{E}-02$ & 0 & 0 & 0 & 0 & 0 & 0 & 0 & 0 & 0 & 0 & 43 & 127 & 1000 & -780 & -283 \\
\hline 14 & $1.0192 \mathrm{E}-02$ & 0 & 0 & 0 & 0 & 0 & 0 & 0 & 0 & 0 & 0 & 7 & 14 & -780 & 1000 & 717 \\
\hline 15 & 1. $2018 \mathrm{E}-02$ & 0 & 0 & 0 & 0 & 0 & 0 & 0 & 0 & 0 & 1 & 84 & 125 & -283 & 717 & 1000 \\
\hline
\end{tabular}


Table B.84: Relative uncertainty (relative standard deviation) and correlation (normalized to 1000) for ${ }^{168} \operatorname{Er}(\mathrm{n}, \mathrm{el})$

\begin{tabular}{|c|c|c|c|c|c|c|c|c|c|c|c|c|c|c|c|c|}
\hline 1 & $9.2830 \mathrm{E}-03$ & 1000 & -428 & 881 & 981 & -722 & -651 & -507 & -143 & 0 & 0 & 0 & 0 & 0 & 0 & 0 \\
\hline 2 & 1. 3583E-02 & -428 & 1000 & -789 & -465 & 931 & 963 & 996 & 525 & 0 & 0 & 0 & 0 & 0 & 0 & 0 \\
\hline 3 & $2.4341 \mathrm{E}-02$ & 881 & -789 & 1000 & 910 & -959 & -926 & -842 & -357 & 0 & 0 & 0 & 0 & 0 & 0 & 0 \\
\hline 4 & $5.4288 \mathrm{E}-03$ & 981 & -465 & 910 & 1000 & -756 & -686 & -544 & -162 & 0 & 0 & 0 & 0 & 0 & 0 & 0 \\
\hline 5 & $5.9564 \mathrm{E}-02$ & -722 & 931 & -959 & -756 & 1000 & 995 & 960 & 454 & 0 & 0 & 0 & 0 & 0 & 0 & 0 \\
\hline 6 & $4.8209 \mathrm{E}-02$ & -651 & 963 & -926 & -686 & 995 & 1000 & 984 & 480 & 0 & 0 & 0 & 0 & 0 & 0 & 0 \\
\hline 7 & $3.0869 \mathrm{E}-02$ & -507 & 996 & -842 & -544 & 960 & 984 & 1000 & 514 & 0 & 0 & 0 & 0 & 0 & 0 & 0 \\
\hline 8 & $2.3213 \mathrm{E}-02$ & -143 & 525 & -357 & -162 & 454 & 480 & 514 & 1000 & 304 & 148 & 68 & 269 & 260 & 258 & 258 \\
\hline 9 & $3.8016 \mathrm{E}-02$ & 0 & 0 & 0 & 0 & 0 & 0 & 0 & 304 & 1000 & 199 & 92 & 370 & 358 & 356 & 356 \\
\hline 10 & $5.3365 \mathrm{E}-02$ & 0 & 0 & 0 & 0 & 0 & 0 & 0 & 148 & 199 & 1000 & 48 & 213 & 209 & 209 & 209 \\
\hline 11 & $8.5974 \mathrm{E}-02$ & 0 & 0 & 0 & 0 & 0 & 0 & 0 & 68 & 92 & 48 & 1000 & 137 & 139 & 140 & 140 \\
\hline 12 & $8.6747 \mathrm{E}-02$ & 0 & 0 & 0 & 0 & 0 & 0 & 0 & 269 & 370 & 213 & 137 & 1000 & 1000 & 1000 & 1000 \\
\hline 13 & $8.8037 \mathrm{E}-02$ & 0 & 0 & 0 & 0 & 0 & 0 & 0 & 260 & 358 & 209 & 139 & 1000 & 1000 & 1000 & 1000 \\
\hline 14 & $8.8270 \mathrm{E}-02$ & 0 & 0 & 0 & 0 & 0 & 0 & 0 & 258 & 356 & 209 & 140 & 1000 & 1000 & 1000 & 1000 \\
\hline 15 & $8.6450 \mathrm{E}-02$ & 0 & 0 & 0 & 0 & 0 & 0 & 0 & 258 & 356 & 209 & 140 & 1000 & 1000 & 1000 & 1000 \\
\hline
\end{tabular}


Table B.85: Relative uncertainty (relative standard deviation) and correlation (normalized to 1000) for ${ }^{168} \operatorname{Er}\left(\mathrm{n}, \mathrm{n}^{\prime}\right)$

$\begin{array}{crrrrrrr}\text { group } & \text { rel.s.d. } & ----------------- \\ 1 & 1.9361 \mathrm{E}-01 & 1000 & -449 & -505 & -501 & -474 & 0 \\ 2 & 1.3428 \mathrm{E}-01 & -449 & 1000 & 853 & 802 & 558 & 0 \\ 3 & 4.4367 \mathrm{E}-01 & -505 & 853 & 1000 & 996 & 890 & 0 \\ 4 & 3.7669 \mathrm{E}-01 & -501 & 802 & 996 & 1000 & 921 & 0 \\ 5 & 7.2765 \mathrm{E}-02 & -474 & 558 & 890 & 921 & 1000 & 235 \\ 6 & 5.0000 \mathrm{E}-01 & 0 & 0 & 0 & 0 & 235 & 1000\end{array}$

Table B.86: Relative uncertainty (relative standard deviation) and correlation (normalized to 1000) for ${ }^{168} \operatorname{Er}(\mathrm{n}, 2 \mathrm{n})$

$\underset{1}{\operatorname{group}}$\begin{tabular}{rr} 
rel.s.d. & ---- \\
\hline $.1277 \mathrm{E}-02$ & 1000
\end{tabular} 
Table B.87: Relative uncertainty (relative standard deviation) and correlation (normalized to 1000) for ${ }^{168} \operatorname{Er}(\mathrm{n}, \gamma)$

\begin{tabular}{|c|c|c|c|c|c|c|c|c|c|c|c|c|c|c|c|c|}
\hline 1 & $3.1955 \mathrm{E}-01$ & 1000 & 426 & 290 & 243 & 93 & 60 & 85 & 263 & 0 & 0 & 0 & 0 & 0 & 0 & 0 \\
\hline 2 & $4.9666 \mathrm{E}-01$ & 426 & 1000 & 773 & 688 & 554 & 417 & 431 & 78 & 0 & 0 & 0 & 0 & 0 & 0 & 0 \\
\hline 3 & $2.1893 \mathrm{E}-01$ & 290 & 773 & 1000 & 981 & 141 & -42 & -22 & 321 & 0 & 0 & 0 & 0 & 0 & 0 & 0 \\
\hline 4 & 1. $2984 \mathrm{E}-01$ & 243 & 688 & 981 & 1000 & -6 & -195 & -184 & 284 & 0 & 0 & 0 & 0 & 0 & 0 & 0 \\
\hline 5 & $1.4969 \mathrm{E}-01$ & 93 & 554 & 141 & -6 & 1000 & 981 & 975 & -368 & 0 & 0 & 0 & 0 & 0 & 0 & 0 \\
\hline 6 & 1.9439E-01 & 60 & 417 & -42 & -195 & 981 & 1000 & 997 & -374 & 0 & 0 & 0 & 0 & 0 & 0 & 0 \\
\hline 7 & $9.7401 \mathrm{E}-02$ & 85 & 431 & -22 & -184 & 975 & 997 & 1000 & -307 & 0 & 0 & 0 & 0 & 0 & 0 & 0 \\
\hline 8 & $3.0999 \mathrm{E}-02$ & 263 & 78 & 321 & 284 & -368 & -374 & -307 & 1000 & 6 & 0 & 0 & 1 & 1 & 1 & 1 \\
\hline 9 & $3.2108 \mathrm{E}-02$ & 0 & 0 & 0 & 0 & 0 & 0 & 0 & 6 & 1000 & 0 & 0 & 9 & 9 & 9 & 9 \\
\hline 10 & $6.1471 \mathrm{E}-02$ & 0 & 0 & 0 & 0 & 0 & 0 & 0 & 0 & 0 & 1000 & 4 & 158 & 157 & 156 & 155 \\
\hline 11 & $5.0485 E-02$ & 0 & 0 & 0 & 0 & 0 & 0 & 0 & 0 & 0 & 4 & 1000 & 603 & 544 & 533 & 531 \\
\hline 12 & $3.2244 \mathrm{E}-02$ & 0 & 0 & 0 & 0 & 0 & 0 & 0 & 1 & 9 & 158 & 603 & 1000 & 989 & 986 & 986 \\
\hline 13 & $3.0674 \mathrm{E}-02$ & 0 & 0 & 0 & 0 & 0 & 0 & 0 & 1 & 9 & 157 & 544 & 989 & 1000 & 1000 & 1000 \\
\hline 14 & $3.0517 \mathrm{E}-02$ & 0 & 0 & 0 & 0 & 0 & 0 & 0 & 1 & 9 & 156 & 533 & 986 & 1000 & 1000 & 1000 \\
\hline 15 & $2.8022 \mathrm{E}-02$ & 0 & 0 & 0 & 0 & 0 & 0 & 0 & 1 & 9 & 155 & 531 & 986 & 1000 & 1000 & 1000 \\
\hline
\end{tabular}

Table B.88: Relative uncertainty (relative standard deviation) and correlation (normalized to 1000) for ${ }^{170} \operatorname{Er}(\mathrm{n}, \mathrm{el})$

\begin{tabular}{|c|c|c|c|c|c|c|c|c|c|c|c|c|c|c|c|c|}
\hline 1 & $9.2073 E-03$ & 1000 & -405 & 873 & 955 & -711 & -620 & 0 & 0 & 0 & 0 & 0 & 0 & 0 & 0 & 0 \\
\hline 2 & 1.2998E-02 & -405 & 1000 & -784 & -548 & 927 & 926 & 0 & 0 & 0 & 0 & 0 & 0 & 0 & 0 & 0 \\
\hline 3 & $2.5762 \mathrm{E}-02$ & 873 & -784 & 1000 & 939 & -959 & -896 & 0 & 0 & 0 & 0 & 0 & 0 & 0 & 0 & 0 \\
\hline 4 & $6.7776 \mathrm{E}-03$ & 955 & -548 & 939 & 1000 & -810 & -726 & 0 & 0 & 0 & 0 & 0 & 0 & 0 & 0 & 0 \\
\hline 5 & $5.6165 \mathrm{E}-02$ & -711 & 927 & -959 & -810 & 1000 & 962 & 0 & 0 & 0 & 0 & 0 & 0 & 0 & 0 & 0 \\
\hline 6 & $4.0651 \mathrm{E}-02$ & -620 & 926 & -896 & -726 & 962 & 1000 & 258 & 258 & 171 & 0 & 0 & 0 & 0 & 0 & 0 \\
\hline 7 & $7.6489 \mathrm{E}-02$ & 0 & 0 & 0 & 0 & 0 & 258 & 1000 & 1000 & 662 & 0 & 0 & 0 & 0 & 0 & 0 \\
\hline 8 & $5.6951 \mathrm{E}-02$ & 0 & 0 & 0 & 0 & 0 & 258 & 1000 & 1000 & 662 & 0 & 0 & 0 & 0 & 0 & 0 \\
\hline 9 & $4.1704 \mathrm{E}-02$ & 0 & 0 & 0 & 0 & 0 & 171 & 662 & 662 & 1000 & 345 & 17 & 93 & 89 & 88 & 88 \\
\hline 10 & $4.8172 \mathrm{E}-02$ & 0 & 0 & 0 & 0 & 0 & 0 & 0 & 0 & 345 & 1000 & 47 & 214 & 209 & 208 & 208 \\
\hline 11 & $7.6994 \mathrm{E}-02$ & 0 & 0 & 0 & 0 & 0 & 0 & 0 & 0 & 17 & 47 & 1000 & 65 & 63 & 63 & 63 \\
\hline 12 & $1.7918 \mathrm{E}-01$ & 0 & 0 & 0 & 0 & 0 & 0 & 0 & 0 & 93 & 214 & 65 & 1000 & 1000 & 1000 & 1000 \\
\hline 13 & $1.7871 \mathrm{E}-01$ & 0 & 0 & 0 & 0 & 0 & 0 & 0 & 0 & 89 & 209 & 63 & 1000 & 1000 & 1000 & 1000 \\
\hline 14 & $1.7893 \mathrm{E}-01$ & 0 & 0 & 0 & 0 & 0 & 0 & 0 & 0 & 88 & 208 & 63 & 1000 & 1000 & 1000 & 1000 \\
\hline 15 & $1.7521 \mathrm{E}-01$ & 0 & 0 & 0 & 0 & 0 & 0 & 0 & 0 & 88 & 208 & 63 & 1000 & 1000 & 1000 & 1000 \\
\hline
\end{tabular}


Table B.89: Relative uncertainty (relative standard deviation) and correlation (normalized to 1000) for ${ }^{170} \operatorname{Er}\left(\mathrm{n}, \mathrm{n}^{\prime}\right)$

\begin{tabular}{|c|c|c|c|c|c|c|c|}
\hline & & & & & & & \\
\hline 1 & $2.6879 \mathrm{E}-01$ & 1000 & -478 & -511 & -514 & -525 & -508 \\
\hline 2 & 1. $4563 \mathrm{E}-01$ & -478 & 1000 & 829 & 781 & 686 & 742 \\
\hline 3 & $5.3410 \mathrm{E}-01$ & -511 & 829 & 1000 & 995 & 944 & 989 \\
\hline 4 & $5.1075 \mathrm{E}-01$ & -514 & 781 & 995 & 1000 & 969 & 998 \\
\hline 5 & 1.9177E-01 & -525 & 686 & 944 & 969 & 1000 & 973 \\
\hline 6 & $4.1365 \mathrm{E}-01$ & -508 & 742 & 989 & 998 & 973 & 1000 \\
\hline
\end{tabular}

Table B.90: Relative uncertainty (relative standard deviation) and correlation (normalized to 1000$)$ for ${ }^{170} \operatorname{Er}(n, 2 n)$

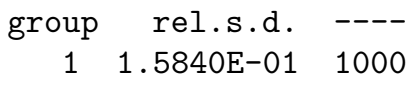

Table B.91: Relative uncertainty (relative standard deviation) and correlation (normalized to 1000) for ${ }^{170} \operatorname{Er}(\mathrm{n}, \gamma)$

\begin{tabular}{|c|c|c|c|c|c|c|c|c|c|c|c|c|c|c|c|c|}
\hline & & & & & & & & & & & & & & & & \\
\hline 1 & $2.5165 \mathrm{E}-01$ & 1000 & 366 & 135 & 106 & 101 & 84 & 0 & 0 & 0 & 0 & 0 & 0 & 0 & 0 & 0 \\
\hline 2 & $2.6003 E-01$ & 366 & 1000 & 625 & 565 & 585 & 494 & 0 & 0 & 0 & 0 & 0 & 0 & 0 & 0 & 0 \\
\hline 3 & 1. $1082 \mathrm{E}-01$ & 135 & 625 & 1000 & 994 & 961 & 775 & 0 & 0 & 0 & 0 & 0 & 0 & 0 & 0 & \\
\hline 4 & $8.9032 \mathrm{E}-02$ & 106 & 565 & 994 & 1000 & 953 & 758 & 0 & 0 & 0 & 0 & 0 & 0 & 0 & 0 & \\
\hline 5 & $7.4658 \mathrm{E}-02$ & 101 & 585 & 961 & 953 & 1000 & 847 & 0 & 0 & 0 & 0 & 0 & 0 & 0 & 0 & \\
\hline 6 & 4.9889E-02 & 84 & 494 & 775 & 758 & 847 & 1000 & 503 & 502 & 410 & 0 & 0 & 0 & 0 & 0 & \\
\hline 7 & $6.2163 \mathrm{E}-02$ & 0 & 0 & 0 & 0 & 0 & 503 & 1000 & 999 & 816 & 0 & 0 & 0 & 0 & 0 & \\
\hline 8 & $4.7035 \mathrm{E}-02$ & 0 & 0 & 0 & 0 & 0 & 502 & 999 & 1000 & 818 & 0 & 0 & 0 & 0 & 0 & \\
\hline 9 & $2.2563 E-02$ & 0 & 0 & 0 & 0 & 0 & 410 & 816 & 818 & 1000 & 36 & 0 & 0 & 1 & 1 & \\
\hline 10 & $3.3759 \mathrm{E}-02$ & 0 & 0 & 0 & 0 & 0 & 0 & 0 & 0 & 36 & 1000 & 3 & 10 & 11 & 12 & 12 \\
\hline 11 & $7.2140 \mathrm{E}-02$ & 0 & 0 & 0 & 0 & 0 & 0 & 0 & 0 & 0 & 3 & 1000 & 892 & 889 & 891 & 891 \\
\hline 12 & 4.9093E-02 & 0 & 0 & 0 & 0 & 0 & 0 & 0 & 0 & 0 & 10 & 892 & 1000 & 1000 & 1000 & 1000 \\
\hline 13 & $3.9181 \mathrm{E}-02$ & 0 & 0 & 0 & 0 & 0 & 0 & 0 & 0 & 1 & 11 & 889 & 1000 & 1000 & 1000 & 1000 \\
\hline 14 & $3.6978 \mathrm{E}-02$ & 0 & 0 & 0 & 0 & 0 & 0 & 0 & 0 & 1 & 12 & 891 & 1000 & 1000 & 1000 & 1000 \\
\hline 15 & $3.4052 \mathrm{E}-02$ & 0 & 0 & 0 & 0 & 0 & 0 & 0 & 0 & 1 & 12 & 891 & 1000 & 1000 & 1000 & 1000 \\
\hline
\end{tabular}


Table B.92: Relative uncertainty (relative standard deviation) and correlation (normalized to 1000$)$ for ${ }^{206} \mathrm{~Pb}(\mathrm{n}, \mathrm{el})$

\begin{tabular}{|c|c|c|c|c|c|c|c|c|c|c|c|c|c|c|c|c|}
\hline & & & & & & & & & & & & & & & & \\
\hline 1 & $6.8883 \mathrm{E}-03$ & 1000 & 811 & 253 & 150 & 0 & 0 & 0 & 0 & 0 & 0 & 0 & 0 & 0 & 0 & 0 \\
\hline 2 & $7.6585 \mathrm{E}-03$ & 811 & 1000 & -351 & -436 & 0 & 0 & 0 & 0 & 0 & 0 & 0 & 0 & 0 & 0 & 0 \\
\hline 3 & 6.9951E-02 & 253 & -351 & 1000 & 974 & 0 & 0 & 0 & 0 & 0 & 0 & 0 & 0 & 0 & 0 & 0 \\
\hline 4 & 1.3249E-02 & 150 & -436 & 974 & 1000 & 73 & 79 & 73 & 59 & 50 & 48 & 47 & 47 & 47 & 47 & 47 \\
\hline 5 & $5.5593 \mathrm{E}-03$ & 0 & 0 & 0 & 73 & 1000 & 520 & 478 & 422 & 371 & 365 & 361 & 360 & 360 & 360 & 360 \\
\hline 6 & $5.8086 \mathrm{E}-03$ & 0 & 0 & 0 & 79 & 520 & 1000 & 707 & 696 & 647 & 650 & 647 & 646 & 646 & 646 & 645 \\
\hline 7 & $6.7666 \mathrm{E}-03$ & 0 & 0 & 0 & 73 & 478 & 707 & 1000 & 963 & 915 & 927 & 925 & 925 & 925 & 925 & 924 \\
\hline 8 & $8.2828 \mathrm{E}-03$ & 0 & 0 & 0 & 59 & 422 & 696 & 963 & 1000 & 970 & 989 & 989 & 988 & 988 & 989 & 988 \\
\hline 9 & $9.5693 \mathrm{E}-03$ & 0 & 0 & 0 & 50 & 371 & 647 & 915 & 970 & 1000 & 960 & 963 & 964 & 964 & 964 & 964 \\
\hline 10 & $9.9351 \mathrm{E}-03$ & 0 & 0 & 0 & 48 & 365 & 650 & 927 & 989 & 960 & 1000 & 1000 & 1000 & 1000 & 1000 & 999 \\
\hline 11 & $1.0061 \mathrm{E}-02$ & 0 & 0 & 0 & 47 & 361 & 647 & 925 & 989 & 963 & 1000 & 1000 & 1000 & 1000 & 1000 & 999 \\
\hline 12 & $1.0089 \mathrm{E}-02$ & 0 & 0 & 0 & 47 & 360 & 646 & 925 & 988 & 964 & 1000 & 1000 & 1000 & 1000 & 1000 & 999 \\
\hline 13 & $1.0091 \mathrm{E}-02$ & 0 & 0 & 0 & 47 & 360 & 646 & 925 & 988 & 964 & 1000 & 1000 & 1000 & 1000 & 1000 & 999 \\
\hline 14 & $1.0090 \mathrm{E}-02$ & 0 & 0 & 0 & 47 & 360 & 646 & 925 & 989 & 964 & 1000 & 1000 & 1000 & 1000 & 1000 & 1000 \\
\hline 15 & $9.8848 \mathrm{E}-03$ & 0 & 0 & 0 & 47 & 360 & 645 & 924 & 988 & 964 & 999 & 999 & 999 & 999 & 1000 & 1000 \\
\hline
\end{tabular}

Table B.93: Relative uncertainty (relative standard deviation) and correlation (normalized to 1000$)$ for ${ }^{206} \mathrm{~Pb}\left(\mathrm{n}, \mathrm{n}^{\prime}\right)$

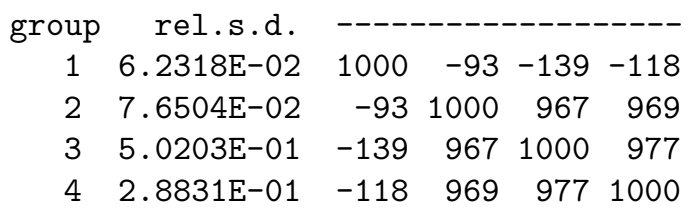

Table B.94: Relative uncertainty (relative standard deviation) and correlation (normalized to 1000) for ${ }^{206} \mathrm{~Pb}(\mathrm{n}, 2 \mathrm{n})$

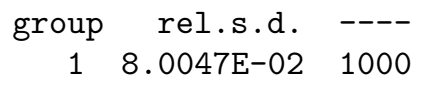


Table B.95: Relative uncertainty (relative standard deviation) and correlation (normalized to 1000) for ${ }^{206} \mathrm{~Pb}(\mathrm{n}, \gamma)$

\begin{tabular}{|c|c|c|c|c|c|c|c|c|c|c|c|c|c|c|c|c|}
\hline 1 & $3.9479 \mathrm{E}-01$ & 1000 & -14 & -97 & 95 & 0 & 0 & 0 & 0 & 0 & 0 & 0 & 0 & 0 & 0 & 0 \\
\hline 2 & $3.9121 \mathrm{E}-01$ & -14 & 1000 & 814 & 86 & 0 & 0 & 0 & 0 & 0 & 0 & 0 & 0 & 0 & 0 & 0 \\
\hline 3 & 1.9764E-01 & -97 & 814 & 1000 & 349 & 0 & 0 & 0 & 0 & 0 & 0 & 0 & 0 & 0 & 0 & 0 \\
\hline 4 & $4.4393 \mathrm{E}-02$ & 95 & 86 & 349 & 1000 & 20 & 0 & 0 & 0 & 0 & 140 & 152 & 152 & 152 & 152 & 152 \\
\hline 5 & $6.0161 \mathrm{E}-02$ & 0 & 0 & 0 & 20 & 1000 & 6 & 0 & 0 & 0 & 226 & 244 & 244 & 244 & 244 & 244 \\
\hline 6 & $1.2660 \mathrm{E}-02$ & 0 & 0 & 0 & 0 & 6 & 1000 & 3 & 0 & 0 & 66 & 70 & 70 & 70 & 70 & 70 \\
\hline 7 & $5.3296 \mathrm{E}-02$ & 0 & 0 & 0 & 0 & 0 & 3 & 1000 & 0 & 0 & 23 & 24 & 24 & 23 & 23 & 23 \\
\hline 8 & $1.5799 \mathrm{E}-02$ & 0 & 0 & 0 & 0 & 0 & 0 & 0 & 1000 & 0 & 10 & 9 & 9 & 9 & 9 & 9 \\
\hline 9 & $4.8847 \mathrm{E}-02$ & 0 & 0 & 0 & 0 & 0 & 0 & 0 & 0 & 1000 & 355 & 153 & 137 & 136 & 137 & 136 \\
\hline 10 & $2.1798 \mathrm{E}-02$ & 0 & 0 & 0 & 140 & 226 & 66 & 23 & 10 & 355 & 1000 & 964 & 959 & 958 & 958 & 958 \\
\hline 11 & $2.0393 E-02$ & 0 & 0 & 0 & 152 & 244 & 70 & 24 & 9 & 153 & 964 & 1000 & 1000 & 1000 & 1000 & 1000 \\
\hline 12 & $2.0337 \mathrm{E}-02$ & 0 & 0 & 0 & 152 & 244 & 70 & 24 & 9 & 137 & 959 & 1000 & 1000 & 1000 & 1000 & 1000 \\
\hline 13 & $2.0331 \mathrm{E}-02$ & 0 & 0 & 0 & 152 & 244 & 70 & 23 & 9 & 136 & 958 & 1000 & 1000 & 1000 & 1000 & 1000 \\
\hline 14 & $2.0333 E-02$ & 0 & 0 & 0 & 152 & 244 & 70 & 23 & 9 & 137 & 958 & 1000 & 1000 & 1000 & 1000 & 1000 \\
\hline 15 & $1.8679 \mathrm{E}-02$ & 0 & 0 & 0 & 152 & 244 & 70 & 23 & 9 & 136 & 958 & 1000 & 1000 & 1000 & 1000 & 1000 \\
\hline
\end{tabular}

Table B.96: Relative uncertainty (relative standard deviation) and correlation (normalized to 1000$)$ for ${ }^{207} \mathrm{~Pb}(\mathrm{n}, \mathrm{el})$

\begin{tabular}{|c|c|c|c|c|c|c|c|c|c|c|c|c|c|c|c|c|}
\hline 1 & $7.8370 \mathrm{E}-03$ & 1000 & 284 & -24 & -67 & -4 & 0 & 0 & 0 & 0 & 0 & 0 & 0 & 0 & 0 & 0 \\
\hline 2 & 1. $1330 \mathrm{E}-02$ & 284 & 1000 & 135 & -193 & -14 & 0 & 0 & 0 & 0 & 0 & 0 & 0 & 0 & 0 & \\
\hline 3 & $2.1051 \mathrm{E}-02$ & -24 & 135 & 1000 & 37 & -1 & 0 & 0 & 0 & 0 & 0 & 0 & 0 & 0 & 0 & 0 \\
\hline 4 & $4.0878 \mathrm{E}-02$ & -67 & -193 & 37 & 1000 & 74 & 0 & 0 & 0 & 0 & 0 & 0 & 0 & 0 & 0 & 0 \\
\hline 5 & $3.0672 \mathrm{E}-02$ & -4 & -14 & -1 & 74 & 1000 & 986 & 955 & 716 & 275 & -82 & -87 & -88 & -89 & -89 & -89 \\
\hline 6 & $1.9617 \mathrm{E}-02$ & 0 & 0 & 0 & 0 & 986 & 1000 & 976 & 732 & 188 & -172 & -177 & -179 & -179 & -179 & -179 \\
\hline 7 & $1.0387 \mathrm{E}-02$ & 0 & 0 & 0 & 0 & 955 & 976 & 1000 & 746 & 109 & -238 & -243 & -244 & -245 & -245 & -245 \\
\hline 8 & $7.9737 \mathrm{E}-03$ & 0 & 0 & 0 & 0 & 716 & 732 & 746 & 1000 & 112 & -118 & -122 & -123 & -123 & -123 & -123 \\
\hline 9 & $7.5477 \mathrm{E}-03$ & 0 & 0 & 0 & 0 & 275 & 188 & 109 & 112 & 1000 & 932 & 931 & 930 & 930 & 930 & 930 \\
\hline 10 & $6.6934 \mathrm{E}-02$ & 0 & 0 & 0 & 0 & -82 & -172 & -238 & -118 & 932 & 1000 & 1000 & 1000 & 1000 & 1000 & 1000 \\
\hline 11 & $8.5826 \mathrm{E}-02$ & 0 & 0 & 0 & 0 & -87 & -177 & -243 & -122 & 931 & 1000 & 1000 & 1000 & 1000 & 1000 & 1000 \\
\hline 12 & $9.1902 \mathrm{E}-02$ & 0 & 0 & 0 & 0 & -88 & -179 & -244 & -123 & 930 & 1000 & 1000 & 1000 & 1000 & 1000 & 1000 \\
\hline 13 & $9.5628 \mathrm{E}-02$ & 0 & 0 & 0 & 0 & -89 & -179 & -245 & -123 & 930 & 1000 & 1000 & 1000 & 1000 & 1000 & 1000 \\
\hline 14 & $9.6285 \mathrm{E}-02$ & 0 & 0 & 0 & 0 & -89 & -179 & -245 & -123 & 930 & 1000 & 1000 & 1000 & 1000 & 1000 & 1000 \\
\hline 15 & $9.3209 \mathrm{E}-02$ & 0 & 0 & 0 & 0 & -89 & -179 & -245 & -123 & 930 & 1000 & 1000 & 1000 & 1000 & 1000 & 1000 \\
\hline
\end{tabular}

Table B.97: Relative uncertainty (relative standard deviation) and correlation (normalized to 1000$)$ for ${ }^{207} \mathrm{~Pb}\left(\mathrm{n}, \mathrm{n}^{\prime}\right)$

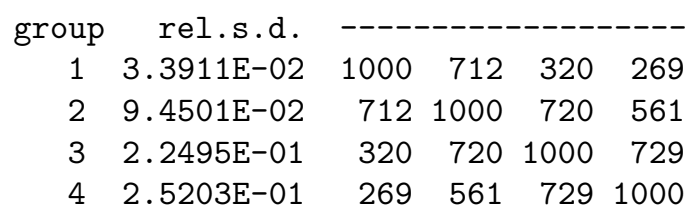


Table B.98: Relative uncertainty (relative standard deviation) and correlation (normalized to 1000$)$ for ${ }^{207} \mathrm{~Pb}(\mathrm{n}, 2 \mathrm{n})$

group rel.s.d. ----

Table B.99: Relative uncertainty (relative standard deviation) and correlation (normalized to 1000) for ${ }^{207} \mathrm{~Pb}(\mathrm{n}, \gamma)$

\begin{tabular}{|c|c|c|c|c|c|c|c|c|c|c|c|c|c|c|c|c|}
\hline 1 & $48 \mathrm{~F}-01$ & 1000 & 560 & 233 & -533 & -88 & 0 & 0 & 0 & 0 & 0 & 0 & 0 & 0 & 0 & 0 \\
\hline 2 & $2.3966 \mathrm{E}-01$ & 560 & 1000 & 784 & -799 & -141 & 0 & 0 & 0 & 0 & 0 & 0 & 0 & 0 & 0 & 0 \\
\hline 3 & $7.5394 \mathrm{E}-02$ & 233 & 784 & 1000 & -272 & -64 & 0 & 0 & 0 & 0 & 0 & 0 & 0 & 0 & 0 & 0 \\
\hline 4 & $9.8855 \mathrm{E}-02$ & -533 & -799 & -272 & 1000 & 162 & 0 & 0 & 0 & 0 & 0 & 0 & 0 & 0 & 0 & 0 \\
\hline 5 & $4.4946 \mathrm{E}-02$ & -88 & -141 & -64 & 162 & 1000 & 11 & 1 & 0 & 0 & 11 & -9 & -10 & -10 & -10 & -10 \\
\hline 6 & $3.0039 \mathrm{E}-02$ & 0 & 0 & 0 & 0 & 11 & 1000 & 7 & 0 & 0 & 13 & -12 & -13 & -13 & -13 & -13 \\
\hline 7 & $3.1776 \mathrm{E}-02$ & 0 & 0 & 0 & 0 & 1 & 7 & 1000 & 7 & 1 & 37 & -10 & -19 & -19 & -19 & -19 \\
\hline 8 & $5.2572 \mathrm{E}-02$ & 0 & 0 & 0 & 0 & 0 & 0 & 7 & 1000 & 0 & 25 & -21 & -23 & -23 & -23 & -23 \\
\hline 9 & $1.8319 \mathrm{E}-01$ & 0 & 0 & 0 & 0 & 0 & 0 & 1 & 0 & 1000 & 13 & -10 & -11 & -11 & -11 & -11 \\
\hline 10 & $1.0801 \mathrm{E}-02$ & 0 & 0 & 0 & 0 & 11 & 13 & 37 & 25 & 13 & 1000 & -891 & -965 & -967 & -967 & -967 \\
\hline 11 & $5.9861 \mathrm{E}-03$ & 0 & 0 & 0 & 0 & -9 & -12 & -10 & -21 & -10 & -891 & 1000 & 979 & 977 & 977 & 977 \\
\hline 12 & $1.8457 \mathrm{E}-02$ & 0 & 0 & 0 & 0 & -10 & -13 & -19 & -23 & -11 & -965 & 979 & 1000 & 1000 & 1000 & 1000 \\
\hline 13 & 1.9794E-02 & 0 & 0 & 0 & 0 & -10 & -13 & -19 & -23 & -11 & -967 & 977 & 1000 & 1000 & 1000 & 1000 \\
\hline 14 & $2.0032 \mathrm{E}-02$ & 0 & 0 & 0 & 0 & -10 & -13 & -19 & -23 & -11 & -967 & 977 & 1000 & 1000 & 1000 & 1000 \\
\hline 15 & $1.8435 \mathrm{E}-02$ & 0 & 0 & 0 & 0 & -10 & -13 & -19 & -23 & -11 & -967 & 977 & 1000 & 1000 & 1000 & 1000 \\
\hline
\end{tabular}

Table B.100: Relative uncertainty (relative standard deviation) and correlation (normalized to 1000) for ${ }^{208} \mathrm{~Pb}(\mathrm{n}, \mathrm{el})$

\begin{tabular}{|c|c|c|c|c|c|c|c|c|c|c|c|c|c|c|c|c|}
\hline 1 & 8 & & 117 & 120 & ? & 0 & 0 & 0 & 0 & 0 & 0 & 0 & 0 & 0 & 0 & 0 \\
\hline 1 & $8.4403 \mathrm{E}-03$ & 1000 & 442 & -139 & -92 & 0 & 0 & 0 & 0 & 0 & 0 & 0 & 0 & 0 & 0 & U \\
\hline 2 & $9.6481 \mathrm{E}-03$ & 442 & 1000 & 178 & 93 & 0 & 0 & 0 & 0 & 0 & 0 & 0 & 0 & 0 & 0 & \\
\hline 3 & $2.1281 \mathrm{E}-02$ & -139 & 178 & 1000 & 571 & 0 & 0 & 0 & 0 & 0 & 0 & 0 & 0 & 0 & 0 & 0 \\
\hline 4 & 1. $4780 \mathrm{E}-02$ & -92 & 93 & 571 & 1000 & 814 & 783 & 763 & 762 & 760 & 759 & 759 & 759 & 759 & 759 & 759 \\
\hline 5 & 1.2043E-02 & 0 & 0 & 0 & 814 & 1000 & 971 & 950 & 951 & 949 & 948 & 948 & 948 & 948 & 948 & 948 \\
\hline 6 & 1. $1021 \mathrm{E}-02$ & 0 & 0 & 0 & 783 & 971 & 1000 & 968 & 982 & 982 & 982 & 982 & 982 & 982 & 982 & 982 \\
\hline 7 & 1. $4887 \mathrm{E}-02$ & 0 & 0 & 0 & 763 & 950 & 968 & 1000 & 997 & 996 & 996 & 996 & 996 & 996 & 996 & 996 \\
\hline 8 & 1. $6523 \mathrm{E}-02$ & 0 & 0 & 0 & 762 & 951 & 982 & 997 & 1000 & 1000 & 1000 & 1000 & 1000 & 1000 & 1000 & 1000 \\
\hline 9 & $1.7193 \mathrm{E}-02$ & 0 & 0 & 0 & 760 & 949 & 982 & 996 & 1000 & 1000 & 1000 & 1000 & 1000 & 1000 & 1000 & 1000 \\
\hline 10 & $1.7453 \mathrm{E}-02$ & 0 & 0 & 0 & 759 & 948 & 982 & 996 & 1000 & 1000 & 1000 & 1000 & 1000 & 1000 & 1000 & 1000 \\
\hline 11 & $1.7458 \mathrm{E}-02$ & 0 & 0 & 0 & 759 & 948 & 982 & 996 & 1000 & 1000 & 1000 & 1000 & 1000 & 1000 & 1000 & 1000 \\
\hline 12 & $1.7459 \mathrm{E}-02$ & 0 & 0 & 0 & 759 & 948 & 982 & 996 & 1000 & 1000 & 1000 & 1000 & 1000 & 1000 & 1000 & 1000 \\
\hline 13 & $1.7461 \mathrm{E}-02$ & 0 & 0 & 0 & 759 & 948 & 982 & 996 & 1000 & 1000 & 1000 & 1000 & 1000 & 1000 & 1000 & 1000 \\
\hline 14 & $1.7460 \mathrm{E}-02$ & 0 & 0 & 0 & 759 & 948 & 982 & 996 & 1000 & 1000 & 1000 & 1000 & 1000 & 1000 & 1000 & 1000 \\
\hline 15 & 1.6887E-02 & 0 & 0 & 0 & 759 & 948 & 982 & 996 & 1000 & 1000 & 1000 & 1000 & 1000 & 1000 & 1000 & 1000 \\
\hline
\end{tabular}


Table B.101: Relative uncertainty (relative standard deviation) and correlation (normalized to 1000) for ${ }^{208} \mathrm{~Pb}\left(\mathrm{n}, \mathrm{n}^{\prime}\right)$

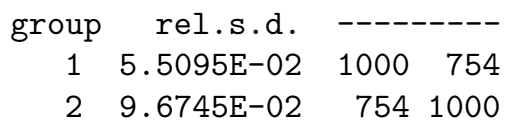

Table B.102: Relative uncertainty (relative standard deviation) and correlation (normalized to 1000) for ${ }^{208} \mathrm{~Pb}(\mathrm{n}, 2 \mathrm{n})$

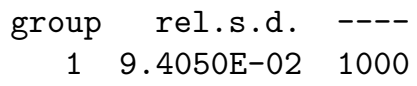


Table B.103: Relative uncertainty (relative standard deviation) and correlation (normalized to 1000) for ${ }^{208} \mathrm{~Pb}(\mathrm{n}, \gamma)$

\begin{tabular}{|c|c|c|c|c|c|c|c|c|c|c|c|c|c|c|c|c|}
\hline 1 & $2.0078 \mathrm{E}-01$ & 1000 & 226 & -533 & -91 & 0 & 0 & 0 & 0 & 0 & 0 & 0 & 0 & 0 & 0 & 0 \\
\hline 2 & 1. $2275 \mathrm{E}-01$ & 226 & 1000 & 572 & 17 & 0 & 0 & 0 & 0 & 0 & 0 & 0 & 0 & 0 & 0 & \\
\hline 3 & 4.9974E-02 & -533 & 572 & 1000 & 105 & 0 & 0 & 0 & 0 & 0 & 0 & 0 & 0 & 0 & 0 & \\
\hline 4 & $7.8146 \mathrm{E}-02$ & -91 & 17 & 105 & 1000 & 1 & 0 & 1 & 192 & 251 & 269 & 274 & 275 & 275 & 275 & 275 \\
\hline 5 & $1.9938 \mathrm{E}-01$ & 0 & 0 & 0 & 1 & 1000 & 52 & 0 & 34 & 42 & 45 & 46 & 46 & 46 & 46 & 46 \\
\hline 6 & $1.4523 \mathrm{E}-01$ & 0 & 0 & 0 & 0 & 52 & 1000 & 4 & 163 & 159 & 154 & 154 & 154 & 153 & 153 & 153 \\
\hline 7 & $4.2013 \mathrm{E}-01$ & 0 & 0 & 0 & 1 & 0 & 4 & 1000 & 24 & 22 & 22 & 22 & 22 & 22 & 22 & 22 \\
\hline 8 & $2.7498 \mathrm{E}-01$ & 0 & 0 & 0 & 192 & 34 & 163 & 24 & 1000 & 992 & 985 & 983 & 983 & 983 & 983 & 983 \\
\hline 9 & $2.7632 \mathrm{E}-01$ & 0 & 0 & 0 & 251 & 42 & 159 & 22 & 992 & 1000 & 999 & 999 & 998 & 998 & 998 & 998 \\
\hline 10 & $2.7534 \mathrm{E}-01$ & 0 & 0 & 0 & 269 & 45 & 154 & 22 & 985 & 999 & 1000 & 1000 & 1000 & 1000 & 1000 & 1000 \\
\hline 11 & $2.7507 \mathrm{E}-01$ & 0 & 0 & 0 & 274 & 46 & 154 & 22 & 983 & 999 & 1000 & 1000 & 1000 & 1000 & 1000 & 1000 \\
\hline 12 & $2.7500 \mathrm{E}-01$ & 0 & 0 & 0 & 275 & 46 & 154 & 22 & 983 & 998 & 1000 & 1000 & 1000 & 1000 & 1000 & 1000 \\
\hline 13 & $2.7501 \mathrm{E}-01$ & 0 & 0 & 0 & 275 & 46 & 153 & 22 & 983 & 998 & 1000 & 1000 & 1000 & 1000 & 1000 & 1000 \\
\hline 14 & $2.7501 \mathrm{E}-01$ & 0 & 0 & 0 & 275 & 46 & 153 & 22 & 983 & 998 & 1000 & 1000 & 1000 & 1000 & 1000 & 1000 \\
\hline 15 & $2.5265 \mathrm{E}-01$ & 0 & 0 & 0 & 275 & 46 & 153 & 22 & 983 & 998 & 1000 & 1000 & 1000 & 1000 & 1000 & 1000 \\
\hline
\end{tabular}


Table B.104: Relative uncertainty (relative standard deviation) and correlation (normalized to 1000) for ${ }^{209} \mathrm{Bi}(\mathrm{n}, \mathrm{el})$

\begin{tabular}{|c|c|c|c|c|c|c|c|c|c|c|c|c|c|c|c|c|}
\hline 1 & $8.2586 \mathrm{E}-03$ & 1000 & 587 & -214 & -169 & -123 & 0 & 0 & 0 & 0 & 0 & 0 & 0 & 0 & 0 & 0 \\
\hline 2 & $1.0191 \mathrm{E}-02$ & 587 & 1000 & 229 & 264 & 276 & 0 & 0 & 0 & 0 & 0 & 0 & 0 & 0 & 0 & 0 \\
\hline 3 & $2.0566 \mathrm{E}-02$ & -214 & 229 & 1000 & 999 & 941 & 0 & 0 & 0 & 0 & 0 & 0 & 0 & 0 & 0 & 0 \\
\hline 4 & $4.5856 \mathrm{E}-02$ & -169 & 264 & 999 & 1000 & 944 & 0 & 0 & 0 & 0 & 0 & 0 & 0 & 0 & 0 & 0 \\
\hline 5 & $2.2234 \mathrm{E}-02$ & -123 & 276 & 941 & 944 & 1000 & 326 & 326 & 233 & 317 & 324 & 322 & 321 & 321 & 320 & 320 \\
\hline 6 & $1.7950 \mathrm{E}-02$ & 0 & 0 & 0 & 0 & 326 & 1000 & 987 & 711 & 961 & 985 & 979 & 976 & 974 & 974 & 973 \\
\hline 7 & 1.8779E-02 & 0 & 0 & 0 & 0 & 326 & 987 & 1000 & 733 & 961 & 985 & 980 & 977 & 975 & 975 & 974 \\
\hline 8 & $2.4121 \mathrm{E}-02$ & 0 & 0 & 0 & 0 & 233 & 711 & 733 & 1000 & 590 & 652 & 650 & 649 & 648 & 648 & 648 \\
\hline 9 & $1.8198 \mathrm{E}-02$ & 0 & 0 & 0 & 0 & 317 & 961 & 961 & 590 & 1000 & 966 & 961 & 959 & 957 & 956 & 956 \\
\hline 10 & $1.9269 \mathrm{E}-02$ & 0 & 0 & 0 & 0 & 324 & 985 & 985 & 652 & 966 & 1000 & 999 & 998 & 997 & 997 & 996 \\
\hline 11 & $1.8483 \mathrm{E}-02$ & 0 & 0 & 0 & 0 & 322 & 979 & 980 & 650 & 961 & 999 & 1000 & 1000 & 999 & 999 & 999 \\
\hline 12 & $1.8217 \mathrm{E}-02$ & 0 & 0 & 0 & 0 & 321 & 976 & 977 & 649 & 959 & 998 & 1000 & 1000 & 1000 & 1000 & 999 \\
\hline 13 & $1.8033 \mathrm{E}-02$ & 0 & 0 & 0 & 0 & 321 & 974 & 975 & 648 & 957 & 997 & 999 & 1000 & 1000 & 1000 & 999 \\
\hline 14 & $1.7997 \mathrm{E}-02$ & 0 & 0 & 0 & 0 & 320 & 974 & 975 & 648 & 956 & 997 & 999 & 1000 & 1000 & 1000 & 999 \\
\hline 15 & $1.7782 \mathrm{E}-02$ & 0 & 0 & 0 & 0 & 320 & 973 & 974 & 648 & 956 & 996 & 999 & 999 & 999 & 999 & 1000 \\
\hline
\end{tabular}


Table B.105: Relative uncertainty (relative standard deviation) and correlation (normalized to 1000) for ${ }^{209} \operatorname{Bi}\left(\mathrm{n}, \mathrm{n}^{\prime}\right)$

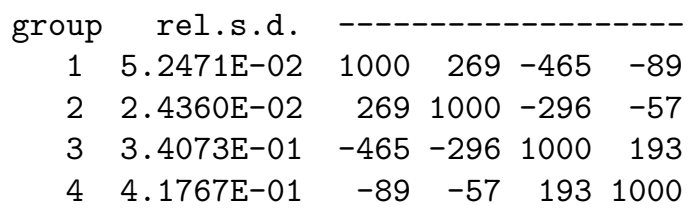

Table B.106: Relative uncertainty (relative standard deviation) and correlation (normalized to 1000) for ${ }^{209} \mathrm{Bi}(\mathrm{n}, 2 \mathrm{n})$

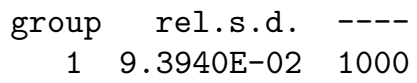


Table B.107: Relative uncertainty (relative standard deviation) and correlation (normalized to 1000) for ${ }^{209} \operatorname{Bi}(\mathrm{n}, \gamma)$

\begin{tabular}{|c|c|c|c|c|c|c|c|c|c|c|c|c|c|c|c|c|}
\hline 1 & $4.7576 \mathrm{E}-01$ & 1000 & 401 & 231 & 196 & 60 & 0 & 0 & 0 & 0 & 0 & 0 & 0 & 0 & 0 & 0 \\
\hline 2 & $2.7736 \mathrm{E}-01$ & 401 & 1000 & 935 & 873 & 603 & 0 & 0 & 0 & 0 & 0 & 0 & 0 & 0 & 0 & 0 \\
\hline 3 & $1.7559 \mathrm{E}-01$ & 231 & 935 & 1000 & 988 & 821 & 0 & 0 & 0 & 0 & 0 & 0 & 0 & 0 & 0 & 0 \\
\hline 4 & $1.1349 \mathrm{E}-01$ & 196 & 873 & 988 & 1000 & 882 & 0 & 0 & 0 & 0 & 0 & 0 & 0 & 0 & 0 & 0 \\
\hline 5 & $8.3177 \mathrm{E}-02$ & 60 & 603 & 821 & 882 & 1000 & 0 & 0 & 0 & 0 & 0 & 0 & 0 & 0 & 0 & 0 \\
\hline 6 & $8.7850 \mathrm{E}-02$ & 0 & 0 & 0 & 0 & 0 & 1000 & 1 & 0 & 0 & 0 & 1 & 0 & 0 & 0 & 0 \\
\hline 7 & $6.0521 \mathrm{E}-02$ & 0 & 0 & 0 & 0 & 0 & 1 & 1000 & 0 & 0 & 0 & 2 & 1 & 1 & 1 & 1 \\
\hline 8 & $3.8543 E-02$ & 0 & 0 & 0 & 0 & 0 & 0 & 0 & 1000 & 1 & 0 & 0 & 0 & 0 & 0 & \\
\hline 9 & $7.1031 \mathrm{E}-03$ & 0 & 0 & 0 & 0 & 0 & 0 & 0 & 1 & 1000 & 0 & 1 & 1 & 1 & 1 & 1 \\
\hline 10 & $4.2685 \mathrm{E}-03$ & 0 & 0 & 0 & 0 & 0 & 0 & 0 & 0 & 0 & 1000 & 74 & 10 & 9 & 9 & 9 \\
\hline 11 & $1.4671 \mathrm{E}-02$ & 0 & 0 & 0 & 0 & 0 & 1 & 2 & 0 & 1 & 74 & 1000 & 976 & 972 & 971 & 971 \\
\hline 12 & $1.8164 \mathrm{E}-02$ & 0 & 0 & 0 & 0 & 0 & 0 & 1 & 0 & 1 & 10 & 976 & 1000 & 1000 & 1000 & 1000 \\
\hline 13 & $1.8575 \mathrm{E}-02$ & 0 & 0 & 0 & 0 & 0 & 0 & 1 & 0 & 1 & 9 & 972 & 1000 & 1000 & 1000 & 1000 \\
\hline 14 & $1.8663 \mathrm{E}-02$ & 0 & 0 & 0 & 0 & 0 & 0 & 1 & 0 & 1 & 9 & 971 & 1000 & 1000 & 1000 & 1000 \\
\hline 15 & $1.8675 \mathrm{E}-02$ & 0 & 0 & 0 & 0 & 0 & 0 & 1 & 0 & 1 & 9 & 971 & 1000 & 1000 & 1000 & 1000 \\
\hline
\end{tabular}

Table B.108: Relative uncertainty (relative standard deviation) and correlation (normalized to 1000) for ${ }^{232} \mathrm{Th}(\mathrm{n}, \mathrm{el})$

\begin{tabular}{|c|c|c|c|c|c|c|c|c|c|c|c|c|c|c|c|c|}
\hline 1 & $1.3888 \mathrm{E}-02$ & 1000 & 189 & 74 & 74 & 102 & 101 & 0 & 0 & 0 & 0 & 0 & 0 & 0 & 0 & 0 \\
\hline 2 & 1. $2163 \mathrm{E}-02$ & 189 & 1000 & 124 & 100 & 132 & 133 & 0 & 0 & 0 & 0 & 0 & 0 & 0 & 0 & 0 \\
\hline 3 & $3.9998 \mathrm{E}-02$ & 74 & 124 & 1000 & 290 & 217 & 164 & 0 & 0 & 0 & 0 & 0 & 0 & 0 & 0 & 0 \\
\hline 4 & $1.7999 \mathrm{E}-02$ & 74 & 100 & 290 & 1000 & 262 & 171 & 0 & 0 & 0 & 0 & 0 & 0 & 0 & 0 & 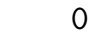 \\
\hline 5 & 1. $6491 \mathrm{E}-02$ & 102 & 132 & 217 & 262 & 1000 & 212 & 0 & 0 & 0 & 0 & 0 & 0 & 0 & 0 & 0 \\
\hline 6 & $1.1832 \mathrm{E}-02$ & 101 & 133 & 164 & 171 & 212 & 1000 & 170 & 168 & 54 & 0 & 0 & 0 & 0 & 0 & \\
\hline 7 & 4.8270E-03 & 0 & 0 & 0 & 0 & 0 & 170 & 1000 & 991 & 322 & 0 & 0 & 0 & 0 & 0 & 0 \\
\hline 8 & $3.1010 \mathrm{E}-03$ & 0 & 0 & 0 & 0 & 0 & 168 & 991 & 1000 & 335 & 0 & 0 & 0 & 0 & 0 & 0 \\
\hline 9 & $4.8340 \mathrm{E}-03$ & 0 & 0 & 0 & 0 & 0 & 54 & 322 & 335 & 1000 & -25 & -4 & -56 & -105 & -110 & -112 \\
\hline 10 & $1.5258 \mathrm{E}-02$ & 0 & 0 & 0 & 0 & 0 & 0 & 0 & 0 & -25 & 1000 & 5 & -64 & -118 & -124 & -126 \\
\hline 11 & $3.8154 \mathrm{E}-02$ & 0 & 0 & 0 & 0 & 0 & 0 & 0 & 0 & -4 & 5 & 1000 & -275 & -450 & -464 & -468 \\
\hline 12 & $1.5349 \mathrm{E}-02$ & 0 & 0 & 0 & 0 & 0 & 0 & 0 & 0 & -56 & -64 & -275 & 1000 & 505 & 496 & 492 \\
\hline 13 & $8.6288 \mathrm{E}-03$ & 0 & 0 & 0 & 0 & 0 & 0 & 0 & 0 & -105 & -118 & -450 & 505 & 1000 & 990 & 983 \\
\hline 14 & $8.0601 \mathrm{E}-03$ & 0 & 0 & 0 & 0 & 0 & 0 & 0 & 0 & -110 & -124 & -464 & 496 & 990 & 1000 & 999 \\
\hline 15 & $7.9245 E-03$ & 0 & 0 & 0 & 0 & 0 & 0 & 0 & 0 & -112 & -126 & -468 & 492 & 983 & 999 & 1000 \\
\hline
\end{tabular}


Table B.109: Relative uncertainty (relative standard deviation) and correlation (normalized to 1000) for ${ }^{232} \operatorname{Th}\left(\mathrm{n}, \mathrm{n}^{\prime}\right)$

\begin{tabular}{|c|c|c|c|c|c|c|c|}
\hline & & & & & & & \\
\hline 1 & $4.8492 \mathrm{E}-02$ & 1000 & 549 & 192 & 51 & 28 & 13 \\
\hline 2 & $3.7680 \mathrm{E}-02$ & 549 & 1000 & 267 & 54 & -41 & -43 \\
\hline 3 & $3.9432 \mathrm{E}-02$ & 192 & 267 & 1000 & 163 & -83 & -102 \\
\hline 4 & $4.4095 \mathrm{E}-02$ & 51 & 54 & 163 & 1000 & 149 & 15 \\
\hline 5 & 1. $2580 \mathrm{E}-01$ & 28 & -41 & -83 & 149 & 1000 & 206 \\
\hline 6 & $2.3602 \mathrm{E}-01$ & 13 & -43 & -102 & 15 & 206 & 1000 \\
\hline
\end{tabular}

Table B.110: Relative uncertainty (relative standard deviation) and correlation (normalized to 1000) for ${ }^{232} \mathrm{Th}(\mathrm{n}, 2 \mathrm{n})$

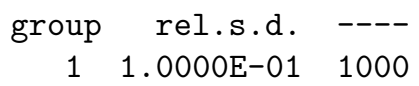

Table B.111: Relative uncertainty (relative standard deviation) and correlation (normalized to 1000) for ${ }^{232} \mathrm{Th}(\mathrm{n}, \mathrm{f})$

$\begin{array}{crrrrrrr}\text { group } & \text { rel.s.d. } & ---------1 & \\ 1 & 2.1081 \mathrm{E}-02 & 1000 & 983 & 980 & 960 & 16 & 8 \\ 2 & 2.0967 \mathrm{E}-02 & 983 & 1000 & 991 & 970 & 16 & 9 \\ 3 & 2.1031 \mathrm{E}-02 & 980 & 991 & 1000 & 974 & 16 & 9 \\ 4 & 2.1478 \mathrm{E}-02 & 960 & 970 & 974 & 1000 & 17 & 10 \\ 5 & 9.5167 \mathrm{E}-01 & 16 & 16 & 16 & 17 & 1000 & 217 \\ 6 & 4.6917 \mathrm{E}-01 & 8 & 9 & 9 & 10 & 217 & 1000\end{array}$


Table B.112: Relative uncertainty (relative standard deviation) and correlation (normalized to 1000) for ${ }^{232} \mathrm{Th}(\mathrm{n}, \gamma)$

\begin{tabular}{|c|c|c|c|c|c|c|c|c|c|c|c|c|c|c|c|c|}
\hline 1 & $1.7397 \mathrm{E}-01$ & 1000 & 36 & 5 & 11 & 9 & 5 & 0 & 0 & 0 & 0 & 0 & 0 & 0 & 0 & 0 \\
\hline 2 & $2.5666 \mathrm{E}-01$ & 36 & 1000 & 36 & 43 & 43 & 26 & 0 & 0 & 0 & 0 & 0 & 0 & 0 & 0 & 0 \\
\hline 3 & $3.4141 \mathrm{E}-02$ & 5 & 36 & 1000 & 306 & 218 & 125 & 0 & 0 & 0 & 0 & 0 & 0 & 0 & 0 & 0 \\
\hline 4 & 1.8910E-02 & 11 & 43 & 306 & 1000 & 402 & 229 & 0 & 0 & 0 & 0 & 0 & 0 & 0 & 0 & 0 \\
\hline 5 & 1. $2432 \mathrm{E}-02$ & 9 & 43 & 218 & 402 & 1000 & 342 & 0 & 0 & 0 & 0 & 0 & 0 & 0 & 0 & 0 \\
\hline 6 & 1. 1407E-02 & 5 & 26 & 125 & 229 & 342 & 1000 & 515 & 309 & 109 & 0 & 0 & 0 & 0 & 0 & 0 \\
\hline 7 & 1.3998E-02 & 0 & 0 & 0 & 0 & 0 & 515 & 1000 & 939 & 310 & 0 & 0 & 0 & 0 & 0 & 0 \\
\hline 8 & $1.4553 \mathrm{E}-02$ & 0 & 0 & 0 & 0 & 0 & 309 & 939 & 1000 & 336 & 0 & 0 & 0 & 0 & 0 & 0 \\
\hline 9 & $2.7999 \mathrm{E}-02$ & 0 & 0 & 0 & 0 & 0 & 109 & 310 & 336 & 1000 & 0 & 0 & 0 & 2 & 1 & 1 \\
\hline 10 & $3.3534 \mathrm{E}-02$ & 0 & 0 & 0 & 0 & 0 & 0 & 0 & 0 & 0 & 1000 & 0 & 0 & 3 & 3 & 2 \\
\hline 11 & $2.2069 \mathrm{E}-02$ & 0 & 0 & 0 & 0 & 0 & 0 & 0 & 0 & 0 & 0 & 1000 & 1 & 130 & 110 & 102 \\
\hline 12 & $3.2750 \mathrm{E}-02$ & 0 & 0 & 0 & 0 & 0 & 0 & 0 & 0 & 0 & 0 & 1 & 1000 & 7 & 5 & 5 \\
\hline 13 & $1.8986 \mathrm{E}-02$ & 0 & 0 & 0 & 0 & 0 & 0 & 0 & 0 & 2 & 3 & 130 & 7 & 1000 & 902 & 838 \\
\hline 14 & $1.3095 \mathrm{E}-02$ & 0 & 0 & 0 & 0 & 0 & 0 & 0 & 0 & 1 & 3 & 110 & 5 & 902 & 1000 & 991 \\
\hline 15 & $1.2506 \mathrm{E}-02$ & 0 & 0 & 0 & 0 & 0 & 0 & 0 & 0 & 1 & 2 & 102 & 5 & 838 & 991 & 1000 \\
\hline
\end{tabular}

Table B.113: Relative uncertainty (relative standard deviation) and correlation (normalized to 1000) for ${ }^{233} \mathrm{U}(\mathrm{n}, \mathrm{el})$

\begin{tabular}{|c|c|c|c|c|c|c|c|c|c|c|c|c|c|c|c|c|}
\hline 1 & $2.5116 \mathrm{E}-02$ & 1000 & 979 & 391 & 15 & 193 & -16 & -131 & -137 & 0 & 0 & 0 & 0 & 0 & 0 & 0 \\
\hline 2 & $4.0235 E-02$ & 979 & 1000 & 543 & -16 & 205 & 119 & 44 & 37 & 0 & 0 & 0 & 0 & 0 & 0 & 0 \\
\hline 3 & $3.0006 \mathrm{E}-02$ & 391 & 543 & 1000 & -20 & 144 & 666 & 809 & 807 & 0 & 0 & 0 & 0 & 0 & 0 & 0 \\
\hline 4 & $1.8815 \mathrm{E}-02$ & 15 & -16 & -20 & 1000 & 102 & -116 & -159 & -159 & 0 & 0 & 0 & 0 & 0 & 0 & 0 \\
\hline 5 & $2.4931 \mathrm{E}-02$ & 193 & 205 & 144 & 102 & 1000 & 148 & 88 & 85 & 0 & 0 & 0 & 0 & 0 & 0 & $\checkmark$ \\
\hline 6 & $3.1580 \mathrm{E}-02$ & -16 & 119 & 666 & -116 & 148 & 1000 & 785 & 784 & 0 & 0 & 0 & 0 & 0 & 0 & 0 \\
\hline 7 & $4.0601 \mathrm{E}-02$ & -131 & 44 & 809 & -159 & 88 & 785 & 1000 & 1000 & 0 & 0 & 0 & 0 & 0 & 0 & 0 \\
\hline 8 & $4.1873 E-02$ & -137 & 37 & 807 & -159 & 85 & 784 & 1000 & 1000 & 0 & 0 & 0 & 0 & 0 & 0 & 0 \\
\hline 9 & $9.0405 \mathrm{E}-02$ & 0 & 0 & 0 & 0 & 0 & 0 & 0 & 0 & 1000 & 317 & 332 & 340 & 356 & 276 & 66 \\
\hline 10 & $6.1702 \mathrm{E}-02$ & 0 & 0 & 0 & 0 & 0 & 0 & 0 & 0 & 317 & 1000 & 997 & 996 & 961 & 658 & 155 \\
\hline 11 & $6.0022 \mathrm{E}-02$ & 0 & 0 & 0 & 0 & 0 & 0 & 0 & 0 & 332 & 997 & 1000 & 998 & 964 & 665 & 157 \\
\hline 12 & $5.6089 \mathrm{E}-02$ & 0 & 0 & 0 & 0 & 0 & 0 & 0 & 0 & 340 & 996 & 998 & 1000 & 972 & 680 & 166 \\
\hline 13 & $4.1560 \mathrm{E}-02$ & 0 & 0 & 0 & 0 & 0 & 0 & 0 & 0 & 356 & 961 & 964 & 972 & 1000 & 758 & 276 \\
\hline 14 & $2.1388 \mathrm{E}-02$ & 0 & 0 & 0 & 0 & 0 & 0 & 0 & 0 & 276 & 658 & 665 & 680 & 758 & 1000 & 251 \\
\hline 15 & $5.3372 \mathrm{E}-02$ & 0 & 0 & 0 & 0 & 0 & 0 & 0 & 0 & 66 & 155 & 157 & 166 & 276 & 251 & 1000 \\
\hline
\end{tabular}


Table B.114: Relative uncertainty (relative standard deviation) and correlation (normalized to 1000) for ${ }^{233} \mathrm{U}\left(\mathrm{n}, \mathrm{n}^{\prime}\right)$

$\begin{array}{crrrrrr}\text { group } & \text { rel.s.d. } & ---1 & - & \\ 1 & 1.0788 \mathrm{E}-01 & 1000 & -741 & -35 & 64 & 0 \\ 2 & 4.4824 \mathrm{E}-02 & -741 & 1000 & 43 & -95 & 0 \\ 3 & 3.1576 \mathrm{E}-01 & -35 & 43 & 1000 & 980 & 0 \\ 4 & 4.0461 \mathrm{E}-01 & 64 & -95 & 980 & 1000 & 139 \\ 5 & 1.4291 \mathrm{E}-01 & 0 & 0 & 0 & 139 & 1000\end{array}$

Table B.115: Relative uncertainty (relative standard deviation) and correlation (normalized to 1000) for ${ }^{233} \mathrm{U}(\mathrm{n}, 2 \mathrm{n})$

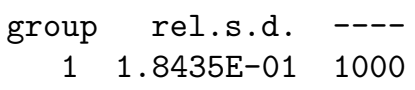

Table B.116: Relative uncertainty (relative standard deviation) and correlation (normalized to 1000) for ${ }^{233} \mathrm{U}(\mathrm{n}, \mathrm{f})$

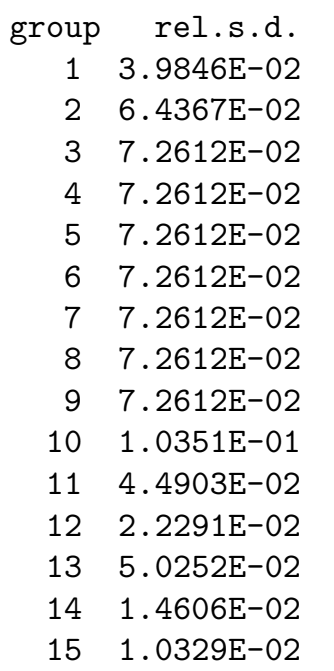

$\begin{array}{rrrrrrrrrrrrrrr}1000 & 795 & 291 & 291 & 291 & 291 & 291 & 291 & 291 & 3 & 0 & 0 & 0 & 0 & 0 \\ 795 & 1000 & 718 & 718 & 718 & 718 & 718 & 718 & 718 & 8 & 0 & 0 & 0 & 0 & 0 \\ 291 & 718 & 1000 & 1000 & 1000 & 1000 & 1000 & 1000 & 1000 & 11 & 0 & 0 & 0 & 0 & 0 \\ 291 & 718 & 1000 & 1000 & 1000 & 1000 & 1000 & 1000 & 1000 & 11 & 0 & 0 & 0 & 0 & 0 \\ 291 & 718 & 1000 & 1000 & 1000 & 1000 & 1000 & 1000 & 1000 & 11 & 0 & 0 & 0 & 0 & 0 \\ 291 & 718 & 1000 & 1000 & 1000 & 1000 & 1000 & 1000 & 1000 & 11 & 0 & 0 & 0 & 0 & 0 \\ 291 & 718 & 1000 & 1000 & 1000 & 1000 & 1000 & 1000 & 1000 & 11 & 0 & 0 & 0 & 0 & 0 \\ 291 & 718 & 1000 & 1000 & 1000 & 1000 & 1000 & 1000 & 1000 & 11 & 0 & 0 & 0 & 0 & 0 \\ 291 & 718 & 1000 & 1000 & 1000 & 1000 & 1000 & 1000 & 1000 & 11 & 0 & 0 & 0 & 0 & 0 \\ 3 & 8 & 11 & 11 & 11 & 11 & 11 & 11 & 11 & 1000 & 17 & -3 & 1 & 1 & 1 \\ 0 & 0 & 0 & 0 & 0 & 0 & 0 & 0 & 0 & 17 & 1000 & 21 & 1 & 4 & 2 \\ 0 & 0 & 0 & 0 & 0 & 0 & 0 & 0 & 0 & -3 & 21 & 1000 & 30 & 55 & 51 \\ 0 & 0 & 0 & 0 & 0 & 0 & 0 & 0 & 0 & 1 & 1 & 30 & 1000 & 148 & 146 \\ 0 & 0 & 0 & 0 & 0 & 0 & 0 & 0 & 0 & 1 & 4 & 55 & 148 & 1000 & 948 \\ 0 & 0 & 0 & 0 & 0 & 0 & 0 & 0 & 0 & 1 & 2 & 51 & 146 & 948 & 1000\end{array}$


Table B.117: Relative uncertainty (relative standard deviation) and correlation (normalized to 1000) for ${ }^{233} \mathrm{U}(\mathrm{n}, \gamma)$

\begin{tabular}{|c|c|c|c|c|c|c|c|c|c|c|c|c|c|c|c|c|}
\hline 1 & $5.7014 \mathrm{E}-01$ & 1000 & 409 & 458 & 498 & 498 & -104 & -297 & -303 & -317 & -16 & 0 & 0 & 0 & 0 & S \\
\hline 2 & $6.1402 \mathrm{E}-01$ & 409 & 1000 & 988 & 953 & 767 & -451 & -726 & -732 & -750 & -37 & 0 & 0 & 0 & 0 & \\
\hline 3 & $3.8879 \mathrm{E}-01$ & 458 & 988 & 1000 & 988 & 839 & -405 & -712 & -719 & -740 & -36 & 0 & 0 & 0 & 0 & \\
\hline 4 & $3.0350 \mathrm{E}-01$ & 498 & 953 & 988 & 1000 & 872 & -391 & -714 & -723 & -745 & -37 & 0 & 0 & 0 & 0 & \\
\hline 5 & $1.0617 \mathrm{E}-01$ & 498 & 767 & 839 & 872 & 1000 & 104 & -289 & -301 & -332 & -18 & 0 & 0 & 0 & 0 & \\
\hline 6 & 8.9427E-02 & -104 & -451 & -405 & -391 & 104 & 1000 & 922 & 917 & 903 & 42 & 0 & 0 & 0 & 0 & \\
\hline 7 & 1. $3287 \mathrm{E}-01$ & -297 & -726 & -712 & -714 & -289 & 922 & 1000 & 1000 & 999 & 47 & 0 & 0 & 0 & 0 & \\
\hline 8 & 1. $3516 \mathrm{E}-01$ & -303 & -732 & -719 & -723 & -301 & 917 & 1000 & 1000 & 999 & 47 & 0 & 0 & 0 & 0 & \\
\hline 9 & 1. $4193 \mathrm{E}-01$ & -317 & -750 & -740 & -745 & -332 & 903 & 999 & 999 & 1000 & 48 & 0 & 0 & 0 & 0 & \\
\hline 10 & $7.9236 \mathrm{E}-02$ & -16 & -37 & -36 & -37 & -18 & 42 & 47 & 47 & 48 & 1000 & 21 & 1 & 0 & 0 & \\
\hline 11 & 4. $2773 \mathrm{E}-02$ & 0 & 0 & 0 & 0 & 0 & 0 & 0 & 0 & 0 & 21 & 1000 & 5 & 0 & 0 & \\
\hline 12 & $3.0200 \mathrm{E}-02$ & 0 & 0 & 0 & 0 & 0 & 0 & 0 & 0 & 0 & 1 & 5 & 1000 & 40 & 14 & \\
\hline 13 & $9.0560 \mathrm{E}-02$ & 0 & 0 & 0 & 0 & 0 & 0 & 0 & 0 & 0 & 0 & 0 & 40 & 1000 & 114 & -57 \\
\hline 14 & $2.5871 \mathrm{E}-02$ & 0 & 0 & 0 & 0 & 0 & 0 & 0 & 0 & 0 & 0 & 0 & 14 & 114 & 1000 & -706 \\
\hline 15 & $4.2279 \mathrm{E}-02$ & 0 & 0 & 0 & 0 & 0 & 0 & 0 & 0 & 0 & 0 & 0 & 0 & -57 & -706 & 1000 \\
\hline
\end{tabular}

Table B.118: Relative uncertainty (relative standard deviation) and correlation (normalized to 1000) for ${ }^{234} \mathrm{U}(\mathrm{n}, \mathrm{el})$

\begin{tabular}{|c|c|c|c|c|c|c|c|c|c|c|c|c|c|c|c|c|}
\hline 1 & $1.6025 \mathrm{E}-02$ & 1000 & -244 & 181 & -20 & -188 & -75 & 0 & 0 & 0 & 0 & 0 & 0 & 0 & 0 & 0 \\
\hline 2 & $2.0591 \mathrm{E}-02$ & -244 & 1000 & 255 & -6 & -51 & -16 & 0 & 0 & 0 & 0 & 0 & 0 & 0 & 0 & 0 \\
\hline 3 & $4.8813 \mathrm{E}-02$ & 181 & 255 & 1000 & 25 & -708 & -289 & 0 & 0 & 0 & 0 & 0 & 0 & 0 & 0 & 0 \\
\hline 4 & $2.0031 \mathrm{E}-02$ & -20 & -6 & 25 & 1000 & 125 & 33 & 0 & 0 & 0 & 0 & 0 & 0 & 0 & 0 & \\
\hline 5 & $2.7521 \mathrm{E}-02$ & -188 & -51 & -708 & 125 & 1000 & 309 & 0 & 0 & 0 & 0 & 0 & 0 & 0 & 0 & \\
\hline 6 & 1. $6014 \mathrm{E}-02$ & -75 & -16 & -289 & 33 & 309 & 1000 & 929 & 925 & 898 & 0 & 0 & 0 & 0 & 0 & \\
\hline 7 & $5.3037 \mathrm{E}-02$ & 0 & 0 & 0 & 0 & 0 & 929 & 1000 & 996 & 967 & 0 & 0 & 0 & 0 & 0 & \\
\hline 8 & $4.8568 \mathrm{E}-02$ & 0 & 0 & 0 & 0 & 0 & 925 & 996 & 1000 & 972 & 0 & 0 & 0 & 0 & 0 & \\
\hline 9 & $3.5837 \mathrm{E}-02$ & 0 & 0 & 0 & 0 & 0 & 898 & 967 & 972 & 1000 & 3 & 2 & 1 & 30 & 30 & 30 \\
\hline 10 & $6.9420 \mathrm{E}-02$ & 0 & 0 & 0 & 0 & 0 & 0 & 0 & 0 & 3 & 1000 & 5 & 2 & 54 & 55 & 54 \\
\hline 11 & $2.3161 \mathrm{E}-01$ & 0 & 0 & 0 & 0 & 0 & 0 & 0 & 0 & 2 & 5 & 1000 & -5 & -25 & -13 & -11 \\
\hline 12 & $1.7123 \mathrm{E}-01$ & 0 & 0 & 0 & 0 & 0 & 0 & 0 & 0 & 1 & 2 & -5 & 1000 & 44 & 43 & 43 \\
\hline 13 & $2.3248 \mathrm{E}-02$ & 0 & 0 & 0 & 0 & 0 & 0 & 0 & 0 & 30 & 54 & -25 & 44 & 1000 & 983 & 969 \\
\hline 14 & $2.0174 \mathrm{E}-02$ & 0 & 0 & 0 & 0 & 0 & 0 & 0 & 0 & 30 & 55 & -13 & 43 & 983 & 1000 & 998 \\
\hline 15 & 1. $9753 \mathrm{E}-02$ & 0 & 0 & 0 & 0 & 0 & 0 & 0 & 0 & 30 & 54 & -11 & 43 & 969 & 998 & 1000 \\
\hline
\end{tabular}


Table B.119: Relative uncertainty (relative standard deviation) and correlation (normalized to 1000) for ${ }^{234} \mathrm{U}\left(\mathrm{n}, \mathrm{n}^{\prime}\right)$

$\begin{array}{crrrrrrr}\text { group } & \text { rel.s.d. } & ----1 & --164 \\ 1 & 3.2405 \mathrm{E}-01 & 1000 & -953 & -971 & -169 & -164 & -163 \\ 2 & 2.9448 \mathrm{E}-01 & -953 & 1000 & 995 & -82 & -84 & -84 \\ 3 & 2.1152 \mathrm{E}-01 & -971 & 995 & 1000 & 9 & 1 & -1 \\ 4 & 1.4608 \mathrm{E}-01 & -169 & -82 & 9 & 1000 & 995 & 992 \\ 5 & 2.5974 \mathrm{E}-01 & -164 & -84 & 1 & 995 & 1000 & 1000 \\ 6 & 3.1494 \mathrm{E}-01 & -163 & -84 & -1 & 992 & 1000 & 1000\end{array}$

Table B.120: Relative uncertainty (relative standard deviation) and correlation (normalized to 1000) for ${ }^{234} \mathrm{U}(\mathrm{n}, 2 \mathrm{n})$

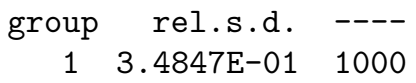

Table B.121: Relative uncertainty (relative standard deviation) and correlation (normalized to 1000) for ${ }^{234} \mathrm{U}(\mathrm{n}, \mathrm{f})$

\begin{tabular}{|c|c|c|c|c|c|c|c|c|c|c|c|c|c|c|c|c|}
\hline 1 & 1.2897E-01 & 1000 & 314 & 243 & 7 & 7 & 7 & 0 & 0 & 0 & 0 & 0 & 0 & 0 & 0 & 0 \\
\hline 2 & $2.3521 \mathrm{E}-01$ & 314 & 1000 & 978 & 944 & 944 & 937 & 0 & 0 & 0 & 0 & 0 & 0 & 0 & 0 & 0 \\
\hline 3 & 1. $3834 \mathrm{E}-01$ & 243 & 978 & 1000 & 921 & 921 & 915 & 0 & 0 & 0 & 0 & 0 & 0 & 0 & 0 & 0 \\
\hline 4 & $3.7974 \mathrm{E}-01$ & 7 & 944 & 921 & 1000 & 1000 & 993 & 0 & 0 & 0 & 0 & 0 & 0 & 0 & 0 & 0 \\
\hline 5 & $3.7974 \mathrm{E}-01$ & 7 & 944 & 921 & 1000 & 1000 & 993 & 0 & 0 & 0 & 0 & 0 & 0 & 0 & 0 & 0 \\
\hline 6 & $3.1605 \mathrm{E}-01$ & 7 & 937 & 915 & 993 & 993 & 1000 & 122 & 122 & 119 & 2 & 0 & 0 & 0 & 0 & 0 \\
\hline 7 & $2.2840 \mathrm{E}-01$ & 0 & 0 & 0 & 0 & 0 & 122 & 1000 & 999 & 976 & 18 & 0 & 0 & 0 & 0 & 0 \\
\hline 8 & $1.9411 \mathrm{E}-01$ & 0 & 0 & 0 & 0 & 0 & 122 & 999 & 1000 & 981 & 18 & 0 & 0 & 0 & 0 & \\
\hline 9 & 1. $3692 \mathrm{E}-01$ & 0 & 0 & 0 & 0 & 0 & 119 & 976 & 981 & 1000 & 17 & 0 & 0 & 0 & 0 & 0 \\
\hline 10 & 1. $4972 \mathrm{E}-01$ & 0 & 0 & 0 & 0 & 0 & 2 & 18 & 18 & 17 & 1000 & 15 & 0 & 2 & 1 & \\
\hline 11 & $5.1074 \mathrm{E}-02$ & 0 & 0 & 0 & 0 & 0 & 0 & 0 & 0 & 0 & 15 & 1000 & 0 & 1 & 1 & \\
\hline 12 & $1.7489 \mathrm{E}-01$ & 0 & 0 & 0 & 0 & 0 & 0 & 0 & 0 & 0 & 0 & 0 & 1000 & 51 & 18 & 17 \\
\hline 13 & $2.1849 \mathrm{E}-01$ & 0 & 0 & 0 & 0 & 0 & 0 & 0 & 0 & 0 & 2 & 1 & 51 & 1000 & 998 & 998 \\
\hline 14 & $2.4671 \mathrm{E}-01$ & 0 & 0 & 0 & 0 & 0 & 0 & 0 & 0 & 0 & 1 & 1 & 18 & 998 & 1000 & 1000 \\
\hline 15 & $2.4806 \mathrm{E}-01$ & 0 & 0 & 0 & 0 & 0 & 0 & 0 & 0 & 0 & 1 & 1 & 17 & 998 & 1000 & 1000 \\
\hline
\end{tabular}


Table B.122: Relative uncertainty (relative standard deviation) and correlation (normalized to 1000) for ${ }^{234} \mathrm{U}(\mathrm{n}, \gamma)$

\begin{tabular}{|c|c|c|c|c|c|c|c|c|c|c|c|c|c|c|c|c|}
\hline 1 & $5.6740 \mathrm{E}-01$ & 1000 & 710 & 404 & 149 & 4 & 20 & 0 & 0 & 0 & 0 & 0 & 0 & 0 & 0 & 0 \\
\hline 2 & $2.6106 \mathrm{E}-01$ & 710 & 1000 & 784 & 304 & -42 & 29 & 0 & 0 & 0 & 0 & 0 & 0 & 0 & 0 & 0 \\
\hline 3 & $1.5911 \mathrm{E}-01$ & 404 & 784 & 1000 & 584 & 76 & 223 & 0 & 0 & 0 & 0 & 0 & 0 & 0 & 0 & 0 \\
\hline 4 & 1. 1992E-01 & 149 & 304 & 584 & 1000 & 837 & 768 & 0 & 0 & 0 & 0 & 0 & 0 & 0 & 0 & 0 \\
\hline 5 & 1. 3981E-01 & 4 & -42 & 76 & 837 & 1000 & 764 & 0 & 0 & 0 & 0 & 0 & 0 & 0 & 0 & 0 \\
\hline 6 & 1. $2921 \mathrm{E}-01$ & 20 & 29 & 223 & 768 & 764 & 1000 & 559 & 559 & 558 & 385 & 0 & 0 & 0 & 0 & 0 \\
\hline 7 & $2.2717 \mathrm{E}-01$ & 0 & 0 & 0 & 0 & 0 & 559 & 1000 & 1000 & 998 & 688 & 0 & 0 & 0 & 0 & 0 \\
\hline 8 & $1.9156 \mathrm{E}-01$ & 0 & 0 & 0 & 0 & 0 & 559 & 1000 & 1000 & 999 & 689 & 0 & 0 & 0 & 0 & 0 \\
\hline 9 & $1.1529 \mathrm{E}-01$ & 0 & 0 & 0 & 0 & 0 & 558 & 998 & 999 & 1000 & 696 & 0 & 0 & 0 & 0 & 0 \\
\hline 10 & $1.8562 \mathrm{E}-02$ & 0 & 0 & 0 & 0 & 0 & 385 & 688 & 689 & 696 & 1000 & 7 & 0 & 0 & 0 & 0 \\
\hline 11 & $2.4153 \mathrm{E}-02$ & 0 & 0 & 0 & 0 & 0 & 0 & 0 & 0 & 0 & 7 & 1000 & 2 & 6 & 14 & 12 \\
\hline 12 & $1.3763 \mathrm{E}-02$ & 0 & 0 & 0 & 0 & 0 & 0 & 0 & 0 & 0 & 0 & 2 & 1000 & 949 & 679 & 538 \\
\hline 13 & $9.3406 \mathrm{E}-02$ & 0 & 0 & 0 & 0 & 0 & 0 & 0 & 0 & 0 & 0 & 6 & 949 & 1000 & 768 & 631 \\
\hline 14 & $3.0754 \mathrm{E}-02$ & 0 & 0 & 0 & 0 & 0 & 0 & 0 & 0 & 0 & 0 & 14 & 679 & 768 & 1000 & 981 \\
\hline 15 & $2.9278 \mathrm{E}-02$ & 0 & 0 & 0 & 0 & 0 & 0 & 0 & 0 & 0 & 0 & 12 & 538 & 631 & 981 & 1000 \\
\hline
\end{tabular}


Table B.123: Relative uncertainty (relative standard deviation) and correlation (normalized to 1000) for ${ }^{236} \mathrm{U}(\mathrm{n}, \mathrm{el})$

\begin{tabular}{|c|c|c|c|c|c|c|c|c|c|c|c|c|c|c|c|c|}
\hline 1 & $1.0090 \mathrm{E}-02$ & 1000 & 998 & 1000 & -994 & -1000 & -985 & 0 & 0 & 0 & 0 & 0 & 0 & 0 & 0 & \\
\hline 2 & $8.9130 \mathrm{E}-03$ & 998 & 1000 & 998 & -999 & -999 & -985 & 0 & 0 & 0 & & & & & 0 & \\
\hline 3 & $3.8391 \mathrm{E}-02$ & 1000 & 998 & 1000 & -994 & -1000 & -985 & 0 & 0 & 0 & 0 & c & & & b & \\
\hline 4 & $6.5408 \mathrm{E}-03$ & -994 & -999 & -994 & 1000 & 996 & 982 & 0 & 0 & c & & & & & & \\
\hline 5 & $3.3384 \mathrm{E}-02$ & -1000 & -999 & -1000 & 996 & 1000 & 986 & 0 & 0 & 0 & 0 & 0 & c & & & \\
\hline 6 & $1.4267 \mathrm{E}-02$ & -985 & -985 & -985 & 982 & 986 & 1000 & 168 & 168 & 75 & ( & 0 & & & & \\
\hline 7 & $7.5595 \mathrm{E}-03$ & 0 & 0 & 0 & 0 & 0 & 168 & 1000 & 1000 & 449 & & & & & & \\
\hline 8 & $4.6211 \mathrm{E}-03$ & 0 & 0 & 0 & & c & 168 & 1000 & 1000 & 449 & 0 & 0 & 0 & & 0 & \\
\hline 9 & $4.5608 \mathrm{E}-03$ & 0 & 0 & 0 & 0 & c & 75 & 449 & 449 & 1000 & 274 & 160 & 146 & 128 & 120 & 18 \\
\hline 10 & $2.2647 \mathrm{E}-02$ & 0 & 0 & 0 & 0 & 0 & 0 & 0 & 0 & 274 & 1000 & 170 & 163 & 149 & 140 & 3 \\
\hline 11 & $5.9574 \mathrm{E}-02$ & 0 & 0 & 0 & 0 & 0 & 0 & 0 & 0 & 160 & 170 & 1000 & 173 & 191 & 188 & $18^{\circ}$ \\
\hline 12 & 2.348 & 0 & 0 & 0 & & c & & 0 & 0 & 146 & 163 & 173 & 1000 & 840 & 833 & 833 \\
\hline 13 & 4.76 & $c$ & 0 & 0 & & & & & & 12 & 14 & 1 & 840 & 1000 & 1000 & 99 \\
\hline 14 & $4.9096 \mathrm{E}-02$ & c & 0 & 0 & $c$ & 0 & & 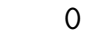 & 0 & 120 & & 188 & 833 & 1000 & 1000 & 1000 \\
\hline 15 & $4.8916 \mathrm{E}-02$ & 0 & 0 & 0 & 0 & 0 & 0 & 0 & 0 & 118 & 139 & 187 & 833 & 999 & 1000 & 100 \\
\hline
\end{tabular}

Table B.124: Relative uncertainty (relative standard deviation) and correlation (normalized to 1000) for ${ }^{236} \mathrm{U}\left(\mathrm{n}, \mathrm{n}^{\prime}\right)$

\begin{tabular}{|c|c|c|c|c|c|c|c|}
\hline oup & rel.s.d. & & & & & & \\
\hline 1 & $3.2822 \mathrm{E}-01$ & 1000 & 216 & -330 & -379 & -396 & -399 \\
\hline 2 & $7.0718 \mathrm{E}-02$ & 216 & 1000 & 136 & -136 & -315 & -496 \\
\hline 3 & $1.5454 \mathrm{E}-01$ & -330 & 136 & 1000 & 963 & 897 & 793 \\
\hline 4 & $3.7202 \mathrm{E}-01$ & -379 & -136 & 963 & 1000 & 983 & 928 \\
\hline 5 & $3.8022 \mathrm{E}-01$ & -396 & -315 & 897 & 983 & 1000 & 980 \\
\hline 6 & $3.4141 \mathrm{E}-01$ & -399 & -496 & 793 & 928 & 980 & 1000 \\
\hline
\end{tabular}


Table B.125: Relative uncertainty (relative standard deviation) and correlation (normalized to 1000) for ${ }^{236} \mathrm{U}(\mathrm{n}, 2 \mathrm{n})$

$\begin{array}{crc}\text { group } & \text { rel.s.d. } & ---- \\ 1 & 1.8490 \mathrm{E}-01 & 1000\end{array}$

Table B.126: Relative uncertainty (relative standard deviation) and correlation (normalized to 1000) for ${ }^{236} \mathrm{U}(\mathrm{n}, \mathrm{f})$

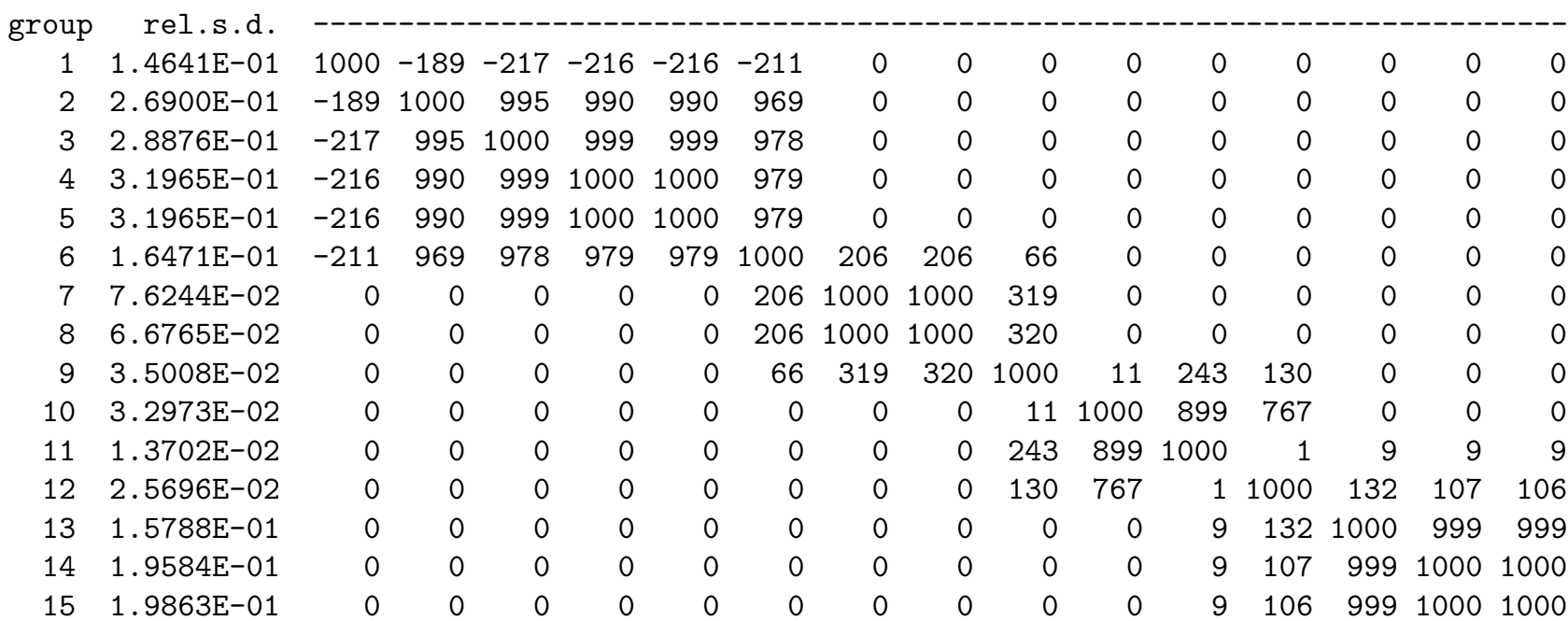

Table B.127: Relative uncertainty (relative standard deviation) and correlation (normalized to 1000) for ${ }^{236} \mathrm{U}(\mathrm{n}, \gamma)$

\begin{tabular}{|c|c|c|c|c|c|c|c|c|c|c|c|c|c|c|c|c|}
\hline 1 & ret.s.d. & & & & & & & & & & & & & & & \\
\hline 1 & $4.8320 \mathrm{E}-01$ & 1000 & 998 & 999 & 523 & 337 & -217 & 0 & 0 & 0 & 0 & 0 & 0 & 0 & 0 & 0 \\
\hline 2 & $4.7921 \mathrm{E}-01$ & 998 & 1000 & 996 & 479 & 289 & -264 & 0 & 0 & 0 & 0 & 0 & 0 & 0 & 0 & 0 \\
\hline 3 & $3.5996 \mathrm{E}-01$ & 999 & 996 & 1000 & 560 & 378 & -175 & 0 & 0 & 0 & 0 & 0 & 0 & 0 & 0 & 0 \\
\hline 4 & $1.5096 \mathrm{E}-01$ & 523 & 479 & 560 & 1000 & 979 & 686 & 0 & 0 & 0 & 0 & 0 & 0 & 0 & 0 & 0 \\
\hline 5 & $1.4251 \mathrm{E}-01$ & 337 & 289 & 378 & 979 & 1000 & 810 & 0 & 0 & 0 & 0 & 0 & 0 & 0 & 0 & 0 \\
\hline 6 & $1.0527 \mathrm{E}-01$ & -217 & -264 & -175 & 686 & 810 & 1000 & 271 & 271 & 269 & 0 & 0 & 0 & 0 & 0 & 0 \\
\hline 7 & $7.8404 \mathrm{E}-02$ & 0 & 0 & 0 & 0 & 0 & 271 & 1000 & 1000 & 994 & 0 & 0 & 0 & 0 & 0 & 0 \\
\hline 8 & $7.0376 \mathrm{E}-02$ & 0 & 0 & 0 & 0 & 0 & 271 & 1000 & 1000 & 994 & 0 & 0 & 0 & 0 & 0 & 0 \\
\hline 9 & $3.8857 \mathrm{E}-02$ & 0 & 0 & 0 & 0 & 0 & 269 & 994 & 994 & 1000 & 4 & 0 & 0 & 0 & 0 & 0 \\
\hline 10 & 1. 2353E-02 & 0 & 0 & 0 & 0 & 0 & 0 & 0 & 0 & 4 & 1000 & 20 & 0 & 1 & 2 & 2 \\
\hline 11 & 1. 1976E-02 & 0 & 0 & 0 & 0 & 0 & 0 & 0 & 0 & 0 & 20 & 1000 & 1 & 18 & 42 & 42 \\
\hline 12 & $4.3545 \mathrm{E}-03$ & 0 & 0 & 0 & 0 & 0 & 0 & 0 & 0 & 0 & 0 & 1 & 1000 & 327 & 271 & 254 \\
\hline 13 & $3.4700 \mathrm{E}-02$ & 0 & 0 & 0 & 0 & 0 & 0 & 0 & 0 & 0 & 1 & 18 & 327 & 1000 & 759 & 722 \\
\hline 14 & $3.4440 \mathrm{E}-02$ & 0 & 0 & 0 & 0 & 0 & 0 & 0 & 0 & 0 & 2 & 42 & 271 & 759 & 1000 & 998 \\
\hline 15 & $3.5764 \mathrm{E}-02$ & 0 & 0 & 0 & 0 & 0 & 0 & 0 & 0 & 0 & 2 & 42 & 254 & 722 & 998 & 1000 \\
\hline
\end{tabular}


Table B.128: Relative uncertainty (relative standard deviation) and correlation (normalized to 1000) for ${ }^{238} \mathrm{U}(\mathrm{n}, \mathrm{el})$

\begin{tabular}{|c|c|c|c|c|c|c|c|c|c|c|c|c|c|c|c|c|}
\hline & & & & & & & & & & & & & & & & \\
\hline 1 & 2.9917E-02 & 1000 & 468 & 80 & 116 & 51 & -9 & -2 & 0 & 0 & 0 & 0 & 0 & 0 & 0 & 0 \\
\hline 2 & $9.8646 \mathrm{E}-02$ & 468 & 1000 & 686 & 6 & 37 & 7 & 3 & 0 & 0 & 0 & 0 & 0 & 0 & 0 & 0 \\
\hline 3 & $5.1728 \mathrm{E}-02$ & 80 & 686 & 1000 & 156 & 44 & 3 & 1 & 0 & 0 & 0 & 0 & 0 & 0 & 0 & 0 \\
\hline 4 & $7.3899 \mathrm{E}-03$ & 116 & 6 & 156 & 1000 & 420 & 38 & 9 & 0 & 0 & 0 & 0 & 0 & 0 & 0 & \\
\hline 5 & $4.8049 \mathrm{E}-03$ & 51 & 37 & 44 & 420 & 1000 & 170 & 12 & 0 & 0 & 0 & 0 & 0 & 0 & 0 & \\
\hline 6 & $9.5875 E-03$ & -9 & 7 & 3 & 38 & 170 & 1000 & 762 & 585 & 0 & 0 & 0 & 0 & 0 & 0 & \\
\hline 7 & $1.8622 \mathrm{E}-02$ & -2 & 3 & 1 & 9 & 12 & 762 & 1000 & 953 & 0 & 0 & 0 & 0 & 0 & 0 & \\
\hline 8 & $2.8961 \mathrm{E}-02$ & 0 & 0 & 0 & 0 & 0 & 585 & 953 & 1000 & 0 & 0 & 0 & 0 & 0 & 0 & \\
\hline 9 & $1.4972 \mathrm{E}-03$ & 0 & 0 & 0 & 0 & 0 & 0 & 0 & 0 & 1000 & 0 & 0 & 0 & 0 & 0 & \\
\hline 10 & $4.7315 \mathrm{E}-03$ & 0 & 0 & 0 & 0 & 0 & 0 & 0 & 0 & 0 & 1000 & 10 & -2 & -3 & -4 & -4 \\
\hline 11 & $1.5274 \mathrm{E}-02$ & 0 & 0 & 0 & 0 & 0 & 0 & 0 & 0 & 0 & 10 & 1000 & -633 & 444 & 423 & 420 \\
\hline 12 & $3.0734 \mathrm{E}-01$ & 0 & 0 & 0 & 0 & 0 & 0 & 0 & 0 & 0 & -2 & -633 & 1000 & -963 & -962 & -961 \\
\hline 13 & $8.5536 \mathrm{E}-03$ & 0 & 0 & 0 & 0 & 0 & 0 & 0 & 0 & 0 & -3 & 444 & -963 & 1000 & 999 & 999 \\
\hline 14 & $7.2937 \mathrm{E}-03$ & 0 & 0 & 0 & 0 & 0 & 0 & 0 & 0 & 0 & -4 & 423 & -962 & 999 & 1000 & 1000 \\
\hline 15 & $7.1430 \mathrm{E}-03$ & 0 & 0 & 0 & 0 & 0 & 0 & 0 & 0 & 0 & -4 & 420 & -961 & 999 & 1000 & 1000 \\
\hline
\end{tabular}

Table B.129: Relative uncertainty (relative standard deviation) and correlation (normalized to 1000) for ${ }^{238} \mathrm{U}\left(\mathrm{n}, \mathrm{n}^{\prime}\right)$

$\begin{array}{crrrrrrrr}\text { group } & \text { rel.s.d. } & ----140 & -10 & -11 \\ 1 & 1.0006 \mathrm{E}-01 & 1000 & 525 & 70 & 40 & -90 & -149 & -1 \\ 2 & 1.4271 \mathrm{E}-01 & 525 & 1000 & 691 & -21 & 18 & 23 & 18 \\ 3 & 5.7474 \mathrm{E}-02 & 70 & 691 & 1000 & 123 & -43 & -40 & 5 \\ 4 & 1.2202 \mathrm{E}-02 & 40 & -21 & 123 & 1000 & 47 & -106 & 73 \\ 5 & 1.9820 \mathrm{E}-02 & -90 & 18 & -43 & 47 & 1000 & 908 & 108 \\ 6 & 2.9219 \mathrm{E}-02 & -149 & 23 & -40 & -106 & 908 & 1000 & 247 \\ 7 & 6.8172 \mathrm{E}-01 & -11 & 18 & 5 & 73 & 108 & 247 & 1000\end{array}$

Table B.130: Relative uncertainty (relative standard deviation) and correlation (normalized to 1000) for ${ }^{238} \mathrm{U}(\mathrm{n}, 2 \mathrm{n})$

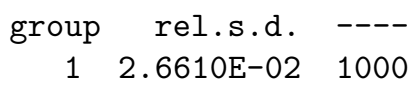


Table B.131: Relative uncertainty (relative standard deviation) and correlation (normalized to 1000) for ${ }^{238} \mathrm{U}(\mathrm{n}, \mathrm{f})$

\begin{tabular}{|c|c|c|c|c|c|c|c|c|c|c|c|c|c|c|c|c|}
\hline 1 & $5.0552 \mathrm{E}-03$ & 1000 & 516 & 365 & 271 & 80 & 9 & 0 & 0 & 0 & 0 & 0 & 0 & 0 & 0 & 0 \\
\hline 2 & $3.4801 \mathrm{E}-03$ & 516 & 1000 & 555 & 416 & 123 & 14 & 0 & 0 & 0 & 0 & 0 & 0 & 0 & 0 & 0 \\
\hline 3 & $4.2412 \mathrm{E}-03$ & 365 & 555 & 1000 & 456 & 139 & 16 & 0 & 0 & 0 & 0 & 0 & 0 & 0 & 0 & 0 \\
\hline 4 & $6.8512 \mathrm{E}-03$ & 271 & 416 & 456 & 1000 & 229 & 23 & 0 & 0 & 0 & 0 & 0 & 0 & 0 & 0 & 0 \\
\hline 5 & $3.1619 \mathrm{E}-02$ & 80 & 123 & 139 & 229 & 1000 & -55 & 0 & 0 & 0 & 0 & 0 & 0 & 0 & 0 & 0 \\
\hline 6 & $1.0366 \mathrm{E}-01$ & 9 & 14 & 16 & 23 & -55 & 1000 & 0 & 0 & 0 & 0 & 0 & 0 & 0 & 0 & 0 \\
\hline 7 & $0.0000 \mathrm{E}+00$ & 0 & 0 & 0 & 0 & 0 & 0 & 0 & 0 & 0 & 0 & 0 & 0 & 0 & 0 & 0 \\
\hline 8 & $1.7604 \mathrm{E}-05$ & 0 & 0 & 0 & 0 & 0 & 0 & 0 & 1000 & 0 & 0 & 0 & 0 & 0 & 0 & 0 \\
\hline 9 & $1.8774 \mathrm{E}-02$ & 0 & 0 & 0 & 0 & 0 & 0 & 0 & 0 & 1000 & 0 & 0 & 0 & 0 & 0 & 0 \\
\hline 10 & $3.8972 \mathrm{E}-04$ & 0 & 0 & 0 & 0 & 0 & 0 & 0 & 0 & 0 & 1000 & -3 & -3 & 82 & 107 & 110 \\
\hline 11 & $6.6799 \mathrm{E}-03$ & 0 & 0 & 0 & 0 & 0 & 0 & 0 & 0 & 0 & -3 & 1000 & -400 & -270 & -210 & -194 \\
\hline 12 & $2.2304 \mathrm{E}-01$ & 0 & 0 & 0 & 0 & 0 & 0 & 0 & 0 & 0 & -3 & -400 & 1000 & 794 & 634 & 588 \\
\hline 13 & 1. $1961 \mathrm{E}-02$ & 0 & 0 & 0 & 0 & 0 & 0 & 0 & 0 & 0 & 82 & -270 & 794 & 1000 & 963 & 945 \\
\hline 14 & $9.2888 \mathrm{E}-03$ & 0 & 0 & 0 & 0 & 0 & 0 & 0 & 0 & 0 & 107 & -210 & 634 & 963 & 1000 & 998 \\
\hline 15 & $8.9256 \mathrm{E}-03$ & 0 & 0 & 0 & 0 & 0 & 0 & 0 & 0 & 0 & 110 & -194 & 588 & 945 & 998 & 1000 \\
\hline
\end{tabular}

Table B.132: Relative uncertainty (relative standard deviation) and correlation (normalized to 1000) for ${ }^{238} \mathrm{U}(\mathrm{n}, \gamma)$

\begin{tabular}{|c|c|c|c|c|c|c|c|c|c|c|c|c|c|c|c|c|}
\hline 1 & $3.2677 \mathrm{E}-01$ & 1000 & 28 & 0 & 0 & 0 & 0 & 0 & 0 & 0 & 0 & 0 & 0 & 0 & 0 & 0 \\
\hline 2 & $3.5693 \mathrm{E}-01$ & 28 & 1000 & 394 & 0 & 0 & 0 & 0 & 0 & 0 & 0 & 0 & 0 & 0 & 0 & 0 \\
\hline 3 & 1.9559E-01 & 0 & 394 & 1000 & 4 & 0 & 0 & 0 & 0 & 0 & 0 & 0 & 0 & 0 & 0 & 0 \\
\hline 4 & 1. $6479 \mathrm{E}-02$ & 0 & 0 & 4 & 1000 & 15 & 1 & 0 & 0 & 0 & 0 & 0 & 0 & 0 & 0 & 0 \\
\hline 5 & 1. 8693E-02 & 0 & 0 & 0 & 15 & 1000 & 21 & 0 & 0 & 0 & 0 & 0 & 0 & 0 & 0 & 0 \\
\hline 6 & $3.9424 \mathrm{E}-02$ & 0 & 0 & 0 & 1 & 21 & 1000 & 568 & -75 & 0 & 0 & 0 & 0 & 0 & 0 & 0 \\
\hline 7 & $3.4607 \mathrm{E}-02$ & 0 & 0 & 0 & 0 & 0 & 568 & 1000 & 513 & 0 & 0 & 0 & 0 & 0 & 0 & 0 \\
\hline 8 & $5.2580 \mathrm{E}-02$ & 0 & 0 & 0 & 0 & 0 & -75 & 513 & 1000 & 0 & 0 & 0 & 0 & 0 & 0 & 0 \\
\hline 9 & $2.9764 \mathrm{E}-03$ & 0 & 0 & 0 & 0 & 0 & 0 & 0 & 0 & 1000 & 0 & 0 & 0 & 0 & 0 & 0 \\
\hline 10 & $6.3700 \mathrm{E}-03$ & 0 & 0 & 0 & 0 & 0 & 0 & 0 & 0 & 0 & 1000 & -1 & 1 & -1 & -1 & -1 \\
\hline 11 & $8.2962 E-03$ & 0 & 0 & 0 & 0 & 0 & 0 & 0 & 0 & 0 & -1 & 1000 & 31 & 121 & 35 & 25 \\
\hline 12 & $4.0519 \mathrm{E}-02$ & 0 & 0 & 0 & 0 & 0 & 0 & 0 & 0 & 0 & 1 & 31 & 1000 & 356 & 312 & 305 \\
\hline 13 & $2.7286 \mathrm{E}-02$ & 0 & 0 & 0 & 0 & 0 & 0 & 0 & 0 & 0 & -1 & 121 & 356 & 1000 & 990 & 988 \\
\hline 14 & $1.9606 \mathrm{E}-02$ & 0 & 0 & 0 & 0 & 0 & 0 & 0 & 0 & 0 & -1 & 35 & 312 & 990 & 1000 & 1000 \\
\hline 15 & $1.8877 \mathrm{E}-02$ & 0 & 0 & 0 & 0 & 0 & 0 & 0 & 0 & 0 & -1 & 25 & 305 & 988 & 1000 & 1000 \\
\hline
\end{tabular}


Table B.133: Relative uncertainty (relative standard deviation) and correlation (normalized to 1000) for ${ }^{237} \mathrm{~Np}(\mathrm{n}, \mathrm{el})$

\begin{tabular}{|c|c|c|c|c|c|c|c|c|c|c|c|c|c|c|c|c|}
\hline 1 & $2.3914 \mathrm{E}-02$ & 1000 & 970 & 197 & 173 & 702 & 329 & 182 & 93 & 237 & 0 & 0 & 0 & 0 & 0 & 0 \\
\hline 2 & $3.7043 E-02$ & 970 & 1000 & 270 & 128 & 671 & 355 & 217 & 130 & 255 & 0 & 0 & 0 & 0 & 0 & \\
\hline 3 & $4.1217 \mathrm{E}-02$ & 197 & 270 & 1000 & -150 & 435 & 815 & 794 & 774 & 302 & 0 & 0 & 0 & 0 & 0 & \\
\hline 4 & $3.6174 \mathrm{E}-02$ & 173 & 128 & -150 & 1000 & 394 & -212 & -290 & -321 & 106 & 0 & 0 & 0 & 0 & 0 & \\
\hline 5 & $3.4690 \mathrm{E}-02$ & 702 & 671 & 435 & 394 & 1000 & 694 & 563 & 487 & 526 & 0 & 0 & 0 & 0 & 0 & \\
\hline 6 & $4.0697 \mathrm{E}-02$ & 329 & 355 & 815 & -212 & 694 & 1000 & 978 & 952 & 630 & 0 & 0 & 0 & 0 & 0 & \\
\hline 7 & $4.3661 \mathrm{E}-02$ & 182 & 217 & 794 & -290 & 563 & 978 & 1000 & 995 & 693 & 0 & 0 & 0 & 0 & 0 & \\
\hline 8 & $4.4808 \mathrm{E}-02$ & 93 & 130 & 774 & -321 & 487 & 952 & 995 & 1000 & 701 & 0 & 0 & 0 & 0 & 0 & \\
\hline 9 & $3.9308 \mathrm{E}-02$ & 237 & 255 & 302 & 106 & 526 & 630 & 693 & 701 & 1000 & 31 & 33 & 33 & 33 & 33 & \\
\hline 10 & $2.4359 \mathrm{E}-02$ & 0 & 0 & 0 & 0 & 0 & 0 & 0 & 0 & 31 & 1000 & 926 & 926 & 923 & 917 & 91 \\
\hline 11 & $2.4133 \mathrm{E}-02$ & 0 & 0 & 0 & 0 & 0 & 0 & 0 & 0 & 33 & 926 & 1000 & 1000 & 996 & 990 & 984 \\
\hline 12 & $2.3148 \mathrm{E}-02$ & 0 & 0 & 0 & 0 & 0 & 0 & 0 & 0 & 33 & 926 & 1000 & 1000 & 996 & 991 & 98 \\
\hline 13 & $2.2347 \mathrm{E}-02$ & 0 & 0 & 0 & 0 & 0 & 0 & 0 & 0 & 33 & 923 & 996 & 996 & 1000 & 994 & 99 \\
\hline 14 & $2.1817 \mathrm{E}-02$ & 0 & 0 & 0 & 0 & 0 & 0 & 0 & 0 & 33 & 917 & 990 & 991 & 994 & 1000 & 99 \\
\hline 15 & $2.0343 \mathrm{E}-02$ & 0 & 0 & 0 & 0 & 0 & 0 & 0 & 0 & 33 & 912 & 984 & 985 & 990 & 998 & 1000 \\
\hline
\end{tabular}

Table B.134: Relative uncertainty (relative standard deviation) and correlation (normalized to 1000) for ${ }^{237} \mathrm{~Np}\left(\mathrm{n}, \mathrm{n}^{\prime}\right)$

\begin{tabular}{|c|c|c|c|c|c|c|c|c|}
\hline & & & & & & & & \\
\hline 1 & $4.2854 \mathrm{E}-01$ & 1000 & -772 & -398 & -267 & -124 & -143 & -359 \\
\hline 2 & $6.5378 \mathrm{E}-02$ & -772 & 1000 & 547 & 313 & 44 & 8 & 138 \\
\hline 3 & $2.2353 \mathrm{E}-01$ & -398 & 547 & 1000 & 950 & 809 & 744 & 576 \\
\hline 4 & $2.8600 \mathrm{E}-01$ & -267 & 313 & 950 & 1000 & 947 & 907 & 737 \\
\hline 5 & $4.4989 \mathrm{E}-01$ & -124 & 44 & 809 & 947 & 1000 & 990 & 832 \\
\hline 6 & $5.4972 \mathrm{E}-01$ & -143 & 8 & 744 & 907 & 990 & 1000 & 895 \\
\hline 7 & 01 & -359 & 138 & 576 & 737 & 832 & 895 & D \\
\hline
\end{tabular}

Table B.135: Relative uncertainty (relative standard deviation) and correlation (normalized to 1000) for ${ }^{237} \mathrm{~Np}(\mathrm{n}, 2 \mathrm{n})$

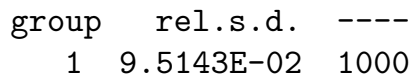


Table B.136: Relative uncertainty (relative standard deviation) and correlation (normalized to 1000) for ${ }^{237} \mathrm{~Np}(\mathrm{n}, \mathrm{f})$

\begin{tabular}{|c|c|c|c|c|c|c|c|c|c|c|c|c|c|c|c|c|}
\hline 1 & $5 \quad 5802 F-02$ & $1 \cap 0 \Omega$ & 212 & 230 & -326 & -310 & -310 & -310 & -310 & -310 & -307 & 0 & 0 & 0 & 0 & 0 \\
\hline 2 & $7.8950 \mathrm{E}-02$ & 212 & 1000 & 853 & 764 & 733 & 733 & 733 & 733 & 733 & 645 & 0 & 0 & 0 & 0 & 0 \\
\hline 3 & $7.6332 \mathrm{E}-02$ & -238 & 853 & 1000 & 986 & 976 & 976 & 976 & 976 & 976 & 859 & 0 & 0 & 0 & 0 & 0 \\
\hline 4 & $5.8154 \mathrm{E}-02$ & -326 & 764 & 986 & 1000 & 999 & 999 & 999 & 999 & 999 & 878 & 0 & 0 & 0 & 0 & 0 \\
\hline 5 & $5.7859 \mathrm{E}-02$ & -349 & 733 & 976 & 999 & 1000 & 1000 & 1000 & 1000 & 1000 & 879 & 0 & 0 & 0 & 0 & 0 \\
\hline 6 & $5.7859 \mathrm{E}-02$ & -349 & 733 & 976 & 999 & 1000 & 1000 & 1000 & 1000 & 1000 & 879 & 0 & 0 & 0 & 0 & 0 \\
\hline 7 & $5.7859 \mathrm{E}-02$ & -349 & 733 & 976 & 999 & 1000 & 1000 & 1000 & 1000 & 1000 & 879 & 0 & 0 & 0 & 0 & \\
\hline 8 & $5.7859 \mathrm{E}-02$ & -349 & 733 & 976 & 999 & 1000 & 1000 & 1000 & 1000 & 1000 & 879 & 0 & 0 & 0 & 0 & 0 \\
\hline 9 & $5.7859 \mathrm{E}-02$ & -349 & 733 & 976 & 999 & 1000 & 1000 & 1000 & 1000 & 1000 & 879 & 0 & 0 & 0 & 0 & 0 \\
\hline 10 & $5.7735 \mathrm{E}-02$ & -307 & 645 & 859 & 878 & 879 & 879 & 879 & 879 & 879 & 1000 & 1 & 1 & 0 & 0 & 0 \\
\hline 11 & $7.5377 \mathrm{E}-02$ & 0 & 0 & 0 & 0 & 0 & 0 & 0 & 0 & 0 & 1 & 1000 & 110 & 5 & 5 & 34 \\
\hline 12 & $4.6415 \mathrm{E}-02$ & 0 & 0 & 0 & 0 & 0 & 0 & 0 & 0 & 0 & 1 & 110 & 1000 & 25 & 5 & 36 \\
\hline 13 & $5.5804 \mathrm{E}-02$ & 0 & 0 & 0 & 0 & 0 & 0 & 0 & 0 & 0 & 0 & 5 & 25 & 1000 & 52 & 65 \\
\hline 14 & $1.4743 \mathrm{E}-01$ & 0 & 0 & 0 & 0 & 0 & 0 & 0 & 0 & 0 & 0 & 5 & 5 & 52 & 1000 & 277 \\
\hline 15 & $4.5504 \mathrm{E}-02$ & 0 & 0 & 0 & 0 & 0 & 0 & 0 & 0 & 0 & 0 & 34 & 36 & 65 & 277 & 1000 \\
\hline
\end{tabular}

Table B.137: Relative uncertainty (relative standard deviation) and correlation (normalized to 1000) for ${ }^{237} \mathrm{~Np}(\mathrm{n}, \gamma)$

\begin{tabular}{|c|c|c|c|c|c|c|c|c|c|c|c|c|c|c|c|c|}
\hline 1 & $11055 \cap 1$ & & 101 & & & 221 & 170 & 207 & -167 & 61 & 156 & 0 & 0 & 0 & 0 & 0 \\
\hline 1 & $4.1465 \mathrm{E}-01$ & 1000 & 444 & 425 & 368 & 351 & $-1 / 8$ & -261 & -161 & 61 & 156 & 0 & 0 & 0 & 0 & 0 \\
\hline 2 & $3.6484 \mathrm{E}-01$ & 444 & 1000 & 983 & 869 & 732 & -421 & -606 & -444 & 2 & 211 & 0 & 0 & 0 & 0 & 0 \\
\hline 3 & $1.7618 \mathrm{E}-01$ & 425 & 983 & 1000 & 946 & 840 & -495 & -719 & -543 & -33 & 211 & 0 & 0 & 0 & 0 & 0 \\
\hline 4 & $1.0336 \mathrm{E}-01$ & 368 & 869 & 946 & 1000 & 962 & -588 & -859 & -669 & -81 & 207 & 0 & 0 & 0 & 0 & \\
\hline 5 & $5.7927 \mathrm{E}-02$ & 331 & 732 & 840 & 962 & 1000 & -551 & -874 & -648 & -13 & 283 & 0 & 0 & 0 & 0 & \\
\hline 6 & $2.0757 \mathrm{E}-02$ & -178 & -421 & -495 & -588 & -551 & 1000 & 874 & 853 & 487 & 220 & 0 & 0 & 0 & 0 & \\
\hline 7 & $6.6594 \mathrm{E}-02$ & -267 & -606 & -719 & -859 & -874 & 874 & 1000 & 899 & 367 & 49 & 0 & 0 & 0 & 0 & \\
\hline 8 & $5.2450 \mathrm{E}-02$ & -167 & -444 & -543 & -669 & -648 & 853 & 899 & 1000 & 737 & 476 & 0 & 0 & 0 & 0 & \\
\hline 9 & $5.2484 \mathrm{E}-02$ & 61 & 2 & -33 & -81 & -13 & 487 & 367 & 737 & 1000 & 935 & 0 & 0 & 0 & 0 & 0 \\
\hline 10 & $5.5373 \mathrm{E}-02$ & 156 & 211 & 211 & 207 & 283 & 220 & 49 & 476 & 935 & 1000 & 1 & 0 & 0 & 0 & 0 \\
\hline 11 & $1.6955 \mathrm{E}-02$ & 0 & 0 & 0 & 0 & 0 & 0 & 0 & 0 & 0 & 1 & 1000 & 47 & 3 & 3 & 26 \\
\hline 12 & $5.5020 \mathrm{E}-03$ & 0 & 0 & 0 & 0 & 0 & 0 & 0 & 0 & 0 & 0 & 47 & 1000 & -36 & 32 & 284 \\
\hline 13 & $6.9900 \mathrm{E}-03$ & 0 & 0 & 0 & 0 & 0 & 0 & 0 & 0 & 0 & 0 & 3 & -36 & 1000 & 117 & 102 \\
\hline 14 & $2.4108 \mathrm{E}-02$ & 0 & 0 & 0 & 0 & 0 & 0 & 0 & 0 & 0 & 0 & 3 & 32 & 117 & 1000 & 279 \\
\hline 15 & $1.5534 \mathrm{E}-02$ & 0 & 0 & 0 & 0 & 0 & 0 & 0 & 0 & 0 & 0 & 26 & 284 & 102 & 279 & 1000 \\
\hline
\end{tabular}


Table B.138: Relative uncertainty (relative standard deviation) and correlation (normalized to 1000) for ${ }^{238} \mathrm{Pu}(\mathrm{n}, \mathrm{el})$

\begin{tabular}{|c|c|c|c|c|c|c|c|c|c|c|c|c|c|c|c|c|}
\hline 1 & $9.1736 \mathrm{E}-03$ & 1000 & 656 & 971 & -266 & -561 & -240 & 0 & 0 & 0 & 0 & 0 & 0 & 0 & 0 & \\
\hline 2 & $8.1875 \mathrm{E}-03$ & 656 & 1000 & 545 & -600 & -679 & -290 & 0 & 0 & 0 & c & & & c & 0 & \\
\hline 3 & $6.2418 \mathrm{E}-02$ & 971 & 545 & 1000 & -189 & -508 & -217 & 0 & 0 & 0 & 0 & 0 & 0 & c & 0 & \\
\hline 4 & $5.9985 \mathrm{E}-02$ & -266 & -600 & -189 & 1000 & 940 & 402 & 0 & 0 & 0 & 0 & 0 & 0 & & 0 & \\
\hline 5 & $9.5231 \mathrm{E}-02$ & -561 & -679 & -508 & 940 & 1000 & 427 & 0 & 0 & 0 & 0 & 0 & 0 & & 0 & \\
\hline 6 & $4.0972 \mathrm{E}-02$ & -240 & -290 & -217 & 402 & 427 & 1000 & 897 & 881 & 867 & 760 & 0 & 0 & & & \\
\hline 7 & $5.2582 \mathrm{E}-02$ & 0 & 0 & 0 & 0 & 0 & 897 & 1000 & 985 & 971 & 848 & 0 & & & & \\
\hline 8 & $4.8540 \mathrm{E}-02$ & 0 & 0 & 0 & c & 0 & 881 & 985 & 1000 & 998 & 848 & & & & & \\
\hline 9 & $4.4301 \mathrm{E}-02$ & 0 & 0 & 0 & 0 & 0 & 867 & 971 & 998 & 1000 & 842 & 0 & 0 & 0 & 0 & \\
\hline 10 & $4.3477 \mathrm{E}-02$ & 0 & 0 & 0 & 0 & 0 & 760 & 848 & 848 & 842 & 1000 & 112 & 9 & 19 & 19 & 19 \\
\hline 11 & $2.0005 \mathrm{E}-01$ & 0 & 0 & 0 & 0 & 0 & 0 & 0 & 0 & 0 & 112 & 1000 & -3 & 2 & 3 & \\
\hline 12 & $1.0108 \mathrm{E}-01$ & 0 & 0 & 0 & 0 & 0 & & 0 & 0 & 0 & 9 & -3 & 1000 & 472 & 74 & 472 \\
\hline 13 & $5.7862 \mathrm{E}-02$ & 0 & 0 & 0 & 0 & c & & 0 & c & 0 & 19 & 2 & 472 & 1000 & 999 & 95 \\
\hline 14 & 5.1 & 0 & 0 & 0 & 0 & 0 & & 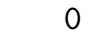 & 0 & 0 & 19 & 3 & 474 & 999 & 1000 & $99 s$ \\
\hline 15 & $4.6944 \mathrm{E}-02$ & 0 & 0 & 0 & 0 & 0 & 0 & 0 & 0 & 0 & 19 & 2 & 472 & 995 & 999 & 00 \\
\hline
\end{tabular}

Table B.139: Relative uncertainty (relative standard deviation) and correlation (normalized to 1000$)$ for ${ }^{238} \mathrm{Pu}\left(\mathrm{n}, \mathrm{n}^{\prime}\right)$

$\begin{array}{crrrrrrr}\text { group } & \text { rel.s.d. } & ----------183 & -839 & -135 & 0 \\ 1 & 2.4559 \mathrm{E}-01 & 1000 & -636 & -785 & \\ 2 & 5.6882 \mathrm{E}-02 & -636 & 1000 & 950 & 855 & 131 & 0 \\ 3 & 2.8645 \mathrm{E}-01 & -783 & 950 & 1000 & 974 & 152 & 0 \\ 4 & 4.4923 \mathrm{E}-01 & -839 & 855 & 974 & 1000 & 159 & 0 \\ 5 & 4.3085 \mathrm{E}-01 & -135 & 131 & 152 & 159 & 1000 & 987 \\ 6 & 2.0808 \mathrm{E}-01 & 0 & 0 & 0 & 0 & 987 & 1000\end{array}$

Table B.140: Relative uncertainty (relative standard deviation) and correlation (normalized to 1000$)$ for ${ }^{238} \mathrm{Pu}(\mathrm{n}, 2 \mathrm{n})$ 
Table B.141: Relative uncertainty (relative standard deviation) and correlation (normalized to 1000) for ${ }^{238} \mathrm{Pu}(\mathrm{n}, \mathrm{f})$

\begin{tabular}{|c|c|c|c|c|c|c|c|c|c|c|c|c|c|c|c|c|}
\hline 1 & $2.5203 \mathrm{E}-01$ & 1000 & 123 & -7 & -11 & -11 & -5 & 0 & 0 & 0 & 0 & 0 & 0 & 0 & 0 & 0 \\
\hline 2 & $2.0534 \mathrm{E}-01$ & 123 & 1000 & 930 & 605 & 605 & 258 & 0 & 0 & 0 & 0 & 0 & 0 & 0 & 0 & 0 \\
\hline 3 & $3.3822 \mathrm{E}-01$ & -7 & 930 & 1000 & 548 & 548 & 233 & 0 & 0 & 0 & 0 & 0 & 0 & 0 & 0 & 0 \\
\hline 4 & $1.7106 \mathrm{E}-01$ & -11 & 605 & 548 & 1000 & 1000 & 426 & 0 & 0 & 0 & 0 & 0 & 0 & 0 & 0 & 0 \\
\hline 5 & $1.7106 \mathrm{E}-01$ & -11 & 605 & 548 & 1000 & 1000 & 426 & 0 & 0 & 0 & 0 & 0 & 0 & 0 & 0 & 0 \\
\hline 6 & $8.7770 \mathrm{E}-02$ & -5 & 258 & 233 & 426 & 426 & 1000 & 895 & 894 & 876 & 777 & 0 & 0 & 0 & 0 & 0 \\
\hline 7 & $1.1906 \mathrm{E}-01$ & 0 & 0 & 0 & 0 & 0 & 895 & 1000 & 999 & 980 & 870 & 0 & 0 & 0 & 0 & 0 \\
\hline 8 & $1.1202 \mathrm{E}-01$ & 0 & 0 & 0 & 0 & 0 & 894 & 999 & 1000 & 986 & 889 & 0 & 0 & 0 & 0 & 0 \\
\hline 9 & $7.4741 \mathrm{E}-02$ & 0 & 0 & 0 & 0 & 0 & 876 & 980 & 986 & 1000 & 949 & 0 & 0 & 0 & 0 & 0 \\
\hline 10 & $4.2644 \mathrm{E}-02$ & 0 & 0 & 0 & 0 & 0 & 777 & 870 & 889 & 949 & 1000 & 10 & 0 & 0 & 0 & 0 \\
\hline 11 & $8.0899 \mathrm{E}-02$ & 0 & 0 & 0 & 0 & 0 & 0 & 0 & 0 & 0 & 10 & 1000 & 1 & 36 & 9 & 4 \\
\hline 12 & $1.8975 \mathrm{E}-01$ & 0 & 0 & 0 & 0 & 0 & 0 & 0 & 0 & 0 & 0 & 1 & 1000 & 27 & 6 & 3 \\
\hline 13 & $4.5674 \mathrm{E}-02$ & 0 & 0 & 0 & 0 & 0 & 0 & 0 & 0 & 0 & 0 & 36 & 27 & 1000 & 545 & 529 \\
\hline 14 & $4.6265 \mathrm{E}-02$ & 0 & 0 & 0 & 0 & 0 & 0 & 0 & 0 & 0 & 0 & 9 & 6 & 545 & 1000 & 998 \\
\hline 15 & $4.8675 \mathrm{E}-02$ & 0 & 0 & 0 & 0 & 0 & 0 & 0 & 0 & 0 & 0 & 4 & 3 & 529 & 998 & 1000 \\
\hline
\end{tabular}


Table B.142: Relative uncertainty (relative standard deviation) and correlation (normalized to 1000) for ${ }^{238} \mathrm{Pu}(\mathrm{n}, \gamma)$

\begin{tabular}{|c|c|c|c|c|c|c|c|c|c|c|c|c|c|c|c|c|}
\hline 1 & $5.0905 \mathrm{E}-01$ & 1000 & 630 & 624 & 278 & -161 & -19 & 0 & 0 & 0 & 0 & 0 & 0 & 0 & 0 & 0 \\
\hline 2 & $2.8805 \mathrm{E}-01$ & 630 & 1000 & 996 & 409 & -300 & -35 & 0 & 0 & 0 & 0 & 0 & 0 & 0 & 0 & \\
\hline 3 & $2.1549 \mathrm{E}-01$ & 624 & 996 & 1000 & 478 & -228 & -27 & 0 & 0 & 0 & 0 & 0 & 0 & 0 & 0 & 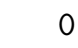 \\
\hline 4 & $9.7421 \mathrm{E}-02$ & 278 & 409 & 478 & 1000 & 738 & 87 & 0 & 0 & 0 & 0 & 0 & 0 & 0 & 0 & \\
\hline 5 & $1.2309 \mathrm{E}-01$ & -161 & -300 & -228 & 738 & 1000 & 118 & 0 & 0 & 0 & 0 & 0 & 0 & 0 & 0 & \\
\hline 6 & 1. $6617 \mathrm{E}-01$ & -19 & -35 & -27 & 87 & 118 & 1000 & 988 & 987 & 982 & 866 & 0 & 0 & 0 & 0 & \\
\hline 7 & $2.2138 \mathrm{E}-01$ & 0 & 0 & 0 & 0 & 0 & 988 & 1000 & 1000 & 994 & 877 & 0 & 0 & 0 & 0 & \\
\hline 8 & $1.8029 \mathrm{E}-01$ & 0 & 0 & 0 & 0 & 0 & 987 & 1000 & 1000 & 996 & 882 & 0 & 0 & 0 & 0 & \\
\hline 9 & $9.5972 \mathrm{E}-02$ & 0 & 0 & 0 & 0 & 0 & 982 & 994 & 996 & 1000 & 911 & 0 & 0 & 0 & 0 & 0 \\
\hline 10 & $3.6901 \mathrm{E}-02$ & 0 & 0 & 0 & 0 & 0 & 866 & 877 & 882 & 911 & 1000 & 76 & 0 & 0 & 0 & \\
\hline 11 & $4.6560 \mathrm{E}-02$ & 0 & 0 & 0 & 0 & 0 & 0 & 0 & 0 & 0 & 76 & 1000 & 1 & 2 & 6 & 3 \\
\hline 12 & $9.1166 \mathrm{E}-02$ & 0 & 0 & 0 & 0 & 0 & 0 & 0 & 0 & 0 & 0 & 1 & 1000 & 5 & 15 & \\
\hline 13 & $3.7069 \mathrm{E}-02$ & 0 & 0 & 0 & 0 & 0 & 0 & 0 & 0 & 0 & 0 & 2 & 5 & 1000 & 52 & 42 \\
\hline 14 & $1.3862 \mathrm{E}-02$ & 0 & 0 & 0 & 0 & 0 & 0 & 0 & 0 & 0 & 0 & 6 & 15 & 52 & 1000 & 999 \\
\hline 15 & 1. $4144 \mathrm{E}-02$ & 0 & 0 & 0 & 0 & 0 & 0 & 0 & 0 & 0 & 0 & 3 & 6 & 42 & 999 & 1000 \\
\hline
\end{tabular}

Table B.143: Relative uncertainty (relative standard deviation) and correlation (normalized to 1000) for ${ }^{239} \mathrm{Pu}(\mathrm{n}, \mathrm{el})$

\begin{tabular}{|c|c|c|c|c|c|c|c|c|c|c|c|c|c|c|c|c|}
\hline 1 & $1.7034 \mathrm{E}-01$ & 1000 & 805 & -338 & -126 & 383 & 357 & 329 & 155 & 7 & 0 & 0 & 0 & 0 & 0 & 0 \\
\hline 2 & $1.3852 \mathrm{E}-01$ & 805 & 1000 & -441 & -116 & 244 & 251 & 259 & 134 & 6 & 0 & 0 & 0 & 0 & 0 & 0 \\
\hline 3 & $5.6797 \mathrm{E}-02$ & -338 & -441 & 1000 & 458 & -262 & -223 & -177 & -76 & -3 & 0 & 0 & 0 & 0 & 0 & 0 \\
\hline 4 & $1.4061 \mathrm{E}-02$ & -126 & -116 & 458 & 1000 & 197 & 42 & -56 & -69 & -3 & 0 & 0 & 0 & 0 & 0 & 0 \\
\hline 5 & 1. $6652 \mathrm{E}-02$ & 383 & 244 & -262 & 197 & 1000 & 879 & 676 & 251 & 10 & 0 & 0 & 0 & 0 & 0 & \\
\hline 6 & $2.0986 \mathrm{E}-02$ & 357 & 251 & -223 & 42 & 879 & 1000 & 905 & 385 & 16 & 0 & 0 & 0 & 0 & 0 & \\
\hline 7 & $2.3923 E-02$ & 329 & 259 & -177 & -56 & 676 & 905 & 1000 & 558 & 80 & 0 & 0 & 0 & 0 & 0 & 0 \\
\hline 8 & $1.5556 \mathrm{E}-02$ & 155 & 134 & -76 & -69 & 251 & 385 & 558 & 1000 & 837 & 0 & 0 & 0 & 0 & 0 & \\
\hline 9 & 1. $6936 \mathrm{E}-02$ & 7 & 6 & -3 & -3 & 10 & 16 & 80 & 837 & 1000 & 0 & 0 & 0 & 0 & 0 & 0 \\
\hline 10 & $3.2285 \mathrm{E}-03$ & 0 & 0 & 0 & 0 & 0 & 0 & 0 & 0 & 0 & 1000 & 11 & 10 & 20 & 21 & 21 \\
\hline 11 & $9.4185 \mathrm{E}-03$ & 0 & 0 & 0 & 0 & 0 & 0 & 0 & 0 & 0 & 11 & 1000 & 17 & 50 & 55 & 64 \\
\hline 12 & $1.8648 \mathrm{E}-02$ & 0 & 0 & 0 & 0 & 0 & 0 & 0 & 0 & 0 & 10 & 17 & 1000 & 554 & 567 & 535 \\
\hline 13 & $3.1444 \mathrm{E}-02$ & 0 & 0 & 0 & 0 & 0 & 0 & 0 & 0 & 0 & 20 & 50 & 554 & 1000 & 958 & 981 \\
\hline 14 & $3.4417 \mathrm{E}-02$ & 0 & 0 & 0 & 0 & 0 & 0 & 0 & 0 & 0 & 21 & 55 & 567 & 958 & 1000 & 936 \\
\hline 15 & $6.6491 \mathrm{E}-02$ & 0 & 0 & 0 & 0 & 0 & 0 & 0 & 0 & 0 & 21 & 64 & 535 & 981 & 936 & 1000 \\
\hline
\end{tabular}


Table B.144: Relative uncertainty (relative standard deviation) and correlation (normalized to 1000$)$ for ${ }^{239} \mathrm{Pu}\left(\mathrm{n}, \mathrm{n}^{\prime}\right)$

$\begin{array}{crrrrrrrrrr}\text { group } & \text { rel.s.d. } & -------10 & -138 & 408 & 390 & 343 & 276 & 268 \\ 1 & 1.1109 \mathrm{E}+00 & 1000 & 811 & -343 & -138 & \\ 2 & 3.7213 \mathrm{E}-01 & 811 & 1000 & -445 & -125 & 256 & 271 & 269 & 238 & 234 \\ 3 & 1.2111 \mathrm{E}-01 & -343 & -445 & 1000 & 475 & -284 & -250 & -189 & -135 & -129 \\ 4 & 3.7713 \mathrm{E}-02 & -138 & -125 & 475 & 1000 & 168 & 31 & -66 & -130 & -139 \\ 5 & 1.0334 \mathrm{E}-01 & 408 & 256 & -284 & 168 & 1000 & 904 & 703 & 471 & 440 \\ 6 & 2.5459 \mathrm{E}-01 & 390 & 271 & -250 & 31 & 904 & 1000 & 923 & 737 & 709 \\ 7 & 6.0580 \mathrm{E}-01 & 343 & 269 & -189 & -66 & 703 & 923 & 1000 & 934 & 917 \\ 8 & 3.0939 \mathrm{E}-01 & 276 & 238 & -135 & -130 & 471 & 737 & 934 & 1000 & 999 \\ 9 & 3.4008 \mathrm{E}-01 & 268 & 234 & -129 & -139 & 440 & 709 & 917 & 999 & 1000\end{array}$

Table B.145: Relative uncertainty (relative standard deviation) and correlation (normalized to 1000) for ${ }^{239} \mathrm{Pu}(\mathrm{n}, 2 \mathrm{n})$

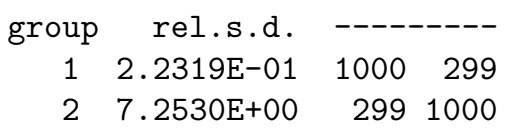

Table B.146: Relative uncertainty (relative standard deviation) and correlation (normalized to 1000$)$ for ${ }^{239} \mathrm{Pu}(\mathrm{n}, \mathrm{f})$

\begin{tabular}{|c|c|c|c|c|c|c|c|c|c|c|c|c|c|c|c|c|}
\hline 1 & $5.5216 \mathrm{E}-03$ & 1000 & 791 & 684 & 677 & 585 & 489 & 233 & 0 & 0 & 0 & 0 & 0 & 0 & 0 & 0 \\
\hline 2 & $5.0775 \mathrm{E}-03$ & 791 & 1000 & 807 & 800 & 695 & 580 & 276 & 0 & 0 & 0 & 0 & 0 & 0 & 0 & 0 \\
\hline 3 & $5.6025 \mathrm{E}-03$ & 684 & 807 & 1000 & 831 & 713 & 592 & 281 & 0 & 0 & 0 & 0 & 0 & 0 & 0 & 0 \\
\hline 4 & $5.4610 \mathrm{E}-03$ & 677 & 800 & 831 & 1000 & 801 & 664 & 317 & 0 & 0 & 0 & 0 & 0 & 0 & 0 & 0 \\
\hline 5 & $6.1655 \mathrm{E}-03$ & 585 & 695 & 713 & 801 & 1000 & 692 & 325 & 0 & 0 & 0 & 0 & 0 & 0 & 0 & 0 \\
\hline 6 & $7.1258 \mathrm{E}-03$ & 489 & 580 & 592 & 664 & 692 & 1000 & 331 & 0 & 0 & 0 & 0 & 0 & 0 & 0 & 0 \\
\hline 7 & 1. $2416 \mathrm{E}-02$ & 233 & 276 & 281 & 317 & 325 & 331 & 1000 & 816 & 740 & 0 & 0 & 0 & 0 & 0 & 0 \\
\hline 8 & $6.7595 \mathrm{E}-02$ & 0 & 0 & 0 & 0 & 0 & 0 & 816 & 1000 & 949 & 0 & 0 & 0 & 0 & 0 & 0 \\
\hline 9 & $5.2934 \mathrm{E}-02$ & 0 & 0 & 0 & 0 & 0 & 0 & 740 & 949 & 1000 & 0 & 0 & 0 & 0 & 0 & 0 \\
\hline 10 & $3.9323 \mathrm{E}-03$ & 0 & 0 & 0 & 0 & 0 & 0 & 0 & 0 & 0 & 1000 & -11 & 2 & -15 & 16 & 11 \\
\hline 11 & $9.9794 \mathrm{E}-03$ & 0 & 0 & 0 & 0 & 0 & 0 & 0 & 0 & 0 & -11 & 1000 & 2 & 2 & 0 & 1 \\
\hline 12 & $2.6346 \mathrm{E}-02$ & 0 & 0 & 0 & 0 & 0 & 0 & 0 & 0 & 0 & 2 & 2 & 1000 & 193 & -202 & -44 \\
\hline 13 & $2.0256 \mathrm{E}-01$ & 0 & 0 & 0 & 0 & 0 & 0 & 0 & 0 & 0 & -15 & 2 & 193 & 1000 & -942 & -35 \\
\hline 14 & $4.7989 \mathrm{E}-02$ & 0 & 0 & 0 & 0 & 0 & 0 & 0 & 0 & 0 & 16 & 0 & -202 & -942 & 1000 & 167 \\
\hline 15 & $1.4841 \mathrm{E}-02$ & 0 & 0 & 0 & 0 & 0 & 0 & 0 & 0 & 0 & 11 & 1 & -44 & -35 & 167 & 1000 \\
\hline
\end{tabular}


Table B.147: Relative uncertainty (relative standard deviation) and correlation (normalized to 1000) for ${ }^{239} \mathrm{Pu}(\mathrm{n}, \gamma)$

\begin{tabular}{|c|c|c|c|c|c|c|c|c|c|c|c|c|c|c|c|c|}
\hline 1 & $6.4910 \mathrm{E}-01$ & 1000 & 408 & 0 & 0 & 0 & 0 & 0 & 0 & 0 & 0 & 0 & 0 & 0 & 0 & 0 \\
\hline 2 & $2.4392 \mathrm{E}-01$ & 408 & 1000 & 820 & 659 & 162 & 35 & 23 & 0 & 0 & 0 & 0 & 0 & 0 & 0 & 0 \\
\hline 3 & $2.7750 \mathrm{E}-01$ & 0 & 820 & 1000 & 804 & 197 & 43 & 28 & 0 & 0 & 0 & 0 & 0 & 0 & 0 & 0 \\
\hline 4 & 1. $2951 \mathrm{E}-01$ & 0 & 659 & 804 & 1000 & 354 & 77 & 50 & 0 & 0 & 0 & 0 & 0 & 0 & 0 & 0 \\
\hline 5 & $9.4968 \mathrm{E}-02$ & 0 & 162 & 197 & 354 & 1000 & 221 & 91 & 0 & 0 & 0 & 0 & 0 & 0 & 0 & 0 \\
\hline 6 & $8.5101 \mathrm{E}-02$ & 0 & 35 & 43 & 77 & 221 & 1000 & 820 & 0 & 0 & 0 & 0 & 0 & 0 & 0 & 0 \\
\hline 7 & $9.4035 \mathrm{E}-02$ & 0 & 23 & 28 & 50 & 91 & 820 & 1000 & 121 & 116 & 0 & 0 & 0 & 0 & 0 & 0 \\
\hline 8 & $6.5124 \mathrm{E}-02$ & 0 & 0 & 0 & 0 & 0 & 0 & 121 & 1000 & 986 & 0 & 0 & 0 & 0 & 0 & \\
\hline 9 & $5.5706 \mathrm{E}-02$ & 0 & 0 & 0 & 0 & 0 & 0 & 116 & 986 & 1000 & 0 & 0 & 0 & 0 & 0 & 0 \\
\hline 10 & $4.4079 \mathrm{E}-03$ & 0 & 0 & 0 & 0 & 0 & 0 & 0 & 0 & 0 & 1000 & 0 & 1 & 1 & -1 & \\
\hline 11 & $8.7665 \mathrm{E}-03$ & 0 & 0 & 0 & 0 & 0 & 0 & 0 & 0 & 0 & 0 & 1000 & -4 & 13 & -8 & 5 \\
\hline 12 & $2.1341 \mathrm{E}-02$ & 0 & 0 & 0 & 0 & 0 & 0 & 0 & 0 & 0 & 1 & -4 & 1000 & 65 & -87 & -13 \\
\hline 13 & $1.7530 \mathrm{E}-01$ & 0 & 0 & 0 & 0 & 0 & 0 & 0 & 0 & 0 & 1 & 13 & 65 & 1000 & -965 & -315 \\
\hline 14 & $2.8745 \mathrm{E}-02$ & 0 & 0 & 0 & 0 & 0 & 0 & 0 & 0 & 0 & -1 & -8 & -87 & -965 & 1000 & 525 \\
\hline 15 & $2.1209 \mathrm{E}-02$ & 0 & 0 & 0 & 0 & 0 & 0 & 0 & 0 & 0 & 1 & 5 & -13 & -315 & 525 & 1000 \\
\hline
\end{tabular}

Table B.148: Relative uncertainty (relative standard deviation) and correlation (normalized to 1000) for ${ }^{240} \mathrm{Pu}(\mathrm{n}, \mathrm{el})$

\begin{tabular}{|c|c|c|c|c|c|c|c|c|c|c|c|c|c|c|c|c|}
\hline 1 & $2.3358 \mathrm{E}-02$ & 1000 & 917 & 442 & 427 & 816 & 638 & 243 & -23 & -86 & 0 & 0 & 0 & 0 & 0 & 0 \\
\hline 2 & $5.1876 \mathrm{E}-02$ & 917 & 1000 & 709 & 634 & 941 & 850 & 524 & 276 & 138 & 0 & 0 & 0 & 0 & 0 & 0 \\
\hline 3 & $5.4165 \mathrm{E}-02$ & 442 & 709 & 1000 & 856 & 798 & 950 & 949 & 861 & 610 & 0 & 0 & 0 & 0 & 0 & 0 \\
\hline 4 & $4.7550 \mathrm{E}-02$ & 427 & 634 & 856 & 1000 & 844 & 906 & 901 & 787 & 548 & 0 & 0 & 0 & 0 & 0 & 0 \\
\hline 5 & $5.5341 \mathrm{E}-02$ & 816 & 941 & 798 & 844 & 1000 & 942 & 706 & 478 & 292 & 0 & 0 & 0 & 0 & 0 & 0 \\
\hline 6 & $5.7615 \mathrm{E}-02$ & 638 & 850 & 950 & 906 & 942 & 1000 & 892 & 732 & 496 & 0 & 0 & 0 & 0 & 0 & 0 \\
\hline 7 & $5.8024 \mathrm{E}-02$ & 243 & 524 & 949 & 901 & 706 & 892 & 1000 & 959 & 693 & 0 & 0 & 0 & 0 & 0 & 0 \\
\hline 8 & $5.0470 \mathrm{E}-02$ & -23 & 276 & 861 & 787 & 478 & 732 & 959 & 1000 & 744 & 0 & 0 & 0 & 0 & 0 & 0 \\
\hline 9 & $2.0817 \mathrm{E}-02$ & -86 & 138 & 610 & 548 & 292 & 496 & 693 & 744 & 1000 & -13 & 0 & 7 & -2 & 11 & 15 \\
\hline 10 & 1. 2591E-02 & 0 & 0 & 0 & 0 & 0 & 0 & 0 & 0 & -13 & 1000 & 38 & 25 & 14 & 8 & 7 \\
\hline 11 & $1.6361 \mathrm{E}-02$ & 0 & 0 & 0 & 0 & 0 & 0 & 0 & 0 & 0 & 38 & 1000 & 49 & 16 & 24 & 26 \\
\hline 12 & $3.2532 \mathrm{E}-02$ & 0 & 0 & 0 & 0 & 0 & 0 & 0 & 0 & 7 & 25 & 49 & 1000 & 164 & 168 & 169 \\
\hline 13 & $4.8438 \mathrm{E}-03$ & 0 & 0 & 0 & 0 & 0 & 0 & 0 & 0 & -2 & 14 & 16 & 164 & 1000 & 988 & 986 \\
\hline 14 & $4.5762 \mathrm{E}-02$ & 0 & 0 & 0 & 0 & 0 & 0 & 0 & 0 & 11 & 8 & 24 & 168 & 988 & 1000 & 1000 \\
\hline 15 & $5.6449 \mathrm{E}-02$ & 0 & 0 & 0 & 0 & 0 & 0 & 0 & 0 & 15 & 7 & 26 & 169 & 986 & 1000 & 1000 \\
\hline
\end{tabular}


Table B.149: Relative uncertainty (relative standard deviation) and correlation (normalized to 1000) for ${ }^{240} \mathrm{Pu}\left(\mathrm{n}, \mathrm{n}^{\prime}\right)$

\begin{tabular}{|c|c|c|c|c|c|c|c|c|}
\hline & & & & & & & & \\
\hline 1 & $3.7110 \mathrm{E}-01$ & 1000 & 608 & 559 & -740 & -539 & -661 & -597 \\
\hline 2 & $9.6525 \mathrm{E}-02$ & 608 & 1000 & 978 & -846 & -870 & -972 & -858 \\
\hline 3 & $1.0086 \mathrm{E}-01$ & 559 & 978 & 1000 & -757 & -795 & -927 & -825 \\
\hline 4 & $7.7915 \mathrm{E}-02$ & -740 & -846 & -757 & 1000 & 908 & 930 & 809 \\
\hline 5 & $9.7824 \mathrm{E}-02$ & -539 & -870 & -795 & 908 & 1000 & 949 & 807 \\
\hline 6 & $4.2552 E-01$ & -661 & -972 & -927 & 930 & 949 & 1000 & 873 \\
\hline 7 & $4.8576 \mathrm{E}-01$ & -597 & -858 & -825 & 809 & 807 & 873 & 1000 \\
\hline
\end{tabular}

Table B.150: Relative uncertainty (relative standard deviation) and correlation (normalized to 1000) for ${ }^{240} \mathrm{Pu}(\mathrm{n}, 2 \mathrm{n})$

group rel.s.d. ----

$15.4091 \mathrm{E}-01 \quad 1000$

Table B.151: Relative uncertainty (relative standard deviation) and correlation (normalized to 1000) for ${ }^{240} \mathrm{Pu}(\mathrm{n}, \mathrm{f})$

\begin{tabular}{|c|c|c|c|c|c|c|c|c|c|c|c|c|c|c|c|c|}
\hline 1 & $9.5597 \mathrm{E}-02$ & 1000 & 741 & -204 & -344 & -337 & -577 & -594 & -594 & -205 & 0 & 0 & 0 & 0 & 0 & \\
\hline 2 & $4.8001 \mathrm{E}-02$ & 741 & 1000 & -374 & -594 & -582 & -941 & -962 & -962 & -331 & 0 & 0 & 0 & 0 & 0 & \\
\hline 3 & $5.6532 \mathrm{E}-02$ & -204 & -374 & 1000 & 965 & 969 & 581 & 454 & 454 & 156 & 0 & 0 & 0 & 0 & 0 & \\
\hline 4 & $5.8233 E-02$ & -344 & -594 & 965 & 1000 & 1000 & 774 & 672 & 672 & 231 & 0 & 0 & 0 & 0 & 0 & \\
\hline 5 & $3.9098 \mathrm{E}-02$ & -337 & -582 & 969 & 1000 & 1000 & 764 & 661 & 661 & 227 & 0 & 0 & 0 & 0 & 0 & \\
\hline 6 & $5.7007 \mathrm{E}-02$ & -577 & -941 & 581 & 774 & 764 & 1000 & 989 & 989 & 341 & 0 & 0 & 0 & 0 & 0 & \\
\hline 7 & $7.4510 \mathrm{E}-02$ & -594 & -962 & 454 & 672 & 661 & 989 & 1000 & 1000 & 344 & 0 & 0 & 0 & 0 & 0 & \\
\hline 8 & $7.4510 \mathrm{E}-02$ & -594 & -962 & 454 & 672 & 661 & 989 & 1000 & 1000 & 344 & 0 & 0 & 0 & 0 & 0 & \\
\hline 9 & $8.0144 \mathrm{E}-02$ & -205 & -331 & 156 & 231 & 227 & 341 & 344 & 344 & 1000 & 20 & 45 & 4 & 1 & -1 & -1 \\
\hline 10 & $2.1617 \mathrm{E}-01$ & 0 & 0 & 0 & 0 & 0 & 0 & 0 & 0 & 20 & 1000 & 357 & 24 & 6 & 16 & 18 \\
\hline 11 & $4.7157 \mathrm{E}-02$ & 0 & 0 & 0 & 0 & 0 & 0 & 0 & 0 & 45 & 357 & 1000 & 40 & 13 & -31 & -30 \\
\hline 12 & $8.9123 E-02$ & 0 & 0 & 0 & 0 & 0 & 0 & 0 & 0 & 4 & 24 & 40 & 1000 & 8 & -21 & -21 \\
\hline 13 & 1.2186E-02 & 0 & 0 & 0 & 0 & 0 & 0 & 0 & 0 & 1 & 6 & 13 & 8 & 1000 & 559 & 478 \\
\hline 14 & $2.9756 \mathrm{E}-01$ & 0 & 0 & 0 & 0 & 0 & 0 & 0 & 0 & -1 & 16 & -31 & -21 & 559 & 1000 & 995 \\
\hline 15 & $4.8464 \mathrm{E}-01$ & 0 & 0 & 0 & 0 & 0 & 0 & 0 & 0 & -1 & 18 & -30 & -21 & 478 & 995 & 1000 \\
\hline
\end{tabular}


Table B.152: Relative uncertainty (relative standard deviation) and correlation (normalized to 1000) for ${ }^{240} \mathrm{Pu}(\mathrm{n}, \gamma)$

\begin{tabular}{|c|c|c|c|c|c|c|c|c|c|c|c|c|c|c|c|c|}
\hline 1 & $5.2163 \mathrm{E}-01$ & 1000 & 655 & 464 & 413 & 411 & 411 & 393 & 393 & 380 & 0 & 0 & 0 & 0 & 0 & 0 \\
\hline 2 & $3.2468 \mathrm{E}-01$ & 655 & 1000 & 848 & 734 & 661 & 641 & 581 & 584 & 571 & 0 & 0 & 0 & 0 & 0 & 0 \\
\hline 3 & $1.9735 \mathrm{E}-01$ & 464 & 848 & 1000 & 971 & 917 & 904 & 836 & 838 & 814 & 0 & 0 & 0 & 0 & 0 & 0 \\
\hline 4 & 1. $6277 \mathrm{E}-01$ & 413 & 734 & 971 & 1000 & 983 & 975 & 934 & 935 & 900 & 0 & 0 & 0 & 0 & 0 & 0 \\
\hline 5 & $1.4292 \mathrm{E}-01$ & 411 & 661 & 917 & 983 & 1000 & 997 & 977 & 977 & 935 & 0 & 0 & 0 & 0 & 0 & 0 \\
\hline 6 & $1.3793 E-01$ & 411 & 641 & 904 & 975 & 997 & 1000 & 972 & 970 & 930 & 0 & 0 & 0 & 0 & 0 & 0 \\
\hline 7 & 1. 1307E-01 & 393 & 581 & 836 & 934 & 977 & 972 & 1000 & 1000 & 948 & 0 & 0 & 0 & 0 & 0 & 0 \\
\hline 8 & $1.0211 \mathrm{E}-01$ & 393 & 584 & 838 & 935 & 977 & 970 & 1000 & 1000 & 948 & 0 & 0 & 0 & 0 & 0 & 0 \\
\hline 9 & $4.3538 \mathrm{E}-02$ & 380 & 571 & 814 & 900 & 935 & 930 & 948 & 948 & 1000 & 1 & 0 & 0 & 0 & 0 & 0 \\
\hline 10 & $1.4720 \mathrm{E}-02$ & 0 & 0 & 0 & 0 & 0 & 0 & 0 & 0 & 1 & 1000 & 1 & 0 & 0 & 0 & 0 \\
\hline 11 & $1.6341 \mathrm{E}-02$ & 0 & 0 & 0 & 0 & 0 & 0 & 0 & 0 & 0 & 1 & 1000 & 5 & 1 & 5 & 5 \\
\hline 12 & $5.4970 \mathrm{E}-02$ & 0 & 0 & 0 & 0 & 0 & 0 & 0 & 0 & 0 & 0 & 5 & 1000 & 2 & 23 & 25 \\
\hline 13 & $4.3621 \mathrm{E}-03$ & 0 & 0 & 0 & 0 & 0 & 0 & 0 & 0 & 0 & 0 & 1 & 2 & 1000 & 7 & 58 \\
\hline 14 & $3.2338 \mathrm{E}-02$ & 0 & 0 & 0 & 0 & 0 & 0 & 0 & 0 & 0 & 0 & 5 & 23 & 7 & 1000 & 962 \\
\hline 15 & $4.7875 \mathrm{E}-02$ & 0 & 0 & 0 & 0 & 0 & 0 & 0 & 0 & 0 & 0 & 5 & 25 & 58 & 962 & 1000 \\
\hline
\end{tabular}

Table B.153: Relative uncertainty (relative standard deviation) and correlation (normalized to 1000) for ${ }^{241} \mathrm{Pu}(\mathrm{n}, \mathrm{el})$

\begin{tabular}{|c|c|c|c|c|c|c|c|c|c|c|c|c|c|c|c|c|}
\hline & & & & & & & & & & & & & & & & \\
\hline 1 & $4.4530 \mathrm{E}-02$ & 1000 & 768 & -24 & $4 b$ & 9 & -14 & -9 & 0 & 0 & 0 & 0 & 0 & 0 & 0 & 0 \\
\hline 2 & $3.7377 \mathrm{E}-02$ & 768 & 1000 & 240 & -562 & -86 & 174 & 111 & 0 & 0 & 0 & 0 & 0 & 0 & 0 & 0 \\
\hline 3 & $4.3915 E-02$ & -24 & 240 & 1000 & -411 & -253 & 88 & 86 & 0 & 0 & 0 & 0 & 0 & 0 & 0 & 0 \\
\hline 4 & $5.3826 \mathrm{E}-02$ & 45 & -562 & -411 & 1000 & 423 & -34 & -68 & 0 & 0 & 0 & 0 & 0 & 0 & 0 & 0 \\
\hline 5 & $5.1610 \mathrm{E}-02$ & 9 & -86 & -253 & 423 & 1000 & 872 & 397 & 0 & 0 & 0 & 0 & 0 & 0 & 0 & \\
\hline 6 & $4.6939 \mathrm{E}-02$ & -14 & 174 & 88 & -34 & 872 & 1000 & 488 & 0 & 0 & 0 & 0 & 0 & 0 & 0 & 0 \\
\hline 7 & $3.9206 \mathrm{E}-02$ & -9 & 111 & 86 & -68 & 397 & 488 & 1000 & 870 & 857 & 0 & 0 & 0 & 0 & 0 & 0 \\
\hline 8 & $9.1350 \mathrm{E}-02$ & 0 & 0 & 0 & 0 & 0 & 0 & 870 & 1000 & 992 & 0 & 0 & 0 & 0 & 0 & 0 \\
\hline 9 & $9.2945 \mathrm{E}-02$ & 0 & 0 & 0 & 0 & 0 & 0 & 857 & 992 & 1000 & 12 & 12 & 12 & 12 & 12 & 11 \\
\hline 10 & $1.0962 \mathrm{E}-01$ & 0 & 0 & 0 & 0 & 0 & 0 & 0 & 0 & 12 & 1000 & 1000 & 994 & 976 & 925 & 885 \\
\hline 11 & $1.0873 \mathrm{E}-01$ & 0 & 0 & 0 & 0 & 0 & 0 & 0 & 0 & 12 & 1000 & 1000 & 994 & 976 & 925 & 885 \\
\hline 12 & $1.0658 \mathrm{E}-01$ & 0 & 0 & 0 & 0 & 0 & 0 & 0 & 0 & 12 & 994 & 994 & 1000 & 948 & 905 & 868 \\
\hline 13 & 1. 1489E-01 & 0 & 0 & 0 & 0 & 0 & 0 & 0 & 0 & 12 & 976 & 976 & 948 & 1000 & 957 & 912 \\
\hline 14 & $9.9124 \mathrm{E}-02$ & 0 & 0 & 0 & 0 & 0 & 0 & 0 & 0 & 12 & 925 & 925 & 905 & 957 & 1000 & 939 \\
\hline 15 & $1.1318 \mathrm{E}-01$ & 0 & 0 & 0 & 0 & 0 & 0 & 0 & 0 & 11 & 885 & 885 & 868 & 912 & 939 & 1000 \\
\hline
\end{tabular}


Table B.154: Relative uncertainty (relative standard deviation) and correlation (normalized to 1000) for ${ }^{241} \mathrm{Pu}\left(\mathrm{n}, \mathrm{n}^{\prime}\right)$

\begin{tabular}{|c|c|c|c|c|c|c|c|c|}
\hline & & & & & & & & \\
\hline 1 & $2.5154 \mathrm{E}-01$ & 1000 & 555 & 474 & -704 & -482 & -619 & -417 \\
\hline 2 & $1.9469 \mathrm{E}-01$ & 555 & 1000 & 965 & -859 & -852 & -969 & -63 \\
\hline 3 & $1.8378 \mathrm{E}-01$ & 474 & 965 & 1000 & -742 & -748 & -907 & -603 \\
\hline 4 & $1.9782 \mathrm{E}-01$ & -704 & -859 & -742 & 1000 & 907 & 942 & 611 \\
\hline 5 & $2.0924 \mathrm{E}-01$ & -482 & -852 & -748 & 907 & 1000 & 935 & 591 \\
\hline 6 & 3.008 & -619 & -969 & -907 & 942 & 935 & 1000 & 651 \\
\hline & $3.7508 \mathrm{E}-01$ & -417 & -638 & -603 & 611 & 591 & 651 & 1000 \\
\hline
\end{tabular}

Table B.155: Relative uncertainty (relative standard deviation) and correlation (normalized to 1000) for ${ }^{241} \mathrm{Pu}(\mathrm{n}, 2 \mathrm{n})$

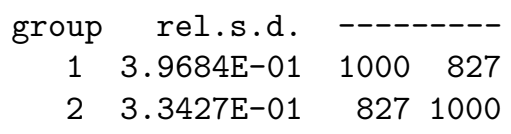

Table B.156: Relative uncertainty (relative standard deviation) and correlation (normalized to 1000) for ${ }^{241} \mathrm{Pu}(\mathrm{n}, \mathrm{f})$

\begin{tabular}{|c|c|c|c|c|c|c|c|c|c|c|c|c|c|c|c|c|}
\hline & & & & & & & & & & & & & & & & \\
\hline 1 & $2.4087 \mathrm{E}-01$ & 1000 & -75 & -98 & -82 & -71 & -78 & -71 & 0 & 0 & 0 & 0 & 0 & 0 & 0 & \\
\hline 2 & $1.4157 \mathrm{E}-01$ & -75 & 1000 & 444 & 170 & 152 & 227 & 214 & 0 & 0 & 0 & & & 0 & 0 & \\
\hline 3 & $2.1257 \mathrm{E}-01$ & -98 & 444 & 1000 & 956 & 928 & 858 & 670 & 0 & 0 & 0 & 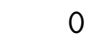 & 0 & 0 & 0 & \\
\hline 4 & $1.6621 \mathrm{E}-01$ & -82 & 170 & 956 & 1000 & 979 & 878 & 675 & 0 & 0 & 0 & & & 0 & 0 & \\
\hline 5 & $1.3538 \mathrm{E}-01$ & -71 & 152 & 928 & 979 & 1000 & 951 & 756 & 0 & 0 & 0 & & & & 0 & \\
\hline 6 & $1.9872 \mathrm{E}-01$ & -78 & 227 & 858 & 878 & 951 & 1000 & 839 & 0 & 0 & & & & & 0 & \\
\hline 7 & $8.7402 \mathrm{E}-02$ & -71 & 214 & 670 & 675 & 756 & 839 & 1000 & 526 & 525 & 0 & $c$ & & & 0 & \\
\hline 8 & $1.1285 \mathrm{E}-01$ & 0 & 0 & 0 & 0 & 0 & 0 & 526 & 1000 & 1000 & 0 & & & 0 & 0 & \\
\hline 9 & $1.0435 \mathrm{E}-01$ & 0 & 0 & 0 & 0 & 0 & 0 & 525 & 1000 & 1000 & 0 & 0 & 0 & 0 & 0 & \\
\hline 10 & $1.2679 \mathrm{E}-01$ & 0 & 0 & 0 & 0 & 0 & 0 & 0 & 0 & 0 & 1000 & 7 & 137 & -233 & 158 & 424 \\
\hline 11 & 1.937 & 0 & 0 & 0 & $c$ & c & & 0 & & 0 & 7 & 1000 & 233 & -80 & 49 & $17 \epsilon$ \\
\hline 12 & $4.2051 \mathrm{E}-02$ & 0 & 0 & 0 & 0 & c & & 0 & c & 0 & 137 & 233 & 1000 & 339 & 134 & \\
\hline 13 & $2.6831 \mathrm{E}-01$ & 0 & 0 & 0 & 0 & 0 & 0 & 0 & 0 & 0 & -233 & -80 & 339 & 1000 & 165 & -771 \\
\hline 14 & $2.9394 \mathrm{E}-02$ & 0 & 0 & 0 & 0 & 0 & 0 & 0 & 0 & 0 & 158 & 49 & 134 & 165 & 1000 & 63 \\
\hline 15 & $3.2656 \mathrm{E}-02$ & 0 & 0 & 0 & 0 & 0 & 0 & 0 & 0 & 0 & 424 & 176 & 26 & -771 & 63 & 1000 \\
\hline
\end{tabular}


Table B.157: Relative uncertainty (relative standard deviation) and correlation (normalized to 1000) for ${ }^{241} \mathrm{Pu}(\mathrm{n}, \gamma)$

\begin{tabular}{|c|c|c|c|c|c|c|c|c|c|c|c|c|c|c|c|c|}
\hline 1 & 5.538 & 1000 & 585 & 561 & 536 & 583 & 588 & 390 & 0 & 0 & 0 & 0 & 0 & 0 & 0 & \\
\hline 2 & $5.4101 \mathrm{E}-01$ & 585 & 1000 & 931 & 814 & 744 & 691 & 445 & 0 & 0 & 0 & 0 & 0 & 0 & 0 & 0 \\
\hline 3 & $3.8405 \mathrm{E}-01$ & 561 & 931 & 1000 & 969 & 928 & 882 & 573 & 0 & 0 & 0 & 0 & 0 & & 0 & 0 \\
\hline 4 & $3.1662 \mathrm{E}-01$ & 536 & 814 & 969 & 1000 & 986 & 953 & 624 & 0 & 0 & 0 & 0 & 0 & & 0 & \\
\hline 5 & $2.0513 \mathrm{E}-01$ & 583 & 744 & 928 & 986 & 1000 & 986 & 654 & 0 & 0 & 0 & 0 & & & & \\
\hline 6 & $1.1285 \mathrm{E}-01$ & 588 & 691 & 882 & 953 & 986 & 1000 & 676 & 0 & 0 & 0 & 0 & & & & \\
\hline 7 & $4.4279 \mathrm{E}-02$ & 390 & 445 & 573 & 624 & 654 & 676 & 1000 & 733 & 730 & 730 & 608 & & & & \\
\hline 8 & $7.7912 \mathrm{E}-02$ & 0 & 0 & 0 & 0 & 0 & 0 & 733 & 1000 & 999 & 998 & 831 & & & & \\
\hline 9 & $7.7309 \mathrm{E}-02$ & 0 & 0 & 0 & 0 & 0 & 0 & 730 & 999 & 1000 & 1000 & 833 & & & 0 & \\
\hline 10 & $7.7358 \mathrm{E}-02$ & 0 & 0 & 0 & 0 & 0 & 0 & 730 & 998 & 1000 & 1000 & 833 & 0 & 0 & 0 & \\
\hline 11 & 7.4258 & 0 & 0 & 0 & 0 & 0 & 0 & 608 & 831 & 833 & 833 & 1000 & 225 & 67 & 148 & -235 \\
\hline 12 & 8.382 & $c$ & c & 0 & 0 & & & & 0 & 0 & 0 & 225 & 1000 & 264 & 398 & -407 \\
\hline 13 & 6.366 & c & ( & 0 & $c$ & & & & $(-2)$ & & 0 & 67 & 264 & 1000 & 636 & 319 \\
\hline 14 & $6.8424 \mathrm{E}$ & 0 & 0 & 0 & 0 & 0 & ( & & 0 & 0 & 0 & 148 & 398 & 636 & 1000 & -6 \\
\hline 15 & $3.5907 \mathrm{E}-02$ & 0 & 0 & 0 & 0 & 0 & 0 & 0 & 0 & 0 & 0 & -235 & -407 & 319 & -6 & 1000 \\
\hline
\end{tabular}


Table B.158: Relative uncertainty (relative standard deviation) and correlation (normalized to 1000) for ${ }^{242} \mathrm{Pu}(\mathrm{n}, \mathrm{el})$

\begin{tabular}{|c|c|c|c|c|c|c|c|c|c|c|c|c|c|c|c|c|}
\hline 1 & $7.9741 \mathrm{E}-03$ & 1000 & 160 & 967 & 196 & -363 & 0 & 0 & 0 & 0 & 0 & 0 & 0 & 0 & 0 & ( \\
\hline 2 & $5.1343 \mathrm{E}-03$ & 160 & 1000 & -2 & -351 & -141 & c & c & 0 & c & & & & & 0 & \\
\hline 3 & $3.3394 \mathrm{E}-02$ & 967 & -2 & 1000 & 293 & -328 & 0 & 0 & 0 & 0 & 0 & 0 & & & 0 & \\
\hline 4 & $3.6844 \mathrm{E}-02$ & 196 & -351 & 293 & 1000 & 432 & 0 & 0 & 0 & 0 & 0 & 0 & & & 0 & \\
\hline 5 & $1.7265 \mathrm{E}-02$ & -363 & -141 & -328 & 432 & 1000 & 762 & 92 & 0 & 0 & 0 & 0 & & & 0 & \\
\hline 6 & $1.7837 \mathrm{E}-02$ & 0 & 0 & 0 & 0 & 762 & 1000 & 121 & 0 & 0 & 0 & 0 & & & & \\
\hline 7 & $1.5902 \mathrm{E}-02$ & 0 & 0 & 0 & 0 & 92 & 121 & 1000 & 993 & 708 & 0 & 0 & & & & \\
\hline 8 & $1.4171 \mathrm{E}-02$ & 0 & 0 & 0 & 0 & 0 & 0 & 993 & 1000 & 711 & 0 & 0 & & & 0 & \\
\hline 9 & $1.5916 \mathrm{E}-02$ & 0 & 0 & 0 & 0 & c & 0 & 708 & 711 & 1000 & 591 & 558 & 627 & 96 & 627 & 627 \\
\hline 10 & $3.7640 \mathrm{E}-02$ & 0 & 0 & 0 & 0 & 0 & 0 & 0 & 0 & 591 & 1000 & 827 & 936 & 143 & 936 & 936 \\
\hline 11 & $2.2909 \mathrm{E}-02$ & 0 & 0 & 0 & 0 & 0 & 0 & 0 & 0 & 558 & 827 & 1000 & 884 & 136 & 884 & 384 \\
\hline 12 & 5.937 & 0 & 0 & 0 & 0 & c & & 0 & 0 & 627 & 936 & 884 & 1000 & 169 & 998 & 98 \\
\hline 13 & 4.68 & 0 & 0 & 0 & 0 & & & & & 96 & 14 & 136 & 169 & 1000 & 118 & 12 \\
\hline 14 & $7.1901 \mathrm{E}-02$ & 0 & 0 & 0 & 0 & c & & & 0 & 627 & 936 & 884 & 998 & 118 & 1000 & 1000 \\
\hline 15 & $6.9903 \mathrm{E}-02$ & 0 & 0 & 0 & 0 & 0 & 0 & 0 & 0 & 627 & 936 & 884 & 998 & 120 & 1000 & 100 \\
\hline
\end{tabular}

Table B.159: Relative uncertainty (relative standard deviation) and correlation (normalized to 1000) for ${ }^{242} \mathrm{Pu}\left(\mathrm{n}, \mathrm{n}^{\prime}\right)$

\begin{tabular}{|c|c|c|c|c|c|c|c|}
\hline & & & & & & & \\
\hline 1 & $2.6251 \mathrm{E}-01$ & 1000 & -519 & -804 & -838 & -363 & 0 \\
\hline 2 & $3.2741 \mathrm{E}-02$ & -519 & 1000 & 865 & 785 & 315 & 0 \\
\hline 3 & $2.9278 \mathrm{E}-01$ & -804 & 865 & 1000 & 989 & 418 & 0 \\
\hline 4 & $5.9782 \mathrm{E}-01$ & -838 & 785 & 989 & 1000 & 428 & 0 \\
\hline 5 & $3.7993 \mathrm{E}-01$ & -363 & 315 & 418 & 428 & 1000 & 903 \\
\hline 6 & $1.8998 \mathrm{E}-01$ & 0 & 0 & 0 & 0 & 903 & 1000 \\
\hline
\end{tabular}


Table B.160: Relative uncertainty (relative standard deviation) and correlation (normalized to 1000) for ${ }^{242} \mathrm{Pu}(\mathrm{n}, 2 \mathrm{n})$

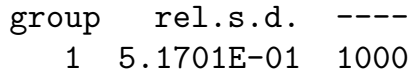

Table B.161: Relative uncertainty (relative standard deviation) and correlation (normalized to 1000) for ${ }^{242} \mathrm{Pu}(\mathrm{n}, \mathrm{f})$

\begin{tabular}{|c|c|c|c|c|c|c|c|c|c|c|c|c|c|c|c|c|}
\hline 1 & $3.7238 \mathrm{E}-01$ & 1000 & -366 & -37 & -32 & -16 & 0 & 0 & 0 & 0 & 0 & 0 & 0 & 0 & 0 & 0 \\
\hline 2 & $1.5095 \mathrm{E}-01$ & -366 & 1000 & 592 & 497 & 253 & 0 & 0 & 0 & 0 & 0 & 0 & 0 & 0 & 0 & 0 \\
\hline 3 & $2.1418 \mathrm{E}-01$ & -37 & 592 & 1000 & 981 & 500 & 0 & 0 & 0 & 0 & 0 & 0 & 0 & 0 & 0 & 0 \\
\hline 4 & 1. 8982E-01 & -32 & 497 & 981 & 1000 & 510 & 0 & 0 & 0 & 0 & 0 & 0 & 0 & 0 & 0 & \\
\hline 5 & $1.8630 \mathrm{E}-01$ & -16 & 253 & 500 & 510 & 1000 & 860 & 103 & 0 & 0 & 0 & 0 & 0 & 0 & 0 & 0 \\
\hline 6 & $3.2071 \mathrm{E}-01$ & 0 & 0 & 0 & 0 & 860 & 1000 & 120 & 0 & 0 & 0 & 0 & 0 & 0 & 0 & 0 \\
\hline 7 & $3.3058 \mathrm{E}-01$ & 0 & 0 & 0 & 0 & 103 & 120 & 1000 & 992 & 680 & 0 & 0 & 0 & 0 & 0 & 0 \\
\hline 8 & $3.3187 \mathrm{E}-01$ & 0 & 0 & 0 & 0 & 0 & 0 & 992 & 1000 & 682 & 0 & 0 & 0 & 0 & 0 & \\
\hline 9 & 1. $3227 \mathrm{E}-01$ & 0 & 0 & 0 & 0 & 0 & 0 & 680 & 682 & 1000 & 0 & 0 & 0 & 0 & 0 & 0 \\
\hline 10 & $5.8878 \mathrm{E}-02$ & 0 & 0 & 0 & 0 & 0 & 0 & 0 & 0 & 0 & 1000 & 2 & 7 & 0 & 5 & \\
\hline 11 & 1.9567E-02 & 0 & 0 & 0 & 0 & 0 & 0 & 0 & 0 & 0 & 2 & 1000 & 32 & 0 & 13 & 15 \\
\hline 12 & $6.4611 \mathrm{E}-02$ & 0 & 0 & 0 & 0 & 0 & 0 & 0 & 0 & 0 & 7 & 32 & 1000 & 337 & 477 & 477 \\
\hline 13 & $7.6041 \mathrm{E}-02$ & 0 & 0 & 0 & 0 & 0 & 0 & 0 & 0 & 0 & 0 & 0 & 337 & 1000 & 708 & 706 \\
\hline 14 & $5.2357 \mathrm{E}-02$ & 0 & 0 & 0 & 0 & 0 & 0 & 0 & 0 & 0 & 5 & 13 & 477 & 708 & 1000 & 1000 \\
\hline 15 & $5.0918 \mathrm{E}-02$ & 0 & 0 & 0 & 0 & 0 & 0 & 0 & 0 & 0 & 5 & 15 & 477 & 706 & 1000 & 1000 \\
\hline
\end{tabular}

Table B.162: Relative uncertainty (relative standard deviation) and correlation (normalized to 1000) for ${ }^{242} \mathrm{Pu}(\mathrm{n}, \gamma)$

\begin{tabular}{|c|c|c|c|c|c|c|c|c|c|c|c|c|c|c|c|c|}
\hline 1 & $7.8469 \mathrm{E}-01$ & 1000 & 369 & 230 & 42 & 0 & 0 & 0 & 0 & 0 & 0 & 0 & 0 & 0 & 0 & 0 \\
\hline 2 & $2.2718 \mathrm{E}-01$ & 369 & 1000 & 936 & 188 & -12 & 0 & 0 & 0 & 0 & 0 & 0 & 0 & 0 & 0 & 0 \\
\hline 3 & 1. $6119 \mathrm{E}-01$ & 230 & 936 & 1000 & 345 & 9 & 0 & 0 & 0 & 0 & 0 & 0 & 0 & 0 & 0 & 0 \\
\hline 4 & 1. $2484 \mathrm{E}-01$ & 42 & 188 & 345 & 1000 & 159 & 0 & 0 & 0 & 0 & 0 & 0 & 0 & 0 & 0 & 0 \\
\hline 5 & $2.4053 E-01$ & 0 & -12 & 9 & 159 & 1000 & 986 & 66 & 0 & 0 & 0 & 0 & 0 & 0 & 0 & 0 \\
\hline 6 & $3.2281 \mathrm{E}-01$ & 0 & 0 & 0 & 0 & 986 & 1000 & 67 & 0 & 0 & 0 & 0 & 0 & 0 & 0 & 0 \\
\hline 7 & $3.7256 \mathrm{E}-01$ & 0 & 0 & 0 & 0 & 66 & 67 & 1000 & 998 & 997 & 0 & 0 & 0 & 0 & 0 & 0 \\
\hline 8 & $3.8632 \mathrm{E}-01$ & 0 & 0 & 0 & 0 & 0 & 0 & 998 & 1000 & 999 & 0 & 0 & 0 & 0 & 0 & 0 \\
\hline 9 & $3.8452 \mathrm{E}-01$ & 0 & 0 & 0 & 0 & 0 & 0 & 997 & 999 & 1000 & 0 & 0 & 0 & 0 & 0 & 0 \\
\hline 10 & $1.7004 \mathrm{E}-02$ & 0 & 0 & 0 & 0 & 0 & 0 & 0 & 0 & 0 & 1000 & 4 & 0 & 0 & 0 & 0 \\
\hline 11 & $2.2263 E-02$ & 0 & 0 & 0 & 0 & 0 & 0 & 0 & 0 & 0 & 4 & 1000 & 12 & 0 & 10 & 11 \\
\hline 12 & $7.4046 \mathrm{E}-02$ & 0 & 0 & 0 & 0 & 0 & 0 & 0 & 0 & 0 & 0 & 12 & 1000 & 66 & 97 & 98 \\
\hline 13 & $3.7810 \mathrm{E}-02$ & 0 & 0 & 0 & 0 & 0 & 0 & 0 & 0 & 0 & 0 & 0 & 66 & 1000 & 688 & 705 \\
\hline 14 & $7.0974 \mathrm{E}-02$ & 0 & 0 & 0 & 0 & 0 & 0 & 0 & 0 & 0 & 0 & 10 & 97 & 688 & 1000 & 1000 \\
\hline 15 & $6.8893 \mathrm{E}-02$ & 0 & 0 & 0 & 0 & 0 & 0 & 0 & 0 & 0 & 0 & 11 & 98 & 705 & 1000 & 1000 \\
\hline
\end{tabular}


Table B.163: Relative uncertainty (relative standard deviation) and correlation (normalized to 1000) for ${ }^{241} \mathrm{Am}(\mathrm{n}, \mathrm{el})$

\begin{tabular}{|c|c|c|c|c|c|c|c|c|c|c|c|c|c|c|c|c|}
\hline 1 & $3.5126 \mathrm{E}-02$ & 1000 & -57 & -244 & -61 & -6 & -7 & -9 & 0 & 0 & 0 & 0 & 0 & 0 & 0 & 0 \\
\hline 2 & $3.7663 \mathrm{E}-02$ & -57 & 1000 & 465 & 53 & -317 & -342 & -329 & 0 & 0 & 0 & 0 & 0 & 0 & 0 & 0 \\
\hline 3 & $5.1177 \mathrm{E}-02$ & -244 & 465 & 1000 & 562 & -155 & -191 & -182 & 0 & 0 & 0 & 0 & 0 & 0 & 0 & 0 \\
\hline 4 & $4.5154 \mathrm{E}-02$ & -61 & 53 & 562 & 1000 & 700 & 670 & 639 & 0 & 0 & 0 & 0 & 0 & 0 & 0 & \\
\hline 5 & $5.5015 \mathrm{E}-02$ & -6 & -317 & -155 & 700 & 1000 & 999 & 952 & 0 & 0 & 0 & 0 & 0 & 0 & 0 & \\
\hline 6 & $5.2028 \mathrm{E}-02$ & -7 & -342 & -191 & 670 & 999 & 1000 & 953 & 0 & 0 & 0 & 0 & 0 & 0 & 0 & \\
\hline 7 & $4.8084 \mathrm{E}-02$ & -9 & -329 & -182 & 639 & 952 & 953 & 1000 & 302 & 299 & 127 & 0 & 0 & 0 & 0 & \\
\hline 8 & $1.1542 \mathrm{E}-01$ & 0 & 0 & 0 & 0 & 0 & 0 & 302 & 1000 & 991 & 421 & 0 & 0 & 0 & 0 & \\
\hline 9 & 1. $2351 \mathrm{E}-01$ & 0 & 0 & 0 & 0 & 0 & 0 & 299 & 991 & 1000 & 434 & 0 & 0 & 0 & 0 & \\
\hline 10 & $9.6996 \mathrm{E}-02$ & 0 & 0 & 0 & 0 & 0 & 0 & 127 & 421 & 434 & 1000 & 886 & 886 & 885 & 885 & 885 \\
\hline 11 & $1.4527 \mathrm{E}-01$ & 0 & 0 & 0 & 0 & 0 & 0 & 0 & 0 & 0 & 886 & 1000 & 1000 & 998 & 998 & 998 \\
\hline 12 & 1. $4030 \mathrm{E}-01$ & 0 & 0 & 0 & 0 & 0 & 0 & 0 & 0 & 0 & 886 & 1000 & 1000 & 998 & 998 & 998 \\
\hline 13 & $1.4204 \mathrm{E}-01$ & 0 & 0 & 0 & 0 & 0 & 0 & 0 & 0 & 0 & 885 & 998 & 998 & 1000 & 996 & 996 \\
\hline 14 & $1.3810 \mathrm{E}-01$ & 0 & 0 & 0 & 0 & 0 & 0 & 0 & 0 & 0 & 885 & 998 & 998 & 996 & 1000 & 1000 \\
\hline 15 & 1. $3033 \mathrm{E}-01$ & 0 & 0 & 0 & 0 & 0 & 0 & 0 & 0 & 0 & 885 & 998 & 998 & 996 & 1000 & 1000 \\
\hline
\end{tabular}

Table B.164: Relative uncertainty (relative standard deviation) and correlation (normalized to 1000) for ${ }^{241} \mathrm{Am}\left(\mathrm{n}, \mathrm{n}^{\prime}\right)$

\begin{tabular}{|c|c|c|c|c|c|c|c|c|}
\hline & & & & & & & & \\
\hline 1 & $5.5289 \mathrm{E}-01$ & 1000 & -20 & -67 & -275 & -375 & -151 & -103 \\
\hline 2 & 1.5199E-01 & -20 & 1000 & 953 & 889 & -305 & -798 & -718 \\
\hline 3 & $2.9632 \mathrm{E}-01$ & -67 & 953 & 1000 & 884 & -409 & -884 & -788 \\
\hline 4 & $2.4449 \mathrm{E}-01$ & -275 & 889 & 884 & 1000 & 61 & -564 & -538 \\
\hline 5 & $2.3026 \mathrm{E}-01$ & -375 & -305 & -409 & 61 & 1000 & 787 & 629 \\
\hline 6 & $4.8530 \mathrm{E}-01$ & -151 & -798 & -884 & -564 & 787 & 1000 & 855 \\
\hline 7 & $5.1781 \mathrm{E}-01$ & -103 & -718 & -788 & -538 & 629 & 855 & 1000 \\
\hline
\end{tabular}

Table B.165: Relative uncertainty (relative standard deviation) and correlation (normalized to 1000) for ${ }^{241} \mathrm{Am}(\mathrm{n}, 2 \mathrm{n})$

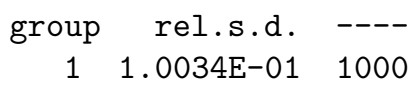


Table B.166: Relative uncertainty (relative standard deviation) and correlation (normalized to 1000) for ${ }^{241} \mathrm{Am}(\mathrm{n}, \mathrm{f})$

\begin{tabular}{|c|c|c|c|c|c|c|c|c|c|c|c|c|c|c|c|c|}
\hline 1 & $1.2743 \mathrm{E}-01$ & 1000 & 293 & -126 & -71 & -75 & -75 & -72 & 0 & 0 & 0 & 0 & 0 & 0 & 0 & 0 \\
\hline 2 & 1. $1665 \mathrm{E}-01$ & 293 & 1000 & 632 & 409 & 331 & 331 & 320 & 0 & 0 & 0 & 0 & 0 & 0 & 0 & 0 \\
\hline 3 & $9.8086 \mathrm{E}-02$ & -126 & 632 & 1000 & 921 & 882 & 882 & 852 & 0 & 0 & 0 & 0 & 0 & 0 & 0 & 0 \\
\hline 4 & $8.2530 \mathrm{E}-02$ & -71 & 409 & 921 & 1000 & 996 & 996 & 962 & 0 & 0 & 0 & 0 & 0 & 0 & 0 & \\
\hline 5 & $8.2853 E-02$ & -75 & 331 & 882 & 996 & 1000 & 1000 & 966 & 0 & 0 & 0 & 0 & 0 & 0 & 0 & 0 \\
\hline 6 & $8.2853 E-02$ & -75 & 331 & 882 & 996 & 1000 & 1000 & 966 & 0 & 0 & 0 & 0 & 0 & 0 & 0 & \\
\hline 7 & $7.3868 \mathrm{E}-02$ & -72 & 320 & 852 & 962 & 966 & 966 & 1000 & 258 & 258 & 258 & 225 & 0 & 0 & 0 & 0 \\
\hline 8 & 1.3709E-01 & 0 & 0 & 0 & 0 & 0 & 0 & 258 & 1000 & 1000 & 1000 & 874 & 0 & 0 & 0 & \\
\hline 9 & $1.3507 \mathrm{E}-01$ & 0 & 0 & 0 & 0 & 0 & 0 & 258 & 1000 & 1000 & 1000 & 874 & 0 & 0 & 0 & 0 \\
\hline 10 & $1.3410 \mathrm{E}-01$ & 0 & 0 & 0 & 0 & 0 & 0 & 258 & 1000 & 1000 & 1000 & 874 & 0 & 0 & 0 & \\
\hline 11 & $8.0804 \mathrm{E}-02$ & 0 & 0 & 0 & 0 & 0 & 0 & 225 & 874 & 874 & 874 & 1000 & 0 & 0 & 0 & 0 \\
\hline 12 & $5.1451 \mathrm{E}-02$ & 0 & 0 & 0 & 0 & 0 & 0 & 0 & 0 & 0 & 0 & 0 & 1000 & -4 & 1 & 12 \\
\hline 13 & $6.7239 \mathrm{E}-02$ & 0 & 0 & 0 & 0 & 0 & 0 & 0 & 0 & 0 & 0 & 0 & -4 & 1000 & 57 & 131 \\
\hline 14 & $8.9340 \mathrm{E}-02$ & 0 & 0 & 0 & 0 & 0 & 0 & 0 & 0 & 0 & 0 & 0 & 1 & 57 & 1000 & 884 \\
\hline 15 & $3.0203 E-02$ & 0 & 0 & 0 & 0 & 0 & 0 & 0 & 0 & 0 & 0 & 0 & 12 & 131 & 884 & 1000 \\
\hline
\end{tabular}

Table B.167: Relative uncertainty (relative standard deviation) and correlation (normalized to 1000) for ${ }^{241} \mathrm{Am}(\mathrm{n}, \gamma)$

\begin{tabular}{|c|c|c|c|c|c|c|c|c|c|c|c|c|c|c|c|c|}
\hline 1 & $2.8826 \mathrm{E}-01$ & 1000 & 391 & 321 & 246 & 253 & 156 & 105 & 0 & 0 & 0 & 0 & 0 & 0 & 0 & 0 \\
\hline 2 & $1.5384 \mathrm{E}-01$ & 391 & 1000 & 935 & 753 & 240 & -204 & -370 & 0 & 0 & 0 & 0 & 0 & 0 & 0 & 0 \\
\hline 3 & $9.1623 \mathrm{E}-02$ & 321 & 935 & 1000 & 932 & 416 & -104 & -329 & 0 & 0 & 0 & 0 & 0 & 0 & 0 & \\
\hline 4 & $6.9022 \mathrm{E}-02$ & 246 & 753 & 932 & 1000 & 618 & 100 & -148 & 0 & 0 & 0 & 0 & 0 & 0 & 0 & \\
\hline 5 & $5.2942 \mathrm{E}-02$ & 253 & 240 & 416 & 618 & 1000 & 843 & 677 & 0 & 0 & 0 & 0 & 0 & 0 & 0 & \\
\hline 6 & $6.7913 \mathrm{E}-02$ & 156 & -204 & -104 & 100 & 843 & 1000 & 957 & 0 & 0 & 0 & 0 & 0 & 0 & 0 & \\
\hline 7 & $7.9615 \mathrm{E}-02$ & 105 & -370 & -329 & -148 & 677 & 957 & 1000 & 122 & 122 & 122 & 121 & 0 & 0 & 0 & \\
\hline 8 & $6.8538 \mathrm{E}-02$ & 0 & 0 & 0 & 0 & 0 & 0 & 122 & 1000 & 1000 & 1000 & 996 & 0 & 0 & 0 & \\
\hline 9 & $6.6629 \mathrm{E}-02$ & 0 & 0 & 0 & 0 & 0 & 0 & 122 & 1000 & 1000 & 1000 & 997 & 0 & 0 & 0 & \\
\hline 10 & $6.5925 \mathrm{E}-02$ & 0 & 0 & 0 & 0 & 0 & 0 & 122 & 1000 & 1000 & 1000 & 997 & 0 & 0 & 0 & \\
\hline 11 & $3.6682 \mathrm{E}-02$ & 0 & 0 & 0 & 0 & 0 & 0 & 121 & 996 & 997 & 997 & 1000 & 0 & 0 & 0 & \\
\hline 12 & $1.8169 \mathrm{E}-02$ & 0 & 0 & 0 & 0 & 0 & 0 & 0 & 0 & 0 & 0 & 0 & 1000 & -157 & 0 & -1 \\
\hline 13 & $5.5364 \mathrm{E}-02$ & 0 & 0 & 0 & 0 & 0 & 0 & 0 & 0 & 0 & 0 & 0 & -157 & 1000 & 32 & 80 \\
\hline 14 & 1. 2581E-02 & 0 & 0 & 0 & 0 & 0 & 0 & 0 & 0 & 0 & 0 & 0 & 0 & 32 & 1000 & 320 \\
\hline 15 & $1.8013 \mathrm{E}-02$ & 0 & 0 & 0 & 0 & 0 & 0 & 0 & 0 & 0 & 0 & 0 & -1 & 80 & 320 & 1000 \\
\hline
\end{tabular}


Table B.168: Relative uncertainty (relative standard deviation) and correlation (normalized to 1000) for ${ }^{242 m} \mathrm{Am}(\mathrm{n}, \mathrm{el})$

\begin{tabular}{|c|c|c|c|c|c|c|c|c|c|c|c|c|c|c|c|c|}
\hline & & & & & & & & & & & & & & & & \\
\hline 1 & $8.3637 \mathrm{E}-02$ & 1000 & 972 & 100 & 959 & 908 & 654 & 306 & 0 & 0 & 0 & 0 & 0 & 0 & 0 & 0 \\
\hline 2 & 1. $2054 \mathrm{E}-01$ & 972 & 1000 & 322 & 998 & 977 & 804 & 507 & 0 & 0 & 0 & 0 & 0 & 0 & 0 & 0 \\
\hline 3 & 1. $1151 \mathrm{E}-01$ & 100 & 322 & 1000 & 367 & 490 & 797 & 952 & 0 & 0 & 0 & 0 & 0 & 0 & 0 & 0 \\
\hline 4 & 1. $2055 \mathrm{E}-01$ & 959 & 998 & 367 & 1000 & 987 & 835 & 551 & 0 & 0 & 0 & 0 & 0 & 0 & 0 & 0 \\
\hline 5 & $1.3658 \mathrm{E}-01$ & 908 & 977 & 490 & 987 & 1000 & 909 & 666 & 0 & 0 & 0 & 0 & 0 & 0 & 0 & 0 \\
\hline 6 & 1. $3909 \mathrm{E}-01$ & 654 & 804 & 797 & 835 & 909 & 1000 & 909 & 0 & 0 & 0 & 0 & 0 & 0 & 0 & 0 \\
\hline 7 & 1. $2761 \mathrm{E}-01$ & 306 & 507 & 952 & 551 & 666 & 909 & 1000 & 153 & 138 & 136 & 20 & 0 & 0 & 0 & 0 \\
\hline 8 & $1.8887 \mathrm{E}-01$ & 0 & 0 & 0 & 0 & 0 & 0 & 153 & 1000 & 930 & 922 & 136 & 0 & 0 & 0 & 0 \\
\hline 9 & $1.9364 \mathrm{E}-01$ & 0 & 0 & 0 & 0 & 0 & 0 & 138 & 930 & 1000 & 997 & 147 & 0 & 0 & 0 & 0 \\
\hline 10 & $1.9423 \mathrm{E}-01$ & 0 & 0 & 0 & 0 & 0 & 0 & 136 & 922 & 997 & 1000 & 151 & 4 & 4 & 4 & 4 \\
\hline 11 & $1.6677 \mathrm{E}-01$ & 0 & 0 & 0 & 0 & 0 & 0 & 20 & 136 & 147 & 151 & 1000 & 989 & 987 & 921 & 984 \\
\hline 12 & 1. $9950 \mathrm{E}-01$ & 0 & 0 & 0 & 0 & 0 & 0 & 0 & 0 & 0 & 4 & 989 & 1000 & 998 & 932 & 994 \\
\hline 13 & $2.0611 \mathrm{E}-01$ & 0 & 0 & 0 & 0 & 0 & 0 & 0 & 0 & 0 & 4 & 987 & 998 & 1000 & 944 & 994 \\
\hline 14 & $1.7644 \mathrm{E}-01$ & 0 & 0 & 0 & 0 & 0 & 0 & 0 & 0 & 0 & 4 & 921 & 932 & 944 & 1000 & 943 \\
\hline 15 & $2.1783 E-01$ & 0 & 0 & 0 & 0 & 0 & 0 & 0 & 0 & 0 & 4 & 984 & 994 & 994 & 943 & 1000 \\
\hline
\end{tabular}

Table B.169: Relative uncertainty (relative standard deviation) and correlation (normalized to 1000) for ${ }^{242 m} \operatorname{Am}\left(n, n^{\prime}\right)$

\begin{tabular}{|c|c|c|c|c|c|c|c|c|c|}
\hline & & & & & & & & & \\
\hline 1 & $5.5815 \mathrm{E}-01$ & 1000 & -300 & -403 & -468 & -444 & -387 & -328 & 0 \\
\hline 2 & $1.7324 \mathrm{E}-01$ & -300 & 1000 & 960 & 874 & 691 & 399 & 207 & \\
\hline 3 & $2.3839 \mathrm{E}-01$ & -403 & 960 & 1000 & 926 & 756 & 460 & 254 & \\
\hline 4 & $2.6470 \mathrm{E}-01$ & -468 & 874 & 926 & 1000 & 938 & 754 & 576 & \\
\hline 5 & $2.7104 \mathrm{E}-01$ & -444 & 691 & 756 & 938 & 1000 & 927 & 768 & 0 \\
\hline 6 & $3.3651 \mathrm{E}-01$ & -387 & 399 & 460 & 754 & 927 & 1000 & 913 & 0 \\
\hline 7 & $3.1146 \mathrm{E}-01$ & -328 & 207 & 254 & 576 & 768 & 913 & 1000 & 332 \\
\hline 8 & $5.0000 \mathrm{E}-01$ & 0 & 0 & 0 & 0 & 0 & 0 & 332 & 1000 \\
\hline
\end{tabular}

Table B.170: Relative uncertainty (relative standard deviation) and correlation (normalized to 1000) for ${ }^{242 m} \mathrm{Am}(\mathrm{n}, 2 \mathrm{n})$

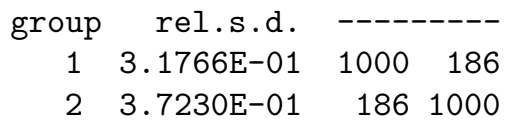


Table B.171: Relative uncertainty (relative standard deviation) and correlation (normalized to 1000) for ${ }^{242 m} \mathrm{Am}(\mathrm{n}, \mathrm{f})$

\begin{tabular}{|c|c|c|c|c|c|c|c|c|c|c|c|c|c|c|c|c|}
\hline 1 & $2.1373 \mathrm{E}-01$ & 1000 & 358 & -148 & -82 & -85 & -85 & -84 & 0 & 0 & 0 & 0 & 0 & 0 & 0 & 0 \\
\hline 2 & $2.3363 E-01$ & 358 & 1000 & 645 & 390 & 343 & 343 & 341 & 0 & 0 & 0 & 0 & 0 & 0 & 0 & 0 \\
\hline 3 & $1.9701 \mathrm{E}-01$ & -148 & 645 & 1000 & 904 & 880 & 880 & 876 & 0 & 0 & 0 & 0 & 0 & 0 & 0 & 0 \\
\hline 4 & 1. $6514 \mathrm{E}-01$ & -82 & 390 & 904 & 1000 & 998 & 998 & 995 & 0 & 0 & 0 & 0 & 0 & 0 & 0 & 0 \\
\hline 5 & $1.6571 \mathrm{E}-01$ & -85 & 343 & 880 & 998 & 1000 & 1000 & 996 & 0 & 0 & 0 & 0 & 0 & 0 & 0 & 0 \\
\hline 6 & $1.6571 \mathrm{E}-01$ & -85 & 343 & 880 & 998 & 1000 & 1000 & 996 & 0 & 0 & 0 & 0 & 0 & 0 & 0 & 0 \\
\hline 7 & $1.4431 \mathrm{E}-01$ & -84 & 341 & 876 & 995 & 996 & 996 & 1000 & 87 & 87 & 87 & 8 & 0 & 0 & 0 & 0 \\
\hline 8 & 1. 1797E-01 & 0 & 0 & 0 & 0 & 0 & 0 & 87 & 1000 & 1000 & 1000 & 91 & 0 & 0 & 0 & 0 \\
\hline 9 & 1. $2360 \mathrm{E}-01$ & 0 & 0 & 0 & 0 & 0 & 0 & 87 & 1000 & 1000 & 1000 & 91 & 0 & 0 & 0 & 0 \\
\hline 10 & 1.2197E-01 & 0 & 0 & 0 & 0 & 0 & 0 & 87 & 1000 & 1000 & 1000 & 92 & 0 & 0 & 0 & 0 \\
\hline 11 & $1.0393 \mathrm{E}-01$ & 0 & 0 & 0 & 0 & 0 & 0 & 8 & 91 & 91 & 92 & 1000 & 23 & 0 & 0 & 0 \\
\hline 12 & $1.0377 \mathrm{E}-01$ & 0 & 0 & 0 & 0 & 0 & 0 & 0 & 0 & 0 & 0 & 23 & 1000 & 5 & 2 & 2 \\
\hline 13 & 6.9997E-02 & 0 & 0 & 0 & 0 & 0 & 0 & 0 & 0 & 0 & 0 & 0 & 5 & 1000 & 159 & 149 \\
\hline 14 & $8.8316 \mathrm{E}-02$ & 0 & 0 & 0 & 0 & 0 & 0 & 0 & 0 & 0 & 0 & 0 & 2 & 159 & 1000 & 979 \\
\hline 15 & $8.0613 \mathrm{E}-02$ & 0 & 0 & 0 & 0 & 0 & 0 & 0 & 0 & 0 & 0 & 0 & 2 & 149 & 979 & 1000 \\
\hline
\end{tabular}

Table B.172: Relative uncertainty (relative standard deviation) and correlation (normalized to 1000) for ${ }^{242 m} \mathrm{Am}(\mathrm{n}, \gamma)$

\begin{tabular}{|c|c|c|c|c|c|c|c|c|c|c|c|c|c|c|c|c|}
\hline 1 & $8.4910 \mathrm{E}-01$ & 1000 & 426 & 431 & 370 & 349 & 378 & 320 & 0 & 0 & 0 & 0 & 0 & 0 & 0 & 0 \\
\hline 2 & $6.3012 \mathrm{E}-01$ & 426 & 1000 & 960 & 822 & 757 & 661 & 376 & 0 & 0 & 0 & 0 & 0 & 0 & 0 & 0 \\
\hline 3 & $4.3345 E-01$ & 431 & 960 & 1000 & 939 & 897 & 830 & 551 & 0 & 0 & 0 & 0 & 0 & 0 & 0 & 0 \\
\hline 4 & $3.9405 \mathrm{E}-01$ & 370 & 822 & 939 & 1000 & 994 & 928 & 655 & 0 & 0 & 0 & 0 & 0 & 0 & 0 & 0 \\
\hline 5 & $2.8998 \mathrm{E}-01$ & 349 & 757 & 897 & 994 & 1000 & 949 & 701 & 0 & 0 & 0 & 0 & 0 & 0 & 0 & 0 \\
\hline 6 & 1.9389E-01 & 378 & 661 & 830 & 928 & 949 & 1000 & 881 & 0 & 0 & 0 & 0 & 0 & 0 & 0 & \\
\hline 7 & $1.8008 \mathrm{E}-01$ & 320 & 376 & 551 & 655 & 701 & 881 & 1000 & 118 & 118 & 118 & 22 & 0 & 0 & 0 & 0 \\
\hline 8 & 1.9171E-01 & 0 & 0 & 0 & 0 & 0 & 0 & 118 & 1000 & 1000 & 999 & 187 & 0 & 0 & 0 & \\
\hline 9 & $2.0227 \mathrm{E}-01$ & 0 & 0 & 0 & 0 & 0 & 0 & 118 & 1000 & 1000 & 1000 & 188 & 0 & 0 & 0 & 0 \\
\hline 10 & $2.0080 \mathrm{E}-01$ & 0 & 0 & 0 & 0 & 0 & 0 & 118 & 999 & 1000 & 1000 & 190 & 0 & 0 & 0 & \\
\hline 11 & 1. $1394 \mathrm{E}-01$ & 0 & 0 & 0 & 0 & 0 & 0 & 22 & 187 & 188 & 190 & 1000 & 25 & 2 & 1 & 1 \\
\hline 12 & $1.3246 \mathrm{E}-01$ & 0 & 0 & 0 & 0 & 0 & 0 & 0 & 0 & 0 & 0 & 25 & 1000 & 47 & 5 & \\
\hline 13 & 1. 3573E-01 & 0 & 0 & 0 & 0 & 0 & 0 & 0 & 0 & 0 & 0 & 2 & 47 & 1000 & 326 & 268 \\
\hline 14 & 1.9867E-01 & 0 & 0 & 0 & 0 & 0 & 0 & 0 & 0 & 0 & 0 & 1 & 5 & 326 & 1000 & 988 \\
\hline 15 & 1.9597E-01 & 0 & 0 & 0 & 0 & 0 & 0 & 0 & 0 & 0 & 0 & 1 & 5 & 268 & 988 & 1000 \\
\hline
\end{tabular}


Table B.173: Relative uncertainty (relative standard deviation) and correlation (normalized to 1000) for ${ }^{243} \mathrm{Am}(\mathrm{n}, \mathrm{el})$

\begin{tabular}{|c|c|c|c|c|c|c|c|c|c|c|c|c|c|c|c|c|}
\hline 1 & $7.5097 \mathrm{E}-02$ & 1000 & 160 & -142 & -61 & -73 & -138 & -72 & 0 & 0 & 0 & 0 & 0 & 0 & 0 & 0 \\
\hline 2 & $4.6414 \mathrm{E}-02$ & 160 & 1000 & 222 & 538 & 510 & 232 & 82 & 0 & 0 & 0 & 0 & 0 & 0 & 0 & 0 \\
\hline 3 & $7.4911 \mathrm{E}-02$ & -142 & 222 & 1000 & 914 & 938 & 989 & 472 & 0 & 0 & 0 & 0 & 0 & 0 & 0 & 0 \\
\hline 4 & $4.1118 \mathrm{E}-02$ & -61 & 538 & 914 & 1000 & 982 & 923 & 429 & 0 & 0 & 0 & 0 & 0 & 0 & 0 & \\
\hline 5 & $5.9039 \mathrm{E}-02$ & -73 & 510 & 938 & 982 & 1000 & 954 & 445 & 0 & 0 & 0 & 0 & 0 & 0 & 0 & \\
\hline 6 & $7.8369 \mathrm{E}-02$ & -138 & 232 & 989 & 923 & 954 & 1000 & 476 & 0 & 0 & 0 & 0 & 0 & 0 & 0 & \\
\hline 7 & $4.4050 \mathrm{E}-02$ & -72 & 82 & 472 & 429 & 445 & 476 & 1000 & 879 & 866 & 0 & 0 & 0 & 0 & 0 & \\
\hline 8 & $9.1268 \mathrm{E}-02$ & 0 & 0 & 0 & 0 & 0 & 0 & 879 & 1000 & 989 & 0 & 0 & 0 & 0 & 0 & \\
\hline 9 & $9.6014 \mathrm{E}-02$ & 0 & 0 & 0 & 0 & 0 & 0 & 866 & 989 & 1000 & 5 & 5 & 5 & 3 & 5 & \\
\hline 10 & $7.6822 \mathrm{E}-02$ & 0 & 0 & 0 & 0 & 0 & 0 & 0 & 0 & 5 & 1000 & 949 & 929 & 648 & 952 & 954 \\
\hline 11 & $8.9578 \mathrm{E}-02$ & 0 & 0 & 0 & 0 & 0 & 0 & 0 & 0 & 5 & 949 & 1000 & 963 & 672 & 986 & 987 \\
\hline 12 & $8.2168 \mathrm{E}-02$ & 0 & 0 & 0 & 0 & 0 & 0 & 0 & 0 & 5 & 929 & 963 & 1000 & 663 & 963 & 965 \\
\hline 13 & $7.0028 \mathrm{E}-02$ & 0 & 0 & 0 & 0 & 0 & 0 & 0 & 0 & 3 & 648 & 672 & 663 & 1000 & 609 & 62 \\
\hline 14 & 1. $2409 \mathrm{E}-01$ & 0 & 0 & 0 & 0 & 0 & 0 & 0 & 0 & 5 & 952 & 986 & 963 & 609 & 1000 & 1000 \\
\hline 15 & 1. $1444 \mathrm{E}-01$ & 0 & 0 & 0 & 0 & 0 & 0 & 0 & 0 & 5 & 954 & 987 & 965 & 623 & 1000 & 1000 \\
\hline
\end{tabular}

Table B.174: Relative uncertainty (relative standard deviation) and correlation (normalized to 1000) for ${ }^{243} \mathrm{Am}\left(\mathrm{n}, \mathrm{n}^{\prime}\right)$

$\begin{array}{crrrrrrrr}\text { group } & \text { rel.s.d. } & -1---15 & -16 & -20 & -24 \\ 1 & 6.1968 \mathrm{E}-01 & 1000 & 208 & -8 & -15 & -1 \\ 2 & 1.7867 \mathrm{E}-01 & 208 & 1000 & 533 & 609 & 647 & 666 & 657 \\ 3 & 3.5300 \mathrm{E}-01 & -8 & 533 & 1000 & 978 & 911 & 784 & 667 \\ 4 & 4.2154 \mathrm{E}-01 & -15 & 609 & 978 & 1000 & 977 & 895 & 805 \\ 5 & 4.0982 \mathrm{E}-01 & -16 & 647 & 911 & 977 & 1000 & 970 & 911 \\ 6 & 7.9525 \mathrm{E}-01 & -20 & 666 & 784 & 895 & 970 & 1000 & 981 \\ 7 & 8.0771 \mathrm{E}-01 & -24 & 657 & 667 & 805 & 911 & 981 & 1000\end{array}$

Table B.175: Relative uncertainty (relative standard deviation) and correlation (normalized to 1000) for ${ }^{243} \mathrm{Am}(\mathrm{n}, 2 \mathrm{n})$

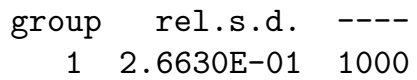


Table B.176: Relative uncertainty (relative standard deviation) and correlation (normalized to 1000) for ${ }^{243} \mathrm{Am}(\mathrm{n}, \mathrm{f})$

\begin{tabular}{|c|c|c|c|c|c|c|c|c|c|c|c|c|c|c|c|c|}
\hline 1 & $1.4436 \mathrm{E}-01$ & 1000 & 129 & 70 & -13 & -19 & -19 & -10 & 0 & 0 & 0 & 0 & 0 & 0 & 0 & 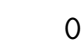 \\
\hline 2 & $1.1028 \mathrm{E}-01$ & 129 & 1000 & 682 & -170 & -223 & -223 & -117 & 0 & 0 & 0 & & & & 0 & \\
\hline 3 & $5.9739 \mathrm{E}-02$ & 70 & 682 & 1000 & 550 & 486 & 486 & 255 & 0 & 0 & 0 & 0 & & & 0 & \\
\hline 4 & $9.1842 \mathrm{E}-02$ & -13 & -170 & 550 & 1000 & 995 & 995 & 522 & 0 & 0 & 0 & 0 & & & 0 & \\
\hline 5 & $9.6178 \mathrm{E}-02$ & -19 & -223 & 486 & 995 & 1000 & 1000 & 525 & 0 & 0 & 0 & 0 & c & & 0 & \\
\hline 6 & $9.6178 \mathrm{E}-02$ & -19 & -223 & 486 & 995 & 1000 & 1000 & 525 & 0 & 0 & 0 & 0 & & & & \\
\hline 7 & $7.1171 \mathrm{E}-02$ & -10 & -117 & 255 & 522 & 525 & 525 & 1000 & 851 & 851 & 851 & 844 & & & & \\
\hline 8 & $1.3789 \mathrm{E}-01$ & 0 & 0 & 0 & 0 & 0 & 0 & 851 & 1000 & 1000 & 1000 & 992 & & & & \\
\hline 9 & $1.3540 \mathrm{E}-01$ & 0 & 0 & 0 & 0 & c & 0 & 851 & 1000 & 1000 & 1000 & 992 & & & 0 & \\
\hline 10 & $1.3408 \mathrm{E}-01$ & 0 & 0 & 0 & 0 & 0 & 0 & 851 & 1000 & 1000 & 1000 & 992 & 0 & & 0 & \\
\hline 11 & $9.6353 \mathrm{E}-02$ & 0 & 0 & 0 & 0 & 0 & 0 & 844 & 992 & 992 & 992 & 1000 & 1 & & 0 & \\
\hline 12 & $5.9527 \mathrm{E}-02$ & 0 & 0 & 0 & 0 & 0 & 0 & 0 & 0 & 0 & 0 & 1 & 1000 & 1 & 13 & 12 \\
\hline 13 & 4.805 & c & 0 & 0 & $c$ & & & & ( & & & & & 1000 & 381 & 240 \\
\hline 14 & $2.2488 \mathrm{E}-02$ & 0 & 0 & 0 & 0 & 0 & & & 0 & 0 & & 0 & 13 & 381 & 1000 & 905 \\
\hline 15 & $2.1229 \mathrm{E}-02$ & 0 & 0 & 0 & 0 & 0 & 0 & 0 & 0 & 0 & 0 & 0 & 12 & 240 & 905 & 1000 \\
\hline
\end{tabular}


Table B.177: Relative uncertainty (relative standard deviation) and correlation (normalized to 1000) for ${ }^{243} \mathrm{Am}(\mathrm{n}, \gamma)$

\begin{tabular}{|c|c|c|c|c|c|c|c|c|c|c|c|c|c|c|c|c|}
\hline 1 & $6.0422 \mathrm{E}-01$ & 1000 & 353 & 246 & 128 & 145 & 147 & 72 & 0 & 0 & 0 & 0 & 0 & 0 & 0 & 0 \\
\hline 2 & $4.1502 \mathrm{E}-01$ & 353 & 1000 & 948 & 725 & 529 & -31 & -171 & 0 & 0 & 0 & 0 & 0 & 0 & 0 & 0 \\
\hline 3 & $2.1658 \mathrm{E}-01$ & 246 & 948 & 1000 & 899 & 728 & -40 & -243 & 0 & 0 & 0 & 0 & 0 & 0 & 0 & 0 \\
\hline 4 & $1.4183 \mathrm{E}-01$ & 128 & 725 & 899 & 1000 & 930 & 26 & -256 & 0 & 0 & 0 & 0 & 0 & 0 & 0 & 0 \\
\hline 5 & $8.9188 \mathrm{E}-02$ & 145 & 529 & 728 & 930 & 1000 & 299 & -67 & 0 & 0 & 0 & 0 & 0 & 0 & 0 & 0 \\
\hline 6 & $6.5961 \mathrm{E}-02$ & 147 & -31 & -40 & 26 & 299 & 1000 & 698 & 0 & 0 & 0 & 0 & 0 & 0 & 0 & 0 \\
\hline 7 & $4.5693 \mathrm{E}-02$ & 72 & -171 & -243 & -256 & -67 & 698 & 1000 & 652 & 652 & 652 & 613 & 0 & 0 & 0 & 0 \\
\hline 8 & $6.7704 \mathrm{E}-02$ & 0 & 0 & 0 & 0 & 0 & 0 & 652 & 1000 & 1000 & 1000 & 939 & 0 & 0 & 0 & \\
\hline 9 & $6.6441 \mathrm{E}-02$ & 0 & 0 & 0 & 0 & 0 & 0 & 652 & 1000 & 1000 & 1000 & 939 & 0 & 0 & 0 & 0 \\
\hline 10 & $6.5778 \mathrm{E}-02$ & 0 & 0 & 0 & 0 & 0 & 0 & 652 & 1000 & 1000 & 1000 & 940 & 0 & 0 & 0 & \\
\hline 11 & $2.3065 \mathrm{E}-02$ & 0 & 0 & 0 & 0 & 0 & 0 & 613 & 939 & 939 & 940 & 1000 & 5 & 0 & 1 & 1 \\
\hline 12 & $1.7412 \mathrm{E}-02$ & 0 & 0 & 0 & 0 & 0 & 0 & 0 & 0 & 0 & 0 & 5 & 1000 & 3 & 14 & 20 \\
\hline 13 & $3.4319 \mathrm{E}-02$ & 0 & 0 & 0 & 0 & 0 & 0 & 0 & 0 & 0 & 0 & 0 & 3 & 1000 & 707 & 754 \\
\hline 14 & $3.7452 \mathrm{E}-02$ & 0 & 0 & 0 & 0 & 0 & 0 & 0 & 0 & 0 & 0 & 1 & 14 & 707 & 1000 & 942 \\
\hline 15 & $3.5761 \mathrm{E}-02$ & 0 & 0 & 0 & 0 & 0 & 0 & 0 & 0 & 0 & 0 & 1 & 20 & 754 & 942 & 1000 \\
\hline
\end{tabular}

Table B.178: Relative uncertainty (relative standard deviation) and correlation (normalized to 1000) for ${ }^{242} \mathrm{Cm}(\mathrm{n}, \mathrm{el})$

\begin{tabular}{|c|c|c|c|c|c|c|c|c|c|c|c|c|c|c|c|c|}
\hline 1 & $3.0140 E-02$ & 1000 & 995 & 996 & -26 & -430 & -627 & -880 & -917 & 0 & 0 & 0 & 0 & 0 & 0 & 0 \\
\hline 2 & $5.2736 \mathrm{E}-02$ & 995 & 1000 & 985 & -123 & -516 & -701 & -923 & -920 & 0 & 0 & 0 & 0 & 0 & 0 & 0 \\
\hline 3 & $2.8487 \mathrm{E}-02$ & 996 & 985 & 1000 & 51 & -362 & -569 & -842 & -906 & 0 & 0 & 0 & 0 & 0 & 0 & 0 \\
\hline 4 & 1. $6611 \mathrm{E}-02$ & -26 & -123 & 51 & 1000 & 906 & 787 & 496 & 109 & 0 & 0 & 0 & 0 & 0 & 0 & 0 \\
\hline 5 & $1.7082 \mathrm{E}-02$ & -430 & -516 & -362 & 906 & 1000 & 973 & 805 & 463 & 0 & 0 & 0 & 0 & 0 & 0 & 0 \\
\hline 6 & $2.0434 \mathrm{E}-02$ & -627 & -701 & -569 & 787 & 973 & 1000 & 920 & 634 & 0 & 0 & 0 & 0 & 0 & 0 & 0 \\
\hline 7 & $2.3351 \mathrm{E}-02$ & -880 & -923 & -842 & 496 & 805 & 920 & 1000 & 846 & 0 & 0 & 0 & 0 & 0 & 0 & 0 \\
\hline 8 & $2.1149 \mathrm{E}-02$ & -917 & -920 & -906 & 109 & 463 & 634 & 846 & 1000 & 359 & 358 & 225 & 0 & 0 & 0 & 0 \\
\hline 9 & $2.8283 \mathrm{E}-01$ & 0 & 0 & 0 & 0 & 0 & 0 & 0 & 359 & 1000 & 999 & 627 & 0 & 0 & 0 & 0 \\
\hline 10 & $2.3537 \mathrm{E}-01$ & 0 & 0 & 0 & 0 & 0 & 0 & 0 & 358 & 999 & 1000 & 629 & 0 & 0 & 0 & 0 \\
\hline 11 & 1. $2638 \mathrm{E}-01$ & 0 & 0 & 0 & 0 & 0 & 0 & 0 & 225 & 627 & 629 & 1000 & 412 & 412 & 403 & 401 \\
\hline 12 & $1.8182 \mathrm{E}-01$ & 0 & 0 & 0 & 0 & 0 & 0 & 0 & 0 & 0 & 0 & 412 & 1000 & 986 & 968 & 963 \\
\hline 13 & 1.9871E-01 & 0 & 0 & 0 & 0 & 0 & 0 & 0 & 0 & 0 & 0 & 412 & 986 & 1000 & 995 & 992 \\
\hline 14 & $1.9673 \mathrm{E}-01$ & 0 & 0 & 0 & 0 & 0 & 0 & 0 & 0 & 0 & 0 & 403 & 968 & 995 & 1000 & 1000 \\
\hline 15 & $1.9679 \mathrm{E}-01$ & 0 & 0 & 0 & 0 & 0 & 0 & 0 & 0 & 0 & 0 & 401 & 963 & 992 & 1000 & 1000 \\
\hline
\end{tabular}


Table B.179: Relative uncertainty (relative standard deviation) and correlation (normalized to 1000) for ${ }^{242} \mathrm{Cm}\left(\mathrm{n}, \mathrm{n}^{\prime}\right)$

\begin{tabular}{crrrrrrrr} 
group & rel.s.d. & \multicolumn{1}{l}{----1} & -10 \\
1 & $3.4346 \mathrm{E}-01$ & 1000 & -780 & -464 & -221 & -193 & -83 & -103 \\
2 & $1.1029 \mathrm{E}-01$ & -780 & 1000 & 129 & -230 & -446 & -550 & -533 \\
3 & $1.1418 \mathrm{E}-01$ & -464 & 129 & 1000 & 930 & 607 & 504 & 518 \\
4 & $1.7995 \mathrm{E}-01$ & -221 & -230 & 930 & 1000 & 809 & 747 & 755 \\
5 & $2.7189 \mathrm{E}-01$ & -193 & -446 & 607 & 809 & 1000 & 991 & 993 \\
6 & $5.3151 \mathrm{E}-01$ & -83 & -550 & 504 & 747 & 991 & 1000 & 1000 \\
7 & $3.1726 \mathrm{E}-01$ & -103 & -533 & 518 & 755 & 993 & 1000 & 1000
\end{tabular}

Table B.180: Relative uncertainty (relative standard deviation) and correlation (normalized to 1000) for ${ }^{242} \mathrm{Cm}(\mathrm{n}, 2 \mathrm{n})$

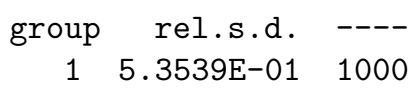

Table B.181: Relative uncertainty (relative standard deviation) and correlation (normalized to 1000) for ${ }^{242} \mathrm{Cm}(\mathrm{n}, \mathrm{f})$

\begin{tabular}{|c|c|c|c|c|c|c|c|c|c|c|c|c|c|c|c|c|}
\hline 1 & $3.1487 \mathrm{E}-01$ & 1000 & 991 & 870 & 356 & 138 & -42 & 788 & 778 & 0 & 0 & 0 & 0 & 0 & 0 & 0 \\
\hline 2 & $5.2589 \mathrm{E}-01$ & 991 & 1000 & 917 & 467 & 259 & 78 & 845 & 819 & 0 & 0 & 0 & 0 & 0 & 0 & 0 \\
\hline 3 & 1.9019E-01 & 870 & 917 & 1000 & 743 & 551 & 318 & 837 & 807 & 0 & 0 & 0 & 0 & 0 & 0 & 0 \\
\hline 4 & $2.3391 \mathrm{E}-01$ & 356 & 467 & 743 & 1000 & 965 & 834 & 715 & 609 & 0 & 0 & 0 & 0 & 0 & 0 & \\
\hline 5 & $6.6002 \mathrm{E}-01$ & 138 & 259 & 551 & 965 & 1000 & 944 & 621 & 487 & 0 & 0 & 0 & 0 & 0 & 0 & 0 \\
\hline 6 & $6.2668 \mathrm{E}-01$ & -42 & 78 & 318 & 834 & 944 & 1000 & 553 & 381 & 0 & 0 & 0 & 0 & 0 & 0 & 0 \\
\hline 7 & $2.8154 \mathrm{E}-01$ & 788 & 845 & 837 & 715 & 621 & 553 & 1000 & 871 & 0 & 0 & 0 & 0 & 0 & 0 & 0 \\
\hline 8 & $1.6203 \mathrm{E}-01$ & 778 & 819 & 807 & 609 & 487 & 381 & 871 & 1000 & 460 & 368 & 82 & 0 & 0 & 0 & 0 \\
\hline 9 & $2.0949 \mathrm{E}-01$ & 0 & 0 & 0 & 0 & 0 & 0 & 0 & 460 & 1000 & 870 & 202 & 0 & 0 & 0 & 0 \\
\hline 10 & $1.1684 \mathrm{E}-01$ & 0 & 0 & 0 & 0 & 0 & 0 & 0 & 368 & 870 & 1000 & 264 & 0 & 0 & 0 & \\
\hline 11 & $9.3185 E-02$ & 0 & 0 & 0 & 0 & 0 & 0 & 0 & 82 & 202 & 264 & 1000 & 1 & 8 & 4 & \\
\hline 12 & $2.4010 \mathrm{E}-01$ & 0 & 0 & 0 & 0 & 0 & 0 & 0 & 0 & 0 & 0 & 1 & 1000 & 11 & 7 & 7 \\
\hline 13 & $3.5580 \mathrm{E}-01$ & 0 & 0 & 0 & 0 & 0 & 0 & 0 & 0 & 0 & 0 & 8 & 11 & 1000 & 996 & 995 \\
\hline 14 & $4.1172 \mathrm{E}-01$ & 0 & 0 & 0 & 0 & 0 & 0 & 0 & 0 & 0 & 0 & 4 & 7 & 996 & 1000 & 1000 \\
\hline 15 & $4.2548 \mathrm{E}-01$ & 0 & 0 & 0 & 0 & 0 & 0 & 0 & 0 & 0 & 0 & 3 & 7 & 995 & 1000 & 1000 \\
\hline
\end{tabular}


Table B.182: Relative uncertainty (relative standard deviation) and correlation (normalized to 1000) for ${ }^{242} \mathrm{Cm}(\mathrm{n}, \gamma)$

\begin{tabular}{|c|c|c|c|c|c|c|c|c|c|c|c|c|c|c|c|c|}
\hline & & & & & & & & & & & & & & & & \\
\hline 1 & $5.2782 \mathrm{E}-01$ & 1000 & 898 & 696 & 187 & 93 & -43 & -218 & -342 & 0 & 0 & 0 & 0 & 0 & 0 & 0 \\
\hline 2 & $3.7410 \mathrm{E}-01$ & 898 & 1000 & 891 & 398 & 300 & 148 & -59 & -212 & 0 & 0 & 0 & 0 & 0 & 0 & 0 \\
\hline 3 & $2.3606 \mathrm{E}-01$ & 696 & 891 & 1000 & 767 & 696 & 574 & 392 & 243 & 0 & 0 & 0 & 0 & 0 & 0 & 0 \\
\hline 4 & 1.9020E-01 & 187 & 398 & 767 & 1000 & 994 & 965 & 890 & 807 & 0 & 0 & 0 & 0 & 0 & 0 & 0 \\
\hline 5 & $1.8183 \mathrm{E}-01$ & 93 & 300 & 696 & 994 & 1000 & 988 & 933 & 864 & 0 & 0 & 0 & 0 & 0 & 0 & 0 \\
\hline 6 & $2.0323 \mathrm{E}-01$ & -43 & 148 & 574 & 965 & 988 & 1000 & 978 & 932 & 0 & 0 & 0 & 0 & 0 & 0 & 0 \\
\hline 7 & $2.2359 \mathrm{E}-01$ & -218 & -59 & 392 & 890 & 933 & 978 & 1000 & 986 & 0 & 0 & 0 & 0 & 0 & 0 & 0 \\
\hline 8 & $2.1253 \mathrm{E}-01$ & -342 & -212 & 243 & 807 & 864 & 932 & 986 & 1000 & 59 & 56 & 12 & 0 & 0 & 0 & 0 \\
\hline 9 & $1.8668 \mathrm{E}-01$ & 0 & 0 & 0 & 0 & 0 & 0 & 0 & 59 & 1000 & 960 & 206 & 0 & 0 & 0 & 0 \\
\hline 10 & $6.7513 \mathrm{E}-02$ & 0 & 0 & 0 & 0 & 0 & 0 & 0 & 56 & 960 & 1000 & 230 & 0 & 0 & 0 & 0 \\
\hline 11 & $4.5526 \mathrm{E}-02$ & 0 & 0 & 0 & 0 & 0 & 0 & 0 & 12 & 206 & 230 & 1000 & 3 & 11 & 5 & 5 \\
\hline 12 & $3.6984 \mathrm{E}-02$ & 0 & 0 & 0 & 0 & 0 & 0 & 0 & 0 & 0 & 0 & 3 & 1000 & 29 & 21 & 20 \\
\hline 13 & $3.2510 \mathrm{E}-01$ & 0 & 0 & 0 & 0 & 0 & 0 & 0 & 0 & 0 & 0 & 11 & 29 & 1000 & 996 & 995 \\
\hline 14 & $3.9233 \mathrm{E}-01$ & 0 & 0 & 0 & 0 & 0 & 0 & 0 & 0 & 0 & 0 & 5 & 21 & 996 & 1000 & 1000 \\
\hline 15 & $4.0770 \mathrm{E}-01$ & 0 & 0 & 0 & 0 & 0 & 0 & 0 & 0 & 0 & 0 & 5 & 20 & 995 & 1000 & 1000 \\
\hline
\end{tabular}

Table B.183: Relative uncertainty (relative standard deviation) and correlation (normalized to 1000) for ${ }^{243} \mathrm{Cm}(\mathrm{n}, \mathrm{el})$

\begin{tabular}{|c|c|c|c|c|c|c|c|c|c|c|c|c|c|c|c|c|}
\hline 1 & $5.6504 \mathrm{E}-02$ & 1000 & 976 & 19 & 536 & 589 & 281 & 47 & 0 & 0 & 0 & 0 & 0 & 0 & 0 & 0 \\
\hline 2 & $9.1210 \mathrm{E}-02$ & 976 & 1000 & 135 & 636 & 686 & 391 & 139 & 0 & 0 & 0 & 0 & 0 & 0 & 0 & 0 \\
\hline 3 & $6.4654 \mathrm{E}-02$ & 19 & 135 & 1000 & 846 & 808 & 941 & 806 & 0 & 0 & 0 & 0 & 0 & 0 & 0 & 0 \\
\hline 4 & $4.8477 \mathrm{E}-02$ & 536 & 636 & 846 & 1000 & 998 & 953 & 714 & 0 & 0 & 0 & 0 & 0 & 0 & 0 & 0 \\
\hline 5 & $1.0708 \mathrm{E}-01$ & 589 & 686 & 808 & 998 & 1000 & 934 & 686 & 0 & 0 & 0 & 0 & 0 & 0 & 0 & 0 \\
\hline 6 & 1. $2773 \mathrm{E}-01$ & 281 & 391 & 941 & 953 & 934 & 1000 & 807 & 0 & 0 & 0 & 0 & 0 & 0 & 0 & 0 \\
\hline 7 & $1.1599 \mathrm{E}-01$ & 47 & 139 & 806 & 714 & 686 & 807 & 1000 & 558 & 558 & 557 & 545 & 0 & 0 & 0 & 0 \\
\hline 8 & $1.7709 \mathrm{E}-01$ & 0 & 0 & 0 & 0 & 0 & 0 & 558 & 1000 & 1000 & 999 & 976 & 0 & 0 & 0 & 0 \\
\hline 9 & 1. $8042 \mathrm{E}-01$ & 0 & 0 & 0 & 0 & 0 & 0 & 558 & 1000 & 1000 & 1000 & 976 & 0 & 0 & 0 & 0 \\
\hline 10 & $1.8022 \mathrm{E}-01$ & 0 & 0 & 0 & 0 & 0 & 0 & 557 & 999 & 1000 & 1000 & 976 & 0 & 0 & 0 & 0 \\
\hline 11 & $1.5540 \mathrm{E}-01$ & 0 & 0 & 0 & 0 & 0 & 0 & 545 & 976 & 976 & 976 & 1000 & 216 & 214 & 215 & 214 \\
\hline 12 & $1.8809 \mathrm{E}-01$ & 0 & 0 & 0 & 0 & 0 & 0 & 0 & 0 & 0 & 0 & 216 & 1000 & 988 & 989 & 984 \\
\hline 13 & 1.9530E-01 & 0 & 0 & 0 & 0 & 0 & 0 & 0 & 0 & 0 & 0 & 214 & 988 & 1000 & 973 & 970 \\
\hline 14 & $2.4913 \mathrm{E}-01$ & 0 & 0 & 0 & 0 & 0 & 0 & 0 & 0 & 0 & 0 & 215 & 989 & 973 & 1000 & 998 \\
\hline 15 & $2.3411 \mathrm{E}-01$ & 0 & 0 & 0 & 0 & 0 & 0 & 0 & 0 & 0 & 0 & 214 & 984 & 970 & 998 & 1000 \\
\hline
\end{tabular}


Table B.184: Relative uncertainty (relative standard deviation) and correlation (normalized to 1000) for ${ }^{243} \mathrm{Cm}\left(\mathrm{n}, \mathrm{n}^{\prime}\right)$

\begin{tabular}{|c|c|c|c|c|c|c|c|c|}
\hline & . d. & & & & & & & \\
\hline 1 & $5.0746 \mathrm{E}-01$ & 1000 & 478 & -488 & -672 & -695 & -589 & -510 \\
\hline 2 & $2.5248 \mathrm{E}-02$ & 478 & 1000 & 208 & 143 & 107 & 87 & 50 \\
\hline 3 & $7.4248 \mathrm{E}-02$ & -488 & 208 & 1000 & 896 & 711 & 454 & 249 \\
\hline 4 & $9.4462 \mathrm{E}-02$ & -672 & 143 & 896 & 1000 & 938 & 742 & 578 \\
\hline 5 & 1. $1780 \mathrm{E}-01$ & -695 & 107 & 711 & 938 & 1000 & 922 & 821 \\
\hline 6 & $2.0241 \mathrm{E}-01$ & -589 & 87 & 454 & 742 & 922 & 1000 & 975 \\
\hline 7 & $2.7752 \mathrm{E}-01$ & -510 & 50 & 249 & 578 & 821 & 975 & 1000 \\
\hline
\end{tabular}

Table B.185: Relative uncertainty (relative standard deviation) and correlation (normalized to 1000) for ${ }^{243} \mathrm{Cm}(\mathrm{n}, 2 \mathrm{n})$

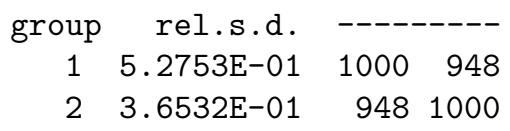

Table B.186: Relative uncertainty (relative standard deviation) and correlation (normalized to 1000) for ${ }^{243} \mathrm{Cm}(\mathrm{n}, \mathrm{f})$

\begin{tabular}{|c|c|c|c|c|c|c|c|c|c|c|c|c|c|c|c|c|}
\hline 1 & $1.8400 \mathrm{E}-01$ & 1000 & 756 & 633 & 64 & 64 & 64 & 62 & 0 & 0 & 0 & 0 & 0 & 0 & 0 & 0 \\
\hline 2 & $3.1383 \mathrm{E}-01$ & 756 & 1000 & 967 & 663 & 663 & 663 & 652 & 0 & 0 & 0 & 0 & 0 & 0 & 0 & 0 \\
\hline 3 & $4.4061 \mathrm{E}-01$ & 633 & 967 & 1000 & 723 & 723 & 723 & 711 & 0 & 0 & 0 & 0 & 0 & 0 & 0 & 0 \\
\hline 4 & $4.9599 \mathrm{E}-01$ & 64 & 663 & 723 & 1000 & 1000 & 1000 & 983 & 0 & 0 & 0 & 0 & 0 & 0 & 0 & 0 \\
\hline 5 & $3.7254 \mathrm{E}-01$ & 64 & 663 & 723 & 1000 & 1000 & 1000 & 983 & 0 & 0 & 0 & 0 & 0 & 0 & 0 & 0 \\
\hline 6 & $4.7345 \mathrm{E}-01$ & 64 & 663 & 723 & 1000 & 1000 & 1000 & 983 & 0 & 0 & 0 & 0 & 0 & 0 & 0 & 0 \\
\hline 7 & $2.6478 \mathrm{E}-01$ & 62 & 652 & 711 & 983 & 983 & 983 & 1000 & 184 & 184 & 184 & 181 & 0 & 0 & 0 & 0 \\
\hline 8 & 1. $2387 \mathrm{E}-01$ & 0 & 0 & 0 & 0 & 0 & 0 & 184 & 1000 & 1000 & 1000 & 988 & 0 & 0 & 0 & 0 \\
\hline 9 & 1.2206E-01 & 0 & 0 & 0 & 0 & 0 & 0 & 184 & 1000 & 1000 & 1000 & 988 & 0 & 0 & 0 & 0 \\
\hline 10 & 1.2188E-01 & 0 & 0 & 0 & 0 & 0 & 0 & 184 & 1000 & 1000 & 1000 & 988 & 0 & 0 & 0 & 0 \\
\hline 11 & $8.0417 \mathrm{E}-02$ & 0 & 0 & 0 & 0 & 0 & 0 & 181 & 988 & 988 & 988 & 1000 & 2 & 0 & 0 & 1 \\
\hline 12 & $3.3438 \mathrm{E}-02$ & 0 & 0 & 0 & 0 & 0 & 0 & 0 & 0 & 0 & 0 & 2 & 1000 & 59 & 33 & 72 \\
\hline 13 & $6.4408 \mathrm{E}-02$ & 0 & 0 & 0 & 0 & 0 & 0 & 0 & 0 & 0 & 0 & 0 & 59 & 1000 & 168 & 349 \\
\hline 14 & 1. $9522 \mathrm{E}-01$ & 0 & 0 & 0 & 0 & 0 & 0 & 0 & 0 & 0 & 0 & 0 & 33 & 168 & 1000 & 855 \\
\hline 15 & $1.0526 \mathrm{E}-01$ & 0 & 0 & 0 & 0 & 0 & 0 & 0 & 0 & 0 & 0 & 1 & 72 & 349 & 855 & 1000 \\
\hline
\end{tabular}


Table B.187: Relative uncertainty (relative standard deviation) and correlation (normalized to 1000) for ${ }^{243} \mathrm{Cm}(\mathrm{n}, \gamma)$

\begin{tabular}{|c|c|c|c|c|c|c|c|c|c|c|c|c|c|c|c|c|}
\hline 1 & $7.7568 \mathrm{E}-01$ & 1000 & 979 & -37 & -158 & 507 & 5 & -330 & 0 & 0 & 0 & 0 & 0 & 0 & 0 & 0 \\
\hline 2 & $4.4117 \mathrm{E}-01$ & 979 & 1000 & -87 & -204 & 509 & -30 & -381 & 0 & 0 & 0 & 0 & 0 & 0 & 0 & 0 \\
\hline 3 & $1.7742 \mathrm{E}-01$ & -37 & -87 & 1000 & 986 & 763 & 987 & 862 & 0 & 0 & 0 & 0 & 0 & 0 & 0 & 0 \\
\hline 4 & $3.1194 \mathrm{E}-01$ & -158 & -204 & 986 & 1000 & 714 & 983 & 889 & 0 & 0 & 0 & 0 & 0 & 0 & 0 & 0 \\
\hline 5 & $2.9719 \mathrm{E}-01$ & 507 & 509 & 763 & 714 & 1000 & 828 & 483 & 0 & 0 & 0 & 0 & 0 & 0 & 0 & 0 \\
\hline 6 & $2.3358 \mathrm{E}-01$ & 5 & -30 & 987 & 983 & 828 & 1000 & 836 & 0 & 0 & 0 & 0 & 0 & 0 & 0 & 0 \\
\hline 7 & $1.8181 \mathrm{E}-01$ & -330 & -381 & 862 & 889 & 483 & 836 & 1000 & 402 & 402 & 401 & 399 & 0 & 0 & 0 & 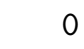 \\
\hline 8 & $1.7967 \mathrm{E}-01$ & 0 & 0 & 0 & 0 & 0 & 0 & 402 & 1000 & 999 & 997 & 992 & 0 & 0 & 0 & \\
\hline 9 & $1.8375 \mathrm{E}-01$ & 0 & 0 & 0 & 0 & 0 & 0 & 402 & 999 & 1000 & 999 & 996 & 0 & 0 & 0 & 0 \\
\hline 10 & $1.8701 \mathrm{E}-01$ & 0 & 0 & 0 & 0 & 0 & 0 & 401 & 997 & 999 & 1000 & 998 & 0 & 0 & 0 & \\
\hline 11 & $1.4520 \mathrm{E}-01$ & 0 & 0 & 0 & 0 & 0 & 0 & 399 & 992 & 996 & 998 & 1000 & 1 & 0 & 0 & 0 \\
\hline 12 & $5.1162 \mathrm{E}-02$ & 0 & 0 & 0 & 0 & 0 & 0 & 0 & 0 & 0 & 0 & 1 & 1000 & 51 & 18 & 15 \\
\hline 13 & $7.9878 \mathrm{E}-02$ & 0 & 0 & 0 & 0 & 0 & 0 & 0 & 0 & 0 & 0 & 0 & 51 & 1000 & 136 & 101 \\
\hline 14 & $1.5497 \mathrm{E}-01$ & 0 & 0 & 0 & 0 & 0 & 0 & 0 & 0 & 0 & 0 & 0 & 18 & 136 & 1000 & 708 \\
\hline 15 & 1. $6379 \mathrm{E}-01$ & 0 & 0 & 0 & 0 & 0 & 0 & 0 & 0 & 0 & 0 & 0 & 15 & 101 & 708 & 1000 \\
\hline
\end{tabular}

Table B.188: Relative uncertainty (relative standard deviation) and correlation (normalized to 1000) for ${ }^{244} \mathrm{Cm}(\mathrm{n}, \mathrm{el})$

\begin{tabular}{|c|c|c|c|c|c|c|c|c|c|c|c|c|c|c|c|c|}
\hline 1 & $1.0583 \mathrm{E}-01$ & 1000 & 488 & 569 & 274 & 322 & 234 & 65 & 0 & 0 & 0 & 0 & 0 & 0 & 0 & 0 \\
\hline 2 & $1.0229 \mathrm{E}-01$ & 488 & 1000 & 852 & 87 & 198 & 44 & -224 & 0 & 0 & 0 & 0 & 0 & 0 & 0 & 0 \\
\hline 3 & $5.5586 \mathrm{E}-02$ & 569 & 852 & 1000 & 594 & 680 & 551 & 213 & 0 & 0 & 0 & 0 & 0 & 0 & 0 & 0 \\
\hline 4 & $1.0771 \mathrm{E}-01$ & 274 & 87 & 594 & 1000 & 993 & 988 & 750 & 0 & 0 & 0 & 0 & 0 & 0 & 0 & 0 \\
\hline 5 & $9.3327 \mathrm{E}-02$ & 322 & 198 & 680 & 993 & 1000 & 971 & 716 & 0 & 0 & 0 & 0 & 0 & 0 & 0 & 0 \\
\hline 6 & $8.3757 \mathrm{E}-02$ & 234 & 44 & 551 & 988 & 971 & 1000 & 739 & 0 & 0 & 0 & 0 & 0 & 0 & 0 & \\
\hline 7 & $9.2095 \mathrm{E}-02$ & 65 & -224 & 213 & 750 & 716 & 739 & 1000 & 586 & 586 & 572 & 0 & 0 & 0 & 0 & 0 \\
\hline 8 & 1.4933E-01 & 0 & 0 & 0 & 0 & 0 & 0 & 586 & 1000 & 999 & 976 & 0 & 0 & 0 & 0 & \\
\hline 9 & $1.4039 \mathrm{E}-01$ & 0 & 0 & 0 & 0 & 0 & 0 & 586 & 999 & 1000 & 975 & 0 & 0 & 0 & 0 & 0 \\
\hline 10 & $7.7188 \mathrm{E}-02$ & 0 & 0 & 0 & 0 & 0 & 0 & 572 & 976 & 975 & 1000 & 136 & 17 & 160 & 160 & 160 \\
\hline 11 & $3.6106 \mathrm{E}-02$ & 0 & 0 & 0 & 0 & 0 & 0 & 0 & 0 & 0 & 136 & 1000 & 77 & 706 & 706 & 706 \\
\hline 12 & $7.7538 \mathrm{E}-02$ & 0 & 0 & 0 & 0 & 0 & 0 & 0 & 0 & 0 & 17 & 77 & 1000 & 5 & 26 & 28 \\
\hline 13 & $6.6248 \mathrm{E}-02$ & 0 & 0 & 0 & 0 & 0 & 0 & 0 & 0 & 0 & 160 & 706 & 5 & 1000 & 999 & 999 \\
\hline 14 & $6.1634 \mathrm{E}-02$ & 0 & 0 & 0 & 0 & 0 & 0 & 0 & 0 & 0 & 160 & 706 & 26 & 999 & 1000 & 1000 \\
\hline 15 & $6.1192 \mathrm{E}-02$ & 0 & 0 & 0 & 0 & 0 & 0 & 0 & 0 & 0 & 160 & 706 & 28 & 999 & 1000 & 1000 \\
\hline
\end{tabular}


Table B.189: Relative uncertainty (relative standard deviation) and correlation (normalized to 1000) for ${ }^{244} \mathrm{Cm}\left(\mathrm{n}, \mathrm{n}^{\prime}\right)$

\begin{tabular}{|c|c|c|c|c|c|c|c|c|}
\hline & & & & & & & & \\
\hline 1 & $3.8256 \mathrm{E}-01$ & 1000 & -562 & -570 & -282 & -50 & 37 & -66 \\
\hline 2 & $2.2673 \mathrm{E}-01$ & -562 & 1000 & 859 & 412 & 43 & -138 & 42 \\
\hline 3 & $1.5097 \mathrm{E}-01$ & -570 & 859 & 1000 & 737 & 241 & 29 & 132 \\
\hline 4 & $1.8176 \mathrm{E}-01$ & -282 & 412 & 737 & 1000 & 788 & 642 & 656 \\
\hline 5 & $2.9094 \mathrm{E}-01$ & -50 & 43 & 241 & 788 & 1000 & 976 & 973 \\
\hline 6 & $6.3307 \mathrm{E}-01$ & 37 & -138 & 29 & 642 & 976 & 1000 & 978 \\
\hline 7 & $5.9718 \mathrm{E}-01$ & -66 & 42 & 132 & 656 & 973 & 978 & 1000 \\
\hline
\end{tabular}

Table B.190: Relative uncertainty (relative standard deviation) and correlation (normalized to 1000) for ${ }^{244} \mathrm{Cm}(\mathrm{n}, 2 \mathrm{n})$

group rel.s.d. ----

1 4.0907E-01 1000

Table B.191: Relative uncertainty (relative standard deviation) and correlation (normalized to 1000) for ${ }^{244} \mathrm{Cm}(\mathrm{n}, \mathrm{f})$

\begin{tabular}{|c|c|c|c|c|c|c|c|c|c|c|c|c|c|c|c|c|}
\hline 1 & $1.7861 \mathrm{E}-01$ & 1000 & 752 & 628 & 58 & 58 & 58 & 55 & 0 & 0 & 0 & 0 & 0 & 0 & 0 & 0 \\
\hline 2 & $3.1254 \mathrm{E}-01$ & 752 & 1000 & 967 & 663 & 663 & 663 & 633 & 0 & 0 & 0 & 0 & 0 & 0 & 0 & 0 \\
\hline 3 & $4.3803 E-01$ & 628 & 967 & 1000 & 725 & 725 & 725 & 693 & 0 & 0 & 0 & 0 & 0 & 0 & 0 & 0 \\
\hline 4 & $5.0007 \mathrm{E}-01$ & 58 & 663 & 725 & 1000 & 1000 & 1000 & 955 & 0 & 0 & 0 & 0 & 0 & 0 & 0 & 0 \\
\hline 5 & $3.6532 \mathrm{E}-01$ & 58 & 663 & 725 & 1000 & 1000 & 1000 & 955 & 0 & 0 & 0 & 0 & 0 & 0 & 0 & 0 \\
\hline 6 & $4.7563 \mathrm{E}-01$ & 58 & 663 & 725 & 1000 & 1000 & 1000 & 955 & 0 & 0 & 0 & 0 & 0 & 0 & 0 & 0 \\
\hline 7 & $2.6256 \mathrm{E}-01$ & 55 & 633 & 693 & 955 & 955 & 955 & 1000 & 298 & 297 & 222 & 0 & 0 & 0 & 0 & 0 \\
\hline 8 & 1. $9034 \mathrm{E}-01$ & 0 & 0 & 0 & 0 & 0 & 0 & 298 & 1000 & 997 & 745 & 0 & 0 & 0 & 0 & 0 \\
\hline 9 & 1. $1918 \mathrm{E}-01$ & 0 & 0 & 0 & 0 & 0 & 0 & 297 & 997 & 1000 & 767 & 0 & 0 & 0 & 0 & 0 \\
\hline 10 & $5.2719 \mathrm{E}-02$ & 0 & 0 & 0 & 0 & 0 & 0 & 222 & 745 & 767 & 1000 & -162 & 0 & 0 & 0 & 0 \\
\hline 11 & $5.7020 \mathrm{E}-02$ & 0 & 0 & 0 & 0 & 0 & 0 & 0 & 0 & 0 & -162 & 1000 & 13 & 9 & 5 & 5 \\
\hline 12 & $1.7085 \mathrm{E}-01$ & 0 & 0 & 0 & 0 & 0 & 0 & 0 & 0 & 0 & 0 & 13 & 1000 & 42 & 20 & 18 \\
\hline 13 & $2.1993 E-01$ & 0 & 0 & 0 & 0 & 0 & 0 & 0 & 0 & 0 & 0 & 9 & 42 & 1000 & 997 & 996 \\
\hline 14 & $2.6401 \mathrm{E}-01$ & 0 & 0 & 0 & 0 & 0 & 0 & 0 & 0 & 0 & 0 & 5 & 20 & 997 & 1000 & 1000 \\
\hline 15 & $2.7178 \mathrm{E}-01$ & 0 & 0 & 0 & 0 & 0 & 0 & 0 & 0 & 0 & 0 & 5 & 18 & 996 & 1000 & 1000 \\
\hline
\end{tabular}


Table B.192: Relative uncertainty (relative standard deviation) and correlation (normalized to 1000) for ${ }^{244} \mathrm{Cm}(\mathrm{n}, \gamma)$

\begin{tabular}{|c|c|c|c|c|c|c|c|c|c|c|c|c|c|c|c|c|}
\hline 1 & $8.9189 \mathrm{E}-01$ & 1000 & 928 & 832 & 247 & 112 & -142 & -169 & 0 & 0 & 0 & 0 & 0 & 0 & 0 & 0 \\
\hline 2 & $5.3782 \mathrm{E}-01$ & 928 & 1000 & 967 & 470 & 331 & 57 & -22 & 0 & 0 & 0 & 0 & 0 & 0 & 0 & 0 \\
\hline 3 & $3.6489 \mathrm{E}-01$ & 832 & 967 & 1000 & 647 & 483 & 229 & 130 & 0 & 0 & 0 & 0 & 0 & 0 & 0 & 0 \\
\hline 4 & $2.0802 \mathrm{E}-01$ & 247 & 470 & 647 & 1000 & 946 & 870 & 732 & 0 & 0 & 0 & 0 & 0 & 0 & 0 & 0 \\
\hline 5 & $2.2540 \mathrm{E}-01$ & 112 & 331 & 483 & 946 & 1000 & 959 & 804 & 0 & 0 & 0 & 0 & 0 & 0 & 0 & 0 \\
\hline 6 & $1.7710 \mathrm{E}-01$ & -142 & 57 & 229 & 870 & 959 & 1000 & 864 & 0 & 0 & 0 & 0 & 0 & 0 & 0 & 0 \\
\hline 7 & $1.7426 \mathrm{E}-01$ & -169 & -22 & 130 & 732 & 804 & 864 & 1000 & 482 & 481 & 340 & 0 & 0 & 0 & 0 & 0 \\
\hline 8 & 1. $9322 \mathrm{E}-01$ & 0 & 0 & 0 & 0 & 0 & 0 & 482 & 1000 & 999 & 705 & 0 & 0 & 0 & 0 & 0 \\
\hline 9 & 1. $2141 \mathrm{E}-01$ & 0 & 0 & 0 & 0 & 0 & 0 & 481 & 999 & 1000 & 711 & 0 & 0 & 0 & 0 & 0 \\
\hline 10 & $4.4715 \mathrm{E}-02$ & 0 & 0 & 0 & 0 & 0 & 0 & 340 & 705 & 711 & 1000 & -366 & 0 & 0 & 0 & \\
\hline 11 & $4.6026 \mathrm{E}-02$ & 0 & 0 & 0 & 0 & 0 & 0 & 0 & 0 & 0 & -366 & 1000 & 1 & 4 & 5 & 5 \\
\hline 12 & $6.6427 \mathrm{E}-02$ & 0 & 0 & 0 & 0 & 0 & 0 & 0 & 0 & 0 & 0 & 1 & 1000 & 821 & 639 & 590 \\
\hline 13 & 1. 1793E-01 & 0 & 0 & 0 & 0 & 0 & 0 & 0 & 0 & 0 & 0 & 4 & 821 & 1000 & 903 & 862 \\
\hline 14 & 1.2159E-01 & 0 & 0 & 0 & 0 & 0 & 0 & 0 & 0 & 0 & 0 & 5 & 639 & 903 & 1000 & 996 \\
\hline 15 & $1.2506 \mathrm{E}-01$ & 0 & 0 & 0 & 0 & 0 & 0 & 0 & 0 & 0 & 0 & 5 & 590 & 862 & 996 & 1000 \\
\hline
\end{tabular}

Table B.193: Relative uncertainty (relative standard deviation) and correlation (normalized to 1000) for ${ }^{245} \mathrm{Cm}(\mathrm{n}, \mathrm{el})$

\begin{tabular}{|c|c|c|c|c|c|c|c|c|c|c|c|c|c|c|c|c|}
\hline 1 & $4.8091 \mathrm{E}-02$ & 1000 & 898 & 246 & 715 & 457 & 214 & 33 & 0 & 0 & 0 & 0 & 0 & 0 & 0 & 0 \\
\hline 2 & $7.2469 \mathrm{E}-02$ & 898 & 1000 & 541 & 903 & 690 & 479 & 128 & 0 & 0 & 0 & 0 & 0 & 0 & 0 & 0 \\
\hline 3 & $7.4494 \mathrm{E}-02$ & 246 & 541 & 1000 & 790 & 864 & 902 & 312 & 0 & 0 & 0 & 0 & 0 & 0 & 0 & 0 \\
\hline 4 & $4.7473 E-02$ & 715 & 903 & 790 & 1000 & 933 & 808 & 258 & 0 & 0 & 0 & 0 & 0 & 0 & 0 & 0 \\
\hline 5 & $9.9405 \mathrm{E}-02$ & 457 & 690 & 864 & 933 & 1000 & 961 & 327 & 0 & 0 & 0 & 0 & 0 & 0 & 0 & \\
\hline 6 & $1.4999 \mathrm{E}-01$ & 214 & 479 & 902 & 808 & 961 & 1000 & 353 & 0 & 0 & 0 & 0 & 0 & 0 & 0 & \\
\hline 7 & $1.3667 \mathrm{E}-01$ & 33 & 128 & 312 & 258 & 327 & 353 & 1000 & 934 & 934 & 933 & 911 & 0 & 0 & 0 & 0 \\
\hline 8 & $1.8136 \mathrm{E}-01$ & 0 & 0 & 0 & 0 & 0 & 0 & 934 & 1000 & 1000 & 999 & 975 & 0 & 0 & 0 & \\
\hline 9 & 1.8233E-01 & 0 & 0 & 0 & 0 & 0 & 0 & 934 & 1000 & 1000 & 1000 & 976 & 0 & 0 & 0 & 0 \\
\hline 10 & $1.8112 \mathrm{E}-01$ & 0 & 0 & 0 & 0 & 0 & 0 & 933 & 999 & 1000 & 1000 & 977 & 0 & 0 & 0 & \\
\hline 11 & 1. 5104E-01 & 0 & 0 & 0 & 0 & 0 & 0 & 911 & 975 & 976 & 977 & 1000 & 213 & 213 & 213 & 213 \\
\hline 12 & $2.0251 \mathrm{E}-01$ & 0 & 0 & 0 & 0 & 0 & 0 & 0 & 0 & 0 & 0 & 213 & 1000 & 999 & 999 & 999 \\
\hline 13 & $2.1778 \mathrm{E}-01$ & 0 & 0 & 0 & 0 & 0 & 0 & 0 & 0 & 0 & 0 & 213 & 999 & 1000 & 999 & 999 \\
\hline 14 & $2.0779 \mathrm{E}-01$ & 0 & 0 & 0 & 0 & 0 & 0 & 0 & 0 & 0 & 0 & 213 & 999 & 999 & 1000 & 1000 \\
\hline 15 & $1.9438 \mathrm{E}-01$ & 0 & 0 & 0 & 0 & 0 & 0 & 0 & 0 & 0 & 0 & 213 & 999 & 999 & 1000 & 1000 \\
\hline
\end{tabular}


Table B.194: Relative uncertainty (relative standard deviation) and correlation (normalized to 1000$)$ for ${ }^{245} \mathrm{Cm}\left(\mathrm{n}, \mathrm{n}^{\prime}\right)$

\begin{tabular}{|c|c|c|c|c|c|c|c|c|}
\hline & & & & & & & & \\
\hline 1 & 8.509 & 1000 & 853 & -603 & -711 & -402 & -304 & -271 \\
\hline 2 & $1.3006 \mathrm{E}-01$ & -853 & 1000 & 509 & 721 & 528 & 464 & 449 \\
\hline 3 & $4.0915 \mathrm{E}-01$ & -603 & 509 & 1000 & 861 & 362 & 121 & -44 \\
\hline 4 & $5.4474 \mathrm{E}-01$ & -711 & 721 & 861 & 1000 & 762 & 590 & 460 \\
\hline 5 & 8.18 & -402 & 528 & 362 & 762 & 1000 & 968 & 905 \\
\hline 6 & $9.4959 \mathrm{E}$ & -304 & 464 & 121 & 590 & 968 & 1000 & 982 \\
\hline & $9.4773 \mathrm{E}-01$ & -271 & 449 & -44 & 460 & 905 & 982 & 1000 \\
\hline
\end{tabular}

Table B.195: Relative uncertainty (relative standard deviation) and correlation (normalized to 1000) for ${ }^{245} \mathrm{Cm}(\mathrm{n}, 2 \mathrm{n})$

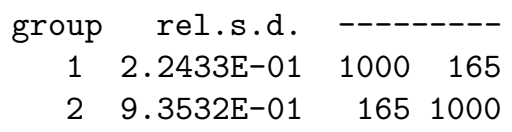


Table B.196: Relative uncertainty (relative standard deviation) and correlation (normalized to 1000) for ${ }^{245} \mathrm{Cm}(\mathrm{n}, \mathrm{f})$

\begin{tabular}{|c|c|c|c|c|c|c|c|c|c|c|c|c|c|c|c|c|}
\hline 1 & $1.8111 \mathrm{E}-01$ & 1000 & 748 & 634 & 58 & 58 & 58 & 57 & 0 & 0 & 0 & 0 & 0 & 0 & 0 & 0 \\
\hline 2 & $3.0961 \mathrm{E}-01$ & 748 & 1000 & 971 & 666 & 666 & 666 & 652 & 0 & 0 & 0 & 0 & 0 & 0 & 0 & 0 \\
\hline 3 & $4.4171 \mathrm{E}-01$ & 634 & 971 & 1000 & 720 & 720 & 720 & 706 & 0 & 0 & 0 & 0 & 0 & 0 & 0 & 0 \\
\hline 4 & $4.9428 \mathrm{E}-01$ & 58 & 666 & 720 & 1000 & 1000 & 1000 & 980 & 0 & 0 & 0 & 0 & 0 & 0 & 0 & 0 \\
\hline 5 & $3.7220 E-01$ & 58 & 666 & 720 & 1000 & 1000 & 1000 & 980 & 0 & 0 & 0 & 0 & 0 & 0 & 0 & 0 \\
\hline 6 & $4.7447 \mathrm{E}-01$ & 58 & 666 & 720 & 1000 & 1000 & 1000 & 980 & 0 & 0 & 0 & 0 & 0 & 0 & 0 & 0 \\
\hline 7 & $2.6531 \mathrm{E}-01$ & 57 & 652 & 706 & 980 & 980 & 980 & 1000 & 198 & 198 & 198 & 191 & 0 & 0 & 0 & 0 \\
\hline 8 & $1.3474 \mathrm{E}-01$ & 0 & 0 & 0 & 0 & 0 & 0 & 198 & 1000 & 1000 & 1000 & 965 & 0 & 0 & 0 & 0 \\
\hline 9 & $1.3177 \mathrm{E}-01$ & 0 & 0 & 0 & 0 & 0 & 0 & 198 & 1000 & 1000 & 1000 & 965 & 0 & 0 & 0 & 0 \\
\hline 10 & $1.3026 \mathrm{E}-01$ & 0 & 0 & 0 & 0 & 0 & 0 & 198 & 1000 & 1000 & 1000 & 965 & 0 & 0 & 0 & \\
\hline 11 & $8.6603 \mathrm{E}-02$ & 0 & 0 & 0 & 0 & 0 & 0 & 191 & 965 & 965 & 965 & 1000 & 5 & 1 & 1 & 1 \\
\hline 12 & $3.8941 \mathrm{E}-02$ & 0 & 0 & 0 & 0 & 0 & 0 & 0 & 0 & 0 & 0 & 5 & 1000 & 29 & 17 & 12 \\
\hline 13 & $6.2109 \mathrm{E}-02$ & 0 & 0 & 0 & 0 & 0 & 0 & 0 & 0 & 0 & 0 & 1 & 29 & 1000 & 321 & 164 \\
\hline 14 & $5.1220 \mathrm{E}-02$ & 0 & 0 & 0 & 0 & 0 & 0 & 0 & 0 & 0 & 0 & 1 & 17 & 321 & 1000 & 773 \\
\hline 15 & $3.8175 \mathrm{E}-02$ & 0 & 0 & 0 & 0 & 0 & 0 & 0 & 0 & 0 & 0 & 1 & 12 & 164 & 773 & 1000 \\
\hline
\end{tabular}

Table B.197: Relative uncertainty (relative standard deviation) and correlation (normalized to 1000) for ${ }^{245} \mathrm{Cm}(\mathrm{n}, \gamma)$

\begin{tabular}{|c|c|c|c|c|c|c|c|c|c|c|c|c|c|c|c|c|}
\hline 1 & $7.1207 \mathrm{E}-01$ & 1000 & 622 & 485 & 371 & 361 & 359 & 128 & 0 & 0 & 0 & 0 & 0 & 0 & 0 & \\
\hline 2 & $3.6169 \mathrm{E}-01$ & 622 & 1000 & 955 & 877 & 863 & 858 & 308 & 0 & 0 & 0 & 0 & 0 & 0 & 0 & 0 \\
\hline 3 & $2.9122 \mathrm{E}-01$ & 485 & 955 & 1000 & 980 & 965 & 960 & 345 & 0 & 0 & 0 & 0 & 0 & 0 & 0 & \\
\hline 4 & $2.4824 \mathrm{E}-01$ & 371 & 877 & 980 & 1000 & 988 & 983 & 354 & 0 & 0 & 0 & 0 & 0 & 0 & 0 & \\
\hline 5 & 1.9317E-01 & 361 & 863 & 965 & 988 & 1000 & 999 & 366 & 0 & 0 & 0 & 0 & 0 & 0 & 0 & \\
\hline 6 & $1.7559 \mathrm{E}-01$ & 359 & 858 & 960 & 983 & 999 & 1000 & 367 & 0 & 0 & 0 & 0 & 0 & 0 & 0 & \\
\hline 7 & $1.0498 \mathrm{E}-01$ & 128 & 308 & 345 & 354 & 366 & 367 & 1000 & 929 & 929 & 928 & 922 & 0 & 0 & 0 & \\
\hline 8 & 1. $2886 \mathrm{E}-01$ & 0 & 0 & 0 & 0 & 0 & 0 & 929 & 1000 & 1000 & 999 & 993 & 0 & 0 & 0 & \\
\hline 9 & 1. $2486 \mathrm{E}-01$ & 0 & 0 & 0 & 0 & 0 & 0 & 929 & 1000 & 1000 & 1000 & 994 & 0 & 0 & 0 & \\
\hline 10 & 1. 2317E-01 & 0 & 0 & 0 & 0 & 0 & 0 & 928 & 999 & 1000 & 1000 & 994 & 0 & 0 & 0 & \\
\hline 11 & $9.6045 \mathrm{E}-02$ & 0 & 0 & 0 & 0 & 0 & 0 & 922 & 993 & 994 & 994 & 1000 & 1 & 0 & 0 & \\
\hline 12 & $7.8749 \mathrm{E}-02$ & 0 & 0 & 0 & 0 & 0 & 0 & 0 & 0 & 0 & 0 & 1 & 1000 & 57 & 24 & 10 \\
\hline 13 & 1. 1787E-01 & 0 & 0 & 0 & 0 & 0 & 0 & 0 & 0 & 0 & 0 & 0 & 57 & 1000 & 136 & 72 \\
\hline 14 & $7.4618 \mathrm{E}-02$ & 0 & 0 & 0 & 0 & 0 & 0 & 0 & 0 & 0 & 0 & 0 & 24 & 136 & 1000 & 966 \\
\hline 15 & $8.3869 \mathrm{E}-02$ & 0 & 0 & 0 & 0 & 0 & 0 & 0 & 0 & 0 & 0 & 0 & 10 & 72 & 966 & 1000 \\
\hline
\end{tabular}




\section{Appendix C}

In the following, plots for the relative $\nu$-bar uncertainties and correlations (normalized to 1000) are given in the 15-energy group representation.

This is followed by numerical tables for the relative $\nu$-bar uncertainties (relative standard deviations) and correlations (normalized to 1000) also given in the 15-energy group representation. 


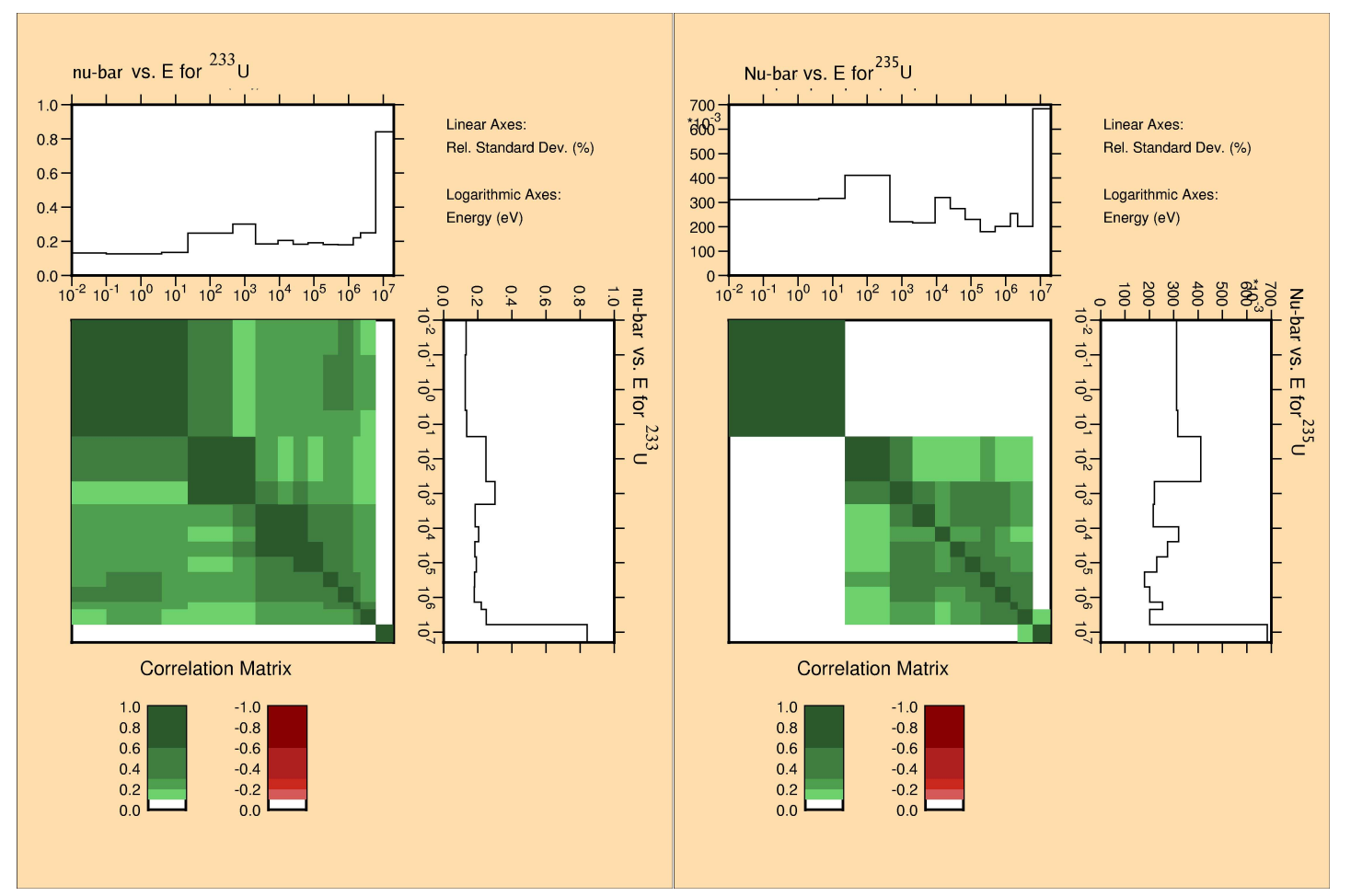

Figure C.1: Correlation and uncertainties for $\nu$-bar in 15 groups for the ${ }^{233} \mathrm{U}$ (left) and ${ }^{235} \mathrm{U}$ (right).

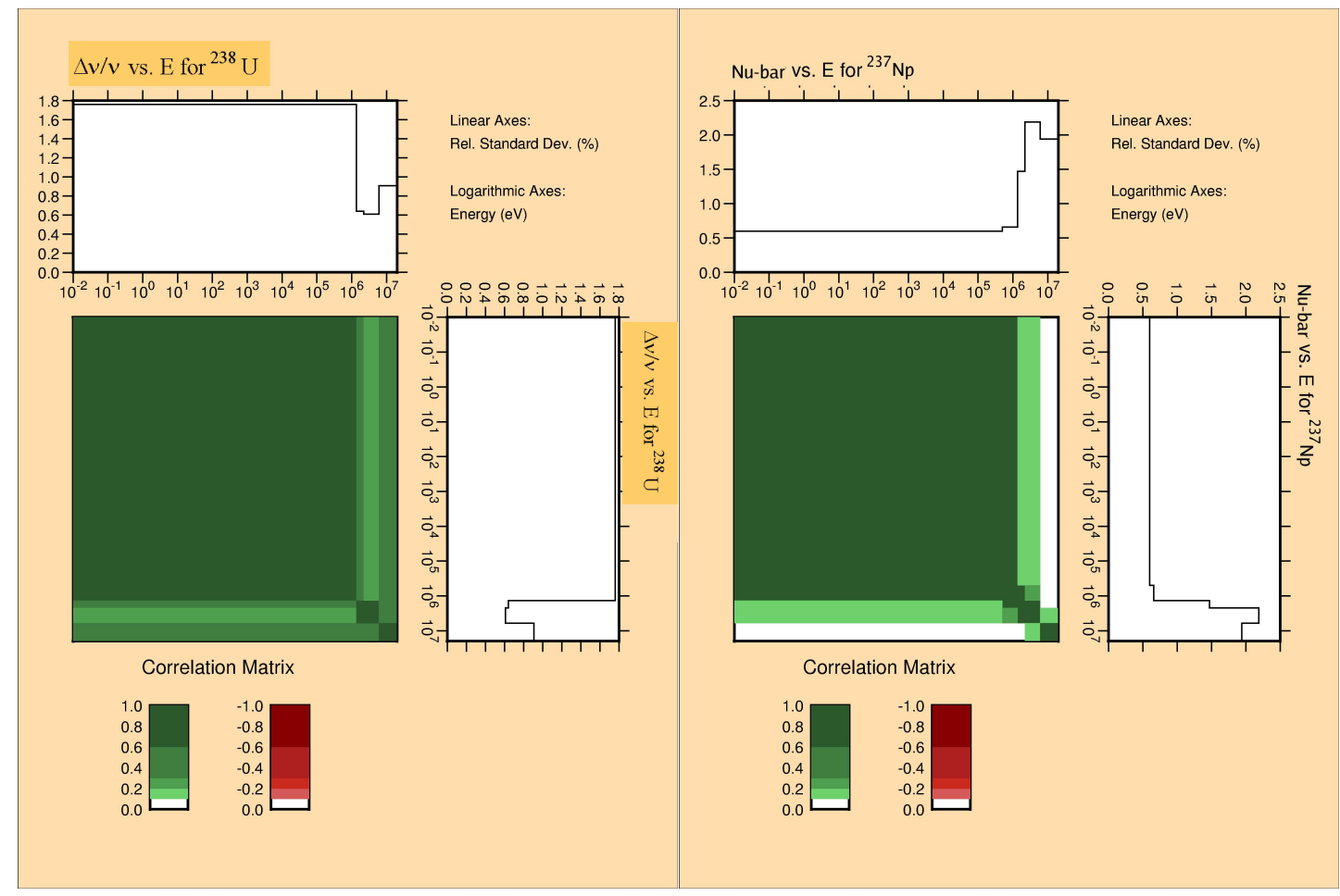

Figure C.2: Correlation and uncertainties for $\nu$-bar in 15 groups for the ${ }^{238} \mathrm{U}$ (left) and ${ }^{237} \mathrm{~Np}$ (right). 


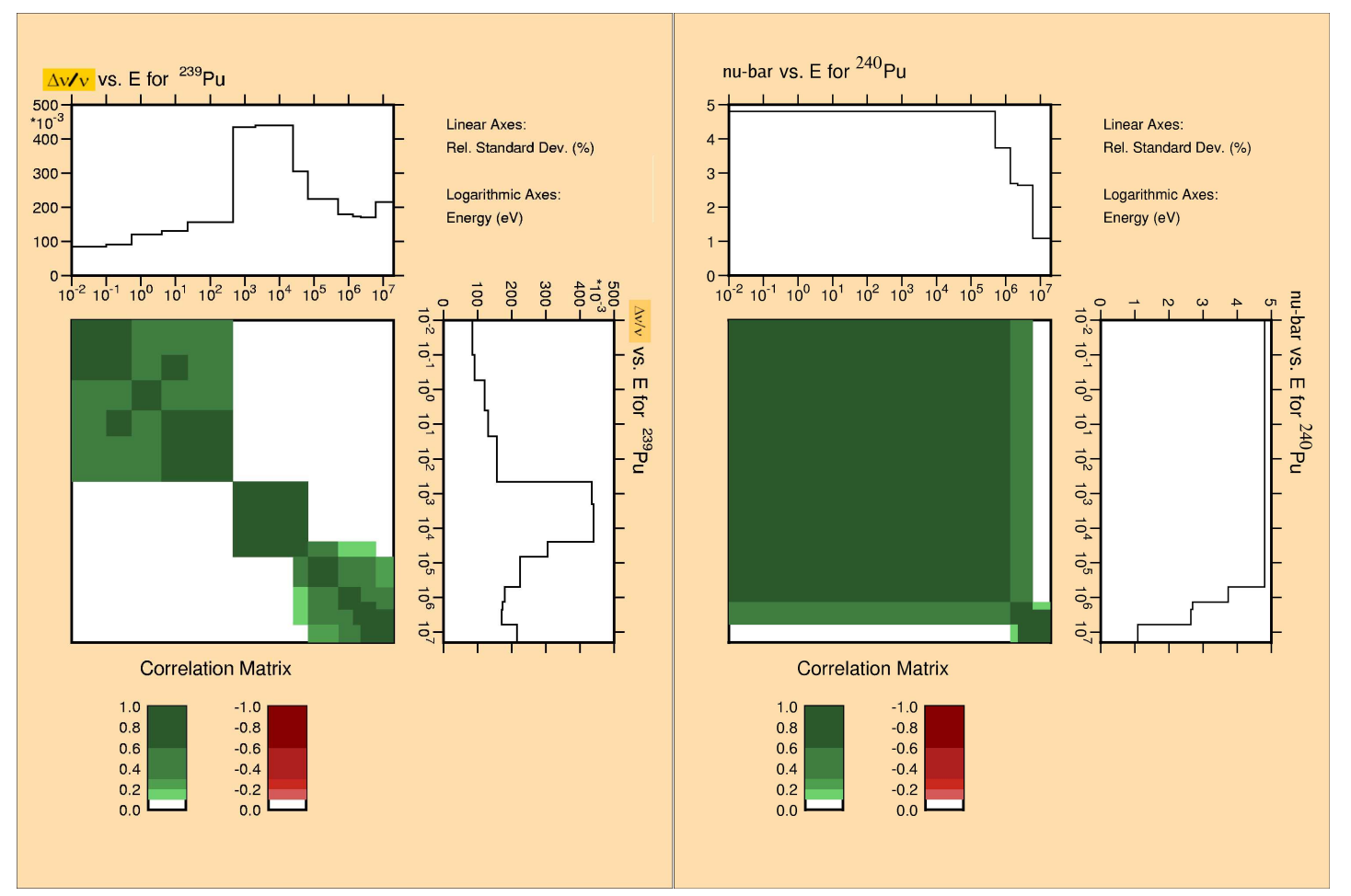

Figure C.3: Correlation and uncertainties for $\nu$-bar in 15 groups for the ${ }^{239} \mathrm{Pu}$ (left) and ${ }^{240} \mathrm{Pu}$ (right).

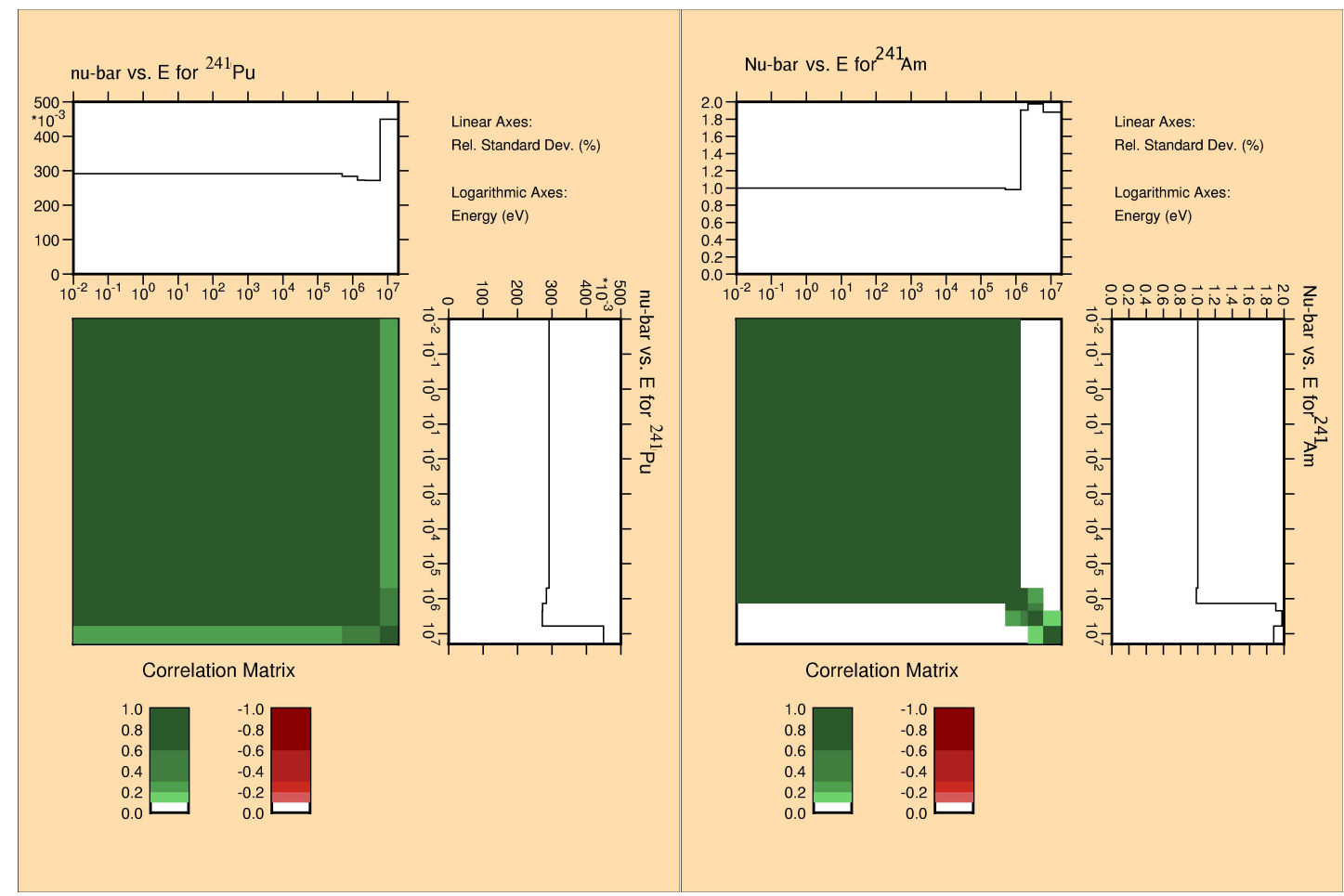

Figure C.4: Correlation and uncertainties for $\nu$-bar in 15 groups for the ${ }^{241} \mathrm{Pu}$ (left) and ${ }^{241} \mathrm{Am}$ (right). 


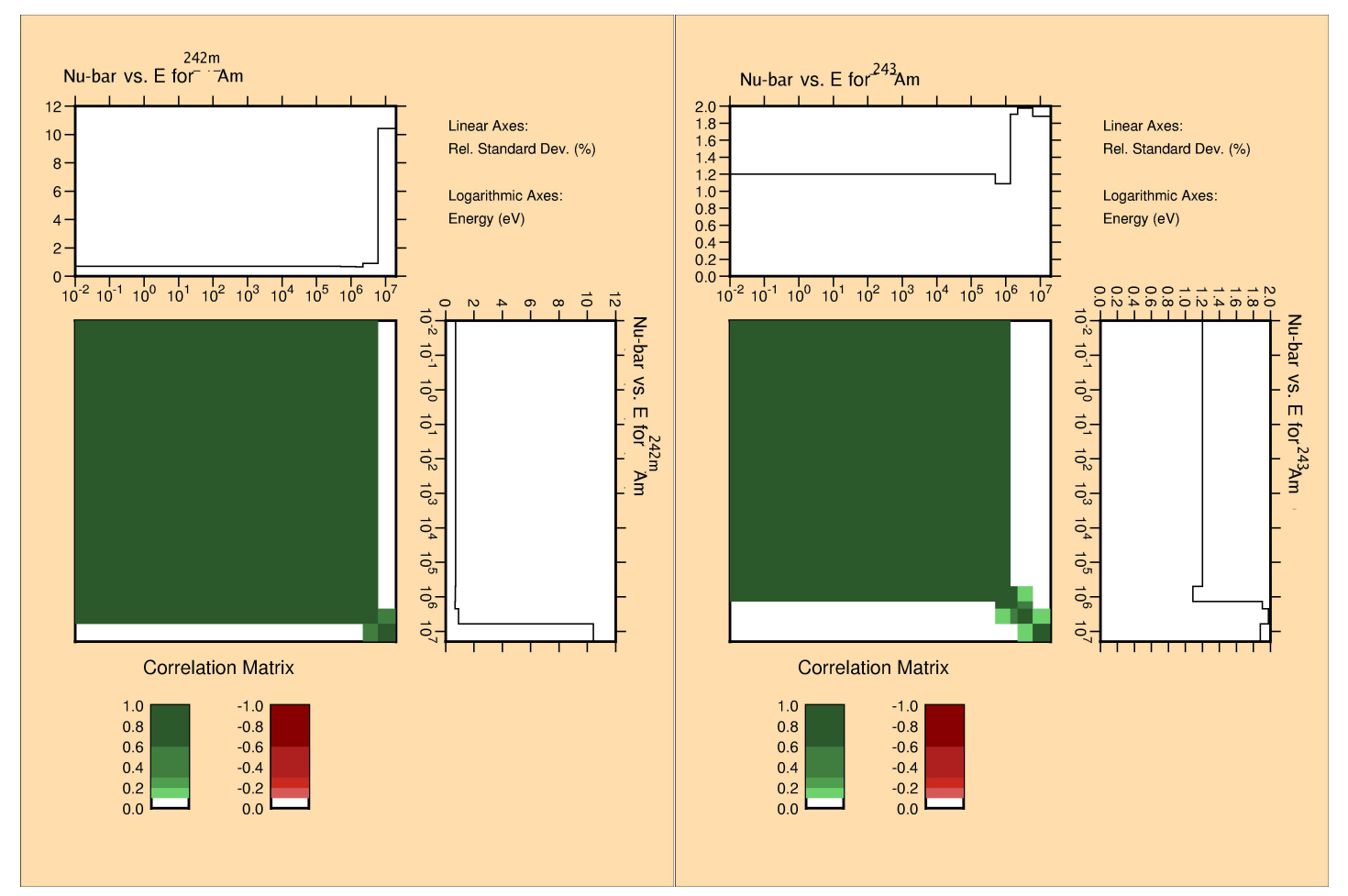

Figure C.5: Correlation and uncertainties for $\nu$-bar in 15 groups for the ${ }^{242 m} \mathrm{Am}$ (left) and ${ }^{243} \mathrm{Am}$ (right). 
Table C.1: Relative uncertainty (relative standard deviation) and correlation (normalized to 1000) for $\nu$-bar for ${ }^{233} \mathrm{U}$

\begin{tabular}{|c|c|c|c|c|c|c|c|c|c|c|c|c|c|c|c|c|}
\hline 1 & $8.4211 \mathrm{E}-03$ & 1000 & 37 & 38 & 55 & 62 & 61 & 68 & 62 & 68 & 43 & 28 & 32 & 35 & 35 & 33 \\
\hline 2 & $2.5122 \mathrm{E}-03$ & 37 & 1000 & 385 & 268 & 232 & 213 & 229 & 206 & 225 & 139 & 122 & 187 & 204 & 204 & 193 \\
\hline 3 & $2.2163 \mathrm{E}-03$ & 38 & 385 & 1000 & 347 & 309 & 267 & 278 & 246 & 270 & 166 & 160 & 261 & 284 & 284 & 269 \\
\hline 4 & $1.7977 \mathrm{E}-03$ & 55 & 268 & 347 & 1000 & 445 & 390 & 415 & 369 & 404 & 254 & 210 & 299 & 324 & 324 & 307 \\
\hline 5 & $1.8181 \mathrm{E}-03$ & 62 & 232 & 309 & 445 & 1000 & 465 & 457 & 412 & 451 & 282 & 212 & 280 & 305 & 305 & 289 \\
\hline 6 & $1.9268 \mathrm{E}-03$ & 61 & 213 & 267 & 390 & 465 & 1000 & 615 & 417 & 457 & 280 & 192 & 247 & 268 & 268 & 254 \\
\hline 7 & $1.8345 \mathrm{E}-03$ & 68 & 229 & 278 & 415 & 457 & 615 & 1000 & 956 & 722 & 313 & 206 & 252 & 274 & 274 & 259 \\
\hline 8 & $2.0560 \mathrm{E}-03$ & 62 & 206 & 246 & 369 & 412 & 417 & 956 & 1000 & 715 & 287 & 185 & 221 & 240 & 240 & 227 \\
\hline 9 & $1.8495 \mathrm{E}-03$ & 68 & 225 & 270 & 404 & 451 & 457 & 722 & 715 & 1000 & 580 & 202 & 243 & 264 & 264 & 250 \\
\hline 10 & $3.0187 \mathrm{E}-03$ & 43 & 139 & 166 & 254 & 282 & 280 & 313 & 287 & 580 & 1000 & 820 & 145 & 158 & 158 & 149 \\
\hline 11 & $2.4814 \mathrm{E}-03$ & 28 & 122 & 160 & 210 & 212 & 192 & 206 & 185 & 202 & 820 & 1000 & 443 & 415 & 415 & 401 \\
\hline 12 & $1.3557 \mathrm{E}-03$ & 32 & 187 & 261 & 299 & 280 & 247 & 252 & 221 & 243 & 145 & 443 & 1000 & 919 & 919 & 891 \\
\hline 13 & 1. $2690 \mathrm{E}-03$ & 35 & 204 & 284 & 324 & 305 & 268 & 274 & 240 & 264 & 158 & 415 & 919 & 1000 & 1000 & 946 \\
\hline 14 & 1. $2690 \mathrm{E}-03$ & 35 & 204 & 284 & 324 & 305 & 268 & 274 & 240 & 264 & 158 & 415 & 919 & 1000 & 1000 & 946 \\
\hline 15 & 1. $3294 \mathrm{E}-03$ & 33 & 193 & 269 & 307 & 289 & 254 & 259 & 227 & 250 & 149 & 401 & 891 & 946 & 946 & 1000 \\
\hline
\end{tabular}


Table C.2: Relative uncertainty (relative standard deviation) and correlation (normalized to 1000) for $\nu$-bar for ${ }^{235} \mathrm{U}$

\begin{tabular}{|c|c|c|c|c|c|c|c|c|c|c|c|c|c|c|c|c|}
\hline 1 & $6.8355 \mathrm{E}-03$ & 1000 & 132 & 80 & 74 & 67 & 50 & 41 & 35 & 54 & 51 & 23 & 0 & 0 & 0 & 0 \\
\hline 2 & $2.0161 \mathrm{E}-03$ & 132 & 1000 & 429 & 360 & 368 & 279 & 230 & 195 & 298 & 284 & 131 & 0 & 0 & 0 & \\
\hline 3 & $2.5371 \mathrm{E}-03$ & 80 & 429 & 1000 & 419 & 353 & 250 & 204 & 171 & 268 & 254 & 117 & 0 & 0 & 0 & \\
\hline 4 & $2.0122 \mathrm{E}-03$ & 74 & 360 & 419 & 1000 & 550 & 347 & 287 & 246 & 369 & 359 & 175 & 0 & 0 & 0 & \\
\hline 5 & $1.7967 \mathrm{E}-03$ & 67 & 368 & 353 & 550 & 1000 & 492 & 358 & 304 & 465 & 445 & 208 & 0 & 0 & 0 & \\
\hline 6 & $2.3035 \mathrm{E}-03$ & 50 & 279 & 250 & 347 & 492 & 1000 & 319 & 268 & 385 & 370 & 164 & 0 & 0 & 0 & \\
\hline 7 & $2.7486 \mathrm{E}-03$ & 41 & 230 & 204 & 287 & 358 & 319 & 1000 & 235 & 325 & 319 & 152 & 0 & 0 & 0 & \\
\hline 8 & $3.2002 \mathrm{E}-03$ & 35 & 195 & 171 & 246 & 304 & 268 & 235 & 1000 & 293 & 275 & 121 & 0 & 0 & 0 & \\
\hline 9 & $2.1589 \mathrm{E}-03$ & 54 & 298 & 268 & 369 & 465 & 385 & 325 & 293 & 1000 & 435 & 186 & 0 & 0 & 0 & \\
\hline 10 & $2.2034 \mathrm{E}-03$ & 51 & 284 & 254 & 359 & 445 & 370 & 319 & 275 & 435 & 1000 & 359 & 0 & 0 & 0 & \\
\hline 11 & $4.1079 \mathrm{E}-03$ & 23 & 131 & 117 & 175 & 208 & 164 & 152 & 121 & 186 & 359 & 1000 & 58 & 53 & 53 & 53 \\
\hline 12 & $3.1620 \mathrm{E}-03$ & 0 & 0 & 0 & 0 & 0 & 0 & 0 & 0 & 0 & 0 & 58 & 1000 & 916 & 916 & 916 \\
\hline 13 & $3.1200 \mathrm{E}-03$ & 0 & 0 & 0 & 0 & 0 & 0 & 0 & 0 & 0 & 0 & 53 & 916 & 1000 & 1000 & 1000 \\
\hline 14 & $3.1200 \mathrm{E}-03$ & 0 & 0 & 0 & 0 & 0 & 0 & 0 & 0 & 0 & 0 & 53 & 916 & 1000 & 1000 & 1000 \\
\hline 15 & $3.1200 \mathrm{E}-03$ & 0 & 0 & 0 & 0 & 0 & 0 & 0 & 0 & 0 & 0 & 53 & 916 & 1000 & 1000 & 1000 \\
\hline
\end{tabular}

Table C.3: Relative uncertainty (relative standard deviation) and correlation (normalized to 1000) for $\nu$-bar for ${ }^{238} \mathrm{U}$

\begin{tabular}{|c|c|c|c|c|c|c|c|c|c|c|c|c|c|c|c|c|}
\hline 1 & & תחל & 4 & 349 & 308 & 30 & 30 & 308 & 36 & 30 & 308 & & & 308 & & \\
\hline 2 & $6.1098 \mathrm{E}-03$ & 411 & 1000 & 923 & 278 & 278 & 278 & 278 & 278 & 278 & 278 & 278 & 278 & 278 & 278 & 278 \\
\hline 3 & $6.4020 \mathrm{E}-03$ & 349 & 923 & 1000 & 550 & 550 & 550 & 550 & 550 & 550 & 550 & 550 & 550 & 550 & 550 & 550 \\
\hline 4 & $1.7627 \mathrm{E}-02$ & 308 & 278 & 550 & 1000 & 1000 & 1000 & 1000 & 1000 & 1000 & 1000 & 1000 & 1000 & 1000 & 1000 & 1000 \\
\hline 5 & $1.7627 \mathrm{E}-02$ & 308 & 278 & 550 & 1000 & 1000 & 1000 & 1000 & 1000 & 1000 & 1000 & 1000 & 1000 & 1000 & 1000 & 1000 \\
\hline 6 & $1.7627 \mathrm{E}-02$ & 308 & 278 & 550 & 1000 & 1000 & 1000 & 1000 & 1000 & 1000 & 1000 & 1000 & 1000 & 1000 & 1000 & 1000 \\
\hline 7 & $1.7627 \mathrm{E}-02$ & 308 & 278 & 550 & 1000 & 1000 & 1000 & 1000 & & & & & & 00 & 00 & 1000 \\
\hline 8 & $1.7627 \mathrm{E}-02$ & 308 & 278 & 550 & 1000 & 1000 & 1000 & 1000 & 1000 & 1000 & 1000 & 1000 & 1000 & 1000 & 1000 & 1000 \\
\hline 9 & $1.7627 \mathrm{E}-02$ & 308 & 278 & 550 & 1000 & 1000 & 1000 & 1000 & 1000 & 1000 & 1000 & 1000 & 1000 & 1000 & 1000 & 1000 \\
\hline 10 & $1.7627 \mathrm{E}-02$ & 308 & 278 & 550 & 1000 & 1000 & 1000 & 1000 & 1000 & 1000 & 1000 & 1000 & 1000 & 1000 & 1000 & 1000 \\
\hline 11 & $1.7627 \mathrm{E}-02$ & 308 & 278 & 550 & 1000 & 1000 & 1000 & 1000 & 1000 & 1000 & 1000 & 1000 & 1000 & 1000 & 1000 & 1000 \\
\hline 12 & $1.7627 \mathrm{E}-02$ & 308 & 278 & 550 & 1000 & 1000 & 1000 & 1000 & 1000 & 1000 & 1000 & 1000 & 1000 & 1000 & 1000 & 1000 \\
\hline 13 & $1.7627 \mathrm{E}-02$ & 308 & 278 & 550 & 1000 & 1000 & 1000 & 1000 & 1000 & 1000 & 1000 & 1000 & 1000 & 1000 & 1000 & 1000 \\
\hline 14 & $1.7627 \mathrm{E}-02$ & 308 & 278 & 550 & 1000 & 1000 & 1000 & 1000 & 1000 & 1000 & 1000 & 1000 & 1000 & 1000 & 1000 & 1000 \\
\hline 15 & $1.7627 \mathrm{E}-02$ & 308 & 278 & 550 & 1000 & 1000 & 1000 & 1000 & 1000 & 1000 & 1000 & 1000 & 1000 & 1000 & 1000 & 1000 \\
\hline
\end{tabular}


Table C.4: Relative uncertainty (relative standard deviation) and correlation (normalized to 1000) for $\nu$-bar for ${ }^{237} \mathrm{~Np}$

\begin{tabular}{|c|c|c|c|c|c|c|c|c|c|c|c|c|c|c|c|c|}
\hline 1 & $1.9421 \mathrm{E}-02$ & 1000 & 116 & 34 & 0 & 0 & 0 & 0 & 0 & 0 & 0 & 0 & 0 & 0 & 0 & 0 \\
\hline 2 & $2.1886 \mathrm{E}-02$ & 116 & 1000 & 643 & 292 & 127 & 127 & 127 & 127 & 127 & 127 & 127 & 127 & 127 & 127 & 127 \\
\hline 3 & 1. $4704 \mathrm{E}-02$ & 34 & 643 & 1000 & 713 & 197 & 197 & 197 & 197 & 197 & 197 & 197 & 197 & 197 & 197 & 197 \\
\hline 4 & $6.6175 \mathrm{E}-03$ & 0 & 292 & 713 & 1000 & 769 & 769 & 769 & 769 & 769 & 769 & 769 & 769 & 769 & 769 & 769 \\
\hline 5 & $6.0000 \mathrm{E}-03$ & 0 & 127 & 197 & 769 & 1000 & 1000 & 1000 & 1000 & 1000 & 1000 & 1000 & 1000 & 1000 & 1000 & 1000 \\
\hline 6 & $6.0000 \mathrm{E}-03$ & 0 & 127 & 197 & 769 & 1000 & 1000 & 1000 & 1000 & 1000 & 1000 & 1000 & 1000 & 1000 & 1000 & 1000 \\
\hline 7 & $6.0000 \mathrm{E}-03$ & 0 & 127 & 197 & 769 & 1000 & 00 & 00 & & 00 & 00 & 00 & 1000 & 1000 & 00 & 1000 \\
\hline 8 & $6.0000 \mathrm{E}-03$ & 0 & 127 & 197 & 769 & 1000 & 1000 & 1000 & 1000 & 1000 & 1000 & 1000 & 1000 & 1000 & 1000 & 1000 \\
\hline 9 & $6.0000 \mathrm{E}-03$ & 0 & 127 & 197 & 769 & 1000 & 1000 & 1000 & 1000 & 1000 & 1000 & 1000 & 1000 & 1000 & 1000 & 1000 \\
\hline 10 & $6.0000 \mathrm{E}-03$ & 0 & 127 & 197 & 769 & 1000 & 1000 & 1000 & 1000 & 1000 & 1000 & 1000 & 1000 & 1000 & 1000 & 1000 \\
\hline 11 & $6.0000 \mathrm{E}-03$ & 0 & 127 & 197 & 769 & 1000 & 1000 & 1000 & 1000 & 1000 & 1000 & 1000 & 1000 & 1000 & 1000 & 1000 \\
\hline 12 & $6.0000 \mathrm{E}-03$ & 0 & 127 & 197 & 769 & 1000 & 1000 & 1000 & 1000 & 1000 & 1000 & 1000 & 1000 & 1000 & 1000 & 1000 \\
\hline 13 & $6.0000 \mathrm{E}-03$ & 0 & 127 & 197 & 769 & 1000 & 1000 & 1000 & 1000 & 1000 & 1000 & 1000 & 1000 & 1000 & 1000 & 1000 \\
\hline 14 & $6.0000 \mathrm{E}-03$ & 0 & 127 & 197 & 769 & 1000 & 1000 & 1000 & 1000 & 1000 & 1000 & 1000 & 1000 & 1000 & 1000 & 1000 \\
\hline 15 & $6.0000 \mathrm{E}-03$ & 0 & 127 & 197 & 769 & 1000 & 1000 & 1000 & 1000 & 1000 & 1000 & 1000 & 1000 & 1000 & 1000 & 1000 \\
\hline
\end{tabular}

Table C.5: Relative uncertainty (relative standard deviation) and correlation (normalized to 1000) for $\nu$-bar for ${ }^{239} \mathrm{Pu}$

\begin{tabular}{|c|c|c|c|c|c|c|c|c|c|c|c|c|c|c|c|c|}
\hline & & & & & & & & & & & & & & & & \\
\hline 1 & $2.1524 \mathrm{E}-03$ & 1000 & 740 & 513 & 334 & 217 & 217 & 79 & 26 & 26 & 26 & 21 & 25 & 21 & 35 & 35 \\
\hline 2 & $1.7031 \mathrm{E}-03$ & 740 & 1000 & 914 & 588 & 382 & 382 & 134 & 41 & 41 & 41 & 34 & 42 & 35 & 58 & 59 \\
\hline 3 & $1.7340 \mathrm{E}-03$ & 513 & 914 & 1000 & 640 & 415 & 415 & 143 & 42 & 42 & 42 & 36 & 45 & 37 & 61 & 63 \\
\hline 4 & $1.7900 \mathrm{E}-03$ & 334 & 588 & 640 & 1000 & 550 & 550 & 185 & 51 & 51 & 52 & 29 & 36 & 29 & 48 & 49 \\
\hline 5 & $2.2400 \mathrm{E}-03$ & 217 & 382 & 415 & 550 & 1000 & 1000 & 303 & 58 & 58 & 58 & 18 & 22 & 18 & 31 & 31 \\
\hline 6 & $2.2400 \mathrm{E}-03$ & 217 & 382 & 415 & 550 & 1000 & 1000 & 303 & 58 & 58 & 58 & 18 & 22 & 18 & 31 & 31 \\
\hline 7 & $3.0540 \mathrm{E}-03$ & 79 & 134 & 143 & 185 & 303 & 303 & 1000 & 969 & 969 & 969 & 6 & 8 & 6 & 11 & 11 \\
\hline 8 & $4.3980 \mathrm{E}-03$ & 26 & 41 & 42 & 51 & 58 & 58 & 969 & 1000 & 1000 & 1000 & 2 & 2 & 2 & 3 & 3 \\
\hline 9 & $4.3980 \mathrm{E}-03$ & 26 & 41 & 42 & 51 & 58 & 58 & 969 & 1000 & 1000 & 1000 & 2 & 2 & 2 & 3 & 3 \\
\hline 10 & $4.3509 \mathrm{E}-03$ & 26 & 41 & 42 & 52 & 58 & 58 & 969 & 1000 & 1000 & 1000 & 6 & 5 & 4 & 5 & 5 \\
\hline 11 & $1.5633 \mathrm{E}-03$ & 21 & 34 & 36 & 29 & 18 & 18 & 6 & 2 & 2 & 6 & 1000 & 730 & 447 & 521 & 485 \\
\hline 12 & 1.3122E-03 & 25 & 42 & 45 & 36 & 22 & 22 & 8 & 2 & 2 & 5 & 730 & 1000 & 585 & 640 & 595 \\
\hline 13 & 1.2082E-03 & 21 & 35 & 37 & 29 & 18 & 18 & 6 & 2 & 2 & 4 & 447 & 585 & 1000 & 531 & 492 \\
\hline 14 & $9.1368 \mathrm{E}-04$ & 35 & 58 & 61 & 48 & 31 & 31 & 11 & 3 & 3 & 5 & 521 & 640 & 531 & 1000 & 819 \\
\hline 15 & $8.5168 \mathrm{E}-04$ & 35 & 59 & 63 & 49 & 31 & 31 & 11 & 3 & 3 & 5 & 485 & 595 & 492 & 819 & 1000 \\
\hline
\end{tabular}


Table C.6: Relative uncertainty (relative standard deviation) and correlation (normalized to 1000) for $\nu$-bar for ${ }^{240} \mathrm{Pu}$

\begin{tabular}{|c|c|c|c|c|c|c|c|c|c|c|c|c|c|c|c|c|}
\hline 1 & $1.0857 \mathrm{E}-02$ & 1000 & 672 & 138 & 0 & 0 & 0 & 0 & 0 & 0 & 0 & 0 & 0 & 0 & 0 & 0 \\
\hline 2 & $2.6479 \mathrm{E}-02$ & 672 & 1000 & 625 & 390 & 303 & 303 & 303 & 303 & 303 & 303 & 303 & 303 & 303 & 303 & 303 \\
\hline 3 & $2.6926 \mathrm{E}-02$ & 138 & 625 & 1000 & 508 & 309 & 309 & 309 & 309 & 309 & 309 & 309 & 309 & 309 & 309 & 309 \\
\hline 4 & $3.7373 \mathrm{E}-02$ & 0 & 390 & 508 & 1000 & 975 & 975 & 975 & 975 & 975 & 975 & 975 & 975 & 975 & 975 & 975 \\
\hline 5 & $4.8100 \mathrm{E}-02$ & 0 & 303 & 309 & 975 & 1000 & 1000 & 1000 & 1000 & 1000 & 1000 & 1000 & 1000 & 1000 & 1000 & 1000 \\
\hline 6 & $4.8100 \mathrm{E}-02$ & 0 & 303 & 309 & 975 & 1000 & 1000 & 1000 & 1000 & 1000 & 1000 & 1000 & 1000 & 1000 & 1000 & 1000 \\
\hline 7 & $4.8100 \mathrm{E}-02$ & 0 & 303 & 309 & 975 & 1000 & 1000 & 1000 & 1000 & 1000 & 1000 & 1000 & 1000 & 1000 & 1000 & 1000 \\
\hline 8 & $4.8100 \mathrm{E}-02$ & 0 & 303 & 309 & 975 & 1000 & 1000 & 1000 & 1000 & 1000 & 1000 & 1000 & 1000 & 1000 & 1000 & 1000 \\
\hline 9 & $4.8100 \mathrm{E}-02$ & 0 & 303 & 309 & 975 & 1000 & 1000 & 1000 & 1000 & 1000 & 1000 & 1000 & 1000 & 1000 & 1000 & 1000 \\
\hline 10 & $4.8100 \mathrm{E}-02$ & 0 & 303 & 309 & 975 & 1000 & 1000 & 1000 & 1000 & 1000 & 1000 & 1000 & 1000 & 1000 & 1000 & 1000 \\
\hline 11 & $4.8100 \mathrm{E}-02$ & 0 & 303 & 309 & 975 & 1000 & 1000 & 1000 & 1000 & 1000 & 1000 & 1000 & 1000 & 1000 & 1000 & 1000 \\
\hline 12 & $4.8100 \mathrm{E}-02$ & 0 & 303 & 309 & 975 & 1000 & 1000 & 1000 & 1000 & 1000 & 1000 & 1000 & 1000 & 1000 & 1000 & 1000 \\
\hline 13 & $4.8100 \mathrm{E}-02$ & 0 & 303 & 309 & 975 & 1000 & 1000 & 1000 & 1000 & 1000 & 1000 & 1000 & 1000 & 1000 & 1000 & 1000 \\
\hline 14 & $4.8100 \mathrm{E}-02$ & 0 & 303 & 309 & 975 & 1000 & 1000 & 1000 & 1000 & 1000 & 1000 & 1000 & 1000 & 1000 & 1000 & 1000 \\
\hline 15 & 4.8100E-02 & 0 & 303 & 309 & 975 & 1000 & 1000 & 1000 & 1000 & 1000 & 1000 & 1000 & 1000 & 1000 & 1000 & 1000 \\
\hline
\end{tabular}

Table C.7: Relative uncertainty (relative standard deviation) and correlation (normalized to 1000) for $\nu$-bar for ${ }^{241} \mathrm{Pu}$

\begin{tabular}{|c|c|c|c|c|c|c|c|c|c|c|c|c|c|c|c|c|}
\hline 1 & $4.4976 \mathrm{E}-03$ & 1000 & 8 & 531 & 358 & 288 & 288 & 288 & 288 & 288 & 288 & 288 & $2 \varepsilon$ & 288 & 2 & \\
\hline 2 & $2.7245 E-03$ & 581 & 1000 & 998 & 968 & 946 & 946 & 946 & 946 & 946 & 946 & 946 & 946 & 946 & 946 & 946 \\
\hline 3 & $2.7345 \mathrm{E}-03$ & 531 & 998 & 1000 & 981 & 964 & 964 & 964 & 964 & 964 & 964 & 964 & 964 & 964 & 964 & 964 \\
\hline 4 & $2.8414 \mathrm{E}-03$ & 358 & 968 & 981 & 1000 & 997 & 997 & 997 & 997 & 997 & 997 & 997 & 997 & 997 & 996 & 996 \\
\hline 5 & $2.9154 \mathrm{E}-03$ & 288 & 946 & 964 & 997 & 1000 & 1000 & 1000 & 1000 & 1000 & 1000 & 1000 & 1000 & 1000 & 99 & 999 \\
\hline 6 & $2.9154 \mathrm{E}-03$ & 288 & 946 & 964 & 997 & 1000 & 1000 & 1000 & 1000 & 1000 & 1000 & 1000 & 1000 & 1000 & 999 & 999 \\
\hline 7 & $2.9154 \mathrm{E}-03$ & 288 & 946 & 964 & 997 & 1000 & 00 & & & 1000 & 00 & 00 & 1000 & 00 & 99 & 999 \\
\hline 8 & $2.9154 \mathrm{E}-03$ & 288 & 946 & 964 & 997 & 1000 & 1000 & 1000 & 1000 & 1000 & 1000 & 1000 & 1000 & 1000 & 999 & 999 \\
\hline 9 & $2.9154 \mathrm{E}-03$ & 288 & 946 & 964 & 997 & 1000 & 1000 & 1000 & 1000 & 1000 & 1000 & 1000 & 1000 & 1000 & 999 & 999 \\
\hline 10 & $2.9154 \mathrm{E}-03$ & 288 & 946 & 964 & 997 & 1000 & 1000 & 1000 & 1000 & 1000 & 1000 & 1000 & 1000 & 1000 & 999 & 999 \\
\hline 11 & $2.9154 \mathrm{E}-03$ & 288 & 946 & 964 & 997 & 1000 & 1000 & 1000 & 1000 & 1000 & 1000 & 1000 & 1000 & 1000 & 999 & 999 \\
\hline 12 & $2.9154 \mathrm{E}-03$ & 288 & 946 & 964 & 997 & 1000 & 1000 & 1000 & 1000 & 1000 & 1000 & 1000 & 1000 & 1000 & 999 & 999 \\
\hline 13 & $2.9146 \mathrm{E}-03$ & 288 & 946 & 964 & 997 & 1000 & 1000 & 1000 & 1000 & 1000 & 1000 & 1000 & 1000 & 1000 & 1000 & 1000 \\
\hline 14 & $2.9154 \mathrm{E}-03$ & 288 & 946 & 964 & 996 & 999 & 999 & 999 & 999 & 999 & 999 & 999 & 999 & 1000 & 1000 & 1000 \\
\hline 15 & $2.9154 \mathrm{E}-03$ & 288 & 946 & 964 & 996 & 999 & 999 & 999 & 999 & 999 & 999 & 999 & 999 & 1000 & 1000 & 1000 \\
\hline
\end{tabular}


Table C.8: Relative uncertainty (relative standard deviation) and correlation (normalized to 1000) for $\nu$-bar for ${ }^{241} \mathrm{Am}$

\begin{tabular}{|c|c|c|c|c|c|c|c|c|c|c|c|c|c|c|c|c|}
\hline 1 & 1.8823E-02 & 1000 & 132 & 27 & 0 & 0 & 0 & 0 & 0 & 0 & 0 & 0 & 0 & 0 & 0 & 0 \\
\hline 2 & 1.9772E-02 & 132 & 1000 & 511 & 218 & 85 & 85 & 85 & 85 & 85 & 85 & 85 & 85 & 85 & 85 & 85 \\
\hline 3 & 1.9067E-02 & 27 & 511 & 1000 & 671 & 91 & 91 & 91 & 91 & 91 & 91 & 91 & 91 & 91 & 91 & 91 \\
\hline 4 & $9.8185 \mathrm{E}-03$ & 0 & 218 & 671 & 1000 & 772 & 772 & 772 & 772 & 772 & 772 & 772 & 772 & 772 & 772 & 772 \\
\hline 5 & $1.0000 \mathrm{E}-02$ & 0 & 85 & 91 & 772 & 1000 & 1000 & 1000 & 1000 & 1000 & 1000 & 1000 & 1000 & 1000 & 1000 & 1000 \\
\hline 6 & $1.0000 \mathrm{E}-02$ & 0 & 85 & 91 & 772 & 1000 & 1000 & 1000 & 1000 & 1000 & 1000 & 1000 & 1000 & 1000 & 1000 & 1000 \\
\hline 7 & $1.0000 \mathrm{E}-02$ & 0 & 85 & 91 & 772 & 1000 & 1000 & 10 & 10 & 00 & 00 & 00 & 00 & 000 & 00 & 1000 \\
\hline 8 & $1.0000 \mathrm{E}-02$ & 0 & 85 & 91 & 772 & 1000 & 1000 & 1000 & 1000 & 1000 & 1000 & 1000 & 1000 & 1000 & 1000 & 1000 \\
\hline 9 & $1.0000 \mathrm{E}-02$ & 0 & 85 & 91 & 772 & 1000 & 1000 & 1000 & 1000 & 1000 & 1000 & 1000 & 1000 & 1000 & 1000 & 1000 \\
\hline 10 & $1.0000 \mathrm{E}-02$ & 0 & 85 & 91 & 772 & 1000 & 1000 & 1000 & 1000 & 1000 & 1000 & 1000 & 1000 & 1000 & 1000 & 1000 \\
\hline 11 & $1.0000 \mathrm{E}-02$ & 0 & 85 & 91 & 772 & 1000 & 1000 & 1000 & 1000 & 1000 & 1000 & 1000 & 1000 & 1000 & 1000 & 1000 \\
\hline 12 & $1.0000 \mathrm{E}-02$ & 0 & 85 & 91 & 772 & 1000 & 1000 & 1000 & 1000 & 1000 & 1000 & 1000 & 1000 & 1000 & 1000 & 1000 \\
\hline 13 & $1.0000 \mathrm{E}-02$ & 0 & 85 & 91 & 772 & 1000 & 1000 & 1000 & 1000 & 1000 & 1000 & 1000 & 1000 & 1000 & 1000 & 1000 \\
\hline 14 & $1.0000 \mathrm{E}-02$ & 0 & 85 & 91 & 772 & 1000 & 1000 & 1000 & 1000 & 1000 & 1000 & 1000 & 1000 & 1000 & 1000 & 1000 \\
\hline 15 & $1.0000 \mathrm{E}-02$ & 0 & 85 & 91 & 772 & 1000 & 1000 & 1000 & 1000 & 1000 & 1000 & 1000 & 1000 & 1000 & 1000 & 1000 \\
\hline
\end{tabular}

Table C.9: Relative uncertainty (relative standard deviation) and correlation (normalized to 1000) for $\nu$-bar for ${ }^{242 m} \mathrm{Am}$

\begin{tabular}{|c|c|c|c|c|c|c|c|c|c|c|c|c|c|c|c|c|}
\hline 1 & $1.0428 \mathrm{E}-01$ & 1000 & 369 & 54 & 37 & 29 & 29 & 29 & 29 & 29 & 29 & 29 & 29 & 37 & 43 & 43 \\
\hline 2 & $9.1295 \mathrm{E}-03$ & 369 & 1000 & 720 & 700 & 686 & 686 & 686 & 686 & 686 & 686 & 686 & 686 & 678 & 671 & 671 \\
\hline 3 & $6.6162 \mathrm{E}-03$ & 54 & 720 & 1000 & 984 & 968 & 968 & 968 & 968 & 968 & 968 & 968 & 968 & 957 & 947 & 947 \\
\hline 4 & $6.8430 \mathrm{E}-03$ & 37 & 700 & 984 & 1000 & 998 & 998 & 998 & 998 & 998 & 998 & 998 & 998 & 994 & 990 & 990 \\
\hline 5 & $6.9995 \mathrm{E}-03$ & 29 & 686 & 968 & 998 & 1000 & 1000 & 1000 & 1000 & 1000 & 1000 & 1000 & 1000 & 999 & 998 & 998 \\
\hline 6 & $6.9995 \mathrm{E}-03$ & 29 & 686 & 968 & 998 & 1000 & 1000 & 1000 & 1000 & 1000 & 1000 & 1000 & 1000 & 999 & 998 & 998 \\
\hline 7 & $6.9995 \mathrm{E}-03$ & 29 & 686 & 968 & 998 & 1000 & 1000 & 1000 & 1000 & 1000 & 1000 & 1000 & 1000 & 999 & 998 & 998 \\
\hline 8 & $6.9995 \mathrm{E}-03$ & 29 & 686 & 968 & 998 & 1000 & 1000 & 1000 & 1000 & 1000 & 1000 & 1000 & 1000 & 999 & 998 & 998 \\
\hline 9 & $6.9995 \mathrm{E}-03$ & 29 & 686 & 968 & 998 & 1000 & 1000 & 1000 & 1000 & 1000 & 1000 & 1000 & 1000 & 999 & 998 & 998 \\
\hline 10 & $6.9995 \mathrm{E}-03$ & 29 & 686 & 968 & 998 & 1000 & 1000 & 1000 & 1000 & 1000 & 1000 & 1000 & 1000 & 999 & 998 & 998 \\
\hline 11 & $6.9995 \mathrm{E}-03$ & 29 & 686 & 968 & 998 & 1000 & 1000 & 1000 & 1000 & 1000 & 1000 & 1000 & 1000 & 999 & 998 & 998 \\
\hline 12 & $6.9995 \mathrm{E}-03$ & 29 & 686 & 968 & 998 & 1000 & 1000 & 1000 & 1000 & 1000 & 1000 & 1000 & 1000 & 999 & 998 & 998 \\
\hline 13 & $6.9965 \mathrm{E}-03$ & 37 & 678 & 957 & 994 & 999 & 999 & 999 & 999 & 999 & 999 & 999 & 999 & 1000 & 1000 & 1000 \\
\hline 14 & $6.9995 \mathrm{E}-03$ & 43 & 671 & 947 & 990 & 998 & 998 & 998 & 998 & 998 & 998 & 998 & 998 & 1000 & 1000 & 1000 \\
\hline 15 & $6.9995 \mathrm{E}-03$ & 43 & 671 & 947 & 990 & 998 & 998 & 998 & 998 & 998 & 998 & 998 & 998 & 1000 & 1000 & 1000 \\
\hline
\end{tabular}


Table C.10: Relative uncertainty (relative standard deviation) and correlation (normalized to 1000) for $\nu$-bar for ${ }^{243} \mathrm{Am}$

\begin{tabular}{|c|c|c|c|c|c|c|c|c|c|c|c|c|c|c|c|c|}
\hline 1 & $1.8823 \mathrm{E}-02$ & 1000 & 132 & 27 & 0 & 0 & 0 & 0 & 0 & 0 & 0 & 0 & 0 & 0 & 0 & 0 \\
\hline 2 & 1. $9772 \mathrm{E}-02$ & 132 & 1000 & 511 & 197 & 71 & 71 & 71 & 71 & 71 & 71 & 71 & 71 & 71 & 71 & 71 \\
\hline 3 & 1. $9067 \mathrm{E}-02$ & 27 & 511 & 1000 & 605 & 76 & 76 & 76 & 76 & 76 & 76 & 76 & 76 & 76 & 76 & 76 \\
\hline 4 & $1.0880 \mathrm{E}-02$ & 0 & 197 & 605 & 1000 & 818 & 818 & 818 & 818 & 818 & 818 & 818 & 818 & 818 & 818 & 818 \\
\hline 5 & 1. $2000 \mathrm{E}-02$ & 0 & 71 & 76 & 818 & 1000 & 1000 & 1000 & 1000 & 1000 & 1000 & 1000 & 1000 & 1000 & 1000 & 1000 \\
\hline 6 & 1. 2000E-02 & 0 & 71 & 76 & 818 & 1000 & 1000 & 1000 & 1000 & 1000 & 1000 & 1000 & 1000 & 1000 & 1000 & 1000 \\
\hline 7 & 1. $2000 \mathrm{E}-02$ & 0 & 71 & 76 & 818 & 1000 & 1000 & 1000 & 1000 & 1000 & 1000 & 1000 & 1000 & 1000 & 1000 & 1000 \\
\hline 8 & $1.2000 \mathrm{E}-02$ & 0 & 71 & 76 & 818 & 1000 & 1000 & 1000 & 1000 & 1000 & 1000 & 1000 & 1000 & 1000 & 1000 & 1000 \\
\hline 9 & 1.2000E-02 & 0 & 71 & 76 & 818 & 1000 & 1000 & 1000 & 1000 & 1000 & 1000 & 1000 & 1000 & 1000 & 1000 & 1000 \\
\hline 10 & 1. $2000 \mathrm{E}-02$ & 0 & 71 & 76 & 818 & 1000 & 1000 & 1000 & 1000 & 1000 & 1000 & 1000 & 1000 & 1000 & 1000 & 1000 \\
\hline 11 & 1.2000E-02 & 0 & 71 & 76 & 818 & 1000 & 1000 & 1000 & 1000 & 1000 & 1000 & 1000 & 1000 & 1000 & 1000 & 1000 \\
\hline 12 & $1.2000 \mathrm{E}-02$ & 0 & 71 & 76 & 818 & 1000 & 1000 & 1000 & 1000 & 1000 & 1000 & 1000 & 1000 & 1000 & 1000 & 1000 \\
\hline 13 & 1.2000E-02 & 0 & 71 & 76 & 818 & 1000 & 1000 & 1000 & 1000 & 1000 & 1000 & 1000 & 1000 & 1000 & 1000 & 1000 \\
\hline 14 & $1.2000 \mathrm{E}-02$ & 0 & 71 & 76 & 818 & 1000 & 1000 & 1000 & 1000 & 1000 & 1000 & 1000 & 1000 & 1000 & 1000 & 1000 \\
\hline 15 & 1.2000E-02 & 0 & 71 & 76 & 818 & 1000 & 1000 & 1000 & 1000 & 1000 & 1000 & 1000 & 1000 & 1000 & 1000 & 1000 \\
\hline
\end{tabular}

